Vrije Universiteit Brussel

Faculteit Letteren en Wijsbegeerte

\title{
HOMO DEMOCRATICUS
}

(O $n$ the U niversal D esirability and the $\mathrm{N}$ ot So U niversal

Possibility of Democracy and H uman Rights)

Thesis voor het behalen van de academische graad van Doctor in de Wijsbegeerte

\section{Filip Spagnoli}

Promotor: Prof. Dr. M. Weyembergh

Martelaarslaan 357

9000 Gent

19/ 03/ $200211: 21$ 

WOORD VAN DANK

Hierbij een woord van dank aan Professor M. Weyembergh, mijn promotor, voor de toegewijde steun, en aan Michael Enright voor het corrigeren van de grammaticale fouten in mijn versie van de Engelse taal. 



\section{TABLE OF CONTENTS}

Introduction

§ 1: $\quad$ The Anti-democrat's Paradox

Section 1: $\quad$ Thelmportance of Public Life

18

24

Section 2: $\quad$ The Protection of Public Life $\quad 28$

§ 18: Free Speech, Freedom of Association and Freedom of Assembly 28

§ 19: The Rule of Law and the Separation Between the State and Society (1) 29

§20: The Rule of Law, Difference, Identity and Criticism

§ 21: Borders Between Concepts 33

§22: The Rule of Law Guarantees Publicity, Openness, Justice and Fairness 34

§23: Security 36

§ 24: No Human Rights Without Tolerance 39

$\S 25: \quad$ Tolerance Linked to Diversity as a Good 40

§ 26: Tolerating Intolerance? (1) 41

§ 27: Religious Liberty Promotes Openness, Disclosure, Pluralism, Tolerance and Debate 43

§ 28: $\quad$ Limiting and Separating the State and the Church

§ 29: Different Sub-Communities With Different Identities Living Together 45

§30: TheHistorical Role of the Reformation 48

§31: ThePrivateSpace $\quad 49$

§ 32: PrivateProperty $\quad 49$

§33: Equal Rights, Non-Discrimination and Justice $\quad 51$

Chapter 2: Negative and Positive Rights $\quad 54$

Section 3: Human Rights Against the State $\quad 54$

§ 34: To Forbear and to Protect $\quad 54$

§ 35: Human Rights Added to, Given to, or Given by the State 57 
Section 4: Human Rights Against Fellow Humans 58

§ 36: $\quad$ Bourgeois Rights 58

§ 37: $\quad$ General Interest and Self-interest, and the Dangers of Both (1) 59

§ 38: The Importance of Boundaries and of the Intimate and Inviolable Space

§ 39: $\quad$ Some Negative Consequences of Boundaries 60

Chapter 3: $\quad$ Political Life, Version 1(The Link Between Democracy and Human Rights) 62

Section 5: $\quad$ Power Struggleand Strugglein Society, Version 1

§ 40: Different Ways of Institutionalizing Conflict

§ 41: $\quad$ Exceptions to the Link Between Democracy and Human Rights?

§ 42: The Right to Democracy and Political Rights 65

§ 43: $\quad$ Self-Control and Self-Government 66

§ 44: TheProblem of Unanimity $\quad 66$

§ 45: $\quad$ Democracy and the Rule of Law $\quad 69$

§ 46: $\quad$ Change and Publicity $\quad 70$

Section 6: Control and Judgment on the Basis of Free Flows of Information 72

§ 47: $\quad$ Power, Accountability and Openness in Two Directions 72

§ 48: $\quad$ Attentiveness, Involvement and Knowledge $\quad 73$

§49: $\quad$ Obscurity and Manipulation $\quad 75$

Section 7: TheConstruction of the Will of the People 77

§50: $\quad$ Human Rights and the Will of the People $\quad 77$

§ 51: The Construction of Communities

§52: $\quad$ Setting the Agenda $\quad 79$

§ 53: Democracy is a Goal and N ot Just a Means (1) 80

§54: The Separation Between State and Society and Between State and Politics 81

Chapter 4: $\quad$ Political Life, Version 2 (Direct and Indirect Participation) 83

Section 8: $\quad$ Participation by Way of Representation 83

$\S 55: \quad$ Actors and Authors $\quad 83$

§56: Historical Perspective $\quad 84$

$\S 57: \quad$ Advantages of Representation: Purification and Clarity vs. Confusion and Vagueness $\quad 85$

§58: $\quad$ Other Considerations $\quad 87$

Section 9: $\quad$ Participation Without Representation $\quad 89$

§59: Disadvantages of Representation 89

$\S 60: \quad$ Advantages of Direct Democracy; Democracy as a Goal and Not Just a Means (2)

§ 61: Different Forms of Direct Democracy and the Problem of the Leader 92

§ 62: Disadvantages of Direct Democracy (1): Scale and Technology 93

§ 63: Disadvantages of Direct Democracy (2): Scale and the Federal System

§ 64: Disadvantages of Direct Democracy (3): Other Solutions to the Problem of Scale

§ 65: Disadvantages of Direct Democracy (4): Demagogy and Emotionality 98

§ 66: Disadvantages of Direct Democracy (5): A pathy and Stupidity 99

§ 67: Disadvantages of Direct Democracy (6): Insufficient Resources to Participate 102

§ 68: $\quad$ Participation as a Goal in Itself 104

§ 69: $\quad$ The Separation Between State and Society (2) 104

$\begin{array}{llr}\text { Chapter 5: } & \text { Humanity (Universality Because of Equality) } & 107\end{array}$

$\begin{array}{lll}\text { Section 10: } & \text { Equal Values } & 107 \\ & \S 70: \quad \text { Natural Rights } & 107 \\ & \S 71: \quad \text { The Right to Belong to Humanity } & 108 \\ & & \\ \text { Section 11: } & \text { Legal Rights } & 110 \\ & \text { \$72: } \quad \text { The Legal Person } & 110 \\ \text { §73: } \quad \text { Positivism } & 111\end{array}$ 
§ 74: The Exception of Political Rights 112

§ 75: $\quad$ The Right to Citizenship $\quad 114$

§ 76: Humanity and the People $\quad 116$

Chapter 6: $\quad$ Culture (Non-Universality Because of Inequality) 118

Section 12: The Impossibility and the Undesirability of Rights and Democracy, Version 1

§ 77: Undesirable 118

§ 78: Impossible $\quad 119$

§ 79: $\quad$ A-Cultural Rights 120

§ 80: Who Criticizes Rights and Democracy? $\quad 121$

§ 81: Is the Identity a Goal or a Means?

§ 82: Identity is both a Myth and a Problem $\quad 123$

§ 83: Contradictions in the Ideology of Culture and Identity 124

§ 84: Individuals A reAllowed to Criticize, but Do N ot; States Criticize but A re N ot Allowed to $\quad 125$

§ 85: The Only and Almighty Authority of Culture $\quad 126$

§ 86: Cultural Relativism and ( $\mathrm{NeO}$ )Colonialism 126

§ 87: Western Rights $\quad 127$

§ 88: The Radical Rejection of Democracy and the 'I-Did-It-My-Way' Syndrome 129

§ 89: $\quad$ Rights Limited to the West are Only Semi-Rights 130

§90: $\quad$ Origin and Effect $\quad 131$

Section 13: $\quad$ Real Diversity 132

§ 91: 'Popular' or Truly Cultural Rejection of Human Rights and the Limits of Identity 132

§ 92: The Relativity of Relativism 133

§ 93: Changing Cultures 134

§ 94: Tolerating Intolerance? (2) 136

§ 95: Cultureand the Individual $\quad 137$

§96: Universalizing Human Rights is not the Same Thing as Universalizing Individualism 138

§97: $\quad$ Rights and Community 139

Section 14: $\quad$ CollectiveRights $\quad 143$

§ 98: $\quad$ Superfluous Rights 143

§ 99: $\quad$ The Right to a State and the Right to Identity $\quad 144$

§ 100: Dangerous Rights $\quad 145$

$\begin{array}{ll}\S 101: & \text { Special Minority Rights } \\ & 147\end{array}$

Section 15: $\quad$ Actual and Normative Universality $\quad 148$

§ 102: Universality at the level of States $\quad 148$

§ 103: Universality at the level of the People (A Minimal Consensus or 'Weltethos')

§ 104: An Intercultural Dialogue $\quad 150$

Part 2: $\quad$ The Economy

Section 16: From Economic Development to Democracy and Rights (The Impossibility and the Undesirability of Democracy and Rights, Version 2)

§ 105: Economic Prerequisites 151

§ 106: Economic Development as a Cause of Democracy and Human Rights 151

Section 17: From Democracy and Rights to Economic Development 154

§ 107: Democracy and Human Rights as a Cause of Economic Development $\quad 154$

§ 108: TheChoice Between Hunger and Oppression $\quad 155$

§ 109: Hunger and Oppression Go Together 157

§ 110: A N ew Inversion of Means and Ends (1) 158

§ 111: The Link Between Identity and the Economy 159 
Section 18: Why Do WeN eed Economic Rights?

§ 113: A Necessary Minimum and Not a Possible Maximum 161

§ 114: In Everybody's Interest 162

§ 115: A Hierarchy of Rights?

§ 116: Urgency vs. Synchronicity 164

§ 117: Private Lifeas a Prerequisite for Public and Political Life 164

§ 118: Humanity 165

§ 119: Universality Because of Equality (2) and Equality as an Excuse

§ 120: Insufficient Conditions 166

Section 19: How Do WePromoteEconomic Rights? 167

§ 121: $\quad$ Public and Political Life as a Prerequisite for Private Life $\quad 167$

§ 122: $\quad$ Catch 22? $\quad 168$

§ 123: TheHierarchy of Responsibility, Duty, Assistance and Redistribution 168

§ 124: Enforcement, Resources and the Long Term $\quad 170$

§ 125: The Right to Property and the Right to theProperty of Someone Else 173

Part 3: $\quad$ Peace

Section 20: Self-determination, Version 1

§ 126: Self-determination: A H uman Right and a Right of a State 175

§ 127: A Necessary Condition and an Unnecessary Obstacle at the SameTime 176

§ 128: $\quad$ Realism and Moralism (International Peace, Rights and Democracy) 177

§ 129: A Consistent System of Rights $\quad 178$

Section 21: Other Ways in Which Rights and Democracy Protect the Peace Between States 179

§ 130: $\quad$ Agreements, Publicity and Popular Support $\quad 179$

§ 131: The Real Importance of Peace $\quad 180$

§ 132: Napoleontism and Neo-Colonialism $\quad 181$

§ 133: $\quad$ The Paradox of Democracy 183

$\begin{array}{lrr}\text { Chapter 10: } & \text { Peace Insidea State } & 186\end{array}$

Section 22: Self-Determination, Version 2

§ 134: Self-Determination of a People $\quad 186$

§135: Revolution or Separation $\quad 186$

§ 136: $\quad$ Borders as an End or as a Problem 188

Section 23: National Unity $\quad 190$

§ 137: Democracy is Impossible and Necessary at the SameTime(1) 190

§ 138: How to Create Unity and Avoid Discord? 192

§ 139: Pacification-Democracy 193 
Part 4: $\quad$ Equality

Chapter 11: The Value of Equality

Section 24: Democracy Produces the Best Decisions 196

§ 140: Why Do WeNeed Equality? $\quad 196$

§ 141: The Epistemological Advantages of Democracy 197

§ 142: Democracy is N ot Necessarily Relativistic, Nihilistic or Amoral 199

$\begin{array}{lll}\text { Section 25: } & \text { Truth vs. Opinion } & 201\end{array}$

§ 143: TheAbsence of Truth 201

§ 144: A Good Content and a Good Procedure 203

$\S 145:$ The Possibility of Contestation 204

§ 146: Procedures are Not Enough 205

\begin{tabular}{ll} 
Chapter 12: & Some Problems With Equality \\
\hline
\end{tabular}

Section 26: Equal or Unequal Value and a Problem of Definition 207

§ 147: TheValue of a Human Being $\quad 207$

§ 148: Unequal Value 208

§ 149: The Combination of Equal and Unequal Value $\quad 209$

§ 150: A Problem of Definition 210

§ 151: $\quad$ Equality Before the Law vs. Material Equality $\quad 212$

§ 152: Equality of Outcomevs. Equality of Procedures 212

§ 153: Political Equality vs. Material Equality 213

Section 27: Efficiency, the A bility to Take Decisions and the Quest for Consensus 216

§ 154: Confusion, Chaos, Complexity, Slowness and Insecurity 216

$\S 155:$ Consensus 218

§ 156: Dangerous Truth (The Truth Threatens Politics) 218

§ 157: Reasonableness Instead of Truth 221

§ 158: Democracy is Impossible and Necessary at the SameTime (2) (Unity of Vision) 225

$\S 159$ : Creating Consensus $\quad 227$

Section 28: Efficiency, the A bility to Take Decisions and to Executethe Will of the People 230

$\S 160$ : Disadvantages of a Multi-Party System $\quad 230$

§ 161: Advantages of a Two-Party System 232

§ 162: Disadvantages of a Two-Party System $\quad 233$

§ 163: Vote Buying 234

§ 164: General Interest and Self-Interest, and the Dangers of Both (2) 236

Section 29: Big Government $\quad 238$

$\S 165:$ Causes 238

§ 166: Elements Working Against $\quad 240$

§ 167: Transnational Democracy 242

Part 5: $\quad$ Freedom

$\begin{array}{llr}\text { Chapter 13: } & \text { Autonomy and Self-Realization } & 244\end{array}$

Section 30: Autonomy or the Freedom to Choose Your Own Good Life 244

§ 168: The Importance of Freedom and the Link With Democracy and Rights 244

§ 169: $\quad$ Some Problems With Autonomy $\quad 248$

§ 170: Widening Autonomy $\quad 250$ 
§ 171: Autonomy and the Economy 251

Section 31: Self-Realization and the Only True Good Life

§ 172: Forcing Peopleto Makethe Best of Themselves 254

§ 173: An Anti-Democratic Definition of Freedom? 256

$\begin{array}{llr}\text { Chapter 14: } & \text { Freedom and Obedience } & 259\end{array}$

Section 32: Unlimited and Limited Freedom

§ 174: Obedience to Yourself (The Law as an Extension of Yourself)

§ 175: Freedom and the State (Anarchism and Liberalism) $\quad 261$

§ 176: Limited, Legal and Equal Coercion (Freedom and Equality) 264

Section 33: Limited Freedom is Anti-Social 268

§ 177: Our Freedom is Limited by the Harm We Can Inflict on Other People 268

§ 178: TheValue of Our Fellow Men $\quad 269$

§ 179: Negativeand PositiveFreedom 270

Chapter 15: The Choice Between Freedom and the Dictatorship of the Majority 272

Section 34: Power Struggleand Struggle in Society, Version 2 272

§180: A Separation of Independent Powers $\quad 272$

§ 181: Limited Independence

§ 182: A Democratic Court of Justice? $\quad 275$

§ 183: Power Struggle and Struggle in General $\quad 275$

§ 184: Separation Insidethe Different Powers $\quad 275$

§ 185: Separation of Powers in a Federal System 276

Section 35: The Rule of Law is Limited by Equality Beforethe Law 277

§ 186: A Law is General, Anonymous and Neutral $\quad 277$

§ 187: The Balance Between Political Rights and Freedom Rights $\quad 280$

$\S 188:$ Do Human Rights and the Law Limit Democracy? $\quad 280$

§ 189: The Minority Protected by theFederal System 281

Concluding Remarks (Universality, Flexibility and Contextuality) 282

§ 190: Universality vs. Uniformity 282

§ 191: Rights and Wrongs, and Different Perspectives in the Drafting of Laws

§ 192: A Different A pplication of Something Universal (Limits on Human Rights) 284 


\section{DRA WINGS AND TABLES}

$\begin{array}{lr}\text { Drawing 1: The Link Between Rights and Values } & 19\end{array}$

Drawing 2: Different Spaces $\quad 34$

$\begin{array}{lr}\text { Table 1: The Hierarchy of Duties and Responsibilities } & 173\end{array}$

Tabel 2: The Combination of Equal and Unequal Value $\quad 209$

$\begin{array}{lr}\text { Table 3: Freedom and Equality } & 266\end{array}$

\section{INTERNATIONAL STANDARDS}

$\begin{array}{lr}\text { Universal Dedaration of Human Rights } & 288\end{array}$

$\begin{array}{ll}\text { International Covenant on Civil and Political Rights } & 290\end{array}$

$\begin{array}{lr}\text { International Covenant on Economic, Social and Cultural Rights } & 299\end{array}$

Convention for the Protection of Human Rights and Fundamental Freedoms (ECPHR) 303

$\begin{array}{lr}\text { Protocol to the ECPHR } & 306\end{array}$

$\begin{array}{lr}\text { Protocol No. } 4 \text { to the ECPHR } & 307\end{array}$

$\begin{array}{lr}\text { Protocol No. } 6 \text { to the ECPHR } & 307\end{array}$

$\begin{array}{lr}\text { Protocol No. } 7 \text { to the ECPHR } & 308\end{array}$ 



\section{INTRODUCTION}

\section{§ 1: The Anti-democrat's Paradox}

Some people do not believe in the universal validity nor the universal application of human rights and democracy. They say that human rights and democracy are not meant for them, or are not meant for somebody else. They forget, however, that one cannot question, challenge or refute human rights and democracy for the simple reason that the act of questioning, challenging or refuting implies respect for human rights and democracy. Something that is unquestionable and irrefutable is by definition universal. Defending human rights and democracy is not the same thing as expressing an opinion, a western opinion, for example, which other cultures, states or groups can call into question. Human rights and democracy are necessary conditions for the appearance of different opinions and for debate between opinions and therefore cannot be reduced to opinions that are not different from other opinions, or to an element in a struggle that they help to institute. They are above the level of opinion and questioning (Lefort 1992:31). Nobody can question human rights or democracy without at least implicitly accepting them.

Besides, most governments that claim the right to have a different opinion on human rights or democracy refuse to grant their subjects the same right to a different opinion not in the least when this different opinion relates to the legitimacy of the government. This is of course a crude example of hypocrisy.

A nother example of this kind of hypocrisy can be found in the so-called cultural defense of the violation or non-application of human rights. One cannot criticize a culture for violating certain human rights - we are told - because all cultures must be treated with equal respect. Such a criticism would be a lack of respect for the culture in question and for cultural equality and diversity in general. This argument is hypocritical because the same equality that is claimed for cultures is not granted to the individuals inside the culture (for example equal rights for men and women, equal participation in the political process etc.).

It is evident that an anti-human-rights doctrine and also an anti-democratic doctrine I am in favor of a strong link between human rights and democracy because democracy is based on a subset of human rights called political rights, and because democratic practice is so thoroughly dependent on and connected with all types of human rights that the difference is sometimes hard to see - is bound to get trapped in contradictions and paradoxes.

The anti-democrat hates the air he breaths, abhors the prerequisites of his existence, his acts and his opinions. He lives by the grace of what he hates. When we take away this detestable oxygen - as he seems to request - then he will drop dead. In fact, the antidemocrat hates himself. We witness an internal struggle of somebody who fulminates against a principle that he himself applies, against something he does, against something he is, namely someone who practices opposition, who freely expresses his opinions etc. At a theoretical level, the anti-democrat seems to preserve what he tries to destroy and only destroys his own background opinions.

Somewhat simplistically, I could say that those who want to promote human rights and democracy - and I am one of them - do not have to change the attitude of the antidemocrat. The only thing we have to do is make him conscious of what he already does. Of course, if it were as simple as that there would in fact be no threats to human rights or democracy because every threat would be an application of the principles of human rights and democracy. However, there are real and serious threats and that is why we have to change the attitude of the anti-democrat. In the real world, it is simply not true 
that the anti-democrat promotes democracy and human rights by struggling against them, even if democracy and human rights constitute the empire of struggle. There is no doubt that democracy and human rights can be destroyed.

To put it in another way, democracy and human rights do not accept heretics or apostates, for the simple reason that they are the prerequisites for the existence of heretics and apostates. Democracy and human rights become a new dogma. It is impossible to be against them. Every objection is a confirmation, because an objection (an objection in general, not only the objections against democracy and human rights) implies the acceptance of democracy and human rights.

Silencing my opponents in this way may seem to be undemocratic and a proof of inconsistency on my part. However, this one exception to the rule of general acceptance of heresy and plurality is necessary. A democracy is a society of conflicting views, but this means that attacking democracy is in principle impossible. This would be a struggle undermining its own foundation. There is a forced consensus on democracy and the rights it protects. Forced of course by logic and not by violence or physical force. The democratic values and rights and the universality of these values and rights are by definition a common frame and a common world, whether you accept this or not. You necessarily live in this world, both by accepting and rejecting democracy and human rights.

If all this were true and sufficient, I could end my book right here. However, that would indeed be inconsistent. Nowadays few people will be convinced by a dogma and least of all those freethinking people we need in a democracy. I still have to give reasons why we need democracy and human rights and why we need them at all times and in all places.

\section{§ 2: Why Do We N eed D emocracy and H uman Rights?}

If we have to apply democracy and human rights in all parts of the world, then this is because there are good reasons for doing so. The best way to discuss these reasons is by explaining the nature of democracy and human rights, by explaining what they are, what they do or what purpose they serve. That is what I will try to do I this book. Giving reasons is the same thing as giving a justification, and a justification presupposes an account of what you want to justify, presupposes that you know what you are talking about. However, the nature of democracy and human rights is a matter of dispute. I will give my personal definition and then try to justify it. I believe I have adopted a definition that is

(1) feasible (which is not the same thing as universally possible - I will discuss the conditions required to make it possible);

(2) justifiable; and

(3) sufficiently close to a common sense definition to make the effort of justification worth while.

I also believe that other definitions are not justifiable, although they might be feasible. Needless to say that other people retain the right to define or justify democracy and rights in other ways.

By describing democracy and human rights, I hope to show that they are valuable and beneficial for human life, not just for western or Christian life, but for human life in general. This will convince more people than the logical necessity of accepting democracy and human rights. Persuasion is more democratic than coercion, even if it is logical coercion.

To persuade is to give reasons. Let us now take a brief look at the five main reasons for accepting and universalizing democracy and human rights (these five reasons are covered in greater detail in Parts 1 to 5; the book is divided into five Parts, each Part dealing with one of the five reasons to accept democracy and rights): 
Statement 1:

Democracy and human rights promote certain widely shared values such as:

(1) Being able to form, experience and preserve an individual as well as a collective identity (my individual identity being my individuality) because they dlow social interaction, cooperation and the creation of communities to take place;

(2) Being able to think and to think more or less correctly;

(3) Being able to lead an active life and a life in a group or a community; and

(4) Being able to lead a responsible and informed life (democracy and rights create an active, informed and interested citizenship that holds opinions and assumes the responsibility that goes with holding opinions).

Democracy and human rights promote these values - which I believe are considered important by the whole of mankind - because they allow us to have a public life and a political life (by a public life I do not mean the life of a public figure, but a life dedicated to and dependent on publicity).

\section{Statement 2:}

Democracy and human rights promote the economy, not just the development or growth of the economy but also economic rights (otherwise known as economic equality).

Statement 3:

Democracy and human rights promote peace between states (because of the right to self-determination, the democratic habit of solving problems by talking instead of fighting etc.) and they promote peace inside states (because they promote tolerance, religious liberty, judicial remedy etc. and because they handle diversity and contradictions better than any other form of government).

\section{Statement 4:}

Democracy and human rights promote equality, not only material equality (see state ment 2) but other forms of equality as well (such as political and legal equality). One of the reasons why this is important is that more political equality means better political decisions. I will show that when the people as a whole have an open and free debate in which every voice has an equal weight, the decisions following this debate will probably be better and more correct than the decisions of a minority or an individual (two heads are better than one). As a consequence of the equal participation in the decision procedure, decisions will also be more legitimate and more acceptable and there fore easier to impose (if it is at all necessary to impose them) than the decisions of other forms of government. They are after all the reflection of the will of the people and why should the people go against its own will? A decision procedure based on equal participation will also generate decisions that take into account the interests of a maximum number of people. Only when the people themselves can decide on matters involving their interests, can their interests be protected. It is not safe to assume that a minority will systematically protect the interests of the rest of the people.

\section{Statement 5:}

Democracy and human rights promote freedom and autonomy, because they allow people to do what they want - instead of what somebody else wants. A maximum number of people can realize their hopes and wishes, can shape their lives and can choose for themselves, instead of being the object of other people's choices. Political life guaranteed by democracy and human rights is the only road to freedom. 
Of course, a number of the phenomena described above, or even all of them, can also be found in other forms of government, but never as widespread and of the same quality as in a democracy that respects human rights.

I will not use religiously inspired justifications, because in my opinion, these can only be universally accepted when the religion on which the justification is based is also universally accepted, and such a religion does not currently exist. Nor will I try to justify democracy and human rights on the basis of a characteristic common to all religions. If it were possible to find such a characteristic, it would most likely be useless because too vague or too general. And then I leave apart the fact that religious practice and theory have in themselves often been contrary to human rights and democratic principles. Besides, we can disapprove of killing or torturing people for other reasons than our faith in God, in hell or in the sacredness of human life. An unbeliever does not refrain from engaging in crime merely because of chance, fear of punishment or hypocrisy. An added advantage of avoiding religious justifications is that it creates the possibility of people of different religions accepting human rights and democracy.

This does not mean that religion necessarily contradicts human rights or democracy. It may even be possible and useful to find some kind of religious justification in certain religions (the Christian idea of the equality of all men in the face of God for instance). My point is that these can only be useful inside the framework of a particular religion, and will only convince the adherents of that particular religion. Given the purpose of my book, this is not enough. Chinese rulers, for instance, will not be convinced to respect the sanctity of human life because the Christian religion tells them to do so. If we want to convince everybody of the universality of human rights, then we have to use arguments which are independent of religion and which are based on values which are acceptable to everybody.

Of course, everybody can try to find his or her own justifications, religious or otherwise. However, this will not suffice. Not everybody will do so, or will want to do so. In many cases, people will have to be convinced and it is very difficult to convince followers of from one religion using justifications from another religion. And the same is true for atheists.

If religion is kept out of the justification of human rights and democracy, then this does not imply that religious persons have to or will reject rights and democracy. A nonreligious justification does not make rights and democracy less attractive to religious persons. I will show in Part 1 how religion needs human rights. Still, it may be useful to try and justify rights and democracy using the religion of religious opponents of rights and democracy. I believe this can be done, even in those cases where a particular religion is used to dismiss democracy or rights. This can even be a very powerful justification, be cause it uses a language familiar to opponents and because it appeals to values which they hold very dear. However, this requires an in-depth knowledge of different religions and I am glad to leave this approach to specialists.

Most of the elements contained in the five statements given above - community life, group identity, individual identity, thinking, prosperity, peace, equality, knowledge and freedom - are almost universally considered to be important values (values not in the sense of norms but in the sense of something important, in the sense of a conviction concerning something valuable). At least they can become universally acceptable given the right interpretation. If I can show that democracy and human rights promote and protect these universal values, I will have shown that democracy and human rights should themselves be considered as universally important values.

This means that democracy and human rights are a means and not a goal. They are important because they promote important values (although they are also a cause of values: they create the interaction and communication necessary for the creation of values). 


\section{§3: Anti-Foundationalism}

The reader should avoid interpreting the word 'justification' in the sense of 'foundation'. I have absolutely no cognitive or scientific pretensions. The purpose is not to establish the truth of the desirability of human rights and democracy, but to convince people - as many people as possible - of this desirability. I am not looking for a proof or for the ultimate and unquestionable foundation that will force every reasonable person to agree with me. I believe this is impossible in the field of philosophy (for many different reasons, one of them being the fact that every demonstration presupposes something which is not demonstrable, Castoriadis 1991:87). As it is impossible to establish a foundation in the sense of a proof, it is better to speak of the justification of human rights and democracy instead of their foundation. It is impossible to proof, but impossible to convince. Whereas a proof is the ultimate goal of a foundation, convincing people is the ultimate goal of a justification. In order to justify you must give reasons or say why, and giving reasons or saying why is necessary in order to convince.

I have to convince because I am dealing with a political problem and a problem concerning values. Politics and values do not (yet) belong to the domain of truth or proof in the sense of a logical reasoning starting from true premises. They belong to the domain of argument, debate and consent, a domain where one can only convince without ever be ing certain of a conviction and where there can only be reasoned consensus, not a consensus that is forced by logic, proof or truth.

I believe that, given the right arguments, it is possible to convince people that a certain value, such as equality, interpreted in a certain way, is important and that certain means for the protection of this value, such as democracy and human rights, are important. Now if it is possible to convince where values are concerned, then this means that it is not useless to discuss values and that it is possible to give reasons for saying that one opinion concerning values (or their protection) is better than another. If no opinion is better than another, then it is impossible to convince. In other words, I reject both moral relativism and moral determinism (a theory according to which moral convictions are innate or so strongly imprinted by way of education that they are immutable). 'W hile it is illusory to think that a satisfactory demonstration of the general superiority of democracy to its alternatives can ever consist of a straightforward axiomatical argument from unimpeachable premises to an 'absolute' and 'objectively valid' conclusion, it is equally mistaken, and even more absurd, to insist that all arguments with a moral flavor are equally arbitrary and therefore equally reasonable or unreasonable' (Dahl 1989:101-102). Some arguments are better than others. You can have opinions on values - for example, democracy is better than another form of government, equality is important, democracy protects equality better than other forms of government etc. - not only because you are attracted to them or because you have acquired them in the course of your education. Discussions, arguments and reasons play a part in your opinions, and can, if you believe they are well-founded, change them.

That is what I will try to do in this book and it is obvious that my story will be a normative or prescriptive one, dealing more with values than with descriptions of facts. It is of course impossible to claim that democracy, as it exists (as a fact), is always valuable or that the universality of democracy and human rights is a fact. The rights of millions of people are violated every day, even by imperfect democracies. I will be arguing the universal desirability of an ideal democracy and an ideal set of human rights. When I say that the universality of an ideal democracy which respects human rights should be a fact, that there are good reasons for it being a fact, then I am evidently proposing a norm. Therefore, the universality of human rights and democracy is, in my use of the language, shorthand for the universal value of human rights and democracy. Universalism would perhaps be a better word than universality, but I will not use it because it sounds awkward.

The statement that democracy and human rights are universal values does not imply that everybody agrees that they are values, still less that everybody lives according to these values. It means that there are good reasons for them being everybody's values. I 
believe that, provided the arguments are good, everybody can come to the conviction that there is something valuable in human rights and democracy.

There is, however, another possible strategy. Rorty for example claims that the results will be better if we try to influence people's feelings instead of their minds (in Hottois 1994:passim). We should not try to convince people by giving reasons or arguments. We should instead try to tell sentimental stories like 'U ncle Tom's cabin' or 'R oots', stories that make the reader sympathize with persons whose rights are violated. These persons, who may be of another class, race or nationality and who were so very different that they did not even seem to belong to the same species and therefore could not possibly claim to enjoy the same rights, are transformed by the story into living human beings. The sympathy engendered by the story gives them a human face. They also grieve for the loss of their children, they also have an opinion, they are not barbarians. As a consequence, they can be given human rights. I think we should and can use both strategies.

This can indeed be a very useful approach. However, just as I declined to use religious justifications because of my lack of religious knowledge, I now decline to use the storystrategy. I am a terrible storyteller and therefore I will stick to the rational approach, rational in the sense of non-emotional.

Some people believe that we should do nothing. According to them, neither reasons nor stories are desirable. In order to respect cultural differences and to improve the chances of universal acceptance of rights and democracy, everybody should establish his or her own reasons for accepting rights and democracy (Taylor in Bauer/ Bell 1999:10). The West will accept rights because they promote individual liberty, Buddhists because rights can assist the process of achieving enlightenment etc. Universality is said to be easier to attain if it remains unjustified. Once we start to justify, we use values and values are always controversial and culturally relative. We do not have to convince because eve rybody will find his or her own reasons. The question is then: why has this not happened yet? There is, of course, nothing wrong with somebody accepting human rights and democracy for his or her own reasons, but it is clear that something more is required if we want to attain universality.

It is true that sometimes reasons as well as stories are insufficient. Some anti-democrats do not engage in discussion and do not listen to stories. They will never be convinced of another point of view, they do not try to convince others of their point of view, and they are so fanatical that it is very hard to touch their emotions. They just act and action is the only means to defend ourselves against these persons. I believe, however, that these persons are a tiny minority and that we do not need to convince them. Containing them will be sufficient.

\section{$\S 4: \quad$ Why do Some People R eject D emocracy and/or H uman Rights?}

The strange thing about all this is that the exercise of justification in some way presupposes the existence of democracy and human rights. Looking for reasons can best be done in a discussion where all possible arguments for and against can appear and can be tested, and where all available sources of information and knowledge can be consulted. This kind of discussion is typical of a democracy that respects human rights. So while we try to justify democracy and human rights, they are already justified, namely by our attempt to do so. Because a justification needs democracy and human rights, they are in a way beyond justification. They cannot be justified because they are presupposed in every justification. This situation is similar to the one of the anti-democrat. You always confirm democracy and human rights, both by justifying them and by rejecting them. If you argue in favor, you al ready have what you want. If you want to argue against, you also have to accept a society in which you can argue (Castoriadis 1991:88).

However, I repeat that this kind of reasoning is not enough to convince opponents that they are wrong and that they should adopt the principles of democracy and human 
rights. Therefore, it remains useful to try to invalidate the main arguments against de mocracy and human rights. The main arguments against are a perfect mirror image of the five statements given above:

Counter-statement 1:

Democracy and human rights have to be rejected because they are a product of the West and exclusively related to certain specific values of the culture of the West. Their application outside of that culture is by definition part of an imperialistic effort at domination and therefore a threat to the existence and the identity of other cultures. This is apparent in for example the individualism and even egoism that always go hand in hand with democracy and human rights. Individualism is a western value which not only threatens other cultural identities when it is spread together with democracy and human rights, but which also has negative consequences for morality, prosperity and civic peace

Counter-statement 2:

Democracy and human rights have to be rejected because they obstruct economic development, especially in Third World countries. One reason why they obstruct the economy is the fact that they promote individualism and selfishness, as opposed to selfless cooperation and sacrifice for the national welfare.

Counter-statement 3:

Democracy and human rights have to be rejected because they endanger international peace The claim of universal application leads to cultural imperialism, which is the attempt to impose western culture - or at least a part of it, namely human rights and democracy - on other cultures. These other cultures will of course reject this kind of imposition, even when it appears in a milder form, such as oral interference in the internal affairs of other states. Given that they care about their independence, identity, morality, prosperity and civic peace, they will react against states or international institutions trying to impose human rights and democracy, or trying to intervene to improve the human rights situation. Because of this play of action and reaction, international relations will suffer and in extreme cases, peace will suffer as well. On top of that, human rights and democracy also endanger the peace inside a state because they are antagonistic and adversarial. They promote discord instead of solidarity.

Counter-statement 4:

Democracy and human rights have to be rejected because they either create too much or too little equality:

(1) Too much equality: The mass of the people tends to be envious of outstanding talents. The latter, being by definition always a small minority, are systematically excluded from any democratic decision. This of course affects the quality of the decisions, but also the quality of the population. High quality people are looked down upon. They are elitist and therefore anti-democratic and they implicitly or explicitly call into question the democratic ideology of universal equivalence (all people have the same worth or dignity). They are given no chance to blossom and to be an example to others. As a consequence, there is a 'nivellement vers le bas'. The great are brought down to the level of the mediocre mass and the mass loses the opportunity to rise to the level of the exemplary few because there are no examples left to imitate. And if there are examples, they are marginalized, powerless and invisible. Society becomes uniform. In order to preserve the possibility of developing talents and of making good decisions, politics must be radically unequal. Politics is a profession and one must be qualified for it, as for every other profession. Rule by the lowest common denominator, by the unfit and the incapable must be brought 
to an end. Politics is a matter for specialists, for an elite, capable of understanding the complexities of life. The people as a whole decide emotionally instead of rationally, based on opinions instead of knowledge, and for the sake of self-interest instead of the general interest. This emphasis on self-interest makes politics very inefficient and very slow. All interests must be considered and difficult compromises and coalitions must be established (this is the socalled interest groups politics). Democratic equality multiplies the number of different interests that have to be taken into account and because of this large number of interests, it is almost impossible to distill a general interest.

(2) Too little equality: Human rights and democracy are also rejected for the opposite reason. They are, it is said, incapable of creating enough equality. All they can do is create and protect a formal kind of legal equality that leaves the underlying (often economic) inequality unaffected. Besides, how can a majority system be qualified as egalitarian? There are always winners and losers.

Counter-statement 5:

Democracy and human rights have to be rejected because they institute the dictatorship of the majority over the rest of the people. There are always people who do not decide, who do not have a choice and who therefore do not have autonomy, freedom or control over their own lives. Some might say that there can never be freedom in politics, because politics and the state always imply coercion, domination and the separation between rulers and ruled. So how can political life be described as the source of freedom? It is the source of unfreedom instead. And only as such can it be justified. After all, unlimited freedom is perhaps not such a good thing. Freedom can only be found outside of politics. Democratic politics diminishes freedom just like any other form of government, because a democracy also has to force people. What is the difference between being ruled by one person and being ruled by the majority? We do not need democracy. We need a limited state, a state which limits freedom as much as necessary, but not more than necessary; or perhaps, if possible, we do not need a state at all.

I will of course elaborate further on these allegedly negative sides of democracy and human rights later in the book. To appraise the true value of something, one must look at both sides of the argument. When I say negative sides, I also mean negative sides of the elements used to justify democracy and human rights, because these negative sides can undo the attempt at justification (equality for example can indeed be more of a problem than an asset). However, democracy and human rights are not only rejected because they promote the wrong values, but also because they fail to promote certain positive values, such as truth and efficiency. I will also investigate the relationship between these values on the one hand and democracy and human rights on the other hand.

\section{§ 5: $\quad$ Some Conflicts}

There can be conflicts between the values that I have chosen as elements of justification. Not all things that are good and desirable are necessarily compatible. Sometimes one good thing will have to be abandoned or limited in order to protect another. Some of these conflicts can be harmless, but others may undo the attempt at justification. For example, if democracy and human rights really promote freedom and equality, how will they deal with a conflict between these values? It is not enough to say that it is better to have values that come into conflict than not having values at all.

It would be a mistake, however, to exaggerate the intensity and frequency of possible conflicts between the values that I have chosen as elements of justification. There is certainly no case to be made in favor of some kind of general incompatibility in the sense of only being able to have one value without the other, although it can happen that some 
values are incompatible in some cases, such as freedom and equality. However, this can happen with all kinds of values (e.g. love and loyalty) and therefore it seems that I do not have to be too concerned with the problem. Anyway, I believe that in most cases there will be no conflicts between the values that I use and that even when there are conflicts, it will not be necessary to severely limit one of the values. On the contrary, these values often reinforce each other, like for example political life and community life, or peace and the economy.

What can be done in case of conflict? It is not the purpose of democracy to decide be tween values. Democracy merely sets the stage on which this and other kinds of conflicts can be shown, discussed and perhaps also be solved, for example by way of compromises, attempts to balance values in a fair way or attempts to convince people that one of two conflicting values is more important and that the other value has to be limited. Democracy tries to assure that this solution - which is always a consequence of publicity and discussion - is fair because it gives equal influence to each person and equal consideration and attention to each value and each point of view.

A reliance on fair discussion is necessary because it is often impossible to decide a conflict between values on the basis of certain knowledge. This is only possible if you believe in one of two hypotheses (or in both). First there might be one fundamental and foremost value which places all other values in a context, which is uncompromising, which always comes out on top, and which can assign weights to or can decide conflicts between subordinate values. Or you may believe that conflicts between values are caused solely by insufficient human knowledge, by the wrong kind of definition or interpretation of values, by an inadequate hierarchy accorded to values, or by the wrongful description of something as a value.

A democracy does not rely on either of these dubious beliefs. Many different values are important and different values are important for different people. There is no evident hierarchy of values and it is doubtful whether we can count on re-interpretations or on advances in moral knowledge in order to clear up the mess of values we are now facing. Therefore, we will probably be stuck with a plurality of equivalent values for some time to come. And maybe this is not even a bad thing - after all, there are many different good and important things in life - even if it sometimes forces us to debate, to balance and to limit some values. The fact that different values are important is a consequence of education or of choices based on arguments and debate and is not necessarily a consequence of insufficient knowledge or misunderstandings. If conflicts between values are not a knowledge problem, then we need human rights and democracy to solve these conflicts, to find a just balance, to find good and convincing reasons to limit some value rather than another, to take into account the interests of as many people as possible when limiting values etc. Limiting democracy and human rights, or putting them at the wrong side of a hierarchy of values is therefore a dubious undertaking.

However, conflicts between the values that I use in the justification of democracy and rights are not the only kind of conflict that can bother us. What can be done if there is a conflict between the values that I use and some other values? If these other values are considered more important, then there is no problem if they do not need human rights or democracy, or if they are irrelevant to the subject (such as marital fidelity). There is only a problem when they are more important and when they require a rejection of human rights and democracy, occasionally or systematically. This can happen with values such as love, friendship or efficiency. The question is of course whether these other values can be considered more important than the values that I use. I do not think that there is a strong case to be made in favor of this point of view. Fortunately, otherwise democracy and human rights would have to be rejected or at least limited, or other types of justification would have to be found. Alternatively, we could create a hierarchy of values, in which the values that need democracy and human rights would come out on top, but then we would be inverting means and ends, and we would, I believe, be trying the impossible. 
It is true that nobody can live without some sort of hierarchy of values, even when it is purely contextual and when it changes according to the circumstances. Nobody thinks that all values are equally important. Every person witnesses numerous conflicts between values in his or her life and in most cases he or she has to decide which value has priority. The problems start when we try to go from the level of the individual to the level of a community and from the level of the purely circumstantial to a more abstract level (liberty can be most important for me today, but tomorrow it can be less important than equality). I fail to see how there can be a hierarchy of values that fits everybody's preferences all of the time.

People who reject the values promoted by democracy and human rights have to reject democracy and human rights as well. Other people who are indifferent towards these values can either be indifferent towards democracy and human rights as well, or they can accept them because it is not impossible that democracy and human rights promote other values that they hold dear.

A nother kind of conflict is the conflict between human rights and democracy. Although they need each other and are so intimately connected that the difference is sometimes hard to make, they can also harm each other. Think for example of the cases in which rights are used to overthrow a democracy, or think of democracy used by the majority to violate the rights of the minority. The failure to address this problem would of course undo the attempt to justify democracy and human rights simultaneously. I will conclude that the problem can be solved once we clear up some misunderstandings about the nature of democracy and human rights.

The conflicts between the counter-statements are also worthy of investigation. These conflicts are very helpful from my point of view. The different ways to reject democracy and human rights are not mutually compatible (they ask for both less and more equality, for an aristocracy and for the protection of the rights and the participation of minorities etc.).

\section{§ 6: Rejecting Democracy and/or H uman Rights Because They A re $\mathrm{N}$ ot Possible $Y$ et}

People often oppose the universal application of democracy and human rights because they believe that in some places, some of the prerequisites are absent. Their point of view is not that democracy and human rights are in themselves objectionable or undesirable, but that some countries are not mature enough yet (as in the case of economic prerequisites for example) or will never be mature enough (as in the case of cultural prerequisites for example). Instead of being undesirable, democracy and human rights are (as yet) impossible. I will have to deal with this line of argument, for two reasons. Firstly, because we will dispose of an additional reason to universalize democracy and human rights if I can show that the argument is incorrect. Secondly, because we will know what to do or change in order to universalize democracy and human rights if it is established that the argument is correct.

I will show that in some cases it is correct. Democracy and human rights are indeed conditional. They depend on certain prerequisites for their existence, survival and development. However, this is not a reason for fatalism or for the rejection of universality. It does not mean that democracy or human rights are impossible. The necessary conditions can be created. An example of this is the absence of media monopolies. It is impossible to introduce democracy if the pre-democratic and authoritarian monopoly ownership of the media is maintained. If this monopoly is not abolished with the introduction of democracy, then the old rulers will use their monopoly in order to maintain or to return to power. The absence of this kind of monopoly is a prerequisite for democracy but it is a 
prerequisite that can be created. The same is true for most if not all the other prerequisites.

What is most interesting is that democracy and human rights do a lot themselves to create or promote the conditions necessary for their introduction and survival. Instead of 'fit for democracy', we should say 'fit through democracy', in the words of Amartya Sen (1999). You can only become fit for democracy when you already have a democracy. Once democracy and human rights begin to win ground, they improve the chances of their own survival and future development. I will explain this in Parts 1, 2 and 3.

However, it remains a fact that, without important efforts, democracy and human rights are not universally possible yet, even if they are universally necessary or desirable. Fortunately, there are many different kinds of prerequisites and the absence of one can be compensated for by the presence of others. Furthermore, many so-called prerequisites are in fact merely excuses for rights violations and authoritarian government. If some people claim that a particular country is not yet mature enough for democracy and human rights, then it is very likely that these people have an interest in rights violations and authoritarian government. Those who suffer never claim that they are not mature enough for rights. We should not rush to conclusions. It is very tempting to call something a prerequisite, especially for opponents of democracy and rights.

Many supposed prerequisites are not really prerequisites. Culture is probably one of them. Democracy and human rights develop somewhere and have their origins in the life of a community, but this does not mean that their development in this community was necessary or that their development in other, very different communities, is impossible. Democracy and rights can develop in communities with very different cultures, even in communities that do not have a democratic tradition (take the case of post-war Germany for instance). They are connected, not to a culture, but to mankind and to the values of mankind. Of course, there can be elements in some cultures which promote the development of democracy and rights and elements in other cultures which hinder this development (perhaps Protestantism and Catholicism respectively). However, the main causes and prerequisites, namely the values which need democracy and human rights, are present everywhere.

The argument for cultural prerequisites implies that certain cultures are destined for democracy and that other cultures can never be democracies. At an even deeper level, it implies that cultures cannot and should not change. The different cultural identities must be protected against more powerful and hostile cultures engaging in cultural imperialism. A culture which is supposed to be incompatible with democracy must remain undemocratic for its own sake. However, this obscures the fact that cultures and traditions do change and often even want to change. On top of that, many traditions are not as old as they seem. They are often recent creations (anti-democratic traditions are in most cases inventions of authoritarian rulers). So why not create a democratic tradition?

\section{$\S 7: \quad$ A Problem of D efinition}

I have al ready referred to some problems with the definition of human rights and democracy. Especially the word 'democracy' is interpreted in very different ways and maybe this is a more important threat than the threat from the declared opponents of democracy. Is democracy a representative system, a system of direct participation, a system which necessarily violates or necessarily respects human rights? Were the totalitarian communist regimes democracies? They dared to call themselves democracies. People's democracies even, as if there is any other type. When we examine them in the light of the original meaning of the word - namely rule by the people - many of the existing democracies, even the 'traditional' western democracies, turn out to be at best only superficially democratic.

There are of course different competing definitions of democracy and human rights and this is perfectly legitimate (and also typically democratic by the way). What is unac- 
ceptable to me is a 'thin' or minimalist definition, both of democracy and human rights (even though such a definition would be easier to universalize). Democracy understood as no more than a means to choose leaders and render them legitimate, without much participation of the citizens in between election days, sometimes even without the need to respect human rights (the so-called 'procedural democracy' or 'illiberal democracy') is an example of such a minimalist view. This, in my view, is not democracy. Democracy should be the rule of the people by the people, not the rule of the people by the leaders chosen by the people. It should therefore make room for participation. A government is democratic to the extent that it permits and encourages participation in decision-making by those affected by decisions. In other words, to the extent that there is self-government.

A similar and equally unacceptable definition is the one in which democracy is merely a political system in which the government is forced to participate in a peaceful and competitive struggle for the votes of the electorate and in which the government is forced to take into account the wishes of the electorate because it depends on the votes of this electorate. This definition, known as 'competitive elitism' or 'leadership democracy', is unacceptable because you can have an undemocratic system in which the government takes into account the wishes of the people. A democracy in my view should do more than that; it should allow the people to realize their wishes themselves. Rule of the people - demo-cracy - is more than a system in which the people choose their rulers.

That is why democracy cannot be reduced to a system of elections. Human rights and participation - and there is no participation without human rights as I will show - are also important parts of an ideal democracy. Elections are useless if you do not have rights, if a candidate cannot express his opinion, if political parties are prohibited, if putting an $\mathrm{X}$ beside a name every few years is considered to be participation and if the people are not allowed to decide on issues as well as on people. The will of the people - a necessary part of every sound understanding of democracy (a people that does not have a will cannot be excepted to rule) - requires people participation. How can the will of the people come into existence in a meaningful way if the people do not have permission to debate, to demonstrate, to join groups and to decide on issues? The will of the people is more than the sum of uninformed, ill-considered and hasty reactions in the voting booth. Considering issues instead of persons is important if we want to have a meaningful will of the people, and there is no better way to consider an issues than by way of discussion and debate. The will of the people is a common opinion on issues that can only exist as the result of a common debate in which all arguments and all sides of a problem can become known. This publicity makes it possible for everybody to form his or her opinions based on the broadest scope of arguments in favor and against. It is only the sum of these kinds of opinions that can truly be called the will of the people.

This focus on debate and publicity is one of the reasons why democracy needs human rights and can only be protected if we protect human rights at the same time. Human rights guarantee debate and publicity. The statement that democracy must be rejected because the will of the people is necessarily ill-considered, emotional, stupid, based on instinctive and hasty reactions and so forth, is only correct if applied to a limited definition of democracy in which there is no place for public debate guaranteed by rights. Similarly, the statement that democracy must be rejected because it endangers the rights of the minorities and can degenerate into the dictatorship of the majority is only true if we consider democracy to be no more than a system of elections and majority rule, without the necessary link with human rights.

It follows that only a 'full' definition of democracy can be unobjectionable and coherent. A democracy without intensive and continuous participation of a large majority of the people (the 'demos') not only runs into problems about legitimacy, but also effectively loses the right to use the name 'democracy'. When we say that democracy means that the people govern themselves, then we mean that they have effective control over their lives. Since their lives are limited, determined and changed by laws, the people can only have control over their lives when they themselves make the laws. This means that a purely representative democracy is not enough because, as I will show in Chapter 4, representa- 
tion does not give people real control over laws. Only a system including at least some degree of direct democracy (e.g. referenda) will give the people real control. This direct democracy as well must be understood in the 'full' sense of the word. A referendum is not an expensive version of an opinion poll. It must be preceded by debates in which the will of the people can take shape in the way described above.

Political life is the name I give to the activity of the people shaping and realizing their will in a direct democracy guaranteed by human rights. Democracy is more than just a form of government, a system for making governmental decisions or an instrument to guarantee certain values. It is a way of life not strictly separated from everyday life. It is a way to be human and that is the reason behind the title of this book. 'H omo democraticus', or democratic man, is a man who lives democratically, who loves the democratic political life both because it guarantees a number of his most treasured values and because it is a value in itself. I will take a number of Chapters to explain this in more detail.

The full definition of democracy incorporates direct democracy. However, representative democracy also has some advantages. An ideal democracy will therefore be a mix of both indirect and direct democracy. In order to avoid confusion, the reader should understand the words '(in)direct democracy' as shorthand for 'the element of (in)direct democracy'. I will tend to avoid the latter expression for the sake of readability.

Human rights and democracy need each other; even more so, they are necessarily connected to each other, but only when we understand democracy in the full sense of the word. This explains why there have been and still are so-called democracies where the protection of human rights is not a part of government policy (the most famous of these is undoubtedly the democracy of the Greek city state, the 'polis', which nevertheless still holds a lot of meaning for us today, especially concerning the importance of political life).

I will also defend a 'full' definition of the concept of human rights, a definition that will in a similar way allow me to explain why there have been and still are non-democratic and even anti-democratic political regimes that seem to be able to protect human rights. The fact is that they can only do so if they restrict human rights to a small and specific number of rights and if they limit the meaning of these selected human rights. It is obvious that political rights, which are the rights that institute and protect democracy, cannot be guaranteed in a non-democratic regime. The so-called freedom rights or civil rights can be guaranteed but must be excluded from or made irrelevant to the political domain. Freedom of expression, for example, cannot include the freedom to criticize the government, otherwise a development towards democracy will be set in motion.

A full definition of human rights will include all types of human rights and will extend the meaning of all rights to all domains of social life. Economic rights for example will play an important role, even in the political domain. Political participation is very difficult when the participants' bellies are empty. The link between democracy and human rights loses much of its meaning when human rights are defined in a limited way, just as it does when democracy is defined in a limited way.

The link between all types of human rights can be a strategic disadvantage. It can be easier to universalize freedom rights without political rights or vice versa. However, this is not an option. All types of rights necessarily go together. They are interdependent and every type loses its meaning when considered in an isolated way.

These full definitions are of course ideals, but realistic ideals, at least in some circumstances. Throughout the different Chapters, I will discuss the possibility of democracy and human rights and the conditions necessary for their existence and survival. In general, I will use the words 'democracy' and 'human rights' to describe the ideals, not the facts. If possible, I will use the words 'existing democracy' or 'actual democracy' wherever I deviate from this rule. 


\section{§ 8: $\quad$ A Provisional Definition}

I defend these ideals with a certain hesitation. I am convinced of their value, but I know I have to defend them in a very specific way. Theory is the result of activity, of democratic activity, of discussion and deliberation by a plurality of persons holding different points of view and using different arguments. Theory is therefore not prior to or superior to politics. Political action is not an implementation of prior knowledge. It creates its own knowledge. Once we have a theory or a definition, the important work of politics is aready done.

A definition should always be a collective decision, not a decision of an individual imposed on a community. Therefore, what I am doing here can only be called a proposal and nothing more. What politics does with it is its business. I do not impose anything. I merely inject something into the public debate to see what happens. '[P]olitics is not the application of Truth to the problem of human relations but the application of human relations to the problem of truth. (...) What we would in any case seem to require in the real political world [is] (...) not absolute certainty but relative conviction; not philosophical incorrigibility but practical agreement; not ultimate knowledge but shared ends, common values, community standards, and public goods in a world where ultimate knowledge may be unattainable. (...) Truth in politics seems (...) to be something which is 'made in the course of experience' rather than something discovered or disclosed and then acted upon. (...) truth [is] (...) a product of certain modes of common living rather than the foundation of common life (...). M en and women would cease to regard themselves as citizens because they once consented to certain abstract truths. R ather, they would see themselves as capable of creating pertinent practical truths because they had become citizens. Citizenship is the root rather than the product of common value; consequently, there must be citizens before there can be common truth' (Barber 1984:64-5). Except then the 'truths' regarding democracy and rights which precede and create common life and citizenship.

Defining something is an inherently democratic activity, quite in the same way as justifying something. Describing the ways in which democracy can be defined is in itself amost the same as giving a definition of democracy, just as the attempt to justify democracy is almost a justification in itself. Since the act of defining something is a democratic activity or an activity that needs democracy, it is unacceptable that a definition of democracy fails to include certain essential characteristics of democracy. A definition of democracy is subject to the limits imposed by democracy. The word 'democracy' can mean very different things - national democracy, international democracy, corporate democracy etc. - but it cannot mean everything. Certain things are clearly not democratic.

A democrat has a theory of democracy (for example the one presented in this book) and wants this theory to become practice because he is convinced of the correctness and desirability of his theory. He is tempted to impose it, to subordinate the will and the judgment of the people to his norms and to force reality in a certain direction. This, of course, makes him undemocratic. He is afraid to act democratically and to let the people decide freely because, in his view, the people can choose tyranny or a misconceived form of democracy. He is a democrat but at the same time convinced that the people cannot decide for themselves. His 'democratic' theory, when it is imposed, is a heteronomous theory incompatible with autonomy and self-legislation. Citizens become subject to theories, practices and laws they did not participate in making.

This kind of democrat forgets that a theory can only be a consequence of practice. It is not the isolated individual but the people engaged in debate and deliberation who create theories, definitions etc. An individual imposing a theory and forcing society in a certain direction is by definition an anti-democrat. We should only make proposals and try to influence people. Democratic politics is acting and thinking together and is fashioned by a plurality of actors, not by individuals, even though exceptional individuals can play a predominant part. Pure and unthinking action is stupid. It must be possible to inject thoughts into actions, to influence and inspire actions and to fashion actions according to theories. Clear thoughts can assist our actions. However, we should never forget how 
dependent our thoughts are on actions. Democracy does not imply that theorists withdraw themselves from politics. It merely implies that they do not impose themselves and that they do not put their thinking in the place of the common thinking and acting of the people. Otherwise, they become elitists, even if their theories are very democratic in themselves.

As to the possibility of the people choosing the wrong things: it is obvious that the people are not allowed to choose against democracy because the choice of the people depends on democracy. It is not in the interest of the people to decide things which make their decisions impossible in the future. I will come back to this in Part 4.

Furthermore, theories are never finished. There is no last word. Theories can al ways be questioned because there is no end to the discussions. Every definition is provisional. It is not, therefore, my purpose to give a definitive definition and to end the discussions on the exact meaning of democracy and rights. That would again be very undemocratic. Of course, these discussions should not result in definitions which question the fundamental concepts of democracy, because otherwise they would destroy their own foundations. Definitions and discussions need democracy. Debate is not debatable, and neither are the institutions necessary for debate. Some things are beyond doubt. Too much certainty destroys politics and public discussion and reduces it to a repetition or implementation of an elitist theory. Too little certainty destroys the principles which guarantee discussion and political participation. Democracy is threatened when ideas are imposed on people, but it is equally threatened when everybody has only his or her own ideas and when everybody can question everything.

\section{§ 9: $\quad$ The $\mathrm{N}$ eed for $\mathrm{D}$ emocratic Imperialism}

Notwithstanding the desire to go from theory to practice, I will not discuss the problem of how to promote the universal application of democracy and human rights, of how to turn the norm into a fact (for example by way of intervention, sanctions, diplomacy etc.). We must have the courage of our convictions and apply our theories in the real world. Not doing so would be cowardice. If we say that democracy and human rights are universally valid, then we must also say how we can arrive at their universal application and what kind of action this implies, and of course we have to act ourselves. But the answers to the questions 'what is universal' and 'why is it universal' will already take so much time and space, that the questions 'how do we universalize democracy and human rights' and 'what are the instruments we can use' have to be postponed to a later date. I will, somewhat provocatively, call this kind of action democratic imperialism.

Is it not too late to fight for democracy? There does not seem to be an acceptable alternative since the end of the cold war, but this is in appearance only. Although in our day and age, there are maybe more democracies in the world than ever before and even big business starts to get worried about human rights, we see fundamental ism of every kind spreading, authoritarianism boasting its economic success in Asia, popular disenchantment with the old democracies of the West and façade-democracies everywhere. Having a clear statement of an ideal and of the reasons for adhering to this ideal will allow us to evaluate and change reality.

\section{$\S 10$ : A Short Description of the Purpose, the Content and the Structure of this B ook}

The purpose of this book is to argue in favor of the universal desirability of democracy and human rights by describing both as ideals that promote important values shared by most people in the world. The assumption is that most people will accept democracy and 
human rights once it is clear that there is a causal link between democracy and human rights on the one hand and some important universal values on the other hand.

I will discuss human rights and democracy simultaneously, except in the first two Chapters that deal exclusively with freedom rights (or civil rights). In the following Chapters I will introduce the subject of political rights and democracy as well as the link with freedom rights. Economic rights come last, in Part 2 dealing with the economic justification for democracy and human rights. This sequence is not arbitrary. It is based on the opinion that political rights cannot exist without freedom rights (although to some extent the opposite is also true) and that economic rights are but an instrument for the realization of both other types of rights. I will discuss the so-called collective rights in between other subjects, and it is therefore not surprising that this discussion will be rather dismissive.

The book contains five Parts and a Conclusion. Parts 1 to 5 give a detailed discussion of the five statements and counter-statements summarized above. Most of the theories, ideologies or 'schools of thought' that have had or still have an important influence on the theory or practice of democracy and/ or human rights will figure in one or more of these five Parts, although sometimes rather briefly. I can mention the following:

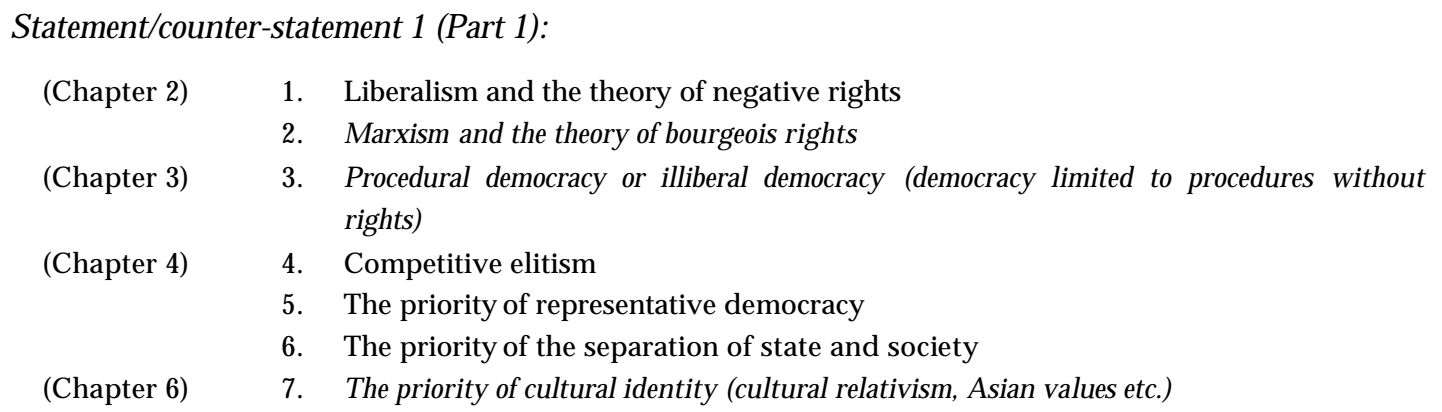

Statement/counter-statement 2 (Part 2):

(Chapters $7 \& 8 . \quad$ The priority of the economy

8)

Statement/counter-statement 3 (Part 3):

(Chapter 9) 9. The priority of peace, also called 'realism'

(Chapter 10) 10. The priority of harmony

Statement/counter-statement 4 (Part 4):
(Chapter 11)
11. Technocracy, guardianship, meritocracy, aristocracy
12. The priority of truth
(Chapter 12)
13. The priority of inequality (N ietzscheism)
14. M arxism and formal equality
15. The priority of efficiency, clarity, speed, security and certainty (the 'strong man' theory, authoritarianism)
16. The system of coalition governments in a multi-party system
17. The system of votebuying and the priority of the private interest
18. The size of the state
19. GLobalization and the powerlessness of the state

Statement/counter-statement 5 (Part 5):

(Chapter 13) 20. The priority of independence

21. The priority of the good life

(Chapter 14) 22. The priority of negative freedom (liberalism, anarchism)

23. The priority of equality over freedom 
(Chapter 15) 24. The dictatorship of the majority or the priority of the majority

25. Constitutionalism, the incompatibility of democracy and rights and the priority of rights over democracy

The theories or practices numbered $2,3,7,8,9,10,11,12,13,14,15,21,24$ and 25 (printed in italic) consciously reject human rights and/ or democracy, and are therefore in one way or another proponents of one or more of the five counter-statements. The other theories or practices also damage democracy and/ or human rights, but unconsciously and without really wanting to do so. Some of these theories might even call themselves democratic or in favor of human rights, but this would be acceptable only if we limit ourselves to a 'thin' definition of democracy or rights. As I have said before, such a thin definition may be more of a threat than an outright rejection of human rights and democracy. N eedless to say that these theories will not be discussed in detail. Many books have been written on every single one of them. I will limit myself to those aspects of the theories which have a direct impact on the problem of the universality of human rights and democracy.

In the Concluding Remarks which follow the five Parts, I will discuss the useful difference between universality and uniformity. I will show that there is some room for flexibility. Circumstances can and must be taken into account. The 'fullness' of human rights and democracy can vary from country to country and from situation to situation. 
Part 1: $\quad$ Public Life, Political Life and Cultural Life

$\bullet$

Chapter 1: $\quad$ Freedom Rights Protect Public Life

$\checkmark$

Section 1: $\quad$ The Importance of Public Life

\section{$\S 11:$ Important Values}

Human rights have many functions, but one of their most important ones is the institution and the protection of a public space and a public life for every individual. This is especially true of freedom rights or civil rights (which of course al so institute and protect a private space, in particular by way of the right to privacy and the right to private property). These rights protect public life because public life guarantees a number of important human values such as being able to form, experience and preserve an individual as well as a collective identity and being able to think more or less correctly. I believe that these values are important for all or most human beings.

The advantage of human rights is that they are equal rights that try to protect public life and the values attached to it for every individual in an equal way. That is what I will try to show in this and the following Chapter. We can of course have a perfectly happy life without having a public life, but then we relinquish the values that are protected by this public life. Let us not forget that we can also have a perfectly happy life with only half our brain. It is also true that we can have a public life without the protection of a state and its legal instruments (such as human rights, judges, police etc.). However, public life would then be fragile, uncertain and most likely unequally distributed among individuals.

In the third Chapter of this first Part, I will try to show that, whereas a private life can to some extent be protected by an authoritarian regime (in particular when such a regime respects the relatively harmless right to privacy), only a democracy can protect a public life because only a democracy can protect human rights (as I have said in the introduction, the opposite is also true: freedom rights protect political life and democracy, and once these rights exist, a trend towards political life and democracy tends to develop).

On top of that, democracy also contributes in a direct way to the protection of public life: our democratic political life is a part of our public life (politics is necessarily a public matter in a democracy, public in the sense of visible and accessible for everybody) and the democratic struggle for power promotes struggle and conflict in society (conflicts in society are part of public life, as I will show in a minute). I will explain this in Chapters 3 and 4, together with the fact that political life is important in itself because it promotes values such as community life, activity and responsibility, knowledge, individual and collective identity etc. Some of these values are also promoted by public life, others not. All this can be put into the following drawing (in which an arrow means "promotes"): 
Drawing 1: The Link Between Rights and Values

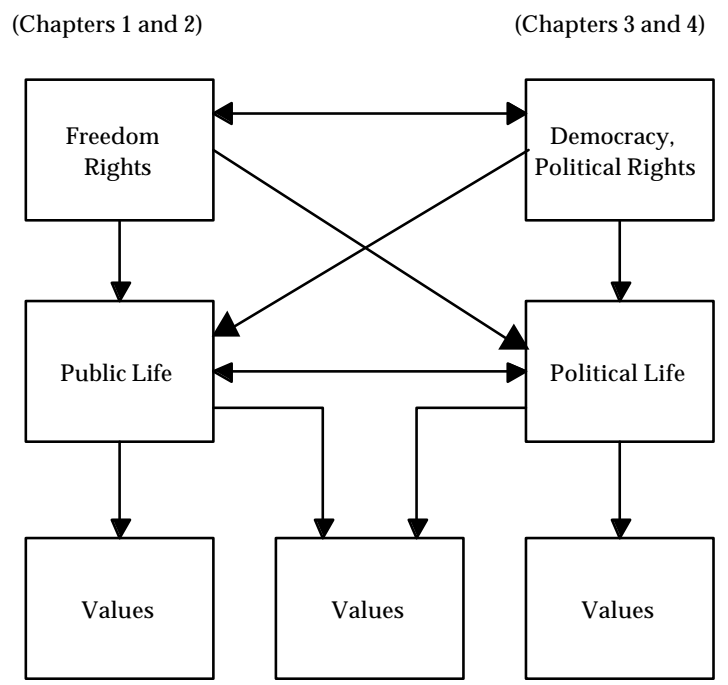

I am conscious of the fact that not everybody will be convinced by this justification of human rights and democracy. Those who desire nothing but a completely private life or a hedonistic life devoid of any public communication or political involvement will have to skip this first Part - except the paragraphs explaining the protection human rights offer to private life - and may find something in Parts 2 to 5 . However, I am sure that, once I have explained the meaning of the words 'public and political life', most of the people in most cultures of the world will agree that they refer to something valuable. Which of course does not mean that they will agree that there is a link between these concepts on the one hand and human rights and democracy on the other hand.

Man will be the central concept in this first Part because I will be discussing values that are important for the whole of humanity or, to put it in another way, for man as a human being, no matter where he lives. This emphasis on things common to all men is not out of place in a book dealing with human rights. In Chapter 6 at the end of this first Part, I will give a detailed account and criticism of the first counter-statement. This counter-statement puts the emphasis not on humanity and what it has in common, but on the division of humanity into separate groups, namely cultural groups each with their own different values. According to this point of view, all things common, and especially human rights, tend to destroy culture and difference. The way to invalidate this counterstatement will be to discuss the importance of human rights and democracy for group identity (democracy is useless without groups, and human rights protect group life as much as individual life).

\section{$\S 12:$ W hy D o We N eed a Public Life?}

Human rights protect our public life, but why do we need a public life? And what is this public life? How does it protect certain values, and how is it protected by freedom rights? Let me start with the first two questions. A public life is a life dedicated to publicity, to public deeds and words, not necessarily in an active way; maybe only in a passive way. Publicity is open interaction, taking place between as many people as possible and with as little limitations as possible. Hidden, private, secret, clandestine or prohibited interaction is not public interaction. 
I will not use the word 'public' in a legal sense. Public law regulates the relationships between the citizens and the state (for example criminal law, constitutional law etc.), while private law regulates the relationships between citizens (for example the law of commerce or the law of succession). This legal way of understanding the word 'public' is too limited for my purpose. (This legal definition also leads to confusion. Hannah A rendt (1992:95) states - and I agree - that the separation of church and state has not transformed religion into an entirely private or intimate affair. Only a tyrant can destroy the public role of religion and churches and can destroy the public space where religious people meet. However, because of her purely political interpretation of the word 'public', she is forced to use the awkward expression 'secular public space' in order to describe the sphere of politics or the state, and the equally awkward expression 'religious public space' for the space left vacant by politics in a system which is characterized by a separation between church and state. She seems to define the word 'public' in a very limited way (public = politics), but also speaks of all forms of public relationships, social as well as political' (A rendt 1990:170). Habermas struggles with the same contradictions: his 'Öffentlichkeit' is a space where private citizens can act in a critical way towards the public political domain. Castoriadis similarly reduces the public to the political: The emergence of a public space means that a political domain is created which 'belongs to all'. The 'public' ceases to be a 'private' affair - of the king, the priests, the bureaucracy, the politicians, and the experts. Decisions on common affairs have to be made by the community', Castoriadis 1991:112).

A public life, in the way I understand it, consists in the first instance of sets of relationships between citizens, although the relationships between the state and its citizens can also be part of a public life (democratic political life is a part of public life, as I will show later on). The public space is larger than the space of politics and the state, although in a democracy the latter is part of the former.

Human life is of course impossible without relationships. We all live in society. No one is self-sufficient or 'atomized'. Man is always a fellow man; existence is always coexistence Other people are there before we are. We need interaction and communication with other people - first our parents but not just our parents - in order to be able to think. Moreover, thinking has to transcend the private sphere because it is dependent on other people besides our relatives, friends and private acquaintances. It needs public interaction. The ability to think is not created and developed in any arbitrary group, but only in a community - if possible the world community - in which publicity reigns and in which there are rules and laws that can enforce this publicity. Immanuel Kant correctly stated that the authority that takes away the freedom of expression also takes away the freedom to think, a freedom usually considered to be inalienable (Kant 1992:87). Thinking needs the public use of reason. Thoughts are not something you develop on your own or in some small and closed group. You first need to listen to as many thoughts as possible in order to develop your own thoughts. (Or, which can be the same thing, you need to read books. Books are thoughts made public, which is why they are called publications). Listening to as many thoughts as possible, expanding the sources of thoughts and information, can only be done by making them public. Thinking, the inner dialogue, is always the result of a public dialogue. How much would you think if you would never speak to anyone, or even if you would always speak to the same, small and private group of people? Thinking needs thoughts that come from outside of your own limited group.

However, not only the ability to think as such, but also the ability to think in a more or less correct way, with as few mistakes as possible, depends on publicity, which is another thing we learned from Kant. By making your thoughts public and thus submitting them to scrutiny and tests by other people - first and foremost to those who are not your private or personal friends, because they might be too kind for you or too like-minded - you are forced to say how you came to have these thoughts and to give an account of the reasons why you have these thoughts instead of others. This will force you to reflect on the reasons and, if necessary, to look for better reasons. Giving a public account of your reasoning, or knowing in advance that you will give this account, makes you very critical 
of yourself and helps you avoid mistakes. Nobody wants to make a fool of themselves. This means that you confront - or prepare to confront - other people and their (possible) objections, not only in order to disprove their objections, but also in order to disprove or possibly improve your own opinions.

Publicity improves the quality of thoughts both because of the a priori self-criticism that it promotes and because of a posteriori testing by other and not necessarily like-minded people (a phenomenon well known in the scientific community). '[A ] particular issue is forced into the open that it may show itself from all sides, in every possible perspective, until it is flooded and made transparent by the full light of human comprehension' (Kant in Arendt 1982:107). If you want to improve the quality of your thoughts, then you need publicity on two levels: first you have to make your thoughts public, and then you have to listen to public arguments. This means that you as well as your opponents have the right to be heard and to defend arguments.

This is the link between publicity and human rights. Giving a public account of your reasoning and taking into account objections, is possible only when you can put yourself in the place of someone else, think like someone else, look at things from another side or perspective, act as if you hold a contrary point of view. This, in turn, is possible only when different perspectives and different points of view are freely expressed. Human rights and in particular freedom rights can help to achieve this (Kant's imagination can also help but is probably not enough). Putting yourself in the place of someone else, looking at something from another point of view or another perspective helps you to better understand things, just as looking at an object from another point of view helps you to better perceive the object. Without human rights, many valuable points of view or perspectives will not be made public, and many valuable objections and counter-arguments will not be known to someone defending a certain thought or idea. This can diminish the degree of correctness of the thought or idea in question.

Thinking correctly means thinking in community with others. Of course, I use the word 'correctly' not in an absolute or scientific sense. The debate is open-ended, new arguments or new objections can always emerge and can lead to an even better understanding. Correctness in this sense can only be an approximation.

If you consider thinking and thinking correctly to be valuable activities - and it is hard not to, because without thinking you cannot consider anything - then publicity or public life as well as the rights that are necessary for its protection must al so be valuable.

The fact that thinking is not an isolated business contradicts a well-known intuition. 'Thinking (...) is the silent dialogue of myself with myself $(. .$.$) and (. .$.$) is a 'solitary business'.$ (...) Also, it is of course by no means true that you need or can even bear the company of others when you happen to be busy thinking; yet, unless you can somehow communicate and expose to the test of others, either orally or in writing, whatever you may have found out when you were alone, this faculty exerted in solitude will disappear' (Arendt 1982:40).

I have said before that we should try to expand the public space beyond the national boundaries. Ideally, the other people who we need to think and to think correctly are not only our compatriots but also the rest of humanity. A global public space is the natural consequence of the widest possible extension of sources of thoughts required for thinking and the widest possible confrontation with counter-arguments and different points of view required for the correctness of thinking. Only by living in this kind of global public space can we hope to become Kant's world citizen or 'W eltbetrachter' and can we avoid national prejudices or national one-sidedness. The western feeling of superiority, for example, needed colonization to become aware of its errors. Both the private sphere and the national sphere have to be transcended in order to transcend our curtailed, narrowminded, one-sided, prejudiced and unthinking existence. A life completely dedicated to intimacy, to that which is your own (idion'), far away from the common world, is by definition an 'idiot' life (A rendt 1983:76). The same thing can be said of life limited to a (national) group.

As for human rights, it is quite certain that they cannot do their job in the global public space as well as they can in the national one. It is difficult to enforce the protection of 
public communication between an A merican and an Iraqi. The best we can hope for at the moment is the establishment of a chain of national public spaces protected nationally by national human rights instruments, although one should not underestimate the effect of cross-border action in favor of human rights. (A topic that is outside the scope of this book). Ideally, human rights can only be justified when they are applied globally. A purely national application in the midst of an anti-human-rights world would lose much of its meaning.

J.S. Mill (1977:1115) has given another reason why human rights promote correct thinking. An opinion is not a purely personal possession and the act that inhibits the possession or the expression of an opinion is not a purely private crime. Suppressing an opinion is a crime against humanity. If the opinion in question is correct, we make it impossible for humanity to distinguish right from wrong. If the opinion is false, we make it impossible for humanity to make what is right more apparent by confronting it with that which is wrong.

Public life also plays a part in the development of an individual's identity, at least to the extent that this identity is consciously created at all. Establishing your identity is intimately linked to thinking and, in the same way as thinking, it is not a purely private, individual or inward activity. It takes place in society and in the institutions of society. You become who you are by thinking, by developing your ideas. To a certain extent, your thoughts, ideas and convictions determine who you are, determine your identity. If thinking depends on publicity, then identity or personality as well depend on publicity.

You also become who you are by expressing yourself, by saying, doing or making things visible to all, by distinguishing yourself (all of which implies the existence of a public or an audience). Thoughts take shape only when they are expressed or prepared to be expressed. By expressing and showing yourself, you make things public about yourself, things that were a secret before, sometimes even a secret to yourself. In this way, you get to know yourself and you shape your identity.

Furthermore, you shape your identity by looking at others, by studying them, by following them or by wittingly contradicting them. An individual identity needs a group in which there is a public life in the sense of showing, listening, following and contradicting (although groups are of course also the product of individuals). 'P olis andra didaskei' , the individual is shaped by the 'polis'.

Because groups not only promote but sometimes also hinder the creation of an individual identity (they can for example be ideological 'schools' or dogmatic churches enforcing conformism), it is important that membership is free and that communication, revelation, studying, following, conflicts etc. taking place inside these groups, are as open and as free as possible. In other words, they should have a public character on top of or instead of their private character.

I will discuss the problem of group pressure, conformism etc. in more detail in Part 5, which deals with freedom. However, al ready now it is useful to point out the difference between identity and individuality. Identity can imply conformism, wittingly or unwittingly. You can define your identity by conforming to a group with a certain identity that you either like or imperatively adopt because of education, propaganda, brainwashing etc. In the latter case, you have an identity, but not necessarily an individuality. You can only have an individuality if:

(1) You consciously choose the identity of a group as a consequence of reasoned reflection of a public nature (of the kind discussed above); and

(2) You have personal and unique characteristics on top of the identity of the group you have decided to join.

Conforming to a group in order to acquire an identity is very important to most people, and rightly so, at least as long as there is room left for individuality. Most people do not feel that their personal uniqueness - which is a fact anyway - is enough to give them an 
identity. They believe that only a link between them personally and something outside of them that they consider to be important - for example socialism - is able to give them an identity (Taylor 1994:46). Most of the time, establishing this link can best be done by joining other people with the same idea - for example the community of socialists. This feeling of belonging to an important group also guarantees that the rest of the world is aware of your identity. The feeling of belonging to something important is crucial here. You do not have an identity because you belong to the community of people with red hair. But even the individual identity or individuality can only exist because of a link with something important, such as an event you have witnessed or caused etc. You do not have an identity because you are the only one with blue hair. Your individuality is not the consequence of a unique but arbitrary characteristic, event or sequence of events.

The process of shaping an identity through group conformity requires publicity and human rights. Groups must be allowed to exist, to make publicity for their identity, to convince people to join them etc. All these things are explicitly provided for in human rights. The process also requires democracy because it implies an egalitarian society. You cannot at the same time emphasize the importance of people shaping their identity and individuality, and accept a hierarchical society in which a people's identity is determined by their social position, role or activity. A democracy, moreover, needs groups because it needs majorities, minorities and political parties. And because it needs groups it tends to protect groups.

It is clear from all this that language and therefore also education and the struggle against illiteracy are extremely important for public life. Language is more than just an instrument to represent or translate reality or to transfer messages (Taylor 1994:10). It also has the power to constitute the human person, to express, understand and develop our personality or individuality, to promote thinking etc. Language, therefore, also creates reality.

The fact that public life and the values resulting from it require the presence of other persons and meeting other persons, does not exclude the possibility of solitude and even Ioneliness. The presence of others can be indirect, for example by way of a book. Sometimes it is even useful to be alone, for example when we want to study, to open up sources of ideas and information etc. This kind of solitude is not the same thing as the absence of relationships. It is not a private solitude, but a public one, if I may say so, be cause it requires the presence of a book; and a book is a public thing (it is a 'publication', the thoughts of someone made public). It is the indirect presence of another person. 'Proust (...) ne croyait plus en la conversation ni d'ailleurs en l'amitié. C'est même de sa longue pratique de la parole vive qu'il avait tiré, contre Sainte-Beuve, la certitude d'un abîme entre le moi social et le moi profond. $M$ ais justement les livres sont silencieux et leur auteur absent. On peut donc les aimer sans faire de manières et sans s'inquiéter de ce qu'ils ont pensé de nous: ' $D$ ans la lecture, I' amitié est ramenée à sa pureté première. A vec les livres, pas d'amabilité'. Et c'est la même image que l' on retrouve chez A rendt quand elle définit la personne cultivée comme quelqu'un qui sait choisir sa compagnie 'parmi les hommes, les choses, les pensées, dans le présent comme dans le passé' ' (Finkielkraut 1996:59).

Reading means having a public life because it means participating in a public phenomenon, namely the published book. This is apparent in the description of the community of readers as the 'public' of the writer (it is still more apparent in the French language in which 'le public' literally means the audience or the readership). A public space does not only contain people who disclose something. It also contains the people to whom something is disclosed. Persons who never meet each other can have a conversation and can even arrive at a common opinion (which, by the way, invalidates a lot of the arguments against direct democracy, but I will come back to this in Chapter 4). 


\section{$\S$ 13: Public and Private}

The publicity, the openness, the light and the revelation in the public sphere can only exist simultaneously with a private sphere that is secret, dark, intimate and closed. Privacy is of course also an important value, which is shown by the fact that people usually dislike intrusions into their private sphere. It is, like the public sphere, protected, and probably best protected, by human rights. (This is another justification for human rights). It includes the family, the house, but also 'I' intimité du coeur', the strictly personal domain. In spite of language, communication and revelation we never completely know somebody ('I' identité intangible' ). Often we do not even know ourselves. Our motives, for example, are by definition invisible and often unclear even to ourselves. Although the private sphere is important, it is not enough. In French, 'être privé de quelque chose' means a lack of something. Only a public life can guarantee certain important values.

The difference between the two spaces is not just a difference in degree or scale. (There are some who want to organize the public space according to the rules of the private space: an authoritarian father figure leading the community and the state and taking care of the people as though they were his children). It is a difference in kind that has to be preserved because both spheres have their own valuable characteristics. Destroying one sphere for the sake of the other is a common but misguided effort, which invariably leads to the destruction of both (the one sphere can only exist if the other exists as well, because the one is defined by using the mirror image of the other).

Public and private are and should remain separated, but there is an overlap. Part of the private life you share with someone else can be a part of your public life. You can have a private love affair with someone and, thanks to this other person, you get to know the published and public work of a writer. Part of our education, the transfer of public knowledge from generation to generation, takes place in the family.

The same thing happens the other way around. A private matter can take on a public nature, for example the love affairs between Le Cid and Chimène and between Dido and Aeneas that became a public and political problem (a bit like some of the love affairs of contemporary politicians). The private sphere can enter into the public sphere and vice versa. The former can sometimes even institute or restore the latter: 'the M others of Plaza the $M$ ayo (...) effectively put into question the dividing line between the personal and the political: their grief as mothers became the first intensely private issue to reconstitute a public space hitherto closed by the government' (F. Panizza in Beetham 1995:169). The same thing can be said of the social movements for the emancipation of women, workers and slaves.

Sometimes the public sphere has to intrude in the private sphere. An example is the father who is condemned for incest. Private life becomes a public matter, just as in the previous examples. The law also rules in the family. Although the public and the private are two different spaces that should not be united, they are never completely separated, independent or unconnected. There are always private faces in public places' and 'public faces in private places' (W.H. Auden in Foqué/ Weyembergh 1997:59).

The need for the lasting existence of two separate and different spaces and the unacceptability of one sphere dominating or destroying the other, do not preclude the possibility of a moving border between the two spaces. The public space can legitimately and within certain absolute limits encroach upon the private space, and this can happen against the will of the latter, for example in criminal law. The public space can determine the limits of acceptable private behavior, and these limits can move. Human rights discussed and claimed in public - for example the right to physical integrity - are one way of determining these limits, even though their most important function is to serve public life. Conversely, the private sphere can extend at the expense of the public sphere, in most cases also by way of human rights. Religion for example was for a long time an exclusively public matter. Your religion was known by everybody and in many cases imposed by the state and the official church. Nowadays, it has also become a private affair (without losing its public function), left to the autonomous choice of every individual. 
The moving borders between the two spheres are decided upon in the public sphere, not in the private sphere. The private sphere does not decide autonomously and privately how far it can go, what it can do and what can be considered as private. This is done in the public sphere. The private sphere uses the public sphere to protect itself. The public sphere on the contrary decides autonomously how far it can go, although it cannot go further than what is allowed by human rights. By way of public conversation, the people try to achieve a consensus or a majority decision on the problem of acceptable private and public behavior and on the problem of the borders of both spaces. It is evident that this agreement is always provisional and open to new and better arguments. There is never a last word, an end to the discussion or a final decision in the public space. The requirement that decisions are limited by what is allowed by human rights is not asking too much, given the fact that public discussion is dependent on human rights.

\section{$\S$ 14: General and Particular}

There is another way of describing the difference between public and private. The public sphere is the world of things that are general, common and shared, of things that belong to everybody and not just to somebody specific. Works of art, knowledge, culture etc. are examples of public things. Private things, such as a house, possessions or a lover, are not shared in the same way as public things. The word 'public' comes from the Latin word 'poplicus', which means belonging to the people, the 'populus' .

The private space is a space of your own - it is your space and not somebody else's. You do not share it, except with the people of your choice The private sphere is not a common world. Public communication or revelation is not meant for a specific public, but for the public in general. When you receive public information, you receive information that was not meant for you in particular but for everybody.

\section{$\S 15: \quad$ General and Private Inter est}

That is why there are many private spaces and only one public space. The private space is my world and your world; the public space is our world. The opposition between the private interest or self-interest on the one hand, and the public or general interest on the other hand, is linked to the opposition between general and particular. Caring for the general interest is caring for those things that are general and common to all. Caring for the private interest is caring for those things that belong only to individuals. This means that caring for the private interest of another individual, is not the same thing as caring for the general interest, not even if you care for the private interest of all individuals. Caring for the general interest is caring for specific things, namely those things that are common and public. The general interest is the interest of the common world.

Egoism is therefore something that is totally alien to the public world. From the moment you think egoistically, you leave the public space and enter the private one (the opposite is not true: you can care for private interests without becoming egoistic, as long as you care for other private interests on top of your own private interest). Property, economy, biology, food, shelter and all things which we can want in an egoistic way are all at home in the private space (this is true even of things which can be public things, such as power or works or art; these things become private things once they are coveted in an egoistic way).

The problem, however, is that public life can be criticized for being egoistic. Does it not reflect a purely instrumental use of other people? I need other persons for myself, for my thinking, my identity etc. The other person is valuable as long as he or she fulfills my needs. This is only a problem when it hurts the other person and when it becomes the 
only preoccupation. Since you need the other person, you will tend to be caring instead of egoistic.

Egoism is caring only for your self-interest and for the things that you (can) possess. Public life is caring for the common world, for those things that are common, and thus for the common interest. Self-interest and the general or public interest deal with totally different objects or goods. The general interest is not identical to the sum of all the private interests, which is also shown by the fact that the latter sometimes have to give way to the former, for example in expropriation. The general interest is not even the sum of the majority of individual interests, contrary to what is implicit in the former sentence. The common world, cared for by way of public action in the service of a general interest, is an entirely different world than the private world.

The general interest is established and pursued, not by way of adding up and pursuing a sum of individual interests, but by way of public discussion and common action. The general interest is, what the people say it is, after they have discussed the matter. By definition, it cannot be determined in an authoritarian way by a minority or a single person, not even by an authoritarian majority. N ot so much because then the interests of other people or the plurality of interests would be denied, but because it deals with caring for the common world, for the things which everybody holds in common and on which everybody has by definition an equal say. An equal say does not necessarily imply unanimity in decision procedures. For practical purposes, a majority may be allowed to decide on the general interest, but only if it respects the human rights - the gates to the common world - of the minority. The general interest is an interest which we cannot know on our own and which does not preclude the existence of different and contradictory individual interests. If we could know the general interest on our own, then this would mean that we claim the right to be the only ones to have a say on things which are the possession of everyone.

\section{$\S 16:$ Equality}

It follows from this that the openness of the public space is an equal openness. No voice is privileged. Everybody can speak and listen freely and equally because the public world is a common world, a world therefore that belongs to everybody equally and that can be used and discussed by everybody equally. It is obvious that this is the ground for claiming that everybody has equal human rights. The right to participate in public life is an equal right. The public space is not a closed space - it is open for everybody and for everybody to the same degree. Everybody can speak and every message is meant for everybody. Nobody is excluded, neglected or oppressed. There is no authority, no higher power or true voice that has to be followed in silence. Again it is obvious that this will lead us to democracy because democracy guarantees that everybody can have an equal say in the business affecting the common world.

If every voice has equal rights and if everybody can speak and listen freely and equally, then everybody must be tolerant and accept the existence of other opinions and convictions. Plurality or a lack of unity, heterogeneity, contradictions and diversity on the one hand and tolerance of diversity on the other hand must be part of the public space. (The private space can of course be totally different). This means that we must have a free and diversified press and human rights in order to protect diversity and enforce tolerance.

The equal openness of the public space and the fact that there is only one public space contrary to the large number of private spaces, indicates that, in theory at least, the public spaces encompasses the whole of humanity. In practice though, there are local public spaces, for example the one instituted by a national state, the stage of a theater, a newspaper etc. which are all 'places' in which by and large the same relatively small group of people interact. These local spaces are very important, but, for the reasons given above, we should try to expand the public space to its natural limit, which is the whole of hu- 
manity. This universal or meta-local public space (Taylor 1996:passim) is not linked to one limited physical or metaphorical place and connects all the local spaces. However, as I have said before, this does not require that the people from each space necessarily meet those of other spaces. The discussion taking place in one space can be connected to what has happened or has been said in another, and can have a consequence tomorrow in a third space etc. (Taylor 1996:88). Discussions evolve in and through different places. The problem is that the less local a space becomes, the more difficult it becomes to protect it.

\section{$\S 17:$ The Element of Time}

The public space in which all voices are free and equal and in which voices can be confronted with each other, is not only trans-local, but also trans-temporal or transhistorical. You also discuss, criticize, refute or follow those that have inhabited the public space before you and you express yourself also for the benefit of those that have yet to be born (Castoriadis 1991:17).

Discussing with the past or speaking to the future requires some kind of permanence, and the best way to have permanence is to write your thoughts down on paper. A book can be preserved. It keeps the mind alive, even after the body has died. The discussion with a book is certainly not a one-sided discussion. It is not the same thing as speaking to a wall. A book can ask a question, can give an answer etc. Books, therefore, play an important role in public life, especially but not exclusively in the trans-historical part of it. Books are also useful means to transcend space. Public life without books does not survive. Again we see how the right to free speech can help to protect public life.

The moment that speech stops its activity, it disappears (see Arendt 1983:259). Public life needs permanence or durability, but is itself also a prerequisite for durability. All that men do, say or think is by definition evanescent. Only in a public space that needs books to function adequately can there be permanence. Publicity in the form of a book guarantees that future generations can still see what happened before and that the common world survives the coming and going of generations. 
Section 2: $\quad$ The Protection of Public Life

$\S 18:$ Free Speech, F reedom of A ssociation and F reedom of A ssembly

Public life guarantees a number of fundamental values of humanity, values without which human life is incomplete and diminished and may even cease to be human. However, it can do so only when protected by human rights and in particular freedom rights. Public life and the values attached to it justify the global existence and protection of human rights. Without human rights, public life is fragile and uncertain. It must be possible to enforce public life and this can be done by creating political and judicial institutions in which it can have a structured, formal and stable existence. Human rights are one such institution; a judicial system which can enforce human rights is another. Of course, the type of political association, the political structure of the nation or the form of government have to allow for the existence and the functioning of these institutions. Only then can the fragility of public life be eliminated and can public life be given a permanent, stable and predictable existence. (There are other types of institutions that do the same thing. Parliament, democratic elections and court proceedings also institutionalize public life because they institutionalize debate, contradiction, argumentation etc. I will come back to these other institutions that protect public life. For the moment, I will limit myself to freedom rights).

How do human rights, and in particular freedom rights, protect public life? Let us take a look at the most important freedom rights, one by one, starting with the right to the free expression of opinions. This right does not protect the possession of an opinion without external interference or coercion (this is more the domain of the freedom of thought). It is not the separation of individuals but the relationships between them that are protected by this right. It enables people to express their opinions, to show who they are and what they think, to object to certain thoughts, to spread information, to communicate, to debate, to make publicity for a cause or a group etc.

It is, however, not only a right to free expression. Perception, gathering information, opinions and thoughts, following an example, studying etc. are also protected under this right. This is manifest in art. 19 of the UDHR that speaks of the right to seek, receive and impart information and ideas' (for a full list of human rights, see the appendix). Public as well as private expression and perception are protected. The link between on the one hand this right to speak and listen in a public world and not only in a private world, and on the other hand the values protected by the public world, is beyond question. The right to free speech is the right of the public world 'par excellence'.

This right implies a certain understanding of the word 'freedom'. I do not want to discuss the concept of freedom at this stage of the book, but later in Part 5. For the present purpose, however, it is unmistakable that the word 'freedom' as it is used in the concept of the freedom of expression is understood as the possibility of saying what you want, without limits or coercion. I will show in Part 5 that this meaning of freedom - the ability to do or say what you want without impediments - is only one among many possible meanings and one which, taken by itself, is not the most important one. 
The right to free speech is closely connected to the right to free association (the freedom to form, join and leave groups) and the right to free assembly (the freedom to gather, meet and demonstrate). People who associate with others and meet others are able to give additional power to their opinions and their voice This is especially the case in political matters. A single voice is useless in democratic politics except when it is the voice of an exceptional individual. A violation of one of these two rights is therefore de facto also a violation of the right to free speech.

Groups and meetings need freedom of speech to be able to function (groups needs to promote their identity in order to attract members; meetings or assemblies cannot function if no one or only few people are allowed to speak). However, the opposite is also true: before opinions are expressed, they may have evolved through participation in a group or a meeting. The right to freedom of association and the right to freedom of assembly are not only linked to free speech, but also to all other rights. Sometimes it is necessary to associate, assemble and demonstrate in order to enforceother rights.

These two rights protect public life because they protect the freedom of speech, but they also protect public life in a more direct way. I have shown that a part of public life takes place in groups and meetings. Groups are important for the shaping of an identity and for the feeling of belonging to something important. Meetings are important for the transfer of thoughts, opinions and information.

Human rights are clearly indivisible and mutually dependent, which is not surprising in view of the fact that they all serve the same purpose. I will show later on that this is also true for other rights (for example, freedom of movement is necessary to be able to assemble and to demonstrate; the right to privacy needs the right to free speech, and vice versa, because there is no light without darkness).

\section{§ 19: The Rule of Law and the Separation B etw een the State and Society (1)}

Human rights institute the rule of law and this is another way in which human rights protect the public space (for the way in which human rights institute the rule of law, read art. 7-12 of the UDHR which for example protect the right to a remedy by a judge for acts violating rights granted by the law, which prohibit arbitrary arrest - arbitrary arrest being an arrest not on the basis of a law or a ruling of a judge - and which also prohibit conviction or punishment for deeds that do not constitute an offense under the law). The rule of law protects the law from possible abuses of power and makes it to a certain extent independent from power and the state; and, by doing this, it also makes the public space independent from power and the state. What does this mean, protecting the law and the public space from power and the state, and making them independent from power and the state? Let us start with the law.

You can make the law independent from power and the state by making power and the state dependent on the law. The law rules instead of those in power or in possession of the state ('les lois gouvernent plutôt que les hommes'). The law does not coincide with power, and is not a consequence of power. The opposite is true: one can have power only because the law says so. Power does not say what the law is or who can make laws; the law says what power is and who can have power. Those in power can only act at the explicit command of the law, and in accordance with the law. 'A lle staatlichen Tätigkeiten, auch Gesetzgebung und Regierung, lösen sich auf in ein nach vorher bestimmten N ormen vor sich gehendes, berechen bares Funktionieren. Alles ist in einem $\mathrm{N}$ etz von Kompetenzen eingefangen' (Schmitt 1993:131). 'N ur ein Staat, in welchem die gesamte V erwaltungstätigkeit, insbesondere die Polizei, unter dem V orbehalt und Vorrang des Gesetzes steht und Eingriffe in die Freiheitssphäre des Einzelnen nur auf Grund eines Gesetzes zulässig sind, heisst dann ein Rechtstaat' (Schmitt 1993:130).

Especially the police and the other branches of the executive power can act only under the guidance of the law. They are the ones who can do most harm when they do not act according to the law, not only because of what they do in such cases, but also because of 
what they fail to do. They are or should be the executors of the law, the power that guarantees the law and that even, if necessary, uses force and violence to coerce conformity to 'the will of the law'. Therefore, if anybody should respect the law, it is the executive power and especially the police. If they do not respect the law, they - just like everybody else - expose themselves to judicial proceedings coming from another branch of state power, namely the judicial branch. The rule of law is therefore necessarily linked to the separation of powers. 'Recht und Gesetz können nur da wahre Bedeutung und M acht gewinnen, wo sie einen Richterspruch zu ihrer Verwirklichung bereit finden' (O. Bähr in Schmitt 1993:132).

The state is not above the law, and, what is more, every action of the state is part of a legal competence that is given beforehand and enforceable by way of judicial proceedings if not respected. The state cannot do what is contrary to the law, and it cannot even do what it is not entrusted to do by the law. However, to enforce this limitation there must be a separation of powers. An independent power must have the ability to defend the law against another part of the state that transgresses the legal boundaries of its power, either by violating the law or by becoming active in a domain that is not regulated by the law. This independent power must be a part of the state, because only a part of state power can correct another part of state power. There is no power that is higher than or equivalent to state power (unfortunately, the international community can only occasionally correct state behavior).

The state should not command or coerce people to do things that the law does not prescribe, and should not forbid people to do what the law does not forbid (read also art. 5 of the Declaration of 1789). However, what the law prescribes must be done, and what the law forbids must be left undone, by everybody, the state as well as its citizens. The law rules, and the state has to do what is necessary to make it rule, as regards its own behavior as well as the behavior of its citizens. The state is the guardian of the law. This shows that the rule of law is not just a ploy to control the state. The law rules over everybody, citizens as well as the state.

Now to the second question: how does the rule of law protect the public space and how does it make the public space independent from the state? A state that is bound by law is a limited state. It is not necessarily a weak state, which is a reproach often directed at the rule of law in general and democracy in particular - an ideal democracy is al ways a rule of law because an ideal democracy always respects human rights. A limited state can be very strong, vigorous and effective within the imposed boundaries of power, even more so than a state that tries to do everything.

When a state is limited in its actions by the law that says what it can and cannot do, a free society independent of power is created. State and society become different spheres and in the latter an independent public life can start to blossom, undisturbed by state interference and coercion. Of course, civil society does not fully coincide with the public space. Private things happen in civil society, and political life al so takes place in the public space. It is clear however that the rule of law is more than a protection of the individual against the over-powerful state (' la liberté du citoyen contre la gloire de l'Etat' ). It transcends the level of the individual because it institutes the public space.

The state is not allowed to determine all human actions. It can interfere only in a specific number of things, namely those things that are regulated by the law in view of an orderly and effective functioning of private and public life. The range, the power of pene tration and the competence of the state are limited and meet with a public space as well as a private space that are to a certain extent impenetrable for the state ('to a certain extent' because not everything is allowed in society, and sometimes the state has to interfere). Society is more than an object of political interference It is also a space of freedom, undisturbed by the state and in which there is a plurality of free and autonomous groups with each their own identity and rules. These groups can be mutually incompatible and can clash and contradict each other, as long as the laws, including the laws that regulate these clashes (e.g. human rights) are respected. This shows that the rule of law is closely 
connected to the right to freedom of association and assembly (another example of the indivisibility of human rights).

The rule of law - the principle that the state can only do what the law allows it to do is not a sufficient condition for a limited state and a relatively impenetrable civil society (both public and private). The law can be written in such a vague and general way that the limits on state actions are close to nothing, or laws can allow the state to interfere drastically in the lives of individuals or in the affairs of groups in civil society. That is why there are three other necessary conditions. Firstly, not everything can be written into a law. If everything could be written into a law, then the rule of law would be a meaningless concept. Even in a democratic rule of law, where the law originates from the will of the people, are there limits on what the law can be. It cannot contradict human rights, for if it does, there is no limited state, no free and independent civil society and no public or private space The power of the state can be even more dangerous when it springs from the people than when it springs from an element that is alien to the people.

Secondly, the law must be stable and predictable in order to avoid that every arbitrary act of state takes on the cloak of the law and thereby seeks the protection of the law. The Rule or Law (...) means, not that everything is regulated by law, but, on the contrary, that the coercive power of the state can be used only in cases defined in advance by the law and in such a way that it can be foreseen how it will be used' (F. Hayek in Held 1998:259). Moreover, only laws that are predictable can be respected. And respect for the law is part of the rule of law.

Thirdly, laws must not be too numerous, otherwise it becomes very difficult to respect the law and without respect for the law, there is no rule of law. A large number of laws is incompatible with one of the goals of the rule of law, namely the creation of a space of freedom. The more laws, the smaller this space of freedom (although one very general and vague law can also reduce this space to nothing).

Only if these four conditions - rule of law, a definition of the law that excludes laws that contradict human rights, and predictable laws that are relatively few in number - are met, can there be a limited state and a relatively free civil society. Human rights create these four conditions, the third and the fourth condition implicitly in the right which institutes the rule of law (there is no rule of law if it is impossible to respect the laws, and it is impossible to respect the laws if there are too many laws); the third condition also indirectly through the prohibition on retroactive laws (see later).

But there is a two-way causation. In one direction, human rights create a limited state and a free society, and make it impossible for the state to hold individuals or groups responsible for no matter what action they undertake (first of all, some rights directly institutionalize the rule of law; secondly human rights in general are a limitation of the content of laws; and thirdly the right which prohibits retroactive laws also protects the rule of law). Responsibility, conviction, punishment etc. cannot cover everything, only those things translated into stable and predictable laws that conform to human rights. As a result, there exists a relatively large domain outside of the reach of the state and the law, a domain in which individuals and groups can unfold their own autonomous, self-chosen private or public activities and thoughts free from political leadership, control or interference (I will show in Part 5 that freedom is more than just "freedom from").

There is, however, also a reverse causation. Human rights institutional ize the rule of law and the separation between state and society, but the opposite is also true. The rule of law and the separation of state and society promote human rights, even though there are states which apply the rule of law and which have a relatively free civil society, but which fail to enforce and respect all or some human rights. A limited state has less opportunity and power to violate human rights than a state that is not limited. The same is true for a state that has to deal with the criticism of a free society. Furthermore, in a free society groups of different kinds can be vehicles for the promotion of certain human rights (the rights of workmen for example). And, finally, in order to be 'confident in the possession and exercise of these freedoms, the citizens of a well-ordered society will normally want the rule of law maintained' (Rawls 1999:211). 
Human rights institutionalize the rule of law, and the rule of law promotes human rights, but the rule of law can exist without human rights (many things can limit government action and can determine laws, for example divine commandments). However, without human rights, we are clearly dealing with another kind of rule of law, a much more dangerous and unstable kind. I will discuss this problem in more detail in Part 5.

We should avoid turning the rule of law into a dictatorship of the law. The question 'what is a good law?' must always remain open (Castoriadis 1991:136). The law, even though it rules, has to be actively criticized, otherwise we get a fetishism of the law, an unconditional surrender to the law, whatever its content and meaning. The necessary permanence of the law - permanence is necessary because of predictability - should not become a dogma either, because in that case the question of the good law will likewise disappear.

\section{§ 20: The Rule of Law, D ifference, Identity and Criticism}

As a consequence of human rights and the rule of law, we live in a public and a private domain that are relatively independent, autonomous and outside of the control and the power of the state (including the power of the majority), and that function according to their own rules (at least as long as these rules are legal and in agreement with human rights). On top of that, our freedom of association takes away most of the restrictions on the diversification of the public and private space into as many independent groups as the people deem necessary, necessary for all kinds of things, but mainly for the protection of their rights and for the shaping of their identity. Having your own rules means having your own identity. Human rights and the rule of law create differences. Rights, identity and plurality need to be protected against the government which always tends to impose its will, to organize and to create order; and which, in other words, wants to destroy difference.

If society can be different from the state - as well as different from itself, in the sense of being divided and plural - then it can also be critical of the state, which is of course very important for democracy and for my argument in favor of the inseparability of democracy and human rights on the one hand and democracy and the rule of law on the other hand, but more of that later. I will show in Chapter 3 that an ideal democracy necessarily respects the rule of law (although a state which respects the rule of law is not necessarily a democracy), mainly but not exclusively because democracy needs criticism. If criticism of the state is important, then human rights and the rule of law are also important for there is no, or certainly less, criticism without them.

But it is the state that makes this criticism possible by its abstinence and forbearance, by the space it leaves for society, and by the judicial mechanisms it uses to enforce its own forbearance. This means that the independence of civil society is not complete. It depends on the state for its existence. Society is, therefore, a political artifact (just as politics is a product of society, at least in a democracy). The state can choose to institute or not to institute civil society. It all depends on the form of government or the political constitution (which is why the rule of law is sometimes called the constitutional state).

The rule of law and human rights, by offering the possibility of difference and criticism, thwart the vision of society as a living body, with all its movements coordinated by the head and with individuals reduced to organs or parts of the collective. This is not only the result of those human rights which directly institute the rule of law. Other rights al so contribute, such as the right to integrity of the person and his body, the right to private property etc.

I believe that the rule of law - or the separation between state and society and the limits on state activity - and therefore also democracy - since a democracy by definition applies the rule of law - are necessarily connected to a free market system (al though I do not claim that a free market system is beyond reproach). The limited state creates a space for free economic activity, exchange and competition between a variety of groups and per- 
sons. This is a consequence of all human rights, because the rule of law exists because of all human rights. But some rights in particular, such as the right to private property, do a little bit extra to promote the free market.

The opposite is not necessarily true. A free market does not guarantee the rule of law although it does promote a limited state and a free space for society. In a certain way, it does help to promote the rule of law (private companies like predictability). Of course, the free market can do great harm to certain human rights, but as I will show in Part 2, human rights and in particular economic rights can correct the wrongs created by the free market. So both the admirers and the critics of the free market can use human rights.

\section{$\S 21:$ Borders Between Concepts}

The border between the state and society is not always what it seems or what it is considered to be. The fact that the state is not omnipresent, is no Panopticon, and cannot spread itself uniformly over the whole of society, does not mean that the state stops where society starts. The state can legitimately interfere in society. The border is not an iron curtain. If civil society would be sovereign in its own house, anarchy and lawlessness would be the consequence. There is interference in society, but in society there is also a space (within the public as well as the private space) that the law cannot appropriate and in which man is free, on the condition that his free actions do not contradict the law or are not a subject of legitimate legislation (legitimate legislation is legislation which is not contrary to human rights and which springs from the will of the people; more on that late on). Where the law is silent, man can do as helikes.

The border between state and society does not correspond to the border between public and private. Private things happen in civil society, and political things happen in the public space, but it is clear that civil society is not just a private sphere. Public things happen in it as well, and private things, intimate things for example, happen outside of civil society. It is equally wrong to equate the public sphere with the domain of the law, and the private sphere with the domain of freedom. The private sphere is subject to the rule of law, as much as the public sphere, and the latter is as much a domain of freedom as the former (freedom in the sense of absence of state interference). (I will show in Part 5 that freedom in a more substantial meaning can only exist in the public sphere and that even political life as a part of public life is a source of freedom, contrary to all theories about the incompatibility of politics and freedom). Freedom and the law are not a straightforward translation of private and public respectively.

I may have been somewhat careless in the use of the words 'political' and 'state'. They are not absolutely the same thing. Without making the difference between these two words it is impossible to hold on to the difference between state and society. Democracy requires the elimination of the difference between rulers and ruled. Democratic politics is everybody's business and takes place, to a large extent, in society. When the citizens and the state desperately try to avoid each other as much as possible - as is implicit in the doctrine of the separation of state and society - then politics becomes a matter only for politicians, and political life becomes a danger instead of a source of values.

So what do we have? At first sight we have a lot of differences and on closer examination we have many things overlapping. Society overlaps the private and the public sphere; the private and the public sphere overlap each other; the law overlaps freedom etc. We also have an important difference that is seldom made: the political and the state. For clarity's sake, I have tried to put all these things in a drawing: 


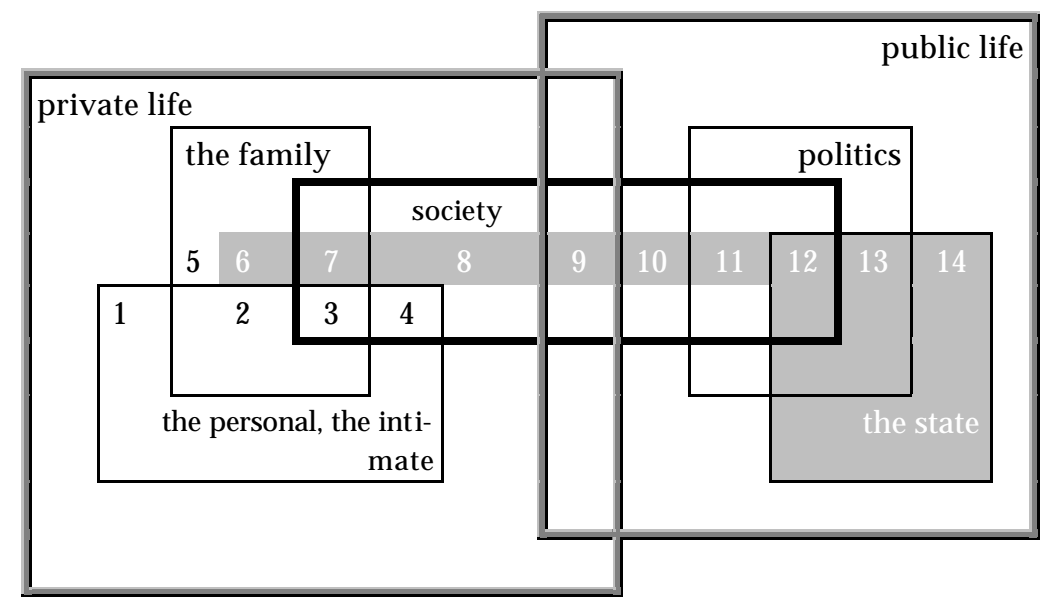

Some examples of the meaning of the digits:

$1=$ Ioneliness, philosophical convictions

2 = unspoken marital hate

3 = certain moral convictions

$4=$ political convictions and certain moral convictions

5 = the division of labor in the family, adultery, marital fidelity (in some countries, adultery and marital fidelity may still be classified under number 6 )

$6=$ incest, violence within the family

7 = raising and educating children

$8=$ a sports club

$9=$ a school

$10=$ a cultural society (political convictions, mentioned above under number 6 , should perhaps be classified under this number, but this would make the drawing unintelligible; in any case, reality is too complicated to be forced into a simple drawing)

11 = political participation (outside government institutions), political demonstrations, pressure groups, lobbying

12 = political participation (within government institutions), village meetings, civil disobedience, a court of justice with a jury-system, political parties

13 = representative politics, parliament, a court of justice without a jury-system, espionage

$14=$ administration, government bureaucracy.

Both the public and the private spaces are at the same time spaces of freedom (in the limited sense of freedom from state interference) and spaces subject to the provisions of the law. The latter are shown as gray areas. As shown above, all state activity is regulated by the law, while the part of the private sphere which corresponds to the purely individual or personal is entirely free from government interference. Needless to say that the drawing depicts an ideal situation.

\section{§ 22: The Rule of Law Guarantees Publicity, O penness, Justice and Fairness}

The rule of law is much more than a means to prevent rulers from acting according to their own private will. It also creates the public space, in more than one way. Look for example at the way it guarantees publicity. The rule of law implies: 
- Publishing the laws (in a democratic rule of law, the act of legislation or the production process of the law is also public);

- Making the judicial court procedures and the verdicts public (with a few exceptions, for example when the privacy of the parties is at stake).

As a result of this publicity - which is a rule included in the main declarations and treaties concerning human rights (for example art. 6 of the ECPHR and art. 10-11 of the UDHR) - the rule of law promotes publicity in general. If the state publishes what it does, why should the population not be allowed to publish its views?

Of course, laws, court procedures and verdicts are not only made public for the sake of publicity in general. There are other reasons as well. A law has to be public, because a secret law, unknown to the subjects of the law, is a plain absurdity. Laws are there to be respected, and in order to be respected they have to be known by all those who can violate them, wittingly or unwittingly. Publicity of the law means knowledge of the law, and knowledge of the law reduces the number of breaches and guarantees the possibility of respect (although, of course, it does not guarantee respect per se). 'Knowing what things (...) [the law] penalizes and knowing that these are within their power to do or not to do, citizens can draw up their plans accordingly. O ne who complies with the announced rules need never fear an infringement of his liberty. (...) U nless citizens are able to know what the law is and are given a fair opportunity to take its directives into account, penal sanctions should not apply to them' (Rawls 1999:212).

Respect for the law does not only require publicity of the law. Laws also have to be clear, understandable and few in number. Unclear laws or laws which are too numerous are difficult to respect. Codifying and publishing the law in a correct way is therefore a very important task, not only because of publicity in general, but also because of the rule of law.

The same reason - giving people an opportunity to plan their lives in such a way that they can respect the law and avoid running foul of the law - justifies the requirement that laws must be promulgated in advance, before an offence has occurred. Hence the rule against retroactive laws.

The need for publicity and prior promulgation clearly shows that it is not enough to have a judicial power. Even though we need, of course, a judicial power in order to avoid revenge and partiality, we al so need a legislative power able to promulgate and publicize laws which can be enforced in an impartial manner by a judiciary. Furthermore, if the decisions of the judiciary are to be enforced in every case, then we also need an executive power, able to use force or violence and to monopolize violence in such a way that violence is eliminated from inter-personal relationships.

General social publicity is not the only reason for the publicity of court procedures and verdicts either. Justice must not only be done, it must also be seen to be done. Publicity is in the interest of justice Every trial is a 'show trial'. The publicity of a trial makes it possible to judge the judge. The secret trial is typical of authoritarian regimes because it allows for abuses of power. It is very hard to use a public trial for power games or oppression. On top of that, false accusations or false testimonies are more likely to remain undiscovered in a secret trial. It is not only the state that can gain from a secret trial.

However, publicity alone does not guarantee that trials and verdicts are fair and just (which is clear from the phenomenon of communist show trials). The following elements are just as important (as with publicity, most of them are included in the main human rights instruments):

- No excessively long detention on remand (detention without a lawful and fair conviction);

- No punishment or imprisonment without:

(1) An indictment

(2) A trial

(3) A conviction 
(4) The possibility of an appeal to a higher court;

- An impartial judge;

- Swift information on the nature of the indictment;

- The possibility to defend yourself and to receive free legal assistance;

- The possibility to argue and to give counter-arguments, to call witnesses for the defense and to question witnesses for the prosecution;

- Innocent until proven guilty;

- No forced confession and no obligation to incriminate yourself (the right to remain silent);

- No excessively tough penalties;

- 'N e bis in idem' : no two trials for the same offense;

- 'N ulla poena sine lege': no crime or punishment without a law voted and published before the criminal deed; in other words, no retroactive laws, no laws with retroactive effect (or laws which make deeds punishable after they have been committed); one cannot punish people for acts that were not a crime at the time when they were committed because people should know what is or is not allowed;

- For the same reason, laws should be predictable and should not change all the time: nobody is responsible for a violation of a law if the law changes from day to day, because if the law changes constantly, then nobody knows the law and then nobody can respect the law; predictability and permanence of the law are prerequisites for obedience, just as knowledge and publicity (this is one of the reasons why democracy is often criticized - the rotation in office causes changes in the laws - but this problem is rather theoretical because the practice of democracy shows that unpredictability is the exception rather than the rule in a democracy);

- There should not be too many rules, otherwise the judges and the police will not have enough time to enforce them all or to punish all violations of all rules, which leads to injustice too many rules also leads to violations of rules, because citizens do not know what they are or are not allowed to do;

All these elements put together make the justice system just, and protect the citizens against the state or against fellow citizens that want to abuse the justice system. If one element is missing, then all the others may become useless.

\section{§ 23: Security}

Those human rights that protect a person's security, bodily integrity and life, and that prohibit physical assault, dismemberment, torture, cruel punishment etc., not only acknowledge deep-rooted needs such as the wish to survive and avoid pain, but also contribute to the protection of public life. They are specified in criminal law and enforced by state action, and they protect citizens from the aggression of fellow citizens and of the state. Without this protection, public life would almost be impossible. Pain, fear and lifethreatening situations do not mix well with public life. Conflicts and animosity are part of public life; they will not and should not go away. They are necessary for thinking, knowledge and identity. However, conflicts are not always the polite public struggle that we would like them to be. They can harm and even kill people.

Now, if it is reasonable to presume that some or even people will not always be able to avoid violence and that it is preferable to avoid having other people revenging violence, then it is also reasonable to create an impartial institution that is above the people and that is strong enough to counter violence. This institution is the state. In many cases, the only way to eliminate or avoid violence is to threaten and punish the perpetrators. In order to be able to threaten and punish, you must be stronger. Citizens are seldom stronger than other citizens because even the strongest have to sleep. Only a state can be strong enough to counter or avoid violence by way of punishments. It can act as a third party which restricts the conflicting parties. It is above the parties, both because of its 
impartiality and because of its superior power. This superior power makes it able to enforcea decision on the conflict. On top of that, it is not involved in the conflict and it has a clear and impartial view of the problem and the possible solutions. The state uses the 'security-rights' to control conflicts.

The state controls or limits conflicts and protects the life and body of its citizens in different ways, by punishing violence, but also by using systems and institutions that formalize, ritualize and soften conflicts, for example court proceedings or the democratic power game (the discussions in parliament and the ritualized changing of leaders in a peaceful way make it possible to avoid revolutions and other violent reactions of opposition movements). Order and organization protect not only public life, but all human activities. Security, peace and the protection of life are the first mission of the state and especially of the judicial power and the police, because this mission, once fulfilled, makes all other human activities possible.

Of course, the state has other missions as well. Some of them, such as public life, justice and freedom, are even more important, albeit perhaps less urgent. Urgency, however, is a debatable matter. One could say that public life or justice should come first because they promote peace and security. Furthermore, it often happens that missions that are more important than security - because they correspond more to human life than others (after all, animals also want peace and security) - are overshadowed by peace and security (as for example in the theories of Hobbes and Kissinger). This is of course reprehensible, and self-destructive. Too much attention to peace and security can endanger peace and security. People whose economic rights or whose right to free expression are violated because the rulers think this is necessary for peace and security, will revolt, and revolt automatically creates insecurity. This is an argument in favor of the statement that all human rights promote peace and security, which is a reason for accepting them (nondiscrimination, religious liberty etc. also enable us to avoid revolt). I will explain this in more detail in Part 3, where I will show that human rights combined with democracy also promote international peace

The problem is that human rights should do more than just regulate the peaceful coexistence of people with conflicting ideas. They should also regulate coexistence in public. For this reason, we should avoid concentrating too much on security. Human rights protect security, not for the sake of security but for the sake of our public life, which of course needs security. However, security alone is not enough, and neither are those human rights that explicitly protect security. Human rights in general and the state acting as guardian of human rights do more than just guarantee peaceful and secure coexistence. Concentrating too much on security also leads to a narrow view of the nature of citizenship. Citizens are more than people trying to achieve contradictory private interests, coming into conflict with one another and causing violence. They also create relationships and groups, they try to convince each other, they debate, and they try to find a common interest. The state makes sure they can do so, both by limiting violence and by creating the structures in which and thanks to which debate and common actions are possible (structures such as elections, parliaments, court procedures, human rights etc.).

Nevertheless, security is important and can help us to justify human rights. I will, therefore, return to the subject of security for a couple of moments. In order to limit violence and realize those human rights that protect security, we need institutions, institutions that either punish violence - such as the judicial system and the police system - or formalize conflicts, such as parliament, elections, court procedures etc. Both kinds of institutions turn potentially dangerous conflicts into something beneficial and something that is part of public life, before and after conflicts degenerate (punishment also has a dissuasive effect). The latter institutions, by formalizing and ritualizing conflicts, channel these conflicts away from violence, and maintain them within certain limits. Channeling and limiting not in the sense of giving direction to conflicts or prohibiting certain conflicts. Only the energy contained in conflicts has to be given a certain direction, away from violence and towards procedures or 'games' in which conflicts can be expressed to the full without degenerating. 
Take for example the way in which a conflict is treated in the setting of a criminal trial. Since every party to the conflict knows in advance that it has every opportunity to express its views and that its views are listened to and taken into account (because of the impartiality of the judge), the tension is relieved and the setting is calmer. Furthermore, the verdict, the sentencing and the public naming of the guilty one, is therapeutic and leads people away from revenge. Revenge, after all, is not only caused by the will to undo an injustice It is also a sign directed towards society, showing society that a person is not to be meddled with, is not an easy victim and does not want to be so in the future. The fact that a criminal trial serves the purpose of relieving tension shows that justice is not only about punishing, even though punishment will probably always remain important as a means to prevent repetitions of evil.

Democratic elections are another example of the way in which rules and procedures or a 'game' if you like - channel conflicts away from violence. When you know that your group has as much chance as any other group of taking over power in a peaceful way, why run the risks involved in a violent take-over? And even when at first you do not succeed, you know that a failure is never a failure for eternity. N othing is lost, except for a few years in between elections.

Of course, these games or procedures are not always enough. Sometimes, we cannot avoid violence Some people can decide not to play the game, for example, because they believe that they should always win, or because they believe that the outcome of a certain game is unjust (unjust because they lose, because a punishment is unjust etc.). These people will resort to violence, and in this case, only the first kind of institution - the one that punishes violence instead of trying to channel it away from violence - can be of any use. That is why we need a power that is above the citizens and strong enough to curb citizen violence. This power tries to monopolize violence, taking it away from society and using it in order to take it away. In most cases, this power is the state, or better, a part of the state, namely the judicial power and the police Why the state? It seems that only the state can have a monopoly of violence and can have sufficient power - or violence - to enforce a decision.

Without a state, the parties in a conflict are left to themselves. They have to protect themselves, revenge themselves if necessary, and take up arms to get what is theirs, which of course only makes things worse because it again causes a violent reaction. People are then forced to be judge in their own case, which is impossible because their selfinterest clouds their judgment and makes them partial, and partiality cannot lead to a just outcome for everyone. A just outcome can only be achieved through the actions of an impartial judge. A partial judge is an absurdity. Such a judge would be completely useless, and people would be better off fighting their cases amongst themselves, one against one instead of one against two.

Being left to yourself and being the judge in your own case does not solve the security problem because it causes reactions, injustices and ultimately war, a war moreover which no one is certain to win. We often are not powerful enough to protect ourselves, not even the strongest among us. The strongest too have to sleep now and then. The state, however, is powerful enough, and can defend and punish everyone.

The monopoly of violence and therefore the removal of violence from society is achieved when the citizens, convinced that their self-interest is not served by being left to themselves, submit themselves to the state, render their violent power to the state, and ask the state to protect and punish in their place. Self-protection, attack, judgment, punishment and revenge are transferred to the state because they are counterproductive. They become judicial protection, judicial accusation, judicial judgment and judicial punishment respectively. Conflicts that are beyond limitation by way of argumentation, debate, second chance policies etc. in the framework of some institutionalized game, can be controlled and terminated by a decision of a supreme and impartial power, strong enough to enforce this decision. Only then is peaceful coexistence possible. And only when this supreme power is absent - for example in an emergency - can there be selfprotection, but this will never be a perfect solution. 
What if there is a conflict between individuals or groups and the state? This can also endanger the security of the citizens. In this kind of situation, two things must be done:

(1) The state has to be governed by the same rules that govern the parties in a conflict between citizens (for example human rights).

(2) The state has to be internally divided: one part of the state has to be able to curb the actions of another part (in other words, separation of powers).

The role of human rights, the state and the justice system is not only to avoid or suppress conflicts (as is taught by Marxism). They also promote conflicts as a part of public life. Only violent conflicts have to be solved, suppressed or avoided (in the two ways described above). And because of the fact that violence becomes less of a risk, conflicts can flourish as never before. By softening conflicts, we of course promote conflicts because we take away the fear of the consequences of conflicts. This, as well as solving or avoiding conflicts is the task of government (some conflicts cannot be solved or avoided anyway). The government brings order to the necessary antagonism in society, channels the conflicts into rituals or games, makes rules, structures and procedures that make it less dangerous to live together, and punishes if all this does not work. This kind of order is not incompatible with freedom, plurality or diversity. Diversity, of course, should not cause a community to break up in violence. The purpose of order and of the channeling and limiting of conflicts is not only to avoid the escalation of conflicts and to guarantee security and peace, but also to promote conflict, public life and freedom. I will show in Part 5 that freedom needs conflict and public life. This means that peace or security should not be equated with the absence of conflicts. Only violent conflicts should be avoided. Without security there is no public life, but without conflicts there is no public life either.

The law is, of course, not the only means to create peaceand security. We see that certain cultures pay a lot of attention to compromise, negotiation, self-discipline, duties and other extra-judicial ways to channel conflicts. However, in addition to these mechanisms, every culture or country in the world reserves a more or less important role for laws, judicial procedures and police activity.

Tolerance also plays an important role. It is a necessary condition for peaceful coexistence in plurality. We have to tolerate and accept disagreement, the different choices of other people and the freedom of other people in the private as well as the public space, even if this is sometimes difficult. I would say especially when it is difficult (there is a famous joke, known as Fish's first law of tolerance-dynamics, which says: tolerance is exercised in an inverse proportion to there being anything at stake). If people, who sincerely believe that 2 and 2 equals 5 are forced to believe that 2 and 2 equals 4 , or if people are forced to praise another God - if, in other words, people are refused a free space and equal rights - then we create violence This does not mean that we should accept everything, because laissez-aller and anarchy also create violence. I will now look at the problem of tolerance in greater detail.

\section{§ 24: No Human Rights W ithout Tolerance}

Human rights have no meaning without tolerance Tolerance is a consequence of human rights. Human rights create difference and plurality, and tolerance is needed to accept this plurality and to accept human rights as the cause of this plurality. It is useless to have the right to freely express an opinion if afterwards this expression is not accepted or tolerated. Tolerance is respect for the other point of view that is expressed with the help of human rights. Respect not necessarily in the sense of accepting the content of the other point of view (because then there would not be a need for tolerance), nor of admiring the content of the other point of view - in the way we might respect a writer, without automatically accepting everything he or she says. This kind of respect is easy. The problem, 
and the need for tolerance and respect, concerns those things we do not admire, things we disagree with or which perhaps we loathe. We have to respect and accept, not the content of these things - that might be impossible - but their existence. We feel that another opinion has the right to exist, but at the same time, we disagree with it, and we might even loathe it. Respect for another opinion does not necessarily mean accepting the content of this opinion or not contradicting this opinion.

Again there is a reverse causation: tolerance supports human rights, but human rights also support tolerance. Thanks to the freedom of expression, we are in a better position to learn and study other opinions, and therefore we have a better chance of understanding these other opinions and their causes in reasoning, education etc. A better understanding promotes tolerance.

If human rights require the support of tolerance, then human rights require a certain lifestyle, a certain attitude of respect toward other people. Respect for other points of view means respect for other people and for the fact that they are different. Opinion and identity are to a large extent the same thing. Accepting people as they are, as they think and do, is an attitude and a lifestyle required by human rights. It is no use accepting human rights if you do not accept this. One could even say that people have a right to re spect and tolerance. This right is a natural consequence of all other human rights. People have this right because they have human rights and because they use these rights to manifest themselves in different ways.

Tolerance therefore means more than leaving everybody to their own devices, means more than letting people do their own thing, as long as they do not harm anybody but themselves and refrain from imposing a point of view, an identity or a way of life. It is more than a lack of interest or concern. Sometimes it may require active protection of somebody's difference, and punishment of those who fail to show respect. Respect is not enough. When you respect your fellow man without responsibility, you are certain to leave him alone when it would be better to intervene, to help or to punish. Tolerance can look a lot like egoism.

\section{§ 25: Tolerance Linked to Diversity as a Good}

This shows that we have to be careful with words like 'tolerance' and 'respect'. A nother person, another opinion or another way of life is not just something we have to tolerate like we tolerate bad weather. Social life is not completely negative or meaningless. The company of other people is not only a burden we have to tolerate, and it certainly is more than a matter of indifference (in the sense of making no difference) or lack of interest. As I have shown in Section 1, the company of others - the public company of others - is beneficial because it is necessary for the realization of some of the most important human values. The other person is a necessary part of each human life. We not only tolerate the other person, we also use him, follow him, contradict him, discuss with him, help him etc.

Diversity and tolerance of diversity can be very beneficial because they make it possible for us to learn from others, to debate with others and take into account their objections and counter-arguments - whereby we can come closer to the truth. We can take advantage of accepting, tolerating and respecting diversity, because diversity means other opinions and criticism of our own opinions. The school of tolerance teaches people to reap the benefits from conflict and difference (Little 1996), and makes people suspicious of all efforts to eliminate conflict or to let it degenerate into violence Tolerance is more than just a restraint on violence. It contributes in a positive way to public life.

Diversity is not, however, something static. Tolerance does not mean accepting diversity as it is and as it will always be. The purpose of tolerance is not to make opinions coexist without interaction of any kind other than bare acceptance, and acceptance is more than an armistice necessary to keep the peace between interests of which no single one is strong enough to impose itself. It must be possible to convince other people, to create a

PART 1: PUBLIC LIFE, POLITICAL LIFE AND CULTURAL LIFE 
common will, a general interest or even a consensus that is limited to a small group. The function of tolerance is not to separate people and opinions, nor to maintain differences as they are, but to make confrontation between opinions possible. Tolerance keeps aggressive people out of each other's way; it does not keep people as such, let alone points of view, out of each other's way. Confrontation can, of course, modify points of view and can eliminate (or enhance) differences. We have opinions on opinions, we judge, we convince, we become convinced, and we change our opinions accordingly. That is why difference in a tolerant world is something dynamic.

It is not because we tolerate someone or some point of view, that we do not have the right to try to convince this person. Without the possibility to convince, the right to free expression loses much of its meaning. The pleasure of expressing an opinion, showing off and expressing our identity are not the only reasons for expressing an opinion. In most cases, we express an opinion because we want to convince other people. However, taking into account the importance of convincing could lead to another aberration. Tolerance should not be considered as something temporary, necessary as long as opinions differ. Opinions will most probably always differ, and we will therefore always need tolerance

Given the importance of convincing, we should not blame people for being intolerant when they criticize or even laugh at another point of view. You can be tolerant and 'politically incorrect' at the same time. After all, tolerance is there to make criticism possible. You are intolerant only when you suppress opinions or customs, when you persecute, physically attack or discriminate people who have another opinion or custom, or when you use force to change people's opinions or customs.

Tolerant people therefore do not have to leave things as they are - for the love of peace, because of indifference, or whatever. If you want things to be different, go ahead and argue. You should not be blamed for intolerance Tolerance is sterile when it is no more than putting up with each other and not persecuting people of different beliefs. Tolerance should create relationships based on the benefits of difference, criticism and public life.

\section{§ 26: Tolerating Intolerance? (1)}

Tolerance is not the same thing as relativism, a-moralism, nihilism or agnosticism. Everything is not equally good and valuable, equally deserving, or equally respectable. We can and should, for example, make a difference between what is good and bad for tolerance, and also between what is good and bad for human rights (because of the link between human rights and tolerance). The enemies of tolerance - and therefore the enemies of human rights - cannot claim to be tolerated. If they are tolerated, then they will, of course, destroy tolerance as well as the institutions that protect tolerance (such as human rights). Unlimited tolerance - tolerance even of intolerance - destroys itself, or at least helps those who want to destroy it. A tolerant society disappears if it tolerates certain things for too long. Intolerant people can use tolerance and the institutions of tolerance in order to destroy tolerance.

In any case, it is difficult to see how intolerant people can honestly complain if they are not tolerated. ' [ $\mathrm{O}$ ]ne has no title to object to the conduct of others that is in accordance with principles one would use in similar circumstances to justify one's actions towards them. A person's right to complain is limited to violations of principles he acknowledges himself' (Rawls 1999:190). You should not ask something for yourself that you deny to others.

Tolerance and respect must therefore be limited. Not everything should be tolerated. Those who are intolerant or who want to destroy the institutions which protect tolerance - maybe for reasons other than their intolerance - should not be tolerated and should be attacked using their own weapons of intolerance. Their freedom and rights are limited, at least if they put their ideas into practice and cause violations of other people's rights. The fact that intolerant people cannot complain if they are not tolerated, is, however, not a sufficient reason to limit their rights (Rawls 1999:192). 
Only tolerance and, at most, theoretical intolerance can be tolerated. Tolerating violations of human rights is a logical contradiction, because human rights guarantee tolerance and because tolerance guarantees human rights. If you want to enjoy the benefits of tolerance - for example as a means to protect your own opinions - then you have to re spect human rights. Tolerance and human rights go together. You cannot choose one without the other. You cannot violate human rights and expect to be tolerated, no more than you can claim rights and reject tolerance. 'The liberties of the intolerant may persuade them to a belief in freedom. This persuasion works on the psychological principle that those whose liberties are protected by and who ben efit from a just constitution will, other things equal, acquire an allegiance to it over a period of time' (Rawls 1999:192). Of course, the intolerants can be so fanatical or their power may grow so rapidly that this strategy is unsuccessful and naive. More forceful measures against intolerance are then necessary.

The risk of equating tolerance with relativism, agnosticism, nihilism or skepticism is that people will start to doubt the superior value of human rights and democracy. This will endanger the institutions that protect tolerance and will ultimately endanger tolerance itself. A relativistic type of tolerance is therefore self-destructive. If all opinions are equally valid, then also opinions on human rights and democracy. Only if people believe strongly in human rights and democracy will tolerance be safe. Skepticism and doubt are incompatible with such a strong belief. They are paralyzing and they leave the field to those who want to destroy human rights and democracy.

Since tolerance needs human rights, it cannot be equated with skepticism and doubt. Tolerance needs a strong belief and an active involvement in human rights and democracy. It needs a kind of certainty or conviction instead of passive doubt. The antidemocratic fanatics will not stop to doubt and will take our passivity as an invitation to act. If we want to defend ourselves, we also have to be fanatical, fanatical democrats. Those who tolerate everything will be overrun. '[A ]gnosticism is not a particularly useful defense against fanaticism, and tolerant skeptics who think that nothing can be known are ineffectual allies of civilization when zealots who think they know everything are on the march. (...) Tolerance is a beneficent and admirable posture, but in itself it can stop nothing. It refrains from doing harm but may permit harm to be done. (...) The struggle for liberty requires an energized faith (...). [I]n a world of necessary actions and ineluctable consequences (...), the liberal's diffidence cannot mean that nothing happens, only that he causes nothing to happen. He may modestly abstain from acting on behalf of public goods that he does not think can be legitimated, but his reticence only means that private and clearly illegitimate forces will control his destiny unopposed. (...) U proot principle, deny the possibility of mutual knowledge of public goods, and what is left except bigotry and brute force?' (Barber 1984:105-106).

Tolerance in the guise of skepticism and relativism clears the way for tyranny and intolerance because it leads to doubt, paralysis and powerlessness in the face of antidemocratic fanatics waiting at the border or organizing within the community. Democratic fanaticism should not be a dirty word. It is a necessary addition to tolerance and the only way to protect tolerance. ' Relativism - the doctrine that maintains that all values are merely relative and which attacks all 'privileged perspectives' - must ultimately end up undermining democratic and tolerant values as well. Relativism is not a weapon that can be aimed selectively at the enemies one chooses. It fires indiscriminately, shooting out the legs of not only the 'absolutisms', dogmas, and certainties of the W estern tradition, but that tradition's emphasis on tolerance, diversity, and freedom of thought as well. If nothing can be true absolutely, if all values are culturally determined, then cherished principles like human equality have to go by the wayside as well' (Fukuyama 1992:332).

It is evident that a tolerant system cannot be viewed as one that imposes nothing in terms of values. It imposes democracy and human rights because there is no tolerance without them. Not all values are equally valuable. Democrats must stick to their opinions and at the same time accept that other people do the same thing, as long as these other people - who may be intolerant or anti-democratic - do not actively try to impose their values. Tolerance is not the same thing as indulgence towards those who are wrong. We cannot let intolerant or anti-democratic people do what they want. No system, and cer- 
tainly not a system of tolerance, can be required to contain the seeds of its own destruction or to remain passive in the face of attack.

\section{$\S 27:$ Religious Liberty Promotes 0 penness, D isclosure, Pluralism, Toler- ance and $D$ ebate}

Religious liberty and the freedom of belief (the absence of coercion in matters of religion, the freedom to practice and profess a religion of your choice, in private as well as in public, to change your religion, or to practice no religion at all) also help to institute the public space. This may seem strange in view of the dogmatism and the blind following (or the absence of thinking) demanded by most religions (e.g. Catholicism with its infallible and incontestable pope). Incontestability and infallibility do not fit well in a public space in which contradiction and the effort to think play an important role.

If religion is not a benefit to public life, why should religious liberty be a benefit? It is a benefit because it promotes publicity, diversity and the freedom of expression (another example of the indivisibility of human rights). It makes a monopoly of one religion impossible - except when culture and demography are such that there is a de facto monopoly which is not contested - and it guarantees the coexistence of different and publicly competing truths. In this way, it guarantees debate in general. If there is religious debate, why should one prohibit other kinds of debate? On top of that, it guarantees tolerance if people can be tolerant - or are forced to be tolerant - in the field of religion, they will probably be tolerant in other fields as well. Also, this shows that religious liberty can be of interest to non-religious persons, not only because it protects them from the imposition of a religious belief, but also because it allows them to live in a public world and a world of tolerance and diversity.

As with the concept of tolerance, there is a downside to the concept of religious liberty. Anyone can call their personal insanity a religion in order to try to get government protection. There is no easy answer to the question of what is or is not a religion in the proper sense of the word. Violations of human rights should not be protected under the right to freedom of religion, not even if there is no doubt that they are an essential part of an established religion. Every human right is limited and has to be balanced with other rights. Freedom of religion is no exception. In particular, the right to absence of discrimination, although closely connected to religious liberty (one should not be treated badly as a consequence of one's religion), can be a problem if everything can be labeled a religion and if every imaginable theological ideology can enjoy the protection granted by the freedom of religion.

\section{§ 28: Limiting and Separating the State and the Church}

Religious liberty implies that the state should not interfere with the religion of its citizens, should not favor or discriminate a particular religion or religions, and should not attach benefits or penalties to any religious affiliation or lack thereof. The limited state created by the rule of law and the difference between state and society are confirmed and strengthened by religious liberty.

If the state should avoid interfering in religious matters, then it should be absolutely neutral as regards religion. There has to be a separation between state and church (but not necessarily between politics and religion). In an ideal democracy, there can be no official state religion. One and the same person cannot be both head of state and head of a church (or an important functionary of a church). In every other case, certain religions as well as atheists and agnostics will be worse off compared to the adherents of the official religion, if they are allowed to exist at all. Religious liberty means religious equality. Even if non-official religions are not actively persecuted or discriminated against, they are 
worse off when there is no separation between the state and religion because they do not have the same means to influencethe public. They are not as free as the official religion.

A nother reason why religious liberty implies the separation between state and religion is the need for an impartial judge to mediate between different religions. If different religions are allowed to exist together, we need a non-religious law which regulates their coexistence It is very unlikely that people adhering to one religion will accept laws which are inspired by another religion. The fact that a religiously neutral state with its religiously neutral laws allows many different religions to exist and to coexist, makes it acceptable to many people. A state which only allows one religion or favors one religion, will only be accepted by the adherents of that particular religion. The historical fact that religious communities become more and more intertwined within the borders of states, will enhance the attractiveness of this kind of state. Democracy is by definition such a neutral state, because a democracy respects human rights.

Religion is kept out of the state. The claims of religion are restricted. A particular religion cannot claim to be the religion of the country in order to take possession of the state or the law and thereby achieve more power than other religions and impose itself on individuals. However, the actions of the state are also restricted. The state is not allowed to prohibit, persecute, discriminate or impose a religion, and it should also avoid using a religion as a means to enhance its authority, as a kind of transcendent confirmation. If you stand close to something glorious, you may hope that something of the glory shines on you as well. You may even hope to become godly, which, historically, has been an enormous advantage to states in pre-modern times. The representative of God on earth is godly as well, and he who is godly is eternal and escapes contestation, which is of course anti-democratic. It is equally unacceptable for a state to use certain religious texts to justify or enforceauthoritarian measures.

The state should not interfere with religion, and religion should not interfere with the state ('Give to Cesar what belongs to Cesar and to God what belongs to God' ). Power does not come from God and does not have to follow God or render an account to God. Power comes from the people and has to render account to the people. State and religion are mutually independent. '[R ]eligiously wrong - a motive of legislation which can never be too earnestly protested against. D eorum injuriae D iis curae. Injustices to the gods are the concern of the gods. It remains to be proved that society or any of its officers holds a commission from on high to avenge any supposed offense to 0 mnipotence which is not also a wrong to our fellow creatures. The notion that it is one man's duty that another should be religious was the foundation of all the religious persecutions ever perpetrated, and, if admitted, would fully justify them. (...) a determination not to tolerate others in doing what is permitted by their religion, because it is not permitted by the persecutor's religion. It is a bel ief that $\mathrm{G}$ od not only abominates the act of the misbeliever, but will not hold us guiltless if we leave him unmolested' (Mill 1977:1162).

Separating state and religion may cause some problems. It will for example make it more difficult to universalize human rights. Many cultures, for example Muslim cultures, see this separation not as an advantage but as a problem because religion - unified religion - is still very important in their societies and is considered to be the foundation of politics. However, state neutrality in religious matters does not imply that democratic politics is necessarily a-religious or atheistic. A democracy executes the will of the people and not the will of God, but if the people believe that their will equals the will of God, then this does not pose a problem as long as the religious rights of the minority are respected and as long as the religion of the majority does not acquire unjustified privileges. The problem is rather that a religious person must al ways follow his religious opinions, no matter what the majority decides. God does not accept to be in the minority or to be overruled by the majority. A religious person can only accept democracy when he or she happens to agree with the majority. I will show in the next paragraph that such a person can have other reasons to accept democracy, even if this democracy does not al ways execute the will of God as he or she understands it.

A nother problem raised by the religious neutrality of the state is the impossibility of using a belief in a future life and in the rewards and punishments of this future life in 
order to restrain actions on earth and to promote a sense of morality. This can also be an argument against the separation of state and religion. However, moral restraints should ideally be established by reason, because this would fit better with the profile of democratic man as a thinking man.

A s in other kinds of separation, the separation of church and state is not al ways what it seems to be. Religion does not have to remain silent when it comes to politics. It can be a source of inspiration for politicians and it can enhance ethical consciousness and behavior. Therefore, it should not be excluded from politics. As before, it is important to make the distinction between politics and the state. The fact that freedom of religion and the separation of state and religion do not imply the separation of religion and politics can make it easier to universalize human rights. Religious people obviously and justifiably fear the separation of religion and politics.

The separation of church and state counters absolutism. In the history of western society we can see for example how the difference between a worldly and a religious authority has often counteracted the autonomy and therefore the power of the worldly authority. If there are several competing forms of authority, then it is more difficult for each of them to control the individual. The individual can use one center of power against another. The worldly power is not all-powerful because there is a power of heaven (repre sented by the church with its own claims to power) and a law of heaven, a law which the worldly rulers have to respect. This worldly power, compared to the power of heaven, must be imperfect, fallible, and therefore open to criticism, which has become the rule in democracy later on. Over the centuries, the church has often been the only limit on state power, and this has been something truly beneficial, although not for everyone. Church power is not necessarily more just than state power.

\section{§ 29: Different Sub-Communities With D ifferent Identities Living Together}

The religious neutrality of the state - but not necessarily of politics - organizes and legitimizes the coexistence of different autonomous sub-communities each with its own identity, values and norms, because it institutes religious freedom and protection for different religions, and because it treats all religions equally. Non-religious sub-communities are also protected in this way. After all, if diversity is possible for religion, why should it not be possible for other kinds of group identity as well? The freedom of religion and the freedom of association are closely linked.

This neutrality of the state is of course limited. Underneath the plurality of individuals and sub-communities there must be a basic overlapping consensus. Human rights must be part of this consensus. These rights have to be general values and norms, overarching the different sub-communities because without them plurality and identity are impossible. It is in the interest of the different sub-communities to adopt these general values because communities need diversity for their own protection. The whole is more than the sum of the parts; it is a collective rather than a collection. Diversity manifests itself in an overall or overarching community - a community of communities - that has human rights as its shared values, and state neutrality stops at these human rights. A state should no be neutral as regards human rights. Groups or sub-communities that violate human rights place themselves outside the general community of diversity, and cannot invoke diversity or human rights for their protection.

The general norms regulating diversity can indeed clash with the particular norms that constitute the identity of groups or individuals. There has to be as much freedom as possible, and as much consensus as necessary. Sometimes freedom has to be limited. The values and norms that apply in the sub-communities cannot be chosen at random. They have to conform to a certain consensus. They cannot contradict the basic overarching norms of the whole community, at least as long as they have an effect on the rights of non-members and as long as the sub-community guarantees a free exit to those members whose rights are violated by the norms of the group. 
Sub-communities that do not respect this rule cut off the branch they are sitting on. After all, the basic norms make it possible for different communities with different norms and values to exist and coexist. Groups that violate these rules endanger their own existence, unless they are large and strong enough to dominate other groups. A neutral, democratic state which respects human rights governs a community characterized by a minimum number of common basic norms and excludes those who do not respect these norms. A fundamentalist religious group oppressing its female members or using force to convert other groups is prosecuted for violations of human rights, and may lose the protection of the freedom of religion and the freedom of association.

Even though some sub-communities may believe that their values and norms are universally valid, they should not try to impose these values and norms on other subcommunities or on the community at large. The latter, however, can impose its overarching values and norms on the different sub-communities, because the only function of these overarching values and norms is to facilitate plurality. Since it is always difficult and undesirable to impose values, the values of the whole should be to a large degree acceptable to the parts, and they are acceptable because they facilitate plurality. The parts accept them as a guarantee for their own survival, at least to the extent that:

(1) They have a clear view of what is or is not in their interest because they think in a more or less rational way (and not in an emotional way); or

(2) They are convinced of their power to suppress others and they are not afraid of reactions.

It is useful to make the difference between inclusive and exclusive norms. Contrary to a widely shared opinion, the reason why we have inclusive norms - such as religious liberty, tolerance, and freedom of association - is not to replace or to soften the undesirable consequences of an insufficient sense of common values or of community. In fact they are the heart of a community, a community above the different sub-communities, and people can feel as attached to these inclusive norms just as they feel attached to any other norms or values.

Exclusive norms - norms which do not try to protect plurality or hold together people with different views, but try to win a competitive struggle with other norms - can threaten this wider community, at least to the extent that these exclusive norms are considered to be universal and applicable to people who are not members of the group that follows these norms (or to people who want to leave the group). A sub-community that feels attached to certain universal exclusive norms or norms that exclude difference - for example the belief that homosexuals are sinners - may try to impose its norms on the rest of the community, even if this means violating human rights and being intolerant. Human rights and tolerance are, in their eyes, lesser values or of no value at all. In this case, inclusive norms take precedence over exclusive norms, whereas normally inclusive norms are there to protect exclusive norms.

The norms of the larger community should be as inclusive as possible, and should alow for as much plurality as is possible and desirable (plurality of exclusive, inclusive and other norms or practices). Suppression and judicial action are not the only solution to the problem posed by certain exclusive norms of sub-communities. Sub-communities should consider adopting as much inclusive norms as possible. They should value the state as facilitator of plurality, because they benefit from plurality.

Of course, this is not al ways easy. It requires a certain denial of your group-identity for the purpose of protecting your group-identity. Your identity is based on universal exclusive norms, and therefore on the elimination of difference, but your identity also requires the protection of the state and of the inclusive norms that regulate and protect difference. The state that protects the other groups from the claims of your own group also protects your own group. Other groups may also have exclusive norms and may be stronger than your group. 
You can try to use force to change other people's identities into your universal and exclusive identity - which means that you also have to attack the state, because the state protects difference against you. Or you do not try this, and you accept certain inclusive norms and the existence of other identities. If you choose the latter option, you are more certain of your survival, but you lose a part of your identity, namely your claim to universality. Adopting inclusive norms and supporting the state as facilitator of plurality is in everybody's interest, on the condition that everybody or most people adopt these norms and support such a state.

The question is: what do groups consider to be more important, their own survival, which implies giving up certain aspects of their identity (or giving up the universal application of certain norms which constitute their identity); or their identity, which implies putting their existence and therefore their identity at risk in a possibly violent struggle with other identities? An identity often requires imposing certain values on the rest of the community, which is likely to be self-destructive because other groups can resist or can follow your example. You have to share the world with others. Any other mentality will probably cause your own demise in the long term. This kind of risk promotes the acceptance of inclusive norms and the maintenance of difference, and is part of the justification of human rights. It can even justify human rights to people who, a priori, do not sympathize with human rights or who have adopted values and norms which are incompatible with human rights.

Inclusive norms have an exclusive side: one should not be too neutral or too tolerant. $\mathrm{N}$ ot everything is allowed. Those that attack the inclusive norms are excluded. Everything else should be accepted. The consensus of the community as a whole should be as small as possible and plurality as large as possible, except if the community is united enough to wish otherwise. Only the attempts to use force in order to diminish plurality by force should be excluded, even if this means using force in order to diminish plurality.

The different exclusive norms of the different sub-communities must be able to compete with one another and to strive towards universal acceptance, but only by way of debate protected by human rights, without coercion or forced conversion. This debate might lead to new universally accepted exclusive or inclusive norms. Some groups may be able to increase their membership and to come a bit closer to universality, but others may not. Debate of course already implies the existence of certain common norms and values. The conflicts caused by the coexistence of a plurality of groups - each with their incompatible claims on the other - can only be solved through conversation, and a conversation implies the acceptance of inclusive norms such as human rights. However, one should not ask somebody to give up his or her identity, except when this identity makes the acceptance of difference impossible and entails the suppression of other identities. In some cases, asking a group to refrain from imposing its identity and its norms and opinions on others means asking the group to give up its identity, and this is necessary but regrettable. In other cases, this limitation will not harm the identity of the group.

The problem of inclusive norms versus exdusive norms often appears in religious matters. Most religions claim to have universal validity. Their values are said to be revealed by God, the only God and the God of all human beings. These values should therefore be the values of all human beings. This, together with the fact that values coming from God cannot be contested, makes it imperative that other groups as well as the state or the guardian of diversity disappear. Other religions are not accepted on an equal basis, and everything contrary to the norms of the religion is something that has to be changed, even if this means changing the lives, habits and convictions of people who do not belong to the religious group in question. Fundamentalist Muslims or Christians try to regulate every aspect of life according to the norms given by their religious belief. This is no problem as long as they limit themselves to their own lives and as long as they allow people to leave their group. However, most of the time, they want to regulate other people's lives as well, and in order to achieve this, they try to take over the state and its instruments of 
power. The wish to see our own ideas reflected in the reality of society should not al ways be considered as normal in every case.

\section{$\S 30$ : The Historical R ole of the R eformation}

The struggle for religious liberty has been very important for the freedom of thought and expression. In the West, this struggle was primarily one between Catholicism and the Reformation. The Reformation proclaimed the right of everyone to interpret the Bible in his or her own way (mostly his own way). It rejected the subjection of the individual Christian to the authority of the church, the pope, the priest or other official and wise interpreters of the Bible. In the Protestant view, a just society is not constructed from above. It starts from the individual, conscience per conscience. It flows from the direct relationship between the individual and God and this alone is sufficient.

In Protestantism, there is no need for a separate class of priests because religion is mainly a matter between the individual believer and God. This belief diminished the importance of hierarchy in general and therefore also of hierarchy in politics. The Catholic Church, with its authoritarian and hierarchical structure, has always been a force in the opposite direction. In Protestantism, church and hierarchy, to the extent that they exist, are of secondary importance. Salvation is achieved individually.

This has contributed to the separation of church and state. A church without a welldeveloped hierarchy or elaborate institutions cannot have a tight grip on the state, and a state that is confronted with a religion in which priests are not very important, cannot use priests to influence the citizens. When the institutions of the church become less $\mathrm{m}$ portant, the power of the church to interfere with the lives of individuals also becomes less important. By loosening the link between the individual and the institution, the individual becomes master of his own fate. To a certain degree, society and politics become independent of the church, at least as long as the norms of the church are respected.

Of course, the Reformation also had its negative sides, especially in the initial phase. Most Protestants were less tolerant or more authoritarian than their Catholic competitors. On top of that, the plurality of religions caused by the Reformation triggered religious wars. However, religious war not only caused harm and tyranny (tyranny because it led to the creation of absolutism by the European monarchies trying to restore peace and tranquility). It also led to the institution of religious liberty. After all, the state had no choice but to put itself above the factions. Only by loosening its ties with a favored religion and guaranteeing a free space for every religion, was it able to channel the struggle away from violence As religion had become a dangerous and dividing power, it became clear that the state had to separate itself from the church, not only to keep the peace, but also to maintain itself.

The duty of the state to support one particular religion was replaced by the duty to protect the plurality of religions. Religious freedom gave citizens who belonged to a religious minority the power to claim protection from the state. In this way, the state not only liberated the people from the horrors of religious wars, but also from the pressure of religious conformity. However, the state soon discovered that it had become the victim of the religious freedom it had granted its citizens (Ankersmit 1997:220-221). It suffered the consequences of its own creation. The individual retreated from the battlefield of religion to the freedom of his conscience, but from this isolated position, he or she entered the battlefield of politics and started to claim the right to decide for him or herself in domains other than that of religion.

The fact that, in our day and age, global mobility and globalization encourage competition between and coexistence of different religions, makes it likely that the historical events which resulted from the struggle between Catholicism and Protestantism - and which have been events limited to the history of the West - will be reproduced elsewhere in the world. Different states in different parts of the world will feel the same need to pacify competing parties by putting themselves above these parties. They can only put 
themselves above competing religious communities if they separate themselves from religion and if they grant religious liberty. Only religious liberty can produce peaceful coexistence in a plural society. The option of suppressing one or all of the competing parties will only produce revolt and will lead us away from rather than towards peace and security. These contemporary historical developments justify and promote the universality of the right to religious liberty.

N ot only the Reformation but also Christianity in general has had a number of positive effects on the development of human rights. The common origin of all human beings and equality in the face of God bring about a unity of humanity, which is an important prerequisite for human rights. The importance of the relationship between man and God diminishes the importance of worldly relationships and presents man as man, and not primarily as a member of a class, a nation, a family etc. Man in general becomes a fact, and can have certain general characteristics, such as the possession of human rights. Man is no longer defined solely by way of his membership of certain groups. He becomes an individual whose place in society is of secondary importance. This is important for the development of human rights because these rights belong to man because he is a human being, not because he occupies a certain social position.

The positive effects of Christianity and Protestantism on human rights are balanced and for some people even outweighed - by negative effects. For example, the importance of the relationship with God can turn attention away from public relationships with other citizens, not to mention some of the more brutal negative effects such as the inquisition, the crusades etc. Still, the facts are what they are, and credit should be given where credit is due.

\section{$\S 31:$ The Private Space}

Paradoxically, human rights also protect the public space by way of the right to privacy. The public world exists thanks to its counterpart, the private world. There is no light without darkness. By recognizing the right to keep certain thoughts, relationships and communications secret, one automatically recognizes the right to make other thoughts, relationships and communications public. The right to privacy is a negative version of the freedom of expression, but is, of course, also a value in itself. Privacy is not only important because it protects publicity. It is also important in itself. People need to have privacy, a space of their own, protected against the intrusion of other people. This is yet another example of the indivisibility of human rights. The universally shared need for privacy is another way to justify the universal application of human rights, or at least of one human right if one does not agree that all human rights are indivisible.

Establishing links between rights necessarily entails balancing rights. As human rights have to be respected in the private sphere, there can be no unlimited application of the right to privacy. Sometimes there has to be interference in the private sphere, for example, when this is required by the protection of other human rights. In such cases, one has to balance two different rights. If the violation of a human right in the private sphere is serious enough, then the right to privacy has to be suspended or limited (I will return to the problem of limiting and balancing rights in the Concluding Remarks).

\section{$\S 32:$ Private Property}

The right to private property (or, more specifically, the right to legal protection of private property and the right to use it freely) is an additional protection of the private space Without private property, without your own house or your own place in the world, and without your own intimate and personal things, it is obviously more difficult to have a 
private life. The four walls of your private house protect you against the public. Nobody can spend his life entirely in public (Arendt 1983:163).

Without private property, there is no private world (another example of the indivisibility of human rights), and without a private world, there is no public world. So private property also contributes, albeit indirectly, to the protection of the public world. Just as there is no light without darkness, there is nothing common to all people and no public space without private property.

Private property also protects public life in other and more direct ways. Independence, self-reliance, autonomy, and therefore also freedom play an important part in public life (as I will show in Part 5), and these capacities rely heavily on private property. Private property is also important for the creation and maintenance of relationships, another important aspect of public life. You have your own house and your own place in the world, but not in the world in general. You live in a particular world, in a very concrete social context of friends, enemies, neighbors and other types of relationships. A place in the world is always a place in a particular community, even if you have to transcend this community now and again.

Furthermore, property is an important tool in the creative design of your personality, especially but not exclusively when you are an artist (designing your personality is another important part of public life). Finally, it is obvious that without private property there can be no help or generosity. Generosity and the absence of egoism are important for the maintenance of a community. Since a public world is al ways - in part at least - a concrete community, we can conclude that publicity needs generosity and is incompatible with egoism. This may contradict our intuition - which says that there is a causal link between private property and egoism - but I still think it is true.

The right to private property, and in particular the right to your own house, is linked to the freedom to choose a residence, which again is linked to the freedom of movement (again another example of the indivisibility of human rights; I will now stop repeating myself and leave it to the reader to find other examples of this indivisibility). Freedom of residence and movement is very important for public life. When you are forced to live somewhere and when you are not allowed to travel, you may find yourself far away from and unable to reach the sources of public life, such as associations, cultural societies, libraries, theatres etc. Public life is not just communication - nowadays, distance is no longer a problem for communication - but also includes the possibility to visit events, places and meetings, to travel, to live in a specific community etc.

The right to private property is, just as most of the other human rights, a limited right. There can and should be redistribution of private property from the rich to the poor, if other human rights of the poor suffer as a consequence of insufficient private property (for example the economic rights of the poor). Taxation and expropriation however should be used carefully, in view of the numerous important functions of private property. The more property a state acquires, the weaker the citizens become. Weaker not only compared to the state, but also compared to fellow citizens. His fellow citizens find themselves in a position in which they can control and intervene in his weakened private space

You also own your own body. Your body is part of your private property. It is something that is yours; it is the thing par excellence that is your own. It is not common to several people and it cannot be given away. It cannot even be shared or communicated. It is the most private thing there is. Owning your body means that you are the master of it. Other people have no say in the use of your body; they should not use it, hurt it or force you to use it in a certain way. This underpins the security rights such as the right to life, the right to bodily integrity, and the prohibition of torture and slavery. It also implies the right to self-determination and therefore the right to die. You carry prime responsibility over your own body and life.

The property of your body can justify private property of material goods. The power of your labor is incorporated in the goods you produce. By working on an object, you mix your labor with the object. If someone wants to take this object away from you, he also 
takes away your labor, which means that he takes away the power of your body. He therefore uses your body, which is incompatible with your right to possess your own body (Locke 1994:79). If man owns his body, he also owns the power of his body and the objects in which this power is incorporated, to the extent that he has not stolen the objects.

The right not to be a slave is the negative version of the right to possess your own body. Those who commit slavery (but also those who steal) act as if the bodies of other people are their property, a property which can be bought and sold. Considering other people as your property diminishes the value and dignity of these other people. Other people should not be considered as a means. As a consequence, we have to give every person the right to be considered as a person before the law (slaves are not considered as persons, they are goods that can be traded).

\section{§33: Equal Rights, N on-Discrimination and Justice}

Closely connected to the prohibition of slavery is the right to have equal rights and the right not to be discriminated. Every human being has equal rights, wherever he or she lives, whether he or she believes in a God or not, is rich or poor, or whatever. Human rights are rights of all people at all times. If everybody has equal rights and if, as a consequence, nobody should be discriminated against in the use of his or her rights, then human rights are universal.

All people must have equal rights because human rights protect the public space. The public space is the equal and common property of all. Everybody has an equal claim on the rights necessary to use the public space because everybody has an equal right to use it (property of something means having the right to use it), and because everybody benefits equally from this use and from the values that result from this use. Everybody needs public life to realize certain values, and because everybody has an equal need for this kind of life, everybody also has an equal need for human rights. Human rights belong to everybody in an equal way because everybody needs them in an equal way to lead a public life and to realize the values attached to this public life. Equal rights and non-discrimination are necessary conditions for each human being to have a good life.

It is unacceptable that some people have, for example, the right to free speech and others do not or only in a limited way. There can be no privileges. Nobody has more rights than another. Everybody's rights are equally important. In a situation of unequal rights and discrimination, certain people have less access to the public space and less opportunity to realize some important values. Of course, someone who considers other values to be more important - and I find it hard to imagine such a person - can waive his or her rights, can accept inequality and can retreat from the public space. However, it seems to me that this can only be his or her decision. Other people should therefore $d$ ways respect this person's equal rights.

Equality is a very important principle. (Of course, equality in the sense of equal human rights is only one of several different forms of equality. I will deal with equality in Part 4). Equality of rights, in the same way as tolerance, supports the application of human rights. Equality means the duty not to discriminate when applying human rights, whereas tolerance means the duty not to suppress certain ways of using human rights. The enjoyment or, better, the possibility to enjoy human rights must be equal for everybody. It is unacceptable that some people enjoy more human rights than others, or enjoy some human rights more than other people enjoy them. The fact that this equality is a right is shown by the fact that most people consider it wrong or consider it to be an injustice if people are treated in an unequal manner. Equality of rights is of course not always a fact, but it is a right, a right to enjoy all other rights to an equal degree, neither less nor more than all other people. The state can enforce this right to equality, and can make it a fact. 
It is clear that there is a link between equal rights and non-discrimination on the one hand and tolerance on the other hand, even though non-discrimination is concerned with equality and tolerance with freedom (or, better, with the acceptance of freedom). When people are discriminated against and when their rights are taken away or limited, we see that this is often the result of intolerance or unwillingness to accept the particular way in which these people use their rights. The statement that some group has fewer rights than other groups can be based on the conviction that one is allowed to tolerate less from this group. Intolerance leads to discrimination, but not necessarily vice versa (discrimination can have other causes).

The idea of equal rights resulted from the emergence and the ascent of the bourgeoisie and was in the first instance a tool for the protection of their interests. The bourgeoisie was, compared to the aristocracy, a relatively open class. One could enter and leave this class in a relatively free and sudden way and the moment of entering or leaving was sometimes hard to predict. For this reason it was undesirable to create a new set of privileges in the style of those of the older classes. If the bourgeoisie was to have rights to protect its interests, they had no choice but to instate rights for everybody (Donnelly 1996:70).

Historically, the transformation of privileges (or freedoms and rights limited to certain groups such as guilds, corporations, the nobility etc.) into general or human rights was the invention of the revolutions of the 18th century. From this moment on, human rights were considered to be rights of individuals as entities detached from concrete relationships and groups. It is therefore not surprising that the misunderstanding that rights are individualistic, anti-social and egoistic dates from the same period. I will explain the reasons why this is a misunderstanding at the end of this first Part (this misunderstanding plays an important part in the cultural critique of human rights).

Having equal rights also means having rights vis-à-vis everyone. We have rights erga omnes. Everybody, states, groups, individuals, have to respect our rights in an equal manner. Every right can be invoked erga omnes, against everybody. Everybody has an equal duty to respect our rights, just as everybody has equal rights. Someone's right is everybody else's duty.

Of course, equality transcends the realm of human rights. There are other important types of equality besides the equality of rights. We consider it wrong and unjust if someone is treated in an unequal manner, whether in the field of human rights or in any other field. According to most people, equality and justice are the same thing, but this is only partially true. Injustice can arise out of an unequal treatment of people that are equal, but also out of an equal treatment of people that are unequal. A pupil, who considers that he earns a higher score than the rest of the class, will feel that he is the victim of an injustice if the teacher gives every pupil the same score. What is deserved should also be a part of justice. Being just is giving everybody what he or she deserves. Discrimination is not wrong or unjust in every aspect of life. It is unjust when it is applied in certain domains such as human rights, where desert is irrelevant because human rights are unconditional - or when it is applied according to the wrong criteria - for example the teacher giving scores according to personal preferences instead of merit.

The question is then: when is equality necessary, and when is discrimination acceptable? Discrimination is clearly unacceptable when dealing with human rights. Every inequality is then an injustice The reason is that, although people are not equal and do not wish to be treated as equals in all aspects of life, they are equal on a certain basic level of humanity and this basic level is the level of the values protected by human rights. That is why people have to be treated equally and have to have equal rights at this basic level.

The case of the criminal may cause a problem. The convicted criminal apparently has fewer human rights than law-abiding citizens, and is treated in an unequal manner. The answer to this is that a criminal is convicted and punished because otherwise he would violate the rights of law-abiding citizens. A system of rights naturally punishes violations of rights - otherwise it would not be able to survive - and this punishment necessarily entails violations or better limitations of rights. 
Indeed, the solution to the problem lies in the difference between violation and limitation. Everybody's rights are limited, not only those of the criminal. For example, you cannot yell 'FIRE!' in a crowd without a reason, because this might lead to violations of the rights of the crowd. People might get trampled as a result of your 'free expression'. Unlimited rights nearly always provoke violations of other rights, the right to life and bodily integrity in my example. In the same way we have to limit the criminal's right to free movement because otherwise he may violate the rights of other people. Therefore, the criminal is not treated in other way than other people. A citizen in a theatre who cannot yell 'FIRE!' has fewer rights than the citizen on expedition in the Sahara desert. In the same way, we can accept that a criminal, who has killed someone and is locked up for it, has fewer rights than law-abiding citizens.

One might answer that the rights of the criminal are more limited than the rights of law-abiding citizens and that, as a consequence, there are no equal rights. Even if this were true - and I believe it is not - it is clear that treating people equally means trying to avoid serious harm done to many people or to an individual in a more rigorous way than less serious harm done to a few people or to an individual. So being more severe to a criminal is in perfect agreement with the principle of equality. Rights should be limited in proportion to the harm they may do to other rights or to the rights of others, otherwise there can be no equal rights.

There is another possible solution to the problem of the rights of a criminal. The right to equal rights can perhaps be limited, just as many other rights and for the same reason as other rights, namely the protection of rights. People should not always be treated equally and should not always have equal rights. Those who violate the equal rights of others - and who therefore create inequality - have to be punished and lose some of their rights. They are treated in an unequal manner and have unequal rights.

Freedom rights invariably protect public life, at least to the extent that they are transformed into a legal system enforceable by the powers of the state. Public life is structured, institutionalized, organized, formalized and given a permanent shape and continuity. It is translated into concrete political and judicial structures and institutions - even into a very particular form of government, namely democracy, as I will show in Chapter 3 whereby its inherent fragility is taken away. Public life needs a protected space and structure in which it can take place, and which is able to enforce public life in case it is threatened. In other words, public life needs power. No public life can last without a power which is able to enforce human rights and to create and protect institutions in which to discuss, to study etc. Relations require obligations. (This even transcends the level of human rights. Ordinary things such as politeness, letting the other one speak, avoiding cacophony and the rules of language etc. are also obligations necessary for public life. However, as human rights are the subject of this book, I will not deal with these other ways of protecting public life).

Human rights protect our public life against our fellow citizens, against our state, and against foreign powers. This international aspect is important, not only because many threats to public life come from across the border, but also because some people believe that the internationalization or globalization that we witness today, creates a situation in which the political and judicial protection of the public space is no longer necessary. Tools like the Internet are supposed to make human rights superfluous in the so-called post-institutional era. It is true that the Internet weakens the power of some entities traditionally hostile to public life, for example the state. But it is possible that the networks will not remain as free as they are at the moment, or that they will become dominated by certain groups which try to impose their information or their software, and which are equally hostile to public life. In any case, even if the networks can take over some of the functions of the state - for example the protection of publicity - other functions - such as conflict management - will probably remain forever with the state. 


\section{Chapter 2: $\quad$ Negative and Positive Rights}

$\checkmark$

Section 3: Human Rights Against the State

\section{$\S 34:$ To F orbear and to Protect}

If human rights are judicial and political institutions that cannot exist without the protection of the state, then they are more than just protective tools directed against the power of the state. The first and most important function of human rights is the protection of the relationships between citizens, not the protection of the citizens against the evil power of the unlimited state.

Of course, protection against the state is an important intermediary function, and should not be neglected. Most violations of human rights are caused by state actions. Power corrupts and that is why we need rights to limit power. However, without power, rights are useless. Human rights limit the actions of the state, determine what a state is not allowed to do or should refrain from doing, and define those areas where the state is not allowed to interfere. But human rights also, and positively, determine what the state should do. They demand positive action and interferencefrom the state ("le droit à la résistance et à la défense' as opposed to 'le droit à l' obtention et à l' exigence' ').

For example: the state should not only avoid torturing its citizens, it should also actively protect and help those citizens who are tortured, either by fellow citizens or by some part of the state. The same is true for economic rights, which I will discuss in Part 2: the state should not only avoid creating or maintaining poverty, it should also try to create a minimum amount of equal prosperity for all.

The state should not only abstain from doing certain things. It also has a duty to act and protect. Even in those cases in which the state has to abstain, it should be actively engaged in enforcing this abstention. Every human right, not only the 'modern' ones such as economic rights, but also those rights that primarily demand the absence of government intervention, require government intervention, for example the judgment of a court of justice concerning an illegal government intervention, and the police measures enforcing this kind of judgment. The state should commit as well as omit, and prevent, provide, protect and engender as well as forbear.

The state, and primarily the justice system and the police, protect us against violations of rights. We only have rights thanks to the state. Something merely negative, such as abstention, forbearance or a limited state, can never constitute a state, because then it would be better to have no state at all. There is a reason for having a state. The essence of a state can 'never be derived from something which is a mere negative, i.e., constitutional limited government' (Arendt 1990:147).

However, protection against violations of rights as the reason for having a state, is al so something negative. There are reasons why we need this protection, and one of them is our public life, which requires respect for human rights. To put it in a positive way: enforcing respect for human rights, protecting its citizens against violations of human rights and thereby enforcing public life are some of the most important tasks of a state. Our public - but also our private - life can only exist when protected and instituted by the state. 
Our rights can become real, thanks to the existence of the state. We can ask the state to enforce our rights, and it is the duty of the state to do so. ' $\mathrm{H}$ enry Shue has developed this argument furthest in his distinction between three different kinds of duty that are required to make a human right effective. There is, first, the duty to avoid depriving a person of some necessity; the duty to protect them from deprivation; and the duty to aid them when deprived' (Beetham 1995:51). The last two duties obviously require action instead of forbearance.

The fact that human rights are more than just protection mechanisms directed against the state is maybe most evident in political rights. It is impossible for the state to protect these rights by doing nothing or by avoiding to do certain things. These rights, still more than other rights, need the state. It is actually impossible to think of these rights outside of the state. This has consequences for other rights as well. Since the right to free speech, for example, is also a political right in certain circumstances - an election is the free expression of the opinion of the people on the work of the elected rulers - one cannot say that this right is merely a protection against the state or a limit on state activity. It is part of the activity of the state, not only the activity of repressing violations and enforcing respect, but also the activity of governing the common life of the citizens. It is clear that human rights are at the center of the state.

The existence of political rights shows that human rights are meant to be more than just a weapon in the struggle of citizens against the state. As I will show in Chapters 3 and 4, political life as guaranteed by human rights in general and by political rights in particular is a means to guarantee some important values, but this becomes impossible if the state is considered to be no more than something negative against which we ought to protect ourselves. The state can be something good. It is not a necessary evil, and neither is it a mechanism to suppress evil that has to be kept as small as possible because it suppresses freedom as well as evil. I will also come back to this problem in Part 5 in which I will discuss the problem of freedom.

It follows that a state which does nothing violates rights. '[E]st un ennemi de la liberté celui qui non seulement s'élève contre elle, mais ne fait rien pour elle' (Mourgeon 1996:91). A state which does not create or maintain the political structures in which people can enjoy their political rights, or does not manage correctly the judicial structures necessary for enforcing human rights, violates rights, just as much as a state which tortures it citizens.

As a consequence, the state cannot fulfill its duty to act if it is not allowed to collect a sufficient amount of tax-revenues. All rights cost money, and therefore there are no rights without taxes. In Part 4, I will discuss some of the phenomena which threaten the power of the state and therefore also the effectiveness of human rights. (I will focus on phenomena such as globalization. The international economy limits the power of the nation state, in particular the power to tax big companies. Without taxes, the state can do nothing at all. In view of the role the state has to play in the protection of human rights, these phenomena can therefore be considered as very dangerous, although they may be beneficial on other levels).

The negative aspect of state forbearance and of protection against the state is of course present in human rights, and it should not be neglected or depreciated. Human rights do protect man against the abuses of state power. Human rights, particularly in the early stages of their historical development, were considered as primarily directed against the state. This was also the main cause of their initial success. The theory of anti-state rights was inherent in the idea of human rights as natural rights. Natural rights, as opposed to positive rights, are not given by the state and can be used by the individual or by a group as an instrument of defense against the state. $\mathrm{N}$ atural things were also considered to have a higher value than artificial things.

Historically, human rights as a protection against the state were an important element in the development of democracy. Democracy is the best way to avoid violations of rights caused by the state and is the best way to protect the rights of the citizens against the state, because in a democracy the business of the state is carried out or at least controlled by the people. And if the people govern themselves, then it is unlikely that they will vio- 
late their own rights. If the people control the government, it is likely that they will remove the government in case of violations of rights.

However, all this should not make us forget that there is something inherently positive in the state. The state does not protect us against evil for the sole purpose of protection. It protects us because protection allows us to have a public life. The state actively guarantees our public and political life, not only by passively abstaining, but also by actively doing something. 'That to secure these rights, governments are instituted among men' says the Declaration of Independence of 1776.

The traditional criticism of economic rights is no longer valid when seen in this perspective. These rights have often been excluded from the canon of human rights because they require action from the state (they are 'rights' you use to ask something), whereas 'real' or 'normal' human rights only ask the state not to interfere (you use these rights to protect yourself and to offer resistance). ' [It is easy] to refute (...) the assumption of a principled difference between the two sets of rights in the character of the obligations each entails, negative and positive respectively. As many commentators have shown, this difference will not hold up. Certainly the supposed 'liberty' rights require the state to refrain from invading the freedom and security of its citizens. However, since governments were established (...) to protect people from the violation of their liberty and security at the hands of one another, it requires considerable government expenditure to meet this elementary purpose. Establishing 'the police forces, judicial systems and prisons that are necessary to maintain the highest achievable degree of security of these (sc. civil and political) rights ... is enormously expensive and involves the maintenance of complex bureaucratic systems' ' (Beetham 1995:51). '[E]conomic and social rights have to be considered as equally solid as civil and political rights, since there is no difference of principle between the state's provision of security for the vulnerable and of social security for the deprived' (Beetham 1995:52). Human rights are both bulwarks against evil and the bearers of goods and values. Human rights do more than just protect us against the state and our fellow citizens.

Those who accept the existence of economic rights often argue that their implementation can be postponed because they, contrary to traditional freedom rights, require action instead of forbearance and are therefore more difficult to implement, especially in situations of scarcity or poverty. Although not completely wrong, the argument is based on an exaggeration. Indeed, the implementation of economic rights requires a certain amount of financial means on the part of the state, but so does the implementation of other rights. The judicial and policeinstitutions necessary for the protection of freedom rights also cost money, and for a developing country, for example, it may be as difficult to pay for these as it is to pay for economic rights. The protection of the right to due process, the right to redress in cases of violations of rights, the right to legal remedies, and the construction of a legal and judicial system as a prerequisite for the enforcement of rights may be very difficult in a state which has little financial means, which does not have the people educated for the job, or which has a recent past of atrocious authoritarian rule. The implementation of economic rights may even seem relatively easy compared to the rest.

The argument that 'classic' freedom rights require only legislation, and that economic rights require much more, is plain nonsense. Every right requires more. Even the opposite argument might sometimes be true. Certain economic rights, such as the right to food in an amount sufficient for survival, are often better served by government forbearance than by government action. Look for example at the Great Leap Forward and its disastrous consequences for the people of China. All human rights need actions as well as forbearance. According to the circumstances, a right can be more or less positive or negative. The right to food in Mao's China was relatively negative and directed against state intervention. In the inner cities of most of the big cities of the West, it is relatively positive and directed at the passivity of the state (Donnelly 1996:33). 
The fact that human rights are not primarily a protection mechanism directed against the state, but rather the driving force behind and the reason for all state actions, shows that the theory which holds that rights can be added to any kind of state, is wrong. Rights can exist only in a state which considers them as its one and only driving force. When rights are added to another kind of state they are ineffective because they have to be balanced with other goals, or they are an unconvincing propaganda effort to give a certain dishonored regime a 'human face' (adding a bit of pluralism, a bit of private property etc.). '[I]ssues of human rights violations [cannot] (...) be adequately addressed without advocating for changes in the overall structure that begets such violations' (R. Brett in Beetham 1995:106).

In case of rights violations, the structure or the system of the state must be adapted so that the whole machinery works only for the benefit of human rights. In other words, the form of government must be changed. I will show in the next Chapter that only a democratic form of government can guarantee that the only objective of the state is the protection of human rights. There is a persistent myth, 'so damaging to international efforts to protect human rights, that a state lacking a democratic form of government and a commitment to the rule of law can nevertheless guarantee the enjoyment of human rights' ( $T$. Buergenthal in Beetham 1995:107).

It is equally preposterous to claim that human rights, or at least some of them, should be given up and transferred to the state, that the people must cede to it [to the government] some of their natural rights in order to vest it with requisite powers' (Hamilton/ Madison/ Jay 1954:5). I will discuss this claim in more detail in Part 5, which deals with freedom. For the present it is sufficient to point out that not rights but power, force or violence is transferred (the state has a monopoly of violence).

The opposite is also incorrect. Human rights are not given by the state. They are not a gift, a reward, or a favor granted by the state to its citizens, possibly in exchange for something else, for example obedience or the entry into a certain social class. Rights are not part of a contractual relationship. The states of the Soviet block were notorious for this kind of reasoning. They not only considered rights to be a favor given by the state to exemplary citizens (in which case they were not rights but privileges), but they also viewed rights in a purely functional way. Exercising human rights was only possible if this was of any use to the progress of communism. Consequently, it was impossible to enforce human rights. The state decided when and where they could be enjoyed, and when and where it could violate them. Human rights, however, are unconditional. People have human rights because they are human beings. No other conditions are necessary. (This also means that one cannot refuse human rights to people who violate human rights. There must be some other reason, for example the fear that they will harm other people's rights). 
Section 4: $\quad$ Human Rights A gainst Fellow Humans

\section{§36: Bourgeois Rights}

Human rights are not primarily directed against the state, but it would be even less true to say that they are primarily directed against fellow citizens, even though protection against fellow citizens is one of their functions (it is not always the state that violates rights). Human rights that only require forbearance are by definition egoistic rights: the only thing we have to do for other people is to avoid doing certain things (Mendus in Beetham 1995:13-14). The problem is that if there is no interference there is no help $\dot{\theta}-$ ther. The expression 'primum non nocere' ('first there shall be no harm done') clearly indicates that something else has to follow, that not doing harm is not the end of the story. Human rights are positive rights in the sense that they impose a duty on citizens to do something. They do not stop at the prohibition of interference. This is most evident in economic rights. When somebody is starving, everybody is obliged to help and to give some of his or her goods to the person in need. Forbearance, non-interference and leaving the other person alone will not protect this person's rights.

However, other types of rights are also more than just instruments to keep people out of each other's way. Freedom of expression is used to convince other people, to create groups, to impress other people etc. Letting people do what they do without interfering is therefore not enough to respect another person's right to free speech. You have to listen, and you have to be open to the possibility of being convinced. Free expression would lose its value in any other case.

Marx was able to criticize rights for their supposed inherent egoism because historically the bourgeoisie considered rights as primarily requiring forbearance. This criticism, although aiming at a simplistic view of human rights - a view however that was undoubtedly widely shared until a few decades ago - has created a kind of tradition. Even today, it is not uncommon to view rights as a function in and a justification of the rise of egoistic bourgeois capitalism.

According to Marx, human rights are the 'rights of the egoistic man, separated from his fellow men and from the community' (Marx in Tucker 1978:43). They are the rights of man as an isolated, inward looking, self-centered creature, who regards his free opinion as his intellectual private property instead of a right to communicate; who uses his right to private property not in order to create a beach-head for his public life but to accumulate unnecessary wealth and to protect unequal property relationships, who uses the right to privacy as a wall keeping out the poor snoopers watching the rich people; who considers fellow men as the only legitimate restraint on his own freedom, and therefore as a limit instead of the source of his own thinking, identity and humanity (read at. 6 of the French constitution of 1793: 'Liberty is the power which man has to do everything which does not harm the rights of others'); who considers freedom to be no more than the ability to pursue selfish interests and to enjoy property, unhindered by the need to help other people, 'without regard for other men and independently of society' (Marx in Tucker 1978:42); and who considers equality to be the equal right to this kind of freedom (everybody can emancipate himself by becoming a bourgeois). 
Human rights, in this view, serve only to protect egoism and the unequal distribution of property, and to oppress the poor who question this. On top of that, human rights obscure this fact because they are formulated in such a way that it seems that everybody profits from them. Contrary to what is implicit in their name, 'human' rights are not general or universal rights. They are the rights of those who have property and who want to keep it. A specific situation of a specific group of people is generalized in human rights.

Of course, this criticism can be justified. No one will deny that human rights can serve to protect and justify egoism, oppression of the poor and indifference. They can help to shield people behind private interest and to transform society into a collection of loose, self-centered, self-sufficient, withdrawn, independent, sovereign and isolated individuals. Because the rich have more means to use for example the freedom of expression, this freedom can be an instrument of the rich to monopolize political propaganda and political power and to use this power to maintain their privileged situation. Economic relationships can be maintained by legal means.

However, in order to judge and possibly reject a phenomenon, one should also look at its intended and ideal functions, not only at the ways in which it can be abused. As I have argued in the preceding Chapter, human rights are not the rights of egoistic man but on the contrary the rights of those people who need relationships and public life. They not only protect man against the attacks and claims of other people (for example the attacks and claims on his property); they also create the possibility of doing something together in a common world. They do not allow you to do something to other people (taking their property, determining their opinion etc.), but at the same time they invite you to do something with other people. In other words, they are not only negative. They not only limit the way we relate to other people, they also stimulate and protect the way we relate to other people. Not only private man, but also public man is the object of human rights. Once human rights are instituted - which means written down in law, enforced in a court of law, and exercised in institutions such as parliaments, referenda, groups in civil society etc. - they cease to be merely individual rights or rights used for protection against the state (liberalism) or against fellow citizens (Marxism). Therefore, they cannot be reduced to instruments of extreme individualism or egoism.

\section{§ 37: General Interest and Self-interest, and the Dangers of Both (1)}

Human rights can indeed be reduced to mere fences around the private world, but let us not forget that exclusive attention to the general interest can be equally dangerous. The 20th century in particular has shown that sacrificing the interest of the individual for some supposed general interest - communism for example, which completely submerged the individual in the collective and was not afraid to break an egg in order to make an omelet - can cause widespread human damage, just as exclusive attention to private interest. Communism has gone way beyond what is necessary to keep a community from disintegrating into a plurality of loose atoms.

It is true that the origin of human rights can be traced to the rise of the western bourgeoisie who needed something new to dismantle the feudal structures of the aristocracy and the powers inhibiting the development of capitalism. The fact that human rights originated from a specific historical situation - the western capitalist revolution - does not imply that they cannot be useful in another time or place. Furthermore, this story of the genesis of human rights is far from complete. Important events, before and after the rise of capitalism, as well as events taking place in other cultures, contributed substantially to the tradition of human rights. 


\section{$\S$ 38: The Importance of Boundaries and of the Intimate and Inviolable Space}

Even though Marx made the mistake of dismissing human rights because of one possible use of human rights, his criticism helped us become aware of the fact that human rights not only regulate the relationships between the state and its citizens but al so the relationships between citizens (al beit other kinds of relationships than those which Marx had in mind). Of course, the awareness of human rights as positive rights necessary to create relationships, should not lead us to neglect their function as boundaries, boundaries be tween citizens and the state and between citizens. Notwithstanding the importance of relationships and communication, there are certain boundaries that neither fellow citizens nor the state can transgress.

Human rights create an inviolable and impregnable space in which the individual can be himself, can make his own decisions and can do as he likes, free and unhindered. This space escapes the control of fellow citizens and of the state. It has been called a space of 'petty sovereignty' or 'non-interference', similar to the larger space of the sovereign nation state. Freedom of thought, the right to bodily integrity and the right to life are particularly important for the creation of this space. Neither the law nor our fellow citizens should determine what we think. Our space for thinking is free from interference, and the same is true of our physical space, the space of our body. Our free space has a mental as well as a bodily character. Both the mind and the body are inviolable. However, freedom of thought is not the same thing as freedom of speech. The latter can be the object of interference. Free speech can be limited, freedom of thought cannot (see also the Concluding Remarks).

Human rights limit the actions and the interference of other people and the state. ' [I]ndividuals have rights and there are things no person or group may do to them' in the words of Nozick (in Barber 1984:37-38). These limits and boundaries protect us against the state and our fellow citizens. (In Part 3, I will show that boundaries are also important in another sense. The boundaries of the state create and protect a limited space in which there can be a public life without the interference of external powers and in which rights can be enforced by a state that is the sovereign power inside the boundaries of its territory).

However, the negative aspect of human rights - the boundary - is not more important than the positive one, the creation of relationships. This duality can be seen in the history of the word 'law'. The Ancient Greek word for law, 'nomos', comes from hemein' which means divide or distribute (A rendt 1983:104), whereas the Latin word for law, 'lex', has a totally different meaning, closer to relationship than separation. 'Lex' not only implies coercion or prohibition, but also connection, agreement or contract. If human rights would be no more than borders and protection mechanisms, then politics would be re duced to zoo-keeping, keeping the animals apart (with the zoo-keeper himself behind bars, namely the bars of the law), and the people would be reduced to homo homini lupus', wild animals that need to be tamed by the law and by human rights.

\section{$\S 39:$ Some N egative Consequences of Boundaries}

The boundaries established by human rights solve the problem of tyranny, violence, domination and oppression, but create other problems in the process. Along with the elimination of oppressive relationships, they can eliminate all useful relationships. '[T] defense of the individual against the old tyrannies of hierarchy, tradition, status, superstition, and absolute political power has been sustained by a theory of the radically isolated individual defined by abstract rights and liberties. Y et this theory, as put into practice in the world of actual social relationships, has eroded the nourishing as well as the tyrannical connections and has left individuals cut off not only from the abuses of power but from one another. A nd without one another, individuals have become easy targets for authoritarian collectivism. The theory that was supposed to defend men and women from power has thus in fact stripped them of the social 
armor by which they could most effectively defend themselves' (Barber 1984:101). Communities, relationships and collective actions in general, are necessary for public life, but also for the protection of humanity against tyranny and oppression - a tyrant likes nothing more than subjects who are atomized and therefore powerless. The irony is that human rights as boundaries - which are meant to protect against tyranny and oppression - can bring about the very thing they were created to resist.

The concept of a boundary preserves the myth - or let us say the exaggeration - of the 'evil state' ('power corrupts') - a myth in which the state, as protector of human rights and public life and as a stage on which human rights and public life can be enjoyed, disappears. On top of that, it preserves the myth of egoistic human rights. 'W here human rights are asserted, they are asserted as claims by individuals and against the power of the state, or against other individuals. But to assume that rights are needed against the state is to assume that there must al ways be antagonism between the interests of the state and the inter ests of individuals, and this is a denial of the kind of ideal society envisaged by socialists and communitarians alike. Furthermore, to suppose that rights are needed against other individuals is, apparently, to endorse an egoistic or selfish understanding of human nature and human flourishing' (S. Mendus in Beetham 1995:12-13).

After all, the protection offered by the boundaries created by human rights, concerns not only our thoughts and our bodies, but also our property, our efforts, our contribution to society etc. 'Chacun, retiré sur sa motte de terre, devenait souverain absolu et indépendant; et toute l'action sociale se réduisait à faire que chacun restât maître de la motte de terre que l' hé ritage, le travail, le hasard, ou le crime lui avaient procurée: Chacun chez soi, chacun pour soi' (P. Leroux in Leleux 1997:188). We use our rights to claim something from other people. We claim what is due to us and other people have the duty to respect these claims. We do not give something in return and we do not care. We get something and that is all. That is the background noise of human rights, at least of human rights understood as mere boundaries.

The concept of a boundary corresponds mainly to the private sphere - the boundary around our body, our thoughts, our private property etc. - whereas the concept of relationship corresponds more to the public sphere. Boundaries are inimical to the public sphere. (This is of course a bit of an exaggeration. The public space is also protected against the interference of the state). Boundaries also imply a way of understanding autonomy that is altogether erroneous and closer to autarchy than real autonomy, but I will discuss this in Part 5.

The fact that the meaning of rights transcends the creation of boundaries is already evident in the language in which human rights are expressed. Rights are rarely called 'rights against'; they are 'rights to', the right to have relationships, to have a public life; to develop one's personality etc. 


\section{Chapter 3: $\quad$ Political Life, Version 1 (The Link Between Democ- racy and Human Rights)}

$\checkmark$

Section 5: $\quad$ Power Struggle and Struggle in Society, Version 1

$\S 40:$ Different Ways of Institutionalizing Conflict

Human rights are not the only means to protect and institutionalize public life. Democracy also plays a part. It protects public life in three ways:

(1) Democracy protects human rights and therefore also public life, albeit indirectly. Democracy and human rights cannot exist separately (and not only because they serve the same purpose). In fact, democracy is also a human right, or, better, a subcategory of human rights called political rights.

(2) Democracy protects public life in a number of direct ways (e.g. it protects conflict and conflict is part of public life).

(3) Democratic political life is a part of public life. I will also show that political life guarantees a number of values that are not guaranteed by public life in general but that are as important for human life as the values guaranteed by public life in general. These values are therefore an element in the justification of democracy, in addition to the values guaranteed by public life in general.

I will now discuss these three statements in some more detail. Democracy and absolute, uncontested power are incompatible. In a democracy, the people give power and can take it away. Nobody can acquire or claim power in a permanent way, as if it were his or her private property instead of a public matter. Nobody can personify, embody or crystallize power. Power in a democracy is undefined, or at most temporarily defined and subject to formal and legal rules that periodically call it into question and either destroy it or reproduce it. Power is the provisional result of a power struggle that can never be abolished and continues indefinitely according to stable and foreseeable legal rules and procedures (for example those regulating the elections and the election campaigns). It is an object of temporary use rather than property.

In a democracy, you can only have power on a temporary basis because your power is the result of an election victory, and you have to undergo the test of future periodical elections in which you make yourself accountable for the things you have done or failed to do. Y ou return to the electorate on a regular basis in order to ask for its judgment. The electorate decides who can have or use power, and who should stop using power. If it decides that it no longer wishes to obey a certain person in power, for example because the person failed to do what he or she was asked to do, then the electorate takes away the power from this person. The leaders do not appoint themselves. They are appointed by the people, and have to render account of their actions to the people. If the people consider that the leaders failed to do what they were instructed to do, then the people can dismiss them. Nobody's power is a matter of course. Power is not self-evident. It must always be assigned, reassigned and legitimized by way of accountability.

These election rules institute conflict. The place of power becomes an empty place (Lefort 1992:20). The law forbids that persons occupy or appropriate this place in a perma- 
nent way. Power is the result of a regulated struggle for this place, a struggle that is periodically restarted because power itself is periodically called into question. However, conflict is not just institutionalized, it is also channeled: potentially dangerous conflicts between groups or parties competing for power can be battled out or decided in a peaceful, formalized and reasonable way. Since there will al ways be a next chance for the losers who, by the way, do not risk loosing anything more than power - there is no need to resort to more forceful means in order to win the battle. In this way, democracy supports the right to security. This is one of the many examples showing that democracy and human rights are linked.

It is very important to notice the connection between the two different kinds of institutionalization of conflict I have discussed thus far, namely the conflict of opinions institutionalized by freedom rights, and the power struggle institutionalized by the democratic election procedures. These two ways of institutionalizing conflict reinforce each other in a fruitful interaction or reciprocity. The legitimate existence of a continuous, open and public political power struggle in which the entire people can participate, justifies and creates public conflict in general, in the society at large and in every domain of life. As a result, democratic power struggle justifies the free expression of opinions (Lefort 1992:46). In this way, democracy protects human rights and therefore also public life. However, democracy institutionalizes public life in a direct way as well because democracy promotes conflicts and conflicts are an important part of public life.

The opposite is also true. Human rights protect democracy because they are necessary prerequisites for a real power struggle. The participants in the power struggle have to be able to express themselves, to present themselves to the electorate, to create a distinct profile for themselves, and to make the electorate familiar with their political program (that is why they need the freedom of expression); they have to be able to organize and associate in a group that is free from government control, because this allows them to gather strength and have a more influential voice (so they need the freedom of association, the rule of law and the separation of state and society); and for the same reasons they have to be able to meet and demonstrate (so they also need the freedom of assembly).

Democracy needs human rights, but it also needs equal human rights. If everybody does not have equal rights, there can be no equal influence, and if there is no equal influence, there can be no democracy. The creation of public opinion or of the will of the people depends on the equal influence of everybody or, in other words, on the equal ability to convince, and this equal ability requires equal human rights. Equal influence also requires respect for economic rights - because these rights limit the unequal influence of money on politics - and for the right to education for everybody - a right that limits the unequal influence of intellect on politics.

All human rights must be respected simultaneously in order to have a proper democratic process. Many tyrannies allow the existence and even sometimes a limited degree of political participation of opposition groups, but these groups are harmless because they do not have equal access to publicity, because they do not have the freedom to organize as they wish, or because the people lack the material or intellectual resources necessary to be able to choose wisely among candidates.

It is apparent from this enumeration that the link between democracy and human rights (all human rights) is quite intense. Of course, this is no reason to accept either democracy or human rights, but it is clear that once you accept one, you have to accept the other as well.

Human rights institutionalize and guarantee conflict in general and political conflict in particular. Choosing political leaders is the expression of an opinion (read also art. 3 of Protocol I to the ECPHR: 'The High Contracting Parties undertake to hold free elections at reasonable intervals by secret ballot, under conditions which will ensure the free expression of the opinion of the people in the choice of the legislature' ). There is obviously a reason for the etymological link between the words 'vote' and 'voice'. Democracy is the application of human rights to the field of government. Human rights are democratic rights because they 
are necessary for democracy, just as democracy is necessary for human rights. The latter is also hinted at in the considerations preceding the articles of the ECPHR: 'those fundamental freedoms which (...) are best maintained (...) by an effective political democracy' .

But human rights are not just a necessary prerequisite for democracy. They bring about democracy. When you have the right to express your opinions and to call all kinds of things into question, why would you stop at the government? You will automatically express an opinion on the government and call the government into question. And because it is futile and sad to express an opinion that has no consequences in the real world, people will begin to claim the implementation of their political opinions, which will be the birth of democracy. The democratic power struggle is the consequence of conflict in general as it is guaranteed by human rights, and conflict in general is the consequence of the democratic power struggle. Again an example of reverse causation.

Democracy and human rights cannot function separately. They need each other and reinforce each other. Where you have one, you also have the other. And where you have one without the other, there is something missing in what you have. A democracy without human rights is not an ideal democracy, because it cannot function adequately. Human rights without democracy are not complete because one of the most important kinds of expression - calling into question the work of the government and creating a common point of view on the work of the government - is not allowed, or, if it is allowed, does not have any useful consequences because it is impossible to have a democratic vote. Human rights are not politically or ideologically neutral. They require democracy and are re quired by democracy. This again supports the statement (see Chapter 2) that human rights are not something primarily directed against politics or a way to limit politics. There are an essential part of democratic politics.

There is a causal link between democracy and power struggle on the one hand, and human rights and struggle in society on the other hand. But this does not mean that the power struggle is necessarily a faithful reflection of the struggle in society. A power struggle be completely different from and unrelated to the struggles in society, even if the people are involved in the power struggle. Political parties can for example use the power struggle for their own egoistic purposes.

\section{$\S 41$ : Exceptions to the Link Between D emocracy and H uman Rights?}

At first sight, there are some persistent facts that seem to contradict the statement that democracy and human rights are necessarily linked to each other. Democracies can apparently exist without respecting human rights (or all human rights), and human rights (or certain human rights) can apparently be respected by non-democratic regimes. An example of the former is of course the ancient Greek $c$ where human rights indeed did not exist, although the ' polis' did guarantee a kind of freedom of speech, not for humanity as such but for a tiny minority of privileged citizens. It is clear however that the 'polis' was not a democracy as we understand it today. It was an oligarchy in which the large majority of the people was excluded from politics. And although the word 'democracy' was invented in the ' polis', it is difficult to maintain that the people ruled the ' polis'. Inside the oligarchic group decisions were made democratically on the basis of freedom of expression and equality, but freedom and equality never became human rights, to wit rights belonging to human beings in general, including those human beings excluded from politics. Today only those states, in which the participants in the political decision making process are the same people as those who are subject to the political decisions, can be called democratic. In the Greek 'polis', self-government was only a reality for a small minority; the decisions of this minority governed the actions of the large majority of women, aliens and slaves.

Some present-day states such as the Islamic republic of Iran regularly hold reasonably fair elections but hardly respect human rights. The question is, of course, what are these elections worth without the free expression of opinions, without deliberations between 
citizens concerning the record of the government and the most appropriate government policies, without free flows of information concerning the work of the government, without the freedom to associate and to form opposition movements etc. Even in those countries in which people can vote for existing opposition movements (for example Malaysia and Singapore), there is never a change of power because human rights are not respected and opposition movements are systematically sabotaged (they suffer from unjustified lawsuits, they do not have equal access to the media, etc.). Of course, the absence of a change of power does not prove that there is no democracy. The people can always decide the same thing. The problem is that the people cannot decide without human rights. A decision which is not based on discussion is no decision at all.

Hong Kong before the takeover by China and the last minute democratic reforms of the British government was considered to be a non-democratic state which respected a great number of human rights. In this case, the question is what are these human rights worth if they cannot be applied or can have no consequence for the workings of the government. If you express an opinion you expect some consequences resulting from this expression. Otherwise it would be better not to express the opinion at all. What is the use of being able to express opinions on the workings of the government if this expression is entirely without consequences?

Respect for human rights will most probably lead to democratization. People who have the freedom of expression will start to claim the right to vote. They will have opinions on the workings of the government and they will want to see these opinions implemented. Conversely, the presence of a democratic form of government will lead to the institutionalization of human rights. If the people can vote and therefore express themselves on things as important as the government, what is the use of prohibiting the expression of other kinds of opinions?

The transition of a rights regime to a democracy and vice versa is of course not as easy as all this seems to imply. A non-democratic government, even though it is kind enough to grant its people a few rights, will cling to power and will have the means to do so. It will resist demands for more democracy. The opposite seems to be easier. Democracies are more inclined to grant rights. Granting rights is also easier than changing the form of government, at least at first sight. Creating the institutions necessary for the enforcement of rights can also be an awesome task.

One can only maintain that there are democracies which do not respect human rights or that there non-democratic regimes which respect human rights, if one adopts some kind of reduced definition of either democracy or rights. An ideal democracy cannot exist without rights, and vice versa.

\section{§ 42: The Right to D emocracy and Political Rights}

Democracy is a human right and is as such included in a number of the most important international human rights standards, such as the UDHR, art. 21 ('1. Everyone has the right to take part in the government of his country, directly or through freely chosen representatives. (...) 3. The will of the people shall be the basis of the authority of government; this will shall be expressed in periodic and genuine elections which shall be by universal and equal suffrage and shall be held by secret vote or by equivalent free voting procedures') and the ICCPR, art. 25 ('Every citizen shall have the right and the opportunity, without (...) unreasonable restrictions: (a) To take part in the conduct of public affairs, directly or through freely chosen representatives; (b) To vote and to be elected at genuine periodic elections which shall be by universal and equal suffrage and shall be held by secret ballot, guaranteeing the free expression of the will of the electors'). These are the so-called political rights that together constitute the right to democracy. This right to democracy was once again confirmed by a vote in the UN Commission on Human Rights in Geneva in 1999 (there were no votes against and only two countries, China and Cuba, abstained). 
This is not a novelty. Political rights are as old and as traditional as freedom rights. The French Revolution al ready claimed sovereignty for 'Ia N ation' or the people. Art. 3 and 6 of the D éclaration of 1789 stated: 'Le principe de toute souveraineté réside essentiellement dans la $\mathrm{N}$ ation. $\mathrm{Nul}$ corps, nul individu ne peut exercer d' autorité qui n'en émane expressément'; 'La loi est l'expression de la volonté générale. Tous les citoyens ont le droit de concourir personnellement, ou par leurs représentants à sa formation' (in Rials 1982:5).

\section{§ 43: Self-Control and Self-Government}

The right to democracy is the right of the people and of every member of the people to participate in the decisions of the government and in the framing of the laws. The underlying justification of this right is the wish of the people to control their own lives. The keynote of democracy as a way of life may be expressed as the necessity for the participation of every mature human being in the formation of values that regulate the living of men together; which is necessary from the standpoint of both the general social welfare and the full development of human beings as individuals' (J. Dewey in Barber 1984:139). Control over your own life is, in my opinion a universal value. Democratic participation and democratic political life guarantee this value and this is one of the reasons or justifications for the universal application of democracy. (I will come back to the link between control and personal development in Part 5 dealing with freedom).

Underneath the principle of self-control or self-government lies the claim that people can only be subject to those laws and decisions which they agree with. This is a fundamental claim of democracy. 'Gültig sind genau die H andlungsnormen, denen alle möglicherweise Betroffenen als Teilnehmer an rationalen Diskursen zustimmen könnten' (J. Habermas in Foqué 1997:83). ' [P ]eople are obligated to obey the laws of government only insofar as people have consented to those laws, or to the power exercised in passing those laws' (Nelson 1980:43).

There are two ways of guaranteeing that the people agree with the laws they are supposed to respect. One way is to allow the people to make the laws themselves, for example by voting in a local meeting or in a referendum. The other way is to allow the people to elect or dismiss representatives who frame the laws. In the latter case, the people contribute indirectly to the framing of the laws. Participation or control can indeed happen on two levels: either directly or through the intermediary of the election or dismissal of representatives; election in the case of representatives who vote for the laws the people would also have voted for themselves, dismissal in the opposite case. I will come back to these two levels in the next Chapter.

The principle of self-control requires that everyone who is subject to the laws has the right to contribute to the framing of the laws; and, what is more, that only those people who are subject to the laws have the right to contribute. This means that the legislator is also subject to the laws he makes, which guarantees the rule of law and makes it very improbable that legislators use the law to oppress their enemies.

\section{$\S 44:$ The Problem of U nani mity}

In a democracy, power and society are places of eternal conflict, of opposition, contestation and difference of opinion. As a consequence, it becomes very difficult to view society as a body or an organic unity coordinated by a clearly defined and permanent head, for there is no such body or head. The only unity is that which is necessary to make struggle and division possible. Conflict is the motor of democracy.

Everything evolves around the people in a democracy because the people are the source of power and of the law. However, the people in a democracy are, just as the power that springs from them, something undefined, indeterminate and unspecified. The 
people are not something which is unified and fixed. The will of the people is only a temporary reality, and when this reality is fixed temporarily - at the moment of an election or a vote - it still accommodates plurality because the will of the people is shorthand for the will of the majority of the people. The will of the people does not stifle minority voices. For this reason, the people cannot coincide with power or incarnate power, no more than any individual usurper of power. As a result, the place of power remains an empty place. The people are not a people with a capital ' $P$ ', contrary to the people of nazi-Germany for instance who were supposed to be fixed in their identity, permanent and without conflict or division.

In a democracy, the identity and the will of the people are constantly - and not only on election day - called into question, discussed and redefined, and are not a definitive, unified and permanent reality as in the example of nazi-Germany. The people are not a static unity, but a dynamic plurality. Of course, the identity of the people is temporarily fixed on election day because an election is the expression of the will of the people, but the next day it is again the object of debate. Even on election day there is the explicit recognition of the existence of minorities and therefore of plurality.

Plurality, diversity, contestation and antagonism are made possible by the system of majority decision. A system of unanimous decision is incompatible with plurality and conflict and is therefore seldom used in a democracy. It is more characteristic of authoritarian regimes. A democratic people are made up of contradictions, even when an election fixes the will of the people temporarily, because the will of the people is in fact the will of the majority of the people. There is a majority whose wishes are given priority at a certain moment, and there is a minority whose wishes are temporarily rejected. But these minority wishes exist and constitute an element of division in society. These wishes not only exist; they can be presented to the public, they can be promoted, and they can perhaps become a new and future will of the people.

This does not exist in a system of unanimity. One could be inclined to think that a truly democratic system should be a system of unanimous decision, because only such a system gives everyone self-control, respects the wishes of everyone and therefore respects the will of the people, the entire people and not just the majority. There is no frustrated minority that has to be coerced to respect the decisions of the majority. However, on the scale of large communities this would be practically impossible apart from exceptional circumstances, and it would also eliminate the benefits of conflict. It would furthermore create a sinister sect-like situation of conformity and of choreographed manifestation of unity.

A nother reason to reject unanimity is its built-in bias for the status quo (Nelson 1980:19). If 'we are concerned about political equality, it seems reasonable to require not only that each person's vote count the same as that of each other person, but also that each person, regarded as someone with particular proposals to advance, have an equal chance to have his proposals adopted' (Nelson 1980:19).

This does not mean that unanimous decisions or decisions by a qualified majority are never desirable. In order to understand the practical problems linked to the choice be tween majority decisions and unanimous decision, one has to look at the balance between on the one hand external costs or costs paid by the minority as a consequence of the decision of the majority, and on the other hand decision making costs or costs paid in order to be able to come to a decision (Thomassen 1981:41). In a unanimous decision the former cost is zero because nobody suffers the consequences of other people's decisions, but the latter cost is very high because in most cases it is difficult to arrive at a unanimous decision. In a dictatorship the opposite is true: it is very easy to come to a decision, but the consequences, not only for the minority, may be very harmful.

The majority system of a democracy seems to strike a correct balance between both extremes by minimizing though not eliminating the elements of duty, coercion, frustration, cost and difficulty. If, however, in some cases the external costs are very high - for example in the case of a decision affecting adversely some of the fundamental interests of a minority - then it can be acceptable to pay a higher decision making cost and try to find some kind of consensus. 
Still, it is acceptable that the decision of a majority is described as the will of the people? Unanimity is apparently closer to the combined ideal of self-government of the people and self-government of the individual. It seems as though democracy can only be a system of self-government if every single individual member of the people is in agreement with every other individual member, because this is what we need if we want to have every individual's decision accepted and implemented. To govern, to rule or to have power can indeed be understood as the ability to realize a desire or an interest. You have power:

(1) If something happens because it is in agreement with the things you wish to happen; and

(2) If you cause it to happen.

If decisions are made by the majority instead of the unanimous people, then it seems to be impossible to claim that the people rule, govern or have power, and then there seems to be no self-government, only the government of the majority over the minority. Only the majority can then have self-government. For this reason, a majority system seems to be incompatible with democracy.

It is true that a majority system always implies the use of coercion towards the minority. The minority is forced to do something or to abstain from doing something, even when its wishes otherwise or its interests tell it to do otherwise. But this is the case even in a system of unanimous decisions. There is al ways a part of the people that rules another part, because there are always certain persons who are excluded (children, aliens, criminals etc.). Furthermore, there is always the phenomenon of someone deciding to do $x$ at $a$ certain moment but having to be forced to do $x$ at another moment and in other circumstances (in Harrison 1996 we find the example of the alcoholic who promises to stop drinking, locks up the wine and throws away the key to force his future self to respect the decision of his present self; he is then governed by his own superior self). So even unanimity does not exclude force or coercion.

The word 'people' never means 'everybody', because today's everybody is different or thinks in a way that is different from tomorrow's everybody, and because some people are by definition excluded. As I will show further on (in Chapter 5) for the case of children and aliens, it is not desirable to include everybody in the group that has the power to decide. It is equally undesirable to create a political system that always fulfills every desire. N ot all desires are acceptable. Of course, it is good that as many people as possible can fulfill as many of their desires as possible, and with the exception of a system of unanimity, majority-democracy is the best way to achieve this. The majority of the people fulfills its desires, and everybody is now and then part of the majority, at least in a well functioning democracy. The minority, the group of persons supposedly living under the rule of the majority, is not a homogenous or unchanging group of persons. It always consists of other persons.

Unanimity can indeed be preferable, but never in all cases. The cost and benefits of unanimity should be calculated in each instance. And these costs not only include the difficulty to arrive at a decision, but also the loss of plurality and heterogeneity and the bias towards the status quo.

Some might say that neither a majority, nor a unanimity is required to realize the wishes of the people. An enlightened despot is said to be better placed to do so, for example because he or she would have a better understanding of the real, the fundamental or the long term interests of the people, or because he or she would have a better knowledge of the ways in which to fulfill desires. But then we forget that the way is as important as the destination. People like to fulfill their desires themselves, because one of their desires is not to be treated as children (I will come back to this problem in Part 5).

It is now possible to identify an additional reason to accept democracy. If government is an instrument to fulfill desires, and if it is a good thing that as many people as possible fulfill as many of their desires as possible, then democracy is also a good thing, better 
than any other known and tried form of government. The democratic majority system guarantees that the interests of the majority are respected. Any other system is based on the doubtful hypotheses that a minority is able to decide matters in such a way that the interests of a majority are respected. Altruism is unfortunately not a widely shared attitude. '[T] he rights and interests of every or any person are only secure from being disregarded when the person is himself able, and habitually disposed, to stand up for them' (Mill in Dahl 1989:93). I myself, more than anyone else, am the one who is most interested in my own well-being, and therefore most likely to stand up for it. I will be able to stand up for my interests only when I have a say in government decisions which affect my interests. I will al ways have a say when government decisions are taken unanimously, but unanimity has a number of drawbacks. In order to avoid these drawbacks, I will perhaps be satisfied with a "mere majority system", on the condition of course, that I am not permanently part of the minority.

Most of the time, therefore, a democracy will be a system of majority voting, but now and again it can be useful to require a unanimous vote. I will discuss in Part 3 what to do with a badly functioning majority democracy, a democracy in which a certain group of persons is always in the minority. This group of persons is by definition and permanently excluded from power and can be said to live under the rule of the majority. I think everybody will accept being in the minority from time to time, especially when the drawbacks of a system of unanimity are clear to everyone. You know that you can have your way another time or in other circumstances, and you know that you can always continue to promote your point of view. You can always try to change the point of view of the majority and reverse its decision. However, if you are always part of the minority, if you never have your way and if you can never change the point of view of the majority (which is the same thing as never becoming part of the majority), then you will rightly reject the system. The system will be undemocratic and will succumb to internal polarization. I will discuss the possible solutions to this problem later on.

If power is the ability to fulfill desires, then the state is more than just a mechanism to suppress certain kinds of behavior, to monopolize violence, to dominate certain people and make them act in a certain way, to make one the ruler of another, to make one group decide and another obey etc. The state is also a mechanism to fulfill desires, although it is of course much more than that.

\section{$\S 45:$ D emocracy and the Rule of $L$ aw}

There is a link between the rule of law and democracy, similar to but without the same tenacity as the link between human rights and democracy. A democracy is by definition a system that respects the rule of law. The democratic procedures and the human rights necessary for the functioning of democracy are written into enforceable laws that are the sovereign rulers and that govern everybody in the same way. A democracy respects human rights and therefore also respects the rule of law, because the rule of law is a part of human rights.

However, a state which respects the rule of law does not have to be a democracy. The laws that rule do not have to be democratic laws, do not have to be framed by the people, and do not have to conform to human rights. In order to have a rule of law, it is sufficient that the law rules and that there is a separation of powers which guarantees and enforces respect for the law. The content and the origin of the laws are irrelevant for the rule of law, but not for democracy and human rights.

The A merican Convention on H uman Rights states the following: 'there exists an inseparable bond between the principle of legality, democratic institutions and the rule of law (...). In a democratic society, human rights and freedoms inherent in the human person, the guarantees applicable to them and the rule of law form a triad (...). Each component thereof defines itself, complements and depends on the others for its meaning'. And although this is true, the equations are not always reversible. 
A state which respects the rule of law does not have to be a democracy, but the rule of law has the best chances of survival in a democracy. When the people frame the laws, it is more likely that the people will respect the laws, and the laws rule when they are re spected. You do not make a law if you plan to break it afterwards. There is no comparison between a law that you impose on yourself and a law that someone else imposes on you.

A democracy without the rule of law is a farce. Elections alone are not enough. Elections can be manipulated and can be used as a ploy of a leader seeking legitimacy. They can be falsified or they can be held and neglected afterwards. Elections can only be fair within the rule of law. Only the rule of law can enforce respect for election rules and election results. Without the rule of law, human rights are not enforceable, and without human rights, there is no proper democracy.

Furthermore, there is no incompatibility between on the one hand the willingness to hold elections and to respect their outcome without tinkering, and on the other hand the unwillingness to respect human rights. In a so-called 'illiberal democracy' (the mirror image of 'liberal autocracy') there can be leaders who have been elected in a legal and fair way but who are legally allowed to violate human rights. The presence of elections which are respected and which are enforced by way of the rule of law is apparently not a sufficient condition for an ideal democracy. Elections are not enough, not even if they are relatively free, fair, competitive, inclusive and effectively protected by the law. A system of universal adult suffrage, enforced by the law, is not necessarily a full fledged democracy (Zakaria 1997). An ideal democracy does not follow from the presence of election, not even if these elections are fair and correct; but neither does tyranny follow from the absence of elections. The rule of law as well as some human rights can be respected without a system of elections, at least temporarily.

Elections make democracy possible, but they do not guarantee democracy. The rule of law and respect for the law (including the laws which regulate elections and the laws which protect human rights as necessary el ements of elections) are al so necessary conditions. The procedures in which power is granted, taken away, or renewed are regulated by laws that have to be respected. The creation and manifestation of the will of the people (during the elections but also in between elections) as well as the election of representatives of the people are guaranteed and protected by enforceable laws. Those in power can be forced to respect these laws. And because the rule of law is a human right, the fact that democracy cannot exist without the rule of law is another confirmation of the link between democracy and human rights.

Of course, a democracy requires more than legal protection of the rules and rights which are necessary for the creation and the expression of the will of the people. Once power is granted on the basis of the expression of the will of the people, it is the job of those in power to implement the will of the people. The way in which this will can be implemented, in other words the exercise of power, is also regulated by laws, otherwise there would be no rule of law. It is not because power comes from the people that this power is always beneficial. It needs to be limited by the principles of the rule of law and by human rights, just as any other kind of power. Furthermore, the fact that power comes from society makes it all the more important to stress the difference between state and society, and this difference can only result from the rule of law.

\section{$\S 46: \quad$ Change and Publicity}

Democracy promotes conflict and protects human rights, but it guarantees public life also in two other ways. Change, as we have seen, is an important part of public life (changing your opinions, correcting your thoughts, developing your personality etc.), and is of course an equally important part of democracy. Uncertainty and unpredictability are some of the basic characteristics of democracy. Democracy is a permanent struggle that nobody can control, decide, terminate or predict. It is an eternal game of action and reac- 
tion. Not even an election victory puts an end to this struggle. The struggle recommences the day after the victory. And at the next election, the struggle reaches a new climax. Democratic struggle is everlasting and its outcome is uncertain. The only certainty is change. A democracy should only exclude one type of change, namely a change away from democracy and away from human rights.

Human rights as well promote change, because they create an independent and durable public space which can be used as a launch-pad for new claims - for example claims for new rights or broader rights - directed at those in power. Universal suffrage is an example of a new right that has been claimed and won in the public space. This claim was possible and successful because there existed a public space protected by human rights such as the right to free expression, the right to assemble and associate etc. The right to strike is another example. Thanks to human rights, people can react to certain circumstances, can put their finger on certain injustices, and can demand change.

This kind of change is not revolutionary change. The form of government is not changed, and the regime is not toppled. On the contrary, change is possible because of the permanence of the form of government. The government itself can be changed, laws can be changed by the existing government which decides to take certain claims into account. All this takes place within the framework of legality, without changing the basic rules of the game, and without the use of violence In a democracy, there is no need for revolution or violence. New and unpredictable things can happen without them and often originate not from the realm of power or the state, but from the public space that is independent of power. History is more than just the history of the great revolutions.

This is perhaps the greatest strength of democracy: it can accommodate change in a far better way than any other type of regime. Change can happen within the system, by dismissing an incompetent government, by changing the policies or laws of a government through the expression of claims, or by doing something independently without the intervention of government. These features clearly give a democracy more chances of survival than any other type of government. The fact that violence is unnecessary makes democracy attractive to those people who dislike violence. You do not have to get rid of democracy or use violence in order to change things. The fact that democratic history is undefined and unfixed goes hand in hand with the fact that democratic power, democratic society and the democratic people are also undefined and unfixed. Democracy is therefore the most historical form of government. It creates history because it promotes change.

Democracy also protects public life because it protects publicity. Democracy needs publicity and hence promotes publicity in general. It needs the publicity of the debates on government policy (without which there can be no renewal or change of government) and the publicity of the political parties that are constantly trying to convince people and to increase their number of votes. Democracy also needs the publicity of the will of the people and the publicity of government policy. Without the latter kind of publicity, there is no way to control and judge government policy. And without control and judgment of the government, there can be no meaningful elections. I will now deal with this topic in greater detail. 
Section 6: $\quad$ Control and Judgment on the Basis of Free Flows of Information

\section{§ 47: Power, Accountability and O penness in Two Directions}

In an ideal democracy, one cannot govern against the will or without the consent of the people. Those in power are chosen by the people and receive from the people an assignment to rule in a specific way, an assignment given on the basis of an election manifesto. Power is temporary because it is a loan rather than a gift. The loan is conditional upon the way in which power is used. Power continues to belong to the people and the people can take it back if they consider that it has not been used in a satisfactory way and that the assignment has not been properly fulfilled. The people know whether or not they are pleased with government policy because they ask those in power to give account of their actions and to inform the people of the way in which power has been used. If, on the basis of this flow of information, the people are not satisfied - for example because the decisions taken by those in power contradict the wishes of the people, even though these decisions have been taken in the name of the people - then the people judge those in power in a negative way and decide to give power to someone else. If they are satisfied, then the loan is renewed.

Accountability implies free flows of information and openness, transparency or visibility of power. How can government policy be judged and controlled if the government is not visible? The ' sécret d' état' is incompatible with democracy, at least in normal circumstances. Democracy and publicity are necessarily linked and all the actions of a democratic government must be public (except perhaps for certain actions that cannot be successful when done in public, such as matters pertaining to national security; in these cases, however, publicity is only postponed, not eliminated).

A ccountability cannot function without respect for the right to free speech understood in the sense of the right to free flows of information. This meaning of the right to free speech is expressed in art. 19 of the UDHR: 'Everyone has the right to freedom of opinion and expression; this right includes freedom to hold opinions without interference and to seek, receive and impart information and ideas'. This right allows the people to seek information, and as information on the workings of the government is not explicitly excluded, we must assume that it is included.

This is further proof of the link between democracy and human rights. The entire democratic process, including accountability, necessarily requires respect for human rights. '[W ]ithout the guaranteed right of all citizens to meet collectively, to have access to information, to seek to persuade others, as well as to vote, democracy is meaningless. D emocratic rights, in other words, are those individual rights which are necessary to secure popular control over the process of collective decision-making on an ongoing basis' (Beetham 1995:190).

The visibility or the public nature of power is a necessary condition for the proper functioning of democracy, and, in the best of circumstances, this condition is given by human rights. Not always though, because visibility can be impaired in many ways (an excessive extension and complexity of the state apparatus, for example, can threaten publicity and this is a disease that is very difficult to cure with human rights).

Visibility, however, is a two-way street. The government must be visible, but it must also be able to see. You can only govern well if there are free flows of information, if you 
know what is happening in the country, or what is not happening, and if you know what should happen and what the people wish to happen. A representative or parliamentary system can help to achieve this, because ideally the representatives come from the midst of the people and should therefore know the people. The right to free speech will of course also help. A non-representative regime which violates human rights will look somewhat like a government by monks unaware of the happenings outside of the cloister (Paine 1992:62). Control means self-control. Leaders who exercise self-control - of course not or not primarily in the moral sense - will try to keep informed as regards the desires of the people.

So there is openness in two directions: power is open to the controlling gazes of the people; and the people are open to the controlling gazes of power. Democracy needs openness and information, bottom-up because having power does not al ways mean being right, and top-down because being the people and having power is not sufficient to correctly judge the functioning of government. This openness in two directions guarantees openness in society as a whole and therefore also guarantees public life. Politics functions as an example for the whole of social life.

\section{$\S 48:$ A ttentiveness, Involvement and Knowledge}

It is clearly wrong to say that, in a democracy, the power of the people is limited to the act of electing the individuals whom the people have to obey for a certain number of years, and that in between elections the people have no power and are not supposed to do anything. The people have power year in year out, in particular the power to control. Only by continuously controlling the government can the people judge and choose adequately on the basis of information and knowledge. This power to control is important in between elections, not during elections. Those in power, because they know that they are constantly watched, anticipate and take into account the criticism of the people concerning some particular element of policy - after all, this kind of criticism is constantly expressed in between elections - and change their policies accordingly. Not doing so would harm their chances at the next elections. By steadily influencing their representatives in this way, the people make sure that their leaders are indeed representatives who do as they are assigned to do.

The people are a constant source of power because they can change the acts of the government. It is true of course that the representatives are persons that have been chosen to rule the people for a certain period, but because of the element of control, this is a limited rule. The power of the representatives collides with the power of the people. The representatives have the power to rule, and the people have the power to control and to influence by way of control.

However, in order to exercise this power, the people have to be interested in the policies and the workings of the government. People who are not interested in politics and who do not use their minds and their voices in order to influence the government, cannot control the government and have no power. And without control, there can be no elections and no democracy. You can only elect or choose a government if you are able to judge a government. And you are only able to judge if you possess knowledge of the workings of the government, knowledge resulting from control and from attentiveness. On top of that, you have to be interested in and you have to have a certain knowledge of the intended policies of the existing government and of the alternatives (the election manifestos of the different parties, including the opposition parties). This is necessary in order to be able to make a choice between the contenders for power.

Hence the importance of education in a democracy. Attentiveness is not enough for meaningful political participation. Attentiveness must result in knowledge. Only people who can read and write, who are aware of what is going on in politics, who read the newspapers, who understand manifestos and who know the democratic procedures can participate in politics. Education is a human right, and is another example of the link 
between human rights and democracy. Of course, knowledge does not depend solely on education. Modern technologies such as the Internet can also promote knowledge. To some degree, participation itself creates the knowledge necessary for participation. I will illustrate this in Section 9. The problem is, however, that democracy does not just need knowledge, it needs equal knowledge, and this is a traditional objection to democracy. I will deal with this objection in more detail in Part 4.

The importance of knowledge justifies the traditional age limit for participation in elections, because children in general have insufficient knowledge of government affairs and are therefore unable to judge these affairs. They have not finished their education yet and thus they lack the capabilities necessary to unerstand and to judge government policy. (This does not mean that children do not have rights or should not be listened to). Of course, it is tempting to extend this argument and to claim that certain adults should be excluded for the same reasons as children. If knowledge is a criterion for exclusion, then surely the great mass of the people should be excluded, because they have not outgrown their infancy. Hence, democracy would not seem to be an option.

The problem with this kind of argument is that it fails to see that if children are excluded, it is because it is impossible that they have the necessary capabilities, whereas adults without mental disorders can always have these capabilities. Everybody who can read a newspaper can judge the government. And if there are people who cannot read a newspaper, then this is an educational and not a political problem, to be solved by better education and not by rejecting democracy as a system of equal participation in politics. Rejecting democracy and permanently excluding certain categories of people will only worsen their predicament. I will show in the next Chapter that inclusion in participation can solve a part of the problem. Participation is formative and creates certain capabilities. Furthermore, knowledge is just one tiny part of politics. Values and opinions play an equally important part (see also Part 4). If politics were merely a question of knowledge, then democracy would indeed be indefensible because knowledge is not equally distributed. A ristocracy or meritocracy would then be the only solution.

The fact, however, remains: knowledge of government policy (but not necessarily of government policy in the abstract, which would be knowledge at a different level) is important, and it is more important than feelings. Alas, real judgment of real government policy is often based on feelings instead of knowledge, feelings such as thoughtless or automatic sympathy or dislike for the government and the political parties in possession of power. This kind of emotional link is quite all right if it is supplemented by knowledge, but it is lethal for democracy if it is not, and often it is not. Traditions (for example the tradition of the family or the class), prejudices and personal affinities often make it impossible to judge on the basis of knowledge of government policy and knowledge of political alternatives. Even if this knowledge is present, it can be overruled by feelings or habits dictating another judgment.

It seems that education is again the only solution. Education can teach us to choose on the basis of an objective evaluation of the merits of each contender. We should not choose a person because we like him, and still less should we believe something because the person or party we like believes something. It should be the other way round: we should choose a person or party because the person or party believes something we also believe. Party affinity is the consequence and not the cause of convictions (although things are of course not as simple as this). Knowledge and rational (as opposed to emotional) behavior are requirements for self-government. This is easier when we are confronted with a choice between issues instead of parties or persons. This, as I will show, is an advantage of direct democracy compared to representative democracy.

Knowledge of the different election manifestos will not only make it easier to choose, but also easier to control the policies of the chosen party afterwards. Policies have to be good, but they also have to correspond to what was promised in the manifesto. The objection to policies that are good but different from what was promised, is that this is amost al ways a happy coincidence The only way to have good policies most of the time, is when these policies are promised in advance. It is true that they do not have to be prom- 
ised in order to correspond to the will of the people, but unless they are promised, it is very difficult to be sure that they do correspond.

A prerequisite for this kind of knowledge of government policy and party manifesto's is pluralism in the media and the absence of information monopolies. The media should report objectively on the different manifestos.

\section{§ 49: $O$ bscurity and $M$ anipulation}

Secrecy, obscurity, manipulation or confidentiality of information and lies do not belong in a democracy because otherwise choice and judgment based on knowledge would become impossible. The often very harsh reactions of the people when covert actions of politicians or civil servants come to light, do not only follow from the often criminal or immoral nature of these actions. They also follow from the fact that they make control and therefore democracy impossible.

Of course, publicity is not just a requirement for those actions that cause indignation when they become public. All actions of government, or better most actions of government (see the remarks at the beginning of this Section), must be public. This is shown by the case of the technocrat, who is rejected for the same reason as the corrupt politician. Although the technocrat does not lie and does not have any immoral secrets, his supposedly superior knowledge of things political - a knowledge he does not share with the people - creates a kind of obscurity that is incompatible with democratic control. A nother threat to openness, control and democracy, is the presence of those extra-political and invisible decision-takers who, to a certain degree, escape political control (big business and labor unions are a few examples of this kind of privatization of politics).

Publicity is, however, not a sufficient condition for democracy. A tyrant can function in public, but he can never guarantee publicity as such, because in his case, publicity is an accidental and not an essential aspect of his reign. He will be tempted to work in secret. A nother difference between him and a democratic ruler, is that he can do unacceptable things in public. A democrat is punished for doing such things, at least in an ideal democracy.

Let me come back to technocracy for a minute. As I have said before, technocracy inhibits openness and control. An open technocracy is impossible because the knowledge of the technocrat is impenetrable for the ordinary citizen. There would be no need for technocracy if this were not the case. A technocrat rules because of his specialist knowledge, knowledge he normally shares only with other technocrats. It is not easy for an ordinary citizen to control these technocrats, because he sees but does not understand their actions. He might be able to judge on the basis of the consequences of their actions, but who says he understands these consequences and what about the long term consequences? Are these not the object of specialist knowledge as well? However, the fact that democracy and technocracy are incompatible does not mean that it is undemocratic for people to listen to experts before taking a decision. I will come back to this topic in Part 4.

Granting the people the right to elect a government and take a collective decision based on discussion and information, is useless if afterwards the people are manipulated by misinformation, are withheld information or are the subject of propaganda, brainwashing or certain types of 'conditioning education'. Here again the media have an important role to play. They have to enforce the publicity of power and to uncover and denounce lies, manipulation and misinformation. And here the word 'power' must be understood in a broad sense. Not only the state, but also certain powerful groups and organizations in society can withhold or manipulate information. It is obvious therefore that the media should not be controlled by the government or by certain powerful groups in society.

However, communicating manifesto's, explaining government policy and revealing lies are not the only tasks of the media. They also have to be a platform for discussion between citizens, especially in the large and complex communities of today, in which com- 
munication and discussion are no longer as easy as in the ancient 'polis'. The media have to show, not only the facts and the information, but also the opinions on the information, and as many opinions as possible, and they have to encourage discussion. Furthermore, they have to treat every opinion, every side of the discussion, and every topic of discussion (or every issue) in an equal manner, including those topics or points of view which seem to be less important at the moment or which are still in search of support. No topics, opinions or arguments should be excluded.

After all, the will of the people is not just the aggregate of all individual reactions to information on the workings of the government. Only after discussion and argumentation based on information, can the will of the people be established and can the conformity of the government's policies with the will of the people be controlled. I will now discuss the process of the creation of the will of the people in greater detail. 
Section 7: $\quad$ The Construction of the Will of the People

\section{§50: Human Rights and the Will of the People}

The fact that power cannot be the property of some person or group and that power has to be exercised in public, shows that power and the relationship between the state and society are public rather than private matters. (Of course, control and publicity of power imply a separation between state and society, and the independence of the latter with regard to the former. I will show in a moment that this separation is sometimes a problem). The way in which the will of the people - the origin of power - comes about supports the claim that power is a public matter.

The right to free speech - the most public of all rights - is of course a necessary element of every election. An election is the free expression of the will of the people. But this is al ready the end of a chain of events which all require free speech. Before there can be an election, the people must know the record of the government and the election manifesto's of opposition parties, and this knowledge comes about through control based on free flows of information. As I have shown, these flows of information require the right to free speech. Free speech is used in a vertical way (top-down or bottom-up) in both these cases, elections and control.

However, free speech is also used in a horizontal way. The will of the people is more than just the simple result of gathering information. The information has to be discussed, debated and interpreted in the light of certain values. The will of the people - which pre cedes the election as well as the act of controlling the government (or part of this act because controlling not only means looking for conformity between the will and its realization but also creating a new will) - cannot come about without the horizontal use of free speech. This will is necessarily discursive, argumentative and public, all the more so when it deals not with the facts of government performance, but with values. After all, government performance is judged in the light of values, and the will of the people as a judgment of government performance often concerns the good or bad realization of a previous will dealing with values.

Only when individuals and groups use free speech to talk to each other and to debate with each other in public, and when different possibilities proposed by different people are evaluated, can people convince each other and can a common opinion come about, initially an opinion on some ideal government policies necessary in order to realize certain values, and afterwards an opinion on the facts of existing government policies and on the compatibility of these facts with the preceding ideal. This common opinion is the will of the people and is expressed in the choice or dismissal of a government or, directly, in the choice of a law. In a democracy, people agree with governments or norms because they agree with each other.

The will of the people as the basis of the choice of governments and norms, requires a plurality of groups using free speech and free argumentation to try to convince each other and to increase the number of supporters in order to become a majority. This kind of convincing and debating takes place in a overall and common space that should aways comprise a plurality of groups as well as a unity of common opinions transcending these groups (these common opinions should include human rights because these rights 
guarantee debate). Out of this chaos arises a majority, the result of a common act of definition based on an exchange of arguments. This majority is not the result of a simple aggregation or of an accidental similarity of opinions. The will of the people is a conscious, informed and debated agreement that can only come about in a public space of discussion guaranteed by human rights.

\section{$\S 51:$ The Construction of Communities}

Agreeing with others, establishing a common or collective conviction or common will (which is not the infamous volonté générale' because there are always many different common convictions), or, in other words, creating communities, is necessary for the proper functioning of democracy. There can be no majority or will of the people without it. Democracy is impossible with a mere 'I want'. Only 'we want' is useful for democracy. Of course, this 'we want' does not destroy plurality. There are numerous 'we's' that 'want', just as there are numerous 'I's' that 'want'.

Moreover, a particular community is not made up of clones. The memebers want the same thing with regard to a particular subject, but this subject does not absorb their entire personality. They remain different notwithstanding their mutual agreement. They agree on one or on a few topics, and if they become part of a group in this way, it is not their whole personality that becomes part of the group. Democracy is not an endorsement of collectivism or conformism. And if only a part of a person is part of a group, other parts of the person can be part of other groups, which means that there can always be a plurality of groups. Furthermore, we are dealing here with a dynamic plurality: if membership is based on agreement, then it is necessarily a temporary and changing thing. People are free to leave a group and join another one if they are persuaded to do so or if they cease to agree with the other members of the initial group.

This is the mistake of a common objection to democracy. Democracy supposedly reduces the individual to the masses and eliminates differences because the will of the individual has to be harmonized with the will of the collectivity. It is true that the concept of the will of the people implies a certain conformity, but this is relatively harmless as long as there is a plurality of conformities and as long as the separate conformities have a tendency to change their nature and composition.

And so we have another justification for democracy. The importance of communities in a democracy corresponds to a widely shared value, namely the importance of group life and of belonging. 'We want' is not only important for democracy, it is important for human beings in need of a life in community with others. Belonging to a group is also a traditional way to acquire an identity ('I am a socialist' for example). This is an important and potentially universal justification of democracy.

'I want' is of no use to democracy, but it is of no use to the individual either, at least to the individual in a democracy. A tyrant can make use of his isolated will, but in a democracy the importance of one voice in a community of thousands or millions, is quite small. The individual has power only when he or she agrees with others. An individual is nothing without the group. Of course, when we decide, I decide as well because my will is equal to our will. This shows how absurd it is to criticize democracy for being too focused on individualism, another mistake of another common objection.

The contrary criticism may be more correct: the collective will can threaten the individual will. It may be useful to repeat that democratic communities are always free communities. In other words, the existence, demise and membership of communities is dways a free choice of the persons involved. Members of a community or third parties should never use force to destroy a community, to keep a community alive, or to maintain certain persons in the membership of a group. For example, if an individual chooses to leave a community, then the community should respect this choice Otherwise, the community would no longer be based on agreement and persuasion, and the democratic decision procedures - which require agreement - would cease to function adequately. Re- 
specting an individual's choice, however, is not only necessary for democracy. The individual himself and his identity would be harmed if his choice were not respected. The common identity should not be considered as more important than the personal identity, because if it is, the personal identity will be harmed. Personal identity is just as important as belonging, at least to most people.

Politics is not a straightforward relationship between individual citizens and the leaders they choose. There are many intermediary levels, for example the public space or spaces necessary for discussion, but also the different groups promoting certain convictions and trying to increase the number of their supporters in order to be able to become a majority and to realize their goals. A political party is one example of these kinds of groups and it is a very useful mechanism for convincing people to rally behind a cause. In our present-day democracies, effective individual action seems to be almost impossible outside of the party system. Of course, this system can also endanger political participation. Parties can become hierarchical structures in which the voice of the individual member is systematically silenced, or they can become dogmatic and insensitive to arguments or to new ideas coming from the outside.

Political parties not only represent cohesion, they also create it. They not only group people, they also make groups, which is not al together the same thing. Hence, parties are more than a mechanism to express the will of the people or the development of this will. They are also important tools for the creation of the will of the people. In view of the fact that this creation cannot happen without discussing the issues and convincing people, there has to be a plurality of parties, not only because otherwise choice would be impossible, but also because otherwise discussion and persuasion would be impossible. A oneparty-state can never be a democracy. Of course, other kinds of groups such as religious groups, labor unions, ethnic groups etc. are also important players in the democratic game and political parties should allow themselves to be influenced by these groups.

The need for discussion and persuasion in the creation of a common will implies reasonableness in the sense of argumentation, logical and understandable reasoning, etc. However, as I mentioned in the introduction, I do not exclude the possibility of an irrational and emotional way of convincing people (for example through the use of emotional stories), on the condition that the space left for this possibility is not filled by opportunistic misuse of irrational anxieties, prejudices or private interests totally alien to reasonable discussion. A political decision is best taken on the basis of reasonable discussions, and powerful groups should not try to influence people by playing on their feelings and their prejudices, or by giving them certain material advantages in return for their votes. Otherwise decisions would no longer be based on discussion, arguments and agreement.

\section{$\S 52:$ Setting the A genda}

Democratic politics (for this paragraph, see Barber 1984:passim) is about convincing people, using arguments to change people's minds and to create a majority or a will of the people; it is also voting for the laws necessary to realize this will, or voting for the persons who will be most likely to realize this will; and finally it is controlling the work of these persons. There is, however, one more thing preceding all these. Democratic politics is not just a debated choice between a set of options given in advance; it also includes the act of determining and changing the options. The options that can be chosen are never fixed. New problems or new solutions can always be put on the agenda. People do not only discuss questions, options or possible answers to questions that are given in advance. They also determine the questions, options and answers which they will discuss.

The right to vote for women is one example. At a certain moment in time, this was not a problem on the political agenda in most western countries. Thanks to discussions in the public space, it became a topic of political discussion, and a solution was decided upon. The choice between nuclear energy and traditional sources of energy is another example, now of a topic that figured on the agenda but with a limited number of options, basically 
two (traditional energy and nuclear energy). After discussion, the people discovered new options, namely wind and solar energy. The options, the problems and the possible solutions to problems on which the people have to decide, can change in the course of a discussion. A discussion can bring about new insights, new solutions and new problems. People also discuss the agenda, not just what is on the agenda.

This is why a request for a referendum for example should always be taken seriously and never rejected out of hand because it comes from an apparently small group of people. I do not mean to say that every such request should be honored, but one should at least initiate a discussion on the topic, in order to see if one should go further. The agenda, and therefore also the initiatives for referenda, should not be decided in a topdown manner. This is why the etymological origin of the word 'referendum' ('to submit a question to the people') is misleading.

A fixed agenda with a limited number of topics and a limited number of choices for each topic may be desirable from a practical point of view but has always been characteristic of authoritarian regimes. Even if you let the people decide according to the standard democratic rules of free, fair and equal elections, this will not result in an ideal democracy if the people cannot decide what they want on any subject they choose. As a consequence, powerful groups and the media should try to unfreeze the agenda and should avoid fixing it in a biased way, for example by systematically neglecting certain problems or solutions.

A nother characteristic of the agenda is its repetitiveness. Deliberation can mean re deliberation; decision can mean redecision. A point is never decided forever. People are free to question every decision that has been made. If this kind of questioning initiates a new discussion, it can happen that new and better arguments come to light, or that $\alpha$ isting arguments convince more people than before. As a consequence, a problem regains its place on the agenda and a new decision can be taken.

\section{§53: D emocracy is a Goal and $\mathrm{N}$ ot Just a M eans (1)}

Democracy needs communities and therefore corresponds to the widely shared need to belong, to associate, to cooperate and to interact. Community life and common action are as important for democracy as for human well-being. We are dealing here with important human values, shared by most people across all cultures. These values are important as such, but are also important because they assist the development of an individual identity, another important and universal value. Membership of groups is an important source of identity. You often define yourself as a member of a certain group with a distinct identity, and this identity influences and often determines part of your own identity. You do not join a group with a personal identity that is al ready finished and complete. Participation in a community shapes your identity. You may join a socialist party because you are a socialist, but it is also possible that you only become a real socialist as a result of your membership of the socialist party.

However, it is not entirely true to say that democracy promotes these values. The people promote these values themselves, but their participation in democracy can help them to do so. For those who do not participate, democracy can do nothing. (This is different in the case of the values promoted by publicity. As democracy promotes publicity, it also promotes the values attached to publicity, and it does this for all citizens, including those citizens who do not give a damn for democracy).

It is not democracy but political life in a democracy that promotes group life, belonging, common action and identity. And I cannot see a better way of promoting these values. Other political systems either allow only a minority to have a political life and the benefits attached to it, or define the word 'community' in an unfree, stifling and conformist way. Most of the time, however, they actively oppose the creation of communities because isolated citizens are powerless and cannot oppose the system. 
Political life also promotes other values. An individual actively engaged in political life is not only able to belong and to have an identity. He or she can also lead an informed and educated life (because participation and control require knowledge and education) and be attentive to politics and to things which he or she has in common with all the other citizens and which transcend his or her own private needs. This is how democracy promotes public life in a direct way - public life is a life in the space that all have in common - just as it does when it promotes conflict, change and publicity.

Given the importance of political life, it is impossible to maintain that democracy is only a means to achieve certain extra-democratic ends, such as for example peace or economic development. It is also a goal in itself. People do not engage in political life for the sole reason of regulating their non-political life. Political life realizes certain values, but these values are not a result or a product that political life leaves behind when it is finished. They are real only as long as political life takes place. Political activity is not purely instrumental; it is valuable in itself. 'W here democracy is end as well as means, its politics take on the sense of a journey in which the going is as important as the getting there and in which the relations among travelers are as vital as the destinations they may think they are seeking' (Barber 1984:118-120).

In this perspective, it is clear that democracy cannot be reduced to a system which is best adapted to protect the rights and interests of the citizens (on the correct assumption that citizens who govern themselves are not likely to violate their own rights or govern in ways contrary to their own interests). This view, although correct, is incomplete and diminishes the importance of democracy. It is indeed possible and even very useful to justify democracy on purely instrumental grounds. One of the functions of democratic participation is the protection of the interests of the people. These interests are protected in a democracy because:

(1) They are expressed and translated into the will of the people;

(2) As they are translated into the will of the people, they steer the election of representatives; only those representatives, which are most likely to advance the interests of the people, are chosen;

(3) Afterwards, they are compared to government policy; the people control the government, see if the government advances their interests, and vote for another government if this is not the case; the urge for self-preservation will force the government to anticipate this control and to govern in accordance with the will of the people.

However, democracy is more than this and there are many other reasons to participate in government.

$\S 54:$ The Separation Between State and Society and Between State and Politics

In a democracy, the creation of the will of the people as well as the act of controlling the government (controlling the government in order to see if it acts in accordance with the will of the people) take place both inside and outside of political structures and mechanisms (such as parliament, political parties, referenda or other officially established channels). A big part of it happens in society, for example in ecological groups, cultural groups, the media, the Internet etc.

The will of the people is of course a political thing, but it is not entirely structured in a political way. Society, therefore, participates in political matters and is not focused solely on private or non-political public concerns. Part of society is a political space (other parts are private spaces or public spaces in a non-political sense). See also Drawing 2. Since democratic politics is part of both state and society, the difference between society and state has to be redefined, especially when we are dealing with direct democracy (in a 
representative democracy there is more 'official channeling' of the construction of the will of the people and of the control of the government).

Of course, the difference has to be maintained because otherwise the state would be tempted to control everything. Non-political life is also worth preserving. On the other hand, if society is entirely non-political, then democracy is impossible. The will of the people is a political fact in society. In order to rescue both democracy and the difference between state and society, we have to establish a difference between state and politics. In this way, politics can overlap society and the state, and the state cannot monopolize politics. The legitimate efforts to limit the state should not lead to limits on politics, because this would be detrimental to democracy. Politics is unlimited. The people freely decide the political agenda (with the one exception of policies which violate human rights or the principles of democracy).

Here are some examples of this kind of political overlap between state and society. Referenda allow the people - in society - to decide something which then becomes a law and therefore part of the state. Political parties are active in society and in the state, mobilize and gather citizens and generate debate, but they also assume executive functions in the state.

In the next Chapter, I will discuss the traditional distinction between direct and indirect democracy, and I will show that especially a direct democracy can add more substance to the concept of political life and can render democracy even more desirable. Before that, however, I wish to draw some conclusions from the current Chapter. Democracy and human rights are necessarily connected and together they protect public and political life. Because they protect public and political life, they also protect a number of values that are extremely important for human life. Since the connection between rights and democracy is so strong that it is sometimes difficult to make the difference, it is reasonable to claim that a justification of one is automatically also a justification of the other. This is true for the justifications al ready given, and also for those yet to be given. 


\section{Chapter 4: $\quad$ Political Life, Version 2 (D irect and Indirect Partici- pation)}

Section 8: $\quad$ Participation by Way of Representation

\section{$\S 55: \quad$ A ctors and A uthors}

Implicitly, the focus of the preceding Chapter was on indirect or representative democracy. Electing leaders who are supposed to execute the will of the people by way of laws and policies, and consequently controlling these laws and policies to see if they conform to the will of the people, are features of a representative system. In such a system, contrary to a system of direct participation, the people do not vote laws and do not decide and pursue policies themselves. They decide what can and cannot be considered as the will of the people, but then they give someone else the power to execute this will in their name and to frame the laws and policies necessary for the execution of their will.

Although this kind of representative system has a number of advantages, it has to be combined with direct democracy if we wish that certain values are protected. Direct democracy is both desirable and possible, contrary to certain persistent myths. It gives the concept of political life a deeper meaning in the sense of adding a number of values (e.g. responsibility, activity etc.) to those al ready promoted by representative democracy. In this Chapter, I will start discussing the advantages of representative democracy and I will then go on to discuss the advantages of direct democracy.

In large groups or countries, it is very difficult to allow all people to participate in all decisions. That is why participation is often limited to the election of representatives in both the legislature and the government. This allows the people to influence indirectly the laws and the policies of the government. The people only elect those representatives who are likely to vote in laws and implement policies in accordance with the wishes of the people. If, afterwards, the people find out that they elected the wrong representatives, then they replace them. The desire to hold on to power, forces the representatives to act in accordance with the wishes of the people.

This means that representatives do not necessarily follow their own personal judgment or their own conscience The people instruct them and tell them which laws or policies to implement, or at least they tell them which values should be promoted by laws and policies. In all their actions, the representatives must never forget whence they came, who elected them and for what reason. They are the servants of the people whom they repre sent and whose wishes they are supposed to realize with the help of laws and policies. If their own wishes and opinions collide with those of the people, then they should either set them aside or resign from their posts.

In other words, they are actors and not authors. The people are the authors and the representatives act out the words of the authors instead of their own words (although their own words might coincide with those of the people). This guarantees the congruence of power and society. The political actors speak and act the words owned by those whom they represent (the authors) and, if necessary, leave their own personality behind while doing their work. Their official personality must be the sum of the opinions of the electors who, for this reason, recognize themselves in the representatives. The representatives act with authority (a word related to the word 'author') and are likely to remain in office as long as this recognition lasts and as long as the representatives act in the way 
they were authorized to do. The difference between rulers and ruled is hereby eliminated, notwithstanding the fact that the representatives and the represented are not the same persons. They are not the same persons but they share the same personality. N ot only the election result, but also the laws and the government policies must be the reflection of the will of the people. Representatives do not have authority on the basis of an election result, only on the basis of their performance in office.

By combining different similar personalities in one new person, the representative system solves the problem of large numbers of people wishing to participate simultaneously. This new person votes for a law in a certain way, the same way as a number of other persons would also vote. Since these other persons would all vote in the same way, there is no reason to let all of them vote individually. In order to make sure that the representatives, in the absence of their electors, vote in the same way the electors would vote if they had the chance, the representatives must take over the opinions and interests of their electors and leave aside their own if necessary. However, as I will show in a few moments, things are not always as simple as this.

\section{§ 56: Historical Perspective}

The representative system is important and has many advantages, even though in itself it is insufficient. Before I deal with these advantages, I wish to give a brief account of the history of the system. One of the historical origins of the representative system is the principle which prohibits taxation not based on laws approved by the people who pay the taxes ('no taxation without representation'). At the time when this principle came into force, the taxpayers were mainly the wealthy members of the new middle class or bourgeoisie. These people demanded representation in return for their money and used this representation to control the expenditures of the government. If the government wished to spend a lot of money on a stupid and unnecessary war for example, then the representatives would refuse to vote in the laws required to spend this money. Still today, budgetary control as a means for the people to check if government spending is worth paying for is an important function of parliaments.

Parliaments and representation owe their existence to taxation. The increasing costs of warfare, administration and infrastructure made the kings of the late Middle Ages de pendent on the money of the wealthiest class of the moment, which happened to be the new middle class. N ow and again, these kings were forced to organize meetings (for example the so-called 'States-General') where the representatives of the cities and the middle class could or could not agree to finance certain government projects. If they agreed, they did so because their interests would be served by the project. They always agreed by way of covenants, contracts or laws whereby they not only authorized spending but also received certain rights and privileges in return. Because they paid, they were able to enforce certain reforms, at first only local and specific privileges, but later also more abstract rights which had the advantage of being applicable in very different situations (De Vlieghere 1994:9-13).

These meetings were gradually institutionalized into what we now call parliaments. Parliaments therefore existed before modern democracy. Starting out as an instrument for budgetary control in the hands of a part of the population, they gradually acquired more power compared to the executive (in most cases compared to the king) and they gradually engaged in legislation. A later development was the extension of the franchise, whereby parliaments became more democratic. 


\section{$\S$ 57: Advantages of Representation: Purification and Clarity vs. Confusion} and $V$ agueness

Direct and indirect democracy have to be combined. Even though only a democracy which allows some degree of direct participation can be labeled an ideal democracy, it is wrong to say that representation is just a necessary evil for large communities. It is more than a second best solution because it has certain advantages which are absent from a purely direct system. The most important one is that 'limitation to a small and chosen body of citizens (...) [is] to serve as the great purifier of both interest and opinion, to guard 'against the confusion of a multitude' ' (Arendt 1990:227). It is not always easy for a representative to know what the people think, if they think something at all. It often happens that a representative guides, purifies or clarifies the thoughts of the people by presenting his own thoughts in a clear and concise way. At the next election, the people are of course free to express acceptance or rejection of these thoughts and to vote for or against the person defending them.

Representatives should be more than mere errand boys faithfully executing the will of their masters and speaking, not with their own voice, but with the voice of the voters. They are more than robots or parrots doing deeds and saying words that are not their own. Of course, a representative of the people 're-presents' someone, makes someone else present in parliament or in an executive function. He plays a part. Like an actor who plays Christ on the stage, the representative plays the character of the people or of the part of the people which he represents. He represents something that is pre-existent.

However, this is not always the case. What is represented often arises after and through the act of representation. By presenting his ideas in a clear and convincing way, the representative can convince the people to adopt his ideas. He can also try to add a certain clarity, direction, consistency and unity to the opinions of the voters. In the case of contradicting desires for example, he can establish a certain priority and favor one desire while putting another one temporarily aside. He decides an issue in the name of the undecided electorate torn between two conflicting desires (for example employment and combating the arms industry) and defends this decision by giving clear arguments to the voters.

Certain characteristics of the thing which is represented always disappear through the act of representation (this is also true for art, which is a kind of representation as well, Ankersmit 1997:218). At the next election, the voters can always disavow the choices of the representatives, but then at least they are forced to decide what is their point of view, to make up their minds, to focus on one of their conflicting views and to end an internal conflict.

Politics should not always focus on every wish or follow every erratic movement in the opinions of the people. It should also try to guide these wishes by offering and forcing a clear choice. This means that a so-called gap between the people and politics is not aways a bad thing and that it is quite all right for a representative to follow his own judgment now and then instead of simply saying what his electors instructed him to say. This kind of independence is of course limited. It cannot be applied to fundamental opinions. For example, a representative chosen on a ticket of anti-racism cannot express racist ideas or execute racist policies while in office

The simple model of democracy - the people making up their minds beforehand and choosing representatives who will faithfully implement their opinions - is sometimes a simplification of reality. The politician is often the 'accoucheur de la vérité d'une société' (Guéhenno 1995:54) and shapes the will of the people. Politicians necessarily take over characteristics of the people and start to resemble the people, otherwise they cannot represent the people and the people will never support the politicians. However, the opposite is also true. The people often start to resemble the politicians because the politicians clarify the sometimes vague and contradictory opinions of the people. 
If the representatives were only allowed to follow the instructions of the electorate, then the affairs of parliament would be no more than an exercise in arithmetic, a sum of opinions. Discussion, deliberation and convincing would no longer be necessary and would even be harmful. If a representative changes his opinions as a consequence of discussion and argumentation in parliament - and this happens very often, because otherwise discussion and argumentation would be useless - then his opinions are no longer those that won him the election and he no longer represents the people who elected him. If representatives must follow the instructions of the electorate in every case, then parliament cannot be a place where different opinions are juxtaposed and discussed and where people try to come to a common opinion based on argumentation rather than the coincidence of identical opinions. A parliament that loses its function as a place of discussion, struggle and the exchange of ideas, cannot have any consequences for society at large. Society as well will cease to be a place of discussion and exchange of ideas and public life will suffer. Remember the way in which power struggle guarantees struggle in society (Chapter 3).

If representatives can only execute instructions, then political decisions al ways reflect the sum of the private interests of the groups that are represented. The elimination of discussion makes it impossible to establish a general interest through the confrontation and discussion of private interests. Representatives should be more than the guardians of the interests of the groups they represent. 'Parliament is not a congress of ambassadors from different and hostile interests, which interests each must maintain, as an agent and advocate, against other agents and advocates; but Parliament is a deliberative assembly of one nation, with one interest, that of the whole - where not local purposes, not local prejudices, ought to guide, but the general good, resulting from the general reason of the whole' (E. Burke in Thomassen 1981:151). That is why representatives are often said to represent the entire people and not just the citizens who voted for them. They not only represent a particular interest for example the interests of a certain social class - but also the interest of society in general and they should try to establish this interest through discussion. If, as a consequence of this discussion, they change their opinion on a certain matter, then they decide according to this opinion and defend this decision at the next election.

A well functioning democracy does not impose the aggregated private preferences of the majority. The representatives of the entire people try to establish if something is or is not in the common interest of all. Persons belong to a minority only because the rest of the population is unable to convince them, not because they happen to find themselves in the smallest part of a simple sum.

Democracy is sometimes promoted as the form of government that is best placed to serve the private interest of a maximum number of people. In particular, utilitarian theorists use this kind of justification (they call it the greatest good for the greatest number). A democracy is then considered to be desirable because it does not allow anybody to rule in a way that harms the interests of the majority. This is a useful kind of justification, but at the same time it is a crude simplification of the democratic decision process. Democracy is also well equipped to establish the general interest. I suppose the general interest can only be established by way of a discussion in which every voice can be heard. If this is true, then democracy seems to be the only system capable of establishing the general interest.

Of course, not all interests can or will be united in a general interest. There will always be differences and contradictions, even if the discussion goes on for centuries. Certain opinions are very hard to change because they are fundamental to someone's identity; other opinions are immune for argumentation or are mutually incompatible and impossible to harmonize into a general interest. We have to warn against the dangers of minimizing differences and of considering the general interest as the outcome of a reasonable process. One of these dangers being the inclination to stigmatize diverging views as 'unreasonable', 'irrational' or 'deviant', as something which must be eradicated, sometimes even in the interest of the people holding these views. There will always be differences and this is even a good thing from the point of view of public life. Those pursuing the general interest have to take this into account. 
It is very doubtful whether the 'follow-thy-instructions' theory of representation is even able to guarantee the implementation of the private interests of the majority. After all, private interests differ and there always has to be some kind of negotiation, bargaining and compromise, which implies that not you cannot have everything. Furthermore, you cannot negotiate, bargain or compromise without changing your initial position. The instructions of the electors can never include all the steps of the negotiation or the bargaining process beforehand. This is why even at this banal level of political decision making, the representatives have to be able to take initiatives independently of the people.

One could of course favor 'back-seat driving' politics, in which the representatives continuously and throughout the whole bargaining process, consult their electors and ask for additional instructions. But then many of the advantages of representation are completely lost and a direct bargaining between individual citizens would perhaps be more efficient. If back-seat driving is unacceptable and at the same time the representatives are not alowed to take initiatives, then deadlock is the consequence. In extreme situations, this can even lead to the disintegration of the political community and the deformalization of political struggle. Differences will then be decided by brute force.

In some cases the people have a will and ask the representatives to execute this will. In other cases the representatives propose a will and ask the people to approve it. The competition between representatives, between government and opposition or between political parties is one way in which the latter can take place. This competition forces the citizens to take sides and adopt a point of view. This has the added advantage of integrating ideas into a larger and coherent whole, an ideology, a party manifesto or a vision of life. In this way, the expressions of the will of the people lose their often contradictory or unconnected nature. A community of opinion arises after and through the act of representation.

Of course, we should avoid going from one extreme to the other. If parliament can act without taking into account the will of the people and without consulting the people (apart from the consultation taking place at the moment of the election), then we do not have a democracy. It is obviously preposterous to claim that the people can never make a good decision and that good decisions, decisions which take into account the general interest can only be the result of free and unhampered discussions in parliament. The will of the people can be more than a hotchpotch of contradictory private interests.

\section{$\S 58: 0$ ther Considerations}

Is it really necessary to have a secret ball ot? It seems not. A vote is something collective and public instead of individual and private. A secret vote makes it very difficult to argue and counter-argue because nobody has to give account of his or her vote. You do not know how your fellow citizens have voted and so you do not know whom to convince of what. Convincing each other, increasing membership of a group and establishing a common will are very difficult in this kind of situation. A secret vote isolates people from each other instead of bringing them together and reduces the people or the majority to a simple aggregate instead of a community of ideas.

I think it is fair to say that the secret ballot is a relic from the time when it was dangerous to make certain public choices and when governments or other powerful groups were in the habit of using their knowledge of the choices of the citizens to try to influence those choices (by way of coercion, bribery etc.). Furthermore, the secret ballot not only endangers the democratic procedures but also endangers publicity in general. All this, together with the fact that there are historical examples of public voting (the Greek 'pol is' for example), makes it very difficult to maintain the secret ballot. This is true for both indirect and direct democracy.

Concerning indirect democracy, I want to make two additional remarks. In view of the fact that the executive power has become - rightly or wrongly - at least as important 
as the legislative power, it is necessary to be able to elect the main executive officers, such as the prime minister, the head of state, the mayor and maybe also officers of the judicial power, such as judges, public prosecutors and the like. These persons are also delegates of the people and the people have to be able to choose or dismiss them in the same way as they choose or dismiss their legislators. Everybody in possession of power has to be $a$ countable. There can be no 'reserved domains of power'. Electing these people is also participation in government.

The executive power ('Ia force appliquée à la loi' ) and the judicial power have to be the object of choice and control by the people. After all, even if the law corresponds to the will of the people, it can be executed or applied in a way that does not correspond to the will of the people. Of course, this kind of direct election implies a presidential regime. And unless the prime minister is elected, a so-called constitutional monarchy is no alternative because the government and the prime minister automatically fill in the void cre ated by the removal of royal prerogatives.

My second remark on indirect democracy concerns the type of representation. The people can be represented in different ways. The election of representatives in parliament is but one way. Interest groups and citizen associations for example also represent the people and can try to influence the 'official' representatives. Representation takes place at different levels. An interest group can also be the link between representation and direct participation. Interest groups are often rather small and can be organized in a way that allows direct participation of the members. These members decide on a common point of view and elect delegates to defend this point of view in other places. I will now go on to discuss direct democracy. 
Section 9: $\quad$ Participation Without Representation

\section{§59: Disadvantages of Representation}

Citizens who engage in indirect participation can only influence decisions and can never decide themselves, at least not on issues. They can only decide on persons who will then decide on the issues. Citizens can only decide on issues in a direct democracy. In an indirect democracy, they influence the decision of the elected rulers, because the latter are given certain instructions and depend on the satisfaction of the citizens for their future existence as rulers.

In my opinion, an ideal democracy allows the people to influence decisions but also to decide for themselves now and again. The ability to control your own life, as well as some other universal values, depends on this. An ideal democracy is therefore a direct democracy, at least in part. People in a non-democratic regime also influence their leaders and influence therefore cannot be the main characteristic of democracy, although it is true that in a representative democracy the people have more influence than anywhere else. Influence in a representative democracy is more structured and more effective than in non-democratic regimes. However, this means that the difference between a representative democracy and other forms of government is merely a difference in degree, namely the degree of influence. The difference between a direct democracy and all other forms of government, including indirect democracy, is a difference in kind because the nature of participation is different. Instead of influencing the decisions of the government - which the people can do everywhere - the people in a direct democracy can decide for themselves. This gives the citizens a greater measure of control over their own lives.

Direct democracy is the decision making process in which the people themselves (or a part of the people for matters that only concern this part) take the decisions that affect their lives. A referendum and a council meeting are examples of direct democracy. Typical of direct democracy is the lack of separation between official and unofficial political discussion. Politics is not something politicians do. Every citizen is a politician in a direct democracy.

Direct democracy solves some of the problems of representative democracy and for this reason has to be added to the latter. The will of the people manifests itself directly in direct democracy. Representation is delegation. By giving my vote to a person, I yield my power. This person acquires the power to decide certain things in my place, things on which I no longer have a say. I can only agree or disagree with the decisions of my representative and I can only do this:

(1) Afterwards, when it may be too late, and

(2) For the whole of his decisions.

I cannot agree or disagree with each decision separately, even though perhaps he took some good as well as some bad decisions. I can only vote for or against the whole person of the representative. This is not only a lack of finesse; it also reduces the power of the people to influencedecisions and to judge politicians. 
In such a system, the will of the people cannot be adequately expressed and therefore cannot be adequately implemented, which means that the people do not rule. The people yield their power and are unable to enforce the adequate implementation of their will. The impossibility of issue-oriented choice rather than person-oriented choice creates the temptation to focus everything on the person of the politician. After all, that is the only thing left. When it is impossible, in a vote, todistinguish between good and bad deeds of the politician, then one is liable to focus on things as vague as personality, general convictions, 'charisma', image etc. The people vote for or against politicians, names or faces, not for or against ideas or acts because they cannot use their votes to distinguish between different ideas or acts. The consequence is 'a mesmerizing politics of media on which millions are spent to promote slick images and avoid substantive issues, in the name of providing an accountability that is also entertaining; it is a politics citizens watch rather than something they do' (Barber 1984:xii).

Direct democracy can move democracy away from a system for choosing and legitimizing (or dismissing) leaders without reference to any specific content whatsoever. It can create a system where the people can decide on ideas and acts and not just on the people who are supposed to decide in their place. It is not without reason that representative democracy is often called leadership democracy. It is an instrument to choose the leaders and the rulers of the people. It is not a structure allowing the people to rule themselves.

Representative democracy tends towards oligarchy or aristocracy. Power comes from the people but does not stay with the people. It is taken over by a limited number of persons standing above the people and forcing the people to be passive in between election days. Control, the only activity allowed by representative democracy in between election days, becomes superfluous. Why monitor the individual actions of the politicians when, at the day of the election, it is impossible to pronounce a judgment on each action separately? When it is all or nothing, an intuitive understanding of the general line of political action is enough and this general line can be adequately understood by looking at the image, the character and the vision of the representative.

It seems, therefore, that representative democracy makes the application of its own rules impossible. In a representative democracy, the limited amount of activity which, in theory, is reserved for the people, is in practice impossible. The people are obviously not allowed to decide on issues - that would be direct democracy - but in theory they are allowed to decide on who has the power to decide on issues. But how can they do this if they can only say 'yes' or 'no' to a person and not to the things this person has done? Do they have to make a sum of the good things and the bad things every representative has done or proposes to do, give a weight to every single action, and then choose the repre sentative or the candidate with the best score. If they do, they will still choose persons who have done things or will do things they do not like. They will never be able to vote against these things, because at the next election their calculation will force them to vote again in favor of the same persons. They can never endorse or reject particular decisions of a representative and they can never give the signal that the representative should stop doing something which is contrary to the will of the people, except if they vote against the representative and thus against the good things he or she has done. The only correct judgment they can make is through non-political channels such as the media. There they can point to specific good or bad deeds without having to endorse or reject the entire person of the representative. The problem is that this kind of judgment may well be without consequences.

The people become passive spectators who can only correct the course of events in extreme cases, for example the case of the politician who hardly does anything in accordance with the will of the people, or who have to throw away a lot of good things in order to get rid of some bad things. The government substitutes its own activity for the activity of the people and the people have to stand aside to enable the government to do their work for them. The problem is, of course, how to separate cause and effect. The elitist vision of representative democracy often justifies itself by pointing to the actual 
passivity, apathy and lack of interest of the citizens. No one asks the question whether this passivity - if it exists at all - is because of the lack of opportunities to act in a representative system. If there were more possibilities for the citizens to act and influence decisions, for example by being able to disapprove of certain decisions, then the citizens would probably be much more active. If your opinions are of no consequence at all, then why would you have opinions, let alone express them? If, on the contrary, you know that your opinions will influence things, then you will have opinions and you will want decisions to conform to these opinions. Moreover, you will have a sense of responsibility be cause you know that what you think will be implemented. You will think twice and study the possible consequences of your thoughts. You will not permit yourself to think indiscriminately.

Only a regular dose of direct democracy can promote this kind of activity and responsibility. It has to be possible to let the citizens vote in a referendum dealing with important decisions of the representatives. At the next election it may be too late or it may be impossible to distinguish the different important decisions and to come to a clear and balanced judgment on the record of the representative in question. An added advantage of this procedure is that it can help to thwart anti-politics. The citizens are themselves responsible and cannot shift responsibility for all kinds of wrongs to 'politics'.

Activity and responsibility are perhaps not values which are universally acceptable, but if people want to have control over their own lives - which I think most people want then they have to understand that they must act themselves. They should not leave things to representatives. And acting means having responsibility for your acts. '[P]olitics is something done by, not to, citizens. A ctivity is its chief virtue, and involvement, commitment, obligation, and service - common deliberation, common decision, and common work - are its hallmarks' (Barber 1984:133). Citizens should not be represented for every decision, otherwise there is no control.

A misconceived representative system robs citizens of their opinions, their sense of responsibility and their activity, and afterwards legitimizes itself by pointing to the lack of these things. If citizens lose their opinions, they also lose their sense of community and their community life. If you have opinions, you naturally want to convince other people of your opinions, you create communities and you guarantee not only an important human value but also one of the major prerequisites of democratic politics. This is another way in which representative democracy cuts off the branch it is sitting on. O ne of the mischiefs of representative government, which insists on governing for a citizenry to which it promises to be accountable, is that it robs individuals of common activities that could form a citizenry into a community. Even if a representative regime governs on behalf of its clients with efficiency, equitability, and due respect for popular liberty, it will impair rather than enhance the people's capacity for lateral public ties and community affection' (Barber 1984:244), and therefore it will destroy one of the foundations of democracy, namely community feeling.

$\S 60$ : A dvantages of D irect D emocracy; D emocracy as a Goal and $\mathrm{N}$ ot Just a $M$ eans (2)

Direct democracy is able to guarantee a number of important values - activity, responsibility, thinking and community life. Furthermore, one of these values, namely political activity, is a prerequisite for autonomy. Political activity or political life - activity in the full sense of the word, not just activity in the sense of control of an activity that has been transferred or delegated to other persons - guarantees autonomy or self-government be cause it allows people to have control over their own lives, to actively shape their own lives, to implement their desires and to decide what happens to them. In other words, it allows people to have power and does not ask them to yield power. In a direct democracy, the government does not have and is not given the power to decide for the people and to shape the lives of the people. If we consider democracy to be, in part at least, a 
system of direct decisions taken by the people, then we have found a second way in which democracy is a goal and not just a means.

Representative democracy has a number of advantages and should therefore be maintained. However, a certain degree of direct democracy is necessary as well because this is the only way to counteract some of the deficiencies of indirect democracy. If people are allowed to govern and to decide on laws and policies now and again - in particular when basic values are at stake or when significant power is deployed - then the people are given power over their own lives and the representatives lose their power over the lives of others. Furthermore, the people are given a means to be active and responsible.

Self-government (the equality of rulers and ruled, government of the people by the people instead of government of the people by an elite sprung from the people) is an important value because it gives people control over their own lives. Most people want to be masters of their own lives and want to be involved in the creation or transformation of the conditions and circumstances of their lives. These conditions and circumstances include of course legislation. You have self-control and self-government only when the laws you have to obey are laws which you have made yourself; 'quod omnes tangit, ab omnibus approbetur', what concerns all has to be approved by all. A representative system does not guarantee that this is always the case. However, self-government also includes agenda setting, deliberation and policy implementation. $M$ en and women (...) are (...) directly re sponsible through common deliberation, common decision, and common action for the policies that determine their common lives' (Barber 1984:145-146).

One could argue that the people also govern themselves in a representative system, because the representatives govern according to the will of the people. However, even when we put aside the difficulties surrounding the execution of the will of the people in a representative system, we cannot eliminate the contradiction between representation on the one hand and activity and responsibility on the other hand. Politics is more than just an institute, a group of persons, a place or a set of rules governing the election of representatives. It is also the common life of the citizens and their cooperation, deliberation and decisions necessary to shape their own lives. Politics is something the citizens do, not something they watch, and it is something that guarantees a number of important values, such as self-control, self-government, autonomy, responsibility etc. Of course, not everything the citizens do is politics. Politics are those actions they do in common and in or through certain institutions guaranteeing deliberation and common decision taking. Furthermore, political actions are those that serve the common good.

\section{$\S$ 61: D ifferent Forms of D irect D emocracy and the Problem of the L eader}

The referendum is, of course, only one form of direct democracy. There are also ways to allow the citizens or some of the citizens to participate in legislative and policy assemblies. Especially at the local level, in municipalities for example, can citizens be directly involved in the decisions, on the condition of course that municipalities have the power to decide certain things. Decentralization and self-government are closely connected. Furthermore, participation at the local level can be more continuous than in representative elections or referenda and the traditional arguments of scale do not apply.

This kind of local participation is a particularly good way to create real selfgovernment and to eliminate the age-old differencebetween rulers and ruled, a difference we even find in representative democracy. The difference between the latter and all previous forms of government is not the existence of governing elites, but:

(1) The ability of the people to recruit their own elites from among themselves ('The 'élite sprung from the people' has replaced the pre-modern élites of birth and wealth; it has nowhere enabled the people qua people to make their entrance into political life and to become participators in public affairs', Arendt 1990:277), and

(2) The degree of control and influence 
The easiest way to implement self-government is to do it at the local level in small face-toface communities, in local 'councils' of all kinds (municipalities but also neighborhood councils, factory councils, labor unions, universities, school councils, companies, professional federations, churches etc.). In these councils or assemblies, everybody has the possibility to speak, to take part in debates and to decide on matters within the jurisdiction of the council. These matters are of course first of all local problems without consequences for the rest of the country or problems affecting only the members of the group in question. However, national matters can also be decided at a local level. The national decision can then be the aggregate of the local decisions.

Direct participation must be equal participation. Everybody has an equal right to speak and everybody's vote counts for one. ' $O \mathrm{n}$ its face, leadership is opposed to participatory self-government; it acts in place of or to some degree encroaches on the autonomy of individual actors. The statesmanship of a leader such as Churchill may stultify the liberty of an admiring but passive followership no less than might the charisma of a $\mathrm{Hitler}$. As a consequence, one might wish to say that in the ideal participatory system leadership vanishes totally. Complete self-government by an active citizenry would leave no room for leaders or followers. (...) It is the country that desperately needs leaders that the strong democrat worries over and pities. As the M exican revolutionary leader Z apata is reputed to have said, strong leaders make a weak people' (Barber 1984:238).

However, given the persistence of differences in natural talents and in social position, it is most likely that there will always be leaders. Everybody does not have the same talent, time and knowledge, and those with more of this can easily become the leaders of those with less. These leaders determine the lives of the rest of the population, which makes self-government and self-control impossible. This is a threat to direct democracy because direct democracy implies the disappearance of the difference between rulers and ruled. Traditional theory from A ristotle to Rousseau argues that the citizen is at once the author and the subject of laws. Y et common lawmaking in a strong democracy may make authors of some persons and subjects of others - depending upon the distribution of talent. Although each has a voice and a vote, trailer-park welfare clients in a rural Vermont town, for example, are likely to feel much less like the authors of their town meeting's business than the articulate lawyers and school teachers of the town who make their living with informed talk and persuasive argument' (Barber 1984:239-240).

One way to solve this problem is the creation of an institution, a person for example controlling the equal participation of all, encouraging the bashful and slowing down the chatterboxes. This person can also force the majority to listen to those with special knowledge on the subject under review. This means, however, that the freedom of speech of some has to be limited in favor of the freedom of speech of others. Those whose freedom of speech has to be limited are not only the talented or the 'natural leaders', but also the weal thy who do not use their talents but their money to gain an unfair advantage. This does not necessarily mean corruption. Buying influence can be done by spending money on publicity or lobbying, by acquiring television channels etc. Although differences in talent and money cannot and probably should not be eliminated completely, there is a need for some kind of income redistribution, some kind or redistribution of influence, and the development of latent talents through education or encouragement.

\section{$\S 62:$ D isadvantages of D irect D emocracy (1): Scale and Technology}

The most important objection to direct democracy is the supposed impossibility to apply it in large groups of people. It may have been possible in ancient rural societies and it may still be possible in small towns without any real power, but it is said to be incompatible with most types of contemporary social organization. Even if it were possible to bring together the population of a modern nation-state on a regular basis, only a small minority would have the possibility to speak and some kind of representative system would be a 
natural outcome. Those who have the chance to speak will be delegated to speak for the rest. So why not formalize this representation, which would have the added advantage of equalizing representation and creating instruments to control whether the representatives have been faithful to the wishes of the represented? If representation is improvised, then not everyone will be represented or will be represented correctly. Those who speak are not elected officially; they elect themselves and in the best of cases speak in the name of the silent majority. They are not accountable and it is very difficult to take away their function as representatives.

Direct democracy seems to be impossible in large groups and irrelevant in small groups. Small groups such as municipalities do not seem to be incompatible with direct democracy, but their power and influence is so small that it does not seem to be worth the trouble to let citizens participate. Organizing referenda is a way to allow large groups to decide without bringing them physically together, but a referendum is said to be very cumbersome and only worthwhile in exceptional cases.

However, technology can solve many of these problems. If, in A ristotle's time, the selfgoverning polis could extend no further than the territory a man could traverse in a day (so that all men could attend any assembly), the ultimate permissible size of a polis is now as elastic as technology itself' (Barber 1984:246). The quasi-disappearance of space as a result of technology is a well-known phenomenon. Modern technology such as the Internet, virtual meetings, e-mail, mobile phones, interactive television and so on can assist the process of participation, beginning with debate and deliberation and ending with vote-taking.

Of course, 'technological politics' is not a panacea. Ultimately, nothing can beat faceto-face discussion. Moreover, technology can also have adverse effects. At first sight, the current craze for opinion polls and televoting - you call a TV-station and vote for a certain subject, for example capital punishment or the late-night movie - seems to be very democratic, but in fact it is no more than a collection of rash, impetuous, unthinking and emotional reactions. Reflecting on and studying the complexities and nuances of a problem and the pros and cons of a certain solution are impossible. Opinion polls and televoting are often a shabby imitation of, or an 'ersatz' for, direct democracy. At best, it testifies to need for participation. This kind of imitation reduces politics to a private matter or, in other words, to the expression of private opinions that do not result from public argumentation and discussion. Good decisions often take some time because reflection and discussion take time. Instant reactions on TV or in opinion polls can do more harm than good to democracy. The number of 'popular decisions' increases, which gives the impression of an intensifying democracy, but the quality of the decisions diminishes and this casts a shadow on the reputation of democracy.

Only well-considered opinions are good opinions and well-considered opinions are those that are tested in discussion and that survive all possible counterarguments. In order to be able to take into account all these counter-arguments, thinking and voting cannot be closed or private. They have to be public. Voting is the consider ed outcome of a process of active deliberation about the facts of public affairs, not a mere expression of personal interest' (Held 1998:100). Since opinions as such, without prior discussion in public, are worthless, it is important to stimulate debate as much as possible. It is regrettable that democracy often makes itself vulnerable to criticism by allowing public opinion to be the result of instant reactions, emotions, habits and fashion instead of considered debate.

A nother adverse consequence of technology on democracy is the excess of information produced by modern technology. This makes it difficult to structure discussions and to bring in all relevant study material. Modern technology, furthermore, creates a problem of computer illiteracy and tends to exclude the lower classes from political decisions. This, of course, is not very democratic. 
The problem of scale can also be solved by implementing some kind of federal system. This system combines representation at the national level with a certain degree of direct democracy at a more local level. Instead of concentrating all power in one central body, certain very important powers are the reserved domain of local entities. A federal system is especially useful in countries that are very large or that are relatively loose and arbitrary aggregates of groups that have little in common.

An individual, when faced with a monolithic monster of a state, threatening and distant at the same time, feels insignificant like a grain of sand on the beach. This, of course, does not encourage participation or the feeling of self-control. Powerlessness instead becomes a fact of life. A single voice is not noticed in the noise of millions and is reduced to indifference. The state does not react to individual claims as quickly as it is supposed to, if it reacts at all. The bottom line is that individuals or small groups cannot hurt the state. Their votes are less significant than pinpricks. The only elements in society able to influencethe centralized state are large, national and centralized pressure groups that are just as distant from the citizens as the state and equally insensitive to individuals' claims.

For the individual or for small groups of individuals, there does not seem to be any reason to participate in politics or in pressure groups; there does not even seem to be a reason to uphold democracy. Bigness may be good in some circumstances (national de fense for example), but has to be considered as an exception and a necessary evil. 'A halfmillion souls whose commonality is defined only by a single vertical tie to a central organization will probably feel more estranged by scale than would several million whose commonality is filtered through several levels of organization where ties are lateral and where participation is initially 'local'. Decentralization, federalism, and other cellular social constructions (...) treat community as a collection of communities' (Barber 1984:248). Federalism is necessary in both large and relatively small countries. In both cases will it encourage participation and counteract al ienation and a feeling of distance between the citizens and the state.

Decentralization and participation at a local level diminish the number of participants and increase the importance and the influence of each individual. The question is, of course, how to distribute powers and functions between the whole and the parts? What can be decided at a local level, and what has to be the reserved domain of the central government? This way of asking the question is not arbitrary. If something can be decided at a local level, then it should be decided at that level. The ideals of self-government and direct participation force us to limit the decisions of the central government to those decisions which cannot or should not be taken at a lower level because they transcend the possibilities, the capabilities or the rights of that level. When a problem can only be solved by large-scale cooperation (e.g. national defense) or when a decision influences people in other localities, in the state in general or even in other states (e.g. the environment, the economy or human rights violations in a certain local ity) then it is probably best to decide this issue at the level of those concerned. This can be the national or even the international level. If all is concentrated in the parts, then we have de facto independence The question is whether in our present age this kind of local independence is desirable and/ or possible. Our 'modern' problems have made us all interdependent to a certain extent. We depend on the cooperation or approval of many people, sometimes people far away. This tendency towards 'bigness' is a threat to participation, but it is a fact of life and there does not seem to be a way to change it. However, we should not forget that many important actions can still be undertaken at the local level, actions which can give a real feeling of self-government to the people involved.

The need for large-scale cooperation does not have to be a threat to democracy. Small groups have the advantage of allowing more people to participate and of giving each individual more influence, but larger groups have the advantage of being able to solve certain problems in a better way than small groups. If democracy means determining your own life, then it also means being able to decide something and to solve problems. A small group which allows everybody to speak and decide and to have a real influence on 
things, can hardly be called democratic if it cannot solve some of the major problems of life. A larger group may force people to participate less and to have less influence, but its size can make it possible to cooperate and to tackle some important problems. Such a group may be more democratic than a smaller group because Its capacity to cope with certain matters (...) would be greater. On this view, a unit large enough to deal with matters of importance to the people concerned will always be more democratic than any smaller unit' (Dahl 1989:205). This is a nice way to counter the argument that democracy is only appropriate for small groups in pre-modern societies.

Coming back to the federal system, it is up to the whole to distribute power between the whole and the parts. This cannot be done by the parts individually, otherwise the whole would not be ruled democratically. When a part decides which element of power must belong to it and must be taken away from the whole, we effectively have minority rule. However, the whole should not change the distribution of power without the agreement of the parts, because then we do not have a federal system. The central government cannot encroach on the functions of the parts once the distribution is decided. It cannot, for example, annul the decisions of a part when these decisions are within the competence of the part. This would be a de facto and unilateral change in the distribution of power and a reduction of the power of the part.

This brings me to another point. The different parts or localities have to be combined in some way or other. If not, the federal system may tend toward provincialism, fragmentation and ultimately disintegration. There has to be a bond between the parts, a willingness to shape their lives together. This means that the parts should transcend their local interests and, if necessary, should be willing and able to give up these interests for the sake of the whole. Feelings of isolation, self-sufficiency and hate or distrust of the other parts lead to polarization and the break-up of the federation. The love for the whole should not be overshadowed by the love for the part or the love for plurality, difference and identity. Both kinds of love are necessary for democracy, the latter because of the advantages of small-scale participation, the former because of the need to solve the larger problems of life (e.g. national defense) and to give a feeling of self-control to the citizens. These large-scale problems can stimulate some kind of large-scale patriotism.

There has to be a balance between the local and the national level. In case of doubt, the decision should be in favor of the local level because of the importance of direct participation. If something can be done locally, then let it be done locally. Only those problems which can only be solved at the national or international level should be solved on that level. As always, extreme positions should be avoided. If you concentrate all or most power in one national body, representative or not, then you end up with passive citizens and alienated rulers. If all or too much power is concentrated in local institutions, then the federation will be too weak or too fragmented to solve large-scale problems and to serve the national interest.

Local participation has to be integrated in national politics. This makes it possible for the local assemblies to represent the localities at the national level, and for the national level to exercise a certain level of control over the localities. An example could be the Unites States of America. The American Senate includes delegates from the states who can express themselves and decide on national matters. On the other hand, there is a national institution, the Supreme Court, which can check and correct local behavior.

This kind of integration, however, is not always easy. You have to create a national government which is above and superior to the local entities, able to correct these entities when they transgress the boundaries of their power but unable to meddle in the legitimate exercise of their power and unable to take their power away. At the same time, you have to convince localities to give up some of their power to a national institution, to accept being outvoted by a national majority on some problem of national importance, and to accept interferencefrom the national authority. 
Local participation is a preparation for national participation. By being able to participate in local institutions, the citizens become familiar with a kind of general interest. They are forced to transcend their private interests because they devote themselves to something bigger than their personal lives and families. They spend time and energy on something other than their private affairs. For example, they work to improve their local school, at first maybe for egoistic reasons - they want a good school for their own children - but gradually the process of collaboration will create sympathy with their peers and they will work for a good school for the community as a whole.

Decentralization has other advantages besides direct participation and a sensibility for the general interest. Even a representative system can benefit from being local. In a small group, those in control of power are closer to the people and more familiar with the local circumstances. For this reason, they are more readily accepted and more likely to find adequate solutions to problems. Because they are more accessible, they are also easier to control. Furthermore, decentralization discourages the phenomenon of free-riding (citizens profiting from social services while contributing as little as possible, and knowing that their individual non-contribution will not significantly affect to total amount of goods or services available). Social pressure in smaller groups discourages this kind of anti-social behavior. The very specific character of the general interest encourages citizen engagement and therefore also limits freeriding. In a small group, you have a general interest which is easier to know and therefore easier to pursue.

\section{$\S 64:$ D isadvantages of D irect D emocracy (3): O ther Solutions to the Prob- lem of Scale}

The problem of scale or size can also be solved by letting everybody participate, but not at the same time. If one hundred people are considered to be too numerous to participate simultaneously and only ten of them can participate at the same time, then everybody gets a number and everybody's turn will come. In the first session, numbers one to ten can participate, in the next numbers 11 to 20 and so on. In this way, everybody can participate now and then, and since the duration of every round is the same, everybody can be said to participate equally.

Selection by lot for a certain limited period can be an alternative system, also guaranteeing equal participation of everybody. If it is impossible for everybody to participate all of the time - for example because it would be difficult to take urgent decisions and government would come to a stand-still if we would have to listen to everybody - then at least everybody can participate some of the time.

The ancient Greeks considered selection by lot the essence of democracy. A ccording to them, representation was more of an aristocratic device. A choice is al ways an attempt to choose the best (the best solution, the best people etc.). Election by lot is totally arbitrary and makes no difference between people. Everybody has an equal chance to be chosen. Nobody can claim to be elected on the ground of superior quality and nobody can bribe an electorate in order to buy his way into office

The problem with election by lot or with other systems of participation in turns, is that you run the risk of being excluded at the moment when important decisions are taken, for example because it does not happen to be your turn. In this case, participation is not equal. It can happen, by chance, that the same people always take the important decisions. This problem can be avoided by adding the requirement of a referendum on the basis of universal suffrage each time an important decision has to be taken.

A jury system in the broad sense of the word - not or not only the juries used in courtproceedings - is another way of letting people participate in turns. These juries are groups of statistically representative citizens who are brought together to discuss or even decide on certain topics. These "deliberative opinion polls' are 'a direct face-to-face society for its participants and a representative institution for the nation-state' (J. Fishkin in Held 1998:321). 
Debating and deciding are made easier by excluding the majority of the people. However, the statistical method of choosing the jury guarantees that decisions are somehow repre sentative of the whole of the people. Of course, one can never be sure that this is the case and this is the main weakness of the system. It is not because the members of the jury are representative of the entire population that their opinions or decisions are representative as well. Even if their opinions are representative, it is likely that these opinions will change in the course of the discussions taking place in the jury. I would recommend juries only as a procedure added to other procedures for the purpose of:

(1) Getting to know the opinions of the people, not simply the opinions as an aggregate of individual opinions but the opinions as a result of debate;

(2) Engaging (some) citizens in political debate; and

(3) Giving a clear image of a problem and of the pros and cons of certain solutions to non-members of the jury, who can then use this to enlighten their opinions and improve their decisions.

The positive effects of point three are enhanced when the juries are allowed to hear $\alpha-$ pert witness. People are no longer forced to give hasty answers to difficult questions, as they often are in opinion polls or referenda. The problem is that the spectator, while watching the jury, can come up with new arguments or problems which cannot be a part of the discussions in the jury and which, for this reason, tend to get lost.

The argument of scale, so often used against direct democracy, can also be used against representation. Representation is not always a solution to the problem of scale. It becomes more and more absurd to attempt to 'represent' a heteronomous mass in all the innumerable problems which arise out of the increasing differentiation of our political and economic life. To represent, in this sense, comes to mean that the purely individual desire masquerades and is accepted as the will of the mass' (R. Michels in Barber 1984:250). It is much easier to represent a small group than to represent a large group. The larger the group, the more differences between the members. These differences tend to disappear in the process of representation and, because of this, representatives tend to become alienated from the people.

Furthermore, large groups are not necessarily a problem. They make it much less likely that a majority of people has the same interest in oppressing the minority (Hamilton/ Madison/ Jay 1954:18-19-75). However, this also means that large groups make it difficult to establish any kind of majority. Large groups almost always consist of many different opinions and interests and it is often very hard to merge these opinions and interests into one harmonious common will of the majority. Sometimes, the best one can hope for is compromise and even this is not easy, especially when one deals with fundamental opinions and interests such as religious and moral convictions. These are arguments against both representation and large-scale direct democracy. It is easier to convince, compromise and negotiate at a face-to-face level. However, it is difficult to imagine a large-scale system that is better equipped than democracy to guarantee the prerequisites for convincing, compromising and negotiation.

\section{§ 65: D isadvantages of D irect D emocracy (4): D emagogy and E motionality}

Another well-known reason to prefer representation rather than direct democracy is the supposed susceptibility of the people. Elites, demagogues and other irresponsible powers, often operating in secret, can use slogans, images, publicity etc. to manipulate the will of the people. However, this is probably a gross exaggeration. The people are often very independent. People do not al ways repeat what they are told. The fact that there are so many would-be manipulators, all saying contradictory things, precludes the spread of something like a political Pavlov-syndrome. Because the freedom in a democracy multi- 
plies the number of would-be manipulators, it is safe to say that democracy reduces instead of increases the risk of manipulation.

There is no alternative anyway. Even if the people are excluded from politics there is likely to be manipulation. It is impossible to protect the people against elites by keeping the people out of politics and by leaving politics entirely to politicians. ' [I]t is foolish to think that a nation can be rescued from the manipulation of elites by reducing the potentially manipulable public's input into the democratic process. O ne might as well combat crime in the subways by keeping the public at home. Indeed, it is more rather than less experience of government that will insulate voters against manipulation and prejudice' (Barber 1984:282).

Many people fear that referenda on 'emotional' subjects such as the death penalty or the forced repatriation of immigrants would have undesired results, especially when they are scheduled immediately after highly publicized events (a gruesome murder committed by an immigrant macho for example). The people are said to be much more susceptible to emotional stimuli than to rational arguments. It is indeed useful to ask questions like: The real questions are: what is the best moment to have a referendum, who decides on the timing, who decides to hold a referendum, who decides the subject of a referendum? It is clear that the people should take these decisions, not the politicians. This does not mean that we have to hold a referendum on the referendum. Some kind of petition is sufficient, followed by a judgment of a court on the admissibility of the referendum. This kind of judgment will avoid referenda which may lead to violations of human rights, for example a referendum on the reintroduction of capital punishment. (Again we see that the people can decide on issues but can also choose the issues to decide on. Setting the agenda is an important part of democracy).

The arguments used against referenda are the same that were used decades ago against universal suffrage. Women and lower class people were deemed unfit for politics because of their supposed emotionality or lack of rationality. The argument of the negative role of emotions in politics can be used against both direct and indirect democracy, just as the argument of scale. In a representative system, the choice for certain persons can also be a very emotional affair and emotional events can influence this choice. In general, arguments against direct democracy tend to become arguments against democracy tout court.

There is something not quite right in the statement that the people react in an emotional way. It is much easier for one man to become overpowered by feelings such as anger or sadness than it is for large groups. It is very difficult for a large group of individuals to become emotional at the same time and in the same way. Therefore, as in the case of manipulation, democracy is best placed to avoid exaggerated emotions because it involves as many people as possible in decisions. Furthermore, sometimes we would wish that the people showed more emotions in the field of politics. A passionate involvement can be beneficial for democratic politics.

And, finally, if it is true that politics appeals too often to the heart instead of the mind for example to personality and charisma instead of arguments and convictions - then it is the responsibility of politicians to act otherwise. They must try to convince and avoid emotional manipulation. Television, for example, has often been blamed for its manipulative potential, but it can also promote debate.

\section{$\S 66$ : D isadvantages of Direct D emocracy (5): A pathy and Stupidity}

The people are also said to be disinterested, apathetic, indifferent and not smart enough to deal with the complex problems of today. This is said to be another reason to exclude the people from political decisions. Even if I put aside the obvious incompatibility be tween this argument and the preceding one (people cannot be apathetic and emotionally impulsive at the same time), the argument does not seem to hold. It is evident that the debates which precede and which are almost automatically engendered by a referendum or a council meeting, vastly increase the willingness and the ability of the people to judge 
complex matters. If the people are allowed to vote on a certain issue, then many of them will instantly start to debate the issue and will become aware of the different arguments in favor of and against a certain solution. The same is true for those merely watching the debates. This awareness not only increases the knowledge of the people, but also their interest in the issue and in related issues. Political participation eliminates the lack of knowledge and interest harmful to its functioning, at least to a certain degree.

It is not clear how a supposed lack of knowledge or interest on the part of the people can be a reason to prefer indirect democracy to direct democracy. The representatives of the people will not be smarter than the people themselves. The people usually get the representatives they deserve. If the people are too stupid to take political decisions, then they are also too stupid to choose the people who are smart enough to take these decisions. It is very difficult to detect knowledge if you do not know what knowledge is. This is another example of an argument against direct democracy turning into an argument against democracy tout court.

Together with the problems posed by large-scal e communities, the supposedly superior abilities of professional politicians are the main reason for preferring representative democracy. Politics is said to be a profession like every other profession and since everybody is not fit for every profession, it seems strange to think that everybody has the ability to make laws. If everybody were to make his or her own laws, the laws would be terrible, just as terrible as clothes would be if everybody were to make his or her own clothes. Although everybody cannot make their own clothes, everybody can judge if clothes are good or bad and if the tailor has done well or not. Representation is justified by the fact that people are able to choose those who make laws, just as they are able to choose their tailor.

Representation is considered to be a good way, although perhaps not the best way, to put the smartest people in places of power. The best people present themselves for office and the best will remain because they are judged by the people, in the same as the people judge and make use of other professionals. To be perfectly sure that this happens, some refinements to the system of representation have been proposed. One example is the socalled multi-stage representation: first one or several general assemblies are chosen by universal suffrage (for example one assembly for every part of the country) and then these assemblies delegate their best elements to a higher assembly (and so on). Since no assembly wishes to make a fool of itself in the higher assembly, one can be sure that the best elements are chosen. Age limits, requirements concerning university degrees etc. are other examples of refinements to the representation system that are said to be necessary to guarantee the quality of the representatives. Even the sex of the representatives has long been considered an adequate measure of quality.

However, I maintain that the people will generally get the representatives they deserve, which may or may not be a good thing. Furthermore, as I will explain in Part 4, there are good reasons for limiting the importance of knowledge in politics. Of course, it is true that participation, direct or indirect, presupposes the ability of the citizens to make a meaningful choice and therefore presupposes knowledge, information and involve ment, but in one way or another, participation automatically takes care of this. The appetite (the interest) comes while you are eating, and so does the sense of taste (or knowledge). The people are indifferent, apathetic and uninformed only when they never get the chance to participate. Once they are allowed to participate, the enthusiasm will come automatically. Why would you be interested in and knowledgeable about something if you can never use your knowledge in active deliberation and decision taking? Why would you have an opinion if this opinion will never have serious consequences, if nothing depends on your decision? Moreover, it is simply wrong to say that the people are not interested in politics or that they do not have opinions. Everyone who regularly visits a pub knows that people talk about politics all of the time. They are not always correct in what they say, but neither are they al ways wrong. 
A pathy and lack of knowledge are indeed important problems that have to be solved, not only because they open the door for despotism (a tyrant likes nothing more than apathetic and stupid citizens) but also because an active, interested, informed and responsible life is something valuable. One important way to solve these problems is the use of direct democracy enabling the people to take decisions on issues, because then they will debate the issues and inform themselves on the pros and cons of possible solutions. Other ways are better education, a well functioning civil society in which free associations can mobilizecitizens, modern information technologies such as the Internet etc.

There is another argument against direct democracy in general and the referendum in particular, closely connected to the argument of stupidity and apathy. A referendum is said to reduce complex problems to simple or simplistic yes/ no questions. Answers in the style of 'yes, but...', 'no, but...' or 'yes , on the condition that...' are impossible in this kind of system. However, it is wrong to say that complex problems cannot have a 'yes' or 'no' answer or that such an answer is necessarily simplistic and devoid of nuances. Of course, you can always go on to add nuances indefinitely, but at a certain moment a decision has to be taken. There may be some urgent need to decide. Besides, the questions in a referendum can be framed in such a way that the voters have a wider choicethan simply 'yes' or 'no'. For instance, the voters may be allowed to express some kind of degree of agreement or disagreement in their answers (a strong yes, an uneasy yes, an uneasy no, a strong no). They can also be asked to give scores, for example a satisfaction score for different possible answers to a question. With the help of a bit of arithmetic, the most favored solution can then be established in a way which is different from a simple sum of 'yes' or 'no' answers regarding one possible solution. On top of that, in such a system you will not have a not entirely convinced majority which imposes its will on a strongly convinced minority. It protects social cohesion.

A referendum with stages promotes the creation of compromise. People who say 'yes' and nothing else and other people who say 'no' and nothing else cannot compromise. However, the question can be framed in such a way that a certain answer leads to a further question. This further question can be something like: 'if you have answered 'yes' to the preceding question, and if it turns out that there is an important minority expressing a strong 'no', would you then be ready to accept the following, less far reaching proposal?'. This could even go down some way towards ever more neutral proposals.

Compromise is important. It is difficult to live together without it. Democracy is the form of government that is best equipped to guarantee the prerequisites for compromise (openness, publicity, free association etc.). However, we should not overlook the negative sides of compromise. When you decide to compromise, you have already given up the hope of convincing your opponents and you are no longer looking for common solutions. You only negotiate, you give up something in order to get someone else to give you something else.

A system of stages can also be applied in a representative democracy. Contrary to a simple system of representation, it does not force the voter to express complete adherence to one party or person and complete rejection of another. Most parties do some good things and some bad things and when the voter is allowed to grade the different parties according to his or her degree of satisfaction with their respective achievements or plans, he or she is able to give every party its due share of credit. The voter is not forced to make a caricature of the different parties (complete acceptance or rejection can only be a caricature). Instead he or she can give a more shaded picture of his or her opinion of all the candidates. This is also an advantage for the candidates. They have to take account of the opinions of the entire electorate and not just of the opinions of their faithful adherents and their possible adherents. Every voter gives them a score and this score is added to the total (A nkersmit 1997:316). This, of course, changes the focus of politics from private interests towards the general interest, because politicians can no longer limit themselves 
to the promotion of the interests of a particular class of the population (the working class for example).

It is again a kind of elitism which is at the root of the argument of democracy's tendency to simplify things. We should not underestimate a people's ability to judge complex problems in a reasonably correct way, just as we should not overestimate the complexity of many problems. There is, however, another reason why some people use the complexity of modern day society as an argument against direct democracy. This complexity makes things difficult - too difficult for ordinary people and for the simplifying procedures of direct democracy - but also multiplies the number of problems politics has to deal with. Politics becomes a full-time job and this means that only those citizens living in an economic paradise can participate in a significant part of the decisions. Because it is doubtful that there will ever be such a paradise for all citizens, it is better that politics is left to professional specialists. I will now discuss this point in greater detail.

\section{$\S 67:$ D isadvantages of D irect D emocracy (6): Insufficient R esources to Par - ticipate}

Our representatives have become professional politicians often without time for any other occupation. Sometimes they are even forced to become specialists in only one part of government policy and it is not unusual that they cannot perform their specialist tasks without the help of large groups of experts. This, it is said, shows how foolish it is to think that the people will find the time and the energy to decide and to inform themselves on every possible subject of politics. There is no time for direct democracy. The work of the world has to be done. This is a reason for claiming that only a representative system can hit the right balance between efficiency, control and influence.

In particular the individuals from the lower social classes lack the necessary means to participate (money and the corresponding leisure time, certain oral capabilities, education etc.). If there is only a formal right to equal participation, then those with more resources will automatically participate more and in a better way. This is both undemocratic and contrary to the interests of those less well off. Those who are better off will be tempted to use their superior position in participation (their voices are louder and their lobbies more powerful) in order to serve their private interests at the expense of the interests of the poor. For example, they will lower the tax burden for the rich, create schools of superior quality only accessible for their own children (which again enhances their political power) and so on. Democracy becomes a plutocracy in which only the rich participate. This enables the rich to determine the lives and the social conditions of the poor.

All this can and does happen, but it does not have to. We should not forget that:

- Participation is not always used for the sole reason of advancing one's own position; the wish to improve someone else's position or to realize the general interest can also be a reason to participate;

- One can use certain mechanisms to enforce the equal participation of the less talented or those with fewer resources (see also the discussion on natural leaders); one should pay attention to the silent voices, to those voices without powerful lobbies, without quality education etc.;

- Rejecting direct democracy and thus making it more difficult for people to participate will make it even more difficult to improve their position; inequality has to have a voice

- Participation is a kind of education and therefore increases certain resources necessary for its functioning.

Some say that giving political power to people with insufficient material resources invites other people to try to buy their votes. They lack certain essential things and will be all too 
ready to sell their votes in return for these things. If this danger is real, it is equally real for representative democracy. This phenomenon is known as vote buying. I will discuss it in detail in Part 4.

Our present day society contains so many different activities and specialized occupations that it is often hard to find the necessary specialists. Therefore, is it not too much to ask people, often badly educated people, to become specialists in the many different domains which can become an object of political decisions? Let the people specialize in one field. That is difficult enough, especially when all fields have to be staffed. Even if politics did not require specialist knowledge, the requirements of people's own specializations would not leave sufficient time and energy for politics. However, specialization can be an asset for politics. When many different specialists give their point of view on a certain issue, it may be easier to come to a reasonable solution. The problem of available time is also a relative one. If all people were to watch one hour less television per day, a lot of time would be made available for politics.

If the modern economy forces people to focus their attention on their own business, then it seems to be better if they elect representatives who take care of the general interest and the common life in the state. However, if it is true that the people do not care for state matters and only aspire to sit at home and enjoy their private life, then the reason may not be a lack of time due to economic responsibilities but instead a lack of opportunities to participate. Direct democracy can pull people out of their houses and into the state.

Of course, political life is not an easy thing. It takes more effort than watching television. The ancient Greeks handed over control of all their private affairs to others (wife, family, slaves, aliens etc.) in order to be able to dedicate themselves entirely to political and public life. Of course, if equality is important, then this is unacceptable. But our present-day attitude is equally unacceptable. Today, we do the exact opposite: we hand over all our political and public responsibilities to others (our representatives or some kind of self-appointed ruler) in order to be able to manage our private affairs in peace and tranquility. Indeed, man is more than just a citizen and today we can no longer afford to have slaves or wives to take care of our private needs. That would be undemocratic. We have to take care of our needs ourselves. However, sometimes we take too much care of our needs and these needs can grow out of proportion, leaving no room for anything else. We do not need slaves in order to be citizens. We just need to pay a little less attention to our needs. Exclusive attention to private needs leads to political passivity and to the loss of the values guaranteed by political life. 'Sitôt que le service public cesse d'être la principale affaire des citoyens, et qu'ils aiment mieux servir de leur bourse que de leur personne, l'Etat est déjà près de sa ruine. Faut-il marcher au combat? ils payent des troupes et restent chez eux; faut-il aller au conseil? ils nomment des députés et restent chez eux. (...) On cède une partie de son profit pour l'augmenter à son aise. (...) Dans un Etat vraiment libre les citoyens font tout avec leurs bras et rien avec de l'argent. Loin de payer pour s'exempter de leurs devoirs, ils paieraient pour les remplir eux-mêmes. Je suis bien loin des idées communes; je crois les corvées moins contraires à la liberté que les taxes' (J.J. Rousseau in Leleux 1997:127).

When there is a real contradiction between justified needs and necessary political participation, then I suppose the needs take precedence. However, this is never a lasting situation - at least in the West - and therefore no reason to condemn participation as such. Besides, political participation can al so serve to express and therefore real ize needs.

Nobody says that citizens have to decide everything themselves. There is a difference between important and less important decisions, and citizens can organize their private concerns in such a way that they can spend some of their precious time on politics. They can manage their time in such a way that they are present at decisive moments. From the point of view of the citizens, it is a problem of priority. If they are allowed to decide on important things, then they will balance this right with the advantages of private life and they may decide that some private concerns can be sacrificed for public ones. If they are never allowed to decide on important political problems, then it is natural for them to think that the only important thing is their private life. 
The advantages of direct democracy are there for all to see. Citizens in a democracy which allows some kind of direct participation, are active citizens. They are interested in public affairs and have knowledge of these affairs; they are responsible for their actions; they are able to transcend their private interests and to take part in community life and group identification; they have some measure of control over their lives etc. This means that direct participation is not only a means to an end (for example the end of having decisions that are acceptable to the people). It is also an end in itself because it guarantees a number of important values. These values are not the result of the process of participation; they are part of the process itself. People participate for the sake of the things which happen while they participate (knowledge, attentiveness, responsibility, activity and a feeling of self-control or control over the decisions which affect them), not only for the sake of something which results from the process of participation after it has finished (for example certain kinds of decisions).

Shaping the will of the people as an instruction for representatives (see Chapter 3 ) is therefore only one part of political life. The realization of this will, by the people themselves, is another part. Only then do we have a political life in the broad definition of the word. Political life according to this definition adds some important values to those dready guaranteed by political life according to the limited definition given in the previous Chapter.

Not only public life in general, but also political life as a part of it, is something valuable for human life and is therefore a justification of democracy. The ancient Greeks even considered political life as the essence of human life, as something that corresponds to the nature of man. Man, in their eyes, is a creature destined for political life, a 'zoôn politikon'. 'H e who is without city (...) is either a poor sort of being, or a being higher than man. (...) The man who is isolated, who is unable to share in the ben efits of political association, or has no need to share because he is already self-sufficient, is no part of the city, and must therefore be either a beast or a god. There is therefore a natural impulse in all men towards an association of this sort' (A ristotle 1998:10-11). Although this is perhaps a one-sided view of human life, it is true that democracy is more than a form of government. It is a way of life, the life of the "homo democraticus', the citizen who participates in politics, as directly as possible and as much as possible, in order to guarantee some of the things which he or she deems important.

The importance of political life shows how foolish it is to reduce democracy to a system in which people can give or take away the consent to be ruled. A form of government that only allows the people to express or withhold consent can never be called a democracy. A dictatorship can also rule with the consent of the people, can realize the will of the people and can collapse once this consent disappears. A democracy is more than just an elegant and peaceful way to change the rulers. It is also a society which can determine the rules for and the conditions of its own life. It gives people control over their own fate and at the same time guarantees some other fundamental values.

\section{$\S 69:$ The Separation Between State and Society (2)}

Democracy in general - the power of the people - and political life in particular seem to eliminate the difference between society and the state. This can be dangerous because it can allow the state to extend at the expense of freedom in society. However, the fact that the people have political power and are active in politics does not mean that the difference between the people and the state disappears. The state (the institutions, the administration, the government machinery etc.) and politics are not the same thing. Political activity is not necessarily state activity. The state, of course, engages in politics, but so does the whole of society. Politics is what happens in the government machinery, but it is also what happens in society. It is not a separate sphere of life, as in the case of science for example. Politics is everyone's business. On the other hand, if we separate politics and 
the state too much, we run the risk of making the administration and the bureaucracy too independent and therefore too powerful.

However, there still remains a separation between power and society, at least in an indirect democracy. The people - society - do not have the power to do things. They only have the power to control and to correct. There is a space of discussion that is regarded as outside of power. Those who have power are supposed to listen to it and maybe also participate in it (Taylor 1996:96). However, it remains separated from power and can only function well without the participation of power. Of course, the result of these discussions forces power in a certain direction and the same discussions take place in the real $\mathrm{m}$ of power (in parliament, in political parties etc.). In this sense, the separation is not absolute.

In a direct democracy, the separation between power on the one hand and on the other hand a place of discussion outside of power where it is decided what those in power should do, has disappeared. The discussions are held by the same people who take decisions and who have the power to do things. The difference between discussions inside and outside of the domain of power has lost its meaning, just as has the concept of a space of power. The entire society is a space of power. 'W hat is central democratic government but civil society organized for common action? Government is civil society's common arm, just as civil society is government's retraining hand' (Barber 1998).

In an indirect democracy, the people have a will and order certain other persons to execute this will. In a direct democracy, on the other hand, the people have a will and execute it themselves. This is the source of a well-known objection to direct democracy. Pulling power out of its circumscribed sphere and placing it in society as a whole may cause power, politics and the state to infiltrate the whole of society. A broad definition of politics can incite those in power - be they individuals or the majority of the people - to increase their control over life in society, with 'big government' and infringements of civil liberties as a consequence.

However, I do not believe that this is a real threat. As I have shown in Section 5, it is impossible to have an ideal democracy that violates civil rights, the principle of the rule of law and the separation of state and society. Anyway, it is clear that the objection is based on an erroneous conflation of state and politics. If politics is a feature of society - the will of the people and the decisions of the people are political matters - and if everything can become something political, then it does not follow that the state infiltrates every section of life. Nobody, the state and the participating majority included, can infiltrate people's protected spaces (protected by human rights). These spaces, by the way, can be private as well as public spaces (see Chapter 2). This means that some issues cannot be the objects of political decisions. Decisions which violate human rights and encroach on the free space of individuals and groups are prohibited, even if these decisions come from the people. Of course, this free space is not unlimited and outside of it there is an unlimited number of issues which are legitimate objects of political decisions. There are no 'natural' political issues. If there were, it would be impossible to add new kinds of problems to the political agenda.

This brings us to another problem. Because direct democracy eliminates the difference between citizens and politics, it can happen that the citizens become unable to recognize dictatorial measures taken by the majority of the people. The dictatorship of the majority - a very important problem for the theory of democracy and therefore the object of a separate Chapter in Part 5 - damages the interests of the minority in unacceptable ways. It is a problem that has to be solved, but some solutions are as unacceptable as the problem. Giving up democracy is obviously a solution, but it is also unacceptable and unnecessary. Maintaining democracy and creating a certain distance between citizens and politics (for example by way of representation) is another solution, less unacceptable. This distance makes it possible for the citizens to recognize democratic despotism. It is indeed difficult to see what you are looking at when you are standing against it. Continuous and intense involvement in politics can hinder a correct evaluation of politics. A certain kind 
of indifference imposed by restrictions on direct democracy may be a solution. I will discuss other solutions in Part 5. 


\title{
Chapter 5: Humanity (Universality Because of Equality)
}

\author{
$\checkmark$ \\ Section 10: Equal Values \\ $\S 70: \quad N$ atural Rights
}

Because public and political life guarantees a number of universally important values and because human rights and democracy protect this kind of life, it is safe to say that human rights and democracy are also universally important values. If everybody is to enjoy the benefits of public and political life, then human rights and democracy should be applied and respected universally. Public life, political life, human rights and democracy are necessary for the realization of a number of values that are important for human life as such, wherever it is situated. Therefore we can say that human rights, including democratic rights, are rights which belong to humanity, just as the values they protect belong to humanity. If human rights belong to humanity, then they can never be taken away, whatever happens at the political or legal level. In other words, they are inalienable rights. Of course, the fact that rights cannot be taken away does not mean that they cannot be violated. People who are tortured still have the right not to be tortured.

Since human rights belong to humanity, all flagrant and structural violations of human rights are crimes against humanity. These violations attack a part of humanity (they attack certain values that are a part of humanity), a part sufficiently important to label an attack on this part an attack on humanity. Incidental violations of one particular human right do not necessarily make it impossible for the victim to realize the values which are protected by human rights and which are a part of humanity, and are therefore not crimes against humanity (although it can happen that they make it impossible; an incidental violation of the right to life, for example, makes it impossible for the victim to realize all kinds of values). These conclusions may or may not be accepted in legal theory. The point is that I believe they should be.

Human rights are not only inalienable rights but also natural rights (as opposed to legal rights), because they are independent from politics, law and other institutions. Human rights are not situated at a political or cultural level, but at a natural level. They belong to all members of a natural species, namely the species of human beings, even if they are not legally recognized. All members of the human species, independently of political or cultural associations, share certain values - in the same way as they share certain biological characteristics, for example the ability to walk on two feet - and should therefore also share the mechanisms necessary to protect these values. A human being does not have human rights because he or she happens to be a citizen of a certain state, a member of a certain class or culture or whatever. He or she has human rights because of his or her humanity and because of the values one can associate with humanity. Since being human means having certain values, one can say that every human being, for no other reason than being human, has rights, independently of race, culture, class, state, agreements, laws or whatever. Each man or woman is entitled to human rights by virtue of being born a human being (the word 'natural' comes from the Latin word 'nasci' which means 'being born'), not by virtue of the body politic, the social group or whatever category he or she belongs to. 
That is why human rights are universal and unconditional. If you have rights for no other reason than being human, then all human beings have these rights. Constitutions, declarations, treaties or laws do not grant rights and are not conditions for the existence of rights; they only declare and protect rights and make them enforceable. It is not the existence of but the respect for rights that is dependent on human creativity and human artifacts such as the state, the law, the judicial system etc. The existence as well as the meaning and content of rights is a consequence of humanity.

By realizing the values I mentioned, human rights make life and humanity a better and more valuable thing. ' [T] here is both a constructive interaction between moral vision and political reality and a constructive interaction between the individual and society (especially the state), which shape [one] another through the practice of human rights. The limits and require ments of state action are set by human nature and the rights it grounds, but the state and society, guided by human rights, play a major role in creating (or realizing) that nature. (...) Human rights point beyond actual conditions of existence; they are less about the way that people are, in the sense of what has al ready been realized, then about how people might live, a possibility that is viewed as a deeper moral reality. (...) The relationship between human nature, human rights, and political society is therefore 'dialectical'. Human rights shape political society, so as to shape human beings, so as to realize the possibilities of human nature, which provided the basis for these rights in the first place' (Donnelly 1996:18-9).

What is called 'human nature' in this citation can be understood in a minimalist way so as to be equivalent to the human values that I use as a justification for human rights. As the concept of human nature is a notoriously difficult one, I shall avoid using it as a basis for human rights.

\section{§ 71: The Right to Belong to H umanity}

If a person has rights because of his or her humanity, then it is important to recognize the right to belong to humanity. The only legitimate way to violate human rights is to exclude people from humanity and to label them members of another and inferior species. As a consequence, these people cannot claim their human rights. The right to belong to humanity is indirectly expressed in art. 6 of the UDHR: 'Everyone has the right to recognition everywhere as a person before the law'. The right to belong to humanity is the same thing as the right to have rights (Arendt 1979:298), because you can only claim to have human rights when you are recognized as belonging to humanity.

Every culture has, at some moment in time, excluded certain classes of humans from humanity. Some cultures still do. Some of the major religions have considered or still consider non-believers to be an inferior species, outside of humanity, not real humans and therefore not entitled to the same rights. Hurting these creatures is or was not considered to be a violation of their rights because they do not have rights, or because they have fewer rights.

Using the concept of humanity and using values typical of humanity and shared by all or most human beings, is not the same thing as denying difference I would be contradicting myself if this were the case. Difference is after all one of the goals of public life and human rights. Everybody is and should be different. Individual and group identity is one of the important and universal values protected by human rights. My reluctance to use the concept of human nature is based on this fact.

The word 'humanity' is, however, unavoidable in a discussion on human rights, and this word automatically negates differences. To avoid the same difficulties as those $\mathrm{t}-$ tached to the concept of human nature, I have chosen not to define the word 'humanity'. I have merely pointed out some, but not all, common characteristics, namely those common values that can justify the universal application of democracy and human rights. Whereas the existence of human nature is a matter of legitimate dispute (does man have an essenceor a character he shares with all other men, and can we define what it means to be a man, or is man what he makes of himself?), this is not the case for humanity. Hu- 
manity exists. Men are not lizards. Humanity is a clearly recognizable and distinct biological species with certain common characteristics, some of which cannot be found in other species. And there is no reason to assume that these common characteristics are limited to biological ones. 
Section 11: Legal Rights

\section{$\S 72:$ The Legal Person}

Human rights are at the same time independent from and dependent on the state. They exist before or above the state and at the same time they can only exist in the state. First of all, they are in sich selbst geltende Normen, welche vor und über jedem politischen Sein gelten, weil sie richtig und vernünftig sind und daher ohne Rücksicht auf die seinsmässige, d.h. positiv-rechtliche Wirklichkeit ein echtes Sollen enthalten' (Schmitt 1993:8-9). Human rights exist before and above the state; they are not given by the state and cannot be taken away by the state. The state can of course violate them, but violating rights does not make them disappear. On the contrary, this makes them all the more real, not necessarily real in a legal sense - rights can be violated by the law - but in a moral sense. When rights are not violated, they retreat to the background, they are not even noticed and they become, in a certain sense, unreal.

However, the role of natural rights in moral claims, important as it is, is not enough. Our natural rights are not very useful at any level other than that of moral claims. Only the state, by way of the constitution, the laws, the judges and the police can effectively guarantee human rights and can enforce them with a good chance of success (something which cannot be said of moral claims; power is often more successful than persuasion). We can enforce and therefore enjoy our natural rights only because the state gives everybody a legal personality - a legal person is an entity subject to the law and holding legal rights and duties enforceable by a judge - on top of everybody's natural personality (the latter is the basis of the common values used as a justification of human rights).

The state gives a tangible reality to our rights because it translates our natural rights into legal rights which can be enforced by an executive and a judicial power. We are not only natural individuals or specimen of a natural species, but also citizens of a state. If we are not recognized as citizens or if we do not have a legal personality - as for example slaves - then we are outside of the range and the protection of the law. We do have rights - we are human after all - but the law does not recognize our rights and, as a consequence, we cannot claim our rights in a legal way. We can only claim them in a moral way and we cannot enforce them, except when we can persuade people of when we are strong enough to use force. ' [I]t is not the natural Ego which enters a court of law. It is a right-and-duty-bearing person, created by the law, which appears before the law. (...) the persona, in its original theatrical sense, was the mask affixed to the actor's face by the exigencies of the play; hence, it meant metaphorically the 'person', which the law of the land can affix to individuals as well as to groups and corporations' (Arendt 1990:107).

Without 'the protecting mask of a legal personality' (Arendt 1990:108), without legal rights and without our citizenship, our natural rights are incomplete and fragile, but they do exist. Without natural rights we would only have legal rights, or the rights which the laws would grant us. There would be no independent standard to judge legal rights. Rights are indeed the children of law (from law come rights), but it is equally true to say that the law is the child of rights because the law serves the protection of rights. The state and the legal person are instruments to protect, enforce and realize human rights (they are of course not the only instruments; international law for example is another one). The 
rights of man are always the 'rights of an Englishman'. The survivors of the extermination camps, the inmates of concentration and internment camps, and even the comparatively happy stateless people could see (...) that the abstract nakedness of being nothing but human was their greatest danger' (A rendt 1979:300).

That is why it is worthwhile to protect the state. A number of relatively recent phe nomena (such as economic globalization, international flight of capital, international crime, ecological problems etc.) limit the power and the resources of the state. This can lead to a situation in which the laws are powerless and human rights ineffective. Of course, the state must not be protected in all cases. A powerful state can be as much of a threat to human rights as a powerless state. Only a certain kind of state, a state respectful of human rights - and this can only be a democracy as I have shown in Section 5 - is worthy of protection.

\section{§73: Positivism}

Natural rights are not guaranteed or enforced by nature, but by the state and the law ('point de droit sans D roit'). Natural rights require legal rights. However, when the state does not guarantee human rights, it is important that they exist independently from the state, because only then can the people appeal to the state to give them what belongs to them on account of their humanity. Human rights are particularly important in these cases. It has to be possible to claim human rights when they are not recognized legally or politically, because then they are most in danger (Donnelly 1996:13). The difference between legal and natural rights has to be maintained, because both types of rights are equally important. Natural rights are available when we have no legal rights. If we would only have legal rights, we would only have the rights recognized by the law, and the law may be insufficient, depending on how and by whom it is established. Natural rights are directed towards the government in an attempt to force the government to give us legal rights when they do not exist yet, or even to apply existing legal rights.

If we agree that human beings have rights coming from nature, then we have to reject the theory of positivism. It is wrong to say that the only rights a human being possesses are those given to him or her by the state or the tradition he or she belongs to. Someone's political or legal status in positive law does not say the last word on his or her rights or duties. There are rights outside of the state and these rights can support claims to limit the state or to change the behavior of the state. Of course, as I have shown in Chapter 2, these rights not only limit the state but also become the purpose of and the basis for the actions of the state.

Human rights transcend and precede positive law, but have to be included in it. Positive law should not neglect or contradict human rights. However, if it does, then the citizens for whom the law has not provided or no longer provides human rights can at least invoke their natural rights and claim that the law be changed. Only the existence of a higher law, superior to the laws of the state, can give us the possibility to question positive law, to expose injustices in the shape of the law and to limit and change the actions of the state. Otherwise, something would be wrong only if it opposes the law. We would then be forced to accept the law and the state as being right in every case.

This shows that the higher law, even if it is not always recognized and enforceable in positive law, is of some use. Even if a positive law or an act of government which contradicts the higher law, cannot always be challenged and invalidated in a judicial way which means that the (legal) injustice remains intact - we can still use the higher law to label the positive law or the act of state morally invalid and illegitimate (as opposed to illegal). And this can have some effect. Higher law which is not translated and incorporated into positive law, is not completely useless and is not merely a possibility instead of a reality, although it is certainly true that invoking a right which is merely moral rather than legal, is no guarantee for success. The fact remains that injustice - for example injustice translated into a positive law - can only be recognized as such and counteracted if 
there is a higher law. No law is worth anything if it contradicts the higher law and every law gets its power and authority from the higher law that it is supposed to serve.

The struggle against violations of human rights - whether legal or illegal violations may require a revolution or a war of independence, although sometimes, rhetorical or moral claims of higher law will suffice to change the behavior of the state (legal or nonlegal behavior). In an ideal democracy, a court procedure is enough. A democratic state can correct itself because it functions on the basis of the separation of powers. Rhetoric is not even necessary. The judge uses the higher law against the legislator or the executive and forces the law or the actions of the executive to be in accordance with the higher law. Of course, this means that the higher law has then become part of positive law, usually in the constitution, a device which allows us to keep the difference between higher and lower law within positive law. Compared to struggle and persuasion, this is the highest degree of efficiency which the higher law can possess. Rights can only be enjoyed in a complete and predictable way if they are part of positive law. In every other situation, they can only be enforced by way of moral claims or physical struggle, and hence they are fragile if we are lucky and mere wishes if we are less fortunate.

The state, although it does not grant rights, has to recognize them and make them real. A constitution is the main instrument for recognizing human rights, and thus we see that many constitutions explicitly guarantee rights for humans, and not merely rights for citizens. Everybody within the territory of the state, not only the citizens of the state, can then enjoy the human rights protected by the constitution, precisely because the word 'human' rights is used in the constitution. Citizens as well as non-citizens can then go to court and challenge unjust laws or acts of state.

Many democratic constitutions protect the rights of all humans as human beings - at least those present on the territory - and not just the rights of the citizens. The legal rights included in the constitution refer to natural rights as their origin because they are general norms addressing themselves to all human beings, except of course those human beings outside of the territory and the jurisdiction of the state. It would be difficult to try to protect the rights of people one cannot protect because they are too far away, because this is the responsibility of their own state or because doing so would mean intervening in the business of other states and risking conflict in the process. However, some state attempt to do this. In Belgium, some Palestinians victims of the Sabra and Chatilla massacre have started court proceedings against Israeli PM Ariel Sharon, on the basis of a law against crimes against humanity. Belgium is, of course, unable to prevent future massacres of the same kind, and probably also unable to punish Sharon if he is found guilty, but a verdict would not be entirely useless because it would be a signal that humanity does not remain silent. A state could also use non-legal actions, such as international pressure or development aid, in order to attempt to enforce the rights of people outside of its territory. A national judicial system for local purposes and used in aid of citizens or people who happen to be on its territory, is not the only instrument a state can use to enforce rights.

I will show in the next paragraph that the constitutional universality of rights - not to be confused with the moral universality - is not a rule for all types of rights. Political rights for example are an exception because these rights are legitimately reserved for citizens only. I will now explain why.

\section{§74: The Exception of Political Rights}

A democratic state guarantees the freedom rights of all persons within its territory, irre spective of their nationality. This group of persons includes of course the citizens of the state (those people having acquired the nationality of the state by birth, naturalization etc.), but also immigrants, refugees, stateless people, visitors, tourists etc. The state is an instrument of the law and not an instrument of the nation or the nationality (A rendt 1979:230). The nation is not more important than the law. The ICCPR states the following: 'Each State Party to the present Covenant undertakes to respect and to ensure to all indi- 
viduals within its territory and subject to its jurisdiction the rights recognized in the present Covenant, without distinction of any kind, such as race, colour, sex, language, religion, political or other opinion, national or social origin, property, birth or other status'.

Although political rights are also part of the ICCPR, I think it is fair to claim that they may be excluded from this rule and that their use may be limited to citizens. Furthermore, it must be possible to grant citizenship and the political rights connected to it in a selective way, and this is also what happens in reality. I think there are four good reasons for doing so:

(1) A definition of citizenship purely based on the physical presence within a territory would be too vague. People would enter and leave the community of citizens all of the time and this would create permanent modifications in the image and identity of the political unity (or the political community). This would endanger the stability and the permanence of the state and would allow passing residents to help shape the future of people with whom they have nothing in common. It would therefore be contrary to the ideal of self-control and self-government, an ideal which I believe to be universally accepted.

(2) Political rights and citizenship cannot be exercised effectively if the people do not speak a common language (not necessarily their native language). There is no persuasion without mutual understanding and there is no common will without persuasion. On top of that, the effective use of political rights requires that the participants in political life know the political system and the political culture in which they participate. There is even a case to be made for knowledge of general cultural customs as a requirement for granting political rights. All these conditions for the effective use of political rights and hence for citizenship and nationality, seem to imply a further condition, namely a certain stability of residence. It is therefore normal to decide a request for naturalization on the basis of these conditions. However, these conditions do not imply the rejection of multiculturalism. The common language does not have to be the native language and you can know and practice other political and cultural customs without denying your own customs.

(3) Non-citizens usually do not pay taxes. As political decisions often deal with the way in which tax-money should be spent, it seems fair to exclude those who do not contribute to that sum of money. Why should you be allowed to decide what is done with someone else's money? Let alone spend it for your own purposes?

(4) If a country allows too many people to become its citizens, it can endanger its economic prosperity, especially when the majority of these people are poor and unskilled. This is not egoism. Economic ruin does not help anybody.

These four reasons are all based on human rights. Reason (1) limits the political rights of passing residents for the sake of the political rights of the permanent residents. Reason (2) deals with the impossibility of political rights when certain kinds of knowledge are absent. Reason (3) limits political rights for the sake of the right to property, and reason (4) for the sake of economic rights. Limiting political rights (or limiting rights tout court) can only be done when these rights are impossible because of the absence of certain prerequisites, or when they endanger other rights. Other reasons for limiting political rights - for example supposed threats to the cultural identity - do not seem to be legitimate or justifiable.

Something comparable can be said of economic rights. These rights can also be granted in a limited way, although the limits are less stringent than in the case of political rights. Non-citizens who have acquired stable residence as well as non-citizens who have not but are clearly in need, have an equally valid claim to enjoy economic rights. However, it seems preposterous to allow tourists, other weal thy visitors or even less fortunate passersby to enjoy social security for example. Just as in the case of political rights, non-citizens can only enjoy economic rights under certain conditions, although in the latter case there are fewer conditions. Only freedom rights are universal and come with no strings t- 
tached. Citizens and non-citizens al ike have freedom rights. Freedom rights are the rights of everybody in all places. All other types of rights are to some extent national rights or rights of citizens only. This does not contradict the principle of the universality of human rights because everybody is a citizen somewhere, or rather, everybody has a right to be a citizen of his or her own state. I will come back to this in a moment.

Because everybody is not always or cannot al ways be in his or her own state, and because political and economic rights are necessary for some important human values which means the values of non-citizens as well - we should try to limit the conditions for the enjoyment of these rights by non-citizens to what is absolutely necessary. Aliens who know the language, the political system and the general culture, who pay taxes and who have lived a certain time in the country should be allowed to enjoy political and economic rights, even when they are not citizens in the sense of having acquired the nationality of the country. Not doing so would be discrimination, would lead to frustration and resentment and would lead to the very problems reason (1) mentioned above is framed to avoid.

\section{$\S 75: \quad$ The Right to Citizenship}

However, even if we limit preconditions to what is absolutely necessary, we will never be able to allow everybody to enjoy all political and economic rights in all states, which would be ludicrous anyway. It is nonsense to try to participate in the common life of every nation or to try to enjoy social security in every state simultaneously. Participation and enjoyment of public benefits in one state is enough for everyone. This, however, pre supposes the existence of a right to nationality or citizenship. Every person should have the right to be a citizen of his or her state. This would make it easier to accept restrictions on political and economic rights in other states (see the UDHR, art. 15). A gain, these restrictions do not in anyway contradict the principle of the universality of human rights. Everybody possesses all human rights, but not all human rights in all places.

The right to belong to humanity is not enough. I also have the right to belong to a state. Being human and nothing else can be quite dangerous because it means giving up the power to enforce my rights, and in particular my political and economic rights. My nationality or citizenship, or the recognition by a state of me as one of its citizens, is of the greatest importance for all my human rights other than my freedom rights. It gives me the possibility to enjoy public benefits if necessary and to participate in the government of my country and, if need be, to enforce these benefits and this participation in a court of justice (I do not have to be a citizen of a certain country in order to be able to enforce my freedom rights in that country, at least if it is a democratic country).

The right to citizenship implies that my state cannot take away my citizenship or my nationality. It cannot make me a stateless person because that would mean taking away my political and economic rights, and probably also my freedom rights, albeit indirectly. All types of human rights are connected, and the loss of one type inevitably means the loss of all other types. As a stateless person, I also run the risk of deportation, of being banned from my home and my country. The possibility of going to another country as a refugee - even if I am not deported - and of enjoying my freedom rights in that country in a democratic state this is a fact, not a possibility - may not make up for the loss of my home.

I can, of course, whether I am a stateless person or not, try to acquire citizenship or nationality in another country, where I then also (re)establish my political and economic rights. If I fulfill certain conditions - the four mentioned above - this other state must grant me citizenship (however, I am not aware of a recognized right to naturalization; there is a right to change nationality - UDHR art. 15 - but it is not clear whether the latter includes the former). This may be acceptable from the point of view of the refugee or deportee. Loosing my home may be a price I am willing to pay for the protection of my rights. What can also make it acceptable is that changing my nationality does not mean 
changing my culture. Learning a language does not mean forgetting another one. And the four conditions for the granting of citizenship do not include the requirement to change religion or ideology.

Strangers seeking to acquire a nationality do not have to assimilate. On the contrary, human rights explicitly protect cultural identity and diversity. People have to be accepted in other societies, within certain limits. The surface of the earth is limited and we have to tolerate other people in our neighborhood. It seems true to say that the earth is everybody's property and that nobody can claim a certain piece of it at the expense of someone else.

Political rights, and to a lesser degree also economic rights, are mainly rights of citizens. The nazi's knew what they were doing when they took away the nationality and the citizenship of the Jews. Stateless people lose their rights, at first their political rights and after that their other rights, because of the interdependence of rights. Stateless people are pariahs, outcasts without rights, at the mercy of the 'proper citizens', without a place in the world, without a community, without the necessary papers to find a job, without the political power or the representation necessary to claim their rights and so on. These people, as well as other people who are not stateless but whose rights are violated in other ways and who can only escape these violations by fleeing their country, have to be accepted in other countries. They have the right to asylum (which is not the same thing as the right to naturalization) and they should not be returned to the country they are fleeing ('Everyone has the right to seek and to enjoy in other countries asylum from persecution', UDHR, art. 14).

The right to asylum protects people from all violations of rights in their country of origin and, if the country of destination is a democracy, it guarantees the enjoyment of at least their freedom rights in that country. If the asylum seekers are allowed to work in the country of destination - and it is difficult to see why they should not be allowed to work then they will probably also be able to enjoy their economic rights. As a consequence of working, they will pay taxes, they will learn the language and they will consider the option of staying in the country. All this will make it easier for them to apply for naturalization and to (re)acquire their political rights. This is another example of the way in which all types of rights are interconnected.

This leads to the question whether economic refugees should be given asylum. I think they should. Poverty is just as much a violation of human rights as forcing someone to change his or her religion. This does not mean that economic refugees should be able to enjoy social protection the day they arrive. As mentioned above, a state can ask that some conditions be fulfilled before granting social protection. However, unrestricted economic asylum does not seem to be possible. Flooding rich countries with millions or even billions of economic refugees will not help anybody. It will destroy economic welfare in the few places where it exist, without offering any improvement for the disadvantaged.

The right to citizenship and the right to asylum are human rights in the same way as for example the right to free speech. The only difference is that they are second level rights, rights that are necessary to enjoy other rights. Again, the nation is not more important than the law. People should be protected, whatever their origin. Of course, a state is no longer obliged to grant asylum if the applicants are so numerous that accepting all of them would lead to chaos and economic problems in the receiving country. Accepting them anyway would mean sacrificing the rights of the people of the receiving country without being able to do much in favor of the rights of the refugees. It is up to the international community to solve refugee problems. It is unfair to place the burden of accepting refugees on one or a few countries only (often neighboring countries). Besides, combating human rights violations in the country of origin is the best way to solve refugee problems. Most people do not want to flee, so accepting them as refugees is not the best solution from their point of view, even though it is still better than not accepting them.

Public and political life in a state framed for this kind of life, is necessary for the realization of some important values. The loss of citizenship - an official loss or a de facto loss 
as a consequence of deportation or exile - is therefore a threat to these values. That is why there is also a right prohibiting deportation (Everyone has the right to leave any country, including his own, and to return to his country', UDHR, art. 13). This again is a second level right, a right necessary for the enjoyment of all other rights.

\section{§ 76: Humanity and the People}

The national state and its parts (municipalities, regions etc.) are hitherto the only possible stage for democratic political life, mainly because of problems of scale and because of errors in the construction of international institutions. In addition, the state is the best instrument to protect our human rights in general and therefore also our public life. Because of the importance of the state, the simple principle of the equality of all human beings is insufficient. This kind of equality can never be the foundation of a state (Schmitt 1993:226). It eliminates every difference, including the borders between states. And without borders, there is no state. Because we need a state, there has to be some kind of difference between groups of human beings as well as some kind of exclusion of certain groups of human beings (we can, for example, exclude people and hence establish states by $\alpha-$ cluding strangers from the enjoyment of political rights). In addition to the concept of humanity, we need the concept of the people, a people being a part of humanity different from the rest of humanity (not necessarily different in a cultural sense; the wish to live together can be a sufficient cause of difference).

Both concepts, humanity and the people, are equally important for human rights and democracy. Humanity is the justification of universal human rights, including political rights. The people, on the other hand, are the foundation of the state as:

(1) An institution capable of enforcing our rights in general; and

(2) A stage on which a people as a separate group of persons can enjoy their political rights.

The people are a group of persons, a separated and different part of humanity, which excludes outsiders - within the reasonable limits mentioned above - and which creates a state, a political unity of the people, a political system in which the members of the group wish to spend, regulate and control their common lives. Belonging to humanity as an equal and undifferentiated whole is not enough. We have to belong to a people, a limited group of persons wishing to live together under one political system (Schmitt 1993:227). This is dictated by the ideal of democratic self-control.

Human rights and democracy require the division of humanity in different groups or different peoples, but do not stipulate the way in which this division has to be executed. However, they do exclude certain ways. Although it is perfectly legitimate to define a people as a group sharing for example a cultural identity, it would be counterproductive to define different peoples as enemies threatening the identity of one another. This would lead to violations rather than the protection of human rights. Too much attention to cultural identity would also make it less easy to grant nationality to strangers, because granting nationality to strangers can be seen as a threat to the cultural identity. This would also harm rights instead of protecting them. A racist definition of cultural identity is similarly unacceptable. Racism is, by definition, a violation of human rights. A definition of a people as a group sharing certain objective characteristics also harms rights if it forces the people who share the characteristics to live together, even if they wish not to. Many of the wars between France and Germany were caused by the desire of the German state to incorporate German speaking French nationals in the German Reich, even when these people preferred to stay in France. This kind of coercion is of course antidemocratic, and therefore it would be contradictory to use it as a basis of a state. A state is necessary precisely for democracy and human rights. It is of course possible - but not desirable - to use racism, cultural equality, necessity as opposed to will, etc. as founda- 
tions for a people and a state, but it is not possible to use these elements as foundations for a democratic state which respects human rights.

Without the division of humanity in different groups, there can be no state and there fore no human rights (the international community and the international police-force are too weak - if they can be said to exist at all - and too far away in order to be able to protect the rights of humanity). In particular political rights are in danger. However, the other extreme, neglecting the unity of humanity, will also harm human rights. This neglect will not make it impossible to have different states and different peoples, but it will make it very difficult to have democratic states which respect human rights. The division of humanity into different groups is a kind of exclusion. It would impossible to have different groups if all non-members of a group would not be excluded. Making a change of nationality conditional and limiting the enjoyment of political rights to citizens of the state is one way to exclude people. Without this kind of exclusion, there would be no groups, no people, no state, no democracy and no human rights. If everybody can belong to a state, without conditions, then there is no state. However, if the criteria for citizenship are too stringent or not relevant, or if citizenship is categorically denied, then it is impossible to have a democratic state (many residents will then be excluded from selfgovernment) and to respect the human rights of all human beings (people who flee oppression or rights violations will then not be admitted or will, if admitted, be denied citizenship; and people who are denied citizenship lose, in the first instance, their political rights and, consequently, all their other rights, on account of the interdependence of rights). 


\section{Chapter 6: Culture (N on-Universality Because of Inequality)}

$\bullet$

Section 12: The Impossibility and the Undesirability of Rights and Democracy, Version 1

\section{§77: Undesirable}

The universal application of democracy and human rights is justified by the existence of certain universal values. These values can only be realized through public and political life and democracy and human rights protect this kind of life. Those who reject the universality of democracy and human rights often argue that some or all of the prerequisites (or necessary conditions) for democracy and human rights are absent, that a particular nation is not mature enough yet, that the level of economic development is as yet insufficient, or that a particular cultural identity is not adapted to democracy or human rights since it contains other norms and values which deviate from rights and democracy. And they are not entirely wrong. Although democracy and human rights are universally desirable, they are of course not universally possible. There are indeed certain conditions which have to be fulfilled. The fact that democracy and human rights protect certain important and universal values should not make us lose sight of differences in circumstances.

The statement that democracy and human rights should be universal and common to all is obviously not a statement of fact. It is a desire or an ideal and it should be a universal ideal in view of the way in which democracy and human rights protect certain universally cherished values. However, as with all ideals, there are certain obstacles on the way to reality. And in certain places in the world, there are more such obstacles than in other places. These differences should not be obscured by the existence of universal values which are the justification for the universal application of democracy and human rights.

Differences, and especially cultural differences, are often used as an argument against the universal value and the universal application of democracy and human rights. The focus is then not on universal values that are part of the way we are as human beings, wherever we live, but on the values typical of a certain culture and part of the way we are as a people; the focus is not on a universal public and political life as a guarantee for common human values, but on cultural life as a guarantee for cultural values. In this line of argument, there are no common human values or, if there are, they are not important enough. Cultural life is most important. The lives of different cultures are equally important and equally valuable and deserve equal protection and respect. Given the priority of cultural life, there is no need for a universal public and political life or for universal human rights and universal democracy as a means to protect this kind of life.

Instead of protecting universal values such as human rights, we need to protect cultural values and cultural life and we cannot do this by introducing human rights and democracy everywhere in the world. One reason is that human rights and democracy are created to protect certain very specific western values and not the values of all other cultures. They may even contradict or they may require the disappearance of certain cultural values. Respect for culture is therefore incompatible with respect for rights and de mocracy.

A nother reason why we are supposed to reject rights and democracy, is that respect for cultural values means respect for cultural identity. We have to avoid introducing $\alpha$ - 
ternal elements in a culture because doing so may change or harm the identity of the culture. Human rights and democracy are said to be such external elements. They are institutions which belong to certain specific cultures and which are alien to certain other cultures. They are not a natural or logical part of the life of every culture and they do not fit into every culture. Therefore it would be wrong to artificially introduce them in all cultures. Certain countries can legitimately claim that these institutions do not belong to their culture, for example because this culture is based on values such as respect for authority and hierarchy, the importance of duties and social harmony as opposed to the importance of the individual etc. These cultural values are not only different from the socalled universal values used as a justification for human rights and democracy. They also contradict human rights and democracy. Violations of human rights are acceptable in certain cultures simply because these other cultures have other values, different from the values expressed in and protected by human rights. Respect for the different and equivalent cultural identities forces us to avoid introducing human rights and democracy in certain cultures.

The universal application of human rights and democracy is said to be undesirable because this universal application is incompatible with the protection of the diversity of equally valuable cultures, each with their own identity and values. Democracy and human rights as well as the values that they protect, contradict and therefore harm certain cultural values. Universalizing human rights and democracy leads to the disappearance of cultures.

\section{§ 78: Impossible}

Some say that it is not only undesirable but also impossible to introduce human rights and democracy in certain cultures. They simple cannot function everywhere. Each culture has its own institutions and norms which have grown and matured almost organically through time and which are therefore best adapted to the circumstances of the culture in question. Throughout the history or the life process of the cultural group, its institutions, norms and values have been constantly modified in order to fit in with the important facts in the life of the group (such as the national character, the values, the religion and even the climate).

Institutions which are not the product of a society and which are introduced or even imposed from the outside - rights and democracy are said to be the product of the West which has imposed or is still imposing them on the rest of the world - are doomed to fail. Institutions have to be confined to their country of origin because tradition has made them adequate for that country only. Human rights and democracy may function adequately in the West, but this is no reason for transferring them to other cultures. A society's institutions, norms, values, laws and political systems are dependent on the nature of that society (they are, in other words, culturally determined or culturally relative) and are only legitimate, valid and useful when they spring from the cultural life of that society. The usefulness of different institutions for different cultures is a matter of reasonable doubt. Every culture is different and needs different rules.

A consequence of this line of argument is that the law is not an artifact or a human creation. It develops through time and is in a way confirmed by time. Something that has endured for years or even centuries should not be changed overnight. It has proven its usefulness to many generations. We must respect traditions and things that are old.

There is indeed some truth in this, even if all the consequences are not acceptable. The past, continuity, confirmation because of continuity and past experiences, are indeed very valuable things. Traditions incorporate centuries of efforts of many people. However, something is not good just because it is traditional. Traditions and long years of experience can lead to mistakes. It has to be possible to criticize and change traditions. Tradition does not have the monopoly of conferring legitimacy on laws, institutions and the like. On top of that, I do not see why democracy and human rights on the one hand and 
traditions on the other hand cannot live side by side. Most traditions, also those of nonwestern countries, are compatible with democracy and are not violations of human rights. It is not fair to label democracy and human rights as anti-traditional, although some traditions are undoubtedly incompatible with democracy and rights.

\section{§ 79: A-Cultural Rights}

These fears are of course understandable. Different cultural identities have often been damaged beyond repair by, for example, colonialism. Especially non-western countries have been forced to introduce alien structures, ideas and norms. This is still happening today in some places, although in a more subtle way. However, those who say that the people preaching the universal value of democracy and human rights commit the same error have forgotten a few important facts. Democracy and human rights are not a part of one culture that is imposed on other cultures; they are not something which is typical of one culture or exclusively connected to one culture, and they are not something which is totally alien to the identity, or better the identities, of the rest of humanity. They transcend the level of culture. They belong to everybody because the values they protect be long to everybody. It is impossible to impose something on someone if that something already belongs to them. Human rights and democracy are never something imposed from the outside. They come from within. They arise out of the inner life of every human. They are part of every human life and not just a part of the cultural life of one particular community.

In any case, it is difficult to see how universal human rights and democracy can harm a cultural identity or the diversity of identities. On the contrary, they are the best instruments to protect identity and diversity (religious liberty, tolerance, freedom etc. all promote diversity). This is one of their justifications as I have shown in the discussion on public life. Cultures do not disappear when democracy and human rights are universally applied and therefore it is wrong to compare this case with the colonial practice of forced assimilation.

Cultures would only disappear under a universal rights regime if they were composed of nothing else but rights violations. Obviously they are not, even though all cultures, including the culture of the West, contain some elements which contradict human rights. However, even the elimination of these few elements is never an attack on a culture as a whole. Culture is above all something which belongs to the inner life (convictions, values etc.) and the inner life is given absolute protection by human rights. From the fact that democracy and human rights transcend the level of culture, does not follow that they necessarily destroy this level. Therefore, I do not see how one can use the cultural argument against human rights or democracy. An attachment to culture should on the contrary lead to an attachment to human rights and democracy.

However, certain elements of a particular culture can indeed be an obstacle for democracy and human rights and may even render them temporarily impossible. A cultural identity can have certain characteristics which make it difficult to accept, apply or maintain democracy and human rights, or which make it difficult to enjoy rights in a permanent and complete manner. The problem is then how to change or eliminate these characteristics and how to create the necessary conditions for democracy and human rights without harming the essence of a cultural identity.

But then again, let us not exaggerate the importance of such characteristics. History has shown that many of the elements of cultures which were or still are considered to be obstacles to or (positively) conditions for human rights and democracy, and which are supposed to make rights and democracy impossible or possible in certain cultures, are in fact nothing of the sort. 'There are numerous examples of countries which do not meet a number of supposed cultural 'preconditions' for democracy, and which nonetheless have managed to achieve a surprisingly high level of democratic stability. The chief example of this is India, which is neither rich and highly industrialized (...), nor nationally integrated, nor Protestant, and 
which nonetheless has been able to sustain an effective working democracy since independence in 1947. A t other times in the past, entire peoples have been written off as culturally unqualified for stable democracy: the Germans and Japanese were said to be hobbled by their authoritarian traditions; Catholicism was held to be an insuperable obstacle to democracy in Spain, Portugal, and any number of Latin A merican countries' (Fukuyama 1992:221).

Many cultures are or were said to be incapable of democracy and of respect for human rights, but it is often this belief which becomes the main obstacle for democracy and human rights in these cultures. 'A certain Russophobia among the Russian elite itself, a deep pessimism in the ability of Soviet citizens to take control of their own lives, and a fatalism about the inevitability of strong state authority, at a certain point become self-fulfilling prophecies' (Fukuyama 1992:376). If a people is labeled incapable of democracy and human rights, then they are put in a situation in which they become unable to get to know democracy and human rights, to practice it and to learn to reap the benefits of it. Then it will indeed be difficult to have a functioning democracy with such a people. N ot cultural identity, but the opinions on cultural identity expressed for example by the ruling elites, are often the major obstacles for democracy and human rights.

It is often a ruling elite who claims that democracy and rights should be rejected in order to protect the cultural identity of the people. The people, when faced with the choice, often choose for democracy and human rights, independently of their culture. In many cases, it is obviously the self-interest of the rulers which causes them to claim that their people are either too immature for democracy, or prefer sacrificing their rights in order to maintain their identity. I will now take a closer look at this hidden agenda.

\section{$\S 80$ : Who Criticizes Rights and D emocracy?}

In most cases, the cultural argument against democracy and human rights, as in fact every other argument, comes from authoritarian rulers and not from the people they rule. I do not systematically deny the honesty of these rulers, but it is clear that in many cases their unexpressed purpose when using the cultural argument, is the defense of their ruling position. The cultural argument is a useful tool to counter criticism of the regime expressed in terms of rights. The rulers evoke the colonial past and play on the western feeling of guilt. Many westerners are afraid to criticize corporal punishment for example, because they want to respect the culture, something their forefathers have never done. And yet, corporal punishment may not be a part or an important part of the culture in question. The rulers claim that it is an important part because then they are allowed to use this kind of punishment for egoistic political purposes. Even a so-called cultural practice that, at first sight, is not useful for political purposes - take for example the case of widow sacrifice - can be used by rulers. If western countries criticize this practice, then the rulers can counter this criticism and thereby turn themselves into the guardians of the culture of the people. They protect the identity against criticism and a request for change coming from the outside, and thus they create a certain kind of legitimacy for themselves. It is an opportunity to show their good side to the people. By accusing the West of meddling and neo-colonialism, the rulers can also stimulate feelings of national pride, of struggle and unity and can use these feelings to their own advantage.

It is very rare that the people themselves express criticism of human rights and democracy. On the contrary, everywhere in the world we see movements and actions for the protection of human rights. Every victim of oppression claims his or her human rights. This may be the best proof of the statement that rights are not the exclusive product of one culture and that they are not imposed on other cultures. Culture is after all what happens at the level of the people, not what happens at the level of the rulers. The people and not their rulers decide what is or is not part of their culture and of their fundamental values. Human rights are not in the first place the object of a debate between East and West or North and South. People all over the world use human rights in their struggles against their own governments. Even though the West sometimes uses human rights as a 
tactical tool to harm enemy regimes, to further western interests or to allow westerners to dictate rules to other people and to consider themselves superior, this is not always the case. It is always dangerous to judge something by the way it is used.

If, however, the people themselves criticize human rights and democracy or if their cultural norms and practices are contrary to human rights and democracy, then there is a problem. This kind of criticism or conflict must be taken seriously and we must see whether and to what degree it can be accepted without diminishing the meaning and importance of rights and democracy. This is the real problem of the incompatibility of culture and rights. I will deal with this problem in one of the following paragraphs.

However, it is safe to assume that in most cases opposition to rights and democracy comes from leaders who act on behalf of their own selfish interests. This kind of opposition is not a weapon of the weak Third World in its struggle with the powerful West. It is a weapon of those in the Third World who are strong against those in the Third World who are weak. Of course, it is not because someone has an egoistic reason for criticizing something, that this criticism is invalid. However, criticizing human rights in order to remain in a situation which allows you to violate these rights, will cloud your judgment and will lead to errors of reasoning. We should not reject off-hand the content of such a criticism, but neither should we forget that the motives behind the criticism can influence the content and can lead to a certain selectivity in the criticism or to certain errors of reasoning that conveniently favor a certain conclusion.

\section{$\S 81:$ Is the Identity a Goal or a M eans?}

The main concern of rulers using the cultural argument, is not culture but self-interest. Human rights and democracy are a threat to their position as rulers and to all the advantages attached to this position. Rejecting human rights and democracy looks like a means to achieve the goal of protecting a cultural identity or the diversity of identities, but in fact it is the other way around. The goal is to reject human rights and democracy, is to be able to violate the rights of the population, and the cultural argument is used as a means to do so with impunity. The elimination of internal diversity (dissidents, contestation, revolt etc.) takes place under the protecting cover of external, cultural diversity. Respect for cultural diversity is a means to justify the non-application and the violation of human rights. The non-application of human rights is not a means to protect cultural diversity. Regime security and the advantages attached to positions of power are often the real motivation for rights violations, while strong rhetoric is used to make people believe that the defense of diversity is the main reason.

The protection of diversity is often an excuse or a pretext for acts which aim at unity, docility, obedience, intolerance, discrimination and the absence of change and criticism. Anti-imperialism can be a cover for tyranny and culture can be a facade for rights violations. It is not cultural identity but regime security which makes democracy and human rights impossible or undesirable. Cultural identity is a convenient and effective excuse for violations of rights (effective because of the feelings of guilt for past colonialism). This makes it particularly difficult for victims to protest against violations of rights, because these violations are said to be part of their culture and their values. Criticizing their state means criticizing themselves. In most cases, however, rights violations are not elements of culture, but convenient elements of government policy used by uprooted and westernized elites who have taken over oppressing colonial structures and who often exaggerate or even invent so-called cultural practices if they feel they can use them. These people are not well placed to be the guardians of culture. There are, of course, authoritarian leaders who honestly try to maintain a cultural identity and who truly believe that some rights violations are necessary to achieve their goal. I will show in the next paragraphs that they are mistaken and that there is no need to violate rights.

In view of these remarks, it is not surprising that the cultural argument has become so popular in recent decades. The theory that there are for example Asian values and Asian 
rules which are different from the values and rules of western societies, is an instrument in the hands of those authoritarian regimes who feel that their legitimacy and security is threatened now that the traditional excuse for authoritarianism - the cold war and the threat of communism - is no longer relevant.

Something similar is happening in China. 'Asian values' such as respect for authority, hard work etc., have become very popular in circles of Chinese rulers. This is rather surprising in view of the fact that the same rulers - at the time when they were still communists - persecuted Confucianism because it was supposed to be a backward philosophy. Now that communism is generally considered to be a backward philosophy, rulers all over the Third World - former communist rulers as well as old allies of the West who were allowed by the West to oppress their people as long as they kept the dominos standing up - are looking for another excuse to violate human rights and another kind of legitimacy for their authoritarian rule. Culture identity (for example Asian values) and economic development (see Part 2) are obvious candidates.

\section{$\S 82:$ I dentity is both a M yth and a Problem}

Identity or tradition, which is supposed to be a reason for not applying human rights and democracy, is in many cases a figment of the imagination, a useful myth created by leaders. A traditional community spirit and a sense of duty towards the community are two values which are said to be typical of oriental societies and which set these societies apart from the individualistic and egoistic West. These values are part of a cultural identity and introducing individual western rights into oriental societies would mean introducing individualism and therefore harming a cultural identity.

In reality, however, we see that many of the oriental societies are as individualistic and egoistic as the West. Let us not forget that some of the most extreme collectivist theories originated in the West (namely nazism and communism). Moreover, it is evident that for example Confucianism has often been manipulated in such a way that only those aspects which justify dictatorship remain. Hence, a culture's own leaders often cause more harm to its cultural identity than the 'imperialistic West'. The so-called identity which the leaders say they protect or reinstate, is a convenient selection or manipulation at best and a fantasy at worst. Take for example the 'traditional courts of justice' reinstated by some A frican dictatorships. These courts are in reality a recent creation used to eliminate political opponents.

The same kind of manipulation of identity can be found in the discussion on Asian values. It is obviously a convenient simplification to say that there is a set of common Asian values, equally present in the whole of Asia. Societies in general, and certainly a 'society' of the size of Asia, are very diverse. The concept of cultural identity obscures the fact that societies consist of different and often even contradictory elements. Before we use a concept like 'Asian values', we should ask ourselves if the word 'Asia' has another meaning than purely geographical one.

The focus on differences between cultures can lead to separation, and this, in my view, is not a good thing. The fact that western colonialism harmed the interests of cultures in order to further its own interests (for example its economic interests but also its religious interests) or harmed these cultures as a consequence of well-meant blunders, makes some people think that they should no longer expect anything from the West. This, together with the often exaggerated exaltation of one's own identity after decades of neglect and disdain, leads to a feeling of self-sufficiency, superiority and closure which can be damaging because it renders positive and beneficial influence impossible. Even the good things of other cultures are rejected because of identity and colonialism. On top of that, voluntary isolation can cause the persistence of certain prejudices. You can only correct your point of view if you know different points of view. It is evident that rejecting influ- 
ence because of the fear of assimilation, can be a useful attitude to protect an identity and the diversity of identities, but it can also impair other values.

Too much attention to identity can cause tyranny. If you wish to reinstate a cultural identity after decades of oppression and colonialism or if you wish to protect it in the face of serious threats, then you will be tempted to incite your people to experience and manifest this identity and to express it in the way they live. You may sincerely believe that every manifestation of pluralism and every deviation from the official cultural ideology is a threat to the identity and a harmful echo of past colonialism. Human rights are also a threat, first of all because they guarantee pluralism and secondly because they come from a foreign culture, a culture moreover which was or still is responsible for colonialism and for the loss of identity. Cultures therefore have every reason to keep away from human rights. The uniform experience of identity is all that counts. Asian values for example can become the basis of a new orthodoxy. Every deviation from these values becomes a deviation from an official ideology considered to be necessary for the protection of a cultural identity. After all, serious threats justify harsh measures. Deviating opinions or ways of life are considered to be a 'fifth column' of the western imperialists, accomplices in cultural murder. Cultural identity can be a threat to human rights in different ways, directly because of its content and indirectly because of the use some people make of the concept.

\section{$\S$ 83: Contradictions in the Ideology of Culture and Identity}

Those who reject human rights and democracy make use of human rights. The nonapplication of human rights is justified with the help of human rights (for example the freedom of expression and the right to self-government and self-determination). The the ory that oppressed people are forced to use the conceptual weapons of their oppressors because the terms of the discussion are determined by the oppressors, is a feeble excuse for a glaring contradiction.

And there are many other contradictions. If cultural values are so important to people, if people automatically and unconsciously accept the values of their culture through the process of education, and if, therefore, these values become self-evident parts of a people's identity - which is precisely the reason why we should protect these values (identity is important) - then how do we explain the claim that a nation which is said to respect authority, needs a strong state? If, for example, the Asian societies are as disciplined, harmonious, focused on the general interest and respectful of authority and hierarchy as is stated by the ideology of culture, then why do they need authoritarian states? Is it not this kind of society in particular which can accommodate a large degree of freedom?

If poverty and oppression are said to be accepted because acceptance is part of the mentality of a culture, then how does one explain the regular uprisings even in situations of fear and oppression? How does one reconcile the existence of strong family ties and strong national ties within the same people? Strong family ties seem to imply strong national divisions. How does one reconcile the protection of ancient values such as family ties (as opposed to modern values such as individualism) and the one-child-policy in China? Or are traditions only important when they are useful?

If A sian values are good for economic development - see Part 2 - then why has economic development started only in recent decades, if it has started at all (not all Asian countries have had economic success)? If the West must respect diversity, then why do some Asians propose the 'Asian model' for the ailing western societies and why do authoritarian states outside of the West not respect the diversity within their cultures? If one promotes the so-called Asian values, for example in the form of Confucianism, can this not be a threat to the plurality of existing local customs which often have little to do with Confucianism? It happens that governments, while trying to maintain a cultural identity, effectively impose this identity on the whole people, as a kind of national ideology, even those people who have other identities and customs. Criticism of injustices done to cultural identities should not be taken seriously when coming from authoritarian 
states. For them, identity and diversity are exclusively for external use. This is shown by the fact that those who lament the harmful consequences of individualism are often the first to fill their pockets with the proceeds of corruption and national riches.

Those who wish to protect cultural identity are often the same people as those who want to boost economic development, often at any price. The problem is that culture suffers more from economic development than from human rights or democracy. Industrialization, urbanization, economic exploitation of the rain forests and other consequences of development often cause the destruction of local communities. Human rights and democracy are rejected because of the unwillingness to westernize, but technology, industry, science, luxury cars, teargas, arms and so on are readily accepted, often with much graver consequences for culture. This kind of selectivity is inconsistent.

The question is, of course, why we should attach any importance to an argument packed with contradictions and inconsistencies. One will probably respond by saying that avoiding contradictions is typical of western rationality and should not be transposed to other cultures. But this is desperation rather than argumentation.

\section{§ 84: Individuals A re Allowed to Criticize, but Do N ot; States Criticize but A re $\mathrm{N}$ ot $\mathrm{A}$ llowed to}

Victims of human rights violations never use the argument of cultural identity to justify these violations. However, violators do. Some distrust of the validity of the argument is therefore not out of place. If human rights were indeed western rights, then it would be natural to see the victims of violations protesting against the universal application of these rights (Baehr 1991:7). Of course, the opposite is true. A ppeals for human rights as well as victims of rights violations are as much a part of a culture as the perpetrators who use a culture in order to justify violations. Maybe even more so because it is the people who constitute a culture, not the rulers.

It is not up to states to decide what belongs to a culture and what is 'alien'. Only the people themselves can decide this, because it is they who are the culture. But if the people decide, then we already think in a democratic way. So it is self-contradictory to use the cultural argument against democracy and human rights. It is never a culture which says that human rights are alien. Such claims are only made by those who have designated themselves as the representatives of the culture but who in fact represent nobody. They only represent themselves and cannot speak in the name of a culture.

It is rather odd to see states invoking cultural identity. States are not a product of local traditions. They are structures imported from the West and taken over by local elites at the moment of independence (De Feyter in De Tavernier 1998:51). On top of that, the universal existence of the state can be another argument for the universal application of human rights. An important function of these rights is the protection of citizens against the state. This can help to solve the supposed problem of the lack of cultural roots of human rights (even supposed problems have to be solved). Even if it were true that nonwestern cultures have never generated human rights because for instance they have never experienced the need to have human rights, then surely today they must have this need. The introduction of the state has changed these cultures in such a way that introducing human rights alongside the state has become inevitable, even if these rights are considered to be 'alien' to these cultures, which is not necessarily true. The same argument holds for the quasi-universal introduction of capitalism and industrialization which are also relatively new phenomena justifying the introduction of human rights as a way to protect people against them. 
A cultural identity can be used to justify almost everything, including some of the worst acts of barbarism. If some kind of cruelty is old and typical, then it is certain to be $\mathrm{m}$ mune to criticism. There are at least two reasons for this. In the first place, a feeling of shame and regret for the attacks on identity during the period of colonialism. Those who claim to protect a cultural identity are allowed to do almost everything because they represent a culture which, after decades of attacks, should not be questioned ever again. Because westerners have never accepted diversity, they now have to accept all of it.

Secondly, culture has become the outstanding and even the only authority, because it is believed that judgments can only be expressed inside a culture and not from within one culture towards another. The latter would be neo-colonialism or cultural imperialism. Judgments are based on values and values differ from culture to culture. Since every culture has its own values, one culture cannot judge another. Cultures can only be judged in the light of their own norms and not in the light of the norms of other cultures. Acts and ideas can only be judged from the standpoint of the value system of the culture in which they take place. A custom for example can only be evaluated in a moral sense once it is placed in the context of all the customs belonging to a particular culture. There can be no discussion on values or criticism of customs between cultures. The values and customs of another culture should be respected unconditionally. Relations between cultures must be value-free. Cultures can only be judged in and by themselves. This not only makes it impossible for one culture to judge another. It also makes universal judgments impossible.

This line of argument is based on two hypotheses: firstly, that all values and norms are linked to and are the product of cultures and that there are no values which transcend the different cultures and which can be used to judge the values and customs of different cultures; and secondly, that the language of human rights is the language of one culture against another or the language of one culture judging another. I have shown that both of these hypotheses are wrong. There are universal values, and human rights and democracy are the language of these values rather than the language of one culture.

If these hypotheses were correct, then there would not be a difference between norms and facts. If there are no norms transcending the different cultures, then the norms which exist - which are a fact - at the local level are the only ones that count. To think of the norms as they should be, can only be done if one takes a higher standpoint than the standpoint of factual norms. N ot taking such a higher standpoint would mean forfeiting the possibility of judging norms and of making them better. Be they good norms or bad norms, they are what matters as long as they exist. They are part of one's culture and of the beautiful diversity we call life, and they should not be questioned.

\section{§ 86: Cultural Relativism and ( $\mathrm{N}$ eo) Colonialism}

The theory of cultural relativism is the most coherent version of the cultural argument and the version most often used by Third World dictators. The theory was originally elaborated on by mainly western anthropologists as a reaction against western colonialism and imperialism. It criticizes the ethnocentric universalism of the expansionist western culture which imposes its values, structures, institutions and religion on the rest of the world. The West tries to recreate every culture according to its own image because it considers its own culture to be better and more developed than the rest. The underdeveloped or 'developing' countries have to be assisted to achieve a higher level. They have to be civilized by the West because the West has the necessary experience; it al ready has gone though the different stages of development.

This 'assistance' used to be colonial occupation, missionary work, crusades or other ways to assimilate other cultures. Nowadays, the West tries to eliminate diversity in more subtle ways. Because the purpose is essentially the same as before - recreating the other cultures in the image of the West as a means to help these other cultures and to protect 
their real interests - the opponents of the West have coined the phrase 'neo-colonialism'. One example of neo-colonialism is the promotion of universal human rights and democracy. Once again, the West is considered to be a pioneer, an avant garde model which is better than the rest and the ideal partner to help non-westerners achieve a higher level of development, legal and political development in this case. The consequences are also the same as before: the disappearance of culture and diversity, people who are uprooted, whose culture is taken away from them and who have another culture imposed on them, no longer in the name of the so-called 'universal ' western religion, but in the name of the so-called 'universal' western rights. Imperialism and the old relations of power and oppression are still intact, al beit in another, more subtle form. Human rights and democracy are used to cover up western intervention and hegemony.

\section{$\S 87$ : W estern Rights}

It is clear that cultural relativism in particular and the people who use the cultural argument in general, do not believe that human rights are universal rights. Human rights are western rights which, as a part of western culture, must exist and must be protected, just like any other culture. However, if these rights are presented as absolute and universal and if they are imposed outside of their region of origin, then they must be stopped because they endanger other cultures. Western values can and should exist only in the West. They cannot and should not be universal. They are not the values of humanity, whatever westerners may think.

Human rights are a western product and belong to the western identity and culture. They are 'culturally relative', related to a culture, typical of that culture and its way of thinking and bound up with its historical experience They can never be a guide for cultures which have a different identity and history. 'From this standpoint [of the distinctiveness or singularity of national and regional political traditions] the supposedly 'universal' human rights can be seen to bear all the hallmarks of their local, Western origin: the el evation of individual freedom above the collective good; of rights above duties; of self-interest above social responsibility; of civil and political liberties above economic and social protection. The assertion of these priorities as universal values may at best be inappropriate to societies with different social and political traditions; at worst it smacks of neo-imperialism' (Beetham 1995:2). Human rights and democracy may be well adapted to the 'values' of the West, but the values, needs and problems of other people require other institutions.

Cultural relativism is therefore a threat to the universality of human rights and democracy. It will do everything to protect the existence of rights and democracy in the West because it will protect the cultural identity of the West, but it will not accept them in the rest of the world (however, in a few moments I will show that it is not possible to protect human rights in one place and to reject them in another place). Only local and traditional norms, values and customs are acceptable and people should respect these local differences as part of a valuable cultural identity instead of criticizing or dictating other cultures from the standpoint of so-called universal norms. This would at best be ineffective because these so-called universal norms are not adapted to the values and the needs of different cultures; at worst it would be harmful to cultural identities because the authentic cultural values would disappear and would often be replaced by 'values' which do more harm than good (such as individualism for example). Cultural relativism maintains that there are no universal values or norms. There is only a large diversity of equivalent local values and norms and the attempt to make some of them universal by imposing them on everybody.

However, I believe that it is possible to show that democracy and human rights are not western rights and that they instead transcend culture, and not only because they protect universal values. We should not forget that the so-called western rights can often be found in other cultures as well (often in a remarkably explicit way) and are often far removed from certain western customs and traditions (e.g. the interference of the Catholic 
church in politics, absolutism, anti-Semitism and so on). Human rights are violated as much in the West as elsewhere, and democracy may be the 'natural' form of government in the West, but only if we use a minimalist definition of the word. Western democracy is often as big a failure as democracy in other parts of the world. Even if it is true that human rights and democracy are a part of western culture, typical of this culture and well adapted to its needs, then we should not forget that western individuals or groups fre quently have to use their rights against their culture. Democracy and human rights are contested and problematic everywhere, in the West as well as in the rest of the world. If human rights and democracy do not coincide with western culture, then exporting human rights and democracy is not the same thing as exporting western culture. The criticism of cultural imperialism is therefore inappropriate.

Severing the link between western culture on the one hand and human rights and democracy on the other hand, will also make westerners aware of the fact that their culture is not better than other cultures and that they should not use human rights to look down upon other cultures. It follows that one of the aims of cultural relativism - the equivalence of all cultures - can only be achieved by regarding human rights and democracy as something which transcends culture and not as something typical of the West.

Nevertheless, the West is said to engage in neo-colonialism or cultural imperialism when it condemns certain practices, values, norms or customs of other cultures (for example mutilation as a punishment for theft, the discrimination of women and nonbelievers etc.) and when it tries to replace local values, norms or customs by its own socalled universal and superior values. The difference with colonialism and imperialism old style is that today the integration or submersion into a larger cultural and moral whole takes place without an accompanying integration into a larger territorial and political whole. Of course, it is much more difficult to impose one's will and one's rules if one does not have political power and moral authority in a territory, but this nicely explains the drive of democratic moralists.

The West continues to suffer from a superiority complex. It still does not respect the different and equivalent cultural identities and it still considers its own norms and values to be better than the rest, to be absolute and general instead of relative and contextdependent. In the opinion of cultural relativists, the West should no longer try to be the standard or the example for the rest of the world. It is only one among many equally valuable cultures. A bit more respect and humility instead of conceit and paternalism would not be out of place, especially given the experience of Auschwitz and the Gulag. It is time for the West to give up its claims of universality and to let other people be. There are other cultural identities which have to be respected even though they contain values, norms and practices contrary to human rights and to the norms of the West.

However, once we accept that human rights and democracy are independent of culture and that promoting human rights and democracy is not the same thing as imposing the culture of the West, then there is no reason to believe that human rights or democracy are a part of western attempts to protect or restore its supremacy, its imperialistic claims on other territories or its feelings of moral superiority. The belief that the culture of the West is more valuable, more modern or better than other cultures is not or should not have to be the motivation behind the universal application of human rights and democracy.

In view of the fact that western countries never applied human rights and democracy in their colonies, are they not inconsistent when they ask the ex-colonies to do so? The West is now imposing what it never conceded in the past. On top of that, it should first try to respect human rights within its own territory, before giving lessons to others. Those who violate or have violated a principle should not impose this principle on others. The problem with this argument is, of course, that a violation of a principle by a proponent of it, does not invalidate the principle. 
$\S 88$ : The Radical Rejection of Democracy and the 'I-Did-It-M y-Way' Syndrome

Cultural relativism claims that democracy is either a political form typical of the West and undesirable or impossible elsewhere, or a political concept which is defined in different ways according to the culture in which it is applied. In the latter case, the western definition is considered to be a eurocentric one which can and should not be imposed outside of the West without taking into account the local, cultural, historical and social circumstances. There should be different models of democracy. The African palaver for example is maybe a less familiar one. The western model is not a panacea and is not adapted to all circumstances. I will discuss both criticisms in turn, starting with the radical rejection of democracy, all models included.

It is said that the different cultures have to remain as they are and have to be able to follow their own path and to organize their societies according to their own views and traditions, and not according to those of the West, even if this means being undemocratic and opposed to human rights. It is not up to the West to decide what is and what is not politically acceptable in countries with entirely different traditions. Democracy is not necessarily better than other forms of government. Every culture has the right to apply its own standards and judgments and can decide freely on its political and legal status. There is therefore only one universal human right left, namely the right to selfdetermination, the right of a nation to do as it likes, to manage its own business, to determine its own fate and way of life without interference and to follow its own morality and traditions.

It is indeed difficult to argue against this, as long as it means that the people of a culture - rather than their rulers - should be allowed to determine their own fate. However, when the people determine their own fate, then we must have some kind of democracy. The option of rejecting democracy altogether seems to be impossible. (In Part 3, I will discuss the contradictions of a people deciding their own fate by rejecting democracy. Such a people in fact decide not to decide their own fate). What is left is the possibility to choose one kind of democracy rather than another. I admit that it is wrong to copy our specifically western view on democracy 'à la lettre' in the rest of the world (the same is true for human rights in general, but I will deal with this problem separately in the Concluding Remarks because it is much more complex). Within certain limits, we have to take local and cultural aspects into consideration and we have to be flexible where we can. These limits, however, are sacred. If cultures were to be allowed to shape their lives and destinies in any way they want, then we would be defending nihilism and a-morality. 'A nything goes' is unacceptable and is in reality never defended in a coherent way.

However, let us briefly return to the problem of flexibility. I agree that the West should for example avoid imposing its specific form of party-democracy on other cultures. It has been shown that a multi-party system can cause problems in Africa for instance. It can reinforce communal or tribal antagonism because the different political parties tend to be formed along the tribal dividing lines. As a consequence, these parties see it as their role to defend the tribal interest and nothing else, and once they are in power they tend to do so by discriminating against other tribes. Political power is often used to settle ancient disputes. Democracy degenerates into an ethnic census in which the largest tribe expects to be in charge of everything, especially when in the past it was excluded from power by a dominant minority tribe.

A certain kind of non-party democracy could be an alternative. It would focus much more on charismatic individuals who are able to transcend tribal divisions. However, let us not fall into the trap of the 'I-did-it-my-way' argument. A so-called 'A frican democracy' or 'Asian democracy' which is said to be a totally different vision of democracy adapted to the needs of the culture in question, is often no more than a smokescreen for the outright rejection of democracy and an attempt to legitimize authoritarian structures. The main lines of the democratic system are not up for grabs. A one-party system, for 
example, can never be called a democracy because it excludes rotation in office There is a limit to the flexibility of words.

Take the 'Asian democracy', for example, which is said to be more communitarian and harmonious and less individualistic and antagonistic than western democracy, more focused on the general interest than on the individual or group interest, more respectful of authority and hierarchy etc. It is easy to see how, in this kind of system, individual rights, contestation of power, rotation in office and therefore also democracy can suffer. We have to find an intermediate position between two extremes. It is not true that we have to choose between either a system which accepts only one kind of democracy or a system in which the nature of democracy is completely determined by culture, traditions and circumstances.

In any case, even if democracy has some difficulties in handling tribalism and communal divisions, it still is the best instrument to deal with these problems. Authoritarianism or 'one-party democracy' is often proposed as a justifiable solution and as the only means to create national unity and to avoid ethnic conflicts. In reality, however, these conflicts and divisions can only be dealt with by a democracy which guarantees the equal rights of every citizen whatever his affiliations, which allows every group to participate equally in the government and which protects the economic rights of everybody so as to avoid unjustifiable differences in wealth. It is precisely the absence of these things and therefore also authoritarianism which causes tribal or communal struggle. Even if a democracy allows a community, which is traditional ly the ruling community, to maintain its position of power because of its numerical superiority, this democracy guarantees that minorities are not oppressed or discriminated against.

\section{§ 89: Rights Limited to the W est are 0 nly Semi-Rights}

Limiting human rights to the West, as asked by cultural relativism, means taking away a large part of their meaning and purpose, even for the people in the West where human rights are said to have a right to exist as a part of a culture. As a westerner, my right to free expression loses much of its meaning if I am not al lowed to communicate freely with someone in China for example. Communicating with someone who is not allowed to speak is pointless. Communication requires openness and therefore requires human rights for both partners. Cultural relativism is not even able to keep its promise that it will defend human rights as a part of western culture.

My rights need the rights of other people. Part of public life takes place at a supranational or transnational level. Its purpose is precisely to transcend borders, because borders inhibit thinking (see Chapter 1). Those engaged in public life should be allowed to speak and listen to everybody, regardless of borders (this is particularly clear in art. 10 of the ECPHR: 'Everyone has the right to freedom of expression. This right shall include freedom to hold opinions and to receive and impart information and ideas without interference by public authority and regardless of frontiers' ). If not, their public life and therefore some of their important values, will suffer. N ot only violations of my own rights, but also violations of the rights of others, harm my interests, at least those interests I seek to protect by way of a public life. My public life suffers not only from violations of my own human rights but also from violations of human rights elsewhere in the world. Universal and equal rights are therefore in everybody's interest. As long as the rights of some are violated, the rights of all are in danger. A violation of human rights is never a purely private or individual matter, directed against one or some persons. It is always and by definition directed against the whole of humanity. This, by the way, is a justification for intervention in countries which violate human rights and is the reason why we can call widespread violations of human rights crimes against humanity.

The objective is to avoid two extremes. Too much attention to the unity of humanity leads to a neglect of the national or cultural community which is important for many reasons (for example political life, personal identity etc.). Cette prétendue infinité que I'on 
voudrait donner à l'homme en détruisant la famille, la cité, la propriété, détruirait l'homme du même coup. (...) [En lui refusant] une communion précise et déterminée avec certains de ses semblables' (P. Leroux in Leleux 1997:189). Focusing too much on humanity, universality and equality can lead to the view that a man's context is unimportant, which is wrong.

However, it is equally dangerous to limit a man to his community, 'sans extension possible'. 'L' homme n' existe pas plus dans le fini resserré et absolument limité que dans I'infini. II a besoin du fini et de l'infini, comme il a besoin de la terre qui est sous ses pieds et du ciel qui est sur sa tête' (ibidem). Man should be able to look further than the length of his nose, to speak to other person, including distant persons. This is the reason why human rights should be recognized in distant places. There has to be a community, but this community can become harmful when it becomes too dominant to it members and too closed. Too many limits is as much of a problem as too few limits.

\section{$\S 90$ : Origin and Effect}

The universality of human rights and democracy is not the same thing as the universality of western culture. Human rights and democracy have indeed originated in the West, at least at long as we only consider their current legal shape because in every culture of the world you can find values which correspond implicitly or even explicitly to some human rights or some democratic practices. It is even true to say that some elements of western culture have determined or promoted the rise of human rights and democracy (for example the State, the A ge of Enlightenment, capitalism, Christianity etc.).

However, their western origin does not make it impossible for human rights and democracy to function outside of the West and does not render them meaningless in other cultures. The origin of something says nothing about its reach or its applicability. The fact that the industrial factory was invented in the West does not diminish its universal usefulness, and neither does the fact that this invention would probably not have been possible without the presence of some specific cultural elements of western society (e.g. capitalism, Protestantism etc.). Elements needed for the creation of something are not necessarily important for its use or functioning. In any case, most of the cultural elements which have contributed to the rise of human rights and democracy in the West have now become part of all cultures.

Since human rights and democracy transcend the level of culture, they also transcend the level of difference They create a global unity, but this unity should not be confused with uniformity or with the disappearance of cultures. On the contrary, it is a unity which makes it possible for diversity to flourish. The best example of this is given by those who use the so-called western rights to attack the great western equalizer and to protect cultural diversity. However, those elements of diversity and culture that violate human rights or democracy cannot be accepted. I will now discuss this topic in greater detail. 
Section 13: Real Diversity

§91: 'Popular' or Truly Cultural Rejection of Human Rights and the Limits
of Identity

The guardians of cultural identity have little to fear. On the contrary, human rights in particular but democracy as well are their most awesome weapons in the struggle for diversity. Instead of rejecting rights and democracy, they should cherish them (in the same way as those who fear diversity and look for means to deal with it in a peaceful way should cherish human rights; see also Part 3). Of course, some parts of some cultural identities will have to give way to human rights. This will happen when the parts in question contradict human rights. Human rights have therefore priority over culture. One reason for this is that identity and diversity need human rights whereas the opposite is not true. However, I admit that a culture, if contemplated in an isolated way, does not act in a self-destructive way, if it does not conform to human rights. Every day, we can see cultures which maintain themselves and which at the same time violate human rights. The problem is that cultures are never isolated. Different cultures often coexist in one and the same country. Human rights are necessary if every one of these cultures is to survive.

There is a right to identity and diversity, but not always or in every case. 'W hile advocating cultural pluralism, those cultural practices which derogate from universally accepted human rights including women's rights must not be tolerated' (The Bangkok NGO Declaration on Human Rights in Beetham 1995:87). 'W hile the significance of national and regional particularities and various historical, cultural and religious backgrounds must be borne in mind, it is the duty of States, regardless of their political, economic and cultural systems to promote and protect all human rights and fundamental freedoms' (Vienna Declaration 1993). We have to respect the diversity of traditions, but not beyond certain limits. And these limits are human rights.

Some parts of some cultures, including the western identity (if there is such a thing), have to give way to human rights. It is impossible that an entire culture has to give way, because a culture is never completely incompatible with human rights. And those who say otherwise, are wrong. ' [W ]e encounter the argument, advanced by some Islamists as much as by many of those hostile to M uslims, that there can be no human rights, no democracy, no rule or law in M uslim societies because of 'Islam' itself. This is an extreme version of what I have (...) termed the 'incompatibility' theory' (F. Halliday in Beetham 1995:164). Cultures never consist entirely of human rights violations, but certain important elements of certain cultures are indeed incompatible with human rights. Maybe even certain elements of all cultures. The West, for example, is no exception.

If elements of a culture - e.g. female circumcision or certain cruel punishments - are condemned, then it is not the culture that is condemned, but only a part of it. It follows that this kind of condemnation does not entail the demand that a culture be given up or changed. The statement that human rights are undesirable because of the threat to identity and diversity is clearly incorrect. Human rights can only be a threat to a part of an identity. The claim that freedom is incompatible with certain cultures because it is a western idea, is both too flattering for the West and an insult to other cultures. 
Is it true that one can refuse to give up those parts of a culture which violate human rights because these violations are an important part of the culture (and, of course, there would be no problem if they were not an important part, because then one could easily give them up). N ow this is strange, at least in the case of some human rights. Is torture a part of and an expression of the cultural identity of Asians for example? Do Asians need to be tortured? Is being tortured part of their identity? Do they suffer less when they are tortured? Only if the answer to these questions is 'yes' can the promotion of universal human rights and the condemnation of rights violations be labeled cultural imperialism. However, this answer comes very close to racism (K. Christie in Beetham 1995:217).

\section{§92: The Relativity of R elativism}

In the previous Section, I have assumed that cultural criticism of human rights and de mocracy is mainly an instrument in the hands of rulers seeking to maintain their rule. In this Section, I deal with a more difficult problem: what do we do when the cultural criticism of human rights and democracy is based on widely shared and popular cultural practices, when even victims often accept these practices (female circumcision is an example, but also discrimination of women, the cast system in India etc.)? How can we respect the diversity and the equality of cultures and at the same time criticize and try to change certain cultural practices in order to make them consistent with human rights and democratic principles? How can we combine pluralism and a common opinion on rights? We should respect and protect identity, culture and diversity as much as possible, but within certain limits determined by the duty to respect human rights and democracy as the only true guardians of identity and diversity. If an element of an identity trespasses these limits and violates human rights or democratic principles, then it must be modified. In all other cases the identity should be considered as a right. And when an identity has to be modified, how do we convince people to change a certain cultural practice?

Relativism stops at a certain moment. (In any case, relativism cannot be absolute without contradicting itself. If no value is better than another, then relativism itself is not better than another point of view. An absolute relativism would betray its own foundation). However, limiting relativism does not mean returning to the days of western supremacy and does not mean judging a culture from the standpoint of another, supposedly superior culture. The standard of judgment is a universal point of view transcending the level of cultures, which is shown by the fact that the culture of the West is also judged and certainly does not always perform better than other cultures when it comes to human rights. We should not bow to the absolute or unconditional plurality and relativity of cultures ('his country, right or wrong').

Of course, if we want to achieve a common opinion on human rights, then we need to engage in dialogue and convince other people, and dialogue requires mutual respect. $A$ lack of respect for other people and for the plurality of cultures will inhibit dialogue and therefore also the universal application of human rights. However, too much respect for plurality will also inhibit the universal application of human rights because it will inhibit the necessary transformation of certain cultural practices. Human rights in a world of diversity would be a nice phrase to sum up the necessity of balancing the two important elements of unity and plurality. Everyone's right to his own culture is conditional upon respect for human rights. The importance of culture does not diminish the duty to respect human rights.

We should, however, avoid overestimating the problem. In general, universal human rights are compatible with cultural diversity and even protect this diversity. However, cultural identities can contain elements which violate human rights. These elements should not be viewed as expressions of a valuable plurality of cultures. A violation of human rights is not justified because it is part of a culture, because it is very old and traditional or because it has become a habit. Customs, practices, laws and acts of state must in the first place conform to human rights, not just to traditions, religions or other ele 
ments of culture. Something is not good simply because it is old or part of an identity. One can never deduce a norm from a fact. Habit and conformism, which we find in all identities, can make many immoral things acceptable. We must be able to criticize and reject old and traditional habits. It is not because in Europe we have anti-Semitism since ages that we have to keep it. Diversity is good and uniformity is bad, but not in an absolute and simplistic sense.

How are we to reconcile universal human rights with those cultures that contain elements contrary to human rights? And can we do so in all cases, without inflicting too much harm on either rights or culture? Stating that human rights should always have priority is not enough. We should not forget that we are dealing with culture in the sense of a popular phenomenon. If the people are not convinced of the importance of human rights, then they will not change their cultural practices.

The reinterpretation of culture is one way to reconcile rights and culture and to make them more compatible. The traditional Islamic misogyny for example can be challenged by using elements from the Islamic tradition itself. People can be reminded of certain less familiar texts emphasizing the equality of the sexes. Other texts can be put into a historical perspective. Today's circumstances may require a different emphasis. Texts can be reinterpreted in a more liberal way. Of course, this does not always work. Some texts simply do not allow for a liberal interpretation and others which do are easily counterbalanced by many less liberal texts. 'The fact remains (...) that with all the reinterpretative energy in the world some of the texts, pertaining to women, non-M uslims, apostates cannot be fudged away and remain. (...) The option of simply rejecting texts is not open, given the claim to divine origin' (F. Halliday in Beetham 1995:164).

The attempt to rephrase human rights in a cultural idiom is another way to reconcile rights and culture. A notable example is the 'U niversal Islamic Declaration of Human Rights' of 1981 in which human rights take on an Islamic vocabulary. This makes it possible to deduce human rights from Islamic traditions. If this works, it can be very successful because it translates human rights into the language of the people. Human rights can only have a real existence if they are respected and applied by the people and if they belong to the fundamental norms and convictions of the people. The problem is that $\mathrm{t}$ tempts like these often result in reduced versions of the body of human rights. In order to accommodate elements of culture which are difficult to harmonize with human rights, one often chooses to restrict human rights instead of cultural practices or norms.

\section{§93: Changing Cultures}

There is only one solution to the problem of incompatibility of rights and (parts of) cultures. Somewhere al ong the line, we have to change cultures and the cultural behavior of people, and we have to do so in a way which respects these cultures. There is nothing wrong with wanting to change cultures. They change anyway. However, if we want to remain consistent with our democratic convictions, then we should not impose such a change from the outside. The people themselves have to decide. (Of course, this is not as straightforward as it seems and I will return to the problem in Part 3 when I discuss the pros and cons of international intervention). We can and must criticize and change traditions. If not, our lives will be limited to the sterile repetition of the past.

However, it is notoriously difficult to change cultures. The cultural argument for example seems to oppose change. How can we change what we have to protect? The fact that cultures are often very old or are believed to be very old, also inhibits change. People believe that something old must have proven its use. After all, if it were useless, it would not have survived for so long. Fortunately, a cultural identity or a tradition is often if not always something artificial. It has been created by man, sometimes in the very recent past, and therefore it can be changed by man.

In the case of female circumcision it might help to organize some kind of information campaign exposing certain prejudices or misunderstandings regarding fertility, hygiene 
etc. or pointing to the fact that neither the Koran nor other Islamic texts prescribe this practice. In addition, one can try to make people conscious of the contradiction between this practice and other values they cherish, such as the right to life and the absence of pain.

Concerning Islam, a big step forward would be to introduce some kind of separation between religion and the state, on the condition that this does not affect the core of the Islamic cultural identity. The state is often used by religion as an instrument to violate human rights (and vice versa). However, even the core of the Islamic cultural identity can and does change. The exact nature of this core is constantly being discussed, as far as discussion is possible of course (Islam provides harsh punishments for heresy and apostasy). Slavery, for example, used to be considered as a part of the core of Islam, but today this is no longer the case.

A separation between religion and the state cannot harm a religious and cultural identity (with the exception of those identities explicitly asking for a link, and this might be the case for Islam depending on who decides on the definition of Islam). The public domain created by such a separation can function according to its own rules and provides enough space for the expression and conservation of a religious identity (of various identities to be correct). This kind of separation does, however, make it more difficult to use the power of the state to impose an identity on others. But then again, this seems to be a good thing from the point of view of both human rights and identities. Culture has to be put in its place. On the other hand, separating the state and society and confining culture to the latter, is not enough. Human rights can be violated in society without the intervention of the state (the Islamic discrimination of women is an example). If a cultural identity still violates human rights after the state and society have been separated, then it may be necessary to change some aspects of this identity.

In Islam, the biggest obstacle to change is the conviction that man cannot change what is given by God. The Koran is considered to be the word of God and some elements of the Koran lead to violations of human rights if applied in a literal sense. However, the Koran and the precepts it contains are not the only basis of Islamic politics. There is also a body of rules destined for everyday life and elaborated on by Muslim scholars on the basis of the Koran in the three centuries following its creation. Together with the rules of the Koran, they form the Shari'a, the holy Muslim law. The Shari'a, although at first sight a human creation - unlike the Koran, it is not the word of Muhammad who was believed to be inspired by God, but an early interpretation of the Koran - is also considered to be of Godly origin. The Koran and the Shari'a are a sufficient basis for the laws of a Muslim country. At best, human rights or other laws can only play a role when they do not contradict the law of God. At worst, the execution of the law of God is the only legitimate role of the state.

The problem is that the Koran as well as the Shari'a often contradict human rights and that changing them is believed to be the same thing as changing the word of God, which is said to be impossible. Human rights advocates can try to convince people that part of the Shari'a is clearly not of Godly origin, not even according to the Muslim faith.

Fortunately, most Muslim states do not or do not completely apply the letter of the Koran and the Shari'a in their laws and acts. They mix certain elements of Islamic traditions with certain elements of western legal traditions as well as local traditions. That is why, in recent decades, Islamist or fundamental ist movements have seen the light of day. These movements wish to see the complete reintroduction of the long neglected laws of the Shari'a and the Koran, although in practice many of the laws of Muslim countries are already inspired by these 'original' precepts. Since many of these existing laws already violate human rights, it is clear that changing them so as to make them more consistent with 'traditional' or correct Islamic practice would only aggravate the human rights situation.

However, not all Muslims agree that the Shari'a is a God-given law adapted to present day needs. 'The term shari' a, literally 'path' or 'way' (...) did not initially denote a legal code at all. The interpretation of (...) divinely sanctioned material, and its elaboration into a set of 
comprehensive legal codes, is known as fiq' (literally 'understanding', hence jurisprudence), and it is this, humanly evolved and variously codified, body of legal material that has come to prevail in M uslim society under the, misapplied, term shari'a. Thus what is today invoked as an unchangeable, and sacred, body of text is, even in Islamic terms, nothing of the sort. A s the Syrian writer Aziz al-A zmeh has written: 'Islamic law is not a code. This is why the frequently heard call for its 'application' is meaningless, most particularly when calls are made for the application of shari'a - this last term does not designate law, but is a general term designating good order (...). Calls for the 'application of Islamic law' have no connection with the M uslim legal tradition built upon multivocality, technical competence and the existence of an executive political authority which controls the legal system. It is a political slogan, not a return to a past reality" (Halliday in Beetham 1995:160). Because the Shari'a is a human artifact and the human interpretation of the word of God, it can be altered by humans.

Traditions are not always as traditional as we are led to believe. Instead of something very old and established, traditions are often recent creations, interpretations or selections adapted to present-day aspirations; they are biased reproductions toncealing contemporary purposes behind the invocation of a time-honoured, and incontestable, continuity' (Halliday in Beetham 1995:162). The claim of transhistorical and established traditional thought is often used to justify contemporary thinking. It is useful to mention this when traditions are used or manipulated in order to be able to violate rights. This will at least eliminate the excuse that violations of rights are old, respectable and part of an ancient culture.

The culture of the West can be an example. It has changed dramatically throughout the centuries and it is still changing today. Many of its supposedly ancient traditions have been adapted or abolished and this has often been very beneficial from the point of view of human rights. Very few westerners wish to return to the practice of slavery, for example, a practice once considered as traditional. Most of them see this change as progress. However, one can only see this as progress and achieve this progress when there is a norm independent of the existing culture. This norm is used to judge existing cultural norms. Because cultural relativism denies the existence of such independent norms, it inhibits progress (Cliteur 1997:56-7). It can only see what is, not what should be.

\section{§ 94: Tolerating Intolerance? (2)}

Cultural relativism urges us to accept and respect other cultures, unconditionally and without exceptions. Every culture, whatever its content, is valuable and should be protected, even if this means giving up certain or all human rights. This means that rejecting intolerance in a certain culture is intolerant and rejecting discrimination is discrimination. Diversity should be tolerated, even if elements of this diversity are expressions of intolerance or discrimination. Otherwise, we would show a lack of respect for cultural identities and we would de facto return to the days of colonization and imperialism.

The problem is, of course, that we can never tolerate intolerance and that we must always discriminate discrimination. One cannot force an idea to be self-destructive. A tolerant system tolerating intolerance or failing to discriminate those who discriminate, will never last very long. Those who are tolerant must be intolerant of those who are intolerant (and the latter include those who attack the institutions protecting tolerance, such as human rights). This has nothing to do with 'an eye for an eye'. It is purely a matter of consistency and self-preservation. We must accept and respect diversity, but not in an unlimited way. There is a fragment of the comic-strip called 'Calvin and H obbes' which neatly summarizes this point: 
Hobbes (thetiger): Do you have any good intentions for the new year?

Calvin (the boy): Certainly not. Look, if you want to improveyourself you have to have an idea of the 'good'. And this entails certain values. However, we know that values are relative. All systems of values are equivalent and we have to tolerate diversity.

Hobbes: I don't know if I want to tolerate this much tolerance.

Calvin: $\quad$ And I refuse to bethe victim of socially adapted behavior.

We now see that cultural relativism, which has a reputation for tolerance, openness and equality, often has the opposite outcome. The least we can say is that cultural relativism is not a sufficient guarantee for tolerance. Without human rights, tolerance remains an individual choice, not enforceable in front of a judge. Furthermore, which person do we tend to tolerate, the one who is totally different and incomparable, or the one in whom we recognize humanity and ourselves? What will lead us away from arrogance and narrow-mindedness? Watching other cultures, learning from them and consequently changing our own practices, or simply accepting the other cultures as totally different and continuing to do what we always do, doing things our own way undisturbed and unaltered, and proud of our identity? Judging our own norms in the light of those of other cultures, or judging every culture, including our own, according to its own norms?

\section{§95: Culture and the Individual}

The past colonial oppression of countless cultures by the imperialist culture of the West has generated such remorse that westerners are now very reluctant to interfere in the socalled internal affairs of other cultures. We hand the individual over to his nation, 'his country, right or wrong'. Individuals lose their rights and cultures have all the rights they want, a right to identity and even a right to oppression on the condition that this oppression is old and traditional and that it belongs to the cultural identity. The right to oppression stands on the same footing as the right to one's own religion or eating practices, because oppression, religion and eating practices are all part of the same identity. Taking away someone's oppression would mean harming his or her interests (Finkielkraut 1989:101-2). Culture is sacred, a long forgotten and cursed God, and the individual is sacrificed on its altar, literally if necessary. Respect for a culture forces us to sacrifice the individual and his rights. For example, a widow who does not wish to be burnt alive to honor her deceased husband is lost if we wish to protect her culture.

If the rights of an individual and the rights of his or her culture contradict each other, then one often chooses the side of culture. It seems that one cannot choose human rights because these rights harm a cultural identity. They are the norms of another culture and they contradict certain aspects of one's own identity. If you want to protect a cultural identity, and if human rights contradict certain elements of this cultural identity, then you must reject human rights. Choosing the individual would also mean choosing western individualism.

However, giving priority to culture seems to imply that cultures can be hurt more than individuals, which is preposterous. Individuals should be considered as holders of rights and not just as expendable parts of a sacred and inviolable culture. A culture is nothing without individuals. It must be possible to use human rights against a culture if necessary, just as it is possible to use human rights in order to protect a cultural against attacks by individuals. An individual has more duties than the duties towards his or her culture or the duty to respect and experience his or her cultural identity rather than harming it. He or she also has duties towards fellow humans. Everything contrary to human rights is unacceptable. 
Of course, one will say that this line of argument implies ranking the individual above the community, that it is again a typically western preference for the individual and for individualism. However, linking the importance of individual human rights (possibly directed against a culture) with a preference for individualism, is too easy. An individual needs a community (cultural or otherwise) and one of the functions and justifications of human rights is precisely the protection of community life (I have shown this in Chapters 1 to 4). This means that a community is there for the individual, and not the other way around. The community does not exist for its own sake and the individual certainly does not exist for the sake of the community. A community, therefore, can never claim to be above the rights of the individual. Giving up the rights of the individual for the sake of the community or forcing individuals to take actions for the benefit of the community even when these actions harm his or someone else's rights, is unacceptable. 'Kymlicka argues that communities and their cultures should be protected only for the sake of individuals (...). Where a set of individuals requires a particular culture for its chosen way of life, it has a right to have it protected against certain actions of outsiders' (M. Freeman in Beetham 1995:34-5). And where individuals are hurt by a particular culture, they have the right to be protected against this culture. This point of view is not an expression of individualism because it takes the importance of community life into consideration.

In the next paragraph, I will present some arguments against the link between individual rights and individualism. However, before that I would like to emphasize the following. Let us not forget that:

(1) Most violations of human rights are the consequence of state oppression, unregulated markets and ordinary crime and have in fact nothing to do with culture; and

(2) The limits on cultural practices necessary for the protection of human rights will never severely restrict cultural life (most cultural practices conform to human rights; on top of that, a large part of cultural life takes place in the mind and the mind is given absolute protection by human rights).

In general, cultures suffer as much as individuals from violations of human rights and benefit as much as individuals from the protection of human rights.

§ 96: Universalizing Human Rights is not the Same Thing as U niversalizing Individualism

The problem of individualism is one of the main battlefields of the cultural argument. Some people believe that individual human rights and democracy necessarily lead to an individualistic society (not only individual human rights but democracy as well, because democracy is adversarial and antagonistic and tears the community apart in rival factions only interested in their private well-being). Societies which are traditionally less individualistic and more focused on the family, the national community and the general interest, cannot use human rights or democracy because it is nonsense to introduce tools for individualism in a communitarian society. Furthermore, they do not wish to introduce human rights and democracy because this would destroy their identity. In their logic, individual rights are less important than the rights and the needs of the group. Individual rights will limit the rights of the group and will destroy the community spirit typical of the culture.

Sure enough, individualism in one sense of the word gives priority to the individual detached from the community and seeking to preserve his rights and his individual freedom in order to pursue his personal development and his self-interest. This kind of individualism is incompatible with community life, with the individual as a social being, with the general interest, the collective good, the community spirit and the duties and responsibilities towards the community. 
It is said that the West has always been more individualistic than other cultures and that western human rights are a product of this individual ism. The supposedly 'universal' human rights bear all the hallmarks of their western origin. They are framed in such a way that they protect the individual and his interests. Non-western societies consider the individual and his well-being to be less important than the community and its well-being. However, unhappy individuals can never make up a happy community and the wellbeing of the community is by definition the sum of the well-being of all individuals. But the opposite is also true: individuals can never be happy in an unhappy community. Many individuals, in the West and elsewhere, work hard and are prepared to temporarily sacrifice their own happiness and well-being to promote the well-being of the community. They do not work exclusively for their own well-being and they do not claim their rights without thinking of their duties. I believe that there are both westerners and nonwesterners who think like this, and that there are egoists and individualists in all cultures. It is wrong to say that non-western societies are more attached to values such as solidarity, consensus, cohesion, stability and harmony and that they reject the western values of autonomy, freedom, self-development, competition, struggle and conflict. It is equally wrong to say that only the latter values are expressed in human rights and democracy. Solidarity and community spirit are also part of human rights and democracy (see also the discussion on economic rights in Part 2).

I believe that there are three unacceptable hypotheses implicit in the argument against individualism:

(1) Community, harmony and solidarity are things which are better protected by a nondemocratic and authoritarian society which violates human rights.

(2) The West is more individualistic and less focused on the general interest than other cultures; in other words, individualism is typically western and belongs to the western cultural identity.

(3) Western human rights and western democracy express and reinforce individualism and the supremacy of self-interest, because they focus on the individual and his or her claims against fellow citizens; they are used primarily to further one's self-interest (this is reminiscent of the Marxist critique discussed in Chapter 2).

I will now discuss these three statements in turn. It is a well-known fact that authoritarian regimes tend to create divisions within the population. People fighting each other will not have the same opportunities to oppose the government as people who can act in common. Divide and rule has always been a very effective principle. Furthermore, authoritarianism does not have the means necessary to create a common interest and to soften conflicts between groups (such as discussion, tolerance, religious pluralism etc.). In addition, authoritarian rulers often force people to confine themselves to their private spaces (and the totalitarian form of authoritarian rule even destroys this private space). Private citizens are less of a threat to a government than citizens speaking to each other. Apathy, conflict, mutual distrust and privacy are authoritarian values and are incompatible with community life.

\section{§97: Rights and Community}

Secondly, I think it is very doubtful that western societies suffer more than other societies from the negative consequences of individualism (such as egoism, atomization etc.). Besides, even if this were a fact, what would it mean for the value of human rights and democracy? It remains to be proven that this 'fact' is at least partially caused by human rights and democracy. Human rights do not promote individualism simply because they are individual rights (individual and individualistic are obviously not the same thing). There has to be some other reason. Human rights are said to promote egoism because people use them in order to make claims on fellow citizens or to protect themselves 
against claims of fellow citizens. Human rights separate individuals from one another and naturally lead to atomism, loneliness and the survival of the fittest. An exaggerated attention to legal claims and to care provided by the government (in the case of economic rights) diminishes the importance of family solidarity and other natural, spontaneous and non-institutionalized forms of solidarity. The priority of rights and freedom over duties leads to the disintegration of the community, normlessness, crime, violence, anarchy, moral decay and conflict and this tendency towards chaos is confirmed by the adversarial nature of the democratic power struggle. The love of consensus, harmony and cooperation can never be as strong in a democracy as in certain non-western cultures which place duties above rights, responsibility for others above freedom, and cooperation above competition.

However, it is clear from the first Chapters of this book that democracy and human rights function at all levels of human life, not only at the levels of the individual and humanity. The intermediary level of groups and communities is just as important. Of course, the community of all human beings and public life in the company of (potentially) all human beings are the foundation of human rights and democracy and help to correct narrow-mindedness and prejudices typical of life in a closed cultural, religious, family and national communities. But there is more to human rights and democracy. Human rights (especially the rights to free assembly and association, the right to religious liberty, the quasi-right to tolerance and the right to a family) and democracy (the creation of a common will in minorities and majorities, and the political rights which require the existence of a nation or a people separated from the rest of the world) protect the creation and the existence of communities of different kinds. Art. 29 of the UDHR even speaks of everyone's 'duties to the community in which alone the free and full development of his personality is possible'. In Part 2, I will discuss economic rights which explicitly provide the duty to assist those fellow citizens in material need.

Moreover, freedom of expression, non-discrimination and political life are completely devoid of meaning outside of a community. Similarly, duties cannot exist without corre sponding rights. The duties of one are the rights of another. Human rights, therefore, cannot be the cause of normlessness and a neglect of duties. Duties can never suffer from the presence of rights. As for the accusation of promoting excessive attention to selfinterest, it is evident that a general interest can only be formed on the basis of free discussion and equal participation. Any other kind of general interest is likely to be a ploy of those in power trying to maximize their glory and wealth by forcing the people to sacrifice their private interests. Real consensus and harmony are also impossible without freedom and equal participation. In Part 3, I will deal with the supposed link between democracy and rights on the one hand and anarchy, conflicts, violence etc. on the other hand.

Human rights and democracy are not an expression of individualism and should not be rejected because of individualism. On the contrary, they are the best protection against it. Social belonging and community life are never as secure as in a democracy which protects human rights, even though human rights are the rights of abstract, a-cultural and universal individuals (human beings have human rights because of their humanity, irrespective of the community to which they belong). The way in which democracy and human rights protect belonging is precisely one of their justifications because belonging is a universal value.

The western affection for human rights and democracy indicates that it is wrong to accuse the West of individualism. If it is wrong to accuse the West of individualism, then it becomes much more difficult to use the argument of cultural imperialism and eurocentrism against the efforts to universalize human rights and democracy. In most cases, western cultural imperialism is rejected because of the supposed individualism of the West and because of the fear that exporting western human rights and democracy means exporting individualism and therefore harming other, more communitarian cultures. However, the universal promotion of human rights and democracy cannot be called cultural imperialism as soon as one recognizes that human rights, democracy and the West 
do not represent individualism, unless one finds another western 'value' which is $\propto$ pressed in human rights and democracy and which harms the identity of other cultures. I do not mean to say that human rights or democracy can never be used for imperialistic purposes. Of course they can. However, it is quite another thing to say that their universal promotion is by definition cultural imperialism because they express western values such as individualism. Besides, the way in which something is used does not necessarily discredit the thing itself.

However, if belonging is a universal value, then the same can be said of some kind of moderate individualism. Most people like to retain some individual independence and do not want to be completely conditioned by the group to which they belong. Independence and belonging, individualism and local, cultural, national, ideological or religious communities should not be presented as necessarily incompatible. The two points of view are linked to one another because they are both protected by human rights and democracy, at least to the extent that neither of them is viewed in an extreme way. Human rights and democracy are a bridge between the individual and humanity on one side and the group on the other side because they simultaneously promote:

(1) Individual development, communication beyond the group, responsibility for one's own life and the protection of individual interests and freedoms against the state or fellow citizens.

(2) The pursuit of the general interest, community life (as, for example, a source of individual identity) and the importance of family values, community protection and duties towards the community.

The choice is not between the individual or the group, except when you decide to define one of them in an extreme way leaving no space or only a very limited space for the other. It is possible to consider both as equally important and human rights and democracy can help you to do so.

Group life is obviously not the only important goal of human rights. The individual and humanity are equally important. Sometimes, the interests of the group as they are protected by human rights (and by democracy as well) must be balanced against other interests which are also protected by human rights, interests such as

(1) The individual freedom to change groups or to think independently;

(2) The individual development of a person stuck in a narrow-minded and closed group;

(3) The duty of solidarity with humanity, etc.

A group can violate human rights, and an individual must be able to assert himself and to use his human rights against this group. The individual is under no obligation to re spect everything the group does to him or her. The group is not more important and does not have more rights than the individual, and an individual is more than a part of a group. An individual is not inferior to the whole and is not forced to deny his or her interests.

Although in a human rights regime the individual has duties towards the group (whatever the opponents of human rights may say) - duties such as respect for the identity of the group and the diversity of groups - these duties are not unlimited and the individual has more than only duties. For example, a group can ask for income redistribution, but it cannot ask for ideological orthodoxy or for excessive financial or physical contributions because this would violate the rights of the individual members. The community cannot be protected or enhanced at the expense of the rights of individuals. No one is duty bound to sacrifice themselves or their rights for the group (just as extreme individualism defined as egoism or as the priority of the individual over the community is not an option). The only duties towards the group are those that do not violate human rights and those that explicitly result from human rights. This is more than sufficient to cover most duties that most groups consider to be necessary. 
Individualism is not necessarily an extreme anti-social stance, just as a communitarian stance is not necessarily anti-individual. Human rights and the duties attached to them confine both positions within reasonable limits and make them compatible.

If it were true that the West is more individualistic than other parts of the world, then there would be no reason to call human rights western rights. It would then be clear to all that human rights are not an element of the culture of the West, invented to criticize and oppress other cultures. it would also be clear that human rights should also be 'exported' to and imposed in the West in order to cure some of the western illnesses (extreme individualism and egoism are also violations of human rights). Individual human rights can indeed foster individualism in its extreme form but they are more likely to be the best protection against it. The disappearance of community spirit is often caused by the absence rather than the presence of human rights (other elements can also cause the disappearance of community spirit, for example industrialization, urbanization etc.). 
Section 14: Collective Rights

\section{§98: Superfluous Rights}

Do universal democracy and human rights lead to uniformity? It is true that we want to apply the same form of government and the same basic norms all over the world and that this uniformity can threaten certain parts of certain cultures. However, I do not see this as a problem. We are dealing with a uniformity that creates more opportunities for the manifestation of difference than any other existing or imaginable structure. Another argument - democracy and human rights threaten the diversity of cultures because of the exaggerated attention to the wishes of the individual - is also easy to counter, as I have shown in the previous Section.

However, it could be said that what I have done in the previous Section is not enough. They believe that we should recognize so-called collective rights or group rights in addition to the mainstream individual rights, because individual rights and democracy do not protect the interests of communities, of community life and of social belonging in a sufficient way. However, most of these new collective rights are in reality existing individual rights disguised as collective rights. For example, the right of a disadvantaged group - e.g. a developing country - to be aided by a wealthier group is just another way of phrasing economic rights (see Part 2). The collective right to self-determination is the same thing as the right of a people to choose their government and to participate in the government. The right of a disadvantaged group - e.g. women, colored people or indigenous populations - to equality and equal participation in politics is a combination of political rights and the principle of non-discrimination. Collective rights as such are superfluous because they are always a rephrasing of individual rights.

Groups and in particular minority groups are often attacked, oppressed and persecuted. They are considered to be groups which are separated from the rest of society and which are legitimate objects of targeted attacks such as racism, xenophobia, discrimination, exploitation or even genocide. These attacks are often collective attacks. Persons are discriminated against or killed for no other reason than their membership of a particular group. Colored people are oppressed because they are colored people. Some people be lieve that a collective problem requires a collective solution. A minority that is collectively oppressed claims a collective right to protection, a collective right not to be oppressed. Acts that are expressed in collectivist terms have to be countered by rights using the same terms.

The question is whether it is really necessary or even opportune to solve the collective problems of some groups by way of collective rights or group rights. I believe that the often genuine problems of different groups and minorities (but also majorities) can be solved by applying a number of individual rights such as the right to equality before the law (a law has to be general and equal for everybody and cannot be directed against or cannot discriminate against certain persons or groups), the right to equal treatment and to equal rights, the right not to be discriminated against, the right to life (in the case of genocide) and religious liberty.

The problem of gender discrimination in a number of Islamic countries is an example of a collective problem that can be solved by applying individual rights. There is no reason to solve this collective problem by adding so-called women's rights or collective rights 
of women to the existing individual rights. Gender discrimination is not a violation of women's rights. It is a violation of the human rights of women. The principles of equality and non-discrimination are sufficient to solve this problem.

A nother example is the economic backwardness of certain minorities, such as colored people in the USA, laborers, single mothers etc. Applying individual economic rights is sufficient. There is no need to look for a solution in special minority rights, for example the right to positive discrimination (favoring a group deliberately or treating a group deliberately in an unequal yet positive way in order to help it advance and gain a status equal to the rest of the population). Applying positive discrimination is accepting the failure of human rights. If the members of the group were able to enjoy and enforce their individual rights, there would be no need for positive discrimination. (The same argument is valid for equal participation in politics).

\section{§ 99: The Right to a State and the Right to I dentity}

Some form of political self-determination is said to be necessary to solve certain minority or group problems. Only self-determination or life in a separate and independent state can guarantee that minorities or other groups are not discriminated against, are not persecuted and are not economically disadvantaged. However, in the light of the preceding remarks, this is evidently false. It is a theory that can only be believed by those who do not believe in the strength of human rights. Struggling for political autonomy - just as applying positive discrimination - is accepting the failure of human rights. I do not mean to say that political autonomy is wrong - there can be no democracy without it - or that it is always wrong for a minority to try to secede. Sometimes human rights do indeed fail to work and then there is perhaps no other solution than independence However, one should first try to protect human rights and only if this fails can one use stronger measures.

If self-determination or political autonomy is sometimes necessary, then this is not be cause it is a collective right. It is a right of peoples and nations, but it is no more than a general wording of the individual right to political participation. Respecting a people's rights to self-determination is the same thing as respecting its political rights.

However, some say that the right to self-determination has another use: it protects the identity of a group. It is granted that classical individual rights can guarantee the physical survival of a group. Cultural, religious or ideological destruction, on the other hand, can only be avoided by using the right to self-determination. The right to the identity of a group - for example the right to a cultural identity - is said to be dependent on its right to self-determination. No individual right is able to protect a group identity. Only in a state of its own can a cultural group fully protect and develop its identity, speak its own language and live according to its own norms.

This is wrong again. Individual rights guarantee the right to an identity. There is no need to rush into self-determination. Freedom of expression, religious liberty, nondiscrimination, tolerance etc. create a duty to accept difference If somebody has the right to express his difference, then we have to accept this difference. Everybody has the right to have another opinion, other norms and values, another religion, another language and so on, with the exception, of course, of the norms, religions etc. which violate human rights. Individual rights guarantee the existence of different identities as long as they do not violate individual rights. The freedom of association permits people to form and join groups with different identities. The individual right to form and join groups implies the right to protect a group as well as the identity of a group. A group without an identity is not a group. Freedom of association is useless if the identity of the association does not have to be respected.

One can only believe that an identity must be protected by way of self-determination and the creation of a new state when all hope is lost for individual rights in the current state. Secession - or revolution, which is also an act of self-determination, not in most 
cases of a minority, but of the majority - can be useful. An identity is after all very important. Living in a community that supports such an identity is part of the good life and must be protected by human rights. However, it does not follow that there has to be collective rights. Women, minorities, laborers, indigenous people etc. do not have rights. Individual human beings have rights. And it is not because the individual rights of members of a group are violated that these rights suddenly become group rights.

Individuals can form groups to claim and enforce their rights, just as groups can use individual rights to protect their identity. It is often necessary to form a group in order to be heard (see for example the feminist movement). However, this is a matter of strategy, not content. Enforcing individual rights through group action does not turn individual rights into collective rights.

\section{$\S 100:$ D angerous Rights}

Individual rights are sufficient in all cases, although I have to admit that protecting groups by way of individual rights ignores or neglects the nature of the problem. Only the right of a group (for example a group of indigenous people) to equal treatment recognizes the existence of a certain kind of discrimination. The individual right to equality, even though it can stop group discrimination, ignores the nature of or the motivation behind the attack on the group and does not distinguish between individual and group discrimination.

H owever, the advantage of countering a collective attack by way of an individual right is that the existence of individuals in the collectivity is thereby accentuated. The cause of a collective attack is precisely the existence of the group as a collectivity and a unity in which the individuals do not count. By using his individual rights to protect a colored person against discrimination, racism or genocide, we accentuate his individuality. He is no longer 'just another nigger', someone belonging to a collectivity which is a legitimate object of discrimination. Collective rights do the opposite. Recognizing collective rights can contribute to the official sanctioning of the existence of collectivities. It makes thinking in terms of collectivities legitimate, it puts the different individualities in the background and it strengthens the opinions of those who oppose and persecute certain collectivities.

A nother danger of collective rights is the way in which they encourage closed groups. The freedom of association implies not only the right to form, join and maintain a group, but also the right to leave a group, the right to stay outside of a group and the right not to be forced to join or stay in a group (the same is true for the freedom of religion). Membership of a group is a free and non-final choice This is not an expression of individualism. Communities are a very important part of an individual's life, but not all kinds of communities. Individuals as members of a particular group must be able to decide when this group is no longer important or has become harmful. It is not up to the groups to decide that they are an important part of their members' lives. Individuals decide which groups are important, which groups they wish to join or to leave.

The right to leave a group is important because groups can violate the rights of their members. For example, the right to identity and the desire to preserve an identity can tempt a group to force its members to express this identity, even when certain members have deviating views. The identity of the group is then more important than the individual identity. This is for example the case in a setting of de-colonization. The long forgotten identity is then forced down the throat of every citizen, especially the 'évolués' . This also happens in some states of the Third World seeking a new and cultural legitimacy now that their anticommunist legitimacy has disappeared. These states often force different ethnic groups in their territory to conform to the national ethnic identity. However, it also happens on a much smaller scale, for example a group of youths worshipping a certain musical group or following a certain fashion and psychologically forcing some individual members to conform. 
Furthermore, individuals who, for this reason, wish to leave a group are often forced to stay. The survival of a group is dependent on the presence of members. Individual rights are seen as instruments used by individuals to attack the group and its identity and must be eliminated. This kind of reasoning is particularly harmful when adopted by a state as a means to protect a national identity. An authoritarian form of government is then necessary to suppress views and attitudes deviating from this identity. Art. 29 par. 7 of the A frican Charter of $\mathrm{H}$ uman Rights and Peoples Rights even mentions that individuals are obliged to protect the values of their culture. This is no longer a right to have an identity; it is a duty to have an identity, a cultural identity which forces the individual identity to disappear into the collective. A group must be able to express and preserve its identity, but it should allow its members to express and preserve their own, individual identities.

Fortunately, this kind of forced conformism is becoming more and more difficult to maintain or to impose. Thanks to increased mobility and modern technology, individuals can look outside of their group and can use the outside world against their group. For example, the attempts of certain Islamic countries to ban the Internet and satellite TV can only succeed with the use of extreme force, something which is likely to create a reaction. On top of that, the economy of the country in question will probably suffer.

The individual should never be subjected to the whole. Individual rights and individuals are just as important as groups and the rights of groups, even if the identity or the existence of a group is at stake as a consequence of the application of individual rights. Groups are there for individuals and not the other way around. It must be possible to impair or change groups as a consequence of the application of individual rights. This impairment or change should be kept to a minimum because groups are important for individuals. The only alternative is harming individual rights in order to protect groups (for example, one can coerce individuals to conform to the group or to remain members of the group). However, this would mean that the group does not exist for the individuals and that it is no longer important for the individuals concerned. On the contrary, the individuals would view such a group as oppressive. After all, difference is as important for human beings as belonging.

There is yet another problem caused by collective rights: supposing that there are collective rights, which groups have such rights? Take for example the right to selfdetermination: which group has this right? In the case of colonies, the answer is clear. Colonies are occupied territories without self-government but with clear albeit not always just or sensible borders. The people of this kind of territory have a universally recognized right to self-determination. ('A state administering a colony is under a legal duty to allow the inhabitants of that colony to exercise their right of self-determination', Akehurst 1991:298). The focus here is on the inhabitants of a territory, which is an unequivocal criterion for the attribution of a right.

Today, however, the right to self-determination is no longer claimed by colonies but by national minorities of all kinds. A national minority is not as easy to define as a colony. What is a national minority? What is a nation? Who is or is not a member of a nation? Almost every group of a reasonable size can call itself a nation and if the common language does not define the common identity, then history, race, religion or something else will. If we give every 'people' or every 'nation' the right to self-determination, then we open the gate to all kinds of centrifugal forces. Every excited separatist who calls himself the spokesman of his 'people' can claim the right to start a war as the ultimate means to realize self-determination.

A pragmatic reason to accept collective rights is the fact that this would take the sting out of the argument that human rights are individualistic and typically western. Most of the advocates of collective rights come from the South. Accepting these rights would make it easier to universalize the whole body of human rights. By recognizing a clearly nonwestern contribution to human rights theory, we make the whole body of human rights more universal because we make it more representative of the diversity of humanity. It 
seems to be a good thing if a universal system combines elements from all continents, even though an argument should be focused on the content of something and not on its geographical situation or origin. Something is not bad just because it comes from the West and is not good just because it comes from elsewhere. However, if collective rights are acceptable for strategic purposes, we need to be aware of the dangers involved and restrict their use so as to avoid unwanted consequences.

\section{$\S 101:$ Special M inority Rights}

There is, I admit, one group problem which individual rights cannot solve, namely the problem of permanent minorities. Normal democratic minorities do not pose much of a problem. They are excluded from a political decision, but the majority cannot vote laws contrary to the rights of the minority. That is why the minority does not have to fear the majority. Furthermore, the composition of the minority constantly changes. For today's decision you are in the minority, for tomorrow's one you may be in the majority. Minorities can also use their rights to make themselves heard, to convince other people and to try to become a majority.

However, it can happen that certain groups are systematically in the minority. In this case, it is obvious that the system of democratic majority government harms the interests of the groups in question. These groups are always excluded from power and have no self-control or self-government. Even when the majority does not take decisions which harm the rights of the minority, it still harms the minority because it excludes it from power, neglects its interests and does not allow it to shape its own life. These minorities are called permanent minorities. Indigenous peoples, immigrants, linguistic or religious minorities often become permanent minorities. Although one does not have to be an immigrant to vote for measures or laws favoring the interests of the immigrant population, we often see that the interests of permanent minorities are neglected by the majority.

Individual rights cannot solve this problem. The permanent majority does not harm the individual rights of the members of the minority, even if it always imposes its will and its decisions on the same minority. However, the democratic process is flexible enough to solve the problem and to give everybody equal citizenship. One can for example install a far-reaching federal system in those case where the minorities are geographically concentrated, or a system of guaranteed minimum representation in at least one of two legislative chambers, or some kind of equal allocation of executive functions. However, it is stretching the point to call these measures collective rights. (One difficulty resulting from these measures is the possible contradiction with the principle of 'one man, one vote'. I will discuss the problem of permanent minorities in more detail in Part 3 when I discuss the so-called pacification-democracy).

It seems as though individual rights cannot protect and often even harm some of the interests of one particular kind of minority, namely indigenous peoples. Individual rights such as the right to free movement can cause an influx of outsiders into the traditional settlements of indigenous peoples. These outsiders often have little respect for the local cultures. Their only worry is to make as much profit as they can, and they use the land and its resources for this purpose. Big government projects can also harm indigenous tribes because these projects can change the environment (for example huge infrastructures such as artificial lakes for power generation). Governments sometimes even expropriate the land and resettle the indigenous people, supposedly for the general economic welfare. However, where rights fail, democracy can come to the rescue. Decentralization can give local groups the power to decide or co-decide on how its land and resources are used. They may even be allowed to veto certain projects or to limit migration into their territory. Freedom of movement is only one among many human rights. Just as all human rights, it has to be made compatible with other rights, and sometimes it has to be limited in order to protect some other right. 
Section 15: Actual and Normative Universality

\section{$\S 102:$ U niversality at the level of States}

A growing number of people believe that human rights and democracy should be universally applied. There is even a growing consensus among states, the principal violators of human rights. The V ienna D eclaration of 1993, accepted by almost all states of the world (171 states to be precise), affirms that the universal nature of human rights is 'beyond question' and that these rights are 'the birthright of all human beings'. The ICCPR and the ICESCR - the two major treaties for the protection of human rights - were signed by more than 140 countries (one of them is China, the largest undemocratic country in the world). All of these countries have undertaken the legal obligation to respect human rights (including political and economic rights). The universality of human rights is a fact in positive law. 'Even though (...) human rights are violated virtually everywhere, the principle that they should be defended is asserted virtually everywhere. 'V irtually no one actually rejects the principle of defending human rights' (Mendus in Beetham 1995:10).

Indeed, all we have is normative universality. Everybody or almost everybody agrees on the norm, but there is as yet no actual universal application of the norm. Theory is one thing, but reality often struggles behind. Promises are not kept, declarations of good intent are outright lies and treaties are violated. Furthermore, it is very difficult to enforce treaties. There is no global police force or executive power and there is the principle of national sovereignty and non-interference in internal affairs.

However, theoretical or normative consensus is not useless. It means that evil is not almighty. Evil has to lie and cheat. Hypocrisy is al ways a compliment to virtue. There can be no hypocrisy if virtue does not have at least some influence Even though a declaration or a commitment often does not change reality immediately and substantially, it can be referred to when yet another dissident is put behind bars. If a state violates a treaty, it will have some difficulty explaining why it has done so, why its actions contradict its words, why the situation supposedly warrants exceptional measures deviating from a self-imposed rule, and why these 'exceptional' measures are a part of everyday life for many citizens.

Normative universality makes it much harder to use the cultural argument or the argument of non-interference in internal affairs to counter criticism of human rights violations. Once there is normative universality, you can no longer accuse human rights of being alien values, imposed by cultural imperialists. When you say that human rights are important, you should not mind external criticism of rights violations. ' $\mathrm{N} o$ doubt the commitment of many countries to human rights is less than authentic and whole-hearted. Y et the fact of the commitment, that it is enshrined in a constitution, and that it is confirmed in an international instrument are not to be dismissed lightly. Even hypocrisy may sometimes deserve one cheer for it confirms the value of the idea, and limits the scope and blatancy of violations' (Henkin 1990:28-9).

Another problem is the equivocal meaning of words. If everybody says that human rights and democracy are important, but everybody has something different in mind, then there is no universality either. The concept of democracy in particular is defined in many different ways. Some believe that it is enough if you organize regular elections and call yourself a 'people's democracy'. A democracy is of course much more than just elec- 
tions; it is even more than honest elections. At best, this inflation or rather deflation of meaning shows that rights and democracy have become so important that even dictators want to be known as or want to give the impression of being democrats who respect human rights.

Furthermore, there can only be real normative universality if the people of the world believe that human rights and the principles of democracy are the rules that should govern their lives. The universal acceptance of human rights treaties is not the same thing as universal acceptance of human rights or democracy at the level of the people. A state can sign a treaty for political and strategic reasons. A treaty is signed by a state and is not always ratified by the people or their representatives. Since the ultimate purpose is the universal acceptance of rights and democracy by the people - rights are always violated by people - it is worthwhile to look a bit closer at the ways in which this can be achieved.

\section{$\S 103$ : U niversality at the level of the People (A M inimal Consensus or 'W el tethos')}

At the level of the people, there is only a minimal global consensus. Not every person accepts every human right and every democratic principle (I would not be writing this book if it were otherwise). However, murder, theft, slavery and torture for example are universally considered as objectionable acts, even though these acts are committed quite regularly (a norm which is never violated has no reason to exist). The values that I use as a justification of human rights and democracy - peace, prosperity etc. - are also quasiuniversal values.

Most people of different cultures and ideologies agree on certain basic norms. This global consensus, even if it is rather shallow, shows that it is wrong to believe that there are no universal values and that all values are linked to and limited to cultures (in other words, that all values are culturally determined). There is a lot of diversity, but all or most human beings in all cultures of the world, even the most extreme relativists, share a number of universal norms and values. These norms and values have been called the 'W eltethos', the common ethics of the world. This consensus, however minimal, seems to grow and to widen.

The problem is that the existing universality of a norm does not allow us to conclude that the norm in question is the norm that we should be following. There surely was a time when the inferiority of women was a universal value, but this did not and does not mean that women ought to be treated as inferior beings. Consensus can be based on a mistake and opponents of universal rights can claim that the consensus should change or disappear. The fact that there is a consensus is no reason to say that this consensus should be preserved, just as the fact that there are differences in cultural values is no reason to say that these values and differences should be preserved. The fact that a norm is or is not universally accepted has no consequences for the moral necessity or desirability of the universal acceptance of the norm. It is not because people disagree that there is not one universal truth or that people should or must disagree. And the fact that people agree does not imply that what they believe is true. To be and ought to be are not the same thing, and one cannot be deduced from the other.

In the case of human rights, however, an existing universality at the level of certain norms contradicts those who are against universality per se. It can also function as a starting point for building a more substantial universality. We should indeed avoid acquiescing in minimalism. Human rights are more than what is truly unacceptable. They have a positive content (relationships, communication etc.). That is why we should try to de velop and enlarge the consensus and add rights such as the freedom of expression and religion which clearly do not yet belong to the W eltethos'. The universally accepted nucleus of norms as it now exists, is too shallow. 'U niversalität ist machbar, $\mathrm{H}$ err $\mathrm{N}$ achbar'. 
We have to work to achieve full universality of all human rights norms and democratic principles.

More important than the existing similarities between cultures and traditions, are the possibilities for such similarities in the future. The global consensus on a number of norms and values is stimulated by the growing number of international contacts and exchanges (in the framework of the globalized economy, the media, tourism, the Internet and other technological innovations). These contacts and exchanges not only make it more difficult to cover up violations of rights; they also make people familiar with other value systems. People of different cultures live together - if not physically then at least intellectually - and influence each other's values.

\section{$\S 104:$ A n Intercultural Dialogue}

This al ready indicates that we should not put too much faith in the 'principe d' addition' trying to find a unity by simply looking for similarities and making the sum. Unity or consensus is often the result of influenceand persuasion and not the result of finding and adding things that are equal and that exist as such independently of each other. Persuasion, however, implies dialogue, intercultural dialogue to be precise. This kind of intercultural dialogue can engender universality, but then it has to be a dialogue between equals. Nobody is persuaded when one of the parties to the dialogue believes himself to be superior and speaks without listening.

It also has to be a dialogue where there is at least a possibility that one convinces the other. A 'dial ogue de sourds' cannot create consensus. This means that extreme relativism is not an option. Cultures have to be allowed to influence each other, to open themselves and to mix with each other. Sealing off cultures and keeping them out of each other's way because of the protection of identities, makes a dialogue impossible. Being persuaded means changing certain elements of one's identity.

The need to convince one another implies that no one should believe themselves to be in possession of the truth and of the only correct and just system. It also implies a certain degree of tolerance, freedom of expression etc. It seems as though the conclusion is implicit in the premises. The attempt to universalize human rights through intercultural dialogue al ready requires human rights. You cannot dialogue with someone who is intolerant or who is not allowed to speak his or her mind.

A dialogue in this case is not a negotiation. There can be no negotiation on democracy and human rights. It is 'take it or leave it'. An inter-cultural dialogue is even less a conversation in which one culture needs to convince other cultures, as if some cultures need more convincing than other cultures. Persuasion is a two-way street and at least as much an intra-cultural affaire as an inter-cultural one. 
Part 2: $\quad$ The Economy

Chapter 7: Economic D evelopment

Section 16: From Economic Development to Democracy and Rights (The Impossibility and the Undesirability

of Democracy and Rights, Version 2)

§ 105: Economic Prerequisites

If democracy and human rights are not impossible or undesirable because of culture, then they are said to be impossible or undesirable because of the economy. The universal application of democracy and human rights is supposed to be impossible, or not yet possible, because many countries have not yet attained a relatively high level of economic development and prosperity. This level of development and prosperity is believed to be a necessary condition for democracy and human rights. The absence of this condition is often used as an excuse to actively violate human rights, as if there is no difference between the impossibility to use or protect rights and the active violation of rights.

Some even go a step further and turn a temporary impossibility into an everlasting undesirability. According to these people, democracy and human rights have to be re jected because they are incompatible with economic prosperity. Democracy and rights make it impossible to achieve prosperity and they undo prosperity wherever it exists. This makes them undesirable in every country (as opposed to impossible in certain economically backward countries). One of the reasons for the incompatibility between economic prosperity on the one hand and democracy and rights on the other hand is said to be the shortsightedness of democracy. Democratic leaders only think of their re-election and this forces them to favor measures which, in the short run, are beneficial for as many people as possible. The longer-term requirements of economic policy, however, often get less attention in a democracy and this is catastrophic for the economy.

According to a third point of view, situated somewhere between the two previous ones, we have to avoid democracy and human rights only in the early stages of economic development. Once there is prosperity, they can be reinstated. The undesirability is only temporary. The three points of view are all in favor of an authoritarian form of government, either because it is believed to be the only realistic alternative, or because it is necessary for economic development, permanently or only in the early stages of development.

§ 106: Economic D evelopment as a C ause of D emocracy and H uman Rights

The first of these three points of view is indeed close to the truth. Economic prosperity is a prerequisite for the creation, the preservation and the efficiency of a democratic state which respects human rights. This much I can admit. The fact that democracy, rights and economic development often go together - more often than authoritarianism and economic development (Bauer/ Bell 1999:8) - is indeed no coincidence Europe, the USA and Japan are democracies - at least in a certain minimalist definition of the word - and at the 
same time they are the most prosperous countries of the world. The states of Asia 'have democratized (or are in the process of doing so) in strict proportion to their degree of development. Of the formerly communist states in Eastern Europe, the most economically advanced among them (...) also made the most rapid transitions to full democracy' (Fukuyama 1992:112).

The problem with economic arguments is that they are often very simplistic. The economy is often believed to be the only cause of something (in the style of 'nazism arose from the economic crisis of $1929 . . . '$ ). Of course, the installation as well as the functioning of democracy and human rights is made easier in a situation of prosperity. However, this is true for almost everything. Democracy and human rights undoubtedly have many causes and prerequisites. It is not clear, therefore, how the absence of prosperity can be an $\alpha-$ cuse for not applying or even violating human rights and the principles of democracy, especially in view of the fact that some of the poorer countries of the world are democracies (for example India). At the moment of the introduction of democracy in the countries of the West, their GDP per capita was much lower than the present GDP per capita in some of the Third World countries deemed economically unfit for democracy (see Chong, undated document, referenced at the end of this book).

Economic prosperity does not seem to be a necessary condition, let alone a sufficient condition, although I admit that it facilitates the installation, the functioning and the preservation of a democratic government which respects human rights. It increases the likelihood and the life-span of democracy and human rights. There is a causal link between the economy on the one hand and democracy and rights on the other hand (however, as I will show in the following Section, there is also a reverse causation). In the following list, I mention some of the reasons for this:

- Prosperity creates time and leisure which can be used for democratic participation, public life and other uses of human rights. We often see democratic aspirations and claims of rights arising almost automatically in states which do well economically (see for example Taiwan, Korea and many South-American countries in the 1980s). People do not live on bread alone. They want something more. Economic misfortune, on the contrary, forces people to focus on the struggle to survive and forces them to give up rights in exchange for material progress. If the expression of an opinion can cause the loss of your job and if there are not many jobs available, then the choice is simple. Certain classes of people in particular will not have the time nor the money to participate in politics and will leave democracy to the rich. Seeing democracy degenerate into a tool for the rich, they will reject it and turn to authoritarian alternatives in despair. Unequal wealth or insufficient wealth for some classes of the population is often a characteristic of a lack of economic development and at the same time it hinders the proper functioning of democracy. Those who are rich will monopolize the democratic procedures not only because of the forced withdrawal of the poor, but also because of their privileged access to the media, education, representative institutions etc. Furthermore, big differences in wealth and bad economic performances are destabilizing for any form of government - democracy included - because they cause revolt.

- Economic development requires education and education promotes equality, the $\Theta$ pression of opinions, communication and political involvement.

- Economic development requires an equal openness of careers and positions without discrimination, because only this kind of equality can guarantee that the most able are hired for the job. Traditional privileges, nepotism, dynastical or corrupt attribution of positions hinder economic development because they make it more difficult to put the right man (or woman) in the right place. This equal openness not only requires protection against discrimination - a democratic value - but also requires equal education, and equal education promotes equality tout court.

- An advanced economy, and especially a free market economy, promotes the development of the means of communication and transportation. Communication and mobility promote the exchange of opinions and therefore promote freedom. Furthermore, 
increased communication and mobility weaken the power of habit and tradition, which in turn can weaken the grip of traditional authoritarian forms of power. 'The relation between economic freedom and political freedom is that initial growth in either political freedom or economic freedom tends to promote the other' (M. Friedman in The Wall Street Journal, 12-2-97).

- Urbanization is one of the consequences of economic development. It results from industrialization and from the constant demand for workers concentrated in industrial areas. Urbanization also weakens traditional and authoritarian forms of power (for example tribal forms of power) and strengthens the resolve to choose other ways of life than those predetermined by the community. Urbanization, moreover, promotes coexistence in diversity and thus also promotes tolerance.

Of course, the economy can also harm democracy and human rights. The focus on property accumulation and consumption for example can impair communication and public life; urbanization can diminish the number of face-to-face relationships, which are very important for public life, etc. An excess of material means, just as a shortage of them, can harm public and political life (there is this joke, known as Buchwald's Law: as the economy gets better, everything else gets worse'). Furthermore, the positive influence of the economy on democracy and human rights stops at a certain level of economic development. The difference between rich and very rich is of no importance for democracy and human rights. A reasonably prosperous middle class person can have a public and political life that is much more interesting than the public and political life of a complacent millionaire who is focused only on property accumulation and consumption.

The economy is not a necessary condition. It only makes things easier. And it is certainly not a sufficient condition. Democracy and human rights do not follow automatically from a certain level of economic development, just as they do not follow automatically from a certain kind of culture. Nothing can guarantee the installation or even the continuation of democracy or human rights. Not the economy, not the cultural identity, not even the law. They do not arise nor survive automatically and they are not just inherited and passed on to the next generation without any effort. They have to be created and fought for, over and over again. There is not a moment's rest. That is why they have to be part of the lives and minds of the people. The only necessary condition is the will of the people and people can be persuaded. Democracy and human rights are first of all a conviction and a state of mind. If the people cannot be persuaded to accept democracy and human rights, then the case is lost, even when there is prosperity, when the culture is beneficial to the development of democracy and human rights, and when the necessary laws and institutions are present. Democracy needs to be reinvented every day by people who participate enthusiastically, and human rights require continuous effort from everybody because everybody can violate them and can help to protect them, even when all the necessary circumstances and preconditions are present. If nobody is convinced of the desirability of democracy and human rights, then nobody will be prepared to participate in politics, to respect human rights and to defend them wherever they are violated, and then democracy and human rights cannot exist. 
Section 17: From Democracy and Rights to Economic Development

\section{$\S$ 107: D emocracy and H uman Rights as a Cause of Economic D evelopment}

As I have said before, we are dealing here with a two-way causation. The economy promotes democracy and human rights, but democracy and human rights also promote economic development and prosperity, mainly for the following reasons:

- The squeaky hinge gets the oil. Only in a democratic society in which human rights are protected, can an economic injustice be exposed and can claims for its abolition be heard and implemented. People can use human rights in order to call on the government or the international community to fulfill its duties and to implement certain economic measures. Most governments, including democratic governments, act only when they are put under pressure. The freedom of expression, the freedom of assembly and association (associations such as pressure groups, labor unions or political parties) and the right to choose your own representatives are instruments in the hands of the economically disadvantaged. They can use their rights and the democratic procedures in order to influence economic and social policy. Poverty must have a voice It is true that without a minimum degree of prosperity, human rights and democracy lose a lot of their value. If you have to struggle to survive, then you do not have the time to form an opinion, let alone express it. ' $P$ rimum vivere, dein de philosophari' ; first you make sure you live, and only then can you philosophize. However, life is more than just living. In a situation of poverty, it is indeed difficult to use rights and democracy, but without rights and democracy it is much more difficult to do something about such a situation.

- If there are no free flows of information, no accountable government which needs to justify its actions in order to be re-elected, and no free press, then you are likely to have more corruption, more embezzlement of public funds and more people who acquire an unfair advantage from the proceeds of natural resources and other sources of prosperity. The rule of law and the openness of government, which are typical of democracy, limit not only corruption but also the ineffective management or outright squandering of natural or other resources by untouchable governments. Furthermore, there is a link between corruption and squandering. Corrupt governments will be more inclined to set up grandiose but foolish and wasteful mega-projects, because this gives them more opportunities for corruption. Corruption is also a tax on investment, which is why it hampers investment and economic growth. Especially the often all-important foreign investments (the import of technology and knowledge) diminish as corruption increases.

- Economic development is supported by free flows of information and freedom of movement. A free press encourages the economy because it allows entrepreneurs to make informed decisions.

- Human rights encourage the economy because they encourage equal, free and subsidized education (education is growth enhancing) and because they reduce the risk of violent conflicts, revolt and anarchy, which are incompatible with economic development.

- Democracy guarantees the rule of law, which means legal security and predictability. The number of investments - foreign and local - will grow when investors are certain 
that their contracts are guaranteed by the law and enforceable by a judge, when oppression does not cause violent revolt and when investors are relatively certain that their property will not be stolen without punishment or will not be nationalized by a new revolutionary government.

- A democratic government which does not oppress its citizens will not cause a brain drain and flight of capital.

- The rule of law creates a limited state and a society that is relatively free and inde pendent of the state. This means that economic activity is also relatively independent. A certain limit on state interference in the economy is traditionally considered as beneficial for economic development. In a free civil society, everybody can be economically active. In many authoritarian states, only a handful of privileged persons can be economically active, and these persons are not al ways the ones most suitable for this kind of activity (for example large landowners, members of the official 'nomenclatura' etc.). A free civil society, guaranteed by the rule of law which in turn is guaranteed by democracy (although not only by democracy), allows everybody to be creative, to cooperate and to exchange on a relatively level playing field. This increases the chances that the best man is in the best place, which in turn encourages economic development. Furthermore, by pumping in as many people as possible in the economy and by letting them move and communicate freely, the economically most efficient and profitable transactions can take place.

- An atmosphere of intellectual freedom gives rise to new ideas, new technologies, new products, new production methods etc. There is no prosperity without creativity and there is no creativity without freedom.

- Sharing know-how, maybe the most important factor in economic growth, is impossible without the freedom of expression.

- Respect for human rights and a democratic form of government increases a government's legitimacy and encourages hard work and sacrifice for national goals (Christie in Beetham 1995:210).

Again the same remark: democracy and human rights assist but do not guarantee economic development. Economic development does not follow automatically from democracy and human rights, or vice versa. In other words, democracy and human rights are not sufficient conditions and probably not even necessary conditions for economic development. This has to be clearly understood in order to avoid a 'democratic hangover'. One should avoid being too enthusiastic about the possibilities of democracy and rights. Disillusionment can cause authoritarian nostalgia. N evertheless, the fact that democracy and human rights can promote prosperity is a reason for their universal application, because prosperity or the freedom from want is undoubtedly a universal value.

\section{$\S$ 108: The Choice Between $\mathrm{H}$ unger and O ppression}

Some say that human rights and democracy have to be sacrificed for the sake of economic development and economic progress and that the economy in general needs an authoritarian regime. They usually give the following reasons to support their opinion:

- Discipline in production and consumption, which is more important for economic growth than freedom, requires discipline in society and therefore also a strong state. The exaggerated attention to rights instead of duties is incompatible with discipline. Duties are much more useful in economic development than rights. Instead of wasting scarce resources in consumption, people should moderate themselves and resources should be used for necessary investments. This, as well as the planning necessary for economic development, requires a strong state. In addition, the free choice of labor is less important than the ability of the state to direct labor towards certain development projects (Christie in Beetham 1995:209). There may even be a rationale for forced b- 
bor. Rights, which are used against the state, are a force against economic development because the state is the main promoter of development. On top of that, rights are individualistic and together with adversarial democracy they discourage the cooperation which is necessary for economic success. (However, I have shown in Part 1 that rights are not individualistic and that there can never be an exaggerated attention to rights at the expense of duties. There are no rights without duties. As for the necessity of planning, I believe that history has shown that planning is not the best way to achieve prosperity and that the state is not necessarily the :most appropriate engine for development).

- A strong state has the power to enforce certain measures which are unpopular in the short run - for example because they imply limits on short term consumption and redirection of funds towards long term investments - but which yield great dividends in the future. Unpopular measures often require limiting and violating human rights, because these rights can be used against these measures. As a country becomes wealthier, human rights may return because there will no longer be a need to limit them. In the meantime, however, national economic interests take precedence over the interests of individuals. A democracy, on the contrary, will take measures which guarantee the short term interests of electors and elected. These measures guarantee the re-el ection of the government and the short term happiness of the voters but are detrimental to the long term economic well-being of the nation. (However, it is difficult to deny that a democratic government, because of the way it comes to power, has more legitimacy and is therefore better placed to take difficult decisions. Besides, most authoritarian leaders only think of the short term, namely their own short term financial profit).

- Economic development requires consistency, coherence, long term planning and so on, all of which is incompatible with democracy and rotation in office Democratic governments, laws and policies change continuously. This goes against the interests of companies that need stability for their investments. (Again, it is difficult to deny that the democratic procedures for changing governments create stability because they help to avoid revolt. Furthermore, if the people decide to change something, this is because they believe that it ought to change, that it is not good as it is. Consistency is not the only value).

- Economic rights in particular counteract development. Wages need to be low, union activity needs to be minimal, working hours need to be long and children need to work if the economy is to grow. Furthermore, economic rights make people dependent and undermine their ability to help themselves, to improve their condition and thereby to invigorate the economy. (I will discuss this problem in the next Chapter).

Some of this goes further than the claim that economic development is most important and that political freedom will follow later, when it becomes possible and when it no longer impairs development. Now we hear that political freedom has to be forgotten entirely because it is by definition incompatible with economic prosperity. It is not even a luxury which poor countries cannot afford yet and which is useless when bellies are empty. The choice is one between hunger and oppression: give me your freedom and your rights and I will give you food, and I will not give you back your freedom once you have your food. If you choose freedom, then be hungry.

The point is that human rights and democracy are magnificent weapons in the struggle for just economic development rather than a luxury which poor people cannot afford or a false blessing which will render every economic achievement impossible or short-lived. There has to be some degree of democracy and some level of respect for rights before economic development can take place at the level of every individual. Economic progress is no more than the realization of needs and we can only know of the existence of needs if people are allowed to express them. In a 'benevolent' dictatorship, leaders often try to realize what they think the people want but what in fact is contrary to the real wishes of the people. There can only be real economic development in a society in which the people can express what they want. 
For example, if we do not know which kind of or which degree of poverty exists in society - and we are not likely to know this in an unfree society - then we cannot do anything about it. The probability that poverty disappears is much higher in a society in which poverty can be shown and questioned than in a society in which violations of human rights make it impossible to show poverty. Furthermore, in a democracy the government does not only have to listen to the needs of the people; it also has to do something about them if it wants to remain in power. A democratic citizen is a partner in a conversation with the government. He or she is not just an object which can be moved about, directed and manipulated in order to achieve the best overall economic result. On top of that, a democratic politician is someone who can be criticized. This criticism allows him to learn from his errors. Mao's disastrous Great Leap Forward for example would never have lasted very long in a democracy. A uthoritarian leaders are not even aware of their mistakes and so they are not likely to learn from them.

Without political participation, without the ability to express your interests and needs in the political arena, these interests and needs will probably remain unsatisfied, except if you are strong enough to satisfy them yourself or if you are one of the rare beneficiaries of philanthropy. In any other case, you need political power to improve your economic situation. You can, of course, pursue your self-interest in any kind of regime, but only a democracy allows all people to pursue their self-interest in a more or less equal way and to claim assistance when this is necessary. Democratic political equality is a value because it promotes economic equality. '[T] he rights and interests of every or any person are only secure from being disregarded when the person is himself able, and habitually disposed, to stand up for them' (Mill in Dahl 1989:93).

Of course, there is more than just self-interest, and a justification of democracy and rights should therefore transcend this level. A state should not attempt to realize all or everybody's desires. Some desires are morally unacceptable. In addition, a state cannot realize all desires, and it has to be clear about this, otherwise it will lose its credibility and legitimacy and it will produce disillusioned, lethargic or rebellious citizens. The reverse, neglecting too many wishes and stifling the voices of too many people, will also harm the state's credibility. All wishes should be heard and should form the basis of a common discussion in which the people decide on the general interest.

\section{$\S$ 109: Hunger and Oppression Go Together}

In general, authoritarian governments do not perform better economically than democratic governments (Barro 1996 and 1997). On the contrary, after decades of authoritarian rule believed to be justified by the requirements of development, most African states for example are poorer than ever before. However, the problem is not only an African one. There are 'many cases in which restrictions on civil liberties coincided with economic stagnation rather than economic progress - the Philippines under Ferdinand $\mathrm{M}$ arcos, India during Indira Gandhi's 'emergency', and the Soviet U nion and Eastern Europe under communist rule' (Christie in Beetham 1995:210). A uthoritarianism has had its chance.

In the rare cases in which authoritarian states have seen increased prosperity - for example in certain states of East-Asia - this is probably not because of authoritarianism but because of other factors such as the existence of a dynamic private sector, a policy of shared growth, low labor costs compared to western countries, a high degree of literacy etc. Without authoritarianism, prosperity would probably have been as high as it is now, maybe even higher (see for example the study of the World Bank, The East-A sian M iracle).

Furthermore, if prosperity does owe its existence to authoritarianism, then the cost is probably too high. Other values suffer when economic progress is achieved in an authoritarian way. It may be preferable to have a little less prosperity and some more freedom. Besides, if authoritarian rule can promote development, then the result must be unequal prosperity because authoritarian regimes lack the tools and values which promote equality and redistribution (e.g. economic rights, equal political participation, equal freedom of 
speech etc.). Economic development is, of course, much more than an increase in GDP. Economic growth in terms of GDP does not rule out the possibility of extreme poverty for large groups of people (see for example the case of Brazil in the sixties and seventies, Donnelly 1996:167).

The choiceis not one between hunger and oppression or between starving liberals and well-fed slaves. On the contrary, hunger and oppression often go together. The real choice is one between hunger and freedom. The end of oppression ultimately means the end of hunger and vice versa (because well-fed people will revolt against oppression, as I have shown). Oppression is not the way to eliminate hunger and poverty. Poor and underdeveloped countries have every reason to install democracy and systems to protect human rights as quickly as they can, even if it is only partially. A democracy of poor people will indeed be only half a democracy. But once there is a momentum, we will see rapid improvements, both at the level of the economy and at the level of democracy and rights.

Human rights and democracy do not threaten economic development. They are not incompatible with economic development and they do not have to be sacrificed or violated - either temporarily or permanently - for the sake of economic development. On the contrary, they assist economic development. Political freedom can lead to economic progress, just as economic progress can lead to political liberalization.

The role of democracy and human rights in the creation and distribution of prosperity justifies their universal application because conomic development and prosperity are universal values. However, the choice for democracy and human rights can and will not be a purely economic choice. It will not be a purely economic choice because history has shown that many people are willing to sacrifice their wealth and even their lives in the struggle for democracy and human rights. It cannot be a purely economic choice because democracy and rights are much more than a lever for the economy. The economy is never an end in itself. It is a means for something higher and more important; for culture for example. Even in the few relatively prosperous dictatorships, the people ultimately revolt. People, therefore, are not motivated solely by the economy.

\section{$\S$ 110: A N ew Inversion of $M$ eans and Ends (1)}

As in the case of the cultural argument, we see an inversion of means and ends in the economic argument. In fact, the economy is, just as the cultural identity, an excuse for authoritarian government, rather than a good reason for having an authoritarian government. Rights violations and undemocratic governments are not a means to achieve economic development or to protect a cultural identity. Economic development and cultural identity are a means to perpetuate authoritarian regimes. We are dealing here with propaganda covering up for power politics. Human rights are violated, not because this is necessary for economic development or culture, but because it is necessary to preserve certain relations of power (including economic relations of power, because rights are also used to question these). However, even if tyrants are sincere in their use of the economic or cultural argument, they are wrong to do so.

A nother parallel to the cultural argument is the way in which the people who use the economic argument try to destabilize the defenders of human rights by using the language of human rights. Remember how one version of the cultural argument admitted the importance of rights and democracy, but insisted that it should be possible to have a different view on rights and democracy. In the economic argument, we see a number of 'moderate' authoritarian regimes admitting that rights are important but at the same time claiming that the priority of the economy forces us to accept a vision of rights in which economic rights are given precedence. This precedence is then believed to imply the possibility of justified limits on or violations of other types of rights (this is an argument typical of the present Chinese leadership for example; it is typical as well that, in reality, the Chinese violate economic rights just as much as the other types of rights). 
It is true that the West traditionally but for no good reason ranks 'classical' rights far above economic rights. However, the opposite extreme is also wrong. Proclaiming the priority of economic rights is very effective because it touches a nerve. The West does not want to be labeled as a bunch of well-fed and complacent liberals who are only interested in freedom rights and political rights, who see no need for economic rights - why should they? - and who impose this restricted and ethnocentric view on rights on the rest of the world. That is why western critics of rights abuses should not focus only on abuses of freedom rights or political rights. If they want to counter the argument of cultural imperialism, they should give due attention to every type of rights. Otherwise they allow themselves to be criticized for looking at the problem of human rights from the point of view of rich people only.

In the next Chapter, I will discuss the problem of the priority of certain types of rights, which is indeed a fundamental problem. However, I would like to anticipate the conclusions of this discussion. Economic rights are certainly not more important or more urgent than other rights. In fact, no rights are more urgent than others. Synchronicity is the magic word here. One of the reasons for this is that the different types of rights need each other to function adequately. There can be no trade-off between rights (one type of rights falling into the category of 'basic needs' and the other into the category of 'luxuries'). It is never one or the other, but al ways one and the other. Rights always come in one package, or they do not come at all.

\section{$\S 111:$ The Link Between Identity and the Economy}

The economy, authoritarianism and cultural identity are said to be linked together. The so-called Asian values, such as respect for authority, humility of the individual, the supremacy of the community, discipline, hard work, modesty (instead of exuberant consumerism) etc. are cultural values which are part of an identity, which promote economic development and which are 'naturally' connected to an authoritarian form of government. An authoritarian form of government promotes economic development because it protects the cultural identity and in particular those elements of the identity which promote economic development. The cultural identity and the economy are mutually compatible and mutually reinforcing justifications for authoritarianism because they both require discipline, the subjection of the individual to the community, duties, solidarity, harmony etc.

Economic development is supposed to require a state and a culture that are focused on discipline because it requires production and consumption that are focused on discipline. The mirror image is also believed to be true: the free and individualistic state and culture of the West exemplified in democracy, human rights, pressure-group politics and redistribution based on economic rights lead to an exaggerated focus on consumption, selfinterest, dependence and freedom (never mind the contradiction between dependence and freedom). There is no place for discipline and cooperation in such a system. Western cultures and states are therefore incompatible with economic development. Authoritarian states backed up by cultural traditions based on discipline, duty, social cohesion, control and harmony are better equipped to deliver the necessary conditions for prosperity. The protection of a cultural identity is not only a goal in itself; it is also necessary for economic development. Importing western values would harm valuable cultural identities and at the same time cause economic ruin.

Culture can undoubtedly contribute to economic development - take for example the case of the influence of Protestantism on the development of capitalism - but it is probably one cause among very many (for example democracy and human rights, but also many western technologies). This is corroborated by the fact that A sian countries for example started to develop their economy only recently - if they started at all - whereas their culture is supposed to be very old. Furthermore, economic development is very unequal in countries with similar cultural identities. 
$\S 112:$ A N ew Inversion of $M$ eans and $E n d s(2)$

Critics of western human rights advocates claim that the latter are also guilty of an inversion of means and ends. Westerners use human rights in order to block the economic development of the countries of the Third World, especially those countries which are rapidly growing and are becoming a competitor of the West. They do this by claiming that Third World countries should respect human rights, especially economic rights. However, when they do this, westerners do not have the interests of the workers or the poor people of the Third World in mind. Human rights are not the goal they want to achieve. They use human rights in order to protect their own economy against what it calls unfair competition (cheap products as a consequence of degrading labor conditions and violations of economic rights). This argument against human rights focuses on the way in which these rights are said to hinder economic development in an international rather than a national setting.

One also claims that the West uses political rights and freedom rights for the same purpose, the weakening of the economies of other societies and the strengthening of its own economy. Political and freedom rights make societies more individualistic and therefore less harmonious, less organized, less coherent and therefore economically weaker. Again, the purpose is not to protect these rights, but to protect the advantage of the western economy by way of rights.

It is obvious that there are, in some cases, egoistic motives behind western idealism, but this is not an argument against human rights. You can do good things for bad reasons. In any case, it is not correct to say that human rights, including economic rights, can only be used against economic development. Real economic development takes place at the level of the individual and human rights, including economic rights, are necessary to ensure this kind of development. I will now discuss this point in more detail. 


\title{
Chapter 8: $\quad$ Economic Rights
}

\author{
Section 18: Why Do We Need Economic Rights?
}

\section{$\S$ 113: A N ecessary $\mathrm{M}$ inimum and $\mathrm{N}$ ot a Possible $\mathrm{M}$ aximum}

Democracy and human rights not only promote economic development in the sense of economic growth pure and simple. They also promote equal development and a fair distribution of the proceeds of development, especially but not only by way of economic rights. Respect for the economic rights of individuals does not follow automatically from economic growth. The benefits of growth do not 'trickle down' automatically to all persons who have a right to these benefits, not even when social privileges are abolished and a level playing field of equal opportunities or equal starting positions is guaranteed. The 'Invisible Hand' is invisible because it does not exist. The free market does not automatically generate respect for economic rights. As I mentioned a few moments ago, you can have growth and even prosperity at a general or national level and at the same time persistent poverty for certain groups in society, sometimes even very large groups. If the situation at the outset is unequal, then growth will only confirm and strengthen this ine quality. The rich will profit more from growth than the poor (Donnelly 1996:178). 'If the initial distribution in a trading situation is unequal, the result of trade will be similarly unequal' (Nelson 1980:84). But even if the starting positions are equal - the famous 'level playing field' which never exists - it can happen that some people become rich while others become poor. Talent and natural abilities also play a role. Those are the reasons why we need economic rights. Circumstances, social and economic structures and the natural lottery will lead to poverty for some people. And as we cannot know in advance who will be poor, it is better to provide general rights for all citizens.

The economic rights of all citizens can only be protected in a democracy that protects the 'classical' freedom rights and political rights, because economic rights depend on freedom rights and political rights, which in turn depend on democracy. The term 'classical rights' is a bit of a misnomer. These rights are not older or more traditional than economic rights. The D éclaration of 1793 al ready contained rights for the poor, the workers and the unemployed. The Versailles Peace Treaty also mentioned certain economic rights and the UDHR contains all types of rights without distinction. Furthermore, the idea of 'classical rights' is related to the idea of generations of rights (first, second and third generation). This is also misleading because the word 'generation' can be interpreted as implying conflict and succession, one generation of rights taking over the reign from another and new rights being in conflict with older rights. Nevertheless, I will continue to use the term 'classical'. It is shorter than 'freedom rights and political rights' and everybody knows what it means.

There are many kinds of equality: equal participation in politics, equal rights, equality before the law and also economic equality or the equal distribution of the material goods necessary for survival in a decent way. In the latter case, however, it is not really equality that is at stake. The problem that economic rights try to address is not that there is ine quality and that some people have more than others or have too much of something. The problem is that some people do not have enough of certain necessities (Kekes 1999:97). (This is also the reason why I discuss the problem in this Part and not in Part 4 dealing 
with equality). Nevertheless, I will continue to use the words 'material inequality and equality'. They are, after all, the traditional jargon in this kind of discussion.

However, when I use these words I do not, of course, defend a policy that equalizes all material resources. The policy I defend is one that guarantees a minimum of material means and protection to all people and that uses economic rights to achieve this. This minimum protection is necessary not only for decent survival but also for a meaningful and equal public and political life. Public communication and political participation are impossible if all efforts go into the struggle to survive. This is how economic rights, just as freedom rights and political rights, guarantee public and political life. Human rights protect the entire human being, the mind but also the body, cultural and spiritual man as well as material and natural man (the right to life, physical security and property also have this material flavor, which is a reason not to separate classical rights and economic rights).

The purpose of economic rights is the equal possession of a minimum supply of those fundamental material means which are necessary for the continuation of life in a decent way. If there are some people who have less than the minimum, economic rights will redistribute some of these means. In other words, these rights will take some things away from those who have enough and give it to those who do not have enough. This is possible because, globally or even nationally in some cases, there is enough for everybody. The only problem is the unequal distribution. Economic rights do not try to increase the total supply of material means of existence. Furthermore, their goal is a necessary minimum instead of a possible maximum; a decent way to survive instead of a life of comfort and luxury; things that are essential rather than things that are merely desirable; basic needs rather than frivolous extravagancies.

Everything that can be added to the equal possession of the necessary minimum, can be unequal and fall outside of the competence of economic rights. These rights deal with the basic needs of the poor, not with the fact that some people are rich. However, this added wealth can perhaps influence public and political life. Rich people can benefit more from public and political life, and therefore it seems that some kind of redistribution on top of the redistribution necessary for a decent life, is a prerequisite for political equality. I will come back to this problem in Part 4.

\section{$\S 114:$ In Everybody's Interest}

There are two reasons why economic rights should be applied universally: they address the universal problem of poverty, and they are prerequisites for public and political life. Poverty hampers public and political life in at least three ways:

(1) A poor individual has insufficient access to public and political life because he or she lacks the time, the means, the education and the information necessary for this kind of life. A certain level of detachment from the urgencies and necessities of nature, from basic biological needs and from the struggle to survive, a certain predictable supply of food, a house, good health etc. are all prerequisites for public and political life.

(2) Public and political life in general, for all individuals, whether poor or not, presupposes the equal participation of everybody. The more participants, the better and richer our public and political life will be. (Remember Chapter 1. I will give another example of this in Part 4).

(3) Poverty leads to violence, revolt and hate, and this destabilizes the institutions necessary for the protection of public and political life (this is true also at an international level: economic development of less advanced classes and countries is in the interest of everybody because it takes away the causes of national or international destabilization). 
Economic rights protect everybody's public and political life, not only the public and political life of those who need economic rights to satisfy their immediate basic needs. Everybody, the rich included, benefit from economic rights because they benefit from maximum participation in public and political life and from the absence of violent revolt.

Of course, economic rights are a necessary but not a sufficient condition for public and political life. Classical rights are needed as well. (Because economic rights are a necessary condition, we can conclude that the classical rights are not a sufficient condition either, although they are, of course, a necessary condition).

\section{$\S 115:$ A Hierarchy of Rights?}

Economic rights are important prerequisites for public and political life and for the full use of freedom rights and political rights. They are seldom claimed for their own sake only. They are a means for something else. If they are respected, they take away an obstacle on the road to public and political life and to the full use of classical human rights. They are only the first step on a long journey. There are values other than a decent continuation of life and we need other types of human rights in order to protect these other values. Economic rights are important but insufficient.

Economic rights guarantee the continuation of life in a decent way (not just the continuation of life tout court, because this is guaranteed by the 'classical' right to life) and thereby guarantee the possibility, and only the possibility, of something more, for example a public and political life. They cannot turn this possibility into a reality. Only freedom rights and political rights can do so.

Economic rights are seldom claimed for their own sake because 'darkness rather than want is the curse of poverty. (...) [T] he predicament of the poor (...) is that their lives are without consequence, and that they remain excluded from the light of the public realm' (Arendt 1990:69). 'The poor man's conscience is clear; yet he is ashamed ... He feels himself out of the sight of others, groping in the dark. M ankind takes no notice of him. He rambles and wanders unheeded. In the midst of a crowd, at church, in the market ... he is in as much obscurity as he would be in a garret or a cellar. He is not disapproved, censured, or reproached; he is only not seen ... To be wholly overlooked, and to know it, are intolerable' (J. Adams in A rendt 1990:69). Man is unknown and unseen and, on top of that, he cannot see, he cannot learn from others, follow others, contradict others etc. Economic rights together with freedom rights and political rights take away this darkness and allow people to see and to be seen.

When economic rights satisfy basic needs, they only create the possibility of and some of the prerequisites for public and political life. Contrary to classical rights, they do not create the reality of such a life. Economic rights give access to this life but they do not regulate and guarantee this life. Economic rights have a rather negative role: they taken away the obstacles on the road to public and political life, whereas the classical rights contribute in a positive way because they protect and promote public and political life. Nevertheless, economic rights are very important, even though some people think of them as a joke (when will we have the right to sunshine, do they ask).

I mentioned above that economic rights are necessary for the full use of classical rights. An economic right is therefore a right to a right. We have the right to be in a position in which we can fully enjoy our rights. Economic rights are required in order to establish the conditions necessary for the exercise of classical rights. '[E ]very human person and all peoples are entitled to participate in, contribute to, and enjoy economic, social, cultural and political development, in which all human rights and fundamental freedoms can be fully realized' (Declaration on the Right to Development). However, the opposite is al so true: you have to have classical rights in order to enjoy your economic rights. I will come back to this in a moment. 
The fact that some rights prepare the way for others or are a means to realize other rights, does not mean that violations of these are less reprehensible or that these rights are more urgent. All rights are indivisible and must be respected simultaneously. Freedom of opinion is useless when you have to struggle to survive. Economic rights then seem allimportant and most urgent, but the struggle to survive cannot be settled if, at the same moment, one does not have classical rights as a means to enforce economic rights.

Furthermore, is there anybody who sincerely believes that biological necessity - satisfied by way of economic rights - is the only thing that counts? Public and political life, religion, belonging, identity etc. seem to be more important than natural necessity. If basic needs were the only goal of life, then man could as well be an animal, and I know few people who want to be an animal.

\section{$\S$ 117: Private Life as a Prerequisite for Public and Political Life}

Bad health and suffering create the same problems as poverty. You have to be healthy and without pain in order to have a public and political life and in order to be able to use freedom rights and political rights. A sick, suffering or toiling person is thrown back upon itself and unable to relate to the outside world, just as a person who concentrates exclusively on his or her body for pleasurable reasons. Intense bodily sensations of any kind positive and negative - shut us off from the world, because they make it impossible to perceive anything except our own body. In other words, they make our public and political life and the use of our classical rights impossible or undesirable.

Hunger and consumption as well force you to concentrate on yourself and your body. You do not have the time, the energy or the desire to concentrate on the world. When you are eating or thinking of eating, you are imprisoned in cyclical biological necessities and in your metabolism with nature necessary for the preservation of life. You have to avoid sickness, pain and hunger - as well as their extreme opposites - in order to be open to the world and fit for public and political life.

The fact that economic rights focus on bodily matters as prerequisites for public and political life, shows that they belong to the realm of private life, of things intimate and dark (pain, sickness, bodily metabolism, consumption, dwelling etc.), of things which often cannot even be adequately expressed and communicated in private, let alone in public. The word 'economy' comes from the ancient Greek word 'oikonomia', which means household, the private place par excellence. Of course, the economy and the preservation of life have become increasingly common matters in which, moreover, the state has come to play an important role. Private life has also more facets than purely economic ones. N evertheless, I think I can safely say that economic rights and the economy in general belong to the private sphere (in view of the definitions of both spheres which I have given in Section 1).

The link between private life and economic rights is also apparent from the concept of private property. One of the functions of private property is to satisfy economic needs. Private property guarantees leisure time and the ability to put work to one side. It allows you to stop to paying continuous attention to the appropriation of consumer goods. Private property guarantees future consumption and thereby puts the issue of necessity at a distance Freedom from necessity becomes at least a possibility where there is private property. Redistribution is in fact not an attack on private property; it gives property, sufficient property, to all. Property is, therefore, a prerequisite for economic rights and therefore also, albeit indirectly, for public and political life (not, of course, a prerequisite in the way it used to be, namely a criterion to exclude those without property from politics).

Property is not a goal in itself and is more than a guarantee for private life (see Paragraph 32). It is also a temporary solution to the most pressing problems of natural neces- 
sity in such a way that these problems do not stand in the way of public and political life. The solution is always temporary because necessity always catches up with us. Putting it at a distance does not mean being able to forget it altogether. Freedom from necessity is always a limited freedom. This liberation has to be realized over and over again. Private property assures that this 'over and over again' is somewhat more comfortable and less pressing than it would be without private property. Our lives remain determined, to a certain degree, by nature. We have to act according to the rules of nature, which shows that democracy in the sense of autonomy or self-government is not omnipotent and cannot solve all problems. The link between private property and economic rights is an illustration of the statement that all types or 'generations' of rights are interdependent and indivisible.

\section{§ 118: H umanity}

Nature - in the sense of sickness, pain, hunger and consumption - makes men equal to each other and even equal to many other living creatures. Public and political life, as something which transcends nature, makes men different from other creatures and different from each other. Identity and individuality are part of humanity and can only be found in public and political life (see Section 1), not in nature.

If we believe that identity, individuality and humanity (or the difference between humans and other living creatures) are important, then we should protect public and political life and the institutions necessary to lead such a life. We should, in other words, try to make the world a bit more human and a bit less natural. If we believe that nature is allimportant, then we do not need public and political life, although we may need human rights, economic rights and other rights, in order to realize our natural needs.

However, I believe that the main reason why human beings need human rights, is not the fact that these rights help them to realize their natural needs, but the fact that most human beings do not believe that nature is more important than humanity. Most people believe that there is something more to life than basic biological needs.

Making the world a bit more human means allowing as many people as possible to put their basic needs to one side and to make room for something else, for example public and political life protected by human rights and democracy. Viewed in this way, human rights, including economic rights, are not natural rights but anti-natural rights and truly 'human' rights (Hersch 1988).

\section{$\S$ 119: U niversality Because of Equality (2) and Equality as an Excuse}

The universality of economic rights can be justified in two ways, an indirect and a direct way. Given the universality of freedom rights and political rights and given the fact that economic rights are a prerequisite for freedom rights and political rights, we can conclude that economic rights are al so universal. However, they correspond to something universal in a direct way as well. It is obvious that the basic biological needs which economic rights try to satisfy are needs which are universal and which all human beings have in common (human beings even have these needs in common with animals, which is why it is a priori not impossible to claim that animals should also be able to enjoy some economic rights). And although values such as rights cannot be derived from facts (biological facts in this case), they can be derived from the importance we attach to the fulfillment of biological needs.

However, biological equality as a concept raises some theoretical difficulties. Too much attention to biological equality can lead to a neglect of differences between people and between people and other creatures. Finkielkraut (1997), for example, has criticized humanitarian organizations for not making a difference between those who cause a conflict 
and those who suffer the consequences. From a humanitarian point of view, all suffering bodies are equal and should be cared for, no matter what uniform they wear. Humanitarian organizations often refuse to take sides in a conflict or to criticize governments. Do well and shut up is acceptable for those who are suffering, but it is not a correct way of handling a conflict (Finkielkraut 1997:114). It only encourages those who start conflicts. The suffering of the victims is comparable to the suffering of the perpetrators and deserves the same attention, but this equality does not dissolve every difference between the parties. Man is more than just pain and illness. The suffering person is somebody with a personal history and purpose, with responsibilities and maybe even guilt. The victim often suffers precisely because of his or her personality, history, belonging, ideology or whatever. If, for example, we see the Jew as a suffering person and not as a person suffering because of his or her Jewishness, then we miss something fundamental. This person is a target for a particular reason and is not interchangeable with any other target, even though, at the level of suffering, he or she is interchangeable with any other target.

A humanitarian organization or a doctor must care for people without distinction, without looking at responsibility, origin, history or whatever. However, not everybody is a doctor or a member of a humanitarian organization and not everybody has the same limited attention to physical things. There are other things in the world than those related to the body - for example responsibility, identity etc. - and the people who are not doctors and are not active in humanitarian organizations should pay attention to these things and should not take over the limited point of view of those caring for suffering people. There is a difference between aggressor and victim, between aggression and misfortune, between a natural disaster and a disaster caused by human hands, between a disaster without and a disaster with a reason (Finkielkraut 1997:119). Suffering has to have a name, a history, a motivation and a reason.

\section{$\S 120:$ Insufficient Conditions}

Of course, neither economic rights, nor classical rights are sufficient conditions for public and political life. No matter how many material means we have and no matter how effective our legal and political guarantees are, if there is no will and no interest, or if we focus exclusively on our natural life, on consumption and entertainment, then there will be no public and political life and none of the values guaranteed by this life. Even the best supermarkets, doctors, lawyers and judges in the world cannot guarantee our public and political life. In order to have a public and political life, we need some kind of discipline and power of the will in order to resist the often overwhelming temptations of natural needs, and this is true in a situation of scarcity as well as in a situation of abundance Maybe even more so in the latter situation. The permanent offer of consumption, amusement and emotions often makes it hard to rise above nature and to prefer something more intellectual such as art or politics. In modern western societies, conviction and power of the will seem to be more important conditions for public and political life than judges, laws, democracy, doctors and farmers.

Contrary to the conditions created by economic or other rights, the government cannot help to realize subjective conditions such as discipline and will-power. If it would try to help, it would quickly turn out to be an 'imperium paternale', Kant's paternalistic empire trying to make people happy and virtuous against their will. Dictatorship is the inevitable result of forcing people to be free, of educating them toward a higher way of life, of 'emancipating' them, of making them 'autonomous' etc. Public and political life has to be a free choice Everybody must be allowed to decide autonomously on his or her plans for life. Nobody has a superior knowledge of the good life and nobody can decide for other people what their lives should look like. I will come back to this in Part 5. 
Section 19: How Do We Promote Economic Rights?

\section{$\S$ 121: Public and Political Life as a Prerequisite for Private Life}

There is yet another instance of reverse causation in the theory of human rights. Economic rights promote public and political life, but public and political life also promotes economic rights. It therefore helps to eliminate many of the material facts that restrict its own functioning (that restrict, for example, the equal access to public and political life, that endanger its stability etc.). Classical human rights and democracy, which guarantee public and political life, make it possible to show, challenge and change many of these material facts. When you engage in public and political life and use the institutions which protect it, you can express and realize claims for the protection of economic rights.

It may be useful to recall an anecdote from Ancient Rome, transmitted to us by Seneca (see also A rendt 1983:280). At a certain moment in the history of Rome, it was proposed that slaves should wear a uniform, which would allow them to be recognized instantaneously. However, the proposal was rejected because it was considered to be dangerous. It would allow the slaves to recognize each other, to become aware of their number and their power, and it would allow them to band together. A ppearance is power. The first labor movements applied the same principle and used a uniform to distinguish themselves and to make a mark in political life. This uniform gave them their name during the French Revolution (they were called the 'sans-culottes' because they wore trousers buttoned up in the manner of a jacket). A ppearance can play a role and can improve the protection of human rights in general and economic rights in particular, even in a situation in which appearance as such is not or not sufficiently protected by human rights.

Does the use of freedom rights and political rights for the promotion of economic rights not contradict the fact that the latter rights belong to the private realm? It does not, because a public and political struggle for basic needs is not the same thing as satisfying these basic needs. Those who are active in a labor movement or a socialist political party do not work. They engage in a public and political struggle.

Because classical rights promote economic rights and therefore also eliminate certain elements which exclude people from public and political life, we see that the public and political space expands through its own efforts. In the previous Section, I showed how economic rights promote classical rights. Both types of rights need each other, strengthen each other, are dependent on each other and are necessary conditions for each other (just as freedom rights and political rights need each other; see Chapter 3). The full use of classical rights requires the realization of economic rights, and vice versa. It is therefore nonsense to say that one type of rights should be sacrificed for another type, even if this is only temporary.

In view of the indivisibility of human rights, I can conclude that human rights, and I mean all types of human rights, are not politically or ideologically neutral. They require a democratic form of government and are required by this form of government. This is also true for economic rights. Democracy and human rights are not only a logical or moral necessity; they are also an economic necessity. 
Can this indivisibility not lead to a freeze in participation instead of an expansion of participation? If different rights are dependent on each other, how can they promote each other? If the material circumstances are such that freedom of opinion or the right to political participation is difficult to use, then how can this freedom and participation be used to improve material circumstances? 'The cure for poverty and the in equalities it breeds is the empowerment of the poor as citizens - even though paradoxically it is those same inequalities that stand between the poor and their citizenship' (Barber 1984:xvi).

However, this freeze is not inevitable. It is never completely impossible to use rights. There is al ways some freedom of opinion. Moreover, you do not have to claim or participate in politics on your own behalf. You can claim rights or participate in politics on behalf of somebody else, someone who finds it difficult to do so himself. This is of course true for all types of rights, not only for economic rights (see for example the rights of small children or persons in a state of coma). History shows that there is an expansion of the public and political space in those countries in which the public and political space is guaranteed by classical rights.

\section{$\S$ 123: The $\mathrm{H}$ ierarchy of R esponsibility, D uty, A ssistance and Redistribution}

N ot only the state has a duty to protect economic rights. The individual should also intervene in order to realize the economic rights of his or her fellow citizens. He or she can intervene in different ways: through caritas or altruism, through negotiation, bargaining or exchange etc. It is only when these interventions fail or never take place, that the state must act by way of redistribution. After all, redistribution is a limit on freedom and on property rights and should therefore be kept to a minimum.

All human rights, including economic rights, are rights erga omnes. Everybody has rights with respect to everybody else and everybody has a duty to respect and realize all the rights of everybody else. The responsibilities arising from economic rights are individual duties just as the duty to respect and tolerate other people which arises from freedom rights. However, the duties arising from economic rights are, to a larger extent than the duties arising from freedom rights, duties to intervene and assist and not primarily duties to abstain (see Chapter 2).

Of course, our duties arising from economic rights are not the same towards everyone. In general, we have more duties towards certain persons than towards other persons. This is because of the principle 'ought implies can' (if you cannot swim, then you do not have a duty to rescue persons from drowning), which is a general principle of law. N one of us can give material assistance to everybody in need of assistance. We all have a limited amount of resources, and even if we have more than we require for our basic needs, we will not be able to assist everybody. That is why we have to be selective. Our own children, for example, take precedence. We have more duties towards our children than towards other people. Closeness means that you can do more, and if you can do more, you ought to do more. Can also implies ought. Closeness, therefore, plays a part in the degree of duty, although not in the existence of duty. If we can help everybody, then we have to help everybody. This is especially the case for wealthy groups - for example a wealthy country or a group of wealthy countries - that can help many people and maybe even everybody.

The possibility to fulfill a duty is a very important factor in establishing responsibility. This means that those who cannot, should not, and those who can do more, should do more. Wealthy individuals and wealthy countries should do more because they have more means to assist. They have no problems satisfying their basic needs; they even have more than is necessary and can easily do without a part of this surplus. Assistance is a duty, not a choice, and people have a right to assistance. 
On the other hand, assistance should not become the rule. If possible, people should be self-supporting and independent. Your first duty is a duty to yourself. Dependence can be comfortable, but it is incompatible with freedom and autonomy. If freedom and autonomy mean anything to you, then you should try to be self-supporting. Your duties towards other people come into play only when these people cannot be self-supporting. You can be too serious about your duties. Offering assistance to those who do not need it can lead to a mentality of dependence and laziness. It can also be seen as paternalism, a lack of respect and unnecessary interference However, even those who need assistance should be guided towards independence Assistance is an option only if and as long as independence is impossible. We should try to create the circumstances in which people can satisfy their own basic needs (or at least we should not eliminate these circumstances) and economic rights are necessary only when we fail to do this. When economic rights become necessary, then they do so first in a face-to-face situation and then - on a larger geographical scale - in a situation where one person should help other and more distant persons (if the surplus is large enough). Only if all this fails can the state intervene. Duty is a bottom-up affair.

Economic rights should not be viewed as primarily the business of the state, otherwise we would lose the benefits of self-support and spontaneous mutual assistance (these benefits are for example freedom and community spirit respectively). We would create a mentality of passive reliance on government support (for yourself and for others) and a mentality of dependence (state help kills self-help). Egoism, isolation, irresponsibility and helplessness would become the main features of society. We would only have rights and no duties, rights moreover which only the government should respect and realize. In order to avoid this, people should be allowed to act responsibly. They should be responsible for themselves and for others, and the state should not take away this responsibility without good reasons (for example the responsibility of parents to care for their children or the responsibility of individuals to find a job).

The state is responsible for economic rights only if everything el se fails. Only those who are helpless and who have been forgotten by private philanthropy can call on the state for assistance. In this case, the state does not abstain or does not make laws which forbid something; it executes policies that result in an equal supply of those goods and services necessary for the satisfaction of basic needs. These policies are mainly taxation and redistribution and can be seen as the enforcement of citizens' duties. When the state forces you to pay taxes, it forces you to fulfill your duties arising from the economic rights of your fellow citizens (which is why tax fraud and tax evasion are particularly reprehensible crimes: the existence of taxes is al ready a stain on the reputation of mankind, because taxes exist as a consequence of the fact that people deny their responsibilities). It is the duty of the state to force the people to fulfill their duties, their duty to be self-supporting if possible and their duties towards each other if necessary. Government policies of this kind are commands and not prohibitions.

The most common reason to reject economic rights is that they are said to cause an unacceptable increase in the size and power of the state and a corresponding and equally unacceptable reduction of freedom. An oversized state also hinders the private economy and therefore hinders the creation of prosperity. Developing the government machinery in order to promote economic rights is then self-defeating because, in the long run, an oversized state will destroy the prosperity which it wants to redistribute. It follows that economic rights are not only useless, but also harmful because they lead to the exact opposite of what they want to achieve. However, this argument is not as strong as it seems if the realization of economic rights is first of all the responsibility of citizens. Economic rights can even counter the tendency of a state to increase its size and power. People whose economic rights are realized are in a position which allows them to resist illegitimate usurpation of power.

The globalization of the economy is a problem for economic rights. States have lost their grip on multinational companies, on financial flows, on tax evasion etc. Getting the necessary revenues for redistribution has become a serious problem for most states. Glob- 
alization is also a problem for classical rights. These rights need government activity just as any other rights and there is no government activity without revenues.

In the preceding sentences, I may have given the impression of artificially limiting the significance of community life. Of course, a community is much more than a means to realize economic rights. The community is also a goal in itself. Belonging is very important as such, irrespective of the role it plays in protecting economic rights. However, the point is that the feeling of belonging can be strengthened by allowing economic rights to be realized at the level of citizens' relationships. The fact that our economic rights are realized in part by our responsible fellow citizens, enhances community feelings and again supports the statement that human rights do not only deal with the relationship between citizens and the state.

\section{$\S 124$ : Enforcement, Resources and the Long Term}

Everybody can declare rights. Realizing rights, turning words into facts, is quite another matter. Economic rights are, compared to other rights, often very difficult to realize because they are more costly. They require relatively high levels of intervention and relatively low levels of abstention. Intervention is, of course, much more expensive than abstention. In addition, governments cannot have a duty to do things that they cannot do. They cannot be forced to do things for which they do not have the resources. This is the case in many developing countries (even though most of the violations of economic rights are not the consequence of insufficient resources but the consequence of an unjust distribution of resources, in which case economic rights can be applied immediately). We can expect these countries to respect freedom of opinion, at least to the extent that government abstention is enough to guarantee respect of this right (sometimes court actions and police actions are also required, and these actions cost money). We cannot demand that they create enough prosperity for everyone if they lack the resources to do so. Again, ought implies can.

Rights have to be enforceable, otherwise we are dealing with aspirations or desires rather than rights. There is no right without a remedy. If a right is violated, it must be possible to redress the situation in a court of justice It has to be possible to find somebody who is responsible for the violation and who can stop the violation. It is no use having a right when nobody can be forced to respect it because nobody has the power to respect it. Take for example the 'right' to have a climate in which the sun always shines and in which the temperature is constantly between 25 and 27 degrees Celsius. This can be a desire but it can never be a right because it is not enforceable. There is no remedy if it is violated; there is no way to redress the violation. A court of justice cannot decide that the government should take action to realize this 'right'. Nobody is responsible for a violation and nobody can stop a violation. Nobody can be forced to respect the 'right' because nobody has the power to respect it.

Some say that the same is true for economic rights. What we do in the case of a violation of classical rights - ask a judge to force the violator, for example the government, to respect our rights - is impossible in the case of economic rights. If there is no work, then a judge cannot force the government to give us work. According to many libertarian thinkers, the best we can do is limit ourselves to classical rights. A fair distribution of prosperity will follow automatically from freedom. Only free trade and the actions of the private sector can guarantee economic rights, not the actions of government. The latter will lead to unacceptable burdens on business and private initiative and will therefore undermine rather than promote economic rights. Free trade, deregulated markets and minimum taxes will allow profits to increase. These profits will then be invested and these investments will increase economic productivity and therefore also prosperity. If low taxes lead to large profits and large profits lead to an increase in prosperity and growth, then this will benefit the poor because they will have a job and an income. All boats rise on a rising tide. Those making large profits will not only invest in production units and in labor; they 
will also spend money on consumption which again creates jobs and profits for 'small' people. Furthermore, inequality is an encouragement to do well economically, because doing well economically is rewarded in an unequal society. Inequality therefore leads to economic growth which benefits everyone.

A ccording to this view, there is no reason for state intervention in the economy or for redistribution of wealth. The state, looking for measures to promote economic rights, thwarts the free actions of businesses because it imposes heavy administrative and financial burdens on businesses, making it impossible for them to create and distribute prosperity. There is no reason to have economic rights. Everything will happen automatically. Economic rights can even harm prosperity. The question is, of course, why the free market, in its long years of existence, has not realized economic rights and instead has led poverty, exploitation and the creation of labor movements.

I admit that business has to play a part in the realization of economic rights, just as everybody else. However, it will probably not do so automatically as a consequence of its normal activities, i.e. profit-making. It has to be conscious of its moral duties and act accordingly. If it fails to do so, the state has to intervene and has to redistribute what is not redistributed voluntarily or automatically. Of course, some things do indeed 'trickle down' automatically (more flourishing businesses means more jobs for instance), although this is never enough to compensate for the many things 'trickling up' (for example the 'surplus-value' created by workers and expropriated by entrepreneurs who pay the workers only a part of the value that they create by working). A free market can indeed help to realize economic rights, whereas an oversized state can harm economic development and can therefore diminish the prosperity which can be redistributed. Classical rights as well can help in the struggle for economic justice, as I have shown before.

However, freedom is not enough, as is proven by experience The policies of Reagan and Thatcher promoting the free market and trickle down economics have led to social catastrophes (their economies were in fact 'trickle up economics'). Economic rights and state activity for the realization of these rights are necessary. The state must intervene when free trade, classical rights, trickle down economics etc. fail, and the state needs economic rights as the norms of its intervention or as standards of achievement.

Be that as it may, what must we do if the state cannot do what it should do? I would like to stress four points which can clarify the discussions on resources and on the possibility of fulfilling the duties inherent in economic rights. Firstly, classical rights also require certain resources and certain actions of the state, although perhaps less than economic rights. Abstention is never enough. Secondly, if a state cannot fulfill its duties inherent in economic rights, then other states or the international community have a duty to assist this state (art. 2 of the ICESCR is a possible candidate for this rule). There is prosperity enough in the world to guarantee a decent existence for everybody. Governments do not only have duties towards their own citizens and citizens do not only have duties towards their fellow citizens (development aid on the basis of taxation is one way to fulfill international duties, although voluntary assistance and measures leading to selfsupport are again preferable, for the same reasons as those mentioned above).

Thirdly, if everything else fails, economic rights can be considered as requiring only progressive achievement. In the short run, a steady progress in, for example, the standard of living or the amount of leisure time etc. can be satisfactory. If it is impossible to enforce economic rights immediately and completely (for example by way of a court action or by way of international assistance), then this is the next best thing. National and international policies will then aim at the long term realization of economic rights and these rights will serve to monitor progress and to convince states and the international community to do as much as possible to realize these rights as quickly as possible. The same is true for classical rights. In some countries, particularly those countries whit a long tradition of authoritarian rule, it can be very difficult to install a system which instantaneously respects all classical rights. Progressive achievement is often the only possible strategy for both economic and classical rights. 
Finally, rights in general are maybe most important when they are not enforceable, because then they are a force for change, change which will lead to a situation in which these rights become enforceable. Economic rights, even when not enforceable, serve as a justification and an encouragement for poor people struggling for a better life. They serve as an authoritative and internationally recognized language which is very useful for $\alpha$ pressing claims (to claim rights is more dignified than to beg). Rights can mobilize people. Anyway, some of the economic rights are enforceable in all circumstances, both in rich countries and in poor countries, with and without international assistance (for example the right to strike and the free choice of labor). In many countries, classical rights are not enforceable either because the necessary legal means are not available. This, however, does not make them useless.

This is the reason why another traditional criticism of economic rights, this time coming from the left of the political spectrum, is just as meaningless as the criticism coming from the side of libertarians. The left criticizes the difference between rights and reality. In theory, all people have economic rights, but we often see little of this in reality. The invention of a noble concept does not seem to change reality. However, if rights were to coincide with reality, then it would be doubtful why these rights should exist in the first place (there is, after all, no right to use toilets). 'Realistic' laws are not necessarily the best laws, no more than unrealistic laws. It is good to have some tension between law and reality. Laws should reflect aspirations and desires instead of reality (but should not be unrealistic either) and if they do, then they can change reality. The difference between having a right to something and having something, or the difference between the recognition of a right and the enforcement of a right is not inevitable. Those who do not have what their rights say they should have are not the victims of a necessary order of things, of nature, fate or whatever. They are the victims of human injustice which can be re dressed. There is enough prosperity in the world to guarantee a decent existence for everybody. It is only a matter of distributing things fairly. If this distribution is not yet a reality, then the victims of injustice are victims of their fellow men.

The fact that there is an international duty to assist states which find it difficult to realize economic rights, can help to solve the problem of whether to accept economic refugees. These refugees are fleeing from human rights violations, just as political refugees. The right to asylum should therefore al so protect these persons. However, economic refugees are potentially very numerous and this is the reason why asylum countries often impose limits on the number of economic refugees they accept. If they accept too many, then these countries will destabilize their own economies and would therefore destroy the possibilities to help asylum-seekers. Accepting economic refugees in asylum countries is, however, the last step in a long chain of responsibility and would not be all that problematic if responsibilities were assumed at all the preceding levels. The international community should first try to solve the economic problems in the countries of origin - for example through development aid - because the first objective should be self-support. Development aid in general and especially development aid aimed at self-support would automatically lower the number of people seeking asylum as a consequence of violations of economic rights. 
Table 1: The Hierarchy of Duties and Responsibilities

\begin{tabular}{|c|c|}
\hline The hierarchy of duties & M eans to fulffll these duties \\
\hline (1) The duty towards yourself, self-support & $\begin{array}{l}\text { Private property, public life, claiming rights, participation in poli- } \\
\text { tics }\end{array}$ \\
\hline (2) The duty towards those close to you & $\begin{array}{l}\text { Caritas, voluntary redistribution, public life, claiming rights for } \\
\text { others, participation in politics for the sake of others }\end{array}$ \\
\hline (3) The duty towards fellow man in general & $\begin{array}{l}\text { Caritas, voluntary redistribution, public life, daiming rights for } \\
\text { others, participation in politics for the sake of others (the fact that } \\
\text { duty (3) comes after duty (2) should not be construed as legiti- } \\
\text { mizing selective compassion, chauvinism etc., even though close- } \\
\text { ness can also justify selectivity in international matters - neighbor- } \\
\text { ing countries are often better placed to assist than countries which } \\
\text { are far away) }\end{array}$ \\
\hline (4) The duty of the state towards its own citizens & Forced redistribution aimed at self-support \\
\hline $\begin{array}{l}\text { (5) The duty of states towards citizens of other } \\
\text { states }\end{array}$ & $\begin{array}{l}\text { Development aid as a type of forced redistribution, aimed at self- } \\
\text { support }\end{array}$ \\
\hline
\end{tabular}

$\S 125:$ The Right to Property and the Right to the Property of Someone EIse

In cases 4 and 5 of the preceding table, economic rights contradict or limit the right to private property, even though this right supports and protects economic rights in case 1 (as I have shown before). Forced redistribution means, of course, the loss of property, and can only be avoided when one believes that the total supply of prosperity can be increased in such a way that assisting the poor does not mean taking away something from the rich. This view is, however, highly problematic in our age of ecological problems.

Rights have to be balanced against each other. Respecting one right often means limiting another. This is true even for rights of one and the same type (freedom of expression must often be balanced with the right to privacy for example). Respecting the right to private property in all cases, even when some people are starving, is unacceptable. Rights should not be used to protect the rich against the poor. If rights mean anything, then things should be the other way around.

However, this does not mean that economic rights are specific rights for certain groups (i.e. poor people), framed to protect the class interests of these groups at the expense of the class interests of other groups (i.e. rich people). Economic rights are universal and equal rights, just as all other human rights. They protect the general interest. Everybody can become poor and sick, everybody has certain necessary basic needs and everybody has an interest in the equal participation of all in public and political life (see above). Some people may not need economic rights, or at least not for the moment. However, the same is true for other rights. Most people in the West, for example, do not need the right to free speech because this right is so evident that is has become almost as normal as breathing air, at least in most cases. Because economic rights try to guarantee a minimum prosperity, it is quite normal that they protect only the interests of those lacking this minimum prosperity. Government activity is indeed only justifiable when everybody can equally enjoy the benefits of this activity, but economic rights do not violate this rule. Everybody who needs human rights, can enjoy them. Those who do not need the right to freedom of expression or the right to work, because they can express themselves freely and because they have a job, are not treated in an unequal way and do not benefit less from government activity. Economic rights do not treat people in an unequal way. On the contrary, they try to eliminate inequality and discrimination. 
Balancing rights is never easy. If we wish to limit property rights by forcing some people to share their wealth with other people, then we have to be aware of the importance and of the many functions of property (see Chapter 1). We have to take all the consequences into account. The property that is left after satisfying our own and possibly other people's basic needs, retains its use. We should, if possible, avoid taking away someone's property - for reasons of redistribution - if this means leaving just enough to satiffy this person's basic needs. Property that we do not need for our own basic needs, should of course be used for the basic needs of others who do not have enough property. However, it should not be used only for this purpose. Property is not immoral when it is used for things other than basic needs. Property is a right of poor people, but not only of poor people.

If poor people do not have enough property, then they have a right to the property of those who have enough, or at least to a share of the property of those who have enough. Nobody has a right to all the property of someone else, because that would mean turning the tables, filling a hole by digging another one. 


\author{
Part 3: $\quad$ Peace \\ Chapter 9: $\quad$ Peace B etween States \\ Section 20: Self-determination, Version 1
}

$\S$ 126: Self-determination: A H uman Right and a Right of a State

Peace or the absence of war and violent struggle is, of course, another important prerequisite for democracy and human rights. Human rights and the principles of democracy are heavily violated in times of war and this is even necessary. And although many human rights violations committed in the course of a war are not necessary, it is impossible to insist that all human rights and democratic principles be fully applied in a war situation. A war, because of the urgency it creates, makes it very difficult to respect certain democratic habits, such as the consultation of large parts of the population, the thorough examination of all alternatives etc. A strong, individual leadership seems better adapted to the urgencies of war. On top of that, the war effort and the war industry require a unity of vision and a high level of cooperation without dissent. Dissent can harm the struggle for survival. It weakens the effectiveness of common actions and it can be exploited by the enemy. In a state of war, society and politics take over many of the undemocratic habits of the military, such as discipline, strong leadership, the absence of criticism, uniformity instead of diversity and so on. Needless to say that a war also means human rights violations. The war industry as well can harm human rights, for example the rights concerning free choice of labor, good working conditions etc.

A right to peace would, therefore, be very useful. I will show that democracy and human rights do a lot to create and maintain the peace they need for their own functioning (in much the same way as they create the economic conditions necessary for their own functioning), and this is true for both international and intra-national peace Assuming that peace - peace as such, and not peace as a precondition for democracy and human rights - is a universally accepted value (which is a reasonable assumption), we have another reason for the universal acceptance of democracy and human rights. I will discuss the link between democracy and human rights on the one hand and international and intra-national peace on the other hand in this and the next Chapter respectively.

The right to self-determination is a human right (see article 1 of the ICCPR) and is at the same time a particularly important instrument in the protection of international peace This right has two different but closely connected meanings: self-determination means either the right of a people to have their own state, or the right of a state - and therefore also of a people - to be sovereign and independent, to retain its territorial integrity and to be free from external interference.

The right to self-determination in the latter meaning (I will discuss the former meaning in another Section because it is more closely related to the problem of intra-national peace) is a necessary condition not only for international peace but also for democracy and human rights in general. Democracy in particular but also human rights can only 
function adequately in a situation of national independence and sovereignty. It is the independent state which makes a democratic political life possible and which is able to enforce human rights. If another state or group of states attack an independent state and take away its self-determination, then we not only see the end of peace but also the end of democracy. Democracy is, after all, a people determining their own fate and is there fore incompatible with foreign occupation.

Furthermore, human rights will suffer. During the conflict, human rights will suffer because of the conflict, but they will also suffer after the conflict and during the occupation. A state which attacks and occupies another state is not likely to be in favor of human rights. If Germany had not invaded Belgium in 1940, Belgium would probably have continued to protect human rights within its territory, even though this is of course not a certainty. The absence of external attacks on national sovereignty and self-determination by a hostile and authoritarian state is a necessary but not a sufficient condition for the maintenance of human rights. Human rights can be attacked from the inside as well, in which case sovereignty is of no use for the protection of human rights, on the contrary. (External attacks by a democratic state are impossible, because this state would then no longer be democratic; attacking another state's self-determination is attacking democracy, except of course when the attack is aimed at introducing democracy in another state; see the next Section).

In any case, even if a state does everything within its power to protect rights and de mocracy from the inside, this will be useless if the state is not master of its own fate, if it cannot guarantee self-determination and self-government for its people. A state has to be sovereign and free from interference if it wants to be able to guarantee human rights and democracy within its territory. If there is interference, then a state must have the means to repel it. The right to self-determination implies the right to self-protection and the right to national liberation.

A state has a right to protect itself against or liberate itself from hostile states because a state is the most important instrument to guarantee democracy and human rights. However, the state must be protected against other threats as well. As I mentioned before, the globalization of the economy, the power of multinational companies, the free flows of money and the loss of fiscal revenues may have an even greater effect on the ability of states to protect human rights and democracy.

\section{$\S 127:$ A N ecessary Condition and an U nnecessary 0 bstacle at the Same Time}

Unfortunately, interference is often necessary in order to force states to respect the rights of their own people. Most violations of human rights do not result from international conflict, occupation, interference etc., but from the way in which a state treats its own citizens. A state that violates the rights of its citizens can use the concepts of selfdetermination, self-government and sovereignty in order to silence other countries which criticize these violations. It can also use these concepts to defend itself against states wanting to interfere in order to stop rights violations. Self-determination can protect human rights because it can be used against external domination, but it can also protect violations of human rights because it can be used to support internal domination. It is obvious that the right of a state to self-determination should not apply in the latter case. Just as most other rights, the right to self-determination is a limited right which must be balanced against other rights. It must be possible to intervene in one way or another in order to stop violations of human rights, in the same way as we must be able to limit the right to private property in order to stop violations of economic rights. The right to intervention then takes the place of the right to self-determination as a means to protect human rights and democracy.

Self-determination cannot be an excuse for rights violations because it is itself a human right and because its main purpose is the defense of human rights. Of course, it is not the only instrument to defend human rights. It is only useful in a situation in which one 
country is attacked by another. In other situations, for example a state that the rights of its own citizens, intervention may be more appropriate. However, in the latter situation, there are also other ways to change the behavior of the state. A revolution is a possibility and should therefore also be a right. I will come back to this in a moment.

The same is true for democracy. The concept of self-determination is often used to protect undemocratic regimes, although self-determination is only another word for democracy. Again, intervention must be possible to (re)instate democracy. Self-determination can only be used against anti-democratic intervention. Intervention, however, is only one of many options. As in the case of human rights, revolution is a possible alternative.

It is obvious that both the right to intervention (especially military intervention) and the right to revolution should be handled with the utmost care. You have to have good reasons to intervene or revolt because intervention and revolution can harm international and intra-national peace respectively and can therefore also harm human rights. This means that human rights violations must be very important before you can consider using intervention or revolution as a means to solve these violations. The cost for human rights can never be higher than the benefits. This is undoubtedly the reason why there is no international agreement on the legal status of these two rights. However, I would like to focus on the topic of intervention for the moment (I will deal with the problem of revolution in another Section because revolution is a possible cause of war within a state and not of war between states, at least not directly).

\section{$\S$ 128: Realism and M oralism (International P eace, Rights and D emocracy)}

'Realism' is one of the main schools of thought in the theory of international relations. According to realists, the international system of states should be considered without looking at the internal policies of states. They believe that the international behavior of states is, to a large extent, independent of their internal policies. War, for example, is not in the first place a consequence of internal policies or ideologies but of the relationships between states (balance of power, protection of allies, arms race etc.). The main objective of foreign affairs policies should, therefore, be the promotion of good and peaceful relations between states, not the promotion of human rights for example. Promoting human rights means interfering in the internal affairs of states and this interference can threaten the peace

However, it is obvious that the internal policies of a state determine its international behavior and determine the way in which the rest of the world reacts to this state. A state that violates the rights of its own citizens will have few moral reasons not to invade or attack other states. A state that, on the contrary, protects the rights of its citizens will have such reasons (human rights are after all universal rights). Even more so, it will feel insulted by rights violations elsewhere and will be inclined to take actions against states which violate the rights of their own citizens. In view of the influence of internal human rights policies on the external behavior of states, actions to improve the human rights situation in other states can have a positive influence on international peace

Of course, these actions can also harm the relationships between states, especially in the short run. This is why realists do not like international pressure in favor of democracy and human rights. According to them, this pressure will threaten the peace Democracy and human rights are all right as long as they are not considered to be universal. It is very dangerous to act in an antagonistic way towards oppressive states, especially in the nuclear age. Human rights pressure - even if limited to rhetoric - can also undo all efforts of détente and disarmament, which again endangers international peace

However, there is more to life than peace Peace is not the only value. It is probably not even the most important value. Oppression and peace can go hand in hand. Sometimes, you have to sacrifice or endanger peace for the sake of some other values. Foreign policy should therefore be 'moral' as well as 'realistic'. 


\section{$\S 129:$ A C onsistent System of Rights}

The fact that the right to self-determination is a necessary condition but not a sufficient condition for the protection of human rights and democracy, together with the fact that this right can sometimes be limited (i.e. when it is used to protect violations of rights), supports the statement - elaborated in Part 2 - that the state is not the only institution responsible for the protection of democracy and the rights of its citizens. Individuals and the international community are al so responsible.

The right to self-determination is necessary only for those states which protect democracy and the human rights of their citizens and which are threatened by other states. If states use the right to self-determination in order to protect violations of rights, then the right to self-determination should give way to, for example, the right to intervention or the right to revolution.

Self-determination not only causes oppression when someone uses it a posteriori in order to fend of external interference aimed at the elimination of oppression. Oppression can be the consequence of too much emphasis on self-determination. You can cause oppression 'en plaçant les exigences du collectif au sommet des impératifs actuels, en maintenant le peuple en alerte permanente contre les menaces pesant sur la sécurité de l'ensemble (...). A lors, I'urgence de la sauvegarde commune rejette dans le futur le soin du sort de chacun' (Mourgeon 1996:45).

However, the fact that the right to self-determination can be abused is not a sufficient reason to abolish it. All rights can be abused (for example, the freedom of expression can be used to overthrow democracy; the right to property can be used to justify egoism etc.). That is why it must be possible to limit rights. A state is free to determine its own fate, but not absolutely free. There is no right to be anti-democratic. Such a right would introduce fatal inconsistencies in the system of human rights (human rights need democracy, see Chapter 3). The self-determination of the state should always be a means for the selfdetermination of the people, for democracy in other words, and that is why it can never be an excuse for rights violations. Otherwise we would introduce an inconsistency in the system of rights (a system of rights can never include a right to violate rights). A state's right to self-determination is not a right to treat its citizens in any way it wants. Selfdetermination does not mean that human rights are a matter of national sovereignty in which others have no right to intervene. Rights are not an internal affair. 


\section{Section 21: $\quad$ Other Ways in Which Rights and Democracy}

Protect the Peace Betw een States

\section{$\S 130:$ A greements, Publicity and Popular Support}

Universal human rights and democracy combined with intervention as a means to achieve this universality, are indeed possible sources of international tension and international war. If some states interfere in the internal affairs of other states in the name of some theory of universality, then this can harm the good relations between states. Supporting dissidents and rebel movements, denouncing certain events or practices and denying development aid may improve the rights situation but can also cause reactions. States will defend themselves and this will endanger the peace However, if you prohibit the protection of human rights because of the threat to peace, then you might as well prohibit protection against thieves and murderers, because this kind of protection can also harm the peace. Conflicts and violence are not caused by those who protect rights, but by those who attack rights.

The right to self-determination is not the only way in which human rights and democracy protect international peace It is a well-known fact that democracies do not wage war among themselves, mainly for the following reasons:

- Democracies are able to make and keep international agreements and to create mechanisms which make it possible to solve international conflicts in a peaceful way. Publicity, as we find it in a democracy, tends to enhance respect for agreements be cause it makes it harder to cover up violations of agreements. A mentality of respect for the law, which is typical of a democracy because the rule of law is typical of a democracy, promotes respect for international agreements.

- Democracies are able to avoid civil strife because they have judicial systems for solving conflicts between persons or between groups (see Section 2). Civil strife often spills over to other countries and can cause international conflicts (international violence is often the consequence of internal violence). Therefore, avoiding civil strife means avoiding international conflicts. Tolerance, respect, religious freedom and nondiscrimination, as guaranteed by human rights, also protect civil peace and therefore international peace

- Democracy also promotes peace because it provides mechanisms for the peaceful transition from one ruler to another. There is no need for a violent succession struggle which can have international consequences. Opposition movements do not have to re sort to extreme tactics in order to prove their point or to take over power. Leaders do not need to engage in dangerous international adventures in order to increase their legitimacy etc.

- Governments which treat their own people with tolerance and respect tend to treat their neighbors in the same way.

- Governments which cannot force people to do something against their will, will find it much harder to go to war. The people most often do not want to go to war, because it is they who suffer in the first place. To some extent, a tyranny does not need the agreement of the people to start or continue a war. 
The universality of democracy and human rights is important for everybody because the absence of war is important for everybody. Democracy and rights are important values because peace is an important value. Democracies avoid wars, whereas tyrannies cause wars. Tyrannies violate human rights and these violations make it very difficult to maintain the rule of law (different human rights institute the rule of law, and the indivisibility of human rights means that the whole body of human rights is in danger when some human rights suffer). Without the rule of law, it is very hard to maintain a justice system which can channel conflicts away from violence As a consequence, these conflicts can escalate and can become violent. People start to take the law in their own hands and to steal in order to compensate for goods stolen. Revenge is seen as the only alternative for justice, and revenge tends to escalate. Large-scale conflict and civil war become a very real threat. And civil wars have a tendency to become international wars.

Moreover, violations of human rights create anger, frustration and revolt (this is true for all types of rights, economic rights included), and can therefore be a direct cause of civil war. And civil war can lead to international war. There is an even more direct link between rights violations and international conflict. Rights violations can create tensions with neighboring countries because of refugee flows which result from rights violations or civil war. Neighboring countries can decide to intervene in these rights violations or in a civil war in order to protect their own safety and prosperity. This intervention can, of course, lead to an international conflict. It is, however, the internal situation in a country and not the intervention from the outside which causes the conflict. It is the country in which human rights are violated which creates international instability.

If violations of human rights and the absence of democracy lead to conflict and war, then respect for human rights and democracy is a prerequisite for peace, just as peace is a prerequisite for human rights and democracy (this is also the view of the authors of the UDHR, who, by the way, include people from all continents and not just westerners). That is why it is not enough when some or other dictatorship hits the dust. We cannot be certain to have peace as long as human rights and democracy are not securely established in all countries of the world.

\section{$\S 131:$ The R eal Importance of P eace}

As I have said before, most people agree that peace is an important value, but not the most important value. Sometimes, peace has to be sacrificed for something else. We do not accept Hitler's invasion or the reign of Idi Amin just for the sake of peace. There is, therefore, a case to be made for the 'bellum justum' , the justified war. War can be a necessary evil, necessary for the protection against foreign aggression or against internal oppression. Independence and freedom are worth fighting for and can justify the temporary loss of peace, especially if there is no other choice than the one between a war for freedom and peace in slavery. 'Give war a chance' in the words of P.J. O'Rourke (1993). Too much attention to peace would leave us at the mercy of evil.

Politics protects human rights and democracy, but sometimes war can or must do the same thing. War then becomes an instrument of politics and continues the work of politics with other means, in the famous words of Clausewitz. War bears the character of politics and is measured by its standards. The goal of a war is a political goal. War is politics which takes up the sword instead of the pen, but does not cease to think according to the laws of politics. Military means serve the political goal. War is not necessarily the continuation of business with other means.

Peace cannot the ultimate goal in life. It is negative and without content. It is not something, but rather the absence of something. That is why it can only be a means, a prerequisite for something which comes after peace, for example public and political life, economic development and other values which have a content, which we consider to be important and which require peace. However, in certain circumstances, war rather than peace is the most appropriate or maybe even the only means to realize these values. In 
general, public and political life, economic development and other values need peace, but sometimes they need war. Sometimes we have to fight, either for the peace which we require for our values, or to eliminate oppression and aggression, which are also threats to our values, just as war or the absence of peace are threats to our values in other circumstances. Peace is not enough. It is not sufficient, nor is it always necessary. It is not sufficient in the sense that sometimes we need war rather than peace, but also in the sense that we need more than peace even when we do not need war.

The pacifists' motto that there is no peace that is so unjust that war would be preferable, is clearly contrary to common sense. We can have peaceful lives in the most atrocious dictatorship or under the most brutal foreign occupation, but we do not accept this and we often start a war if there is no other way to solve our problems. If war is always worse than any unjust peace, then all tyrants will be safe until the end of their lives and Europe would still live under a unified regime of nazism.

\section{$\S 132: \mathrm{N}$ apoleontism and $\mathrm{N}$ eo-Colonialism}

The focus of the preceding paragraph was on war as the ultimate means to protect yourself against aggression or oppression, foreign or domestic - the ultimate means because it can do more harm than good and because there are many other means which are less dangerous but perhaps also less effective. However, is war also justifiable if it is used in order to protect other people against aggression and oppression? Can we, in other words, go to war to liberate the world?

In this case too, there are many other and less dangerous ways to promote democracy and human rights. We should try to avoid 'napoleontism'. Napoleon Bonaparte propelled his armies across Europe on behalf of the universal principles of liberty, equality and fraternity, somewhat in the style of the religious armies two or three centuries earlier. The latter also went to war on behalf of a law which was superior to the law of the states. Napoleon's armies occupied Europe because they wanted to export French principles and French civilization. Everybody had to follow the French lead and had to enact a 'French' Revolution, assisted by Franceif necessary. France was the advance guard of the struggle of humanity for freedom and against old-style authoritarianism. French militarism was therefore based on a curious mixture of national pride and universal principles.

A revolutionary and military kind of democratic imperialism in the style of Napoleon is only one of many options and certainly not the best one. Attacking, conquering and occupying other countries, even with the purpose of liberating these countries from oppression and archaic authoritarian forms of government, is by definition incompatible with the principles of democracy (democracy is self-determination). This is shown by the fact that, in most cases, the democratic crusade of the French failed to produce democracy in the 'backward' countries of destination. On the contrary, it created resentment. The occupied countries rejected France, and rejected its principles as well, perhaps for the only reason that it were principles of a hostile and conquering country. Traditional and often non-democratic political practices were reinvigorated by feelings of national pride that came with the struggle against France. Of course, the French ideas did take root in some countries, but this often meant that the people used these ideas not only against their own state but also against the French state (Furet 1996:62).

If you want to liberate the world, then you will tend to see yourself as a model, superior to the rest and more 'civilized' than the rest. This kind of megalomania will cause a reaction and will incite people to stress their difference It will, in other words, create the opposite of what is intended. It will not force people to change. This superior attitude was adopted by France and also by the nations colonizing the Third World. However, universalizing democracy and human rights can be done without occupation or colonization, except maybe in extreme cases (for example in a country in which the state has completely disintegrated, such as $\mathrm{H}$ aiti in the eighties and nineties). 
The strategy of neo-colonialism is not necessary either. Neo-colonialism is the softer form of colonialism and is also called cultural imperialism. It tries to impose one cultural model or one set of beliefs on other cultures without territorial expansion (it is a purely cultural expansion of one culture at the expense of another). Making other countries more democratic does not mean recreating them in your own image. Even if this were acceptable from the point of view of peace and identity (if it were not a threat to peace and identity), it would not take us very far. Everybody needs more democracy and the West is not necessarily more democratic than the rest. Cultural imperialism would make other countries more western but not necessarily more democratic.

Instead of using the image of one culture in order to recreate other cultures, we should use the ideal image of democracy in order to change everybody, and we should try to avoid war, violence and occupation as means to achieve this end. Democratic imperialism should not be something of the West directed at the rest. It should be something directed both at others and at yourself. Instead of convincing others to become more democratic and more like yourself, you should first look at yourself and look at ways to become a better example for the rest. The success of every type of imperialism is conditional upon the strength of the imperialist. Since the only strength of democratic imperialism is the strength of the democratic idea, the democratic imperialists should do everything to prove this strength in the way they apply the idea. An idea can only be exported if the promoters of the idea apply it successfully. The first step of democratic imperialism is the full application of democracy in the country of the would-be imperialists.

Cultural imperialism or neo-colonialism would not take us very far and would even create international tensions and conflicts, although undoubtedly to a lesser degree than outright colonialism or other kinds of occupation. People are attached to their cultural identity and do not like other cultures imposing their so-called superior model in the rest of the world and telling the rest of the world how to live. They will react against these other cultures. Instead of turning the laws of one country into universal laws or into the laws of nature, we should look for a truly universal system transcending the level of culture and use this system to criticize every culture on an equal basis. This will avoid resentment and tensions between cultures, and will therefore also avoid international conflicts.

Although the use of violence as a means to universalize democracy and human rights should not be rejected by definition - it can be acceptable in extreme cases, such as an armed intervention in an ongoing genocide, where the gains clearly outweigh the losses it is evidently not the first or most important means. We should start by giving the example, questioning the political structures, laws and practices of a country, using foreign policy, diplomacy, international law, condemnations, UN-resolutions and other ways to influence other countries, although some countries al ready see this as unjustified interference in so-called internal affairs and as a threat to good international relations.

Nevertheless, this kind of intervention should be possible. Contrary to military intervention, occupation, (neo)colonialism etc., it is difficult to see how it can harm international peace It can be justified by the make-up of the world of today. Violations of rights in one country can easily affect other countries (refugee problems, the centripetal force of a civil war etc.). These other countries have a right to protect their interests, even if this means trying to influence human rights elsewhere. Very few present-day problems re main limited to the territory of one state. Events in one country can influence the lives of many citizens in many countries. Countries have become more interdependent and have to rely on international cooperation and interaction in order to solve problems such as pollution, international crime, terrorism, drug traffic, national defense etc. A country which benefits from this international interaction cannot cut itself off from the world when the world asks questions regarding its human rights situation. Human rights have become part of the global rules which regulate international cooperation and interaction in an interdependent world and countries cannot violate these rules without forfeiting the benefits of international cooperation and interaction. Participation in a global society requires respect for global rules. 


\section{$\S$ 133: The Paradox of D emocracy}

Can we, irrespective of the problems it may cause for peace, intervene in a country for the purpose of promoting democracy and human rights if the people in this country do not want to have a democracy or human rights? If they do want to have democracy and rights, then it is of course possible and acceptable, maybe even necessary to assist them and to help them in their struggle against their government, as long as we put the problems related to violenceand peace aside momentarily.

However, what can we do if they do not want democracy and rights? Is it not undemocratic to force someone to be democratic? On the one hand, democracy implies respect for the will, the choice and the consent of the people. But, on the other hand, there seems to be no good reason to reject the creation of democracy with undemocratic means. Peace is not al ways created with peaceful means either.

If you are allowed to impose democracy from the outside and without the agreement of the people, then you obviously contradict yourself because you do not act in a democratic way. You are not interested in the will of the people (the will of the state is of no importance here, although in most cases it is this will rather than the will of the people which hinders democratization). The question is: are we allowed to impose or enforce democracy and human rights in an authoritarian way? Or do the people have a right to reject democracy? Does democracy not imply the right of the people to decide against democracy and to choose something else?

There are two problems with this kind of question. First it forces a system to be selfdestructive (it forces democracy to respect the will of the people in all cases, even when this means respecting the choice of the people against democracy), which is clearly an unreasonable requirement. The second problem is that the question reduces democracy to a system of choice and obscures all other functions of democracy. However, the choice of the people is indeed important and it can only have effect in a democracy. Choosing something other than democracy is choosing a system in which you cannot choose. It is difficult to call this a choice. The decision not to decide cannot be called a decision either. A people who choose against democracy contradict themselves and are at odds with their own opinions, in the same way as the democrat forcing democracy down the throat of the same unwilling people. By making a choice against democracy, the people act in a democratic way. The choice of a people is an essentially democratic act. Choosing to be undemocratic is self-defeating, because choosing as such is democratic.

Democracy cannot include the right to choose against democracy because democracy cannot be forced to contain the seeds of its own destruction. The supposed suicidal tendencies of democracy are based on a wrong understanding of democracy. The choice of the people is a principle of democracy, but it is not an absolute principle. The choice of the people is not sacred and can be limited. If, in a democracy, the people make undemocratic choices, choices against democracy or choices which violate human rights, then this is legally unacceptable. The same is true for a people who do not live in a democracy. Besides, a people can only choose for or against a democracy when they live in a democracy. In a non-democratic regime, their choice is of no importance; it is not taken into account and often even impossible to determine.

In spite of all this, however, many people will continue to choose against democracy and so the question remains: are we allowed to impose democracy against the choice of those concerned? Or, in other words, are we allowed to promote democracy with undemocratic means? If we say that that peace is not always promoted with peaceful means either, then Stal in could reply that he tried to liberate the Russians from barbarism by using barbaric means. There is not much difference between Stal in's statement and the statement that we can liberate nations from undemocratic regimes by using undemocratic means. So we must be careful with this kind of reasoning. We should first try to convince people to choose for democracy, rather than try to impose democracy. This is also less problematic from the point of view of peace. 
However are there no exceptional situations in which we can impose democracy and use force against a people who decide that they want to live in a dictatorship? Can we force people to be free? We have the historical examples of post-war Germany and Japan. However, 'it is difficult to see on what principles but those of tyranny [a people] can (...)be pre vented from living (...) under what laws they please, provided they commit no aggression on other nations and allow perfect freedom of departure to those who are dissatisfied with their ways (...). So long as the sufferers by the bad law do not invoke assistance from other communities, I cannot admit that persons entirely unconnected with them ought to step in and require that a condition of things with which all who are directly interested appear to be satisfied should be put an end to because it is a scandal to persons some thousands of miles distant who have no part or concern in it. Let them send missionaries, if they please, to preach against it; and let them, by any fair means (of which silencing the teachers is not one), oppose the progress of similar doctrines among their own people' (Mill 1977:1163).

There is, however, an error is this argument, pointed out by the same author. The reason why we do not meddle with the free choice of someone else, is precisely his or her freedom. By choosing to submit to a tyrant, this person alienates his or her freedom. One free choice makes all other free choices impossible. 'H e ther efore defeats (...) the very purpose which is the justification of allowing him to dispose of himself. (...) The principle of freedom cannot require that he should be free not to be free. It is not freedom to be allowed to alienate his freedom' (Mill 1977:1169-70).

A nother problem in the argument is that it is based on the hypotheses that we should not meddle because the happy subjects of a tyrant know best what is good for them. Unfortunately, there is no way to know whether subjects of tyrants are happy or not be cause they cannot express themselves. However, errors or contradictions in an argument are not sufficient elements to authorize the imposition of democracy and human rights on an unwilling people. I still have not answered the question whether this can ever be authorized.

If we want to avoid what I will call the paradox of democracy, then we have to intervene with the consent of the people. This, however, makes it impossible to intervene in a number of cases, namely those cases in which the people refuse their consent. If this re fusal is only a matter of national pride, habit, ignorance or a lack of knowledge of the possible alternatives, then trying to convince people can solve the problem. Habit can make many things acceptable. Even more so, it creates a feeling of tradition and when something belongs to a tradition, it also belongs to an identity. And who wants to lose his identity? It can be more frustrating to lose your identity than to suffer rights violations. People can also become accustomed to a situation. Because they have lived for centuries (or because they believe they have lived for centuries) in a particular situation, they now consider it as a natural and unchangeable state of affairs. They do not wish to change it. They do not feel the need to be protected against something and they certainly do not have the impression that their rights are violated. They accept their situation just as they accept facts of nature.

This would be true if human rights were only a protection mechanism. They are, however, much more than that. They create possibilities and once people are aware of these possibilities, they will perhaps start to feel the need for rights. The advantage is that consent is not required if we want to make people aware of possibilities. However, in some circumstances, we do have to protect people who do not feel the need to be protected. We could then make the people aware of this need. We could show other situations and show that their situation is not God-given or somehow natural and inescapable. We could also point out the recent origins of some 'traditions' and thereby delegitimize them or we could point out the error of confusing something that is old with something that is good. Of course, we have to be careful not to destroy cultural identities.

Instead of imposing democracy, we have to try to achieve consent. Consent is important, not only if we want to avoid paradoxes, but also because real and lasting changes can only be effected by the people themselves and not by outsiders. Democracy requires the active and continuous participation of the entire population. People who are not con- 
vinced and who do not consent to democracy will not participate. A democracy without participation is not a democracy. In such a case, foreign intervention or imposition will at best create an empty shell. Democracy can only be the result of the will of the people, although an empty shell is often better than nothing. It often creates its own momentum. Democratic activity has a tendency to create its own support, as I have shown in Chapter 4. Once there are institutions, even institutions in which only a handful of people participate, people tend to be attracted by these institutions.

Democratic imperialism is more a matter of persuasion than coercion. It is first of all the effort to convince people. However, as I have shown in the introduction, democracy is a prerequisite for convincing. A discussion between opponents and proponents of democracy and human rights seems useless, because the opponents, by engaging in the discussion, already agree with the proponents because they accept the importance of discussion.

It seems as though democracy and human rights can never be introduced with democratic means such as discussion etc., because then we start with our conclusion and we presuppose what we want to achieve. Introducing democracy and human rights with undemocratic means is, however, also a logical error, although there seems to be some room for undemocratic means. Peace, after all, is not always introduced with peaceful means either. As we have to choose between these two options, the former seems to be the lesser evil, especially from the point of view of peace In general, people know best what is good for them and we should not impose our views or systems on others, not only for the sake of peace but also for the sake of consistency. It is not because opponents of democracy are inconsistent that proponents are authorized to be inconsistent as well.

The problem is that we are never sure that we can convince people in an undemocratic setting. We do not even know whom to convince, because people cannot express themselves adequately. If there is no call for help, if we have the impression that the people are satisfied with their situation, then perhaps this is because the people are against democracy, or perhaps this is because it is impossible to complain. The lack of consent should not automatically force us into passivity. It can be impossible to know whether there is consent or not.

This is also why it is wrong to believe that the only acceptable way to promote democracy is to support proponents of democracy in authoritarian regimes (for example opposition movements). We should also promote democracy in those countries in which there is no or just a small democratic opposition, even though in this case we must be more care ful and we must avoid imposing democracy straightaway (when a majority favors democracy, it is acceptable to impose democracy). However, it is wrong to say that we should avoid every action in these cases. A democrat should indeed try to avoid imposing the will of the (democratic) minority on the (undemocratic) majority - consent is important - but we can never know if the minority is a real minority and if the consent of the majority is indeed absent or simply counteracted and silenced by government oppression, ignorance, habit or whatever. The absence of a numerically important democratic opposition can be caused by oppression, ignorance etc. rather than a conscious and free choice We should at least be allowed to assist the minority in its attempts to become a majority and we should be allowed to look for the real voice of the majority and to explain the advantages of democracy. The minority can be the voice of the silent and frightened majority.

It is obviously impossible to force people to accept democracy and to agree that democracy and rights are important. An agreement is al ways a voluntary agreement. A forced agreement will lead to revolt sooner or later. People do not like to be forced and prefer to live according to their own views. However, if you prefer to live according to your own views, then you prefer to live in a democracy. We should, therefore, search for other means than coercion if we want to achieve agreement. 


\section{Chapter 10: Peace Insi de a State}

$\bullet$

Section 22: Self-Determination, Version 2

\section{$\S$ 134: Self-D etermination of a People}

The right to self-determination is, in the first instance, the right of a state and a people to be sovereign in their territory and the right not to suffer foreign intervention, occupation or aggression. This right is necessary for democracy and human rights, because intervention, occupation and aggression often if not always go hand in hand with violations of human rights and democratic principles. Occupation is incompatible with democracy because the government does not result from the will of the people people. Conquest and consent cannot go together. A democracy can never conquer, because if it does, it ceases to be a democracy. If it conquers, it may of course remain a democracy in its original territory and it may even contribute to the development of democratic institutions in the conquered territories, voluntarily (as with the occupation of Japan by the USA) or involuntarily (as with the American colonies of the UK). However, even if the latter takes place - and there is no reason why it must take place - we will only see democracy arise in these territories if the people of these territories regain their independence or if they agree to become an equal part of the occupying country.

The right to self-determination can contribute to the struggle for independence National liberation and the elimination of alien subjugation are necessary conditions for the protection of democracy (or self-government) and often also for the protection of human rights. 'There is general agreement that peoples who have a legal right to self-determination are entitled to fight a war of national liberation. Even W estern states do not dissent from this view, if only because there is no rule in international law against rebellion' (A kehurst 1991:299).

A nation which is occupied by another state has a right to self-determination and a right to fight for national liberation. It needs these rights in order to protect its human rights and its democratic rights, even if it means endangering the peace (again, the costs violations of human rights because of the absence of peace - should not outweigh the benefits for human rights which may result from the liberation struggle). N ow it is obvious that a people or a minority group inside an existing state - not a conquering state which are in a similar situation and which cannot enjoy rights and democracy either, should have the same right to self-determination and liberation. This is a second meaning of the right to self-determination.

\section{$\S 135:$ Revolution or Separation}

There are two possibilities. The first one is that the entire people or a very large part of the people are oppressed by their undemocratic state. In this case, the right to selfdetermination is in fact the right to revolution. Revolution is often the only way - apart from or in combination with foreign intervention - to regain self-determination, to make the state more democratic, and to reinstate human rights. A revolution can only be a democratic revolution, a revolution with the purpose of changing the form of government 
and installing democracy, human rights and the sovereignty of the people. Any other revolution will lead us away from self-determination. Of course, the right to revolution is incompatible with peace and should therefore only be used in the last resort. Other strategies, such as civil disobedience or conspiracy, should be tried first.

The second possibility is that only a relatively small part of the people ('a people within a people') is oppressed by its undemocratic state and maybe by the rest of the population as well. In this case, one solution is to grant that part of the people the right to separation, a right which can lead to self-determination but also to violence, just as the right to revolution. States always react in extreme ways when their territorial integrity is questioned, especially when it is questioned from the inside. However, separation can also promote peace because it can prevent or terminate internal warfare. Nevertheless, if one of two separating parties does not agree to separate, then the right to separation can cause violence and should only be used in the last resort. One should try to protect the rights including the democratic rights - of the minority in other ways. The right to revolution, which is also an ultimate solution, does not seem appropriate in this case, because one part of the people cannot impose its will on the other part (the other part may not want democracy or may already live in democratic circumstances).

It is obvious that the right to separation can only be a right to democratic separation. You can only dismember an undemocratic state in order to create a new and democratic state. The purpose of separation is to regain democracy and human rights. Again we see that separation and revolution are treated in the same way. Separation and revolution are unacceptable in a democratic state because such a state al ready respects everybody's rights.

Neither the right to separation nor the right to revolution is legally recognized. It is, of course, legal to separate if both parties agree, but then we do not exercise a right. It seems that Article 1 of the ICCPR only deals with the first version of the right to selfdetermination as discussed in the previous Chapter. The right to separation is a second version of the right to self-determination and is incompatible with an established rule of international law, namely the respect for the territorial integrity of states.

However, not only a state but also a people inside a state have rights and need the right to self-determination, the right to self-government and, if necessary, the right to revolution or separation as a means to acquire self-government and to protect their other rights. If a state violates the human rights of a minority or a majority or if it systematically excludes a minority or a majority from self-government, then this minority and majority have a right to separation and revolution respectively and can use these rights to (re)acquire their human rights and their right to self-government and democracy. Separation can only be democratic separation, just as a revolution can only be a democratic revolution. In a democracy, neither separation nor revolution is necessary. In any other form of government, they are possible only when every other solution has failed, when the purpose is democracy and rights and when there is a real chance that the goal can be achieved without too much damage to other rights or to peace The cost can never outweigh the benefits.

Separation or revolution is only justified if the new state or the new form of government respects human rights and the principles of democracy. A people liberating themselves from an oppressive state by way of separation or revolution, create a state for themselves or take the state into their own hands. Both these actions are explicitly democratic. If they separate or revolt in order to create a new authoritarian state, then they do not create self-determination but a mirror-image of the state they fled or the form of government they destroyed. What is then the purpose of revolt or separation? If you want to liberate yourself from the rule by another group of people - either the politicians in the case of a liberation by way of a revolution, or the rest of the population in the case of a liberation by way of separation - then you do this because you want to have selfgovernment. If you want to have self-government, then you want to have democracy and rights. Therefore, you cannot use separation or revolution to install a non-democracy. It is logically unacceptable to use the right to self-government in order to create an oppressive 
regime. '[A ] group's claim to autonomy is less justifiable the stronger the reasons for believing that if it gains autonomy the group will inflict serious harm, whether to its own members or to persons outside its boundaries' (Dahl 1989:208).

Concerning the dangers of separation or revolution, we have to balance one evil against another. Again, peace should not be the only concern. Human rights, selfdetermination and self-government are important values as well and sometimes the cost of separation or revolution is less than the cost of oppression.

\section{$\S 136:$ Borders as an End or as a Problem}

The right to separation is a second version of the right to self-determination but is incompatible with the territorial integrity of a state, whereas the first version of the right to selfdetermination is meant to protect this territorial integrity. The reason for this difference is the nature of the state. In a democratic state, the borders cannot be questioned, neither by a foreign power, nor by an internal power, except of course when all parties agree. In a non-democratic state, the borders can be questioned by both an external democratic power (the right to intervention) and an internal democratic power (the right to separation). You can intervene, separate or revolt as long as you are dealing with a nondemocratic state and as long as your goal is democracy.

A state should only have a right to self-determination and territorial integrity if it is a democracy. A people, on the contrary, always have a right to self-determination because a people have a right to democracy. However, they cannot use revolution or separation to achieve their self-determination except when they live in an undemocratic regime and when all other means to end this regime have failed. In a democracy, self-determination is already a fact - everybody has self-government and there are no permanent minorities systematically excluded from power - and therefore cannot justify revolution or separation. The same is true for rights violations in a democracy. These violations cannot justify revolt, separation or intervention either. If there are rights violations in a democracy, then they are never systematic and they can be dealt with in a judicial way.

The right to self-determination is by definition respected in a democracy and 'shall not be construed as authorizing (...) action which would dismember or impair, totally or in part, the territorial integrity or political unity of sovereign and independent States conducting themselves in compliance with the principles of equal rights and self-determination of peoples and thus possessed of a Government representing the whole people bel onging to the territory without distinction of any kind' (Vienna Declaration). '[T] his might perhaps be interpreted as implying that action to dismember an independent state is permitted if the government does not represent the whole people' (Akehurst 1991:296); if, in other words, the state is not a democracy.

Democracy is the same thing as self-determination because self-determination is selfgovernment and the absence of alien subjugation. The word 'alien' can mean foreign or colonial but also the subjugation of a people by a national elite which is not elected by the people. Only in a democracy can a people determine their own fate and govern their own affairs. That is why the right to self-determination as well as the rights attached to this right - separation, revolution and intervention - can never be used to maintain or create undemocratic regimes or violations of human rights (because of the link between democracy and rights) and can never be claimed in a democracy.

Of course, intervention, separation and revolution are acceptable only if the violations of human rights and of the right to self-government are structural and systematic instead of accidental (everybody is in a minority now and then) and cannot be solved in another way (judicial redress or decentralization are some of the other options). Not every rights violation is an excuse for intervention, revolution or separation and you cannot start a civil war every time you lose a democratic vote. There are some specific conditions for separation, for example the group which wants to separate must be geographically concentrated or prepared to move to another territory. 
Separation can also be useful even when democratic principles are not violated voluntarily. The social or geographical circumstances can be such that some groups enjoy less self-government than others. For example, if a national boundary is such that two groups, which consider each other as their archenemy, live together in one state, and one of the two groups is a numerical majority, then it can happen that the minority group is systematically excluded from power. '[0]ne set of boundaries is better than another to the extent that it permits more persons to do what they want to do. (...) a proposed unit is less desirable the more that it will increase conflict over goals and thereby increase the number of persons who cannot achieve theirs' (Dahl 1989:208).

On the other hand, this possibility is clearly limited. No one can always do as he or she likes or can always achieve his or her goals. If this were the objective, then the ideal boundary would be one around every person. Only this kind of boundary would be best adapted to the goals and desires of everyone. Nobody would ever be in the minority. However, the fact that this is impossible (everyone needs cooperation, and people will therefore always form groups and boundaries between groups) and that, at the same time, a world of consensus groups is very unrealistic, leads to the conclusion that there are no boundaries and no definitions of groups that allow the realization of all the goals and desires of everyone. However, it is possible that more people can do as they like in some boundaries or units than in other boundaries or units. And people have a right to strive for the geographical unit which gives them the highest possible level of selfgovernment. Of course, this aim does not necessarily require separation and certainly not violent separation. There can be units within units for example. 
Section 23: National Unity

\section{$\S$ 137: D emocracy is I mpossible and N ecessary at the Same Time (1)}

A certain degree of national unity and of involvement or connection with this unity is another example of a prerequisite for democracy and human rights. Democracy is impossible when there is fundamental hostility between large groups in the state, when one group fears that a political victory of another group will harm its fundamental interests and when, as a consequence, groups are unwilling to live together. The tensions between communities resulting from this kind of situation makes the functioning of democratic procedures impossible and can lead to rights violations and even to civil war.

To some extent, national unity is a prerequisite for the preservation of any form of government, although an authoritarian state is undoubtedly better equipped to suppress communal hostility. The ability to survive and to maintain communal peace is a classic argument in favor of authoritarian forms of government. Indeed, these forms of government seem to be able to separate warring factions, to avoid chaos, violence, separation and disintegration and to focus attention on loyalty, patriotism and the community. They limit the use of rights because rights are a means to incite or aggravate divisions. These regimes are able to violate rights if this is deemed necessary in order to keep antagonists apart.

However, what is the cost of authoritarian peace? Grave violations of human rights in the first place, and more violence after than before. Rights violations often create more violence than the violence which was the initial reason to violate rights. If you hit me, I will hit you back and if I hit you back, you will hit me back again, and so on. Violating rights in order to suppress communal tensions is counterproductive in the long run. A strong hand always causes revolt and violence, the opposite therefore of what is intended. Rights violations, which are deemed necessary for the preservation of communal peace, cause violent opposition and revolt. Rights violations can lead to violent revolt even when these violations do not imply the use of violence. Without human rights, it is impossible to express claims and people who cannot claim something will resort to more extreme means in order to get what is theirs. Authoritarianism promotes the evil it wants to combat, although in the short run rights limitations and the use of violence may be the only alternative. Acquiescing in a civil war may lead to even graver violations of rights. Sometimes, rights have to be limited in order to avoid an even greater evil (see also the Concluding Remarks).

If groups do not want to live together and if everything has been done to convince them to stay together - i.e. everything but rights violations - then let them separate. Why violate rights to keep people together? If stability and unity depend on oppression, then it is maybe better to separate the parties and thereby avoid oppression. The different groups can then lead an independent, stable and unified life at different sides of the border. Their mutual hostility and the absence of a feeling of national unity will then no longer impede the democratic procedures or lead to rights violations and communal violence Stability and unity do not depend on oppression. On the contrary, oppression divides and destabilizes. 
Democracy and human rights are said to promote discord, chaos, violence etc. Indeed, rights can be used to incite communal violence, and democracy cannot function if there is no division and contest between groups. The adversarial aspect of democracy does make it difficult to see how democracy can promote communal peace I will focus on democracy for a moment, because the argument against human rights is much weaker (although rights can indeed be used in order to aggravate communal tensions - which is the reason why they can sometimes be limited - it is evident that most groups that use violence do so because they feel that their rights are somehow violated; respect for human rights will therefore diminish rather than increase violence).

Democracy is obviously adversarial and does divide society into different, antagonistic groups. However, it does not push divisions to such an extreme that living together becomes impossible or undesirable. The unwillingness to live together is not caused by democracy but by fundamental convictions concerning religion, morality, justice etc. Democracy does not even enhance this unwillingness. On the contrary, it offers ways to bridge fundamental differences between groups (e.g. it offers places of discussion and negotiation) and it creates mechanisms which guarantee peaceful coexistence when it is impossible to bridge differences (such as tolerance, religious freedom etc.).

Like in the case of the economy and peace, we can see a two-way causation at work here: although democracy and human rights undoubtedly need national unity, they are also a prerequisite for this unity. A group will question the national unity, will revolt, will cause violent conflicts or will try to separate only if it is discriminated against, if its human rights are violated, if it does not enjoy tolerance and respect for its difference, if it is excluded from power, if it is not granted local autonomy etc. If, in other words, it does not live in a democracy. National unity, the conviction of belonging to the same group and of sharing the same destiny whatever the differences, can only arise as a result of debate. Freedom of expression can indeed be dangerous in a divided society, but without it, it is hard to see how divisions can be overcome or accommodated, as opposed to merely suppressed. Democracy is necessary in a divided society because the alternative oppression - only reinvigorates what is tries to eliminate.

Let us take a closer look at the arguments against and in favor of the statement that democracy and rights promote rather than harm national unity, or limit rather than enhance communal tension. Democratic procedures are adversarial and for this reason they are said to promote discord, conflict, struggle and exclusive attention on the interests of individuals and groups. Togetherness, solidarity, community spirit and the general interest are incompatible with democracy. Democracy aggravates divisions (ethnic, religious and other divisions) because the electoral competition and the electoral victory of one group polarize conflicts.

A nother reason why democracy and human rights are said to cause social and political disintegration, is the fact that people hostile to social and political cohesion can use democratic procedures and human rights. Separatists can use the democratic openness to question the state. Democracy and human rights threaten the internal peace, just as they threaten the external peace.

However, because democracy formalizes conflicts in different ways (elections, parliaments, courts of justice etc.) and provides systems for deciding conflicts by impartial judges, it diminishes the need for violence, revenge etc. Democracy guarantees the rule of law and the rule of law means that crimes are punished and that revenge is obsolete.

In a democracy, people feel more connected to the political unity because they recognize themselves in this unity and because they can actively participate in it by way of elections and referenda. In an authoritarian system in which those who dare to be politically active are punished, the people will leave politics to the politicians and they will focus on their private lives and private interests.

Democracy can undo this kind of private isolation because it allows and even requires citizens to associate for the purpose of becoming a majority or for the purpose of being able to promote their interest. These associations promote a feeling of national unity and 
patriotism because they eliminate social isolation and make it possible for citizens to $\bullet$ operate and to discover a general interest, not only the general interest of the group in which they cooperate but also a general interest at a higher level. Associations make it possible to look further than the individual interests and to become aware of the possibility of a general interest.

The religious neutrality of the democratic state and the separation between state and church make it easier for a religiously divided population to accept the state and the national unity. A state which identifies itself with one religion will alienate groups which have another religion. In some cases, these groups will also be discriminated against, and this will result in violent revolt.

It is very likely that means and ends are again inverted, just as in the case of culture and the economy. National unity, the willingness to live together and the absence of communal tensions or communal violence is not the goal served by rights violations and strong government. It is an excuse for rights violations and strong government. Some states even create or encourage discord in order to be able to justify their strong government afterwards (sometimes, they provoke opposition movements or encourage hostile propaganda between groups). They are then 'forced' to intervene the hard way in order to restore 'order' and 'unity' in the country.

Of course, there are situations in which rights must be limited, for example when the existence of the democratic state is at stake (in a so-called 'state of emergency'). H owever, authoritarian regimes seem to believe that cohesion and unity are all that matter. Cohesion is only a value when it is a democratic cohesion and strong measures to ensure cohe sion should al ways be directed at the restoration of democracy.

\section{$\S 138:$ How to Create U nity and A void Discord?}

Coercion is not the best way to create unity. It is like suppressing the symptoms of a disease without tackling the causes. If people do not want to live together, then let them separate. The multicultural society may be a lofty ideal, but in reality it is often better to separate communities. Some things make unity impossible. A long history of hostility, for example, such as the history of the Balkans, makes it difficult for people to continue to live together in peace

Where unity is possible, it can be promoted in different ways. One way is the use of a common goal. People who share a common goal feel connected to each other and form a unity. The common goal of defending the country against a foreign military threat has often served to create unity and to make people forget divisions and tensions. Fortunately, we do not need foreign threats in order to have a common goal. Politicians have a major role to play in the creation of common goals and should therefore resist the temptation of interest-group politics or vote buying. If the common pursuit of individual interests is the only common identifier and if society is reduced to a collection of individuals or groups pursuing their own egoistic goals, then we will never have a long lasting political unity.

The democratic habit of different groups trying to become a majority and trying to persuade as many people as possible and to enlist as many members as possible, is an exercise in common goal-setting which can be used to create common goals at a national level. In a non-democratic form of government, people do not have the opportunity to engage in effective common action and are thrown back upon themselves. Fragmentation is more common in non-democratic states than in democratic states (Taylor 1996:129). Non-democratic states often even encourage fragmentation because it helps to weaken the power of the people and of the opposition movements.

The federal model, which is by definition democratic (federal means giving more power to the people instead of taking it away), can also be useful in roughly the same way. In large, centralized states, it is more difficult to have common goals because the population 
will probably be more diverse than in small countries. Decentralization in large countries makes common goal-setting easier and communal tension less likely.

In large, centralized states, it is also more difficult to form effective groups which can have an impact on the state because these groups have to be of the same dimensions as the state. Influential groups have to be organized nationally. For this reason, they are just as distant from the citizens as the centralized state and will not have much recruiting power. Therefore, the common goals of these large groups will not promote a feeling of national unity at the level of the people. In a federal model, this is much less the case. It allows citizens to have an almost face-to-face cooperation, which not only promotes common goal-setting but also discourages mutual distrust, fear, xenophobia, chauvinism etc. It is clear to see how democracy can promote unity. If you cooperate with your neighbors and if you learn to trust your neighbors because of your cooperation, then why not trust your fellow citizens in general? Federalism counteracts the alienation between citizens and the state and between groups of citizens and therefore counteracts the risk of fragmentation. The federal model also promotes unity if the different groups are separated geographically. If every regional group has some autonomy, then it will feel less threatened by decisions of other groups.

The best way to create unity is to avoid discord. People will not feel connected to the nation and will use every opportunity to revolt or separate if:

(1) Their interests and rights are systematically ignored;

(2) They cannot pursue their interests in a peaceful, constitutional and democratic way;

(3) They are harmed or discriminated economically or politically;

(4) They are not allowed to experiencetheir identity etc.

This shows that national unity depends on democracy and rights. It also shows that avoiding discord does not imply rejecting multiculturalism. The unity we need for democracy is not an all-out unity. It does not imply unity of culture, religion etc., merely a unity on the level of the willingness to live together, to participate together in democratic institutions and to accept human rights and the outcome of democratic procedures.

\section{$\S$ 139: Pacification-D emocracy}

What can we do if all the democratic guarantees for unity - tolerance, rights, identity, associations, federalism etc. - are not enough? What can democracy do when groups do not overlap, when the same people are always opposed to the same people no matter what subject they are dealing with, when there are no organizations which transcend or overlap different groups and when one or a few of these groups always form the same democratic majority? The other groups are then systematically excluded from power and often also from the economy. These groups will revolt, perhaps in a violent way. What is certain is that the national unity will suffer, which means that one of the prerequisites of a well-functioning democracy will disappear.

What can democracy do about these permanent minorities? Not a lot, at first sight. The most obvious solution would be separation, on the condition that the different groups are geographically concentrated. However, democracy is flexible enough to provide other solutions. The so-called pacification-democracy or consociational democracy (Lijphart 1977:passim; Thomassen 1981:130; Dahl 1989:256) is well adapted to deal with this kind of problem and to counteract tensions and divisions between communities. This type of democracy has the following characteristics:

- A pacification-democracy eliminates permanent minorities as much as possible and creates mechanisms to guarantee a certain degree of participation for every group. Some of these mechanisms are: 
(1) A guaranteed number of representatives, government ministers, civil servants etc. from each group (disproportional representation).

(2) Two-thirds majorities or even larger majorities for important decisions, which guarantees that at least most of the groups participate in these decisions.

(3) Veto-powers for important decisions. Each group, even a minority group, can block decisions that are contrary to its fundamental interests. In very heterogeneous and divided societies, this creates a de facto consensus-democracy instead of the classical majority-democracy. This may be necessary to avoid the 'dictatorship of the majority' and the systematic exclusion of certain minorities. As in point (2), this system always tries to have the consent of all important groups in society, especially for important decisions. A drawback of the system is that it can lead to minority rule and the dictatorship of the minority (one small minority can block decisions which are very important for the large majority).

(4) Comprehensive government coalitions including representatives from all or most political parties, even those parties which are not mathematically necessary to have a majority.

(5) A second parliamentary chamber exclusively for the representation of minorities etc.

It is not necessary to use all these mechanisms simultaneously. Some of these mechanisms are more difficult to apply in a situation in which one group forms the majority of the people than in a situation in which none of the groups is a majority.

- A pacification-democracy tries to create systems of communication and cooperation between groups (for example in government coalitions). Groups which do not cooperate tend to shut themselves off from other groups and tend to avoid mutual penetration. Groups which do cooperate tend to be more tolerant of each other. You cannot love what you do not know. A pacification-democracy also works on the readiness to compromise. That is why ethnic, cultural and religious divisions are so difficult to handle. These divisions do not allow compromises and can be particularly oppressive and exclusive, as history has shown.

- A pacification-democracy provides a large degree of self-government for each group, especially regarding the decisions that only concern the group in question. This can lead to a federal system but the principle is also valid when the groups do not live in distinct geographical zones. Religions for example have often been granted some degree of autonomy to handle their own affairs. Groups will be more willing to accept a national unity if the centralized state does not intervene in its internal affairs. However, some kind of intervention is always necessary. Rights violations, for example, cannot be tolerated.

- A pacification-democracy will also be a redistributive democracy and will avoid large differences in wealth between groups.

This model can be applied in all divided countries and should not be limited to countries with permanent minorities. It particularly well adapted to some of the artificial states of the Third World which have been created by colonialism without regard for the existing social and ethnic structures. It is, of course, no guarantee for success. Pacification is not always possible and some groups will never accept to live together, no matter how much they participate or cooperate.

However, the model limits some of the fundamental democratic principles such as 'one man, one vote', rotation in office, choice between opposition and government etc., be cause it tries to achieve equal participation of all groups, large or small. Furthermore, it can aggravate divisions instead of softening them. Guaranteed political representation can be used to strengthen the power and the organization of groups. The model institutionalizes divisions.

A solution for the long term would be to look for overlaps between groups. There is no reason why a group that speaks another language should also have another religion and 
other opinions on morality or justice The dividing lines should cross each other. Individuals who are members of one group as a consequence of their language or religion, must be able to become members of a political group for example which has a completely different membership than the membership of their original group. This will guarantee national unity in the long term. 
Part 4: $\quad$ Equality

$\bullet$

Chapter 11: The Value of Equality

$\checkmark$

Section 24: Democracy Produces the Best Decisions

$\S 140:$ W hy D o W e N eed Equality?

The value of equality is not as obvious as the value of peaceand prosperity, and so I have to explain why equality is a value and why it can be used as a justification of human rights and democracy. Human rights and democracy promote equality. Human rights are by definition equal rights and they create more economic equality. In a democracy, the law is equal for everybody. Democracy is obviously impossible without equality. The principles of 'one man, one vote', equal access to elected positions etc. show that democracy tries to be the rule of everybody and of everybody in the same degree. Everybody participates equally in the government of the country, in the decisions as well as in the discussions preceding the decisions. This is the modern-day translation of the ancient Greek principles of 'isegoria' and 'isophephia' : everybody has an equal right to speak in the assembly and nobody's vote counts for more than anybody else's vote.

There are two well-known problems with this. First of all, the majority-system seems to impose the will of one group of people, the majority, on another group, the minority. The input may be equal but the output in the sense of power and satisfaction can be very unequal (Harrison 1996:181). Is majority rule compatible with equality? Or is unanimity required? I have shown in Paragraph 44 that a majority system rather than a system based on unanimity gives equal power to everybody. Nevertheless, the outcome of a vote seems to be unequal in a majority system. The majority gets its way, the minority does not. A solution could be to introduce some measure of intensity in the system. If the intensity of a 'yes' or a 'no' is measured, instead of just the number 'yes's' or 'no's', then an intense minority can get its way. Moreover, we never or rarely have monolithic and lasting majorities. Everyone is now and again part of the majority. This equalizes influence A nother solution could be to bundle decisions. 'The intense minority and apathetic majority may not agree on the specific issue in question, but the minority might persuade the majority to vote the minority position on this issue in exchange for some concession on another issue about which some members of the majority feel more strongly' (Nelson 1980:79). I will discuss the problem of minorities in Part 5. Secondly, there is the problem of the unequal influence of unequal prosperity on democratic decisions. I will discuss this problem in Chapter 12.

Democracy needs equality. It cannot function adequately without the equal participation of everybody. If everybody does not use political rights in the same way, then we do not have a democracy because then it is not the people who govern but only a part of the people. Some people govern more than others because they make more use of their rights. Democracy, therefore, has to promote the equal possibility to use rights. Redistribution of prosperity is one way in which it can do this. Democracy requires not only equal political rights but also equal economic rights and equal freedom rights (in many circumstances, 
freedom of opinion and expression, of assembly and association etc. are also political rights). On the other hand, equal rights are a protection against certain excesses of democracy (see Part 5). A majority cannot take decisions which violate the equal rights of the minority. This does not mean that rights are something external to democracy. They are an integral part of a well-functioning democracy. Democracy cannot function without them (see Section 5).

However, why is equality a value? We know why democracy needs equality, but why do we need democratic equality? In the first place, we should not forget that equality is al ready justified when we try to justify it in a discussion. 'If I try to 'found' equality rationally, I am able to do this only in and through a discourse which addresses itself to all and refuses all 'authority', a discourse therefore which has already presupposed equality of humans as reasonable beings' (Castoriadis 1991:135-6).

A nother, less formal reason why we need equality, is the fact that most people do not want to be considered as inferior beings. Most people do not accept to be treated as inferior beings or as beings with fewer rights. Everybody wants to count when decisions are made, wants to have influence and power, and the only way to respect this universal desire is to give everybody equal influence I have shown in the paragraph on unanimity (Paragraph 44) that a democratic majority system gives people equal influence.

The need to give everybody equal influence is just as important as the quality or the content of decisions. A procedure for arriving at decisions which gives everybody equal influence can of course produce good or bad decisions. The point is that even when it produces a relatively bad decision, it can be considered as a better procedure than an unequal procedure which would have produced a better decision in the same case. The quality of decisions is not the only important thing. Influence is also important. People may accept less quality is they gain influence.

Equality seems to be a universal value. Of course, we have to leave room for desert, effort, punishment, responsibility and other kinds of inequality which are:

(1) The result of a deliberate choice of those involved;

(2) Necessary for the protection of equal human rights; or

(3) Consistent with the protection of a minimum standard (for example the inequality between persons who are rich and other persons who are very rich). I will deal with this in Section 26.

A second reason why equality is a universal value is the need for equality in public and political life (at least when we accept that public and political life is a universal value). Public and political life requires equal rights, and I have shown that equal participation in public and political life is in the interest of every participant (see Sections 1 and 18).

Furthermore, everybody has interests and wants these interests to be taken into consideration. This is possible only when everybody's interests receive equal consideration. Of course, all interests cannot and should not be taken into consideration all of the time, but a majority system at least realizes the interests of the majority. Besides, human rights protect the fundamental interest of the minority as well.

Everybody wants to be master of his or her own fate. It is obvious that a system of majority decision, based on the equal participation of all, makes more people master of their own fate than an authoritarian system. In Part 5, I will discuss the concept of freedom and I will show that equality is a value because it makes freedom or the power to shape your own life available to everybody.

\section{$\S 141:$ The Epistemological A dvantages of D emocracy}

Another reason why we need equality is the fact that equality results in better decisions than inequality. The opinion of the people is - potentially at least and given certain preconditions - better than any other opinion (which does not mean that the people are in- 
fallible). In ideal circumstances, the opinion of the people results from a wide and free discussion guaranteed by human rights. A discussion in which as many people as possible participate in an equal way contains the largest possible number of arguments for and against. This discussion makes it more likely that false arguments are refuted and that good arguments are recognized and are widely tested. Two heads are better than one (Mill 1977:1117).

A group of individuals is more intelligent than the sum of the individual intellects. Massive participation means massive criticism and this improves the quality of a proposal which can survive this massive criticism. '[W ]e normally assume that an ideally conducted discussion among many persons is more likely to arrive at the correct conclusion (by a vote if necessary) than the deliberations of any one of them by himself. Why should this be so? In eve ryday life the exchange of opinion with others checks our partiality and widens our perspective; we are made to see things from their standpoint and the limits of our vision are brought home to us. (...) D iscussion is a way of combining information and enlarging the range of arguments. At least in the course of time, the effects of common deliberation seem bound to improve matters' (Rawls 1999:315).

Political equality is a value because it improves the quality of decisions. The inequality of the sexes has deprived society of a vast pool of tal ent. If women had 'the free use of their faculties' along with 'the same prizes and encouragements' as men, there would be a doubling of the 'mass of mental faculties available for the higher service of humanity'. The injustice perpetuated against women has depleted the human condition: 'every restraint on freedom of conduct of any of their human fellow creatures (...) dries up pro tanto the principal fountain of human happiness, and leaves the species less rich, to an inappreciable degree, in all that makes life valuable to the individual human being"' (Mill in Held 1998:113).

Political leaders have every reason to listen to the will of the people and should be elected by the people. It is obvious that the people should also be allowed to decide certain matters themselves. Excluding or neglecting certain opinions or certain people does not only harm the interests of the people concerned but also harms the thinking process of the community and the quality of common decisions. Democracy, in order to produce the best decisions - on average - requires the equal participation and activity of as many persons as possible. This means that we need regular doses of direct democracy.

Elitism has always been very popular, both at the right and at the left of the political spectrum. Decisions of the 'common' people are said to be stupid by definition. The people are not qualified to rule and are not even qualified to choose their rulers. An elite must rule the people and this is in the best interest of the people. The people must be protected against their own stupid decisions. Only an elite has the necessary qualifications to rule. It knows better than the people what the people need and it knows better how to achieve the real goals of the people.

However, an elite is more likely to make wrong decisions because it does not know all possible arguments and it does not have to submit itself to criticism (remember Section 1, where I mentioned the way in which criticism improves the thinking process). Discussion is not an obstacle for action; it is a necessary condition for wise action. The majority of the plain people will day in and day out make fewer mistakes in governing themselves than any smaller body of men will make in trying to govern them' (Th. Roosevelt in Barber 1984:261).

The argument in favor of elitism or aristocracy (the rule of the best) is aimed at both direct and indirect democracy, although perhaps in the first place at direct democracy. A ristocrats claim that even a representative democracy does not produce the best leaders. You need experts to choose and judge experts. The people will only choose the leaders they deserve.

In reality, however, the quality of the leaders, the laws and the decisions on issues depends on the people and on the way they communicate, persuade, argue and ultimately establish their will. Establishing this will is a never-ending process. Every decision can always be questioned and revised. The will of the people and therefore the people themselves are al ways a temporary reality, fluctuating and open to criticism. If a better 
argument shows up, the decision of the people may change. This open and provisional character of the will of the people means that it takes into account future knowledge and future arguments as well as present-day knowledge and present-day arguments. The will of the people improves continuously.

Be that as it may, how do I explain the phenomenon of demagogy and the often very irrational, unreasonable and emotional reactions of the people (lynching, for example, or voting for Hitler)? Of course, nobody in his right mind would maintain that the people are always reasonable, rational or infallible. The quality of the decisions of the people can only be good in the setting of ideal democratic procedures in which discussion, deliberation and argumentation take a prominent place. This setting is an ideal but many existing procedures come very close to this ideal. If the right institutions, mentalities etc. are given, then the ideal can become a fact.

Besides, individuals or elites are often just as unreasonable, emotional or irrational as large groups of people. It is even easier to excite a small group than it is to excite a large group, because it is more difficult to have a unity of feeling in a large group. There are more conflicts and contradictions in large groups than in small groups, which makes it unlikely that a large group of people gets excited in the same way. Furthermore, it is important to find a good timing for decisions. Decisions should not be taken directly after a very emotional event because emotions would then inhibit the careful and reasonable evaluation of all contradicting arguments.

Of course, the quality of democratic decisions is not the consequence of equality only. Publicity, plurality etc. also contribute. The plurality of the media for example will make it less likely that lies are spread and maintained without contradiction, that some arguments are neglected for egoistic reasons, etc.

\section{$\S 142:$ D emocracy is $\mathrm{N}$ ot $\mathrm{N}$ ecessarily Relativistic, N ihilistic or A moral}

This shows that a democracy does not consider all opinions to be equally valuable. Relativism, skepticism, nihilism or a-morality are not necessarily democratic schools of thought, although democracy does indeed grant individuals and groups the freedom to choose different ways of life and different views on morality. The fact that democracy is designed in such a way that its procedures produce, on average and in an ideal setting, high quality decisions, invalidates the claim that all opinions are considered to be equally valuable in a democracy. To some extent, democracy takes all opinions into consideration in an equal way, at least at the beginning of the discussion (there is a difference between equality in procedures and equality of outcome). In the end, however, some opinions are better or worse than others.

If all opinions were equivalent, then criticism, argumentation and debate would have no meaning and no reason to exist. Democracy would then indeed be no more than an exercise in arithmetic, and a democratic vote would be no more than the simple sum of different opinions. Furthermore, the risk of moral decay would then be a powerful argument against democracy. Human rights would also lose their 'raison d'être'. The reason why we express an opinion is the wish to prove the superior worth of this opinion, the wish to be criticized etc.

A democracy cannot be relativistic because relativism means that all opinions, including the opinions on democracy, are equivalent. This kind of relativism would be selfdestructive. Democracy is not as good as anything else. An anti-democratic and a democratic theory are not equally valuable. There are many good reasons to defend democracy.

Everything can be criticized and shaded indefinitely and it is always possible to find new arguments. Democracy, however, is a decision procedure (even though it is much more than that) and at a certain moment, democracy wants to decide. This decision is not arbitrary but is not the best possible decision either. It is the best possible decision at a 
certain moment in time. This decision is provisional because the minority can always continue to criticize it and can always express new arguments. As a result of this, the decision may change. 
Section 25: Truth vs. Opinion

\section{$\S 143:$ The A bsence of Truth}

The argument in favor of an elite leading the people and having the necessary qualifications and knowledge to rule, loses much of its strength once we take into account the necessity of looking at as many arguments as possible. Politics that neglects the people is bad politics. Another reason why the elitist argument is not as strong as it looks, is the absence of truth in politics. There is no certain knowledge of the way in which community life should be organized. What ought to happen in a community is not a matter of truth and error. No one can tell with certainty what is the good life. If truth were available in these matters, then it would be likely that some people know more about it then others and power would have to belong to these people and not to the entire community. If truth were available, then the best elements in society would have a better knowledge of it and aristocracy would be the best form of government. The aristocracy would decide on the basis of their knowledge and these decisions would be better than the decisions of the people. Knowledge is never equally distributed. It would be in the interest of the people to follow these decisions. Inequality would be better than equality and would be in the interest of the people at the wrong side of the inequality. 'Suppose that values are objective, so that what ought to happen in a state is a matter of fact independent of any particular individual's thoughts about it. Suppose further that (...) it is something about which human beings can have knowledge. Then it is certainly possible (...) that some people will know more about what ought to happen in the state than others. So: some people are better judges than others. N ow, suppose that we' re trying to decide the best thing to do in a society, that is, what ought to be done in a state, and we are considering whose views should count. Clearly, (...) it would be absurd to consider everyone equally and give them all equal weight. For surely we gain more of the truth, a closer approach to the right answer, if we give greater weight to those who know more about it' (Harrison 1996:148-9).

This argument rests on two unacceptable hypotheses. Imagine that there is truth in political matters. Does this mean that we should consider truth to be the only or even the most important value? There are different values that should be taken into consideration. In some circumstances, some things are more important than having a true and correct decision: the greater conflict which might arise if the views of the expert minority were followed, might be sufficient to outweigh the greater chance of getting the right answer' (Harrison 1996:158). Sometimes, it can be better not to shock the majority by taking away its power to decide or by allowing a certain decision to be taken by a minority of experts, even if this means having decisions which are slightly worse. 'Something which would be, in itself, the best solution might impose too high costs en route. Something which might get more truth could leave us worse off by the time we got there' (Harrison 1996:158).

The second unacceptable hypothesis is that political decisions can al ways be based on truth. Some government actions are of course based on truth. The job of building bridges, for example, is better left to experts. You have to know a certain kind of truth in order to be able to build bridges which do not fall down. However, the people still play a role. They choose the experts. '[T] he best method of choice (...) is to choose experts by their success. (...) the best experts to choose are the ones (...) whose bridges have not fallen down (...). In this the more views about what is actually happening, or has happened, the better. Dictators or oli- 
garchies are more insulated from what is going on than the people at large. To find out whether the people have actually been fed, the best people to consult are the people themselves' (Harrison 1996:161). 'The proper judge of the expert is not another expert, but the user: The warrior and not the blacksmith for the sword, the horseman and not the saddler for the saddle. And evidently, for all public (common) affairs, the user, and thus the best judge, is the polis' (Castoriadis 1991:109).

Even though the people often need individuals with expert knowledge, it is up to the people to choose and judge the experts and the result of the experts' work. It is wrong to say that you al ways need an expert to judge an expert. A system of experts (for example in a bureaucracy or government administration based on merit) must always be integrated in and subject to a democratic system. Experts should only play a supporting role. They use their knowledge and truth to assist the people, often at the level of means and not at the level of goals. First, there has to be a decision on whether or not to build a bridge and only then can the experts come into play. The decision to build a bridge is not only based on facts, mathematics, if-then calculations etc. Values and interest play an important part (for example ecological values). It is up to the people to decide on their goals. They decide if they need a bridge and they determine which values will be served by having a bridge and which other values can possibly be harmed by the bridge. These value-questions will never result in knowledge or truth and will never be the consequence of knowledge and truth. They cannot, therefore, be left to experts.

In politics, values are more important than truth. There can never be a certain answer to the question whether a particular bridge ought to be build or not, whether refugees ought to be expelled or not, whether education has to continue until the age of 18 or not etc. Once there is a decision on these questions, we can leave the technical aspects to the experts: how do we expel refugees, which techniques do we use, what is the planning etc. It may be possible to find elements of truth and knowledge at this level. But it can happen that these techniques give rise to value-questions (for example the use of stock cars for the expulsion of refugees).

Politics does not in the first place deal with questions concerning facts (for example, is this bridge well constructed?). Most political problems concern values which have to be realized by way of decisions. Questions such as 'do we have to build a bridge?' and 'do refugees have to be expelled' are examined in the light of the values we want to realize. Do the proposed measures promote certain values or do they harm other values? In the case of the question whether or not to build a bridge, the value which we can aim at is, for example, mobility. A nother value such as the environment, however, must also be taken into account and the proposed measure can promote one value and at the same time harm another value. Trade-offs can be acceptable but there is no knowledge which can help us decide.

There is as yet no truth or knowledge concerning the importance or the priority of values. The role of experts is therefore limited in this field. Everybody is just as competent and qualified as the next person, which does not mean that every judgment is equally valuable. We need to involve as many people as possible precisely because judgments are not equivalent. We need to have a wide discussion and argumentation in order to be able to answer value-questions. If knowledge were available, we would not need argumentation. Values are a matter of persuasion and agreement instead of truth. And the best way to persuade and agree is to consider as many arguments as possible and to allow the equal participation of as many people as possible.

Politics is not a science, but this does not imply that political decisions or decisions on values in general are by definition subjective, personal, arbitrary and equivalent. Argumentation, confirmation by experience etc. can help us to distinguish good from bad decisions and can allow us to arrive at an intersubjective decision, in-between objective truth and subjective arbitrariness. Aristocrats could use this against democracy. Even if there is no science of politics and values, they say, there still is a difference between persons who have a better knowledge of arguments, who have more experience and who are better able to make the distinction between good and bad decisions, as opposed to true and false 
decisions. 'It might be said, then, that even though the guardians [i.e. aristocrats] could not really possess knowledge of a 'science of ruling', their moral judgments would nonetheless be so superior to those of ordinary people that they should be entrusted with rulership. But to concede that the guardians do not understand an objective 'science of ruling', while not necessarily fatal to the idea [of guardianship], vastly increases the practical problems of identifying and appointing the guardians and removing those who prove to be unfit' (Dahl 1989:67). Anyway, the argument is fundamentally flawed. Knowledge of all possible arguments and confirmation through experience require the active participation of as many people as possible and hence require democracy.

\section{$\S 144:$ A Good Content and a Good Procedure}

I want to return briefly to a problem that I mentioned a few moments ago. You have to take into account the consequences of a decision. Even a perfect decision has to be put into practice. If the majority of the people is against this decision, for whatever reason, then you have problems. It is, therefore, advisable to involve the majority in a decision, because then at least the majority will not be against, will not obstruct the execution of the decision and will not have to be coerced. The cost of the execution of a decision will be less. Freedom or the absence of coercion is also a value. Truth is not the only thing that counts.

There is a difference between a reasonable content of a decision and a reasonable procedure needed to arrive at the decision, and both are equally important. The content of a decision can be better or worse, but so can the procedure. If a good decision - good at the level of content - is comes out of a bad procedure, then the outcome can be less good than might be expected. This is the case when a good decision taken by a minority is forced upon the majority. Majority rule is a better procedure from the point of view of freedom and the absence of coercion.

A less than perfect outcome may be acceptable when it is based on a good procedure. A majority decision is a good procedure because it is relatively easy to enforce and to execute (a unanimous decision is even easier to enforce but the fact that it is difficult to have unanimity, means that this procedure is perhaps not as good as majority rule). It may be better to defend a worse position with three-quarters of an army than a better position with one-quarter of an army' (Harrison 1996:159). Many people will abide by a decision taken by a majority. First of all the individuals belonging to the majority, but also other individuals because the decision of the majority is known to have survived massive criticism and numerous counter-arguments, at least in theory. 'It is not en ough to get the right answer. It must also be got in the right way. Sometimes it may be preferable to have a less good answer reached by a better route' (Harrison 1996:162). The decision is not always more important than the way which led to the decision.

Formal procedures of deliberation and decision play an important role. These proce dures include not only systems such as majority rule, but also modern media, federal systems etc. These procedures outlive the outcomes and the decisions and can even be used against outcomes and decisions. Nobody, not even the majority, is the final judge. Every judgment can al ways be questioned again and again as a consequence of the permanence of the procedures. However, the decision must be executed, otherwise we would not have a decision procedure. Questioning does not mean disobedience.

We limit the right to political participation to adults and we exclude children, the mentally ill and certain criminals. Elitist thinkers react to this by asking why we do not exclude more people. If we exclude children and the mentally ill, then the reason must be their inability to participate in politics. There are many adults who are not mentally ill but who are not sufficiently competent either. Should we not limit participation to the few people who are most competent? 
The problem with this argument is that competence is not the only requirement for good decisions. The acceptability of the decision is also a requirement. The people are more likely to accept a decision in which they have participated than one in which they have not participated. We exclude children, the mentally ill and criminals, not only because they lack the necessary abilities, but also because they lack a sense of responsibility. Competence should not be the only standard for participation.

\section{$\S 145:$ The Possibility of Contestation}

The absence of truth and the permanence of procedures make it possible to dispute decisions. If decisions were always based on truth and were always the result of knowledge, then it would be impossible to question them because it is impossible to question the truth. Democratic decisions are not binding because they are true. They are binding because they are the result of a certain procedure involving deliberation, voting and control by the entire people.

However, a democracy allows you to dispute decisions without having to reject or disregard these decisions. The procedures make it possible to continuously re-deliberate a decision (freedom of speech is also part of the procedure) and even to have a new decision if necessary and if there is a new majority following the re-deliberation. Every decision is provisional. This permanent availability of procedures, together with the fact that decisions are based on persuasion rather than truth, creates the possibility of contestation. Non-provisional and true decisions cannot be disputed. Abiding by decisions does not mean acknowledging the wisdom of those who decide. We can be loyal citizens who obey the law and at the same time oppose the laws which we believe to be dumb or irre sponsible. Only if we can obey a law without having to accept the content of the law, can we criticize and change the law. Our duty to obey the law does not imply a duty to change our convictions. This is why it is possible to improve the laws. The fact that equal political participation, as we find it in democracy, makes it easier to improve laws, is one of the justifications of equality and democracy.

Democratic decisions are binding even if some people believe that they are stupid or wrong. These people may be right, even if in theory a majority system produces the best decisions. The majority can make mistakes, but the fact that the democratic system can be corrected and can revise and improve its decisions, makes it even better than other systems.

The content of a law is a conviction, not a truth. If the law is true, then you cannot dispute it. If the law is based on procedures, then you can use these procedures in order to dispute the law. At the same time you obey the law because of your affection for the procedures from which it results. You like the procedures precisely because they allow you to dispute and change a law that you detest. If procedures make it possible to dispute and change laws, then people do not have to resort to extreme measures in order to get what they want. If you can dispute a law and if there is a chance that ultimately your view comes out on top - providing you use the right arguments - then you do not need to use violence It is much easier to obey a wrong law when there is hope for the future and when there is a chance that your view becomes the one of a future majority. People will obey the law precisely because they can disagree with the law and because they can challenge and possibly change the law. The fact that procedures are open (free speech) and open-ended allows you to gather support for a point of view which opposes the law and to become a majority which overturns the law.

Democracy is highly acceptable because of its procedures, even if everybody cannot always accept the results of these procedures. Democracy is acceptable because it gives the opportunity to challenge and change decisions without violence This means that people who disagree fundamentally with one another can accept democracy, on the condition that they have a reasonable chance of being part of the majority once in a while. Acceptance, however, also depends on results. Nobody will accept a system in which 
procedures can result in decisions which violate rights, no matter how easy it is to challenge such decisions. I will return to this problem in the next paragraph in which I will show that procedures, although important, are not enough.

First though, I would like to discuss a related problem, known as the paradox of Wollheim. 'Suppose (...) we take a simple situation with a single issue with only two alternatives, to be decided by majority decision. Suppose that I think that $A$ ought to be enacted. So I vote for $A$. The majority, however, vote for the alternative, B. So they think that B ought to be enacted. But suppose that I am also a democrat. Then I also think that what the majority thinks ought to be enacted. This is B. So I think that B ought to be enacted. But B is incompatible with A. So I seem to think both that $A$ ought to be enacted and also that it is not the case that $A$ ought to be enacted. I seem to have contradictory beliefs about what ought to be done' (Harrison 1996:223).

You do not have to contradict yourself when you believe that both $A$ and $B$ ought to be enacted. You believe $A$ is the best solution, although the majority chooses $B$. Since $B$ can be considered as a provisional decision, you use your rights and your participation in the procedures in order to challenge $B$ and to find a majority for $A$, which will then be come, hopefully, a final decisions. At the same time, however, you continue to abide by $B$ because you believe that the procedures which led to B are worth protecting. After all, you are using the same procedures in order to challenge $B$.

\section{$\S 146:$ Procedures are N ot Enough}

Democratic procedures are justified because they improve the quality of the decisions which these procedures produce (and for other reasons as well: they give everyone equal influence, they create active, responsible and informed citizens etc.). Democratic procedures are good procedures. However, good procedures are not enough. Even the best procedure can sometimes result in unacceptable decisions. It is important that a decision or a law results from good procedures, but other things are important as well. A good or valid law is more than just any law which happens to result from good procedures. A law must 'satisfy independent, substantive standards' (Nelson 1980:33). For example, it cannot contradict human rights; it has to be neutral and equal for all etc.

Procedures, even good procedures, should not be allowed to lead to any kind of outcome. The possible and acceptable outcome of a procedure must be limited. The law is more than the will of the people established by majority vote after careful and open deliberation. We have to adopt a more than purely formal definition of a law. A law is more than the actions of the legislator according to the procedures of legislation. It is not enough to say how a law must be made and who can make it. We also have to say what a law can or cannot be. Good decisions and good procedures, good laws and good ways of legislation, 'justice of outcome' and 'procedural justice' are equally important. Moreover, there is not always a clear difference between procedures and results. Procedures influence results (massive participation improves the quality of decisions) and are chosen over other procedures because they are more likely to yield good results.

However, democracy should not be chosen as a form of government for the only reason that it is a good procedure which produces good decisions in a good way and which is limited by what is acceptable to human rights. Democracy does more than that (see Part 1). Good decisions are not the only purpose of democracy. N evertheless, even if democracy is much more than a procedure for arriving at decisions, it is very valuable as such, much more valuable than the usual prejudices concerning the intelligence of the people lead us to believe. Not only does it improve the quality or the intelligence of decisions; it also improves the quality or the intelligence of the individual decision takers (see Section 9). The publicity of democracy does not only generate passive knowledge (the passive reception of information from the government in view of the control of the government, or the reception of information by the government concerning the wishes and the claims of the people). It also generates active knowledge, knowledge created by discussion, argumentation, persuasion etc. Democratic and public argumentation diminishes 
the difference between those who know and those who do not know. The word 'knowledge' should, of course, be understood in a rhetorical and not in a scientific way. 


\title{
Chapter 12: Some Problems With Equality
}

\author{
Section 26: Equal or Unequal Value and a Problem of Defi- \\ nition
}

\section{$\S$ 147: The Value of a H uman Being}

Equality is not only a value. It can also cause problems and these problems can of course undo the efforts to justify and universalize democracy and human rights. They can even be used as arguments against democracy and human rights. Instead of a value which justifies democracy and human rights, equality then becomes a problem which undermines democracy and human rights. That is why we have to solve these problems. One of them is the need for inequality. People want to be extraordinary, outstanding, remarkable and exceptional or at least witness people or things that have these qualities. Universal equivalenceis indeed the end of civilization and the end of all values.

The problem is that democracy regards and must regard all people as equally valuable (the equal worth or the equal dignity of the human being, see art. 1 of the UDHR). A citizen of a non-democratic society can be considered as more or less valuable than other citizens because of his or her family, class, status, sex, race etc. In a democracy, however, nobody is a lesser human being because he or she is poor, black, stupid, non-Muslim, female or whatever. Nobody is inferior or superior; nobody's life is worthless, expendable, disposable or in any way less valuable; and nobody's interests are less worthy of protection. Democracy tries to give equal protection to everybody's interests. Every human be ing has a certain value simply because of his or her humanity, not because of the person he or she is, the things he or she has done or the group he or she belongs to. Being human automatically means having a certain value and this value is by definition equal for all human beings.

This is a principle of democracy because you cannot at the same time give everybody equal influence - as is the purpose of democracy - and believe that some people are inferior. If some people are inferior, then it is natural to think that they have interests which should not be taken into consideration in an equal way. However, if everybody's interests must have an equal weight, then everybody must have equal influenceand vice versa. It is impossible to consider everybody's interests in an equal way if everybody cannot participate equally in politics and if everybody's voice does not have an equal weight in decisions. Democracy promotes the equal value of each because it gives everybody equal influence and an equal right to participate and to pursue interests, and because it is a system which gives everybody's interests an equal chance of being protected (even on the assumption that not all interests are morally entitled to satisfaction). This is one of the reasons to accept democracy.

Without equal political participation, it is impossible to consider everybody's interests in an equal way, because equal consideration of interests is, to some extent, everybody's individual responsibility. Everybody has to take responsibility for him or herself and has to fight for his or her own interests. You cannot count on others to do this for you. This is both realistic and morally necessary. Self-support means freedom, while counting on others means dependence There is no democracy without freedom. However, this means that people have to be assertive and aware of the proposals on the political agenda. They have to be able to appraise the advantages and disadvantages of a proposal in the context 
of their own interests and they have to be able to co-decide on the proposal in such a way that their interests are best protected. Citizens have to be informed and educated but, as I have shown, democracy does a lot to spread the information that it requires in order to function adequately. Democracy means openness and openness means discussion. It is well known that information circulates best by way of discussion.

Why are all people equally valuable; or why do all people have an equal value? This seems to be something we believe intuitively. It is an idea with a long history. Christianity, for example, is based on it (all people are children of God and created in His image). Everybody understands the importance of being recognized and treated as a human be ing with a certain value equal to that of all other human beings. No one wants to be treated as an inferior being, as an animal or a thing. If this belief in universal equivalence were absent, then it would be acceptable for one man to treat another as a means, an animal or a disposable thing. Man would be allowed to subjugate other men. The will of one would be a duty for another. However, there is nothing which can prove that one man should be subject to another man's will or authority. Every man is his own sovereign and is just as free as the next person (Locke 1994:passim). It is generally accepted that there is something we call a degrading existence and that everyone has a right to what we call an existence worthy of a human being. An existence worthy of a human being is by definition the same for everybody because it is an existence which respects the value of an abstract human being.

\section{$\S$ 148: U nequal Value}

However, we also have an intuitive belief in the importance of unequal evaluation. We want to be recognized as special and extraordinary human beings, or we want to experience special and extraordinary things done by special and extraordinary human beings. Life would not be acceptable without this. Art, science and civilization in general are based on this belief. Some things or persons have and must have a superior and unequal value.

Unequal evaluation based on abilities, achievements or desert is important and democracy should find a way to deal with it if it does not want to lose its appeal. There is no courage without it (courage is necessary for the protection of democracy), no excellence, no art and no science Only mediocrity and shades of gray. If nobody is superior, exceptional or exemplary, then there is no ambition or envy and, as a consequence, no effort to improve. There are no contests in which to compete with those who are better and in which you can develop your talents. The love of equality can be both an advantage and a disadvantage for democracy. Democracy should not focus exclusively on the protection of the equal value of all. Equal evaluation can be a threat to democracy because it can lessen its appeal. Of course, too much attention to unequal evaluation can also be dangerous. Unequal evaluation can give rise to art and science, but can also cause war, conquest, colonialism, racism, slavery, exploitation, discrimination, chauvinism and elitism. Democracy must try to position itself between both extremes.

Democracies often dislike unequal evaluation or unequal recognition. It is never very agreeable to be at the wrong side of an unequal evaluation. Since excellence is by definition limited to the happy few, the masses will resent the few. They will envy the excelence that they lack and they will despise the arrogance, the elitism and the privileges of the few. They may decide to use their majority position and their democratic power against the intellectual elite and against excellence or superiority as such. Excellence is despised and those who raise themselves above the crowd or even try to raise themselves are discouraged in every way. Every flower that pops up above the grass is cut down. No one is encouraged to improve himself or to believe in his own possibilities. No one should believe in his superiority or possible superiority. ' [P ]eople (...) would never push themselves to their own limits if they simply wanted to be like everyone else. For the desire to be recognized 
as superior to others is necessary if one is to be superior to oneself' (Fukuyama 1992:304). A democracy can force the excellent to become or remain mediocre and seems to be unable to produce anything worthwhile. However, one look at reality is enough to understand that things are not as bad as they may seem. While tyrannies have contributed a lot to civilization, in most cases they have done so in spite of themselves. The arts and sciences flourish just as much in democracies as they do in tyrannies, and perhaps even more so.

\section{$\S 149$ : The Combination of Equal and U nequal Value}

We have to combine equal and unequal evaluation in a democratic society. Both are necessary. An exclusive attention to equal evaluation results in mediocrity and in the disappearance of all values. There is nothing valuable left if everything is equally valuable. Evaluating means distinguishing between better and worse and is by definition inegalitarian, although it does not exclude the possibility of an equal value on a certain level. If everything is equally valuable, then nothing is valuable any more. On the other hand, a society in which there is only unequal recognition cannot be a democracy and is by definition cruel and inhuman because it denies the existence of the basic value of every human being. It does not know the concept of a degrading treatment of human beings.

This concept of degrading treatment should be the basic of a minimum value that is equal for all. Nobody should be treated as if he or she is worth less than this minimum, as if he or she is less than human. Everybody is a human being and should not be treated as something which is less than human. Being human means having a certain value and having the right to be treated according to this value. After that, we can see whether and in which case there is a need for unequal recognition on top of a basic equal recognition and without harming this equal recognition.

We have to fight for the equal value of so-called inferior people or people who are treated as if they were less than human. At the same time, however, we will never be content with universal equality and we will value certain persons for what they have done and for their personalities. We not only value people because they are human be ings. We also value them as artists, scientists, inventors, statesmen etc. We not only grant or receive recognition as human beings, but we also grant or receive recognition as special human beings. We look for extraordinary achievements and we recognize the superior value of the people behind these achievements. This special recognition of others and of ourselves is a widely shared need. Shame, respect, self-respect, self-esteem, pride etc. are feelings that prove the existence of this need.

However, even if we believe that some people deserve a special recognition of their superior value on top of the recognition of their value as abstract human beings, we are not allowed to consider other people as being below a certain value which is common to all people. For example, we are allowed to punish a criminal and we are certainly dlowed to regard him or her as less valuable than Einstein. However, we are not allowed to treat him or her in an inhuman or degrading way, or in a way which does not respect his or her value as a human being (art. 5 UDHR and art 10 ICCPR).

Tabel 2: The Combination of Equal and Unequal Value

\begin{tabular}{|l|l|}
\hline $\left.\begin{array}{l}\text { This is necessary, } \\
\text { but not universal : } \begin{array}{l}\text { Desert, recogni- } \\
\text { tion, admiration } \\
\text { etc. }\end{array}\end{array}\right\} \begin{array}{l}\text { More than an equal } \\
\text { value, more valuable } \\
\text { than others }\end{array}$ \\
\hline $\begin{array}{l}\text { This is necessary } \\
\text { and universal : }\end{array}$ \\
\hline $\begin{array}{l}\text { This is universally } \\
\text { unacceptable: }\end{array}$
\end{tabular}


Equality can only be part of the appeal of democracy if it is a limited equality. Radical equality or equality applied in every field of life is a curse rather than a value. An ideal democracy restricts equality and is not based on the principle that everything should be equal. Democratic equality is equality of a very specific kind. Equality should not step outside of its democratic limits.

Democracy defines equality in a limited way because there are, in fact, five and only five types of democratic equality. First of all, democracy means political equality. Political participation is an equal right. Everybody has the same right to rule, irrespective of class, status, race etc. Many social distinctions are politically irrelevant. Everybody has one vote and is politically equivalent. Every vote is as important as the next one, no matter whose vote it is.

Equal human rights, equality before the law, material equality and the equal value of human beings are four other types of democratic equality. Every other kind of equality is unnecessary and maybe even harmful. (Equality of opportunity is no more than a combination of material equality and equal rights. People should have an equal opportunity to use their rights, talents and disposition, and should not have different prospects in life because of their social position, their wealth or their natural assets. Equality of opportunity is made possible by material equality and equality of rights. ' [T] hose who are at the same level of tal ent and ability, and have the same willingness to use them, should have the same prospects of success regardless of their initial place in the social system. In all sectors of society there should be roughly equal prospects of culture and achievement for everyone similarly motivated and endowed. The expectations of those with the same abilities and aspirations should not be affected by their social class. (...) Chances to acquire cultural knowledge and skills should not depend upon one' s class position, and so the school system, whether public or private, should be designed to even out class barriers. (...) [This] still permits the distribution of wealth and income to be determined by the natural distribution of abilities and talents. (...) distributive shares are decided by the outcome of the natural lottery; and this outcome is arbitrary from a moral perspective. There is no more reason to permit the distribution of income and wealth to be settled by the distribution of natural assets than by historical and social fortune', Rawls 1999:63-64).

In a democracy, we sometimes witness an exaggerated attention to equality or, in other words, a widening of the definition of equality. Equality breaks out of its restrictions. A radical definition of equality will not only discredit equality but also democracy, except if democracy manages to hold on to the limited definition of equality and to check all illegitimate definitions of equality.

People tend to accept longstanding inequalities between social classes because they perceive them as natural and beyond redress. However, if there is a certain degree of social mobility and if the inequality between classes decreases - as happens in a democracy - then people become more aware of the remaining inequalities. These tend to hurt more than longstanding inequalities, even if they are less profound. The more equality, the less explanations there are for the remaining inequalities. Inequality becomes less acceptable when there are more possibilities to abolish inequality. When certain inequalities are abolished, attention shifts to other inequalities which may have escaped attention before. Increasing equality may give the impression of increasing inequality. Hence democracy tends to abolish more and more types of inequality.

Equality can also be defined as the elimination of plurality. The democratic individual, who is no longer defined by his or her natural place in the social order, by his or her status, class, birth etc. - all these things have become politically irrelevant in a democracy - tries to find his or her identity elsewhere. The identity of the people ('das Volk') is the obvious candidate in view of the political importance of the people in a democracy. However, this means that the people are given a permanent and unified identity. In an ideal democracy, we always have a temporary and plural definition of the people and it is very difficult to identify with such a people. That is the reason for the temptation to give the people a permanent and unified reality - the people become, for example, the 'Aryans' or 
the 'Workers'. Everything which deviates from this identity - Jews and capitalists in my example - is excluded in order to maintain the purity, the unity and the oneness of the identity, and in order to maintain something which one can identify with. Those who are not excluded can at least identify with something specific and can escape the changing and contradictory society of democracy in which all the traditional and quasi-natural hierarchical structures are irrelevant and unable to give people an identity - if they have not disappeared completely.

This is the way in which nazism and communism have used democracy and the importance of the people, the loss of traditional structures, natural links and social positions, and the need for identification. Nazism and communism defined the people in such a way that all elements which did not fit into this definition and which were 'volksfremd' or 'class enemies', had to be excluded. Both nazism and communism were egalitarian ideologies. Both these ideologies were based on democratic practice, but neither could accept that people are different. A person with a different identity had to be re-educated or exterminated. For nazism and communism, there was only one kind of social division - all social divisions were reduced to a racial division and a class division respectively - and even this division had to be eliminated by the victory of one of the struggling races or classes. Everybody had to become equal and diversity was a curse.

Of course, democracy is not the only cause of this kind of egalitarianism or radical equality. Christianity, for instance, has also contributed to the widening of the definition of equality. Christianity teaches that everybody is equal for God, regardless of individual qualities and deficiencies. It was in the name of this equality for God that the Christian religion was imposed in the colonized territories and that other religions and cultures were destroyed. However, equality for God has not softened the Christian opinion on non-believers. N on-believers have often been considered as ' $U$ ntermenschen' who have to be exterminated ('Incroyants et paiens sont des sous-hommes aux yeux des apôtres. Saint Pierre les compare à des 'animaux sans raison, voués par nature à être pris et détruits' . (...) Les 'ennemis de Dieu', avait écrit Saint Paul, 'méritent la mort'. Thomas d'A quin précise: 'L'héré tique doit être brûlé'. L'un des canons adoptés au Concile the Latran déclare: 'Ils ne sont pas homocides, ceux qui tuent des hérétiques' ', de Benoist 1979:172).

A nother cause of egalitarianism is the exaggerated attention to material needs. These needs are the same for everybody. Our biology, our natural characteristics, our corporeality and consumption make us all equal. In biology, it is impossible to distinguish tween identities. Too much attention to consumption, materialism, wealth, health, fitness, humanitarian assistance etc. favor the equality of men and favor the animal side of men, at the expense of humanity and difference

Egalitarianism - materialistic or otherwise - can only be countered in the public space. Difference, identity and personality can only result from public life. That is why democracy and human rights are the best remedy against egalitarianism. Both diversity and equality are goals of democracy and human rights. Human rights contain elements of both equality and inequality. On the one hand, they are the rights of abstract and quasiempty human beings, devoid of all differences, which is why they can belong to all human beings in an equal way. On the other hand, they contribute to the development of everyone's identity and individuality. The function of rights can only be understood in this area of tension between equality and difference These two goals do not contradict or exclude each other because they are defined at a different level. In any case, equality without the possibility of inequality is logical nonsense.

Of course, democracy does not automatically lead to communism, nazism or other forms of egalitarianism. There are, however, certain elements in the logic of democracy which contribute to the widening of the definition of equality. The question is whether this is a sufficient reason to reject democracy. I think it is not, on the condition that democracy tries to keep equality within the limits of the five definitions given earlier and tries to focus attention on the diversity of public life. 
Equality also becomes a problem when some of the five different kinds of equality contradict each other, for example equality before the law on the one hand (laws must be equal for everybody and should not discriminate) and material equality on the other hand. Material equality is often promoted by way of taxation based on legislation (material equality in the sense of economic rights, not in the sense of outright equality). The purpose of taxation is the redistribution of property. The problem is that redistribution only benefits one group of people and harms the interests of the rest of the population. Taxation laws do not seem to be equal for everybody and do not have the same result for everybody. It seems as if they discriminate against certain people. A wealthy person can claim that laws must be the same for everybody and that a law which forces one person to give and allows another to receive is illegitimate. A law against murder does not, at the same time, force one person to abstain from murder and allow another person to murder. So why should a law on taxation be allowed to discriminate?

First of all, there is no reason to believe that the principle of equality before the law is an absolute principle. It must be possible to make trade-offs between principles. If one principle - for example equality before the law - does serious harm to another principle for example material equality - then it may be acceptable to sacrifice or limit one principle for the sake of another. Sometimes, one has to make a choice and one has to establish priorities. This goes both ways. Too much attention to material equality can be counteracted by way of the principle of equality before the law.

However, it may not be necessary to limit the principle of equality before the law. Taxation laws do not discriminate, at least when we define discrimination as giving something to one person and denying it to another without good reason. Economic rights indeed give something to one person and not to another. Even more so, they take away something from one person in order to give it to another. However, the former person is not denied the thing that is given to the latter. He or she has and continues to have the same thing as the one given to the latter. The consequences of taxes are equal for everybody because they make sure that everybody has the same minimum of material means. Taxation laws do not cause discrimination or inequality. On the contrary, they are designed to eliminate discrimination and inequality, not only at the level of material wellbeing but also at the level of political influence, because material inequality causes political inequality. We have discrimination when a law only benefits one group of persons and when there is no good reason why other persons should not benefit. It is clear that there is no good reason why wealthy people should benefit from taxation laws in the same way as poor people, except of course when they themselves become poor. Everybody can be in a position in which he or she needs taxation laws.

The right to free speech does not benefit everybody in an equal way either. Some people gain more from this right than other people. A colored person suffering from discrimination needs this right more than a white, middle-class person without political worries. However, there is no reason to claim that this right contradicts the principle of equality before the law.

\section{$\S$ 152: Equality of O utcome vs. Equality of Procedures}

In the case of taxation laws, there is a difference between equality of outcome and equality of procedure. An unequal method leads to an equal outcome. If we were to have equality of procedure, then the outcome in the sense of material well-being and political influence would be very unequal. Doing, or supplying, exactly the same thing in different circumstances may produce very unequal results. (...) Equal procedures may not lead to equal outcomes. Conversely, equal outcomes may be the result of quite unequal procedures. The notion of equality applied to the goal, or outcome, seems to be quite different from equality applied to the method, or procedure. As a goal, the requirement is that whatever procedures are adopted, 
people should end up in similar positions. (...) Achieving this may involve treating people in very unequal ways, for example taxing some people harshly in order to redistribute wealth to others who are less well off' (Harrison 1996:180).

However, equality of outcome is not always more important than equality of proce dure. The two kinds of equality are important and they have to be balanced against each other when they contradict each other. Too much attention to either can cause problems. Equality of procedure leads to unequal material well-being and unequal political influence. There can be formal equality in the democratic procedures - equal rights to participation etc. - but at the same time unequal prosperity. As a result, the equal procedures do not have the same effect for everybody. The rich, because of their privileged access to the procedures - they have more money and therefore more input in decisions, they have a better education etc. - have more political power and can use this political power for their own purposes. They can, for example, impose policies which increase their prosperity at the expense of poor people.

Too much attention to the equality of procedures can also result in the tyranny of the majority. Everybody has an equal right to participate in the procedure, but the outcome may lead to rights violations for the minority if equality of the outcome - in the sense of equal rights - is unimportant. On the other hand, too much attention to equality of outcome can justify a benevolent dictator distributing goods equally or prohibiting people to participate in decisions (as I have shown, the way in which a decision is reached is just as important as the decision itself).

It may seem that the outcome is what matters, but procedures influence outcomes and are therefore important as well. Some procedures produce better outcomes than others. Majority rule for example produces decisions which are more acceptable and therefore better than other procedures. We can guarantee good procedures, but we cannot guarantee good outcomes. This is true for majority rule but also for the rules concerning 'fair trial' (see Section 2). These rules are obviously superior to other rules in the sense that they are more likely to produce good decisions. However, they cannot guarantee good decisions. They do not make mistake or miscarriages of justice impossible.

\section{$\S$ 153: Political Equality vs. M aterial Equality}

According to Marxism, democracy suffers from a contradiction between political equality on the one hand (equal votes but also equal rights, equality before the law etc.) and economic or material equality on the other hand. The absence of the latter prevents the full realization of political and even judicial equality (equality before the law). Wealthy persons have more means (such as money, time, education etc.) to inform themselves, to lobby, to influence, to get themselves elected, to defend themselves in court etc. A merely formal principle such as political equality loses much of its effectiveness when some can use their wealth to control political debates and decisions. Even more so, political equality, democracy and equal human rights (not only the right to private property) serve to cover up, justify and even maintain material inequality, exploitation and class rule in a capitalist society. Real material equality and therefore also real political and judicial equality can only be brought about by an anti-capitalist revolution which brings down the capitalist system of property along with the legal and political tools that are used to protect this property. Material redistribution is not enough because it does not affect material inequality in a substantial way. It only provides a minimum of basic goods. The remaining material inequality still affects political equality. Democracy is self-defeating. It can never deliver what it promises because it does not go far enough. It can only give people formal instead of substantial equality. Elections, rotation in office, economic rights etc. are superficial phenomena without effect on the deeper economic processes of exploitation and class rule. Democracy must therefore be replaced by something better.

Marxism claims that there can only be real political equality and real equality of power when the most important goods - the means of production - are the equal property of all 
citizens. In all other cases, the rich will have more opportunities to benefit from political participation and judicial protection. Equal rights will lead to an unequal outcome, and this is intentional.

Much of this is, of course, correct. Wealthy groups can and do use elections and human rights to pursue their interests, often at the expense of less fortunate groups. They may even use democracy to maintain exploitation. They can speak better thanks to their education; they have a better knowledge of the ways in which to defend interests; they know their rights; they have friends in high places, etc. That is why compensating measures have to be taken, not only in order to respect economic rights, but political rights as well. By way of these measures, the state redistributes wealth from the rich to the poor, in order to grant the poor more political influence Other measures enhance the independence of political parties with regard to wealthy pressure groups (for example public instead of private funding for political parties). 'W hat is necessary is that political parties be autonomous with respect to private demands, that is, demands not expressed in the public forum and argued for openly by reference to a conception of the public good. If society does not bear the costs of organization, and party funds need to be solicited from the more advantaged social and economic interests, the pleadings of these groups are bound to receive excessive attention' (Rawls 1999:198).

It is clear that we are not dealing with a potentially fatal argument against democracy and human rights. Democracy and human rights are in fact the only solution to the problem of the unequal political result of economic inequality. Democracy and human rights are not merely formal. Equal voting power, equality before the law and equal rights do not cover up and do not maintain the social division between rich and poor. Democracy does not hide divisions; it shows them and it shows them in a better way than any other form of government. And because it allows divisions to become public, it offers the best chance of eliminating or softening unjust divisions. Democracy does not only serve the interests of the wealthy classes. Poor, exploited or oppressed groups also benefit from freedom of expression, from the election of their own representatives and from the possibility of claiming rights (economic rights, for instance, equalize political influence because they create leisure time which can be spent on politics). Even the bare fact of being able to show an injustice is an advantage in the struggle against this injustice. If you are not able to see an injustice - and this can happen in an unfree society - then you are not aware of its existence and you can do nothing about it. Democracy at least gives poverty a voice

The struggle against injustice means questioning society and the powers that be (also the economic powers). It is easier to question social relationships in a society in which political power can be questioned. Publicly questioning political power in a democracy is a process in which the entire people, rich and poor, are involved. This process legitimizes the act of questioning per se and therefore also the act of questioning injustices in society (see Section 5). Elections and rights are not a force against change. They create infinite possibilities, including the possibility to change economic structures.

Of course, the political and legal elimination of the difference between rich and poor (they all have an equal vote, equal rights and equality before the law) does not automatically result in the elimination of the social difference between rich and poor. However, democracy and human rights can diminish the influence of property and wealth because:

(1) they give legal and political means to the poor in order to defend their interests; no other form of government performs better in this field because no other form of government gives the same opportunities to the poor (the opportunity to show injustices, to elect representatives, to lobby governments, to claim rights etc.); and

(2) they diminish the difference between rich and poor by way of redistribution; they allow for compensating measures to be taken, measures which help to preserve the value of political participation for all (for example redistribution, but also measures such as subsidies for independent TV-channels or for political parties which then become more independent from private wealth and private interests). 
If certain divisions are made politically and legally irrelevant (by way of equal rights, equality before the law, equal vote etc.), then this is not necessarily part of a conscious strategy to maintain these divisions in real life. If it were part of such a strategy, it would probably produce the opposite of what is intended. The chances that injustices disappear are much higher in a society in which injustices can be shown and questioned, and only a democracy can be this kind of society. A society which can question itself because it can question the relations of power (see Section 5), is more likely to change. This is shown by the recent history of most western democracies where many injustices have been abolished by way of democracy and human rights. The labor movement, the suffragette movement and feminism would have been impossible without democracy and rights. Workers, women, immigrants etc. have all made successful use of the possibility to claim rights, to elect representatives, to enact legislation etc.

Political influence will probably never be equal for everybody (talent also plays a role, and it is difficult to correct for the effects of talent). But there is more and there is less. Democracy is probably the best we can hope for. On top of that, democracy constantly enhances the equality of influence, even though every victory creates a new problem. The Internet, for example, will empower many people and will enhance political equality, but it will also exclude many other people, namely those without the necessary computer skills or without the infrastructure necessary to use the Internet on an equal basis. It can become a new source of political inequality. We will have to finds ways in which to equalize the access to and the use of the Internet because we want to maintain or $\mathrm{n}$ crease political equality. In the meanwhile, however, a new kind of inequality should not make us lose sight of the enormous progress for equality which the Internet allowed us to achieve. Many people, who today use the Internet to participate in politics, never participated in the past. 
Section 27: Efficiency, the Ability to Take Decisions and the Quest for Consensus

\section{$\S 154:$ Confusion, Chaos, Complexity, Slowness and Insecurity}

In a democracy, decisions are taken by a majority. Unanimity or consensus is not required. This means that there is always disagreement, which is beneficial, as I have pointed out in Section 1. However, disagreement also means confusion and this confusion seems to be the result of political equality. Political equality leads to continuous confrontations between a maximum number of different opinions coming from a maximum number of levels of society, all of which have to be treated equally, with the same respect and attention. We have to listen to and take into consideration every opinion on an equal basis. This confuses, complicates and extends the debates. Debates have many different antagonists and often take a very long time before they reach a conclusion. This introduces an element of slowness and inefficiency.

Furthermore, the larger the number of different interests or different groups participating, the more difficult it is to reach a decision which pleases a majority. It often takes much effort, time and complexity to unify different and contradicting interests into a single compromise decision. This again introduces elements of inefficiency. And as if this is not enough, a democracy makes it possible to question a decision over and over again. New arguments have to be taken into account and the debate is open-ended. As a result, decisions change.

All these facts of democracy create complexity, obscurity, confusion, chaos, slowness, unpredictability, doubt, insecurity and discontinuity. It is not surprising, therefore, that many people long for the relative simplicity, certainty, clarity, invariability, reassuring stability, order and swiftness of the decisions in a dictatorship, where there is only one voice that speaks.

Efficiency, resolve, clarity of vision, firm direction and the ability to do things become the most important values and the equal participation of all has to be sacrificed in order to realize these values. Tyranny becomes less objectionable when people tire of social conflicts, struggle, confusion, compromise, insecurity and change resulting from equal democratic participation. To decide once and for all, quickly and in a simple way, to do something and to be active is indeed easier when decisions are made by only one person who must listen to nobody but himself (in most cases it is a 'him'). The decisions of a dictator can be fast, efficient, simple, clear and definitive. He does not have to take other opinions into account, he does not have to consult all layers of the population, he does not have to wait and see which opinion wins the struggle of ideas and he does not have to make compromises. He is master of the situation because he can force people. As a result, he can act and he can develop an image of resolve, forcefulness, decisiveness and efficiency. People may even accept the violations of human rights that result from dictatorial action, if this is the price to pay for clarity, decisiveness etc.

It is true that democracy is sometimes incompatible with simplicity, clarity, speed, steadfastness and continuity. In a democracy, it is sometimes difficult to take fast, efficient, simple and definitive decisions. This is a weakness because swiftness, simplicity, efficiency etc. are important to many people. Insecurity, unpredictability, obscurity, confusion etc. generally cause dissatisfaction and even fear. Every individual tries to avoid 
obscure, uncertain and unpredictable situations for him or her personally, so why cherish them at the level of society and politics? Only those who want to hide something can make use of them. On the other hand, discussion, equal participation and massive consultation do not have to be an impediment to action as long as decisions are not postponed indefinitely. On the contrary, they are necessary conditions for wise action, as I have shown in Chapter 11.

This al ready indicates that decisiveness is clearly not the only or most important value. Quality and acceptability are also important. What is the use of having a fast and simple decision if it is a stupid one or if it is unacceptable to the people and therefore thwarted by the people? Acceptability is one of the justifications of democracy because large-scale and equal participation guarantees a large degree of acceptability. Acceptability and easy implementation are therefore also elements of efficiency, just as speed and simplicity. In a democracy, decisions may be more difficult and more time-consuming because of the large number of equal participants and equal interests, but they are also more acceptable and therefore easier to implement and enforce

Another reason to prefer a 'strong man' is the continuous risk of deformalization of democratic conflicts. As long as there are conflicts, there is a risk that conflicts step out of their predetermined forms designed to channel conflicts away from violence (see also Section 2). The so-called ritualization of struggle can stop functioning and, as a consequence, conflicts can intensify and can become violent. This risk can convince people to abolish conflict and division altogether. In a 'well-ordered tyranny' there are no conflicts and therefore no risk of deformalization.

This is especially tempting when the divisions, the insecurity and the relative chaos of democracy are made more extreme by an economic crisis or a war, or when certain groups move their struggles out of the predetermined democratic forms and institutions and into the streets. In these kinds of situation, chances are high that we witness the rise of the Unified People, fixed, determined and undivided. Everything that opposes unity is then considered as a symptom of social decomposition and destruction (Lefort 1992:112). Divisions in general and democracy in particular - as a free-market of divisions - are considered to be objectionable. Instead of democracy and freedom rights, we need a strong state which is able to deal with divisions, which is not questioned and which is not disfigured by struggles for power and the risks linked to these struggles. The changing and contradictory ideas of the people are replaced by the unified and simple principles of one man or one party. Out of the incoming and outgoing waves of public opinion arises a rock of unity, conviction, trust and will power.

Tyranny waits impatiently at the end of anarchy. 'Preoccupation with the perils of inordinateness (...) allows the fear of anarchy to bear the fruit of connivance with tyranny' (R. Niebuhr in Barber 1984:101). After years of inefficient and confused multi-party rule that continuously balances on the edge of violence, a one-party system can come as a relief because it is by definition stable, permanent, coherent and able to suppress violence.

However, chaos and division are inevitable in a democracy and are not objectionable as such, as long as they stay at the level of ideas and do not descend on the streets. There is no democracy without chaos and division. The risk of democratic chaos and division turning into violence should not be overestimated. Conflicts of words can become physical conflicts, but the practice of democracy shows that this is the exception rather than the rule. Physical conflicts are much more common in non-democratic states. The places of debate are also places of friendship and relationships. The very fact that conflicts are formalized in democracy, makes deformalization less likely. Formalization works as a valve for physical energy and prevents violence. The tyrannical use of violence in order to suppress conflicts has the opposite effect. It necessarily creates reaction. 
The rejection of equal participation goes together with the introduction of another kind of equality, namely consensus. Consensus or uniformity is indeed the same thing as clarity and certainty. It destroys the cacophonic, conflictual, contradictory and therefore uncontrollable politics of mass-democracy. Disagreement and the confusion, slowness uncertainty and indecisiveness it implies constitute a heavy burden for many people, but consensus is necessarily dictatorial and therefore a burden of another kind.

Disagreement is often linked to individualism. A strong state is said to be necessary in order to impose a collective goal as an alternative for the anarchy and the divisions caused by individualism. Individualism results from the equal treatment of all individual interests in a democracy. Because all individual interests are treated equally, people feel free to pursue their individual interests. They know that there is a chance that their interests are taken seriously and that they are not neglected by definition, and so it is worthwhile to put some effort in them. However, since these individual interests are by definition very numerous, very different from each other and often even opposed to each other, we find ourselves in a situation of confusion, complexity, chaos, fragmentation and possibly even violence Individualism or the exaggerated attention to and equal treatment of everybody's individual interests leads to anarchy, both in politics and in the streets, and has to be replaced by a collective goal imposed by a strong hand able to enforcecohesion.

This is the age-old dream of a society in which everybody lives in perfect harmony and has the same common will and common faith, without conflicts and without secrets for each other. A common goal or a common will can indeed solve problems such as indecisiveness, insecurity, confusion, slowness, conflicts, violence etc. However, this would mean accepting a social order in which the goals of many individuals are abandoned and the voices of many others smothered. Besides, it would be counterproductive. Conflicts and differences are inevitable and suppressing them means sharpening them. Conflicts and contradictions can cause violence, but the desire to eliminate conflicts and contradictions can cause violence as well, first because of the actions against contradictions, and then because of the reactions (Finkielkraut 1993:81-82).

Disagreement caused by the equal right to participate is supposedly not the only reason why democracy fails to act in a swift and unified way in order to achieve a collective goal or a general interest. The fact that laws and rights limit the power of a democratic state is said to be another reason for the ineffectiveness of democracies. However, limited power is not the same thing as weakness. On the contrary, a state that can and must only do certain very specific things will be more efficient. History has shown that democracies can be able to handle severe crises in a unified and collective way (look at World War 2 , for example), even if this means limiting democracy temporarily. The argument of the lack of power in a democracy fails to distinguish between power and authority. A state that has the support of the people can do more than a state that does not have this support. It is more confident and it is assured of the cooperation of the citizens.

In any case, the argument of the incompatibility of democracy and collective goals is mistaken. Democracies must have and indeed have collective goals, just as any other form of government. Democrats may be divided on almost everything; but they cannot be divided and they are not divided when it comes to the survival of democracy. The common goal in a democracy is the common conviction and the consensus regarding the value of democracy.

\section{$\S$ 156: D angerous Truth (The Truth Threatens P olitics)}

Equal participation is not the only cause of the quest for consensus. The democratic addiction to truth is another cause. Both the opponents and proponents of democracy can 
be tempted to create a reign of consensus, the opponents because they hate disagreement and the consequences of disagreement; the proponents because they love truth.

Truth is very important in a democracy, and rightly so. Politicians are supposed to tell the truth. Representatives of the peoples who lie to the people are a contradiction in terms. There are supposed to be no hidden decisions, no powers behind the scenes and no obscure government practices. Openness and publicity are perhaps the most important democratic values. Nobody should lie to the people or should try to convince the people that some lie is in fact the truth or that something which happened in fact never happened. The people should be aware of all government practices, otherwise there can be no accountability and no control. Indoctrination is unacceptable for the same reason. Especially the press has a role to play is the search for and the defense of the truth of politics. The justice system as well is in essence a search for the truth. The education system supported by the state is concerned with the transmission of the truth. It is, therefore, obvious that the truth is very important in democratic politics.

The truth, however, can also be a problem in democracy, and not only because of the elitism inherent in truth (see Section 25). The truth is linked to consensus and consensus is linked to tyranny. A democracy is essentially a system of disagreement and of differences of opinion. It is realistic in the sense that it accepts the inevitability of disagreement and tries to find ways to arrive at decisions which please a maximum number of people. At the same time, it tries to protect the basic interests (the human rights) of those who do not agree with the decisions taken (the democratic minority in other words), and it tries to formalize conflicts that cannot be resolved.

The truth is incompatible with disagreement. Who dares to contradict, to resist or to reject the truth? Only a fool or a half-wit, it seems. The truth is always accepted and is accepted by everybody in the same way. It is, therefore, by definition a matter of agreement and consensus. There is no truth without the exclusion - instead of the formalization - of contradictions, conflict and plurality. The truth makes everything uniform because all competing opinions disappear. The truth is also despotic and coercive. It forces itself on everybody and it transcends discussion, agreement, consent, persuasion and many other important democratic categories. 'Euclide est un véritable despote; et les vérités géométriques qu'il nous a transmises, sont des lois véritablement despotiques' (Mercier de la Rivière in Arendt 1994:138).

Total itarianism has shown what happens when we give too much attention to truth in politics. Diversity and dissenting opinions are suppressed. We witness 'ein Gebrüll, das nur sein Echo liebt' (in the words of Günther Grass), with the right arm stretched into the air or waiving with the little Red Book ('the whole country must participate in the U niversity of the Thought of $\left.\mathrm{M} \mathrm{ao}^{\prime}\right)$. A political theory that believes to be in possession of the truth is forced to suppress other theories and points of view. It is forced to yell, because nobody can accept lies and stupidity. Universal agreement and the disappearance of plurality are the result. Politics becomes an exercise in consensus from the moment it embraces truth as its main goal. The accusation is that democracy's natural affection for truth can make it gravitate towards totalitarianism.

If you do not agree with someone who believes to be in possession of the truth, then you are not someone who holds another opinion and has the right to hold this other opinion. You are an idiot, unable to see the truth. You do not have the right to be wrong, to be mistaken or to believe lies. If you are wrong, then you must be re-educated in order to be able to understand the truth. The truth can become a tool for authoritarian rulers who can protect themselves against to criticism by claiming that their ideologies are 'true' or 'scientific'. And vice versa: if truth becomes the goal, then we rapidly find ourselves under authoritarian rule.

Communism and nazism were so-called 'scientific' systems. They supposedly derived their legitimacy from the laws of history and nature respectively. Both communism and nazism narrowed politics down to a system that only knows truth and that is ruled by scientific laws that have to be known by, applied by and taught to all citizens. Those who have a superior knowledge of these laws have a right to claim the position of rulers. Who 
needs a majority when the truth is all-important? It is sufficient that the few persons who have a superior knowledge of the truth transform the truth into laws. The opinion of the majority is irrelevant because it does not change the truth. The plurality of individuals or groups is abolished and only a single 'We' is left, for example the 'We' of the communist Party - the smiling brotherhood - or the 'We' of the race

Politics is a system of conflicts between opinions - which may be regarded as truths rather than a system based on truth. Let truth be a matter for God, in the words of Lessing, and let man be content with his opinions (in A rendt 1994:131). The reason why we have to give up or better limit the truth is that debate, conflict and contradiction are inevitable. And as long as there is disagreement, we are dealing with opinions rather than truth. On the other hand, disagreement is necessary for the creation and expression of the individual identity and for the improvement of the quality of opinions (see Section 1). The truth or the ultimate agreement and uniformity of each is obviously not the only value. Divisions, diversity and discord are important as well.

Politics is the space necessary to deal with diversity (see Sections 2 and 5). Politics is not one all-encompassing, true and exclusive explanation of the world, as it was considered to be by nazism and communism. It is instead a collection of different and contradictory opinions on what is or is not 'true'. Democracy deals with opinions rather than truth and this is shown by the fact that a democratic decision is binding, not because it is true, but because it is the opinion of the majority, even if this opinion is manifestly or supposedly untrue. The strength of a democratic political assertion does not depend on the truth of this assertion, contrary to for example scientific or journalistic assertions. It depends on the size of the group who believes that the assertion is meaningful, correct or true. This belief, however, is an opinion rather than a true belief, because there are always other and contrary beliefs and none of the beliefs in question has as yet ascended to the realm of science From the moment there is science, there is no longer a need for politics (who would want to vote on the choice between $e=m c^{2}$ and $e=m c^{3}$ ?). In the same logic, we see that the weakness of a democratic political assertion does not depend on its incorrectness but on the degree of indifference or contempt it engenders.

In a democracy, unanimity as a consequence of truth is unimportant. Everything stands or falls with the majority of the people who, through debate, argumentation and persuasion, have arrived at an agreement on a certain opinion. The majority may even believe that its opinions are in fact truths, but it should not believe this too fanatically. After all, its opinions are the result of argumentation, and better arguments for opposing beliefs can al ways turn up.

Democratic politics is the stage for discussion on many different arguments and many different convictions. Argumentation and the struggle between different opinions are what politics is all about. Truth is of no use to politics and vice versa. In the struggle be tween opinions, people convince each other and themselves on the basis of good arguments. People are not forced by the impersonal evidence of truth that only needs contemplation instead argumentation or persuasion. Human diversity is preserved because people can always change their opinions, even when they have agreed to something.

A gain we see that democracy is more than just a collection of opinions, some of which are strong because they happen to have a large numbers of adherents, and others which are weak and irrelevant because they only engender indifference or contempt. The fact that there is a struggle between opinions shows that democracy distinguishes between opinions, between good and bad opinions, between opinions that can claim to be backed by good arguments and others that cannot (see also Section 24). People do not 'happen' to have an opinion and do not 'happen' to be in the majority or the minority. They have an opinion because they are persuaded by arguments.

People do not engage in a political debate because they want to prove the irrelevance or indifference of opposing opinions. They do not try to make another opinion irrelevant or to engender as much indifference as possible (for example by suggesting marginality or by ignoring the other opinion). They attack the content first. They give counter- 
arguments, they sum up disadvantages etc. They attack the soundness of the opinion and try to show that there are better opinions. Irrelevance or indifference is only a by-product.

However, this does not mean that they have to believe in the possibility of finding the truth. They can only claim to have found the best possible opinion in the given circumstances. The future may prove them wrong. New arguments can al ways produce an improvement in the quality of opinions. Instead of the difference between correct and incorrect or between true and false, it is the difference between better and worse which is important. Irrelevance means that it does not matter whether you are right or wrong, but it is not because nobody is ever completely or definitively right that everything is irrelevant.

Democratic decisions do not have to be correct or true. They are not binding because they are true and they are not worthless when they are untrue. In any case, the purpose of a decision is not to conform to the truth, but to make the truth, to change facts. You do not need a decision to establish a fact. That would be pointless. Decisions are normative and not descriptive. They deal with values instead of facts, with the things that have to be done instead of the things tout court. Politics is not about knowing; it is about acting. A decision is binding when it has been produced in the right way, according to certain rules and procedures. The truth is, of course, binding as well - nobody can be against the truth - but for completely different reasons.

\section{$\S$ 157: R easonableness Instead of Truth}

Democracy may indeed be complicated and slow, but it is more than just an open-ended system of perpetual debate. Some decisions need to be taken, and often need to be taken quickly. The failure to decide and to decide quickly can have enormous consequences. Certain things have to be done and it is no good continuing discussions forever. Democrats are well aware of this. We cannot dwell eternally on the diversity of opinions or competing claims of truth, as we can do for example in philosophy. We have to decide, even if this is difficult, even if we know that we have failed to settle an issue in a satisfactory way. The fact that there are still some open questions, some unexplored nuances, some arguments (including future arguments) which we have not taken into account, makes it impossible to decide a particular conflict of opinion once and for all. Neverthe less, the circumstances can force us to decide anyway, even if it is not certain whether the decision is correct, or what the consequences of the decision will be. This lack of certainty - based on the urgent need to decide, the impossibility to study all existing arguments, and the possibility that better arguments for other decisions turn up in the future - forces us to accept that all decisions are provisional decisions. Democracy and human rights guarantee the provisional nature of decisions, whereby they make it possible to improve decisions. They allow people to claim that decisions should be modified and to express the arguments which support this claim.

Sometimes we have to decide and to solve certain problems. It can be a matter of life and death. We have to decide on one of several possible actions, without the option of delaying the decision until all possible and imaginable arguments for and against a decision have been studied. Discussions have to be limited in one way or another, but we must try to balance the urgency of a decision with the advantages of slowness, advantages in terms of the quality of the decision. A decision is a temporary end of a discussion. Differences of opinion are left aside for a while. A struggle is settled provisionally.

Now, if there is a need to decide, and if the best way to decide is unacceptable because of the urgency of many decisions (the best way to decide something implies a prolonged study of all possible arguments for and against, and even a continuous re-decision each time there is new and useful information), which is the second best way to decide (the best way to decide is? We have seen that in a democracy, decisions do not have to be based on truth. Decisions do not have to be true and do not have to be the result of truth. Conflicts between possible decisions do not have to be decided on a cognitive basis and often cannot be decided on such a basis. What shall we do when something has to be done 
that affects us all, we wish to be reasonable, yet we disagree on means and ends and are without independent grounds for making the choice' (Barber 1984:120)? In politics, we often have to choose 'under the worst possible circumstances, when the grounds of choice are not given a priori or by fiat or by pure knowledge (...), being without guiding standards or determining norms yet under an ineluctable pressure to act, and to act with deliberation and responsibility as well, (...) to choose and act responsibly, reasonably, and publicly yet without the guidance of independent consensual norms' (Barber 1984:129).

If truth and certainty are not available and maybe not even desirable, and if we have to decide anyway, then how do we decide? How do we distinguish good from bad decisions? We decide, not on the basis of an a priori given truth or knowledge, but on the basis of reasonable procedures guaranteeing the best possible decisions in a situation of uncertainty and urgency. In other words, we look for a reasonable decision, not a true or rational decision, and we need procedures in order to identify these reasonable decisions. It is not because truth and certainty are unavailable and undesirable that we have to find ourselves at the other extreme of arbitrary, impulsive and purely individual decisions. It is not because we cannot be certain of something that we cannot act in a reasonable way.

Reasonable decisions have at least the following six characteristics:

(1) First of all, reasonable decisions have to be acceptable and relatively easy to attain and to execute. The decisions of the majority of the people are more difficult to attain but also more acceptable and therefore easier to execute than the decisions of an individual, a monarch or a minority. A decision by consensus is, of course, even more acceptable, but it is also much more difficult to attain. The system of majority decisions seems to be the most reasonable one because it strikes the right balance between the two different criteria of acceptability and simplicity.

(2) However, a reasonable decision has other characteristics as well. A decision of a majority can have terrible consequences, even if it is highly acceptable to the majority and easy to attain and to execute, especially when it is directed against a minority. A decision is a solution to a problem and should not cause problems that are worse than the one it tries to solve. The consequences of a decision should be taken into account. In other words, a reasonable decision is a responsible decision, in the sense that responsibility means taking into account and being accountable for the consequences of your actions.

(3) A reasonable decision must be the best possible one under the given circumstances. This means that all possible decisions must be allowed to appear in public. They must be defended in public, and the advantages and disadvantages of each one of the must be compared to the advantages and disadvantages of all other possible decisions. The choice between competing decisions must take place in public and as many people as possible have to participate in this choice, otherwise we may not find the best possible decision. If we exclude some people, we may exclude some possible solutions or some arguments against or in favor of some solutions. In order to be able to identify the best solution, the choice of a solution should be preceded by thorough examination of every possible or proposed solution and by public argumentation and deliberation. Everybody should consider every proposed solution. Reasonable decisions or reasonable solutions to problems should be public and should involve massive participation. Dictatorial, secret or impulsive decisions can never be the best possible decisions, even if they are the decisions of the majority. 'Just as we would not understand a sleepwalker to be a human agent or a hysteric to be a human actor, so a rabble is not an el ectorate and a mob is not a citizenry. If action is to be political, it must ensue from forethought and deliberation, from free and conscious choice' (Barber 1984:126). However, participation should be voluntary. Someone who knows the best solution or the best argument in favor of a solution should not be forced to participate for the sake of reasonableness or for the sake of a reasonable decision. Reasonableness is not the only value.

(4) We should not be impulsive, but some things are urgent nevertheless. Sometimes we do not have time for massive participation and for thorough consideration of all pos- 
sible solutions and arguments. Timeliness is also a characteristic of reasonableness. A decision that comes too late can never be called reasonable. '[W ] hile politics begins with conflict and uncertainty, it al ways ends with what we may call the consensus of action - with a decision that is singular and historically determinative, however conflicted and plural was the process of arriving at it. 0 ut of the diversity of the process comes the unity of the deed' (Barber 1984:161). The word 'unity' is perhaps too strong. There is al ways a minority and therefore plurality.

(5) The characteristic of timeliness is balanced by the characteristic of provisionality. Every reasonable decision is provisional, experimental and therefore possibly transitory. It must be possible to correct or revoke a decision if it turns out to be the wrong one, if better arguments for other decisions turn up or if the circumstances change. This makes the speed of some decisions more acceptable. Regret and self-criticism are important democratic values. '[0 ]nce we choose a road to take, [we must] keep on the horizon of our common imagination all the roads not taken' (Barber 1984:259). There is a Scottish rockband that sings: 'what do you do when democracy's all through, when 'minority' means you, when the rest can't see its true?' . The members of the band are Scottish nationalists who favor independence However, there seems to be no Scottish majority ready to follow them. The error in their argument is that democracy is never 'all through'. You can al ways continue to advocate your case and maybe, some day, you will find the right argument to convince a majority. If not, it may be that you are wrong.

(6) The provisional character of a decision should, of course, be balanced against the need for stability and continuity. Decisions that change all the time are not the best possible decisions either.

These remarks indicate that direct democracy instead of an exclusively representative democracy is necessary in order to arrive at the best decisions. The people must be involved in the decisions. Again we see that politics is not just a matter for the state. Decisions are, in part at least, taken or prepared in a space that is beyond the control of the state, even though this space is protected by the state.

Large scale and equal participation confirms my original hypotheses because it multiplies the number of conflicting opinions. It reduces the likelihood of achieving consensus, and hence it reduces the relevance of truth in politics. Most of the time, conflicts between opinions cannot be settled on a cognitive or scientific basis (in other words, they are not caused by the ignorance or stupidity of one of the parties). This means that we need politics, procedures, argumentation and deliberation in order to choose between opinions. If we want to choose the best possible opinion, then we need large scale and equal participation in public decision procedures which lead to provisional, timely, stable, responsible, acceptable and attainable decisions. And thus everything starts all over again.

We do not need politics or citizen activity when there is knowledge and when conflicts can be settled on a cognitive basis or by reference to science and truth. No one will propose a referendum to decide on the correctness of the theory of relativity for example. 'But Laetrile and genetic engineering, while they belong formally to the domain of science, have aroused sufficient conflict among scientists to throw them into the political domain - and rightly so. Where consensus stops, politics starts' (Barber 1984:129). To say that politics is the search for reasonable choices, which must be made in the face of conflict and in the absence of independent grounds for judgment, is to say that politics seeks choices that are something less than arbitrary even though they cannot be perfectly Right or True or Scientific. A bstract rationality is not at stake, for that concept suggests some prepolitical standard of truth. (...) Reasonableness (...) is a rather more commonsensical notion, whose color is practical rather than metaphysical. A reasonable choice or a reasonable settlement is not necessarily rational at all, but it will be seen as deliberate, nonrandom, uncoercive, and in a practical sense fair. The word reasonable bespeaks practicality. It suggests that persons in conflict have consented to resolve their differences in the absence of mediating common standards' (Barber 1984:127-8). 
Most of the time, there are no certain, true or scientific solutions to political problems and no extra-political and a priori given norms or principles which can be used to judge political problems. That is precisely why we need politics as a system of procedures designed to produce decisions which are neither absolutely correct nor completely arbitrary. These decisions are reasonable. They are the best ones possible under given circumstances. "[T] he condition of politics is the absence of an independent ground by which conflicts might otherwise be settled' (Barber 1984:156).

In politics, it is more important to act correctly than to know with certainty and it is more important to decide in a reasonable way than to reason scientifically. If there is knowledge in politics, it is a relative and provisional kind of knowledge which results from citizen activity. Activity does not result from knowledge; 'knowledge' results from activity. Politics is independent of rather than subordinate to knowledge, science, truth and extra-political or pre-political norms. Political decisions cannot be based on pre political knowledge.

Of course, the participants in political life have their own ideas concerning the truth of certain matters and shape their actions according to these ideas. Democratic politics 'gives to each individual's convictions and beliefs an equal starting place and associates legitimacy with what happens to convictions and beliefs in the course of public talk and action rather than with their prior epistemological status. The legitimacy of a value is thus a feature of its publicness, of how it is refined, changed, or transformed when confronted with a public and the public norms which that public has already legitimized through its politics. Politics in the participatory mode does not choose between or merely ratify values whose legitimacy is a matter of prior record. It makes preferences and opinions earn legitimacy by forcing them to run the gauntlet of public deliberation and public judgment. They emerge not simply legitimized but transformed by the processes to which they have been subjected' (Barber 1984:136).

Participants in political life 'put whatever moral codes, principles, interests, private ideas, visions, and conceptions of the good they may bring into the process as individuals or groups to the test of politics itself. This does not mean that values and ideas will not be drawn from religious and metaphysical systems of the kind offered by Christians or liberals. Rather, it means that such values will acquire their legitimacy from their political fecundity - from their acceptance into and transformation through the democratic political process. Instead of focusing on the pre political roots or the epistemological status of conceptions of freedom or law or right or justice in the abstract, strong democracy regards these terms as rudimentary symbols for competing ideas and perspectives, as encapsulations of normative paradoxes that are constantly being adjudicated, challenged, modified, transposed, reinterpreted, emended, unpacked and repacked, depreciated and revalued, and edited and transformed in accordance with the historical circumstances and evolving needs of concrete political communities. D emocratic politics cannot assume a paradigmatic language that is rooted in prepolitical syntax because it is itself about paradigmatic language. Through participatory deliberation and ongoing public talk it contrives to define and redefine the crucial terms that we use in turn to define and redefine our common lives. The language of politics is thus necessarily compound, protean, and controversial' (Barber 1984:1567).

What is freedom, equality etc.? ' $\mathrm{N}$ ot one of these questions can be answer ed a priori or by reference to some abstract philosophical lexicon. For what we want the terms freedom and equality and justice and right to stand for is what politics is about. (...) when values have been named, issues identified, agendas set, and options delineated, most of what is meaningful in politics has al ready taken place. A nd by the same token, if we agreed on how to use words like freedom and justice, there would be no political debate in the first place and thus no need for politics (...). [E]ssential contestability is the premise of politics, and citizenship rather than epistemology is the key to the resolution of conflicts over values and ends' (Barber 1984:157). However, there is something that is not contestable, namely contestability itself and all the democratic structures that guarantee this contestability.

Instead of the a priori given truth which can be known and seen individually and amost passively, we look for a judgment and a decision which can only be the a posteriori result of common action, deliberation, debate, public argumentation and agreement. 
' $[P]$ olitics is a rag and bone shop of the practical and the concrete, the everyday and the ambiguous, the malleable and the evanescent. There is no firm stairway to nature or to some higher realm from which one can borrow shaping norms and fixed standards to lend abstract order to inchoate experience. If there is political truth, it can only be the kind of truth that, in William James's phrase, 'is made in the course of experience' ' (Barber 1984:130). Political decisions must conform to the standards of reasonableness, not to some pre-given 'laws', principles or observations. Political 'truth' - if such a thing exists - does not give an image of the world; it shapes the world.

Politics is not concerned with an a priori given truth. Laws do not exist because some one declares them after contemplation of the truth. They exist because a democratic majority has taken a decision with its limited knowledge of the moment and after reasonable, public and large-scale discussion, and because afterwards experience has shown that the decision has done what was expected and that arguments for other decisions have remained unconvincing. Reasonable procedures and experience, rather than truth, tradition, God, authority, nature, History etc. give legitimacy to decisions.

However, we should be careful with the concept of reasonableness. Reasonableness is on the one hand common instead of individual, inter-subjective instead of subjective and public instead of private. But this does not mean that it is universal and objective (as is rationality in science for instance). Pluralism remains a fact of life. Good procedures result in reasonable and common decisions, but there are al ways competing decisions. A particular reasonable decision does not have to be accepted by everybody simply because it is reasonable (it would have to be accepted by everybody if it were a true or rational decision). Those who do not accept a reasonable decision are not irrational or stupid. They simply have another idea of what is reasonable. They can respect the decision of the majority without having to conform to the content of the decision. Contrary to the truth and rationality, reasonableness can accommodate diversity and contradictions. Different reasonable decisions, goals and values can contradict each other and can be incompatible, which is not the case for different statements of truth.

\section{$\S$ 158: D emocracy is I mpossible and N ecessary at the Same Time (2) (U nity of Vision)}

We have to protect politics against the truth because the truth eliminates debate and diversity. However, the disappearance of truth may imply the appearance of doubt, and doubt can lead to passivity when action is necessary, for example when we need to protect the principles of democracy against fanatics inspired by an undemocratic 'truth'. If we do not act because we cannot justify our actions on the basis of truth, then it is not certain that nothing happens. We run the risk that other people decide our fate in a way we do not accept. These other people can impose their opinions in the name of truth. It is not because we lack truth that we should be passive. Freedom requires the rigorous defense of certain opinions against the claims of truth of anti-democrats. It requires an energetic faith and a unity of vision that is justified and based on arguments but not necessarily true.

The absence of truth and consensus and the presence of conflicts are the 'raison d' être' for politics. Politics is the search for a reasonable way to deal with problems and conflicts where truth or certainty are not available (although the promotion of conflict is also a function of politics; see Section 5). As regards the conduct of our life, we are frequently obliged to follow opinions which are merely probable, because the opportunities for action would in most cases pass away before we could deliver ourselves from our doubt. A nd when as frequently happens with two courses of action, we do not perceive the probability of the one more than the other, we must yet select one of them' (Descartes in Barber 1984:163). Democratic politics is the most reasonable way to select urgent, provisional, acceptable, uncertain, non-arbitrary and high quality solutions to problems. This reasonableness is necessary to 
avoid the jungle in which problems are solved in an unreflected, arbitrary and stupid way and with the use of force and violence.

This implies that we need a consensus on the democratic procedures and institutions that guarantee politics in the sense of the quest for reasonable solutions. 'T heorists have traditionally distinguished substantive, quotidian conflict (the raison d'être of politics) from procedural, long-term consensus (the sine qua non of politics). The latter, in the form of basic law, a constitution, the social contract itself, makes the former tolerable' (Barber 1984:128) and possible. This kind of consensus is of another type than the consensus resulting from truth. The latter is basically despotic, while the former remains a free choice based on the acceptance of good arguments in favor of democracy and human rights.

Consensus is not al ways inappropriate. In some cases, we need the consensus of truth; in other cases, we need a consensus on the importance of democratic procedures. A unity of vision is an important prerequisite for democracy and human rights, just as the economy, peace and national unity. If there is no consensus on the importance of democracy and human rights, then we are likely to see violations of democratic principles and human rights. And even if there are no violations, democracy and human rights are likely to remain empty shells without the active involvement of the large majority of the people. It will also be impossible to resist foreign aggression. There can only be active involvement if the people are convinced of the importance of democracy and human rights. They may be divided on almost everything, but they must be united in the belief that democracy and human rights are the best way to resolve or contain their differences; the best way to find the best possible solutions to common problems if such a solution is possible, and to avoid escalation of conflicts if a solution to conflicts is impossible.

Although democracy and human rights are capable of dealing with marginal rejection or disaffection, the absence of large scale consensus on the importance of democracy and human rights - in other words, the absence of a democratic culture - means the end of democracy and human rights. It can indeed be a reason against the application of democracy and human rights in particular country, and therefore a reason against the universality or at least the immediate universality of democracy and human rights. Without a democratic culture or a widespread acceptance of the importance of democracy and human rights, the existence and survival of democracy and human rights are precarious if not impossible. Large groups of anti-democrats - especially powerful anti-democrats, for example in the military - or even large groups of neutral and disinterested people, make democracy in particular but also human rights impossible. The first task for democrats is to convince people, to counter challenges and to advertise the usefulness of democracy and human rights.

However, the absence of challenges should not be the only goal. A tyranny can survive if there are no challenges and even encourages indifference A democracy, on the contrary, not only needs the absence of challenges; it also needs the presence of a democratic culture. This does not mean that the absence of a long democratic tradition or the absence of a long history of evolution towards democracy make democracy and human rights impossible. People can be convinced and a unity of vision can be created. Democracy is not the consequence of a distant past, and certainly not the inevitable consequence of culture, tradition or genetically determined characteristics.

Not only a country's elite has to accept the principles of democracy, although an unconvinced elite can do more damage to democracy and human rights than the ordinary people. If the people reject democracy and human rights or are not interested in democracy and human rights, then democracy and rights can survive as an empty shell, dthough chances are that they will not survive.

Challenges make the birth and the survival of democracy and human rights impossible in the short term. Indifference makes the survival of democracy and human rights impossible in the longer term. Indifference is just as harmful as challenges. Democracy needs a conviction and actions or involvement based on this conviction. If the people are not convinced, then there is no participation; and there is no democracy if there is no participation. Widespread indifference will not cause the immediate destruction of democratic 
institutions, but it will turn these institutions into empty shells because nobody will be present in them. The problem here is not the unwillingness to live together with people who cherish completely different values (see Section 23) but the necessity of having some common values.

The necessary consensus on the importance of democracy and human rights is a pre requisite, but also has its own prerequisites, for example a consensus on the importance of equality, the absence of elitism etc. However, just as in the case of other prerequisites - the economy, peace and national unity - there is a two-way causation at work. Only a wellfunctioning democracy can guarantee the existence of a fundamental consensus on democracy and human rights, can promote the development of democratic values, can counter challenges and can eliminate indifference Even a democracy that does not function perfectly - for example in a transition period after a period of authoritarian rule - can promote its own acceptability.

\section{$\S 159:$ Creating Consensus}

However, the automatic creation of support for democracy and rights will probably not be enough. The question is then: what can we do to create support for democracy and rights? If indifference is the only problem, then there is a chance that democracy solves it almost automatically (see Section 9). If, however, we face a problem of active opposition to democracy and human rights, then we have to distinguish between opposition by a minority and opposition by a majority of the people. In the first case, the democratic state obviously has the right and even the duty to suppress anti-democratic actions if necessary and to foster democratic convictions if possible.

However, what can we do when the majority of the people opposes democracy? Does democracy imply that the view of the majority must be implemented, even if it is an antidemocratic view? Of course not. Democracy is much more than a system of majority rule, otherwise it would be self-destructive. It is unreasonable to claim from any system that it encompasses the seeds of its own destruction. Furthermore, I have already discussed the paradoxical nature of the theory that allows for a choice against democracy (see Section 21). However, paradoxes rarely stop people from acting. Therefore, we have to take antidemocrats seriously, especially when they are the majority of the people, and we cannot simply say 'les cons ne comptent pas' . Fortunately, anti-democratic majorities are very rare. The rejection of democracy is in most cases a privilege of authoritarian leaders or extremist fanatics in the fringes of society.

However, the anti-democrats together with those who are merely skeptical or indifferent, may form a large group of people, large enough to turn the democratic institutions into empty shells, or perhaps even large enough to endanger the survival of these institutions. What can we do to convince large groups of people? If democracy is not a part of the political culture of a people, then democracy can only be fully implemented in the long term. Actions to change convictions and values often take a long time. A democratic culture is not created overnight. Democratic institutions - which, strictly speaking, do not create an ideal democracy, only the possibility of an ideal democracy - can be created immediately and can survive, even without a democratic culture. The advantage of institutions is that they create their own culture. Seeing institutions at work, even if there are only few participants at first, can convince people. Democratic participation, however limited, promotes a democratic culture and hence promotes participation. Without democracy, it is very difficult to create or maintain a democratic culture, just as you only learn a language if you use it.

The concept of political culture is closely related to the concept of culture in general. The statement that for example the political culture of Indonesia is incompatible with democracy and human rights and requires an authoritarian form of government, is often linked to so-called 'facts' in the cultural identity of the people in question, facts which make it difficult to create a democratic political culture (respect for hierarchy etc.). This, 
however, is cultural determinism. If a certain non-democratic political culture is supported by a certain culture in general, then this is supposed to be a necessary and inevitable reason to reject democracy. Cultures do not change because they are a transmission of traditions. Traditions are incompatible with change because they are the preservation of the past. Cultures are valuable as such and changing them should be prohibited. The problem with this argument is that cultures do change, that people sometimes change their fundamental political convictions, and that other elements beside culture influence politics.

Creating a political consensus does not imply eliminating all diverging views. People of different religions or different social and cultural backgrounds can be democrats. Diversity is an important value and a common democratic vision guarantees the existence of diversity because it encompasses values such as tolerance, religious liberty etc.

The importance of a political culture has consequences for the way in which democracy and human rights are promoted internationally. Promoting elections or other institutions is relatively easy. Institutions can even be imposed. It is much more difficult to promote real political participation, because this implies that you have first promoted political convictions and democratic mentalities (e.g. respect for the law, respect for decisions of judges and for human rights etc.). The effort to change political convictions is directed in the first place at influential groups in society, such as the media, the military, the police, the judicial system, the business class etc. It is very important that these people accept the values of democracy because they can do a lot of harm if they do not accept these values. Ultimately, however, the large majority of the people has to be convinced because democracy is the rule of the people, and the rule of the people is impossible without massive support. Elections can be imposed, but not the convictions and the support of all the major parts of the population. This often requires a very long learning process and a process of discussion, persuasion, reform and construction.

The best way to create support is to guarantee the adequate functioning of democracy and human rights. Experience with a well-functioning democracy has a positive influence on the political views and behavior of the people. This is true even in those countries in which the number of people participating is relatively low, or in countries in which an economic crisis for example has a negative influence on the legitimacy of democracy. The economic performance of a country is not the only cause of regime support. Other, less material things such as the degree of freedom are also important. If democracy does not function adequately, if it is not able to change things and if it does not guarantee freedom and equality, then no amount of economic prosperity can buttress the regime. The same is true for a non-democratic regime.

A cult of foundation can also help to create a lasting unity of vision. Every democracy has been founded. This foundation is often the consequence of a revolution and of the revolutionary overthrow of a dictatorship. Democracy justifies revolution. A revolution is 'a people's right to seize the power necessary to govern themselves. Liberty is rarely a gift of the powerful. It must be wrested from them in democratic revolutions that are just because they are democratic' (Barber 1998).

A revolution has a dual purpose: the overthrow of a dictatorship (which is negative) and the (re)creation and foundation of both a democratic political and public space and the judicial and political means and institutions necessary to protect and stabilize this space (institutions such as elections, courts of justice, parliaments, human rights etc.) (which is positive). This foundation is often translated into a constitution, a fundamental law establishing the form of government and the fundamental institutions necessary to guarantee freedom after the act of liberation and to guarantee political and public life after a period of anti-politics and of life in obscurity. The constitution is the incarnation of the political culture. It is not surprising therefore that constitutions are seldom adopted or changed by a simple majority. A majority of two-thirds or even three-quarters of the people is required and some basic elements of a constitution, elements which determine the form of government, cannot be changed at all, except when a new constitution is 
adopted, which is in fact a revolutionary act because it means changing the form of government. This element of 'consensus' in the management of a constitution is necessary in order to have a widespread agreement on the political culture and on the fundamental rules of society.

A lasting unity of vision is the result of widespread respect for the foundation, for the past and for the political traditions. It implies the preservation of something permanent (that is why it is relatively difficult to change a constitution), and hence it implies conservatism. The beginning, the foundation, must be respected and preserved and the best way to do this is to repeat, remember and keep alive the act of foundation - or the source of the political community - through a certain recurring ritual in which the principles established in the beginning are honored or even worshipped and handed down as an example to the next generations (for instance in a yearly and traditional celebration in which the constitution plays an important part; the American 'pledge of allegiance' is another example). Democracy only has a future when we return to the past. Worshipping implies religion, and the original meaning of the word 'religion' is 'being linked to a beginning' (A rendt 1990:213). It is not a coincidencethat patriotism has al ways been a kind of religion.

Of course, this can become ridiculous, as is often the case in the USA for example, where the 'founding fathers' are revered as if they were supernatural beings, descended from heaven in order to give mankind a superior knowledge of political affairs. No present-day A merican can resemble these fathers, let alone improve what they have done. Everyone remains a child compared to them. Ideally, we should have some freedom with regard to our inheritance. The present should be able to improve the past instead of blindly repeating it. The past should be repeated, remembered and respected, but it should not determine all our actions. There has to be room for creativity and innovation. Nobody should rule from the grave because nobody is wiser than all posterity. Nobody has a right to determine the existence of all future generations. Democracy is precisely the power of the people over themselves, autonomy instead of heteronomy. Social order is a product of the present generation only and not of the forefathers, of nature, God or whatever, even if this generation can decide to follow, respect and even revere its forefathers. It must be possible to change institutions. After all, the value of something is not determined by its age.

Education is another important instrument in the creation of a unity of vision. Children should be told about the foundation and about the values of democracy. Education makes democracy and human rights more acceptable and contributes to the development of a democratic culture, but it is also necessary for the functioning of democracy and rights. Democratic procedures can only function adequately if the participants are familiar with them and rights can only be claimed and protected when those who suffer from rights violations know their rights and know the ways in which to defend their rights. 
Section 28: Efficiency, the A bility to Take Decisions and to Execute the Will of the People

\section{$\S 160:$ Disadvantages of a M ulti-Party System}

Some people believe that democracy is logically impossible because it is unable to execute the will of the people. The reason for this inability is the fact that most democracies are multi-party systems (i.e. systems containing more than two political parties). One of the causes of a multi-party system is the equal political participation and the equal political treatment of everybody. The inability to execute the will of the people proves that democracy is an inefficient system which has to be rejected. It also proves that equality equals inefficiency (this argument is therefore similar to the one discussed in Paragraph 154).

I will show that this argument against democracy is entirely correct - contrary to most other arguments - and that the proposed solution to the problem - imposing a two-party system by way of modifications in the electoral system, modifications which limit political equality - is a good solution, although not the only one and not even the best one. The proposed solutions do not imply the rejection of democracy. They merely imply a preference for a certain type of democracy. The claim that democracy is inefficient is an unwarranted generalization.

In a multi-party system, one often needs party coalitions in order to establish a political majority. The problem with coalitions is that the electorate cannot decide on the composition of coalitions and therefore cannot decide on the composition and the political program of the government. Coalitions (or organized majorities) and therefore the government and the government program, are the result of negotiations that often take place after the elections (although sometimes political parties announce their alliances in advance). Sometimes, these negotiations are even hidden from the public and can result in the return to government of parties that have been decimated in the elections. It is possible that a voter would have voted for another party if he had known the result of the coalition negotiations in advance.

In a multi-party system, the voter does not even know the result of the election after the election has taken place. He or she has to wait for the result of the negotiations between parties and has no input at all in these negotiations. Only then does he or she know which government will take office and which government program will be implemented. There is no direct election of the government, and the composition and the program of the government are unpredictable, even after the results of the election of parliament are known. The result of an election is, of course, al ways unpredictable, but in a multi-party system, this result remains unpredictable after the election has taken place. This is not the case in a two-party system, in which the winner of the election forms the government without further ado and in which the manifesto of one party becomes government policy without further ado. The result of the election determines automatically and immediately the composition and the program of the government. There is a direct link between the votes and the government and A party that loses the election cannot be part of the government.

In a multi-party system, the government and the government policies are unpredictable because it is uncertain who will be part of the government. Even when this is known, it is often unclear what the parties have had to surrender in order to achieve the 
compromises necessary to forge the coalition and the government agreement. Furthermore, it is unclear which compromises will be necessary in the future in order to maintain the coalition.

As a consequence, election campaigns and government policies are by definition very different things. Politics loses its credibility and people stop participating because there is no link between cause and effect, between a vote or a party manifesto on the one hand and government policy on the other hand. Voters have practically no influence on the composition and the policies of the government. They can only express their disappointment afterwards, but there is no guarantee that new coalition negotiations take this expression into consideration. Democracy ceases to exist when citizens have no influence and when government policies reflect compromises between political parties rather than the will of the people.

Political parties and individual politicians suffer a loss of credibility and motivation. They need party coalitions because they seldom have an absolute majority. As a consequence, they cannot implement their manifesto completely. In the best case, they can only implement a diluted version resulting from compromises with other ruling parties. In the worst case, these compromises force politicians to modify the policies which they have presented to the electorate. Ultimately, the loss of politicians' credibility and trustworthiness which results from this, can affect the entire political system and even the concept of democracy in general.

The often lamented discrepancies between promises and policies are, in part at least, the consequence of a multi-party system. This system makes it impossible to execute the will of the people and therefore makes it impossible to preserve democracy. The will of the people is translated into a number of votes for a number of party manifestos, but government policy is not the implementation of the manifesto with the majority of votes be cause there is only rarely such a majority manifesto in a multi-party system. Government policy is not even the implementation of a sum of different manifestos. It is the implementation of a negotiated compromise between different manifestos, a compromise moreover which is not subject to the approval of the electorate.

The multi-party system is of course not the only cause of discrepancies between election propaganda and government policies. Power politics also plays a role. Winning the election and profiting from the benefits of elected positions are often the only reasons why politicians formulate policies and promises. They often do not have the intention of effectively implementing these policies. They intend to pursue their self-interest. This also diminishes the credibility of persons and institutions.

The lack of stability and decisiveness of coalition governments is another phenomenon which makes it difficult to execute the will of the people and which therefore undermines democracy, or, better, a certain kind of democracy. A coalition between different political parties can only result from a mix of different and often contradictory political ideologies and manifestos. The problem is that some things cannot be mixed together. Some contradicting opinions cannot be harmonized into one compromise opinion and some opinions are so fundamental that every compromise is unacceptable. If, during the years in government, a problem related to these fundamental and conflicting opinions arises, then the politicians can act in different ways:

(1) Decisions and even discussions regarding this matter are prohibited by the coalition agreement. The advantage of such a strategy is the relative stability of the government. Coalitions do not break up because conflicts between opinion are excluded from the political agenda. The downside is that the government is indecisive and ineffective. Problems are not solved and the political parties lose their identity and their distinctive character. A party cannot implement its fundamental principles which distinguish it from other parties when these other parties are necessary partners in government and claim to protect other and incompatible principles. Parties lose their attractiveness and credibility and citizens become indifferent. A related phenomenon is the 
so-called 'move to the political center'. All parties start to look alike. Vagueness does not encourage political participation and politics loses its attractiveness for citizens.

(2) Second option: decisions regarding a contested matter are not excluded beforehand but avoided the moment the problem enters the political scene. It is decided not to decide. The advantages and disadvantages are exactly the same as in the first possibility. Problems are not solved and political parties are seen as institutions that are more interested in safeguarding the government and thus their own power, than in preserving and defending fundamental ideological principles. Politics becomes a world of pragmatism and opportunism in which basic principles are given up for a seat in the government. Democracy loses its legitimacy.

(3) If it is impossible to decide not to decide and if everybody holds on to his or her initial ideological position, then there can be no decision. The coalition will most likely break up. The problem is not only indecisiveness but also instability. Citizens are not pleased if they have to elect a new government every year. Politicians are praised for their ideological purity, but this does not solve the problem. After all, the image of politicians is less important than efficient decisions and stable government.

(4) The last possibility is a compromise decision of some kind. Contrary to the three previous possibilities, there is now a decision, but it is a decision that pleases none of the parties involved because it corresponds to none of their fundamental principles. As in the first two possibilities, politicians are criticized for their ideological wavering.

A multi-party system is therefore often indecisive and this is another reason why it is very difficult to execute the will of the people in such a system. The problem of the execution of the will of the people is not even a real problem because the vagueness of politics and its lack of credibility force people to turn away from politics altogether. They do not have a will anymore. And as if this is not enough, a system of coalition governments also cre ates a problem of responsibility. A political party will never accept complete responsibility for government policies. Every responsibility is a shared responsibility.

Indecisiveness is often a consequence of the pursuit of stability. Decisions are avoided because they can endanger the coalition and therefore the government. It seems that decisiveness and stability cannot go together in a multi-party system. The fear of instability not only leads to indecisiveness. It can also lead to extreme decisions. Sometimes, parties need the support of small and extremist parties in order to form a majority and a government. These extremist parties can blackmail the government by threatening to leave the coalition, to break up the majority and to bring down the government. These minorities can therefore force the government to take extreme decisions and they create a system of de facto minority rule.

It follows that we should not focus our political criticism exclusively on the behavior and the ethics of politicians and parties. There are also problems of a structural and organizational nature, such as the problems caused by the multi-party system. Structural as well as behavioral problems are at the root of the infamous chasm between politics and citizens. Changing the behavior of politicians or parties does not solve the structural problems. Structural problems can only have structural solutions. Some people believe that the only structural solution is the rejection of democracy. I will show that this is incorrect and that the problems can be solved within the framework of democracy. One possible solution is the so-called two-party system as it is or was practiced in Great Britain for example.

\section{$\S$ 161: A dvantages of a Two-Party System}

- In a two-party system, politicians do not have to decide independently on the composition and the policies of the government after the election has taken place. There is no need for compromises between political parties (in a multi-party system, one needs to make compromises in order to create a coalition and in order to maintain a coalition). 
The voters are not excluded from important decisions such as the choice of the government or the choice of the policies of the government. The voters decide who is part of the government and which party manifesto becomes government policy. The only thing they have to do is vote for one party or another.

- Government policy is much more predictable because there is no need for compromises as a means to save the government and to avoid a break-up of the coalition. There is no need for compromises as a means to create a government either. Governments are not coalitions. As a consequence, election propaganda and government policies are more compatible.

- Political parties can hold on to their ideological profile because they do not have to adapt their policies to the wishes of their partners. They can reach their goals, they can be decisive and efficient and this means that they can keep their attractiveness. Politics itself remains attractive. On the other hand, if there are only two parties, these parties are bound to contain many different currents. This may limit their ability to take decisions and may force them to make compromises.

- Responsibility becomes possible again, because the acts of a government are the acts of one party only.

\section{$\S$ 162: D isadvantages of a Two-P arty System}

A two-party system can therefore solve some of the problems created by a multi-party system. However, one has to pay a price for this solution. Political equality, for example, has to be limited. Here are some of the disadvantages of a two-party-system:

- Choices are limited in a two-party system. Instead of being able to choose between many different parties and ideologies, the voter can only choose between two parties. It is very difficult to represent all the different ideological currents when there are only two parties. However, the two parties in a two-party system can be heterogeneous and can incorporate different albeit related and compatible ideological currents. Unfortunately, this means reintroducing the problem of indecisiveness we find in multi-party systems. We are not likely to have a stable majority and a stable government able to take decisions when the governing party is divided on issues.

- Changing the electoral system and introducing a threshold - for example a threshold limiting representation in parliament to parties that have more than $5 \%$ of the votes is one of the ways in which to enforce a two-party system. Such a threshold, however, means limiting political equality. Not all voters are treated equally. Those who have voted for small parties are not represented. Their voices are not heard, their interests are not protected and they have less influence on policies. Minorities are discriminated. History has shown that small parties are very useful because they function as a stage for the appearance of new issues (the green parties for example). Large parties have often reacted positively and have incorporated these issues in their own manifestos. They probably would not have done so if small parties had not proven the existence of a grassroots interest in these issues. If an issue can attract votes, even relatively few votes, then large parties will be interested.

- A threshold system makes it much more difficult for parties to grow. A party that is not represented cannot use parliament as a stage to show itself and to generate support. As a consequence, there is a kind of exaggerated stability in politics.

- The so-called 'first-past-the-post' system combined with a system of election districts whoever has most votes in a district (not necessarily the majority of votes) gets the seat in parliament reserved for this district and becomes the only representative for the district ('winner-takes-all') - is another way in which to enforce a two-party system. In some cases, this electoral system gives power to a relative majority and therefore not necessarily an absolute majority (a party which has a few more votes than all other parties in a majority of districts, will have a majority of seats in parliament, but per- 
haps a minority of the votes). In fact, it can result in the rule of a minority. An important minority or maybe even a majority may not be represented at all. Again, political equality is limited. There is no longer a perfect match between the views of the people and the views present in parliament. A system of districts also limits political equality when the districts are not of the same size. If both a small group of people and a large group of people have one representative, then we can hardly claim to have political equality. (In some countries, rich minorities have often been given small districts, which favored them politically and offered them a very large and disproportional share of the seats in parliament). However, I believe that some modifications can make the district system acceptable. There can be some kind of safety net for minorities failing to get represented (some kind of guaranteed representation for example). There can also be supplementary conditions for representation, in order to avoid giving power to relative majorities that are in fact absolute minorities.

Direct democracy is the only way to avoid the disadvantages of both a multi-party system and a two-party system. In a direct democracy, the majority and the policies are also unpredictable, but not after the results of the votes are known. The majority and the policies depend exclusively on the votes and not on subsequent negotiations. There is no problem of decisiveness or government stability either and there is no need to limit political equality. It is obvious that the problems posed by a multi-party system or two-party system should not force us to reject democracy altogether.

\section{$\S 163:$ V ote Buying}

It is dangerous to use metaphors in politics. The image of the chasm between politics and citizenry is very useful to describe a certain lack of contact, cooperation and agreement. Politicians often have ideas, goals and ways of speaking which are incompatible with the will of the people. However, the image of the chasm tends to obscure other phenomena that imply a rather intimate yet harmful cooperation between politicians and citizens.

Vote buying is the most important of these phenomena. Vote buying is a system in which groups of citizens try to force the government to take decisions that correspond to their self-interest and that give them certain advantages, such as tax breaks, subsidies etc. Citizens try to force politicians by giving or threatening to take away their votes. They desire something and the price they pay is their vote. They give their votes and expect to be compensated for this. They sell their votes and their electoral fidelity for certain advantages. Citizens have votes and politicians need these votes; politicians have access to government provided benefits and citizens need these benefits. hence it is natural that $\alpha-$ changes take place. However, this kind of logic can be detrimental to democracy. It is not only the pursuit of self-interest by politicians that can harm democracy.

A first problem is that a benefit for one group is always at the expense of the rest of the population. The financial loss that results from a tax cut or a subsidy for a certain group, has to be compensated by increased contributions by the rest of the taxpayers. The advantages given to some people in return for their votes are of course not paid by the politicians themselves, but by the rest of the population. In fact, politicians buy their votes with the money of others.

In this system, the politicians as well can be motivated by self-interest, but not necessarily. They can believe - often correctly - that vote buying is the only way to remain in power and to achieve higher goals. They know that they run the risk of losing power, because the voters will go elsewhere to sell their votes if the politicians do not deliver the goods. Therefore, we see politicians outbidding each other and promising ever more mportant benefits in order to preserve or conquer power. Politicians can be forced against their will into a system in which they have to buy votes and fidelity by way of more and more benefits. Politics becomes a kind of inverted sales. Politicians have to grant ever more important benefits in order to entice voters in their camp. Votes are scarce and de 
mand is high, especially before election periods. If demand is high and if there are several competing buyers, then prices go up. Buyers can be played off against each other.

An economic logic is applied to politics, which as a result loses its identity. Democracy degenerates into an economic system in which groups of citizens use the competition between political parties (the competition for the votes of the citizens instead of the competition for the money of the citizens, as in the real economy) in order to achieve as many material benefits as possible in return for their votes (their only political 'capital'). The political process has become a market process. The laws of economics (offer and demand, free competition etc.) take over politics. Of course, it is true that democracy is a free competition between would-be leaders searching for as many votes as possible, but it should be much more than that.

A multi-party system suffers more from the phenomenon of vote buying than a twoparty system. In a multi-party system, competition is more important. Therefore, the risk of parties outbidding each other is also more important. However, the number of parties is not the only factor. The number of members of a group asking for a benefit is also important. A large group of citizens has a bigger 'capital' of votes than a small group and has therefore more power. It will be able to receive more benefits because it is more interesting for politicians. By giving one favor to a large group, the politician buys many votes at once.

Here we see how equality leads to inequality. The absence of restrictions on representation (restrictions such as thresholds, winner-takes-all etc.) leads to a multiparty system, which in turn leads to vote buying and discrimination of small groups or groups with a small 'political capital'. Of course, it is not only the size of a group which determines the share of benefits. Small groups can have more influence than large groups, for example because they are more visible or because they have good relations in high places. This means that large groups can al so be discriminated.

Either way, the system of vote buying results in a social division between those who get many benefits and those who get few. It is a system of privileges instead of equal rights because all interest groups do not have equal power and equal influence Politics is not the execution of the will of the people but the execution of the will of some interest groups. Politicians represent groups and interests instead of society as a whole and the will of the people as a whole. Resources are redistributed, not from the rich to the poor, but from everybody to those who have either many votes or few but important votes. Transfers depend more on electoral importance than on real needs. Large groups, groups with friends in high places and groups that are very vocal and well-organized - and these are, by definition, not the poorest of groups - receive most benefits. Vote buying implies 'strategies that disperse the worst effects of economic and political problems onto vulnerable groups while appeasing those able to mobilize claims most effectively' (Held 1998:252).

Since there are al ways many different and often contradictory interests (or a 'plurality of pressure points' ), governments have to determine the relative strength of each interest. Only by acknowledging the most powerful interests can a government stay in power. Governments seem to have given up the attempt to use discussions in order to harmonize interests into a general interest or a will of the people. They can decide to attenuate the consequence of the inequality they create by acknowledging every interest in turn or by distributing extra benefits in order to compensate their disregard for some interests. The problem is that this is very expensive and that everybody pays for it in the end.

A gain, direct democracy is the only solution to the problem of vote buying. In a direct democracy, there are no representatives who have to grant all kinds of benefits to pressure groups in order to cling to power.

One should not confuse the system of vote buying with corruption, even though there is only a thin line between these two phenomena. Corruption seems to be typical of a democracy. In a dictatorship, the economy is the private property of the ruler and of the state. There seems to be no need for corruption. Granting personal benefits to a ruler in return for favors is useless if the ruler already owns everything. On the other hand, the larger the number of people involved in a decision, the smaller the risk of corruption. If 
many people are involved, many have to be corrupted. This, in combination with the presence of an independent judge and an independent press, indicates that democracy is the best protection against corruption rather than a safe haven for it.

\section{$\S 164:$ General Interest and Self-Interest, and the D angers of B oth (2)}

The system of vote buying does not recognize the real nature of politics. It gives the impression that the first objective of politics is not to serve the general interest but to serve a variety of private interests expressed by pressure groups whose support the government must buy by way of special benefits, simply because it cannot retain its supporters when it refuses to give them something it has the power to give (Hayek in De Vlieghere 1994:17-18). In a system of vote buying, the state rules in the interest of certain groups, not in the general interest. This system also fails to recognize the ideal role of the citizen. It views the citizen exclusively as a consumer of collective goods and services, not as a discussing decision taker looking for the common good.

What kind of state do we desire? What kind of education? What kind of health care? These questions and many others concern us all, no matter which interest group(s) we belong to, and they should be the basis of discussions and decisions. However, only if we are not preoccupied with the interests of our own limited group or with our own short term advantages can we engage in such discussions. The phenomenon of vote buying and the fragmentation of society in different interest groups make it very difficult to organize large, national majorities for the purpose of implementing national projects of general interest.

On top of that, we find ourselves in a vicious circle. The majorities that do exist are not inspired by a general interest. They are no more than mutually beneficial agreements between different pressure groups which have all been promised benefits in exchange for their votes. It is not surprising, therefore, that democracy loses its attraction and that people consider politics to be merely a game of well-organized pressure groups (Taylor 1994:114). The best one can do is to play the game and try to win as many benefits as possible, otherwise you end up paying for the benefits of the rest of the population. In this way, everybody is forced into the economic logic of vote buying.

The people do not see themselves as a community that can identify with the state and with politics. They only identify themselves with a particular interest group or with several interest groups, and they see politics as an instrument to fulfill their interests or as a warehouse of advantages ready to be looted by whoever comes first. At worst, this fragmentation leads to decomposition and maybe even violence At best, it makes effective common actions and actions that serve the general interest impossible. And vice versa: the absence of common actions promotes fragmentation because it forces people to fall back on their private interests. If the state cannot prove itself as a vehicle for common action and for the general interest, then people will not be encouraged to use the state in this manner. Only successful common action can enable people to transcend fragmentation, to escape decomposition, to identify with the political community and to think of the state as something else than a loot. On the other hand, if the meaning of this political community is diluted, then it is very difficult to mobilize people for a common action (Taylor 1994:116-118).

This focus on private interests and sub-communities is completely different from the way in which the Ancient Greeks for example reflected on politics. In the Greek city states, the inhabitants of border regions were not allowed to participate in a vote concerning a declaration of war with neighboring countries. It was assumed that these inhabitants were unable to vote in accordance with the general interest. Their immediate private interest would inhibit a reasonable reflection on the general interest. We seem to have gone from one extreme to the other.

Some believe that a democracy is by definition the rule of self-interest and cannot be anything else, because the common people are more inclined to pursue their own interest 
than an elite. It is said that the common people are unable to identity the general interest (even though it is granted that democracy provides mechanisms which attenuate this rule of self-interest and which limit the possible actions of a majority, such as the human rights of the minority). I do not believe that this is correct. In any case, there is nothing wrong with self-interest. A conception of the general interest that is established without the cooperation of everybody or that is incompatible with the interests of a majority is likely to cause resistance. We have to start from self-interest, but we do not have to end there. A general interest is always a reformulation of self-interest. Discussions allow people to see their interests in another way, to notice the contradictions between their different self-interests (for example their short term and long term interests) etc.

Politics is more than a sum of or a compromise between private interests. However, the other extreme is also incorrect. Exaggerating the importance of the general interest can be very dangerous as well. Those who have witnessed nazism or communism - or both - can testify to this. The general interest - whatever it is - can justify oppression because it can require the sacrifice of 'small' private interests which hinder the development of the community, of the race etc.

Furthermore, there is an error in the argument that reduces politics to a struggle or a negotiation between self-interests. A political discussion between parties, classes or interest groups requires certain common premises such as the acceptance of freedom of expression and association, respect for the rules of conversation and of courtesy (speaking in turns for example), a common language etc. We al ways start from a certain consensus, from certain premises that we all agree upon. These basic premises are part of the general interest. A discussion can never be reduced to a conflict of interests or to a negotiation on conflicting interests. As soon as there is a discussion, there is a common interest. There is al ways a community or a collective rather than a collection.

In the case of coalition governments, the democratic procedures lose their credibility because they do not function adequately, which can be fatal in the long term. In the case of vote buying, however, there is no such loss of credibility, at least as long as the people have the impression of getting more than they contribute. If this impression is correct, then we have either an increase in government debt or extreme burdens on minorities or silent majorities. The system can remain in place and can retain its credibility and legitimacy as long as this government debt remains manageable, as long as benefits can be distributed and as long as the exploited remain subdued or few in number.

If, however, the source dries up, if benefits are not forthcoming or if a majority believes that it loses rather than gains from the system, then the system is doomed. In a system of vote buying which uses politics only as a means for the fulfillment of interests, we have political parties outbidding each other in order to seduce as many voters as possible. Promises become more and more exuberant as a consequence of this competition. At the same time, there is an increase in the level of expectations. And where expectations are exaggerated, disillusionment and a loss of credibility are inevitable. In the short run, democracy and its procedures remain in place because they are needed and because they are well adapted to a system of vote buying. However, they remain in place as long as benefits are distributed and in a formal way only. They are misused and they serve other purposes than the ones they were designed for.

Only by way of direct democracy and education can the people be led away from vote buying and can the general interest regain its place in democratic decisions. There are different ways of focussing people's attention on the general interest, but democratic participation is undoubtedly the most important one. 
Section 29: Big Government

\section{$\S 165:$ Causes}

The ideal of equality can cause other problems as well. It can lead to an increase in the size of the democratic state apparatus as well as an extension of the power and the influence of this apparatus. The state expands, becomes stronger and more wide-ranging, and intensifies its control of society, of the economy, of private life etc., even if, ideally and in theory, a democratic state is a limited state subject to the rule of law (see Sections 2 and 5). (This extension can, of course, have other causes as well, such as the availability of modern technologies, the apathy of citizens etc.).

In a democracy, hereditary or class-related privileges are replaced by more equal conditions. The democratic state is often inclined to enact more and more rules and regulations in order to move closer towards the ideal of equality. Only the state seems to have the power and the ability to realize equality. Especially those on the left side of the political spectrum are in favor of this kind of government intervention in society.

This intervention is not limited to income redistribution. If a state wants to provide social security, it has to infiltrate in the lives of the citizens. It has to know if someone needs help, if his or her income, health, state of mind etc. are such that assistance is needed. This can harm our privacy, but not only our privacy. The growth of the bureaucratic apparatus of the state and the increase in the number of rules also limit the independence of society and the freedom of the citizens. (Of course, the view at the other extreme of the political spectrum - civil society will automatically and independently solve all problems, without the intervention of the state - is just as harmful, albeit in another way). Equality is an important value, but it has to be limited for the sake of other values such as privacy and freedom. Values have to be balanced against each other, $a$ though I will show in the Part 5 that freedom and equality can also be mutually beneficial.

There are other ways as well in which equality causes an extension of the size and the power of the democratic state. The disappearance of a 'natural order' of things, of 'natural hierarchies' and of every supernatural guarantee of the order in this world, together with the disappearance of traditional taboos and religious commandments, forces the state to become the sole defender of order. On top of that, these changes in social structures and norms make society more uniform and more difficult to organize and control. We no longer know 'our place' as we used to in a pre-democratic society, and there are no clear hierarchical relations. Some can consider this as a threat and decide to increase the power of the state in order to control this threat. Democracy is relatively unorganized and a lack of organization can cause people to become afraid of anarchy. It is well known that the fear of anarchy can cause authoritarian reactions.

Of course, equality is not the only cause of the extension of the size and the power of the democratic state. The anonymous and undetermined character of power in a democracy or the fact that power is no longer linked to very concrete, visible and identifiable institutions or persons but to the people in general, can also lead to an extension of power. If power comes from the people, how can it do something contrary to the wishes of the people? And if it cannot, then why should we be afraid of a state spreading its power to 
all people and to everything they do? If power comes from the people, it can do as much or as little as the people wish and it no longer needs limits. Limits on power are necessary only where power does not come from the people and where the people need to be protected against power. They hardly need protection against their own power, or so it seems.

If power is linked to the undetermined and continuously redetermined people and if it is therefore delocalized - the place of power has become an 'empty place' - then power will transcend its limits and start to intervene everywhere. It becomes omnipresent and almighty. Power as well has ceased to know its place. 'A s the struggle proceeded for making the ruling power emanate from the periodical choice of the ruled, some persons began to think that too much importance had been attached to the limitations of the power itself. That (it might seem) was a resource against rulers whose inter ests were habitually opposed to those of the people. What was now wanted was that the rulers should be identified with the people, that their interest and will should be the interest and will of the nation. The nation did not need to be protected against its own will. There was no fear of its tyrannizing over itself. Let the rulers be effectually responsible to it, promptly removable by it, and it could afford to trust them with power of which it could itself dictate the use to be made. Their power was but the nation's own power, concentrated and in a form convenient for exercise' (Mill 1977:1106). If power comes from the people, then it seems to have the right to do everything and to intervene everywhere, because it is the people who do something to themselves and who intervene in their own lives.

The problem with this view is that it fails to notice that the people are always divided and that one part of the people - for example the minority - does not always appreciate the actions of another part - for example the majority. It is not as if democratic power is the implementation of a uniform decision of the entire people. Individual freedom can suffer if limits on the power of the people are no longer considered to be necessary. The sovereignty of the people can harm the sovereignty of the individual (Berlin 1996:90). The will of the people has to be limited just as any other kind of power. I will come back to this in Part 5. Furthermore, a representative system translates the will of the people into the actions of representatives. Since this translation can be incorrect - there can be misunderstandings or deception on the part of the representatives - it can be very useful to limit the actions of representatives even though these actions are, in theory, translations of the will of the people.

A nother cause of the extension of the size and the power of the democratic state is the feeling of collective omnipotence we often see in a democracy (Ankersmit 1997:106). Why would we have a democracy if the collective effort of a whole people were not enough to solve almost every problem? As a consequence, the democratic state will try to do everything.

The instability of democracy, the permanent replacement of those in power and the impossibility of a permanent identification of ruler and power can cause an increase in the size and the power of the anonymous bureaucracy, because the bureaucracy is the only permanent and stable element in the state. It will position itself in the center of power, for lack of an alternative. The growth of the bureaucracy is also linked to equality. The elaborate organization necessary for social security requires a large bureaucracy. The problem is that a bureaucracy is not accountable to and not removable by the people, which further extends its power.

The system of vote buying is yet another cause of big government. If politicians have to compete for the votes of the citizens, then they will be inclined to outbid each other and to promise always more important benefits. Promises have to be kept, at least most of the time, and this means providing more and more benefits. As it is the state that has to provide these benefits, the state tends to grow. Democracy leads to big government because it allows the expression of a maximum number of claims directed at the state. Because eve rybody is equal and because everybody's claims have to be treated equally, the only choice is to realize either all claims or none of them. In fact, there is no choice because it is 
very difficult to realize no claim at all. (The ideal of equality often leads to a loss of credibility and legitimacy. When politicians outbid each other, they inevitably arrive at a point where they are no longer able to deliver what they promise. Instead of an extension of the state, we may see a collapse).

These are the reasons why a democratic state may demand ever more contributions, provide ever more services and goods, take on more and more functions and enact innumerable rules and laws, until it becomes a very powerful and omnipresent entity intervening everywhere and severely limiting the resources, the freedom and the privacy of its citizens. In return for this, it gives the citizens order, protection and care. This transformation of a limited state which guarantees freedom, into an unlimited state can be, in part at least, a result of democracy. Democracy can lead to dictatorship and should try to counteract this tendency.

On the other hand, a large number of laws is also a condition for freedom (Hamilton/ Madison/ Jay 1954:176). If we want to avoid arbitrariness in court, for example, we have to regulate every case and every possibility and we have to limit the freedom of the judge. Government intervention in the economy creates more economic equality and economic equality is a condition for freedom. Hunger and freedom are incompatible. Planning can make government policy more transparent, more predictable and more verifiable, and can therefore promote freedom.

Economic equality often becomes the main goal of politics. This not only leads to big government but also to a neglect of public life, of communication etc. The economy is part of our private life and of the realm of nature and necessity. It is not because public life is a prerequisite for private life - at least the economic part of our private life (see Part 2) - or because freedom can help in our struggle against necessity, that our private life is more important than our public life or that necessity is more important than freedom. Necessity is not the ultimate goal and freedom is more than an instrument in the struggle against necessity. If freedom struggles against necessity, then it does so for its own sake.

However, economic equality can also harm our private life, as I have shown. It requires the intrusion of the state into our private lives and the discussion of private things in public. Furthermore, big government can harm economic equality. A big government needs loads of resources for its own functioning, resources that it can no longer use for redistribution.

\section{$\S$ 166: Elements Working A gainst}

Fortunately, there are some elements working against an extension of the state. Power and size can be inversely proportional to each other. A state that is too big can go bankrupt because it can no longer generate the funds it needs in order to continue functioning. In a democracy, the power of the state is constantly challenged and questioned by those claiming rights against the state, rights that often cannot be ignored. The actions of the state are strictly limited, not only by rights but also by the possibilities and capabilities of the state itself. Think for example of the pain caused by an unrequited love. 'H ow small of all that human hearts endure/That part which laws or kings can cause or cure' (S. Johnson in Barber 1984:118).

Secondly, there is a tendency to privatize many functions of the state. Even the monopoly of violence is sometimes privatized (in some countries, prisons are run by private firms). Sometimes, this happens without the consent of the state. Many political decisions are not taken by the public institutions that were initially set up to take these decisions. These decisions are privatized because they are taken in private, by interest groups such as labor unions together with employers, by lobbyists sitting on the Prime Ministers couch, by multinational companies etc. These private groups are often accountable to nobody but themselves and they do not create freedom or equality for anybody but themselves. 
The state also loses its power over the economy. Multinationals are spread all over the world and become untouchable for the individual states. If they leave a state, they cause unemployment and a fall in tax-revenue, which forces states to pamper them. This not only threatens the power of the state over the economy but also the power of the state in general - for example the power to protect rights - because a state cannot act without revenues. The state will tend to make itself as small as possible and to act as little as possible, because any action, any law and any regulation might discourage investors and encourage flight of capital. States are afraid to antagonize multinational companies, be cause if they do - e.g. if they impose taxes, environmental regulations, labor regulations etc. - the companies in question may decide to move to another country, which leads to increased spending (more money goes to unemployment benefits) and a fall in tax revenue. Even the laws that exist will then be enforced in a 'pragmatic' way.

This 'power deflation experienced by the states (...) vis-a-vis the market and international economic agents' means that 'decisions affecting the well-being of the population are being taken or are perceived to be taken outside the democratically elected government by powerful private agents' (Panizza in Beetham 1995:180). It is obvious that this is incompatible with democracy and with the sovereignty of the people. It does solve the problem of the size of the state, but it creates another problem along the way. Democratic control over events is an important value, but one which implies the presence of a state capable of imposing its will.

States also lose power because they lose their independence Many present-day problems, such as the protection of the environment, refugee flows, drugs, international crime, national defense etc., can only be solved by way of international cooperation. Sometimes, it is even necessary to create international institutions such as the EU or the NATO in order to solve international problems. States then have to transfer parts of their power and functions to these institutions and have to accept the rules and decisions of these institutions. States not only lose power; they also lose their credibility because they have to admit that they cannot solve some important problems.

National democracies are powerless in many domains of life, unable to change the course of events. Why give power to the people if this power is insufficient to solve major problems? We can just as well settle for something less, such as tyranny. International institutions, on the contrary, can have power, but they also suffer from a lack of credibility because it is very difficult to organize these institutions in a democratic way. They comprise many states and many nations and it is often very difficult to frame a harmonious popular will overlapping all these nations. In many cases, the people of the different nations do not decide the policies and the actions of international organizations. If these organizations are non-democratic (which is not the same thing as anti-democratic), then we find ourselves in the same situation as the one created by multinationals: decisions that affect the people are not taken by the people.

A loss of power, trust and credibility is just as harmful to democracy and rights as an exaggerated extension of power. If a state does not have the power to enforce rights, then rights lose their 'address'. It is unlikely that the new centers of power - multinationals, international organizations or private groups such as labor unions - will enforce our rights. We often need a judge, as a part of our national state, to whom we can address ourselves if our rights are violated, and we need a policeman to enforce the decision of the judge. International institutions, multinationals etc. are not likely to listen to our complaints, let alone do something about them.

A weak state is not a blessing for democracy. Having self-government means holding your fate in your own hands. If external powers decide the fate of a state - and these external powers can also be other states, for example a state that causes massive flows of refugees - then the people of this state do not have self-government. 
Is democracy possible at a level that is higher than that of the state? A number of problems can only be solved at a transnational level. It is therefore important that all transnational decisions and organizations are democratic and based on the agreement of the people. But is it possible? Democracy is not at its best on a large scale. Efficient participation is difficult in very large groups. On the other hand, international cooperation can stop events taking place without the agreement of the people. If we have international cooperation, we can avoid the situation in which one country takes a decision that has a negative effect in another country (for example, the decision to build a nuclear plant just at the border with another country, without involving the people of this other country; or the decision of one country to start destroying its rainforests, irrespective of the consequence for the global climate). International cooperation in the sense of defense cooperation in institutions like the NATO can protect the national sovereignty of individual states and therefore also the right to self-government of the people of these individual states. And finally, international cooperation allows a nation to solve problems which it cannot solve on its own (pollution for example). In everyone of these three cases do we see that international cooperation has a positive influence on self-government.

More and more decisions have international consequences. Many things that we consider to be important are dependent on or influenced by foreign decisions (not only the environment, but also our security, our economy etc.). This means that the democratic actions of a single nation can influence these things only in part or maybe not at all. Democracy and self-government can only be saved by bringing together different states that influence each other.

It is obvious that international organizations, set up to solve international problems, must be democratic, at least when we remember that democracy and self-government are among the reasons for solving international problems. Some of these problems inhibit selfgovernment because an individual nation is not able to deal with them. International organizations are set up to recreate self-government by solving problems that inhibit selfgovernment. This reasoning is the same as in the case of a break up of states, exactly the opposite movement. As I have said in Part 3, a group cannot separate from its state if it intends to form a new and undemocratic state, because the purpose of separation is selfgovernment. One should not create an undemocratic international institution, because the purpose of such an institution is precisely self-government.

How can we make international organizations more democratic? There are not many examples to inspire us. In any case, the people of the different states have to be repre sented in these organizations and not only in their own states. Direct democracy is also a possibility. Perhaps we can presume that we have a democratic decision from the moment that democratic states, in their position of members of the organization, take a common decision. These states represent the people and hence the people are indirectly involved in the decision. However, do these states have to decide unanimously? Or can we also apply the system of majority rule at an international level? In the latter case, we put aside entire nations. Is this acceptable? It is certainly not acceptable for the nations concerned. The reason why these nations joined the organization in the first place, was to solve problems that escaped their power and to recapture their sovereignty. They will never accept to be outvoted. '[T] he (...) notion that the relevant constituencies of voluntary agreement are the communities of a bounded territory of a state, become[s] open to question as soon as the matter of national, regional and global interconnectedness is considered and the nature of a supposed 'relevant community' is contested. Whose agreement is necessary and whose participation is justified in decisions concerning, for example, the use of non-renewable resources, or the disposal of nuclear waste (...)? To whom do decision-makers have to justify their decisions? To whom should they be accountable? Further, what are the implications for the idea of legitimate rule of decisions taken in polities, with potentially life-and-death consequences for large numbers of people, many of whom might have no democratic stake in the decision-making process?' (Held 1998:338). 
The fact that international organizations take away a part of the sovereignty of states in order to be able to solve certain problems, does not have to imply a weakening of democracy. On the contrary, it can imply the rescue of democracy, on the condition of course that these organizations are governed democratically. The people of every individual state have less democratic power because they are minorities in a larger entity, but the 'people' of the whole have more democracy because they are now able to solve problems they were not able to solve when they were still divided.

International cooperation can also promote democracy because it implies mutual influence. A state that needs other states in order to solve environmental problems for example will find it more difficult to ignore demands from these other states aimed at an improvement of the human rights situation. The shield of sovereignty loses its strength and can no longer be used to counter criticism of human rights violations, because it is precisely the lack of sovereignty or self-government which forced the states to cooperate. 
Part 5: $\quad$ Freedom

$\checkmark$

Chapter 13: Autonomy and Self-Realization

$\checkmark$

Section 30: Autonomy or the Freedom to Choose Your Own Good Life

$\S$ 168: The Importance of F reedom and the Link W ith Democracy and Rights

The definition of freedom is and has always been a very difficult problem. What is freedom and how do democracy and human rights protect freedom? These are the questions I will try to answer in this final Part. As I do not want to limit the attractiveness of democracy and human rights, I will discuss a number of different definitions of freedom as well as the ways in which democracy and human rights protect these different definitions.

The word 'freedom' has a number of different meanings, just as the word 'equality'. A preference for one of these meanings is linked to a preference for a certain kind of ideology or morality. Freedom can, for example, be defined as autonomy. Autonomy is the ability to frame the rules which guide or govern your own life and to organize your life in a way that you decide for yourself, independently and without interference Being autonomous is being independent, is having self-government, self-determination and control over your own life. An autonomous person can decide on the fundamental matters of his or her own life and chooses and pursues his or her own vision of the good life. He or she is not subject to the laws and desires of other people.

The first question is then: can there be a widespread agreement on the value of freedom in the sense of autonomy? The second question will be: can human rights and democracy promote this kind of freedom? If the answer is 'yes' to both questions, then we have an additional reason to accept human rights and democracy. If the answer to the first question is 'no' and the answer to the second question is 'yes', then this is no reason not to accept human rights and democracy, unless I can show that autonomy is undesirable. In any case, I will show that the answer to the second question is definitely 'yes'. Human rights and democracy even promote many different kinds of freedom, but without imposing any of them. Hence, a rejection of autonomy should not imply a rejection of human rights and democracy.

Let me start with the first question. Autonomy will probably be considered as a value by most people because most people do not like to lose control over their own life, do not like to be unable to decide what to do with their life and do not like to live under the rule of powers or laws which they cannot control. Few people like to be dependent on either political rulers or ideological rulers (so-called 'authorities' of the mind). In general, people do not like to be in a situation in which other people decide what they do and think. They like to act and think in a way they decide for themselves. The life of a slave - a physical or a mental slave, a political or an economic slave - or the life of someone who plays an imposed part in a play written by someone else, is undesirable for most people. Ideally, man is free from physical or intellectual domination, subordination, coercion and oppression. 
There is no reason to believe that one person is allowed to dominate another person's mind or actions.

People want to be free to reject 'accepted ways of life' and the opinions or prejudices of a group, a leader or a church. Most people want to organize their lives in their own way and want to determine their thoughts and actions as they please. They do not have to and they do not want to depend on the minds of others, on convention, on the established truth or the established way of life, at least not always. They want to free themselves from conformism, public opinion, tradition, propaganda and other 'tyrannies of thought' because they want to act and think autonomously.

A utonomy is the ability to use your own mind and to determine your thoughts and actions in your own way. It is the ability to be master of your own life and of your own thoughts and actions. It means being able to decide and choose for yourself. You are not the object of other people's decisions and choices and you do not accept opinions, standards of behavior and established ways of life just because someone tells you to accept them. You accept them only because you have convinced yourself to accept them, cause you have your own reasons to do so, and because you know that you can always reject them. You shape your own life.

An autonomous person is not dominated and does not dominate. He does not receive nor give commands, he does not obey forces beyond his control and he does not use his own force to control other people. He only uses his power in order to control his own life. $\mathrm{His}$ life and decisions depend on himself and are not the result of some outside force. $\mathrm{He}$ is the instrument of his own will and not the instrument of the will of someone else. He is driven by his own reasons, not by external causes. An autonomous person is a driver, not a passenger. He is a ruler, not a subject. He has his own goals and his own ways to attain them (Berlin 1996:52).

This is, of course, reminiscent of democracy. Autonomy is a democratic value because democratic self-government is in fact the same thing. Both autonomy and democracy are concerned with self-government, self-determination and the ability to shape your own life and to determine the rules and the decisions governing your own life.

The fact that autonomy is incompatible with conformism does not mean that it is incompatible with group identification. Groups and common identities are necessary for the functioning of democracy and are important for human well-being. However, if the identification with a group is to be compatible with autonomy, then it has to be a voluntary identification. You have to arrive at an identification with a group through autonomous reasoning. Your own way of life does not have to be different from the ways of life of the rest of humanity in order to be autonomous. It has to be a conscious and reasoned way of life, however, and not the result of socialization, blind following, indoctrination or coercion. You have to have reasons for your choices and you have to convince yourself. And, ultimately, you have to be free to reject certain choices.

Having your own goals or being able to decide the purposes of your actions is important because you are being used and dominated if your goals come from someone or something else. You are unfree if your actions are decided outside of you, if your actions are not your own, if you are a consequence rather than a cause, and if you are an instrument used by other people to achieve their goals. Someone else acts through you and this makes you unfree. A person's free action is an action which comes only from himself, which can only be attributed to himself and not to someone or something else (for example a spiritual leader, nature, fate etc.).

If, for example, you are led or governed by your biological needs or by the prejudices of your group, then it is not you who decides on your views, your actions and your goals. You are dominated by causes other than your own will. If you want to be free, then you have to decide your thoughts and actions yourself and you cannot let nature, leaders, groups or whatever decide them for you. Autonomy, therefore, is not the ability to choose whatever way of life. A dependent or conformist way of life or a life dominated by the laws of nature can never be called autonomous. 
Self-determination is the right to determine your own life. It is the right to live the way you decide and not the way someone or something else decides for you. This is a right even if someone else thinks you are wrong, stupid or evil and even if your way of life may destroy you. To adopt autonomy as a value is to hold that people are to be perfectly entitled to damn themselves. It is thought better for people to choose the worst than have the best thrust on to them' (Harrison 1996:163).

Autonomy requires that you question yourself. You have to reflect on your opinions and actions, evaluate them and try to find the reasons behind them. Only if you reflect on your opinions and actions can you freely accept them and can they become yours instead of the opinions and actions of someone else. If you do not look for the reasons behind your opinions and actions, then you may be aping someone without knowing it. That is why autonomy requires that you give up habit, passion, conformism and other kinds of unreflected opinions or actions, at least in part. Again, autonomy is not the freedom to choose whatever way of life. It requires a life of thinking.

A utonomy is the freedom to shape your own life and to choose your own vision of the good life, but this choice is not completely free because not all ways of life lead to autonomy. Autonomy implies the freedom to damn yourself, but not the freedom to be thoughtless. Not every choice of the good life is an expression of autonomy. As a consequence, it is wrong to say that men are born free. Men acquire their freedom in and through public life because only public life can give men the ability to know the opinions and actions of others, to reflect on their own opinions and actions, to question themselves and to find out whether their opinions and actions are really theirs instead of those of someone else. The link between autonomy and public life implies a similar link between autonomy on the one hand and democracy and rights on the other hand. Freedom is 'a tangible, worldly reality, something created by men rather than a gift or a capacity' (A rendt 1990:124).

There is another reason why autonomy requires thinking. We have to think because we have to be sure - or as sure as possible - that we do not regret our choice of the good life later on in life. The absence of regret seems to be a part of every imaginable good life. We can be wrong and we can choose the wrong kind of life.

The choice between different ways of life is meaningful only when all ways of life are not considered as equivalent. Individuals have to make a difference between good and bad ways of life. The state and the fellow citizens, however, should not do so and should not impose one or another way of life (at least within certain limits), otherwise there would be no freedom in the sense of autonomy. Everybody should be able to choose his or her own preferred way of life and neither the state nor the citizens should influence or impose this choice.

Everybody should choose for himself but not by himself. Only in the public space can you acquire an overview of the different possible ways of life and of the arguments for and against each of these ways of life. You can only choose a way of life in the public space. This choice needs public life and therefore it also needs democracy and human rights as institutions necessary to protect public life. As a consequence, a way of life should not contradict or harm democracy, human rights or the public space (these are the limits I mentioned a few moments ago). You decide on your way of life and nobody else should decide this for you, but you do not decide this by yourself and you do not decide this in any way you want.

Autonomy needs democracy, but democracy also needs autonomy. If the people - or at least the majority of the people - have opinions which are in fact the opinions of others, then democracy cannot function. Democracy is the realization of the will of the people and not the will of certain 'authorities' or ideological masters (for example a church) who speak through the mouths of the people. Judgment as well as self-judgment are important abilities in a democracy. People should be able to judge for themselves and should not repeat the judgments of others. They should also be able to judge themselves and to decide if their thoughts are really theirs. Autonomy is yet another prerequisite for democracy and the absence of autonomy makes democracy impossible. 
Now suppose that certain persons, who are not the majority of the people, are not (yet) autonomous enough for democracy. Should we exclude them from the democratic procedures in order to save democracy? Of course not, because if we do so, we make it impossible for these people to become autonomous. Democracy is the best, if not the only means to become autonomous and autonomy is more important than democracy. The former is a value and a goal, whereas the latter is only a means to achieve this goal.

Autonomy is not only important because it allows you to do things and to choose your own way of life. It is also important because the ability to make and obey your own laws is part of political life and I have already discussed the importance of political life. If autonomy is the ability to decide your own laws, then freedom needs politics (which is quite different from the liberal view on freedom, for example). Self-government is freedom and self-government needs political life. Freedom is not only freedom from the state or from politics and is not only the ability to do as you like, unhampered by the state. It is also freedom in the state and in politics. Of course, there is also freedom in social life, in private life and even in non-political public life. However, the link between freedom and politics does not mean that freedom is al ways safe in the hands of politics. Politics can indeed harm freedom and that is why politics must be limited. It is obvious though that politics is more than just coercion and violence It is power as well. In a democracy, it is power over your own life and therefore freedom and self-government.

A nother advantage of autonomy is that it gives people the ability to protect their interests. By making your own laws you can protect your interests against attacks by the government or by some kind of elite. Both governments and elites can harm the interests of the people, either by pursuing their self-interest at the expense of the interests of the people, or by determining what are the real interests of the people and by imposing these real interests even if they are contrary to the convictions of the people. If you can make your own laws, then you do not have to count on other people to realize your interests and you do not have to count on altruism or compassion. We should not expect too much from other people. In most cases, we know best what our own interests are and we are therefore the best guardians of our interests. People who are excluded from politics and legislation are and have always been unable to protect their interests. Those who are included systematically fail to protect the interests of those who are excluded, either cause they only protect their own interests or because they have a mistaken view of the interests of those excluded. In any case, the ability to take care of yourself is also a value and it is not sufficient for people to have their interests realized, regardless of the person or persons who realize them. Democracy allows people to get what they want and what they think is best for them, and it allows people to get it themselves. The people are not dependent on others to get what they want or to decide what they want and what is best for them.

If we accept certain premises:

(1) People can only realize their interests effectively when they participate in politics and when they create their own laws;

(2) People are, in general, the best judges of their interests and of the ways in which to realize them (I will come back to this in the next Section);

(3) People should, when possible, realize their interests themselves;

(4) People's interests should be considered as equally important (see Part 4);

(5) There is no single and certain answer to the question of the good life,

then we also have to accept that autonomy is an important value. And if autonomy is important, then there is no reason to consider some people as less qualified for politics (on the condition that politics is considered as the sum of the decisions regarding everybody's self-interest, which, of course, is only part of the story). 
Autonomy is an important and a universal value, but there is also a phenomenon called the fear of freedom. Many people are afraid of the free choices they have to make, of the mistakes they can make and of the consequences of their choices. It can be very difficult to make your own laws and to decide your own way of life without the support of tradition, authorities or convention. Some prefer comfort and follow blindly the existing rules and opinions. The fear of freedom is also the fear of democracy. Democracy imposes a heavy responsibility on the shoulders of many people and responsibility can be frightening. The possible consequences of acts can convince people to remain passive and to hand over responsibility to other people.

However, this is not an argument against democracy or human rights because neither democracy nor human rights impose autonomy. There is no obligation to participate or to govern yourself. The fear of freedom only makes it more difficult to promote democracy and human rights. Some people will not be convinced by the argument that democracy and human rights protect freedom because they do not consider freedom to be an important value.

The fear of freedom is not the only problem. Autonomy, independence and selfdetermination can be seen to imply isolation and egoism. Although the choice of a life of altruism can also be an autonomous choice, an autonomous person seems to be selfcentered, occupied only with his way of life, with the search for the best possible life for himself and with his struggle against conformism and against the coercive influence of the group. He will tend to see the world and fellow man either as a problem or as instruments for the realization of his good life. If he wants to go his own way, free from paternalistic objectives of others, then it is important to leave each other al one and to have as little interference as possible. Isolation is then only one step away. If he does not want to listen to other people because he does not wish to be dominated, then he will not hear their call for help either. He will have passed the border between healthy and harmful individualism. And if he does not listen to other people, then he will lose the benefits of public life, and so in the end he will also harm himself.

It would indeed be dangerous to deny that human beings are dependent upon each other. We need our fellow human beings (biologically but also psychologically and intellectually) and our fellow human beings influence us. We are not self-sufficient and we do not exist on our own. And this is good. Public life, for example, is a process of mutual influence and at the same time it is something very valuable. Even freedom in the sense of autonomy requires intense relationships, as I have shown in the previous paragraph.

Only some types of relationships and some types of dependence or influence are harmful to autonomy. It is not because we struggle against coercive influence that we have to end up as isolated and egoistic beings. Isolation and absolute independence are probably not even possible. There is al ways influence. We shape our own lives but at the same time we are shaped by our environment, whether we want it or not. Nobody can live without the care, the advice or the minds of others (take for example our language). This is not incompatible with autonomy as long as we choose and accept a particular kind of influence - rather than another - in a conscious way and as a part of our reflected convictions.

It is necessary but not sufficient to be independent, to be free from domination or coercion by other people, to be left alone, to be ourselves and to be able to shape our own lives, unhindered and unharmed by others. If this is all we understand by the word 'freedom', then we will indeed create a distance between people, and we will not be free in the end. We have to deal with people if we want to be free and autonomous. We have to listen to them, see how they live, how they argue in favor of one or another way of life and we have to examine whether our opinions are or are not unconscious copies of other people's opinions. We have to be interested in other people. Extreme independence can be a threat to autonomy. A tomism and narcism are the end instead of the cause or the consequence of autonomy. 
However, we do not only engage in relationships for the sake of our freedom, our autonomy and our good life. We do not focus exclusively on our own life, but also on the lives of others and on the good life of the community as a whole. Freedom, after all, is not the only value and probably not even the most important value. There is no reason why it should be impossible to limit autonomy in order to protect another value.

This is important because autonomy can result in license. If everyone can organize his life in his own way, if every way of life is equivalent and if everyone can decide to respect only his own laws, unhindered by the control of others, then every new Hitler can do as he wants. I have al ready expressed my conviction that autonomy is not the same thing as complete independence or the absolute freedom to choose whatever way of life. Freedom should not include the freedom to choose a way of life which implies violations of rights or limits on the freedom or the autonomy of others. If, in the opinion of some people, freedom does include this kind of freedom, then their freedom together with their instruments of freedom - such as their human rights - should be limited in order to protect the freedom, the rights and the other values of other people. Autonomy can only exist within the limits given by human rights and by the autonomy of other people. Rights and autonomy limit autonomy.

Unnecessary coercion, such as intellectual coercion or coercion with the purpose to impose heterosexuality for example, is unacceptable, but the coercion implicit in the rule of law is necessary in order to enforce human rights, because there is no freedom without human rights. Autonomy can result in morally bad acts which have to be suppressed. There is no absolute freedom to choose whatever way of life and there is no absolute freedom from control. Otherwise we will be unable to protect the choices of people who suffer the consequence of the absolute freedom of other people, and we will be unable to protect other values as well as the instruments necessary to protect these other values (human rights for example).

There has to be a legal framework including coercion and obedience in order to avoid harm being done by the independent and free actions of some. Independence, selfdetermination and self-government are limited because coercion is by definition external determination and external government.

Of course, a lot of evil does not result from the autonomous actions of people. Many evil actions are non-autonomous actions (Kekes 1999:25). Some people have no choice or only have a choice between evil and starvation. Other people may be motivated by prejudices or may act as a result of indoctrination. More autonomy can also result in less evil (just as less autonomy can result in less evil: young people, for example, can be taught to apply morally good principles and can still live according to these principles when they are adults, without consciously reflecting on the justifications of these principles).

More autonomy can result in less evil, but people who do evil for non-autonomous reasons today can do evil for autonomous reasons tomorrow. Non-autonomous evil implies responsibility (Kekes 1999:passim) - contrary to a widely shared conviction - because otherwise there would be no limit on this kind of evil. Of course, the non-autonomous nature of an action is a valid reason for a diminished punishment on the ground of extenuating circumstances.

A utonomy has to be limited in order to safeguard the autonomy of others or in order to safeguard values different from autonomy, because some people do evil even if they can choose otherwise, even if they are not poor or indoctrinated. They know that what they do is evil and still they do it, for pleasure or because they believe it is legitimate. These people can be autonomous. People are not good by nature and can act in evil ways for other reasons than necessity or indoctrination. In other words, people are not only evil because they are not autonomous. There are moral obligations inconsistent with the obligation of autonomy.

A utonomy or, better, too much autonomy can cause problems (isolation, egoism, the rejection of externally imposed but legitimate rules in combination with the rejection of conformism and convention, but also moral relativism and a lack of respect for nature as 
a consequence of the wish to control your own life). However, this is no reason to conclude that:

(1) Autonomy - limited autonomy - cannot be a value;

(2) Autonomy cannot be used to justify democracy and human rights; or

(3) Democracy and human rights have to be rejected because of autonomy.

We do have to be careful with the concept of autonomy, but autonomy is beneficial in many cases and is, for many people, a legitimate reason to accept democracy and human rights.

\section{§ 170: Widening A utonomy}

I have already shown that human rights and democracy promote autonomy. You need human rights to question yourself, to make sure that your opinions are in fact your own opinions instead of the opinions of someone else, and to reflect on the advantages and the disadvantages of the different possible ways of life. It has to be possible to show and defend different ways of life in order to allow people to make a reasoned and reflected choice Human rights not only make it impossible to discriminate people as a result of their choices. They also give people certain instruments necessary to be able to choose (and these instruments include also the distribution of material means, for example by way of economic rights).

Democracy as well promotes autonomy, qualitatively because it protects public and political life, but also quantitatively. In a democracy, more people decide on what concerns them, establish their own laws, govern themselves and shape or control their lives than in any other form of government. The people of a democracy, or at least the majority of the people, are not subject to laws and powers which they cannot shape or control and are not dependent on others to protect their interests. Equality in the sense of equal political participation promotes freedom because it allows the majority of the people to shape their own lives. Equality is therefore not by definition incompatible with freedom (Castoriadis 1991:137). Limiting or pushing back the state - which is the way in which liberalism and anarchism try to promote freedom - can harm freedom instead of promoting it, because it means limiting or giving up the political structures which allow people to participate in the creation of the rules which regulate their lives.

There is, of course, the problem of the minority in a democracy. The minority does not have control over its own life and does not have self-government. It is governed by the majority and by laws which it has not created and which limit its free and independent actions. The minority does not establish its own laws and is therefore not autonomous. 'If we require of government that it respect the autonomy of its citizens, we cannot permit a government that requires of any of its citizens that he act contrary to his own will' (Nelson 1980:63). In other words, we cannot permit a majority system and we should favor a system of unanimity. However, I have al ready pointed out a few problems with a system of unanimity (see Section 5).

Moreover, there can be more or less autonomy. It is not because it is impossible to have all, that we should decide to have nothing. A system in which at least the majority has control and can decide is much more valuable than any other known system, with the exception of unpractical or undesirable alternatives such as a system based on unanimity, a naturally harmonious society without a state or a complete withdrawal from all social relationships. (Isolation seems to be the best protection of our freedom since both the state and fellow man are liable to infringe upon our independence and to control our lives. Every social system and every state - including a democratic state - produces coercion and rules. The problem with this view is not so much that it is unrealistic, but that relationships can also promote freedom). 
On top of that, there are no permanent minorities in an ideal democracy (nobody is permanently part of the minority) and therefore it is likely that everyone is just as much a part of the autonomous majority as everyone else, although not at the same time as everyone else. In any case, the autonomy of the minority also benefits from democracy and human rights. Independence requires a limited government which does not determine all aspects of life and which leaves room for a free and plural society. Independence also requires legal means - i.e. human rights - to enforce the freedom to choose different ways of life. Freedom needs pluralism and pluralism needs democracy and rights. People who belong to a democratic minority have a large degree of control over their lives. I fail to see how a system which does not respect human rights can provide more or even the same level of control.

The autonomy of the minority also benefits from the existence of a public space guaranteed by human rights and democracy. Independence needs public life, as I have shown. A minority may not have power, but it has rights and it can use these rights to choose and protect its way of life and to protect the public space which is necessary for its autonomy.

It may seem contradictory, but a democratic state also makes more people autonomous by interfering in society. A government which does not interfere when some of its citizens are starving, diminishes the freedom and independence of these citizens. They have fewer opportunities and choices and they cannot choose and realize their own vision of the good life (Harrison 1996:170). If you spend your life struggling for survival and looking for food, then you may be free in the sense of free from the interference of the government and your fellow citizens. Nobody stands in your way or makes it difficult or impossible for you to pursue your goals. However, the absence of harm done by other people or by the state is obviously not a sufficient condition for autonomy. That is why the state should do more than protect people from this kind of harm. Other kinds of state interference are necessary as well.

Arbitrary and egoistic interference, interference based on domination or interference without the purpose of increasing autonomy is of course harmful. Freedom is precisely the power to oppose this kind of interference by way of an appeal to the state. The powers of the state are needed to provide the conditions for freedom and both the absence of unwanted interference and the presence of sufficient material means are part of these conditions. On the other hand, autonomy is the power to decide for yourself as much as possible, which means that the state should be limited to a minimum.

The state, to some extent even a non-democratic state, can promote freedom in the sense of autonomy. A gain we see that pushing back or even eliminating the state often harms freedom instead of promoting it (and of course also harms other values such as justiceand public life).

\section{§ 171: A utonomy and the E conomy}

Is freedom in the sense of the ability to shape your own life compatible with capitalism? Capitalism means leaving the circumstances of people's lives open to be determined by the pressures of private capitalist investment. It means succumbing to the consequences of the economic decisions of a weal thy minority, where those decisions are not taken with any reference to general costs or ben efits. It means a reduction of freedom to unfettered capitalist competition, and the subordination of the mass of the population to forces entirely outside their control' (Held 1998:137). If control over your own life is important in politics, then it is also important in the economy. However, it seems to be much more difficult to implement democracy and self-government in non-political matters, especially when we wish to preserve other values such as private property, privacy etc.

The economic freedom of one person limits the freedom of another person when the former creates a hierarchical organization - a company - in which the latter has to func- 
tion. N ot everybody has enough resources to create his or her own economic organization. Only 'capitalists' can do so. Those who have many economic resources have the power to determine and organize the economic activity of other persons. The unequal possession of and control over economic resources not only creates unequal prosperity and unequal political participation, power and influence (see Section 26). It also creates unequal freedom. Equal freedom and the capitalist economy seem to be incompatible. Capitalism is by definition a system in which some people have power and control over others.

What can be done about this? Common and equal property of the means of production seems to be a solution. This would extend the democratic principles to the work-floor because it would allow the workers to have an equal say in the workings of the company. As a consequence, it would give workers control over their lives, autonomy and selfgovernment. However, this solution contradicts a number of other important values, such as private property (see Paragraph 32), and must be balanced against these other values. Making all companies the property of the state is not an option because it would give power and control to the state and not to the workers.

Companies can be democratized without the elimination of the capitalists. Companies do not have to be the common property of the workers in order to be organized in a democratic way. Why should only those who own the company be allowed to have a say in the workings of the company? Perfect democracy does not seem possible as long as we wish to maintain the right to private property, because private property implies some sort of privileged control. However, there are other options in between the two extremes of the economic dictatorship exercised by the capitalist and the 'communist' attack on private property. There can be an agreement on power sharing between capitalists and workers. We can look for a system in which all parties involved can exercise power, maybe not in a perfectly equal way - this would imply eliminating private property - but at least in a way which is more equal than the power-structure we find in traditional capitalism. In order to achieve this, we have to limit the right to private property, otherwise the capitalist would be able to do as he likes with his property and would be able to refuse power sharing.

Freedom requires:

(1) Political participation;

(2) Human rights including the rights which protect our material well-being;

(3) A separation between the state and society which results in pluralism; and

(4) Some kind of power sharing in the economy in general and in companies in particular.

Democratic control of the economy is very important for freedom, especially when we consider the importance of work in our daily lives. It is obvious that this control cannot always be left to the people in companies. The nation also has a right to intervene in companies, for example when the autonomy of the workers in a particular company leads to violations of the rights of people outside of the company.

The argument for power sharing at the level of companies is not an argument against the free market. Freedom requires the free market because a free market is the freedom to produce, to buy and to sell and this kind of freedom promotes freedom in general. However, a free market is not incompatible with power sharing in individual companies, and is therefore not incompatible with economic freedom in the sense of economic autonomy.

I wish to make a final remark concerning the equality of freedom. Autonomy is realized in political participation and in democratic self-government. As a consequence, autonomy is equal freedom. There is no democratic participation without common actions, common expressions of the will and common identifications. As we exercise our freedom in common actions, it is natural to view freedom as a common good (Taylor 1996:34). 
Those who believe that other people do not need freedom, take away the meaning of their own freedom. 
Section 31: Self-Realization and the Only True Good Life

\section{$\S 172$ : Forcing People to $M$ ake the Best of Themselves}

Freedom can also be understood in another way, not as autonomy but as self-realization or the ability to make the best of yourself. You are free when you consider your life as a work of art, when you constantly try to improve yourself, when you develop your possibilities, when you work on yourself, when you enrich your life and when you try to become what you are potentially. What you make of your life is not for you to decide. Some ways of life - for example mediocre, irrational, self-destructive, blunted, superficial, stupid, hedonistic or easy ways of life - are not acceptable in this definition of freedom. There is a clear difference between good and bad ways of life in this definition of freedom, contrary to the definition of freedom as autonomy, which protects the freedom to choose different ways of life (within certain limits). Autonomy, independence and selfgovernment are less important than the effort to improve yourself. This effort may even require abandoning autonomy altogether because people may not know or may not be able to determine in an autonomous way how to make the best of themselves. They may need other people to help them develop themselves.

For example, you cannot make the best of your life and you cannot develop your possibilities when you focus on pleasure and desire and when you dislike the efforts necessary to develop. Other people may decide to take away your life of pleasure and to force you to develop yourself, to become a better human and to become what you are supposed to be, for your own good. You no longer have a right to do with your life as you please because one way of life - a life of personal development - is forced on you. Other people decide what is your good life and there is only one proper understanding of the good life. You must control your needs, passions and instincts if you want to improve yourself (development requires exercise and study, two activities which require discipline and which are incompatible with license and passions). If you are unable or unwilling to control yourself, then other people may decide to help. They will put external discipline and control in the place of self-discipline and self-control. They will ignore your desires for your own good because they see themselves as the higher elements of society, more rational and more in tune with the real and higher goals of humanity.

This kind of control and coercion is often justified by way of the metaphor of education. Some people are like children who do not know what they should do with their lives or how they should develop their possibilities. They need a leader to advise them and to bring them where they fail to go themselves. Only later in life will they understand and appreciate the reasons why they were forced to do certain things. It is in their interest to obey those who are wiser, even if they are not aware of this yet. When they become aware of this, they will be grateful.

However, even if it is not stupid to believe that freedom can be considered as the result of the effort to make the best of yourself - only a fully developed person has the capacity to use all his or her abilities - it is difficult to see how external control can result in freedom or how you can make people free by treating them as infants or idiots dependent on coercion and education. If someone does not want to improve himself and if other people decide to force him to improve himself, then he is forced to be free. One might as well steal from people in order to make them more prosperous. This kind of 'freedom' is clearly 
incompatible with autonomy and independence because one way of life is forced upon people. Freedom is no longer the ability to do what we want (we may want to indulge in pleasure, we may want to be stupid etc.); it becomes the ability to do what we should want and what other people want us to do. If necessary, we are forced to want what we should want. We are free only if we want the good life. Forcing people to choose the good life and to improve themselves is believed to lead to freedom but it leads to oppression instead. Fanatical al truism or the effort to force people to realize their real interests can be just as dangerous as focusing exclusively on your own interest. This kind of freedom is certainly not a universally accepted value, and that is the reason why it cannot be used to justify the universal application of democracy and human rights, even though democracy and human rights can promote this kind of freedom (they give access to the arts, to culture and scienceetc.). I will come back to this in a moment.

The problem is that it is sometimes acceptable to ignore someone's desires for the sake of his or her own well-being. In some cases, people have to be coerced for their own good because they fail to understand and to pursue their good or their interest autonomously. Other people, who understand things better and who have a better knowledge of people's interests than the people in question, can then legitimately force them to get what is in their interest. It can be acceptable to act in the interest of other people and to force them to do what is good for them. Paradoxically, the fact that someone else decides in your place can promote your freedom (Berlin 1996:54-5). Other people may understand yourself better than you do. We can force a drug addict not to use drugs, for his own good, even if the addict considers the use of drugs to be in his interest and to be part of his good life. It is generally accepted that he does not understand his real interest. We can al so force bikers to wear a crash helmet. And when we go to a doctor, we do not believe that we know best what is good for us and we do not insist on having control over our own life. This clearly shows that we sometimes believe that it is legitimate to hand over decisions which are not strictly other-regarding.

However, this must be an exception rather than the rule for the simple reason that it is very difficult to prove that somebody does not understand his interest in the right way and that there is somebody else who has a better understanding of this interest. How are we going to select these 'wiser' persons? Who will select them? Moreover, most adults know very well what is or is not in their interest, what is or is not good for them and what is their best way of life. In most cases, therefore, we do not need anybody else to decide in our place. Democracy would be impossible otherwise. Only if people know their own interests can they be given the power to decide for themselves and the power to control whether laws or policies are in their interest. Otherwise, some form of guardianship or paternalistic form of government would be more appropriate.

In general, we should allow people to decide for themselves, to determine their own way of life and their own interests, even if we believe that the people in question have chosen a wrong, inferior or offensive way of life and harm themselves as a consequence of the way in which they understand their interests (if they harm other people as well, then it is easier to intervene). We should not allow ourselves to be carried away by care and compassion for other people. We can advise people and try to convince them, but we should be very careful if we want to impose a way of life on people, no matter how reasonable and beneficial this way of life seems to us. What is best for me is not necessarily best for everybody. Most people value the possibility to decide for themselves. It is much more dangerous to enact laws which only deal with people's own lives than it is to enact laws which deal with social relations. In the former case, persuasion, encouragement, assistance etc. are more appropriate than rules. All errors which he is likely to commit against advice and warning are far outweighed by the evil of allowing others to constrain him to what they deem his good' (Mill 1977:1153).

Self-determination is an important and universal value. '[E]ven if the state can encourage or force people to pursue the most valuable ways of life, it cannot get people to pursue them for the right reasons. Someone who changes their lifestyle in order to avoid state punishment, or to 
gain state subsidies, is not guided by an understanding of the genuine value of the new activity' (Kymlicka 1997:232). 'W e can coerce someone into going to church (...) but we will not make her life better that way. It will not work, even if the coerced person is mistaken in her belief that praying to $\mathrm{G}$ od is a waste of time, because a valuable life has to be led from the inside. A perfectionist policy (...) is self-defeating. It may succeed in getting people to pursue valuable activities, but is does so under conditions in which the activities cease to have value for the individuals involved. If I do not see the point of an activity, then I will gain nothing from it. H ence paternalism creates the very sort of pointless activity that it was designed to prevent. (...) we [have to] lead our life from the inside, in accordance with our beliefs about what gives value to life' (Kymlicka 1997:204).

That is why we can only propose the good way of life (if we have an idea of what it is) and argue for it (and we need democracy and human rights to do that). We should not impose this way of life and we should accept other ways of life, not because these ways of life are better, but because they are other people's autonomous choices. The good way of life should be led from the inside. It should be a choice, a conviction, not something which is imposed from the outside. What we can impose is a way of life that is compatible with human rights. Remember that autonomy does not imply the right to violate human rights. If we impose human rights, we limit autonomy, but within these limits there is an infinite number of possible ways of life. Even more so: it is only because of human rights that many ways of life are possible.

\section{$\S 173:$ A n A nti-D emocratic D efinition of Freedom?}

Democracy requires self-determination or the ability to decide for yourself on the grounds of a proper understanding of your own interests. As a consequence, the definition of freedom as self-realization can only be a justification of democracy and human rights when:

(1) Many people, in different parts of the world, are convinced that self-realization is important;

(2) Self-realization needs democracy and human rights; and

(3) Self-realization is not imposed on people.

If self-realization or self-improvement is imposed, then it is incompatible with and a threat to democracy and human rights, for several reasons.

Firstly, if self-realization is imposed, then it leads to unity and a restriction of pluralism. Everybody's plan for life is the same and 'inappropriate' ways of life are suppressed because there is only one acceptable way of life. Democracy promotes autonomy or the freedom to shape or determine your own life without discrimination or negative consequences. It also promotes the freedom to argue for and to advertise different conceptions of the good life, but it does not allow people to impose their conceptions. A democracy is neutral and respects many different ways of life which unfold within a protected space, but at the same time it avoids moral relativism or the equivalence of all choices (see the previous Section). The freedom to choose can only have a meaning if some choices are better than others. If all choices were equivalent, then a government which imposes one way of life would not be a problem.

Secondly, if self-realization is imposed, then the will of the people becomes irrelevant because some people impose their will on others. If most people do not or even cannot want what they should want, then a concept such as the will of the people has no meaning. Finally, democracy requires distrust of leaders, whereas imposed self-realization requires blind faith in those leading the people away from ignorance, passion etc. and towards a better and richer life. In the ideology of self-realization, people are believed to be like children who do not know what they should do with their lives or how they 
should develop their possibilities. Like children, they do not know what the 'teachers' plan to do with them. This lack of know ledge makes criticism and judgment impossible.

However, as I have indicated above, there is a certain affinity between self-realization on the one hand and democracy and human rights on the other hand. This is because of the affinity between public life and self-realization. The latter needs and is part of the former (see Section 1). Again we see how freedom needs public life, democracy and human rights. Equal freedom or the equal opportunity for all to engage in self-realization obviously needs a democratic state. Freedom outside of the state is a highly questionable concept.

Democracy and human rights give the largest possible freedom to the largest possible number of different ways of life, but at the same time they provide the necessary instruments for self-realization. However, they do not impose a life of self-realization on all those who are too 'stupid' to recognize the one and only good life, who prefer to curtail their possibilities and who choose a life of pleasure and instincts instead of public life and a life of personal development. Rights and democracy do not force people to make the best of themselves (people who are forced are never the best possible people, because nobody likes to be forced); they merely create the possibility of a life of personal development in the public space, and for this reason they protect the public space, and they even keep aside a certain amount of social resources necessary to preserve works of art, culture, education and other public things which can be used in the process of selfrealization.

Nobody is forced to live a life of personal development, just as nobody is forced to enjoy his or her human rights or to participate in politics (compulsory voting is incompatible with the freedom to choose a way of life and imposes one way of life, namely a life of selfgovernment and autonomy). Everybody is free to choose for example a life of passion and pleasure and to believe that this life is a life of freedom. People who use democracy and rights to live a life of self-realization (for example, a life in the arts or sciences) are not entitled to a greater liberty, to more rights or to other discriminating advantages compared to other people, otherwise we would impair the freedom and equality of other persons (they may, however, be entitled to certain grants that do not harm the equal rights and the equal basic needs of others).

We should avoid interfering in other people's opinions on the good life. We should not tell people how to live and we should tolerate different ways of life. Democracy and human rights protect and enforce this kind of tolerance, but this does not mean that all ways of life are equivalent. However, we can propose and defend a life of personal development and create the possibility of this kind of life, for example because we are interested in other people and concerned for their well-being, their well-being as they see it but also as we see it. ' $\mathrm{H}$ uman beings owe to each other help to distinguish the better from the worse, and encouragement to choose the former and avoid the latter. They should be forever stimulating each other to increased exercise of their higher faculties and increased direction of their feelings and aims toward wise instead of foolish, elevating instead of degrading, objects and contemplations. But neither one person, nor any number of persons, is warranted in saying to another human creature of ripe years that he shall not do with his life for his own ben efit what he chooses to do with it. He is the person most interested in his own well-being' (Mill 1977:1152).

Those who aim at personal development will see it as another reason to accept democracy and human rights. For other people, personal development is not a reason to reject democracy and human rights because a democracy does not impose a duty to develop. Democracy does not impose participation, public life, human rights or personal development, but it does impose the human rights of others. If your way of life implies forfeiting your rights, then you are allowed to lead this kind of life, to the extent that you have a choice and that you are conscious of the consequences of your actions. If, however, this way of life implies violating the rights of others, then you are not allowed to lead this kind of life and your choice of a way of life is limited. 
I have shown in the previous Section that autonomy must not be allowed to contradict human rights and democracy because it needs human rights and democracy. A way of life which violates human rights or which destroys democracy makes the free choice of a way of life impossible because human rights and democracy guarantee this free choice No system can be forced to include the seeds of its own destruction. In some cases, there fore, the state can force people to change their way of life and to respect certain values. Anti-democratic values and values which contradict human rights can be part of your convictions and you can even choose a way of life which is anti-democratic and antihuman-rights, as long as you do not harm the rights of others and as long as you do not try to destroy democracy for others. Anti-democrats retain the right to their private convictions but have to be loyal to the public values of democracy. They can accept this because they know that it is in their interest. Their choice of life also needs democracy and human rights. They will be loyal, not because it is their conviction, but because of practical reasons. In their point of view, the loss of their freedom is worse than the preservation of democracy.

If a political structure is to be accepted by everyone, then it must be build on elements which all people have in common or which all people can accept. It should therefore avoid imposing one way of life. There are many different and often incompatible ways of life and one should find a structure which allows these ways of life to coexist. Imposing one way of life is not only an injustice to other ways of life; it is also self-destructive because many people will not accept this kind of political arrangement.

However, I have al ready shown that political neutrality is not absolute. N ot every way of life is acceptable and political communities can also be destroyed as a result of too much tolerance The importance of tolerating and combining as many ways of life as possible in one political community is not a reason to reduce democracy to a system of procedures without values. This would be impossible anyway, because it would fail to create enthusiasm and support. Connecting democracy and rights to certain values is the whole point of this book. Democracy is compatible with many values - as is evident from my attempt at justification - especially when compared to other systems which often focus on one value only (equality in communism or freedom in liberalism). On top of that, democracy has found ways to make different values and different ways of life exist together in peace (such as tolerance, rights, discussion etc.). This is maybe the strongest defense of democracy.

Imposing a way of life is not the only negative side of self-realization. Developing your possibilities and making the best of yourself can be dangerous if your name is Hitler, for example. A tree that grows - or 'develops' - needs space and often grows at the expense of other trees (van der Graaf 1996:49). Development has to take place with regard for other people. In any case, there is no development without relationships with other people development needs public life and your personality is never your own exclusive product and so development on the one hand and egoism and egocentrism on the other hand are incompatible. You should not try to develop your possibilities at the expense of other people because that would be self-defeating. 


\title{
Chapter 14: Freedom and 0 bedience
}

\author{
Section 32: Unlimited and Limited Freedom
}

\section{$\S$ 174: O bedience to Y ourself (The Law as an Extension of $Y$ ourself)}

As I have shown in the previous Chapter, freedom can only exist together with obedience because only a democratic state with its rules and laws can make freedom possible for all. Obedience to rules opens up the public space in which freedom can develop and it protects people against intolerance, coercion and domination. Freedom is, therefore, not incompatible with power and coercion, contrary to a widespread opinion. This means that the definition of freedom as the absence of coercion and the ability to do as you want is difficult to accept from the point of view of autonomy and self-realization. This kind of freedom is license rather than liberty. It has been described by Hobbes in the following way: 'By LIBERTY, is understood, according to the proper signification of the word, the absence of externall Impediments: which Impediments, may oft take away part of a mans power to do what hee would' (Hobbes 1982:189). This is a negative definition of freedom because it focuses on the absence of impediments, constraints or limits on actions (limits imposed by other human beings, by the state, by nature or perhaps even by our own passions). This definition is believed to be possible only outside of the state and the law.

However, is it possible at all? If everybody can do as he or she likes, then we create offenders and victims rather than free citizens. Victims obviously cannot do as they like. And we can all become victims. Not even the strongest among us can do as he likes, be cause he has to sleep now and again and we are weak when we sleep. Unlimited and lawless freedom as in the definition of Hobbes cannot and should not exist. Freedom is al ways freedom in the state and freedom within the limits of the rule of law.

Of course, freedom does not follow automatically from the coercion of the law. The law must be the right kind of law :

(1) It must protect the human rights of possible victims;

(2) It must protect the public space as a necessary condition for freedom in the sense of autonomy and self-realization;

(3) And it must be the product of the people.

If the latter is the case, then the coercion of the law is the coercion of people over themselves. If people make their own laws, then obeying the law means obeying yourself. And people who obey themselves can be said to do as they like. They decide for themselves and they are autonomous. They do not obey an external force and they are free from external rules and external coercion. The law is an extension and expression of themselves and of their convictions. They obey an internal law. Obeying a law is merely a matter of internal coherence, of being in agreement with their own convictions regarding the actions that can or cannot be done. People obey the law because they can recognize their convictions in the law and they can recognize their convictions because they make the law themselves.

In a democracy, the people find the laws in themselves and agree with the laws which they obey. A law that forbids me to do what my conviction also forbids me to do, does 
not limit my freedom. (I will explain in the following sentences why we need a law as a copy of our convictions when our convictions al ready force us to act in a certain way). " have got to be able to discover my duties in an ethical life which exists independently of me as an individual. On the other hand, if it is to be my duty, it has also got to be something which I can will myself into, so that I take on its own commands as being my own will. O nly then will I find perfect freedom. I will have subjected my volition to discipline so as to elevate it to free obedience' (Harrison 1996:116).

Of course, in a democracy there is always a minimum of external control. Only the majority exercises voluntary self-legislation, self-control and self-obedience because only the majority accepts and desires the law voluntarily. The minority or even individuals longing to the majority can decide to break the law because they disagree with the law, because they do not identify with it or because they have a moment of weakness which disables their self-control and self-legislation and which destroys the identification tween external an internal law. However, their disagreement with the law does not necessarily force them to break the law; they can decide to respect the law because they do not wish to be punished, because they like order and predictability, or because they have an attitude of respect towards the law in general. If they do break the law, then the law is forced upon them, in which case there is coercion and external control. Those who break the law do not obey themselves and cannot do as they like. If we define freedom as the ability to do as you like, then these people are not free. The law does not come from the inside. It is not a part of the people in question and the people do not respect or accept it voluntarily. These people cannot do what they want because they are controlled from the outside. They do not impose their laws on themselves. Other people impose laws on them.

This is necessary because if there is no external control, then rights will be violated. Some people will be victims of others and will not be free, not in any sense of the word. They cannot do as they like and they have no autonomy because their public life is harmed by rights violations. And we can all victims in certain circumstances. Laws and obedience are not just obstacles or impediments, limits on our freedom or elements of oppression. They are prerequisites for public life and therefore prerequisites for freedom as well because freedom needs public life. The laws which exist and which I, as a member of the minority do not accept, do not limit my freedom. They limit the things I can do and the ways in which I can act, in such as way that a public space comes into existence in which my freedom can unfold (A rendt 1994:81), freedom as autonomy, independence and self-realization, but also freedom in the sense of the ability to do as I like. In a situation of lawlessness, I can only do as I like if I am the strongest of all, which is very unlikely. Without laws, there is no freedom, no public life and probably no life tout court. If I accept the law, then I will gain rights, publicity, freedom and survival. If I do not accept the law, then I will only create the freedom of the fox in the chicken-house, and I will probably not be the fox.

The so-called 'constraining rules' are also 'enabling rules'. By limiting certain kinds of behavior, the laws create the possibilities for other kinds of behavior. These other kinds of behavior are part of public life and can result in freedom in every sense of the word. Laws do not only limit the actions of people; they also link the actions of people because they create a public life. And these links make freedom possible. Laws are rules for public life and should not disappear. The state is a mechanism to coerce people, but this is not necessarily negative. On the contrary, coercion creates possibilities. The state creates the prerequisites for public life - such as security, human rights, the rule of law and democracy - and therefore creates the possibility of freedom.

External control must remain a marginal phenomenon in a democracy because selfcontrol and self-government are universally accepted values. There is no individual or popular sovereignty if the majority of the people cannot obey self-imposed laws. A nation which has to obey laws that come from somewhere else - God, the leader, the elite, another nation etc. - is not sovereign and does not constitute a democracy. Of course, obey- 
ing self-imposed rules is not only a prerequisite for freedom. It is also a prerequisite for widespread acceptance and observance of rules, which does not mean that rules that are observed are always good rules.

\section{$\S$ 175: Freedom and the State (A narchism and Liberalism)}

Freedom in every sense of the word - including the freedom to do as you like - needs the state and the rule of law. N atural freedom is therefore a highly contestable concept. It is very unlikely that man lived in a situation of natural and unlimited freedom in those pre historical times in which states or laws did not exist. In those days, man did not do as he liked because there were al ways individuals stronger than him. Other kinds of freedom were also impossible because there was no public life or at least no stable, equally accessible and predictable public life protected by the state and the law. (There is no natural freedom, but there are natural rights. Rights and freedom are not necessarily the same thing, even though the word 'liberties' is often a synonym for the word 'rights').

It is equally unlikely that the disappearance of the state will result in freedom, universal peace fraternity and happiness. A war of all against all is much more likely. The 'chickens' among us need protection and protection is best provided by an impartial third party in order to avoid the spiral of revenge caused by self-defense (see Section 2). This third party is almost always, and perhaps inevitably, the state.

The description of the entry into and the submission to a state as a voluntary surrender of a part of our 'natural' freedom in exchange for protection, security and peace - things that are impossible without a surrender of a part of our freedom - seems to be inaccurate. Of course, the state provides protection, security and peace, but it does not demand a surrender of a part of our pre-political or natural freedom. The state exercises coercion and limits the things we can do in order to allow us to do as we like. Freedom is created on the basis of and after the law. The entry into a state is the foundation and the beginning of freedom instead of the surrender of freedom. The state is the actuality of concrete freedom. (...) Society and state (...) are the only situations in which freedom can be realised' (Hegel in Harrison 1996:114). Only a state, a democratic state to be more precise, can protect the 'chickens', can allow people to do as they like within the boundaries of the law, and can create self-government and a public space in which autonomy, independence and self-realization can become possible. Freedom is situated in the state and in politics.

This means that anarchism or the elimination of the state is incompatible with free dom. A narchists do not accept the state, not even a democratic state, because a democratic state, just like any other state, restricts freedom and exercises coercion and oppression, in the first place but not exclusively with regard to the minority. However, the elimination of every type of coercion will not give us freedom, not even at the basic level of the ability to do as we like.

In this respect, anarchism is akin to a certain kind of liberalism. Liberalism does not wish to eliminate the state altogether, but it does want to keep the state as small as possible. There is no incompatibility between liberalism and the definition of freedom as the ability to do as we like, because liberalism generally does not want to weaken the state to a point at which it becomes unable to guarantee protection and security. However, the kinds of freedom which need the public space - autonomy, independence and selfrealization - may not be safe in the hands of certain liberals. Public and political life - and therefore also self-government and autonomy - need all types of human rights and liberals traditionally support only freedom rights, and perhaps to some extent also political rights. They do not like economic rights, which is understandable once we take account of the fact that their defense of freedom rights is primarily an economic matter.

Liberalism focuses exclusively on freedom in the sense of the ability to do as we like without interference from the state or from our fellow citizens. The name 'liberalism' is therefore somewhat of a misnomer. From the liberal point of view, the state cannot pro- 
mote freedom. It al ways harms freedom because it is no more than a mechanism of coercion necessary to oppress evil, and coercion takes away the power to do as you like. Liberals accept that some freedom is taken away by the state, because they accept that freedom and security need to be balanced against each other. However, both values are as important for liberals, and the state should therefore be kept to a minimum.

Liberals do not acknowledge that the state is a part of public and political life and a part of freedom in the sense of autonomy (autonomy or self-government needs the state, which means that there is something called political freedom and that freedom is more than the sum of extra-political activities). For liberals, the state can never be something positive. It is a necessary evil, 'necessary' because of certain aspects of human nature which have to be suppressed and because of the need to protect people against the acts of other people; 'evil' because it al ways limits people's freedom. All coercion is bad, but some kind of coercion is necessary. If people were always friendly to each other, the state would not be necessary and people would not have to accept a limitation of their freedom. Coercion limits freedom because it forces people to act in a way that is contrary to their wishes. Liberals do accept that coercion can actually promote freedom. Coercing one person and thus limiting his or her freedom, can promote the freedom of other persons, namely the freedom of the 'chickens'. But they do not accept that coercion can promote the kinds of freedom which needs public life. (Coercion can promote other values as well, such as the values realized in public life, because public life needs coercion). Coercion is not necessarily incompatible with freedom, al though it is evident that coercion can take away someone's freedom.

Those who regard the state as a necessary evil also fail to see that the state makes it possible to have a political life and therefore makes it possible to pursue autonomy as well as certain other important values linked to political life. Liberalism tends to see the good life as a life completely outside of the state and politics. However, we need the state both to protect us against other people and to create relationships with other people. We need the state because we need other people. Our freedom, for example, needs other people; not freedom as the ability to do as we like but freedom as autonomy, self-government and self-realization.

In any case, there is also coercion without a state. People coerce each other and take away each other's freedom. State coercion is meant to stop this kind of coercion - this is accepted by liberalism - but is also meant to create the possibility of autonomy and other values linked to public and political life. Anarchism is therefore even less realistic than liberalism. Without state coercion, we are the victims of the coercion of the strongest. Our freedom - freedom in the sense of the ability to do as we like as well as in every other sense - and our other values will suffer. '[W ]hy is avoiding coercion a supreme end that dominates all other ends? What makes noncoercion superior to justice, equality, freedom, security, happiness, and other values? If any of these ends are superior to noncoercion, then would not coercion be justified if it were the sole means in some situations for achieving the superior value? A Iternatively, if one believes that the world of values is not dominated by a single absolute end but is (...) a pluralistic universe, then one must make judgments about trade-offs between coercion and other values' (Dahl 1989:45-6). This is something which is compatible with liberalism, but not with anarchism.

It is obvious that not every kind of state or state coercion is beneficial. A state which coerces in order to steal from the people, for example, cannot promote freedom. Only a democratic state that protects human rights can do so because only such a state can promote security, self-government, autonomy, public life etc. (security depends on a number of human rights, and since all human rights are interdependent and connected to democracy, it is fair to say that security needs human rights and democracy; see also Paragraph 23 and Part 3).

One of the goals of politics is freedom and politics is the only way to protect freedom. Freedom on the one hand and power, politics and coercion on the other hand are not incompatible and one is not defined by the absence of the other. Freedom does not begin 
where politics, the state and coercion stop. Pushing back politics, the state and coercion can diminish freedom instead of increasing it. Freedom from politics may result in the end of freedom. Freedom is not the art of anti-politics. However, freedom and power are not just compatible. Freedom in the sense of autonomy is a kind of power, namely power over your own life. Democracy promotes the autonomy and the power of the people and therefore promotes the freedom of the people.

Liberalism believes that the only way in which the state can promote freedom is by guaranteeing the security of the weak. The state should only protect the weak against the strong. In this way, it makes it possible for the weak to do as they want. For the rest, the state should not do anything and should keeping itself as inconspicuous as possible. It should create an area which is free from state coercion and in which people can do as they like. In a certain sense, liberal liberty is a stateless liberty. The area of noninterference must be as large as possible in order to allow freedom to become as comprehensive as possible. Freedom and politics can only go together because and insofar as politics guarantees freedom from politics (Arendt 1994:79). Liberals fail to see, therefore, that involvement in politics can promote freedom. This involvement results in selfgovernment and self-government is autonomy. Society is more than a limit on politics. It is also a medium for politics.

Contrary to anarchists, however, liberals believe - rightly - that the area of freedom or non-interference cannot be unlimited because this would result in insecurity, chaos and war. The problem is that liberals sometimes consider insecurity, chaos and war as a threat to freedom (the freedom of the weak who can no longer do as they like), but often also as the ultimate expression of freedom. Insecurity is the consequence of our ability to do as we like. This is the reason why absolute freedom is an impossible ideal. Liberals admit that security can justify restrictions of freedom. A part of our freedom must be given up in order to protect our security, no matter how sad this is. Freedom is not the only liberal value.

The problem is that liberals do not understand the different ways in which security and the limits on actions which security requires can promote freedom rather than limit freedom. They accept that security promotes freedom because it allows people do to as they like without the coercion of fellow men. They do not accept that the fact that security promotes public and political life can have a beneficial influence on freedom.

A narchists do not accept limits on freedom, not even a minimum number of limits necessary for security, and consider every state action and every law to be a criminal aggression and an insult to freedom. Every instance of state coercion, every limitation of actions is evil. They believe that unlimited action is beneficial for everybody. The theory of the Invisible Hand is an example of this belief and shows how anarchism and liberalism are connected. Both anarchism and liberalism believe in unlimited freedom. For the former it is an ideal for the future, for the latter it is something which belongs to a perhaps mythical past and which can only be desirable if human beings learn to behave and to respect each others security.

Liberals do not understand freedom correctly, but they are much more realistic than anarchists when it comes to understanding human nature. Moreover, their wish to keep state interference restricted as much as possible is entirely justified. The number of limits on actions should indeed be as small as possible. The power of the state cannot be absolute or unlimited (see Section 2), but the minimum number of limits on actions is much larger than the number of limits necessary for security. Security is not the only value. Poverty as well can impair freedom, even at the basic level of the ability to do as you like. Hence, laws which eliminate poverty can also be acceptable limits on actions. Moreover, reducing the state to something very small and eliminating politics from society as much as we can, can harm political life and freedom in the sense of autonomy, at least as long as we continue to deny the distinction between politics and the state. Harming political life does not only mean harming freedom (in the sense of autonomy and control over our 
lives). It also means harming all the other values which result from political life, such as group life, activity, knowledge, responsibility etc. (see Chapters 3 and 4).

Restricting the state can harm freedom in another way as well. If society, which is free from politics, is ruled by the Invisible Hand, if the economy becomes a self-regulating mechanism impervious to the will of the people, then the people are not free. Freedom in every sense of the word - means having control over your life. You can hardly be called free when you lay your fate in the hands of blind economic forces. You must try to control these forces and political interference is one way of doing this. It is obvious that the extra-political sphere should not be considered as the only strong-hold of freedom. Limiting politics, the state and coercion should not be our only worry. We should also try to make politics compatible with self-government, autonomy and independence and we should try to see state coercion as something which is necessary for our ability to do as we like. However, we should not only try to regulate power on the basis of collective decisions. Everything which determines our lives should be regulated on this basis, and this includes the economy.

$\S$ 176: Limited, Legal and Equal Coercion (Freedom and Equality)

Coercion should be :

(1) Self-coercion when possible, because the ability to shape your own life is a universal value;

(2) Limited coercion - limited in the sense of :

(2a) compatible with human rights, and

(2b) limited to what is necessary for freedom, security and public and political life, because we need a civil society in the sense of a free space beyond the reach of the limited state, a space in which we can realize our freedom on the basis of, for example, a public and political life; this space is both free from state coercion and protected by state coercion;

(3) Legal coercion because a good law is framed in such a way that it is always limited; a law has the added advantage of being predictable, general, equal to all, neutral with regard to persons and compatible with human rights (see Chapter 15 on the definition of a law).

A democratic law generates:

(1) Self-coercion, at least for the majority of the people; and

(2) Limited coercion because:

(2a) At least the majority agrees with the law and does not have to be forced to respect it;

(2b) A democratic law is by definition compatible with human rights (a democracy cannot afford to violate human rights because it needs human rights for its own functioning); and

(2c) A law is limited by definition. Coercion by persons is much more arbitrary than coercion by the law. It tends to be unlimited coercion because the meaning of personal commands is not as well-defined and as stable as the meaning of laws. Personal commands can be anything, whereas a law is what it is. It is written down, in a very specific manner, and it remains the same, otherwise there would be no reason to write it down. A tyrant also coerces, but he coerces in an unlimited way. In general, he does not use laws or if he does, he uses them in an improper way. He does not respect the democratic definition of the law. The meaning of his laws is unlimited, unpredictable and changing. Moreover, his 
laws violate human rights and are aimed at particular groups in society (they are not general or neutral).

Coercion by persons, or the rule of one man or a group of men over the rest of the people, is incompatible with freedom because:

(1) It does not guarantee limited and predictable coercion - only the rule of law can do so (see above) - and it forces people to accept domination and rights violations (rights are necessary in order to be able to do as you like, and in order to be autonomous in a public space); it forces people to submit to the arbitrary rule of another without the protection of a law which is limited, equal for everybody and compatible with human rights;

(2) It does not guarantee an independent and free civil society beyond the reach of a limited state - only the rule of law can do so; and

(3) It does not create autonomy or independence because:

(3a) It does not create a public space necessary for autonomy;

(3b) It is incompatible with self-coercion; and

(3c) It does not create political life and self-government - only democratic participation in a democratic rule of law can do so.

Freedom, therefore, needs democracy, human rights and the rule of law. The rule of people over people does not even create the ability to do as you like because in most cases tyrannical coercion is not meant to abolish inter-personal coercion. It is unlimited coercion for the purpose of material gain, power, domination or whatever, and it leaves interpersonal coercion as it is. In a tyranny, only the tyrant can do as he likes.

However, a tyrant is not more free than his subjects, at least when we consider freedom to be something more than the ability to do as you like. A tyrant does not have access to a public space which is indispensable for freedom in the sense of autonomy or selfrealization. A public space needs the protection of democracy and human rights and is therefore incompatible with tyranny. 'The point of H erodotus' s equation of freedom with norule was that the ruler himself was not free; by assuming the rule over others, he had deprived himself of those peers in whose company he could have been free. In other words, he had de stroyed the political space itself, with the result that there was no freedom extant any longer, either for himself or for those over whom he ruled' (A rendt 1990:31). Freedom in the sense of autonomy, independence and self-realization can only exist among equals because it needs the public space and because all are equal in the public space. Everybody has an equal right to speak and listen in the public space. This shows that freedom and equality are not by definition incompatible.

Freedom needs equality in another way as well. Freedom needs the rule of law and legal coercion is by definition equal coercion. In the rule of law, there are no people ruling over and coercing other people. The law rules over and coerces everybody in the same way. In a situation of inequality, of people ruling and coercing other people - instead of a situation in which nobody rules except the law and in which everybody obeys nothing but the law - there is no freedom, because there is no self-government, no public space and no limited coercion.

Freedom and equality are both very important and often go together. The traditional disputes over the priority of one over the other lose much of their meaning, just as the opinion that equality and not freedom is typical of democracy. It used to be a widespread opinion that freedom is not typical of democracy because freedom can be found elsewhere as well. It is obvious that freedom can be found elsewhere - especially when we limit ourselves to freedom as the ability to do as we like - but then it is al ways a privilege of a minority. Equal freedom can only be found in a democracy which respects human rights. 
Of course, freedom and equality can be incompatible and they can destroy each other. Too much economic freedom for example creates material inequality and that is why there are laws which limit the economic freedom and the property rights of some people (which, in other words, limit the free market) in order to create some more material equality. On the other hand, too much equality can destroy freedom, as for example in communism. The attempt to eliminate differences often makes it necessary to resort to a strong state and to rights violations.

I have tried to summarize the links between freedom and equality in the following table:

Table 3: Freedom and Equality

\begin{tabular}{|c|c|}
\hline \multirow{6}{*}{ 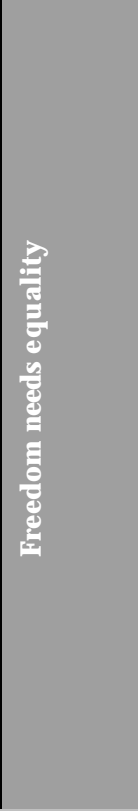 } & $\begin{array}{l}\text { Only in a public space where everybody is equal and where everybody can speak and listen in an } \\
\text { equal way, can we examine our opinions, can we be independent and free from prejudices, habit } \\
\text { etc., and can we engage in self-realization. }\end{array}$ \\
\hline & $\begin{array}{l}\text { Only in a public space can we choose our own way of life because only a public space permits the } \\
\text { examination of the advantages of all ways of life. }\end{array}$ \\
\hline & $\begin{array}{l}\text { Freedom as the ability to realize desires and to control your own life needs democracy, needs the } \\
\text { equal participation of all in common decision-taking (without political equality, there is no free- } \\
\text { dom because one man rules another). }\end{array}$ \\
\hline & $\begin{array}{l}\text { Freedom can only exist within the rule of law and not within the rule of people over people } \\
\text { (freedom needs the public space, the public space needs human rights, and human rights need the } \\
\text { rule of law); the rule of law implies equality, namely equality before the law. }\end{array}$ \\
\hline & $\begin{array}{l}\text { People without sufficient material means cannot enjoy or realize their freedom in any sense of } \\
\text { the word; freedom, therefore needs material equality. }\end{array}$ \\
\hline & $\begin{array}{l}\text { Freedom needs equal rights, because otherwise minorities may not be able to live according to } \\
\text { their chosen way of life. }\end{array}$ \\
\hline \multirow{2}{*}{ 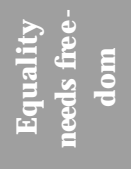 } & The equal ity of public life needs freedom rights. \\
\hline & $\begin{array}{l}\text { Material equality can only be enforced when those who suffer from economic hardship can use } \\
\text { their freedom rights and their political freedom in order to improve their situation. }\end{array}$ \\
\hline \multirow{2}{*}{ 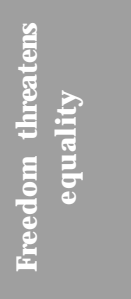 } & $\begin{array}{l}\text { In most cases, economic equality as prescribed by economic rights is not the automatic product of } \\
\text { voluntary caritas or free solidarity. There is no Invisible } \mathrm{H} \text { and. Freedom al one does not guarantee } \\
\text { economic equal ity. Some kind of government intervention is necessary in order to redistribute } \\
\text { wealth. An absolute protection of property - a freedom right - threatens economic equality. }\end{array}$ \\
\hline & $\begin{array}{l}\text { Absolute freedom of opinion and expression makes it impossible to counter incitement to hatred } \\
\text { and discrimination and therefore contributes to hatred and discrimination. }\end{array}$ \\
\hline \multirow{3}{*}{ 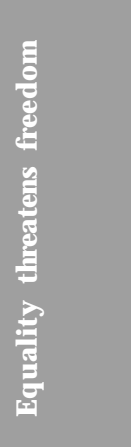 } & $\begin{array}{l}\text { Equality - especially economic equality as expressed in economic rights - needs organization and } \\
\text { government control. }\end{array}$ \\
\hline & $\begin{array}{l}\text { In many countries, the economy - which is biology and therefore equality - is considered to be } \\
\text { the most important goal and therefore an excuse for rights violations. Non-economic injustices } \\
\text { are often readily accepted once people are convinced that these injustices are needed to combat } \\
\text { economic injustices. }\end{array}$ \\
\hline & $\begin{array}{l}\text { The principle of non-discrimination may require limiting the freedom of some, especially the } \\
\text { freedom of expression, for example when certain opinions promote racism or other forms of } \\
\text { discrimination. }\end{array}$ \\
\hline
\end{tabular}


Much of political philosophy is an attempt to answer the following question: how do we promote freedom without stumbling into anarchy, and how do we use power without stumbling into tyranny? If we believe that freedom gravitates towards anarchy, then we assume that freedom is no more than the ability to do as we like and that we should abolish all rules or as many rules as possible in order to protect freedom. However, we know that freedom needs rules and that it can only exist in a democratic rule of law. The question is therefore based on a false understanding of freedom. Freedom, if understood correctly, does not gravitate towards anarchy, on the contrary. If power and coercion gravitate towards tyranny, then we assume that they are evil - maybe necessary but certainly evil - and that we should try to push them back as far as the development of human nature permits. However, we know that rules not only constrain; they also enable. They create a public and political space which can be used for the development of freedom. 
Section 33: Limited Freedom is A nti-Social

\section{§ 177: O ur Freedom is Limited by the $\mathrm{H}$ arm We Can Inflict on O ther People}

The previous Section focused on protection. However, if you need protection, then you tend to see fellow man as a problem, an obstacle, something you try to avoid or some thing you try to defend yourself against. Social life is reduced to unwelcome interference and freedom is reduced to being left al one and left in peace Isolation and withdrawal are the result. Social life is of course much more than people bumping into each other and laws are much more than traffic rules. People influence each other, learn from each other, talk to each other and generally need each other. Public life is precisely the activity in which people let other people into their lives because they see other people as something positive, as an opportunity or an asset instead of a problem. Shields are incompatible with public life. Shields can therefore harm freedom because public life promotes freedom. People accept a state for more reasons than security and non-interference They know that they need the state as a system in which they can enjoy publicity and autonomy.

We can find the same anti-social disposition in the definition of freedom as the ability to do the things we like with the exception of those things which inflict harm on other people or which reduce other people's freedom. The only freedom which deserves the name is that of pursuing our own good in our own way, so long as we do not attempt to deprive others of theirs or impede their efforts to obtain it' (Mill 1977:1112).

Ideally, we would like to have unlimited freedom, maybe even the freedom to damage other people if this would serve our interests or 'our own good'. However, we do not want other people to have the same unlimited freedom to damage us, and therefore we accept laws which limit our freedom to do as we like and to damage others, on the condition that everybody else does the same. 'La liberté consiste à pouvoir faire tout ce qui ne nuit pas à autrui: ainsi, l'exercice des droits naturels de chaque homme n'a de bornes que celles qui assurent aux autres membres de la société la jouissance de ces mêmes droits. Ces bornes ne peuvent être déterminées que par la loi', art. 4 of the D éclaration des droits de I'homme et du dtoyen of 1789 (Rials 1982:5).

This means that the freedom of one person can be the unfreedom of another person. One person's free actions can harm another person's freedom. The freedom of the latter requires limiting the freedom of the former. This is enforced by the state which operates as a kind of zookeeper or traffic controller and which limits our freedom to do as we like. Indeed, freedom is not an inviolable principle, at least freedom in the sense of the ability to do as we like. The unlimited freedom of one person can be incompatible with the freedom of another. If my assailant can do as he likes, than I can no longer do as I like. Freedom, therefore, has to be limited. If someone is harmed by a free act of someone else, then this act should not be considered as a legitimate exercise of freedom. Freedom can be misused, in which case it should no longer be called freedom. It should then be limited by government rules. The freedom of many individuals has to be made compatible. The freedom of one must be limited so as to be able to coexist with the freedom of another.

It follows that freedom can only be limited when it harms someone else or someone else's freedom. Behavior which does not harm other people can never be limited and the state should not interfere with this behavior. This behavior is part of the right to do as 
you like, even if you harm yourself because of the way in which you behave. The state should not try to protect people against themselves (at least in most cases). Freedom includes the ability to do the wrong things and to make the wrong choices, as long as these choices do not harm other people.

This definition of freedom is of course preferable to the definition of freedom as the ability to do as you like. However, we can criticize this definition in roughly the same way. Rules and laws do not only limit freedom; they create freedom because they offer people the ability to do as they like - without rules, only the strongest have this ability and because they create a public space in which other kinds of freedom can unfold. In many cases, rules are prior to freedom and therefore cannot limit freedom. Furthermore, fellow man is seen as something negative instead of something positive. I will now explain this in more detail.

\section{$\S 178:$ The Value of Our Fellow M en}

If freedom is limited by the freedom of others and by the things which can harm others, then my fellow man is the border of my freedom and is therefore something negative. I can only protect my freedom or my ability to do as I like, by avoiding other people as much as possible, by withdrawing from society and by becoming self-sufficient. Freedom is isolation. The more you avoid other people, the less restricted are your actions, and your freedom increases together with the disappearance of restrictions. The more you avoid people, the more free you are. If you avoid people, then no one stands in your way, no one interferes with your life, no one impedes your actions or prevents you from doing something, and no one's freedom limits your own freedom. No one makes claims on your property or your physical powers, and everyone leaves you in peace You can only do as you like when you leave the community and when your actions are no longer limited by other people's actions or by other people's freedom.

If we understand freedom as the ability to do everything, with or without the things which harm other people, then we isolate people. 'The limits within which each individual can act without harming others are determined by law, just as the boundary between two fields is marked by a stake. It is a question of the liberty of man regarded as an isolated monad, withdrawn into himself' (Marx in Tucker 1978:42). This kind of freedom, contrary to autonomy and self-realization, 'is not founded upon the relations between man and man, but rather upon the separation of man from man. It is the right of such separation. The right of the circumscribed individual, withdrawn into himself' (Marx in Tucker 1978:42). Fellow man is merely a limitation or a restriction - the only legitimate restriction of my freedom - and not harming him is the only thing I do for him.

This kind of freedom is incompatible with public life because it is incompatible with relationships and communication. It separates and isolates individuals. It is extremely individualistic and even egoistic. It is difficult to see how it can be compatible with freedom in the sense of autonomy, independence and self-realization because these kinds of freedom need the company of others. Limited freedom 'leads every man to see in other men, not the realization but rather the limitation of his own liberty' (Marx in Tucker 1978:42), whereas autonomy, independence and self-realization are types of freedom which need other people and public life with other people, and which can only exist in the midst of other people. Limited freedom forces us to see other people not as necessary conditions for our freedom but as restrictions of our freedom. It makes us think of other people as the end rather than the beginning of our freedom. It is an inner freedom, a freedom in an inner space in which we can escape the coercion of the outside world, in which nobody can intrude and in which our actions, thoughts and will are protected against other people.

This extra-social character of limited freedom makes freedom in any other sense than the ability to do as you like, impossible. Limited freedom makes us forget that the world of appearances is of the utmost importance to freedom. Freedom is more than a with- 
drawal from the world, from the threatening world of other people who do not allow us to be free and who limit our actions, either voluntary as a consequence of their own actions, or involuntary as a consequence of our respect for their freedom. Freedom is more than the experience of some inner power such as the will or thinking. It is also our life in the world, in the public world. Freedom is made real by way of interaction with other people. Interaction with ourselves - such as in thinking or willing - is not enough. This means that freedom is not something purely individual. If we try to flee the community in order to free ourselves from the evil of others, then we may lose our freedom instead of gaining it.

The advantage of limited freedom is that it is by definition an equal freedom. The freedom of one is not more important than the freedom of another. Freedom is distributed in an equal and fair way because the freedom of one is not allowed to harm the freedom of another. The freedom of one is limited by the equally important freedom of another. So it looks like a very 'social' kind of freedom which takes the equally important interests of other people into consideration, but it is really an anti-social kind of freedom. The existence of only one individual on earth would mean the perfect realization of this kind of freedom (the same is true for unlimited freedom as discussed in the previous Section). '[This] conception of liberty keeps men free only by keeping them apart and thus, ironically, prepares them for the more tyrannical forms of community' (Barber 1984:99) because a tyranny needs isolated individuals. Individuals who can form a community can become strong enough to resist.

It is of course important not to harm other people or other people's freedom, but this does not imply that we need to stumble into isolation, egoism or egocentrism. In Section 31, I have pointed out the importance of not forcing people to live the kind of life we deem best and there as well I have suggested that we do not need egoism in order to avoid the pitfalls of extreme altruism. Furthermore, there is a whole world of communication, cooperation and conflict between the extremes of not harming people and forcing people to live a certain life. Security and protection are indeed important, but they should not be the only objectives of politics. Communication, conflict and other aspects of public life are just as important and security can be a means for these other objectives.

\section{§ 179: N egative and Positive Freedom}

Freedom is not only negative freedom, just as human rights are not only negative rights. Rights are more than just a protection against something or someone. And freedom is more than abstaining from something (as in limited freedom) and more than the absence of impediments (as in unlimited freedom). We have to struggle against impediments and we should avoid inflicting harm on people or interfering in their ways of life, their choices, their opinions and their freedom, but freedom in any substantial meaning of the word also requires some kind of positive action. Negative freedom - 'freedom from', not doing something or the absence of something (harm, limitations, interference etc.) - is not enough. We also need positive freedom, 'freedom to', the freedom to do something with other people.

You need the company of other people in a formalized and structured public space protected by the state if you want to take your life in your hands, if you want to examine your opinions in order to become independent, if you want to choose a way of life and if you want to improve yourself. The state guarantees public life and public life guarantees freedom in the sense of autonomy, independence and self-realization. The state is more than a set of rules and instruments to enforce rules. It is also a structure in which you can participate, in which you can determine the conditions which govern your life, in which you can establish relationships, communities, identities etc.

Every kind of negative freedom - freedom from coercion, limitations, harm or interference, freedom from chains or external impediments, freedom outside of politics etc. - implies the absence of something but also the absence of other people. Other people can 
coerce me, can invade my space and security and can limit the things I can do. Negative freedom makes it very difficult to appreciate the true value of relationships.

Negative freedom in the sense of the freedom to do what we want without harming other people can be self-destructive. If we do not interfere with people who are starving and if we avoid harming them, then we do not protect their freedom. These people cannot do what they want and they do not have a choice They do not have the freedom to do any thing apart from trying to stay alive. More government can mean more freedom because the government can assume the responsibility which is rejected by citizens who back away from interference The more choices, the more freedom. By giving food to people, the government gives the people more choices and therefore more freedom.

Negative freedom is also compatible with tyranny. As long as the citizens do not wish to interfere in politics, a tyrant can decide to grant them a relatively large space of negative freedom in which he promises not to interfere and in which people can do as they like. Negative freedom certainly does not imply self-government or democracy. Selfgovernment or autonomy is the ability to shape your life in a certain way and to control your life, and is definitely not negative. N egative freedom is concerned with the problem of the size of power and of the area in which power interferes, not with the problem of who exercises power (Berlin 1996:50). However, this is also self-defeating because without political participation, there is no control of the state. As a consequence, the state can al ways limit the things which the people are allowed to do. The people can no longer do what they want.

Of course, I do not wish to claim that negative freedom is unimportant. People wish to do as they like with a minimum of limitations and interference. They wish to be able to pursue a wide range of objectives, as many as possible, without discrimination or punishment (with the exception of those objectives which impede the objectives of others). They rightly consider this as a kind of freedom. Human rights are justified because they guarantee this kind of freedom (see Section 2).

In addition, people do not wish to be harmed by the freedom of others or by the lack of limits on actions. Some actions or objectives have to be suppressed. A gain, human rights are justified because they provide security and protection against harm (see also Section 2). However, negative freedom is not sufficient for most people because most people also want autonomy, self-government, independence and other kinds of positive freedom. Again, human rights and democracy are justified because they guarantee these other kinds of freedom without imposing them (see Chapter 13). The problem is, of course, how democracy can make negative and positive freedom compatible. Different definitions of freedom can contradict or impair each other and democracy has to strike some kind of balance between both. I necessary, one kind of freedom must be limited for the sake of another. 


\section{Chapter 15: The Choice Between Freed om and the D ictatorship of the $M$ ajority}

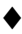

Section 34: $\quad$ Power Struggle and Struggle in Society, Version

2

\section{$\S 180:$ A Separation of Independent Powers}

A nother definition of freedom is the ability to enjoy civil rights, also called civil liberties or freedom rights. Implicit in most freedom rights is a conception of freedom as the ability to do as we like without limitation or interference (think as we like, speak as we like etc.). I have already discussed the way in which an ideal democracy promotes freedom rights (see Chapter 3), but I will discuss it in more detail in this Chapter.

However, the allegation is that democracy does exactly the opposite. The problem with democracy is not the majority. The majority will probably not take decisions which harm its own freedom rights. The problem is the minority. According to some, democracy does not or even cannot protect the freedom rights or the freedom of the minority (freedom in the sense of the ability to do as you like). There is nothing in the system of majority rule which opposes rights violations. A democracy destroys the freedom of the minority be cause it is necessarily a dictatorship, namely the dictatorship of the majority over the minority. The majority may be free, but the minority certainly not. The minority does not only lack control over its own life; it also suffers violations of its rights and 'liberties' by the majority.

The traditional solution to this problem is to grant priority to human rights. Democracy and majority rule come second and are confined by human rights. Some even propose an aristocracy which is said to be better able to govern in the light of the general interest - the majority always governs in its own interest - and which is supposed to be a better guardian of the rights of all citizens.

However, these solutions introduce a contradiction between democracy and human rights, whereas I have shown that democracy and human rights need each other. In order to understand that this contradiction is a false problem, we need to understand that democracy is much more than just a system of majority rule. An ideal democracy can guarantee that the rights or freedoms of all - including the members of the minority - are protected and that the application of these rights is controlled and enforced when necessary. It can do so because it applies the system of separation of powers. This system limits the power of the majority. Majority rule without a separation of powers would indeed lead to violations of the rights of the minority because the decisions of the majority would be applicable without further ado. The majority would be entirely free to decide as it likes and would tend to become dictatorial.

Human rights are just as important to democracy as majority rule and in order to protect and enforce the human rights of the minority (or the rights of the majority for that matter), democracy needs to have a separation of powers. It must be possible to have one power inside the state - for example the judiciary - able to rebuke another one - for example the legislative power - if this other power violates human rights. There is no democracy without a combination of majority rule, human rights and separation of powers.

The theory of the separation of powers traditionally differentiates between three branches of power, the legislative power (parliament), the executive (the government, the admini- 
stration and the police) and the judiciary. Separation of powers means independence of powers with regard to each other. The three powers are separated and divided organizations of the state. No power can assume the competence or functions of another power or can interfere with another power's business (Schmitt 1993:187). A few examples:

(1) The executive should not vote laws (the so-called 'government by decree') and should not appoint judges;

(2) The legislative power should not appoint or dismiss the government or the head of the executive (this should be a prerogative of the people) and should not be allowed to give a judicial verdict on a case involving the acts of government officials;

(3) The judiciary should be able to work without political interference from the legislative power or from the executive, and should be able to judge cases in an independent and impartial way (the judge should not be an instrument of politics or a 'political worker' who executes the decisions of the executive, as was the case in Soviet Russia for example; he is subject only to the law and the law, contrary to an order by Comrade Stal in for example, cannot be used to influence verdicts because it is general and neutral);

(4) Judges should not interfere in legislation or politics (they enter the stage when the work of politics is already accomplished; they apply the law as it is voted by the legislative).

\section{$\S$ 181: Limited Independence}

However, this is not the end of the story. Independence does not mean that a power can do as it likes without accountability. The independence is limited because one power can control, correct, rebuke, limit or stop another power if there is an abuse of power or a violation of rights (Schmitt 1993:127). Some interference is necessary. Separation does not mean isolation. If all power is concentrated in the same person or institution, then this power cannot be checked. There is no higher power than the state and hence the state must control, limit and correct itself (the 'international community' is still very weak). If power has to limit itself, then it has to be divided into different parts. There must be powers and counter-powers, checks and balances. Every power moderates the other powers because every power holds the reins to force the other powers in a certain direction. The citizen must be able to go to one power in order to claim redress or compensation for violations of rights by other powers. Power protects against power and power can contradict power.

Violations of human rights by one part of the state must be corrected by another part, otherwise human rights remain words without reality. Judges can control the laws of the legislature and the actions of the executive. If they find that these laws or actions are incompatible with the human rights included in the constitution or in an international treaty, then the judges can declare these laws to be invalid or these actions to be unlawful, even if these laws and actions are supported by a democratic majority (which is normally the case in a democracy). The power of the legislative, the executive and the majority is limited. The judiciary makes sure that both the legislative power and the executive act according to the highest law of the land, which is, after all, also an expression of the will of the majority (at least in an ideal democracy, because an ideal democracy allows the citizens to vote on the constitution and on international treaties). Human rights and the constitution can be used against the legislator in order to counteract the tyranny of the majority (also known as democratic oppression). The legislator can be wrong and laws can be oppressive. The law is more than just the will of the legislator. A valid law has to conform to certain requirements at the level of content, independently of the will of the legislator. A law cannot be anything, otherwise the rule of law would be a meaningless concept. 
I mentioned in the previous paragraph that the judiciary should not interfere with politics or legislation. However, is judicial review not a part of legislation? Controlling and invalidating laws, overruling the legislative power by way of a veto-right, creating a certain coherence in legislation, making sure that ordinary laws conform to the higher law (the constitution), is this not legislation? And is it not legislation enacted by a nonelected minority which imposes its will on the majority of the people as it is represented in the legislative power, and which takes its decisions outside of the public debate? Should not an ideal democracy reject judicial review? In other words: is it not impossible for an ideal democracy to protect the rights and freedoms of the minority?

These questions are based on a false hypothesis. When a judge controls the conformity of an ordinary law and a higher law, he does not engage in legislation. He only makes sure that the higher law is strictly applied. And as the higher law is the supreme expression of the will of the people - in an ideal democracy, the people can vote the constitution - he only makes sure that the will of the people is strictly executed. There is nothing undemocratic about this and it has nothing to do with legislation. A judge who is confronted with a law which contradicts the constitution cannot apply this law because otherwise he would be acting in an unlawful manner. The higher law has priority over the lower law. A lower law has to conform to the higher law; otherwise it is invalid and nonexisting, 'null and void'. A judge can declare the illegality of a law and can destroy a law without engaging in legislation.

The judge remains subject to the law and does not put himself above the law or above the legislator when he invalidates a law. He remains subject to the higher law. Judicial review does not imply that the judiciary is more important or more powerful than the legislative power or than the will of the people. It only implies that the higher law is more important than the lower law and the higher legislator is superior to the lower legislator. Judicial review does not imply an exaggerated or a predominant political or legislative role for the judiciary compared to the role of the legislative power, at least as long as we consider the framing of a constitution to be part of the legislative power. A judge can never decide on fundamental social problems or political conflicts. He can only apply the law, first the higher law and then the lower law.

Human rights ' possess a threefold significance: they are themselves standards of behaviour; they constitute criteria for assessing the lawfulness of other rules (since they override all other norms, which are null and void in case of conflict); [and] they embody 'instructions and guide lines' (...) for the creation and development of other rules' (Cassese 1992:113). Individuals can coerce the state - even though most of the time it is the other way around - but only on the condition that there is a separation of powers and that one power can be used against another.

However, this means that judges should not be appointed by the legislative power or by the executive, otherwise we run the risk of having a body of judges which is predominantly in favor of one political party. These judges will then be tempted to review the laws from one and the same political perspective. If the judiciary is predominantly conservative, for example, then it will treat liberal laws in a very critical way and it will tend to systematically invalidate these laws because of their conservative interpretation of the constitution (something like this often happens in the USA, for example). Judges must be politically independent.

It is probably just as wrong to allow the people to elect the judges. Judges have to be independent from the will of the people as well, because this will can contradict the constitution and may have to be corrected. The will of the people is allowed to contradict the constitution, but then it has to create a new constitution. In day-to-day business, it has to conform to the constitution. Election campaigns force judges to take sides and to give up their neutrality. Peer-selection seems to be the best way to appoint judges.

Judicial control of the constitutionality of laws and government actions is only one example of a power limiting another. These are some other examples: 
(1) A judicial verdict applies the law and is therefore dependent on the law (a judge cannot decide what is contrary to the law, which means that the legislator de facto limits the actions of the judiciary);

(2) The executive is accountable to and is controlled by the legislative power (it has to give account of the way in which it has applied the laws; however, the legislative power cannot dismiss the government as a consequence of this control, at least as long as the government is directly elected, which is the case in an ideal democracy);

(3) A president who is engaged in a conflict with parliament can dissolve parliament and can organize a referendum on a law voted by parliament, on the condition that he or she is directly elected and in certain cases only (a so-called 'appeal to the people' is sometimes necessary in order to safeguard the rights of the people or in order to remedy some of the deficiencies of the representative system);

(4) A president often has a veto-right and can block certain laws voted by the legislative power (this is acceptable on the condition that the president is directly elected).

\section{$\S$ 182: A D emocratic Court of Justice?}

As I have already indicated, the judiciary seems to be the only power that is impervious to democratic principles. Hierarchy is a fundamental aspect of the judiciary. There is aways one person - the judge - who is above the parties and who can take a decision that is binding and authoritarian. On top of that, expert knowledge seems to be more important in the judiciary than in the two other powers.

The jury-system may be a solution and may also be beneficial to the citizens who take part in it. 'Le jury, et surtout le jury civil, sert à donner à l' esprit de tous les citoyens une partie des habitudes de l'esprit du juge; et ces habitudes sont précisément celles qui préparent le mieux le peuple à être libre. II répand dans toutes les classes le respect pour la chose jugée et l' idée du droit. II enseigne aux hommes la pratique de l'équité. II revêt chaque citoyen d'une sorte de magistrature; il fait sentir à tous qu'ils ont des devoirs à remplir envers la société, et qu'ils entrent dans son gouvernement. En forçant les hommes à s'occuper d'autre chose que de leurs propres affaires, il combat l'égoïsme individuel, qui est comme la rouille des sociétés. A insi le jury, qui est le moyen le plus énergique de faire régner le peuple, est aussi le moyen le plus efficace de lui apprendre à régner' (Tocqueville in Leleux 1997:202).

\section{$\S$ 183: Power Struggle and Struggle in General}

The separation of powers is necessary to protect human rights. It therefore promotes public life and freedom in an indirect way. However, it also promotes social struggle and conflict and it therefore promotes public life in a direct way as well, because struggle and conflict are part of public life. The open and visible separation of powers is in fact a struggle between powers. In Section 5, I explained how power struggles - at that moment I limited myself to election struggles - promote social struggles. Power struggles can symbolize social struggles in general and can therefore create a kind of decompression of society. If the people see how even power and the state divide themselves and how the different parts contradict each other - for example the judiciary opposing the laws voted by the legislative power - then contradiction and struggle in general become more acceptable.

\section{$\S 184:$ Separation Inside the D ifferent Powers}

On top of the ordinary separation between three kinds of powers, there has to be some kind of separation inside the different powers. This internal separation also serves the 
purpose of control and limitation. The legislative power, for example, is often divided into two parts, an Upper House and a Lower House or a House of Representatives and a Senate. This division makes it possible to correct mistakes made in one House. One House can slow down or stop another House when some decisions are too risky or are taken without the necessary reflection or discussions. This system 'doubles the security to the people by requiring the concurrence of two distinct bodies in schemes of usurpation or perfidy, where the ambition or corruption of one would otherwise be sufficient' (Hamilton/Madison/ Jay 1954:119). Again, this division of powers guarantees the decompression of society and creates pluralism instead of conformity and unity.

If we expect two houses or chambers to control and correct each other, then the participants of both must be selected in different ways. This does not mean, of course, that one of them has to be formed in an undemocratic and unrepresentative way, as is often the case. There is, for example, no place for hereditary privileges in a democracy. The purpose of the division within the legislative power is not the protection of old and privileged classes against the up-and-coming masses of ordinary people. The argument that a hereditary chamber creates continuity as opposed to the ever changing composition of a truly democratic chamber, is a bit feeble.

If there has to be a separation and a difference in composition, then maybe we should take advantage of the occasion and make sure that a second chamber contains some kind of expertise and experience (which is another argument against hereditary representation because there is no better way to select fools than to select people on the basis of their family relations). This kind of 'knowledge-chamber' does not have to be undemocratic by definition. We can for example limit the power of this chamber by allowing only a vetoright or an advisory function (and a right of the first chamber to overrule the veto or the advise by for example a two-thirds majority, which would give an added protection to the minority), or we can mix democratically elected and appointed representatives in one and the same chamber. A system of guaranteed representation of minorities can also be applied in a second chamber. Minorities may need this in order to protect their rights. In a federal system, the second chamber is often composed of representatives of the 'states' or the regions who thus dispose of an instrument to protect their interests. This is an especially effective way to protect minority rights.

A nother example of a separation inside a power is the possibility to have a case reviewed by a higher court. Mistakes by one judge can then be corrected (including judgments which violate human rights and the constitution; there is a kind of judicial review inside the judiciary as well). Sometimes, there is also a division within the executive. The government and the president can limit and correct each other's actions. An example is the requirement of a second signature.

\section{$\S$ 185: Separation of Powers in a Federal System}

In a federal system, there is an additional separation of powers, namely a separation be tween the level of the states or the regions on the one hand and the level of the national government on the other hand. The competence of one level is by definition different from the competence of the other level. Normally, one level cannot interfere in the business of the other. Only in very specific cases can one level overrule the other level. Both levels can limit each other. Citizens who feel that they are treated in an unjust manner by one level, can always appeal to the other level. 'The different governments will control each other at the same time that each will be controlled by itself' (Hamilton/ Madison/ Jay 1954:75). 


\section{Section 35: The Rule of Law is Limited by Equality Before} the Law

\section{$\S$ 186: A Law is General, A nonymous and N eutral}

The rule of law, contrary to the rule of men, is believed to be the best way to avoid oppression and rights violations, and rightly so (see Sections 2 and 32). However, the rule of law can result in oppression because a law can allow or even force people to violate rights and to harm other people in such a way that they are no longer free (e.g. that they can no longer do as they like). Governments can frame laws in such a way that they can use them for the purpose of domination. The rule of law can be a cover for and an $\mathrm{ex}-$ pression of the rule of man over man. People can use laws to harm other people. A dictatorship can give the impression of respecting the rule of law by functioning according to laws and by using laws to oppress people. Respecting the law is clearly not enough. There is something called legal injustice, legal oppression or legal dictatorship. This feature is (...) apparent in countries like Peru and Colombia, where special courts and draconian anti-terrorist legislation has led to the expedient trial of thousands of alleged 'subversives', many of whom are not members of armed opposition groups. This has led to a new twist in those countries' pattern of human rights violations. While in the 1980s 'disappearances' and 'extrajudicial executions' were the most usual means of getting rid of alleged subversives, the 1990s witnessed an increase in the number of prisoners of conscience, condemned by special courts and anti-terrorist legislation which fell well short of international standards for fair trial' (Panizza in Beetham 1995:183-4). Positive law is no guarantee for freedom or for the absence of oppression, not even if the law is the product of the will of the people. A democracy as well can vote oppressive laws. The separation of powers is not enough either. If there is no higher law which protects human rights, then the courts cannot invalidate oppressive laws or laws which violate human rights.

There is only one solution to this problem. We have to define the words 'law' and 'rule of law' in a very specific way - in a specifically democratic way - and enforce respect for this definition by way of a verdict of a judge. A democratic law has four characteristics:

(1) A law is voted by the people or by representatives of the people;

(2) A law is compatible with human rights;

(3) A law is reviewed by a second legislative chamber and by independent judges on the basis of the human rights contained in the constitution (the rule of law requires the separation of powers);

(4) A law is equal for all and all are equal for the law.

A democratic rule of law has, therefore, the same characteristics. A system which enforces rules and prohibitions by way of laws, but:

(1) Does not allow the people or their representatives to vote the laws;

(2) Establishes laws which violates human rights;

(3) Does not include subsystems such as bi-cameralism or the separation of powers; and

(4) Establishes laws which are not equal and general,

cannot be a democratic rule of law. 
We can only have a proper democratic law and avoid oppression, rights violations and limits on the freedom of all citizens if the four characteristics of a democratic law are combined. Without a democratic law and a democratic rule of law, we cannot protect rights and freedom, certainly not the rights and freedom of the minority. If we understand a right to be the ability to do as we like - speak as we like, think as we like etc. then we can safely say that only a democratic law and a democratic rule of law can protect freedom in the sense of the ability to do as we like. Other kinds of laws - undemocratic laws or misconceived democratic laws - may very well be oppressive and incompatible with rights and freedom. Although the separation of powers and the rule of law or better a rule of law - can exist in non-democratic regimes, I believe that only a democratic regime which respects the democratic definition of the law, the separation of powers and the other principles of the democratic rule of law can defend human rights and freedom. I have discussed the reasons why rights and freedom (freedom in the sense of the ability to do as you like) need a separation of powers in the previous Section. There fore, I will now the other reasons why I believe that rights and freedom need a democratic definition of the law and the rule of law. There are four such reasons:

(1) In a democracy, a law is voted by the representatives of the people and the people can always elect other legislators if they believe that their current legislators vote laws which harm their rights. This is not, of course, a solution for the minority. The majority can still vote or approve oppressive laws directed at the minority. The consent of the majority is not enough; it is only one of four characteristics of a democratic law. This first characteristic cannot guarantee the protection of everyone's rights and freedom when regarded in an isolated way.

(2) That is why a democratic law must conform to a second requirement as well. It must be compatible with human rights as they are included in the constitution (see Section 34). The law, even if it is accepted or voted by the majority of the people, cannot be everything this majority may desire. That is why the Déclaration of 1789 and the French constitution of 1791 mention first that the objective of the state is the protection of human rights (art. 2), and only then declare that sovereignty resides with the people (art. 3). By determining the objective of power, one also determines the limits of power.

(3) On top of that, there is the requirement that a democratic law is decided by two legislative chambers. A second chamber can compensate for the precipitation or the mistakes of the first chamber. It can soften the will of the majority of the people; it can suggest some deeper thinking and hence it can give some added protection to the rights of the minority or the rights of the regions (the 'states'). The minorities or the regions can also have some kind of privileged representation in the second chamber. However, if the power of such a second chamber is too important, then we may have the opposite problem, namely the minority which imposes its will on the majority. This can happen when for example a majority of states opposes national legislation giving equal rights to colored people. These states can represent a minority of the national population, but may still be able to block this legislation because the states in question have a majority in the second chamber as a consequence of privileged and disproportional representation, for example one representative for each state, irrespective of the size of the states.

(4) A fourth and last requirement: democratic laws have to be equal for everybody. All citizens are equal before the law 'and are entitled without discrimination to the equal protection of the law. In this respect, the law shall prohibit any discrimination and guarantee to all persons equal and effective protection against discrimination on any ground such as race, colour, sex, language, religion, political or other opinion, national or social origin, property, birth or other status' (art. 26 of the ICCPR). A law cannot favor or harm a particular group or particular interests. It can only favor or harm everybody in the same way. It has to be neutral with regard to persons. In an ideal democracy, the legislator cannot 
make a law against or in favor of a particular person or group. A law should never apply to a limited group of people and should never treat people in different ways. It should by definition be general. The same laws apply to everybody in the same way, including the legislator. This means that a legislator will think twice before voting or accepting an oppressive law. The law must be the same for everybody and everybody must be the same for the law (this implies a right to legal assistance in court procedures). This neutrality is a requirement for both the content and the application of a law. A neutral law can still be applied in a selective way. Breaches of the law can be prosecuted or punished in an unequal and discriminatory way (take for example the demography of 'death row' in the USA). As in the second characteristic of an ideal democratic law, this fourth characteristic limits the possible meanings or contents of a law. A law cannot be anything. A judge can invalidate a law which does not respect the equality before the law (as in the second characteristic). This equality is a human right (see the citation above) and must be included in the constitution. A law which does not respect this equality is therefore unconstitutional and invalid. That is why there must be judicial means to enforce the definition of the law.

This definition of the law, made up of four elements, makes it impossible for a legislator for example the majority of the people - to claim that his or her will - whatever it is should always and in every case become the law. It makes legal and democratic oppression impossible. The sovereignty of the people, the ability of the people to do things, is not absolute or unlimited (unlike the sovereignty of the king in early modern times). It is limited by the definition of the law and the definition of the rule of law (which includes also the separation of powers). The will of the people or the will of the majority of the people can be limited and frustrated, and this can only be considered as undemocratic if democracy is defined as nothing more than a system of majority rule. If there are no limits on the possible meanings of a law and no limits on what can be considered as the rule of law (limits such as the separation of powers), then the will of the majority, as expressed in a law, can violate the rights and harm the freedom of the citizens belonging to the minority.

The majority cannot decide anything it wants, cannot impose whatever it wants on the minority. There are certain things one cannot do to people. N ot even the majority can do these things, not even the entire people minus one (B. Constant in Leleux 1997:166). ' $M$ en have been found to resist the most powerful monarchs and to refuse to bow down before them, but few indeed have been found to resist the crowd, to stand up alone before misguided masses, to face their implacable frenzy without weapons and with folded arms to dare a no when a yes is demanded' (Clemenceau in Arendt 1979:114). The voice of the people is not the voice of God. The majority must be blocked if it fails to take the rights and the freedom of the minority into consideration.

The fact that the rights and the freedom of the minority are guaranteed, whatever the decision of the majority, makes it easier for the minority to accept this decision. Another fact - the minority can become the majority and can change the current decisions, provided it uses the best arguments - also makes it easier for the minority to accept majority decisions (just as a majority can accept becoming a minority because the loss of power does not impose a physical risk, as it does in some non-democratic regimes). We should not consider members of the minority simply as outvoted individuals who are powerless and who have to accept everything. The minority has the power to block the majority if this majority intends to harm its rights and freedom.

Rejecting democracy because of the tyranny of the majority is therefore a bit rash. A democracy is much more than the unconditional rule of the majority. Accepting democracy means more than submitting to the majority. The consent of the majority is not enough to have a valid democratic law. If there is a problem regarding the behavior of the majority, then we need more democracy instead of less. In an ideal democracy - a democracy in the full sense of the word - the minority and even a lonely individual can claim their rights 
against the will of the oppressive majority. Democracy is doomed without human rights (see Chapter 3), and so it has every reason to protect human rights. As human rights are equal and universal rights, it is very dangerous to disregard a single violation of the rights of a single individual, because that would destroy the whole philosophical basis of human rights in general. It would question the fact that human rights are equal rights. It would also, in the end, destroy democracy.

An oppressive majority can never represent a democracy. The people are the source of the law, but not of any law and not of a law without the proper definition of the word. They are the source of the law but at the same time subject to the constitution and to the law of the law. The people are not above or outside of the law, if only because the will of the people can only be established and expressed by way of the human rights included in the constitution. Human rights are prior to and therefore above the will of the people. If the majority would violate rights, then it would destroy the conditions for its own existence because it would destroy the prerequisites for the creation of the will of the majority.

\section{$\S$ 187: The Balance Between Political Rights and Freedom Rights}

The difference between political and freedom rights is a bit artificial because in certain circumstances, freedom rights become political rights and because political rights need and at the same time guarantee freedom rights (see Chapter 3). However, the difference is important. Too much attention to political rights can harm freedom rights and vice versa.

Too much attention to a democratic right such as the sovereignty of the people can harm the freedom rights of some because the people can decide to violate rights. On the other hand, too much attention to freedom rights can incite or even force people to lead an exclusively private life in which there is no room for public and common discussion on common problems and solutions, on the general interest and on the best way to organize social life. These things are then left to others. It leads to a situation in which people can only see their individual rights, the right to their opinion and their property or, in short, the right to individual protection against the rest of the world (human rights as the $\alpha$ pression of the sovereign individual). People who cannot organize politically will tend to become isolated, individualistic and preoccupied with their private interests.

\section{$\S$ 188: Do Human Rights and the Law Limit D emocracy?}

Human rights and the definition of the law limit the things a majority can decide and take some matters out of ordinary democratic procedures. However, this does not mean that human rights or the definition of the law are anti-democratic or undemocratic. They do not limit democracy and they are not used against democracy. They limit majority rule, but democracy is more than just majority rule. Human rights and the definition of the law are not a means to protect people against democracy and they are not above democracy. They are an integral part of democracy, just as much as majority rule. If they are absent, then we cannot claim to have a democracy (see Section 5), not even when we have a majority system. If the majority violates rights or the definition of the law, then it violates a substantial part of democracy. Such a majority is an undemocratic majority. It undermines democracy and it ultimately undermines its own power. The same institutions which grant a majority its power and legitimacy - e.g. human rights - grant protection to the minority (Harrison 1996:231). Something is not democratic just because it has been decided by the majority. The definition of the law makes it impossible for the majority to rule as it likes and makes the rule of man over man impossible. 
This means that the majority cannot decide to destroy democracy. If the majority were absolutely sovereign and if democracy were no more than a system of majority decision, then the democratic destruction of democracy would indeed be a legitimate option. The right to democracy is one of those human rights which limit the power of the majority. The majority does not have the right to destroy democracy because then it would violate a human right. Of course, the fact that the majority does not have this right does not mean that it is unable to destroy democracy.

The statement that human rights and democracy are incompatible because of the limits which rights impose on the decisions of the majority, is contrary to empirical facts. Rights are best protected by democracies. The argument in favor of the incompatibility of rights and democracy becomes highly questionable once we remember how democracy needs human rights (Chapter 3). If a system of government needs human rights, then it will tend to protect human rights instead of violating them.

Laws have to be accepted by the majority, otherwise large numbers of people will not respect them. Laws which are not accepted by large numbers of people will only be respected if the state is able to use overwhelming violence Fear, punishment and coercion are not the best ways to enforce laws. This is a justification of democracy. Of course, this does not mean that a law must simply repeat the opinions or practices of the majority. That would be just as meaningless as a law which is accepted by no one. It is al so wrong to believe that every law which is accepted by a majority and which is easy to enforce, is automatically a good law. A good law is more than a law which is easily accepted and executed. A law has to change things and must be situated on a normative rather than a descriptive level. A law which says that people have to eat in the evening has just as little sense as a law which says that people cannot eat in the evening. However, laws must not be completely unacceptable to the minority either - unacceptable in the sense of incompatible with rights.

\section{$\S 189:$ The M inority Protected by the Federal System}

The rights of all individuals and the rights of the minority in particular can also be protected by way of a federal system. '[T] he fewer the distinct parties and interests, the more frequently will a majority be found of the same party (...). Extend the sphere, and you take in a greater variety of parties and interests; you make it less probable that a majority of the whole will have a common motive to invade human rights of other citizens. (...) the greater security afforded by a greater variety of parties, against the event of any one party being able to outnumber and oppress the rest. (...) so many separate descriptions of citizens as will render an unjust combination of a majority of the whole very improbable, if not impracticable' (Hamilton/ Madison/ Jay 1954:18-19-75). A federal system is much more likely to have this plurality of interests than a centralized state.

A large state can be an advantage to democracy. The more interests there are, the less likely it is that a majority can be found which agrees to have a common interest harmful to the minority. If there are only two parties, then it can happen that the largest one be comes a threat to the smallest one, if only because the largest one excludes the smallest one from political power. 


\author{
CONCLUDING REMARKS (UNIVERSALITY, FLEXIBILITY AND \\ CONTEXTUALITY)
}

\title{
§ 190: U niversality vs. U niformity
}

Universality is not the same thing as uniformity. If we insist on uniformity, then we will not achieve universality. We will convince more people if we take local circumstances into consideration than if we simply copy things coming from the outside. We do not want to hurt the cultural feelings of people by insisting on uniformity. In any case, I will show that we do not need uniformity.

Regional differences are possible both at the level of the laws which create democracy and protect human rights, and at the level of the ways in which these laws are applied, and all this without impairing the universality of democracy and human rights. We can frame the law in a flexible way and we can apply the law in a flexible way. I will start with the first options.

\section{$\S 191:$ Rights and W rongs, and Different Perspectives in the D rafting of Laws}

Laws are necessary for the effective application of human rights and democracy. However, it is obviously impossible and undesirable to have the same laws in all countries. The way in which human rights and democracy are translated into laws and into concrete legal wordings can differ from country to country as well as from period to period. Laws and rights cannot be formulated in a globally uniform way or in a way that does not take the concrete circumstances in which they have to function into consideration. As these circumstances differ from country to country, the laws have to be different as well. Laws have to correspond to specific needs. A certain social or political context can make it necessary to focus attention on one particular right, on one particular group of rights or on one particular aspect of a right.

A 'Bill of Rights' is always a 'Bill of Wrongs'. Rights begin with the experience of an injustice According to the nature of the injustices or 'wrongs' in a particular society, some rights have to be especially accentuated. Sometimes, rights have to be declared which do not exist in the law of other countries because the rights in question are so obvious in other countries that there is no need for a law.

For example, we can imagine that in post-Soviet Russia for example, there is a need for a right establishing the freedom to criticize the works of Marx and Engels, or a need for a particular emphasis on the right to private property. In the constitutions of other countries there is no need for such a right or such an emphasis, because the things one wants to protect are never threatened. Some rights are never questioned. Another, and somewhat frivolous example: there is, generally speaking, no right to use the toilets because this right is so obvious that it does not needs protection. However, if in some country a tyranny sees the light of day which prohibits the use of toilets, then in this country it may be useful to declare a right to use the toilets.

Of course, this does not mean that cultures and circumstances should be given priority over rights, or that cultures are allowed to violate rights. It only means that the need for certain rights can be different in different cultures or countries. There is no reason to forget or violate certain rights. We can, however, accentuate certain rights if respect for these rights is less than obvious. Human rights have to be integrated in concrete legal systems and concrete societies each with its own history and its own problems. Even the UDHR, for example, which aspires to be a universal document, carries the marks of the Holocaust, which was obviously not a universal disaster. 
Choosing only one global wording and one global list of human rights also disregards the fact that rights evolve. The body of rights as it exists now, is not fixed for all times. New rights or new and wider definitions of existing rights can be created when new wrongs are created, for example as a consequence of technological or scientific developments (think of genetic engineering which may lead to new rights for the unborn life). It can also happen that we need new rights because we only now become conscience of certain wrongs which have existed for ages but which have been neglected (this was the case for women's rights and universal suffrage). Of course, many new rights are elaborations of existing rights, such as the right to equality. However, this does not make them useless.

Human rights have to address the problems of today and have to adapt. Adaptation means adding rights to the existing body, not eliminating rights. Eliminating rights is unacceptable unless respect for these rights has become self-evident. New wrongs come into existence, but old wrongs usually stay with us. As a consequence, there can be a problem of 'rights inflation', an increase in the number of rights which also is unacceptable (it creates confusion, it gives an easy excuse for violations - 'we cannot do all at once' - and it puts too many burdens on those who have a duty to respect and enforcerights).

Adding a 'bill of duties' to the already existing 'bill of rights' (which is the combination of the UDHR, the ICCPR and the ICESCR) is another way of expressing the flexibility of human rights. Talking about duties means taking the context into consideration. Some cultures attach more importance to duties than other cultures. If we declare a 'bill of duties', we do not impair human rights because rights by definition include duties. However, by making the duties explicit instead of implicit, we open ourselves to the needs of other cultures. Of course, duties cannot be more important than rights, cannot be an excuse to violate rights and cannot become prerequisites for human rights (the enjoyment of rights is not conditional upon the fulfillment of certain duties).

The same is true for the recognition of the right to development. This right is of particular importance to certain cultures in the Third World. If we recognize it, we do not impair the existing bill of rights because the right to development is implicit in economic rights (A bi-Saab in Cassese 1992:369). We can make it explicit, but again it should not become the most important right or a right which justifies violations of other rights. It is strictly speaking a superfluous right, but it can be useful in our relationships with other cultures and in our efforts to promote human rights at a global level. It can be seen as a contribution of the Third World to the international body of human rights. This body then becomes more inclusive and more universal because it encompasses aspects and visions of other cultures. Adding the right to development to the body of human rights makes this body more legitimate and more acceptable internationally. It ultimately leads to more respect for human rights in general. Human rights show their flexibility by accommodating the concerns of other cultures.

The concrete shape of human rights or the ways in which rights are expressed in laws can differ from place to place and can carry the markings of the places in which the rights have to function. Human rights can adopt different forms in positive law. Legal texts do not have to be identical all over the world.

However, contextuality does not imply ethical relativism or 'anything goes'. There is something called a core of human rights which is inviolable. In my view, this core is the list at the end of this book, which is a translation of the list one can find in the UDHR, the ICCPR and the ICESCR. A nything less than this list has no sense because one right needs another. This core must always be present, explicitly or implicitly, and cannot be mpaired, even though different emphases may be necessary in different contexts. There is no reason to believe that this core can be replaced by different regional bodies - western rights, Islamic rights, eastern rights etc. - which may have very little in common. The core must be the same, wherever we are, and must be present in the rights as they apply in every part of the world. There are limits to diversity, contextuality and flexibility. Rights can be adapted in such a way that nothing remains. We can 'expand our understanding 
of rights' in order to take into account almost everything. And 'other forms of democracy' are often very clumsy disguises for authoritarianism. All the rights that belong to the core must remain inviolable. We must avoid minimalism (so called 'basic rights') or regionalism. $N$ ot every circumstance justifies flexibility and violations cannot be justified by any circumstance.

\section{$\S$ 192: A D ifferent Application of Something Universal (Limits on Human Rights)}

There is room for flexibility at the level of the application of laws as well. In order to take into account certain specific needs, laws can be applied in a flexible or different way according to the context. Most human rights are not absolute. They can be limited by way of laws - for example an anti-racism law - when limits are required in order to protect:

(1) Other rights;

(2) The rights of others; or

(3) The values which are normally defended by human rights but which can also be impaired by human rights.

Someone's right to property for example can be limited if this is necessary to realize the economic rights of other people. We have a right to property but not at the expense of the rights of people who do not have enough property to survive. Rights can contradict each other or can be used or misused to harm people, and when this happens, priority has to be given to one right or another, or to the rights of one person or another person. The protection of one right may require limits on other rights.

How do we decide which right has priority? I would say, the one that best protects the different goals and values of rights. Take for example the conflict between the right to freedom of expression of a journalist and the right to privacy of a public figure. What value is served by the publication of the sexual habits of a politician? N one, I believe, except of course when these habits influence his or her public role. Normally, the right to privacy should prevail in such a case. A publication describing the sexual habits of someone does not contribute to anybody's public life, to prosperity, to peace etc. The right to privacy of the politician, however, contributes to his or her public life (see Section 2) or maybe even to his or her prosperity.

The flexibility of human rights is expressed in the way in which these rights are limited. A country with a serious problem of violence, crime or terrorism needs a strong police force Certain rights will then have to give way to the so-called integrity rights (life, physical integrity, security etc.) and will have to give way to a larger extent than in other states. States that face a persistent and widespread problem of racism can be forced to impose more severe limits on the freedom rights of some in order to protect the equality of others. Differences in possibilities can also cause differences in human rights. Rights cost money (a judicial system, a police force, leisure time, education etc.) and scarcity can force countries to make choices on priorities. However, we should also remember what I have said in Part 2: limiting certain rights or giving priority to certain rights in order to protect other rights is a dangerous option, because some rights are necessary in order to protect other rights (e.g. freedom rights are necessary to protect economic rights).

Of course, the ultimate goal of limits or priorities is al ways the full application of all rights, not some other goal such as economic growth or national glory. Rights can only be limited when this is necessary for rights. However, this goal of full application is true in the examples just given, but not true in the example of the conflict between the right to privacy of the politician and the freedom of expression of the journalist. In the latter case, limits are necessary not because of some imperfections in the social or economic situation 
- imperfections which may be overcome by progress - but because of inherent contradictions between rights.

Rights can be a problem and the way in which rights are applied or limited can differ in different countries according to the different problems that are caused by rights, or $x$ cording to the different problems that create circumstances which do not allow the effective application of some rights. States have a certain 'margin of appreciation' or freedom of judgment when deciding on the acceptability of limits. Of course, the international community has a right to question the ways in which some states limit the rights of their citizens. Circumstances can be used as an excuse to violate rights. Violations of rights and limits on rights are obviously completely different things. Limits on rights are temporary emergency measures in order to protect other rights or in order to create the conditions necessary for the application of rights in the future. Violations are committed because people believe some other goal is more important than rights. States should not abuse the possibility to limit rights and should not use this possibility to violate rights.

We have to take different social circumstances and needs into consideration and this can result in different kinds or degrees of limits on rights. This does not impair the universality of rights because there are limits everywhere. Even in a perfect democracy, some rights have to be limited. Take for example the right to freedom of speech of certain journalists who violate the right to privacy of politicians, or the freedom rights and the political rights used by some to destroy democracy and human rights and perhaps also the values represented and defended by democracy and human rights. Sometimes limits on rights are necessary to protect a rights-supporting community against anti-democrats who use democracy against democracy. The problem of flexibility is not a problem of limits or no limits; it is a problem of the degree or the kinds of limits. In any case, we can only limit what is al ready there. Universality comes first. 


\section{LIST OF HUMAN RIGHTS AND INTERNATIONAL STANDARDS}

This is a list of the most important human rights included in the $U$ niversal $D$ eclaration of Human Rights (UDHR), the International Covenant on Civil and Political Rights (ICCPR), the International Covenant on Economic, Social and Cultural Rights (ICESCR) and the European Convention for the Protection of Human Rights and Fundamental Freedoms (ECPHR) (the complete texts are printed below this summary):

1. Civil Rights or Freedom Rights:

- Equality of rights without discrimination

- Life

- Security and integrity of the person

- Protection against slavery, torture and cruel or inhuman punishment (humane treatment when detained)

- Protection against arbitrary arrest or detention (arrest or detention only on the basis of a law and with prompt notice of the charges)

- A public, fair and prompt trial before an independent, impartial and competent judge

- Presumption of innocence until proven guilty

- Means necessary for your defense

- Protection against compulsory confession

- The right not to testify against yourself

- 'N e bis in idem', no two convictions or punishments for the same offence

- Case reviewed by a higher tribunal

- Protection against 'ex post facto' laws, laws established after the deed

- 'N ullum crimen sine lege', there is no offense without a law

- Recognition as a person before the law

- Equality before the law and equal protection by thelaw

- Judicial protection of rights and access to legal remedies for rights violations (the right to apply to a court which offers redress for violations)

- Protection of privacy, family, home and correspondence

- Freedom of movement and residence

- Asylum from persecution

- The right not to be deprived of your nationality, the right to change your nationality

- Protection against arbitrary expulsion of nationals and aliens

- Leave and return to your country

- The right to marry and beget a family of your choice

- Protection of the family

- The right to own property

- Freedom of thought and religion

- Freedom of expression (seeking, receiving and imparting information regardless of borders)

- The absence of attacks on your honor and reputation

- Freedom of assembly and association (including the right to leave an association)

2. Political Rights or D emocratic Rights:

- Political participation, directly and through freely chosen representatives 
- Equal access to public service, the right to be elected

- The will of the people is the basis of the authority of government

- Periodic and genuine elections

- Universal and equal suffrage

- Secret vote

3. Social, Economic and Cultural Rights:

- Social security

- A certain standard of living

- Work, of your own choice and under favorable conditions

- Protection for the unemployed, the elderly, the disabled and sick persons

- Fair wages and equal wages for equal work

- Free trade unions (right to form and join)

- Strike

- Rest and leisure

- Food, clothing and housing

- Health care

- Special protection for children and mothers

- Education

- Participation in the cultural life of the community

- Self-determination

- International solidarity

Of course, there are other kinds of classifications of rights. One example is the classification according to first and second degree rights. First degree rights are rights such as freedom of speech. Second degree rights are rights which we need in order to protect our first degree rights (and sometimes our second degree rights as well). For example, we need the rights to 'due process', judicial remedy etc. in order to defend our other rights. The right to life, economic rights, the right to citizenship, the right to asylum, the right to strike, the right to education etc. are also second degree rights because we cannot enjoy our rights when we are dead or poor, when we are outcasts or when we lack the proper education. However, I have chosen not to use this kind of classification. In my view, all rights are first as well as second degree rights. All rights are useful in the protection of all other rights.

One might perhaps ask why I only mention the UDHR, the ICCPR, the ICESCR and the ECPHR. There are indeed dozens of other conventions and declarations concerning human rights. In some cases they deal with human rights in general; in other cases only with some specific rights or sets of rights. In view of the fact that many of these conventions or declarations originated in the Third World, it may seem astonishing that they are almost completely neglected in a study on the universality of rights. However, it was never my intention to make a comparative study of different human rights treaties. The main reason for this self-imposed limitation was the obvious fact that the UDHR, together with the ICCPR and the ICESCR, have become the international standard in matters of human rights. A part from clarifications and elaborations, the other texts have very little to add to the main core of human rights. The ECPHR is interesting in the sense that it offers far-reaching tools for the enforcement of rights. 


\section{UNIVERSAL DECLARATION OF HUMAN RIGHTS}

\section{Preamble}

Whereas recognition of the inherent dignity and of the equal and inalienable rights of all members of the human family is the foundation of freedom, justice and peace in the world,

Whereas disregard and contempt for human rights have resulted in barbarous acts which have outraged the conscience of mankind, and the advent of a world in which human beings shall enjoy freedom of speech and belief and freedom from fear and want has been proclaimed as the highest aspiration of the common people,

Whereas it is essential, if man is not to be compelled to have recourse, as a last resort, to rebellion against tyranny and oppression, that human rights should be protected by the rule of law,

Whereas it is essential to promote the development of friendly relations between nations,

Whereas the peoples of the United Nations have in the Charter reaffirmed their faith in fundamental human rights, in the dignity and worth of the human person and in the equal rights of men and women and have determined to promote social progress and better standards of life in larger freedom,

Whereas Member States have pledged themselves to achieve, in cooperation with the United Nations, the promotion of universal respect for and observance of human rights and fundamental freedoms,

Whereas a common understanding of these rights and freedoms is of the greatest importance for the full realization of this pledge,

Now, therefore, The General Assembly, Prodaims this Universal Declaration of Human Rights as a common standard of achievement for all peoples and all nations, to the end that every individual and every organ of society, keeping this Dedaration constantly in mind, shall strive by teaching and education to promote respect for these rights and freedoms and by progressive measures, national and international, to secure their universal and effective recognition and observance, both among the peoples of Member States themselves and among the peoples of territories under their jurisdiction.

\section{Article I}

All human beings are born free and equal in dignity and rights. They are endowed with reason and conscience and should act towards one another in a spirit of brotherhood.

\section{Article 2}

Everyone is entitled to all the rights and freedoms set forth in this Declaration, without distinction of any kind, such as race, colour, sex, language, religion, political or other opinion, national or social origin, property, birth or other status.

Furthermore, no distinction shall be made on the basis of the political, jurisdictional or international status of the country or territory to which a person belongs, whether it be independent, trust, non-self-governing or under any other limitation of sovereignty.

\section{Article 3}

Everyone has the right to life, liberty and security of person.

\section{Article 4}

No one shall be held in slavery or servitude; slavery and the slave trade shall be prohibited in all their forms.

\section{Article 5}

No one shall be subjected to torture or to cruel, inhuman or degrading treatment or punishment.

\section{Article 6}

Everyone has the right to recognition everywhere as a person before the law.

Article 7

All are equal before the law and are entitled without any discrimination to equal protection of the law. All are entitled to equal protection against any discrimination in violation of this Declaration and against any incitement to such discrimination.

\section{Article 8}

Everyone has the right to an effective remedy by the competent national tribunals for acts violating the fundamental rights granted him by the constitution or by law.

\section{Article 9}

No one shall be subjected to arbitrary arrest, detention or exile.

\section{Article 10}

Everyone is entitled in full equality to a fair and public hearing by an independent and impartial tribunal, in the determination of his rights and obligations and of any criminal charge against him.

\section{Article 11}

1. Everyone charged with a penal offence has the right to be presumed innocent until proved guilty according to 
law in a public trial at which he has had all the guarantees necessary for his defence.

2. No one shall be held guilty of any penal offence on account of any act or omission which did not constitute a penal offence, under national or international law, at the time when it was committed. Nor shall a heavier penalty be imposed than the one that was applicable at the time the penal offence was committed.

\section{A rticle 12}

No one shall be subjected to arbitrary interference with his privacy, family, home or correspondence, nor to attacks upon his honour and reputation. Everyone has the right to the protection of the law against such interference or attacks.

\section{A rticle 13}

1. Everyone has the right to freedom of movement and residence within the borders of each State.

2. Everyone has the right to leave any country, including his own, and to return to his country.

\section{A rticle 14}

1. Everyone has the right to seek and to enjoy in other countries asylum from persecution.

2. This right may not be invoked in the case of prosecutions genuinely arising from non-political crimes or from acts contrary to the purposes and principles of the United Nations.

\section{A rticle 15}

1. Everyone has the right to a nationality.

2. No one shall be arbitrarily deprived of his nationality nor denied the right to change his nationality.

\section{A rticle 16}

1. Men and women of full age, without any limitation due to race, nationality or religion, have the right to marry and to found a family. They are entitled to equal rights as to marriage, during marriage and at its dissolution.

2. Marriage shall be entered into only with the free and full consent of the intending spouses.

3. The family is the natural and fundamental group unit of society and is entitled to protection by society and the State.

\section{A rticle 17}

1. Everyone has the right to own property alone as well as in association with others.

2. No one shall be arbitrarily deprived of his property.
A rticle 18

Everyone has the right to freedom of thought, conscience and religion; this right includes freedom to change his religion or belief, and freedom, either alone or in community with others and in public or private, to manifest his religion or belief in teaching, practice, worship and obsevance.

A rticle 19

Everyone has the right to freedom of opinion and expression; this right includes freedom to hold opinions without interference and to seek, receive and impart information and ideas through any media and regardless of frontiers.

A rticle 20

1. Everyone has the right to freedom of peaceful assembly and association.

2. No one may be compelled to belong to an association.

A rticle 21

1. Everyone has the right to take part in the government of his country, directly or through freely chosen representatives.

2. Everyone has the right to equal access to public service in his country.

3. The will of the people shall be the basis of the authority of government; this will shall be expressed in periodic and genuine elections which shall be by universal and equal suffrage and shall be held by secret vote or by equivalent free voting procedures.

A rticle 22

Everyone, as a member of society, has the right to social security and is entitled to realization, through national effort and international co-operation and in accordance with the organization and resources of each State, of the economic, social and cultural rights indispensable for his dignity and the free development of his personality.

A rticle 23

1. Everyone has the right to work, to free choice of employment, to just and favourable conditions of work and to protection against unemployment.

2. Everyone, without any discrimination, has the right to equal pay for equal work.

3. Everyone who works has the right to just and favourable remuneration ensuring for himself and his family an existence worthy of human dignity, and supplemented, if necessary, by other means of social protection.

4. Everyone has the right to form and to join trade unions for the protection of his interests. 


\section{Article 24}

Everyone has the right to rest and leisure, including reasonable limitation of working hours and periodic holidays with pay.

\section{Article 25}

1. Everyone has the right to a standard of living ade quate for the health and well-being of himself and of his family, including food, clothing, housing and medical care and necessary social services, and the right to security in the event of unemployment, sickness, disability, widowhood, old age or other lack of livelihood in circumstances beyond his control.

2. Motherhood and childhood are entitled to special care and assistance. All children, whether born in or out of wedlock, shall enjoy the same social protection.

\section{Article 26}

1. Everyone has the right to education. Education shall be free, at least in the elementary and fundamental stages. Elementary education shall be compulsory. Technical and professional education shall be made generally available and higher education shall be equally accessible to all on the basis of merit.

2. Education shall be directed to the full development of the human personality and to the strengthening of respect for human rights and fundamental freedoms. It shall promote understanding, tolerance and friendship among all nations, racial or religious groups, and shall further the activities of the United Nations for the maintenance of peace.

3. Parents have a prior right to choose the kind of education that shall be given to their children.

\section{Article 27}

1. Everyone has the right freely to participate in the cultural lifeof the community, to enjoy the arts and to share in scientific advancement and its benefits.

2. Everyone has the right to the protection of the moral and material interests resulting from any scientific, literary or artistic production of which he is the author.

\section{Article 28}

Everyone is entitled to a social and international order in which the rights and freedoms set forth in this Dedaration can be fully realized.

\section{Article 29}

1. Everyone has duties to the community in which alone the free and full development of his personality is possible.

2. In the exercise of his rights and freedoms, everyone shall be subject only to such limitations as are determined by law solely for the purpose of securing due recognition and respect for the rights and freedoms of others and of meeting the just requirements of morality, public order and the general welfare in a democratic society.

3. These rights and freedoms may in no case be exercised contrary to the purposes and principles of the United Nations.

\section{Article 30}

Nothing in this Dedaration may be interpreted as implying for any State, group or person any right to engage in any activity or to perform any act aimed at the destruction of any of the rights and freedoms set forth herein.

\section{INTERNATIONAL COVENANT ON CIVIL AND POLITICAL RIGHTS}

Adopted and opened for signature, ratification and accession by General Assembly resolution 2200A (XXI) of 16 December 1966

entry into force $23 \mathrm{M}$ arch 1976, in accordance with Article 49

Preamble

The States Parties to the present Covenant,

Considering that, in accordance with the principles proclaimed in the Charter of the United Nations, recognition of the inherent dignity and of the equal and inalienable rights of all members of the human family is the foundation of freedom, justice and peace in the world,

Recognizing that these rights derive from the inherent dignity of the human person,

Recognizing that, in accordance with the Universal Declaration of Human Rights, the ideal of free human beings enjoying civil and political freedom and freedom from fear and want can only be achieved if conditions are created whereby everyone may enjoy his civil and political rights, as well as his economic, social and cultural rights,

Considering the obligation of States under the Charter of the United Nations to promote universal respect for, and observance of, human rights and freedoms,

Realizing that the individual, having duties to other individuals and to the community to which he belongs, is under a responsibility to strive for the promotion and observance of the rights recognized in the present Covenant,

Agree upon the following articles:

PART I

Article 1

1. All peoples have the right of self-determination. By virtue of that right they freely determine their political 
status and freely pursue their economic, social and cultural development.

2. All peoples may, for their own ends, freely dispose of their natural wealth and resources without prejudice to any obligations arising out of international economic co-operation, based upon the principle of mutual benefit, and international law. In no case may a people be deprived of its own means of subsistence.

3. The States Parties to the present Covenant, including those having responsibility for the administration of Non-Self-Governing and Trust Territories, shall promote the realization of the right of self-determination, and shall respect that right, in conformity with the provisions of the Charter of the United Nations.

PART II

Article 2

1. Each State Party to the present Covenant undertakes to respect and to ensure to all individuals within its territory and subject to its jurisdiction the rights recognized in the present Covenant, without distinction of any kind, such as race, colour, sex, language, religion, political or other opinion, national or social origin, property, birth or other status.

2. Where not already provided for by existing legislative or other measures, each State Party to the present Covenant undertakes to take the necessary steps, in accordance with its constitutional processes and with the provisions of the present Covenant, to adopt such laws or other measures as may be necessary to give $f$ fect to the rights recognized in the present Covenant.

3. Each State Party to the present Covenant undertakes:

(a) To ensure that any person whose rights or free doms as herein recognized are violated shall have an effective remedy, notwithstanding that the violation has been committed by persons acting in an official capacity;

(b) To ensure that any person claiming such a remedy shall have his right thereto determined by competent judicial, administrative or legislative authorities, or by any other competent authority provided for by the legal system of the State, and to develop the possibilities of judicial remedy;

(c) To ensure that the competent authorities shall enforce such remedies when granted.

\section{Article 3}

The States Parties to the present Covenant undertake to ensure the equal right of men and women to the enjoyment of all civil and political rights set forth in the present Covenant.

\section{Article 4}

1. In time of public emergency which threatens the life of the nation and the existence of which is officially pro- claimed, the States Parties to the present Covenant may take measures derogating from their obligations under the present Covenant to the extent strictly $\mathrm{e}$ quired by the exigencies of the situation, provided that such measures are not inconsistent with their other obligations under international law and do not involve discrimination solely on the ground of race, colour, sex, language, religion or social origin.

2. No derogation from articles $6,7,8$ (paragraphs I and $2), 11,15,16$ and 18 may be made under this provision.

3. A ny State Party to the present Covenant availing itself of the right of derogation shall immediately inform the other States Parties to the present Covenant, through the intermediary of the Secretary-General of the United $\mathrm{N}$ ations, of the provisions from which it has derogated and of the reasons by which it was actuated. A further communication shall be made, through the same intermediary, on the date on which it terminates such derogation.

\section{Article 5}

1. Nothing in the present Covenant may be interpreted as implying for any State, group or person any right to engage in any activity or perform any act aimed at the destruction of any of the rights and freedoms recognized herein or at their limitation to a greater extent than is provided for in the present Covenant.

2. There shall be no restriction upon or derogation from any of the fundamental human rights recognized or existing in any State Party to the present Covenant pursuant to law, conventions, regulations or custom on the pretext that the present Covenant does not recognize such rights or that it recognizes them to a lesser extent.

PART III

Article 6

1. Every human being has the inherent right to life This right shall be protected by law. No one shall be arbitrarily deprived of his life.

2. In countries which have not abolished the death penalty, sentence of death may be imposed only for the most serious crimes in accordance with the law in force at the time of the commission of the crime and not contrary to the provisions of the present Covenant and to the Convention on the Prevention and Punishment of the Crime of Genocide. This penalty can only be carried out pursuant to a final judgement rendered by a competent court.

3. When deprivation of life constitutes the crime of genocide it is understood that nothing in this article shall authorize any State Party to the present Covenant to derogate in any way from any obligation assumed under the provisions of the Convention on the Prevention and Punishment of the Crime of Genocide. 
4. Anyone sentenced to death shall have the right to seek pardon or commutation of the sentence. Amnesty, pardon or commutation of the sentence of death may be granted in all cases.

5. Sentence of death shall not be imposed for crimes committed by persons below eighteen years of age and shall not be carried out on pregnant women.

6. Nothing in this article shall be invoked to delay or to prevent the abolition of capital punishment by any State Party to the present Covenant.

\section{Article 7}

No one shall be subjected to torture or to cruel, inhuman or degrading treatment or punishment. In particular, no one shall be subjected without his free consent to medical or scientific experimentation.

\section{Article 8}

1. No one shall be held in slavery; slavery and the slave trade in all their forms shall be prohibited.

2. No one shall be held in servitude.

3.

(a) No one shall be required to perform forced or compulsory labour;

(b) Paragraph 3 (a) shall not be held to preclude, in countries where imprisonment with hard labour may be imposed as a punishment for a crime, the performance of hard labour in pursuance of a sentence to such punishment by a competent court;

(c) For the purpose of this paragraph the term "forced or compulsory labour" shall not include:

(i) Any work or service, not referred to in subparagraph (b), normally required of a person who is under detention in consequence of a lawful order of a court, or of a person during conditional release from such detention;

(ii) Any service of a military character and, in countries where conscientious objection is recognized, any national service required by law of conscientious objectors;

(iii) Any service exacted in cases of emergency or calamity threatening the life or well-being of the community;

(iv) Any work or service which forms part of normal civil obligations.

\section{Article 9}

1. Everyone has the right to liberty and security of person. No one shall be subjected to arbitrary arrest or de tention. No one shall be deprived of his liberty except on such grounds and in accordance with such proce dure as are established by law.

2. Anyone who is arrested shall be informed, at the time of arrest, of the reasons for his arrest and shall be promptly informed of any charges against him.

3. Anyone arrested or detained on a criminal charge shall be brought promptly before a judge or other officer authorized by law to exercise judicial power and shall be entitled to trial within a reasonable time or to re lease. It shall not be the general rule that persons awaiting trial shall be detained in custody, but release may be subject to guarantees to appear for trial, at any other stage of the judicial proceedings, and, should occasion arise, for execution of the judgement.

4. Anyone who is deprived of his liberty by arrest or detention shall be entitled to take proceedings before a court, in order that court may decide without delay on the lawfulness of his detention and order his release if the detention is not lawful.

5. Anyone who has been the victim of unlawful arrest or detention shall have an enforceable right to compensation.

\section{Article 10}

1. All persons deprived of their liberty shall be treated with humanity and with respect for the inherent dignity of the human person.

2.

(a) Accused persons shall, save in exceptional circumstances, be segregated from convicted persons and shall be subject to separate treatment appropriate to their status as unconvicted persons;

(b) Accused juvenile persons shall be separated from adults and brought as speedily as possible for adjudication.

3. The penitentiary system shall comprise treatment of prisoners the essential aim of which shall be their reformation and social rehabilitation. Juvenile offenders shall be segregated from adults and be accorded treatment appropriate to their age and legal status.

\section{Article 11}

No one shall be imprisoned merely on the ground of inability to fulfil a contractual obligation.

\section{Article 12}

1. Everyone lawfully within the territory of a State shall, within that territory, have the right to liberty of movement and freedom to choose his residence.

2. Everyone shall be free to leave any country, including his own.

3. The above-mentioned rights shall not be subject to any restrictions except those which are provided by law, are necessary to protect national security, public order (ordre public), public health or morals or the rights and freedoms of others, and are consistent with the other rights recognized in the present Covenant.

4. No one shall be arbitrarily deprived of the right to enter his own country.

\section{Article 13}

An alien lawfully in the territory of a State Party to the present Covenant may be expelled therefrom only in pursuance of a decision reached in accordance with law and shall, except where compelling reasons of national 
security otherwise require, be allowed to submit the reasons against his expulsion and to have his case reviewed by, and be represented for the purpose before, the competent authority or a person or persons especially designated by the competent authority.

\section{A rticle 14}

1. All persons shall be equal before the courts and tribunals. In the determination of any criminal charge against him, or of his rights and obligations in a suit at law, everyone shall be entitled to a fair and public hearing by a competent, independent and impartial tribunal established by law. The press and the public may be excluded from all or part of a trial for reasons of morals, public order (ordre public) or national security in a democratic society, or when the interest of the private lives of the parties so requires, or to the extent strictly necessary in the opinion of the court in special circumstances where publicity would prejudice the interests of justice; but any judgement rendered in a criminal case or in a suit at law shall be made public except where the interest of juvenile persons otherwise requires or the proceedings concern matrimonial disputes or the guardianship of children.

2. Everyone charged with a criminal offence shall have the right to be presumed innocent until proved guilty according to law.

3. In the determination of any criminal charge against him, everyone shall be entitled to the following minimum guarantees, in full equality:

(a) To be informed promptly and in detail in a language which he understands of the nature and cause of the charge against him;

(b) To have adequate time and facilities for the preparation of his defence and to communicate with counsel of his own choosing;

(c) To be tried without undue delay;

(d) To be tried in his presence, and to defend himself in person or through legal assistance of his own choosing; to be informed, if he does not have legal assistance, of this right; and to have legal assistance assigned to him, in any case where the interests of justice so require, and without payment by him in any such case if he does not have sufficient means to pay for it;

(e) To examine, or have examined, the witnesses against him and to obtain the attendance and $\boldsymbol{\alpha}$ amination of witnesses on his behalf under the same conditions as witnesses against him;

(f) To have the free assistance of an interpreter if he cannot understand or speak the language used in court;

(g) N ot to be compelled to testify against himself or to confess guilt.

4. In the case of juvenile persons, the procedure shall be such as will take account of their age and the desirability of promoting their rehabilitation.

5. Everyone convicted of a crime shall have the right to his conviction and sentence being reviewed by a higher tribunal according to law.
6. When a person has by a final decision been convicted of a criminal offence and when subsequently his conviction has been reversed or he has been pardoned on the ground that a new or newly discovered fact shows conclusively that there has been a miscarriage of justice, the person who has suffered punishment as a result of such conviction shall be compensated according to law, unless it is proved that the non-disclosure of the unknown fact in time is wholly or partly attributable to him.

7. No one shall be liable to be tried or punished again for an offence for which he has already been finally convicted or acquitted in accordance with the law and pe nal procedure of each country.

\section{A rticle 15}

1. No one shall be held guilty of any criminal offence on account of any act or omission which did not constitute a criminal offence, under national or international law, at the time when it was committed. Nor shall a heavier penalty be imposed than the one that was applicable at the time when the criminal offence was committed. If, subsequent to the commission of the offence, provision is made by law for the imposition of the lighter penalty, the offender shall benefit thereby.

2. Nothing in this article shall prejudice the trial and punishment of any person for any act or omission which, at the time when it was committed, was criminal according to the general principles of law recognized by the community of nations.

\section{A rticle 16}

Everyone shall have the right to recognition everywhere as a person before the law.

A rticle 17

1. No one shall be subjected to arbitrary or unlawful interference with his privacy, family, home or corre spondence, nor to unlawful attacks on his honour and reputation.

2. Everyone has the right to the protection of the law against such interference or attacks.

A rticle 18

1. Everyone shall have the right to freedom of thought, conscience and religion. This right shall include freedom to have or to adopt a religion or belief of his choice, and freedom, either individually or in community with others and in public or private, to manifest his religion or belief in worship, observance, practice and teaching.

2. No one shall be subject to coercion which would impair his freedom to have or to adopt a religion or belief of his choice.

3. Freedom to manifest one's religion or beliefs may be subject only to such limitations as are prescribed by law and are necessary to protect public safety, order, health, or morals or the fundamental rights and free 
doms of others. 4. The States Parties to the present Covenant undertake to have respect for the liberty of parents and, when applicable, legal guardians to $€$ sure the religious and moral education of their children in conformity with their own convictions.

\section{Article 19}

1. Everyone shall have the right to hold opinions without interference.

2. Everyone shall have the right to freedom of expression; this right shall include freedom to seek, receive and impart information and ideas of all kinds, regardless of frontiers, either orally, in writing or in print, in the form of art, or through any other media of his choice.

3. The exercise of the rights provided for in paragraph 2 of this article carries with it special duties and responsibilities. It may therefore be subject to certain restrictions, but these shall only be such as are provided by law and are necessary:

(a) For respect of the rights or reputations of others;

(b) For the protection of national security or of public order (ordre public), or of public heal th or morals.

Article 20

1. A ny propaganda for war shall be prohibited by law.

2. Any advocacy of national, racial or religious hatred that constitutes incitement to discrimination, hostility or violence shall be prohibited by law.

\section{Article 21}

The right of peaceful assembly shall be recognized. No restrictions may be placed on the exercise of this right other than those imposed in conformity with the law and which are necessary in a democratic society in the interests of national security or public safety, public order (ordre public), the protection of public health or morals or the protection of the rights and freedoms of others.

\section{Article 22}

1. Everyone shall have the right to freedom of association with others, including the right to form and join trade unions for the protection of his interests.

2. No restrictions may be placed on the exercise of this right other than those which are prescribed by law and which are necessary in a democratic society in the interests of national security or public safety, public order (ordre public), the protection of public health or morals or the protection of the rights and freedoms of others. This article shall not prevent the imposition of lawful restrictions on members of the armed forces and of the police in their exercise of this right.

3. Nothing in this article shall authorize States Parties to the International Labour Organisation Convention of 1948 concerning Freedom of Association and Protection of the Right to Organize to take legislative measures which would prejudice, or to apply the law in such a manner as to prejudice, the guarantees provided for in that Convention.

\section{Article 23}

1. The family is the natural and fundamental group unit of society and is entitled to protection by society and the State.

2. The right of men and women of marriageable age to marry and to found a family shall be recognized.

3. No marriage shall be entered into without the free and full consent of the intending spouses.

4. States Parties to the present Covenant shall take appropriate steps to ensure equality of rights and $\mathrm{re}$ sponsibilities of spouses as to marriage, during marriage and at its dissolution. In the case of dissolution, provision shall be made for the necessary protection of any children.

Article 24

1. Every child shall have, without any discrimination as to race, colour, sex, language, religion, national or social origin, property or birth, the right to such measures of protection as are required by his status as a minor, on the part of his family, society and the State.

2. Every child shall be registered immediately after birth and shall have a name

3. Every child has the right to acquire a nationality.

\section{Article 25}

Every citizen shall have the right and the opportunity, without any of the distinctions mentioned in article 2 and without unreasonable restrictions:

(a) To take part in the conduct of public affairs, directly or through freely chosen representatives;

(b) To vote and to be elected at genuine periodic elections which shall be by universal and equal suffrage and shall be held by secret ballot, guaranteeing the free expression of the will of the electors;

(c) To have access, on general terms of equality, to public service in his country.

\section{Article 26}

All persons are equal before the law and are entitled without any discrimination to the equal protection of the law. In this respect, the law shall prohibit any discrimination and guarantee to all persons equal and effective protection against discrimination on any ground such as race, colour, sex, language, religion, political or other opinion, national or social origin, property, birth or other status.

\section{Article 27}

In those States in which ethnic, religious or linguistic minorities exist, persons belonging to such minorities shall not be denied the right, in community with the other members of their group, to enjoy their own culture, to 
profess and practise their own religion, or to use their own language.

PART IV

\section{A rticle 28}

1. There shall be established a Human Rights Committee (hereafter referred to in the present Covenant as the Committee). It shall consist of eighteen members and shall carry out the functions hereinafter provided.

2. The Committee shall be composed of nationals of the States Parties to the present Covenant who shall be persons of high moral character and recognized competence in the field of human rights, consideration being given to the usefulness of the participation of some persons having legal experience.

3. The members of the Committee shall be elected and shall serve in their personal capacity.

\section{A rticle 29}

1. The members of the Committee shall be elected by secret ballot from a list of persons possessing the qualifications prescribed in article 28 and nominated for the purpose by the States Parties to the present Covenant.

2. Each State Party to the present Covenant may nominate not more than two persons. These persons shall be nationals of the nominating State.

3. A person shall be eligible for renomination.

\section{A rticle 30}

1. The initial election shall be held no later than six months after the date of the entry into force of the present Covenant.

2. At least four months before the date of each election to the Committee, other than an election to fill a vacancy dedared in accordance with article 34, the SecretaryGeneral of the United Nations shall address a written invitation to the States Parties to the present Covenant to submit their nominations for membership of the Committee within three months.

3. The Secretary-General of the United Nations shall prepare a list in alphabetical order of all the persons thus nominated, with an indication of the States Parties which have nominated them, and shall submit it to the States Parties to the present Covenant no later than one month before the date of each election.

4. Elections of the members of the Committee shall be held at a meeting of the States Parties to the present Covenant convened by the Secretary General of the United Nations at the Headquarters of the United $\mathrm{Na}$ tions. At that meeting, for which two thirds of the States Parties to the present Covenant shall constitute a quorum, the persons elected to the Committee shall be those nominees who obtain the largest number of votes and an absolutemajority of the votes of the representatives of States Parties present and voting.

A rticle 31

1. The Committee may not include more than one rotional of the same State.

2. In the election of the Committee, consideration shall be given to equitable geographical distribution of membership and to the representation of the different forms of civilization and of the principal legal systems.

A rticle 32

1. The members of the Committee shall be elected for a term of four years. They shall be eligible for reelection if renominated. However, the terms of nine of the members elected at the first election shall expire at the end of two years; immediately after the first election, the names of these nine members shall be chosen by lot by the Chairman of the meeting referred to in article 30, paragraph 4.

2. Elections at the expiry of office shall be held in accordance with the preceding articles of this part of the present Covenant.

\section{A rticle 33}

1. If, in the unanimous opinion of the other members, a member of the Committee has ceased to carry out his functions for any cause other than absence of a temporary character, the Chairman of the Committee shall notify the Secretary-General of the United Nations, who shall then dedare the seat of that member to be vacant.

2. In the event of the death or the resignation of a member of the Committee, the Chairman shall immediately notify the Secretary-General of the United Nations, who shall declare the seat vacant from the date of death or the date on which the resignation takes effect.

\section{A rticle 34}

1. When a vacancy is declared in accordance with artide 33 and if the term of office of the member to be re placed does not expire within six months of the declaration of the vacancy, the Secretary-General of the United Nations shall notify each of the States Parties to the present Covenant, which may within two months submit nominations in accordance with article 29 for the purpose of filling the vacancy.

2. The Secretary-General of the United Nations shall prepare a list in al phabetical order of the persons thus nominated and shall submit it to the States Parties to the present Covenant. The election to fill the vacancy shall then take place in accordance with the relevant provisions of this part of the present Covenant.

3. A member of the Committee elected to fill a vacancy dedared in accordance with article 33 shall hold office for the remainder of the term of the member who vacated the seat on the Committee under the provisions of that article. 


\section{Article 35}

The members of the Committee shall, with the approval of the General Assembly of the United Nations, receive emoluments from United Nations resources on such terms and conditions as the General Assembly may decide, having regard to the importance of the Committee's $e$ sponsibilities.

\section{Article 36}

The Secretary-General of the United Nations shall provide the necessary staff and facilities for the effective performance of the functions of the Committee under the present Covenant.

\section{Article 37}

1. The Secretary-General of the United Nations shall convene the initial meeting of the Committee at the Headquarters of the United Nations.

2. After its initial meeting, the Committee shall meet at such times as shall be provided in its rules of proce dure.

3. The Committee shall normally meet at the Headquarters of the United Nations or at the United Nations Office at Geneva.

\section{Article 38}

Every member of the Committee shall, before taking up his duties, make a solemn declaration in open committee that he will perform his functions impartially and conscientiously.

\section{Article 39}

1. The Committee shall elect its officers for a term of two years. They may be re-elected.

2. The Committee shall establish its own rules of proce dure, but these rules shall provide, inter alia, that:

(a) Twelve members shall constitute a quorum;

(b) Decisions of the Committee shall be made by a majority vote of the members present.

\section{Article 40}

1. The States Parties to the present Covenant undertake to submit reports on the measures they have adopted which give effect to the rights recognized herein and on the progress made in the enjoyment of those rights:

(a) Within one year of the entry into force of the present Covenant for the States Parties concerned;

(b) Thereafter whenever the Committee so requests.

2. All reports shall be submitted to the Secretary-General of the United Nations, who shall transmit them to the Committee for consideration. Reports shall indicate the factors and difficulties, if any, affecting the $m$ plementation of the present Covenant.

3. The Secretary-General of the United Nations may, after consultation with the Committee, transmit to the specialized agencies concerned copies of such parts of the reports as may fall within their field of competence.

4. The Committee shall study the reports submitted by the States Parties to the present Covenant. It shall transmit its reports, and such general comments as it may consider appropriate, to the States Parties. The Committee may also transmit to the Economic and Social Council these comments along with the copies of the reports it has received from States Parties to the present Covenant.

5. The States Parties to the present Covenant may submit to the Committee observations on any comments that may be made in accordance with paragraph 4 of this article.

Article 41

1. A State Party to the present Covenant may at any time declare under this article that it recognizes the competence of the Committee to receive and consider communications to the effect that a State Party claims that another State Party is not fulfilling its obligations under the present Covenant. Communications under this article may be received and considered only if submitted by a State Party which has made a declaration recognizing in regard to itself the competence of the Committee. No communication shall be received by the Committee if it concerns a State Party which has not made such a declaration. Communications received under this article shall be dealt with in accordance with the following procedure:

(a) If a State Party to the present Covenant considers that another State Party is not giving effect to the provisions of the present Covenant, it may, by written communication, bring the matter to the attention of that State Party. Within three months after the receipt of the communication the receiving State shall afford the State which sent the communication an explanation, or any other statement in writing clarifying the matter which should include, to the extent possible and pertinent, reference to domestic procedures and remedies taken, pending, or available in the matter:

(b) If the matter is not adjusted to the satisfaction of both States Parties concerned within six months after the receipt by the receiving State of the initial communication, either State shall have the right to refer the matter to the Committee, by notice given to the Committee and to the other State:

(c) The Committee shall deal with a matter referred to it only after it has ascertained that all available domestic remedies have been invoked and exhausted in the matter, in conformity with the generally recognized principles of international law. This shall not be the rule where the application of the remedies is unreasonably prolonged;

(d) The Committee shall hold closed meetings when examining communications under this article;

(e) Subject to the provisions of subparagraph (c), the Committee shall make available its good offices to the States Parties concerned with a view to a 
friendly solution of the matter on the basis of re spect for human rights and fundamental freedoms as recognized in the present Covenant;

(f) In any matter referred to it, the Committee may call upon the States Parties concerned, referred to in subparagraph (b), to supply any relevant information;

(g) The States Parties concerned, referred to in subparagraph (b), shall have the right to be represented when the matter is being considered in the Committee and to make submissions orally and/ or in writing;

(h) The Committee shall, within twelve months after the date of receipt of notice under subparagraph (b), submit a report:

(i) If a solution within the terms of subparagraph (e) is reached, the Committee shall confine its report to a brief statement of the facts and of the solution reached;

(ii) If a solution within the terms of subparagraph (e) is not reached, the Committee shall confine its report to a brief statement of the facts; the written submissions and record of the oral submissions made by the States Parties concerned shall be attached to the report. In every matter, the report shall be communicated to the States Parties concerned.

2. The provisions of this article shall come into force when ten States Parties to the present Covenant have made declarations under paragraph I of this article. Such declarations shall be deposited by the States Parties with the Secretary-General of the United Nations, who shall transmit copies thereof to the other States Parties. A declaration may be withdrawn at any time by notification to the Secretary-General. Such a withdrawal shall not prejudice the consideration of any matter which is the subject of a communication already transmitted under this article; no further communication by any State Party shall be received after the notification of withdrawal of the declaration has been received by the Secretary-General, unless the State Party concerned has made a new declaration.

\section{A rticle 42}

1.

(a) If a matter referred to the Committee in accordance with article 41 is not resolved to the satisfaction of the States Parties concerned, the Committee may, with the prior consent of the States Parties concerned, appoint an ad hoc Conciliation Commission (hereinafter referred to as the Commission). The good offices of the Commission shall be made available to the States Parties concerned with a view to an amicable solution of the matter on the basis of respect for the present Covenant;

(b) The Commission shall consist of five persons $a-$ ceptable to the States Parties concerned. If the States Parties concerned fail to reach agreement within three months on all or part of the composition of the Commission, the members of the Commission concerning whom no agreement has been reached shall be elected by secret ballot by a two-thirds majority vote of the Committee from among its members.

2. The members of the Commission shall serve in their personal capacity. They shall not be nationals of the States Parties concerned, or of a State not Party to the present Covenant, or of a State Party which has not made a declaration under article 41.

3. The Commission shall elect its own Chairman and adopt its own rules of procedure.

4. The meetings of the Commission shall normally be held at the Headquarters of the United Nations or at the United Nations Office at Geneva. However, they may be held at such other convenient places as the Commission may determine in consultation with the Secretary-General of the United Nations and the States Parties concerned.

5. The secretariat provided in accordance with article 36 shall also service the commissions appointed under this article.

6. The information received and collated by the Committee shall be made available to the Commission and the Commission may call upon the States Parties concerned to supply any other relevant information.

7. When the Commission has fully considered the matter, but in any event not later than twelve months after having been seized of the matter, it shall submit to the Chairman of the Committee a report for communication to the States Parties concerned:

(a) If the Commission is unable to complete its consideration of the matter within twelve months, it shall confine its report to a brief statement of the status of its consideration of the matter;

(b) If an amicable solution to the matter on tie basis of respect for human rights as recognized in the present Covenant is reached, the Commission shall confine its report to a brief statement of the facts and of the solution reached;

(c) If a solution within the terms of subparagraph (b) is not reached, the Commission's report shall ®nbody its findings on all questions of fact relevant to the issues between the States Parties concerned, and its views on the possibilities of an amicable solution of the matter. This report shall also contain the written submissions and a record of the oral submissions made by the States Parties concerned;

(d) If the Commission's report is submitted under subparagraph (c), the States Parties concerned shall, within three months of the receipt of the e port, notify the Chairman of the Committee whether or not they accept the contents of the report of the Commission.

8. The provisions of this article are without prejudice to the responsibilities of the Committee under article 41.

9. The States Parties concerned shall share equally all the expenses of the members of the Commission in accordance with estimates to be provided by the SecretaryGeneral of the United Nations.

10. The Secretary-General of the United Nations shall be empowered to pay the expenses of the members of the Commission, if necessary, before reimbursement by 
the States Parties concerned, in accordance with paragraph 9 of this article.

\section{Article 43}

The members of the Committee, and of the ad hoc conciliation commissions which may be appointed under article 42, shall be entitled to the facilities, privileges and immunities of experts on mission for the United Nations as laid down in the relevant sections of the Convention on the Privileges and Immunities of the United Nations.

\section{Article 44}

The provisions for the implementation of the present Covenant shall apply without prejudice to the procedures prescribed in the field of human rights by or under the constituent instruments and the conventions of the United Nations and of the specialized agencies and shall not prevent the States Parties to the present Covenant from having recourse to other procedures for settling a dispute in accordance with general or special international agreements in force between them.

\section{Article 45}

The Committee shall submit to the General Assembly of the United Nations, through the Economic and Social Council, an annual report on its activities.

\section{PART V}

\section{Article 46}

Nothing in the present Covenant shall be interpreted as impairing the provisions of the Charter of the United Nations and of the constitutions of the specialized agencies which define the respective responsibilities of the various organs of the United Nations and of the specialized agencies in regard to the matters dealt with in the present Covenant.

\section{Article 47}

Nothing in the present Covenant shall be interpreted as impairing the inherent right of all peoples to enjoy and utilize fully and freely their natural weal th and resources.

\section{PART VI}

\section{Article 48}

1. The present Covenant is open for signature by any State Member of the United Nations or member of any of its specialized agencies, by any State Party to the Statute of the International Court of Justice, and by any other State which has been invited by the General Assembly of the United Nations to become a Party to the present Covenant.

2. The present Covenant is subject to ratification. Instruments of ratification shall be deposited with the Secretary-General of the United Nations.

3. The present Covenant shall be open to accession by any State referred to in paragraph 1 of this article.

4. Accession shall be effected by the deposit of an instrument of accession with the Secretary-General of the United Nations.

5. The Secretary-General of the United Nations shall inform all States which have signed this Covenant or acceded to it of the deposit of each instrument of ratification or accession.

Article 49

1. The present Covenant shall enter into force three months after the date of the deposit with the Secre tary-General of the United Nations of the thirty-fifth instrument of ratification or instrument of accession.

2. For each State ratifying the present Covenant or aceding to it after the deposit of the thirty-fifth instrument of ratification or instrument of accession, the present Covenant shall enter into force three months after the date of the deposit of its own instrument of ratification or instrument of accession.

\section{Article 50}

The provisions of the present Covenant shall extend to all parts of federal States without any limitations or exceptions.

\section{Article 51}

1. A ny State Party to the present Covenant may propose an amendment and file it with the Secretary-General of the United Nations. The Secretary-General of the United Nations shall thereupon communicate any proposed amendments to the States Parties to the present Covenant with a request that they notify him whether they favour a conference of States Parties for the purpose of considering and voting upon the proposals. In the event that at least one third of the States Parties favours such a conference, the SecretaryGeneral shall convene the conference under the auspices of the United Nations. Any amendment adopted by a majority of the States Parties present and voting at the conference shall be submitted to the General Assembly of the United Nations for approval.

2. Amendments shall come into force when they have been approved by the General Assembly of the United Nations and accepted by a two-thirds majority of the States Parties to the present Covenant in accordance with their respective constitutional processes. 3 . When amendments come into force, they shall be binding on those States Parties which have accepted them, other 
States Parties still being bound by the provisions of the present Covenant and any earlier amendment which they have accepted.

A rticle 52

Irrespective of the notifications made under article 48, paragraph 5, the Secretary-General of the United Nations shall inform all States referred to in paragraph I of the same article of the following particulars:

(a) Signatures, ratifications and accessions under article 48;

(b) The date of the entry into force of the present Covenant under article 49 and the date of the entry into force of any amendments under article 51.

\section{Article 53}

1. The present Covenant, of which the Chinese, English, French, Russian and Spanish texts are equally authentic, shall be deposited in the archives of the United Nations.

2. The Secretary-General of the United Nations shall transmit certified copies of the present Covenant to all States referred to in article 48.

\section{INTERNATIONAL COVENANT ON ECONOMIC, SOCIAL AND CULTURAL RIGHTS}

Adopted and opened for signature, ratification and accession by General Assembly resolution 2200A (XXI) of 16 December 1966

entry into force 3 January 1976, in accordance with article 27

\section{Preamble}

The States Parties to the present Covenant,

Considering that, in accordance with the principles proclaimed in the Charter of the United Nations, recognition of the inherent dignity and of the equal and inalienable rights of all members of the human family is the foundation of freedom, justice and peace in the world,

Recognizing that these rights derive from the inherent dignity of the human person,

Recognizing that, in accordance with the Universal Declaration of Human Rights, the ideal of free human beings enjoying freedom from fear and want can only be achieved if conditions are created whereby everyone may enjoy his economic, social and cultural rights, as well as his civil and political rights,

Considering the obligation of States under the Charter of the United Nations to promote universal respect for, and observance of, human rights and freedoms,

Realizing that the individual, having duties to other individuals and to the community to which he belongs, is under a responsibility to strive for the promotion and observance of the rights recognized in the present Covenant,
Agree upon the following articles:

PART I

\section{Article 1}

1. All peoples have the right of self-determination. By virtue of that right they freely determine their political status and freely pursue their economic, social and cultural development.

2. All peoples may, for their own ends, freely dispose of their natural wealth and resources without prejudice to any obligations arising out of international economic co-operation, based upon the principle of mutual benefit, and international law. In no case may a people be deprived of its own means of subsistence.

3. The States Parties to the present Covenant, including those having responsibility for the administration of Non-Self-Governing and Trust Territories, shall promote the realization of the right of self-determination, and shall respect that right, in conformity with the provisions of the Charter of the United Nations.

PART II

\section{Article 2}

1. Each State Party to the present Covenant undertakes to take steps, individually and through international assistance and co-operation, especially economic and technical, to the maximum of its available resources, with a view to achieving progressively the full realization of the rights recognized in the present Covenant by all appropriate means, including particularly the adoption of legislative measures.

2. The States Parties to the present Covenant undertake to guarantee that the rights enunciated in the present Covenant will be exercised without discrimination of any kind as to race, colour, sex, language, religion, political or other opinion, national or social origin, property, birth or other status.

3. Developing countries, with due regard to human rights and their national economy, may determine to what extent they would guarantee the economic rights recognized in the present Covenant to non-nationals.

\section{Article 3}

The States Parties to the present Covenant undertake to ensure the equal right of men and women to the enjoyment of all economic, social and cultural rights set forth in the present Covenant. 


\section{Article 4}

The States Parties to the present Covenant recognize that, in the enjoyment of those rights provided by the State in conformity with the present Covenant, the State may subject such rights only to such limitations as are determined by law only in so far as this may be compatible with the nature of these rights and solely for the purpose of promoting the general welfare in a democratic society.

\section{Article 5}

1. Nothing in the present Covenant may be interpreted as implying for any State, group or person any right to engage in any activity or to perform any act aimed at the destruction of any of the rights or freedoms recognized herein, or at their limitation to a greater extent than is provided for in the present Covenant.

2. No restriction upon or derogation from any of the fundamental human rights recognized or existing in any country in virtue of law, conventions, regulations or custom shall be admitted on the pretext that the present Covenant does not recognize such rights or that it recognizes them to a lesser extent.

PART III

\section{Article 6}

1. The States Parties to the present Covenant recognize the right to work, which includes the right of everyone to the opportunity to gain his living by work which he freely chooses or accepts, and will take appropriate steps to safeguard this right.

2. The steps to be taken by a State Party to the present Covenant to achieve the full realization of this right shall include technical and vocational guidance and training programmes, policies and techniques to achieve steady economic, social and cultural development and full and productive employment under conditions safeguarding fundamental political and economic freedoms to the individual.

\section{Article 7}

The States Parties to the present Covenant recognize the right of everyone to the enjoyment of just and favourable conditions of work which ensure, in particular:

(a) Remuneration which provides all workers, as a minimum, with:

(i) Fair wages and equal remuneration for work of equal valuewithout distinction of any kind, in particular women being guaranteed conditions of work not inferior to those enjoyed by men, with equal pay for equal work;

(ii) A decent living for themselves and their families in accordance with the provisions of the present Covenant;

(b) Safe and heal thy working conditions; (c) Equal opportunity for everyone to be promoted in his employment to an appropriate higher level, subject to no considerations other than those of seniority and competence;

(d) Rest, leisure and reasonable limitation of working hours and periodic holidays with pay, as well as remuneration for public holidays

Article 8

1. The States Parties to the present Covenant undertake to ensure:

(a) The right of everyone to form trade unions and join the trade union of his choice, subject only to the rules of the organization concerned, for the promotion and protection of his economic and social interests. No restrictions may be placed on the exercise of this right other than those prescribed by law and which are necessary in a democratic society in the interests of national security or public order or for the protection of the rights and freedoms of others;

(b) The right of trade unions to establish national federations or confederations and the right of the latter to form or join international trade-union $\sigma$ ganizations;

(c) The right of trade unions to function freely subject to no limitations other than those prescribed by law and which are necessary in a democratic society in the interests of national security or public order or for the protection of the rights and free doms of others;

(d) The right to strike, provided that it is exercised in conformity with the laws of the particular country.

2. This article shall not prevent the imposition of lawful restrictions on the exercise of these rights by members of the armed forces or of the police or of the administration of the State.

3. Nothing in this article shall authorize States Parties to the International Labour Organisation Convention of 1948 concerning Freedom of Association and Protection of the Right to Organize to take legislative measures which would prejudice, or apply the law in such a manner as would prejudice, the guarantees provided for in that Convention.

Article 9

The States Parties to the present Covenant recognize the right of everyone to social security, including social insurance.

\section{Article 10}

The States Parties to the present Covenant recognize that:

1. The widest possible protection and assistance should be accorded to the family, which is the natural and fundamental group unit of society, particularly for its establishment and while it is responsible for the care and education of dependent children. Marriage must 
be entered into with the free consent of the intending spouses.

2. Special protection should be accorded to mothers during a reasonable period before and after childbirth. During such period working mothers should be $x-$ corded paid leave or leave with adequate social security benefits.

3. Special measures of protection and assistance should be taken on behalf of all children and young persons without any discrimination for reasons of parentage or other conditions. Children and young persons should be protected from economic and social exploitation. Their employment in work harmful to their morals or health or dangerous to life or likely to hamper their normal development should be punishable by law. States should also set age limits below which the paid employment of child labour should be prohibited and punishable by law.

\section{A rticle 11}

1. The States Parties to the present Covenant recognize the right of everyone to an adequate standard of living for himself and his family, including adequate food, clothing and housing, and to the continuous improvement of living conditions. The States Parties will take appropriate steps to ensure the realization of this right, recognizing to this effect the essential importance of international co-operation based on free consent.

2. The States Parties to the present Covenant, recognizing the fundamental right of everyone to be free from hunger, shall take, individually and through international co-operation, the measures, including specific programmes, which are needed:

(a) To improve methods of production, conservation and distribution of food by making full use of technical and scientific knowledge, by disseminating knowledge of the principles of nutrition and by developing or reforming agrarian systems in such a way as to achieve the most efficient development and utilization of natural resources;

(b) Taking into account the problems of both foodimporting and food-exporting countries, to ensure an equitable distribution of world food supplies in relation to need.

\section{A rticle 12}

1. The States Parties to the present Covenant recognize the right of everyone to the enjoyment of the highest attainable standard of physical and mental health.

2. The steps to be taken by the States Parties to the present Covenant to achieve the full realization of this right shall include those necessary for:

(a) The provision for the reduction of the stillbirth-rate and of infant mortality and for the healthy development of the child;

(b) The improvement of all aspects of environmental and industrial hygiene;

(c) The prevention, treatment and control of epidemic, endemic, occupational and other diseases; (d) The creation of conditions which would assure to all medical service and medical attention in the event of sickness.

A rticle 13

1. The States Parties to the present Covenant recognize the right of everyone to education. They agree that education shall be directed to the full development of the human personality and the sense of its dignity, and shall strengthen the respect for human rights and fundamental freedoms. They further agree that education shall enable all persons to participate effectively in a free society, promote understanding, tolerance and friendship among all nations and all racial, ethnic or religious groups, and further the activities of the United N ations for the maintenance of peace.

2. The States Parties to the present Covenant recognize that, with a view to achieving the full realization of this right:

(a) Primary education shall be compulsory and available free to all;

(b) Secondary education in its different forms, including technical and vocational secondary education, shall be made generally available and accessible to all by every appropriate means, and in particular by the progressive introduction of free education;

(c) Higher education shall be made equally accessible to all, on the basis of capacity, by every appropriate means, and in particular by the progressive introduction of free education;

(d) Fundamental education shall be encouraged or intensified as far as possible for those persons who have not received or completed the whole period of their primary education;

(e) The development of a system of schools at all levels shall be actively pursued, an adequate fellowship system shall be established, and the material conditions of teaching staff shall be continuously improved.

3. The States Parties to the present Covenant undertake to have respect for the liberty of parents and, when applicable, legal guardians to choose for their children schools, other than those established by the public authorities, which conform to such minimum educational standards as may be laid down or approved by the State and to ensure the religious and moral education of their children in conformity with their own convictions.

4. No part of this article shall be construed so as to interfere with the liberty of individuals and bodies to establish and direct educational institutions, subject always to the observance of the principles set forth in paragraph I of this article and to the requirement that the education given in such institutions shall conform to such minimum standards as may be laid down by the State. 
Article 14

Each State Party to the present Covenant which, at the time of becoming a Party, has not been able to secure in its metropolitan territory or other territories under its jurisdiction compulsory primary education, free of charge, undertakes, within two years, to work out and adopt a detailed plan of action for the progressive implementation, within a reasonable number of years, to be fixed in the plan, of the principle of compulsory education free of charge for all.

\section{Article 15}

1. The States Parties to the present Covenant recognize the right of everyone:

(a) To take part in cultural life;

(b) To enjoy the benefits of scientific progress and its applications;

(c) To benefit from the protection of the moral and material interests resulting from any scientific, literary or artistic production of which he is the author.

2. The steps to be taken by the States Parties to the present Covenant to achieve the full realization of this right shall include those necessary for the conservation, the development and the diffusion of science and culture.

3. The States Parties to the present Covenant undertake to respect the freedom indispensable for scientific re search and creative activity.

4. The States Parties to the present Covenant recognize the benefits to be derived from the encouragement and development of international contacts and cooperation in the scientific and cultural fields.

PART IV

Article 16

1. The States Parties to the present Covenant undertake to submit in conformity with this part of the Covenant reports on the measures which they have adopted and the progress made in achieving the observance of the rights recognized herein.

2.

(a) All reports shall be submitted to the SecretaryGeneral of the United Nations, who shall transmit copies to the Economic and Social Council for consideration in accordance with the provisions of the present Covenant;

(b) The Secretary-General of the United Nations shall also transmit to the specialized agencies copies of the reports, or any relevant parts therefrom, from States Parties to the present Covenant which are also members of these specialized agencies in so far as these reports, or parts therefrom, relate to any matters which fall within the responsibilities of the said agencies in accordance with their constitutional instruments.
Article 17

1. The States Parties to the present Covenant shall furnish their reports in stages, in accordance with a programme to be established by the Economic and Social Council within one year of the entry into force of the present Covenant after consultation with the States Parties and the specialized agencies concerned.

2. Reports may indicate factors and difficulties affecting the degree of fulfilment of obligations under the present Covenant.

3. Where relevant information has previously been furnished to the United Nations or to any specialized agency by any State Party to the present Covenant, it will not be necessary to reproduce that information, but a precise reference to the information so furnished will suffice.

\section{Article 18}

Pursuant to its responsibilities under the Charter of the United Nations in the field of human rights and fundamental freedoms, the Economic and Social Council may make arrangements with the specialized agencies in $\mathrm{e}$ spect of their reporting to it on the progress made in achieving the observance of the provisions of the present Covenant falling within the scope of their activities. These reports may include particulars of decisions and recommendations on such implementation adopted by their competent organs.

\section{Article 19}

The Economic and Social Council may transmit to the Commission on Human Rights for study and general recommendation or, as appropriate, for information the reports concerning human rights submitted by States in accordance with articles 16 and 17, and those concerning human rights submitted by the specialized agencies in accordance with artide 18.

\section{Article 20}

The States Parties to the present Covenant and the specialized agencies concerned may submit comments to the Economic and Social Council on any general recommendation under article 19 or reference to such general recommendation in any report of the Commission on Human Rights or any documentation referred to therein.

\section{Article 21}

The Economic and Social Council may submit from time to time to the General Assembly reports with recommendations of a general nature and a summary of the information received from the States Parties to the present Covenant and the specialized agencies on the measures taken and the progress made in achieving general observance of the rights recognized in the present Covenant. 
A rticle 22

The Economic and Social Council may bring to the attention of other organs of the United Nations, their subsidiary organs and specialized agencies concerned with furnishing technical assistance any matters arising out of the reports referred to in this part of the present Covenant which may assist such bodies in deciding, each within its field of competence, on the advisability of international measures likely to contribute to the effective progressive implementation of the present Covenant.

\section{A rticle 23}

The States Parties to the present Covenant agree that international action for the achievement of the rights recognized in the present Covenant includes such methods as the condusion of conventions, the adoption of recommendations, the furnishing of technical assistance and the holding of regional meetings and technical meetings for the purpose of consultation and study organized in conjunction with the Governments concerned.

\section{A rticle 24}

Nothing in the present Covenant shall be interpreted as impairing the provisions of the Charter of the United $N$ ations and of the constitutions of the specialized agencies which define the respective responsibilities of the various organs of the United $\mathrm{N}$ ations and of the specialized agencies in regard to the matters dealt with in the present Covenant.

\section{A rticle 25}

Nothing in the present Covenant shall be interpreted as impairing the inherent right of all peoples to enjoy and utilize fully and freely their natural weal th and resources.

PART V

\section{A rticle 26}

1. The present Covenant is open for signature by any State Member of the United Nations or member of any of its specialized agencies, by any State Party to the Statute of the International Court of Justice, and by any other State which has been invited by the General A ssembly of the United Nations to become a party to the present Covenant.

2. The present Covenant is subject to ratification. Instruments of ratification shall be deposited with the Secretary-General of the United Nations.

3. The present Covenant shall be open to accession by any State referred to in paragraph 1 of this article.

4. Accession shall be effected by the deposit of an instrument of accession with the Secretary-General of the United Nations.
5. The Secretary-General of the United Nations shall inform all States which have signed the present Covenant or acceded to it of the deposit of each instrument of ratification or accession.

A rticle 27

1. The present Covenant shall enter into force three months after the date of the deposit with the Secre tary-General of the United Nations of the thirty-fifth instrument of ratification or instrument of accession.

2. For each State ratifying the present Covenant or aceding to it after the deposit of the thirty-fifth instrument of ratification or instrument of accession, the present Covenant shall enter into force three months after the date of the deposit of its own instrument of ratification or instrument of accession.

\section{A rticle 28}

The provisions of the present Covenant shall extend to all parts of federal States without any limitations or exceptions.

\section{Article 29}

1. Any State Party to the present Covenant may propose an amendment and file it with the Secretary-General of the United Nations. The Secretary-General shall there upon communicate any proposed amendments to the States Parties to the present Covenant with a request that they notify him whether they favour a conference of States Parties for the purpose of considering and voting upon the proposals. In the event that at least one third of the States Parties favours such a conference, the Secretary-General shall convene the conference under the auspices of the United Nations. Any amendment adopted by a majority of the States Parties present and voting at the conference shall be submitted to the General Assembly of the United Nations for approval.

2. Amendments shall come into force when they have been approved by the General A ssembly of the United Nations and accepted by a two-thirds majority of the States Parties to the present Covenant in accordance with their respective constitutional processes.

3. When amendments come into force they shall be binding on those States Parties which have accepted them, other States Parties still being bound by the provisions of the present Covenant and any earlier amendment which they have accepted.

\section{CONVENTION FOR THE PROTECTION OF HUMAN RIGHTS AND FUNDAMENTAL FREEDOMS (ECPHR)}

The governments signatory hereto, being members of the Council of Europe, 
Considering the Universal Declaration of Human Rights proclaimed by the General Assembly of the United Nations on 10th December 1948;

Considering that this Declaration aims at securing the universal and effective recognition and observance of the Rights therein declared;

Considering that the aim of the Council of Europe is the achievement of greater unity between its members and that one of the methods by which that aim is to be pursued is the maintenance and further realisation of human rights and fundamental freedoms;

Reaffirming their profound belief in those fundamental freedoms which are the foundation of justice and peace in the world and are best maintained on the one hand by an effective political democracy and on the other by a common understanding and observance of the human rights upon which they depend;

Being resolved, as the governments of European countries which are like-minded and have a common heritage of political traditions, ideals, freedom and the rule of law, to take the first steps for the collective enforcement of certain of the rights stated in the Universal Declaration, Have agreed as follows:

\section{Article 1 - 0 bligation to respect human rights}

The High Contracting Parties shall secure to everyone within their jurisdiction the rights and freedoms defined in Section I of this Convention.

Section I - Rights and freedoms

\section{Article 2- Right to life}

1. Everyone's right to life shall be protected by law. No one shall be deprived of his life intentionally save in the execution of a sentence of a court following his conviction of a crime for which this penalty is provided by law.

2. Deprivation of life shall not be regarded as inflicted in contravention of this article when it results from the use of force which is no more than absolutely necessary:

(a) in defence of any person from unlawful violence;

(b) in order to effect a lawful arrest or to prevent the escape of a person lawfully detained;

(c) in action lawfully taken for the purpose of quelling a riot or insurrection.

\section{Article 3 - Prohibition of torture}

No one shall be subjected to torture or to inhuman or degrading treatment or punishment.

A rticle 4 - Prohibition of slavery and forced labour

1. No one shall be held in slavery or servitude.
2. No one shall be required to perform forced or compulsory labour.

3. For the purpose of this article the term "forced or compulsory labour" shall not include:

(a) any work required to be done in the ordinary course of detention imposed according to the provisions of Article 5 of this Convention or during conditional release from such detention;

(b) any service of a military character or, in case of conscientious objectors in countries where they are recognised, service exacted instead of compulsory military service;

(c) any service exacted in case of an emergency or calamity threatening the life or well-being of the community;

(d) any work or service which forms part of normal civic obligations.

Article 5 - Right to liberty and security

1. Everyone has the right to liberty and security of person. No one shall be deprived of his liberty save in the following cases and in accordance with a procedure prescribed by law:

(a) the lawful detention of a person after conviction by a competent court;

(b) the lawful arrest or detention of a person for noncompliance with the lawful order of a court or in order to secure the fulfilment of any obligation prescribed by law;

(c) the lawful arrest or detention of a person effected for the purpose of bringing him before the competent legal authority on reasonable suspicion of having committed an offence or when it is reasonably considered necessary to prevent his committing an offence or fleeing after having done so;

(d) the detention of a minor by lawful order for the purpose of educational supervision or his lawful detention for the purpose of bringing him before the competent legal authority;

(e) the lawful detention of persons for the prevention of the spreading of infectious diseases, of persons of unsound mind, alcoholics or drug addicts or vagrants;

(f) the lawful arrest or detention of a person to prevent his effecting an unauthorised entry into the country or of a person against whom action is be ing taken with a view to deportation or extradition.

2. Everyone who is arrested shall be informed promptly, in a language which he understands, of the reasons for his arrest and of any charge against him.

3. Everyone arrested or detained in accordance with the provisions of paragraph 1.c of this article shall be brought promptly before a judge or other officer authorised by law to exercise judicial power and shall be entitled to trial within a reasonable time or to $\mathrm{e}$ lease pending trial. Release may be conditioned by guarantees to appear for trial.

4. Everyone who is deprived of his liberty by arrest or detention shall be entitled to take proceedings by which the lawfulness of his detention shall be decided 
speedily by a court and his release ordered if the detention is not lawful.

5. Everyone who has been the victim of arrest or detention in contravention of the provisions of this article shall have an enforceable right to compensation.

\section{A rticle 6 - Right to a fair trial}

1. In the determination of his civil rights and obligations or of any criminal charge against him, everyone is entitled to a fair and public hearing within a reasonable time by an independent and impartial tribunal established by law. Judgment shall be pronounced publicly but the press and public may be excluded from all or part of the trial in the interests of morals, public order or national security in a democratic society, where the interests of juveniles or the protection of the private life of the parties so require, or to the extent strictly necessary in the opinion of the court in special circumstances where publicity would prejudice the interests of justice.

2. Everyone charged with a criminal offence shall be presumed innocent until proved guilty according to law.

3. Everyone charged with a criminal offence has the following minimum rights:

(a) to be informed promptly, in a language which he understands and in detail, of the nature and cause of the accusation against him;

(b) to have adequate time and facilities for the preparation of his defence;

(c) to defend himself in person or through legal \$sistance of his own choosing or, if he has not sufficient means to pay for legal assistance, to be given it free when the interests of justice so require

(d) to examine or have examined witnesses against him and to obtain the attendance and examination of witnesses on his behalf under the same conditions as witnesses against him;

(e) to have the free assistance of an interpreter if he cannot understand or speak the language used in court.

A rticle 7 - No punishment without law

1. No one shall be held guilty of any criminal offence on account of any act or omission which did not constitute a criminal offence under national or international law at the time when it was committed. Nor shall a heavier penalty be imposed than the one that was applicable at the time the criminal offence was committed.

2. This artide shall not prejudice the trial and punishment of any person for any act or omission which, at the time when it was committed, was criminal according to the general principles of law recognised by civilised nations.

Article 8 - Right to respect for private and family life

1. Everyone has the right to respect for his private and family life, his home and his correspondence.
2. There shall be no interference by a public authority with the exercise of this right except such as is in acordance with the law and is necessary in a democratic society in the interests of national security, public safety or the economic well-being of the country, for the prevention of disorder or crime, for the protection of health or morals, or for the protection of the rights and freedoms of others.

\section{A rticle 9 - Freedom of thought, conscience and religion}

1. Everyone has the right to freedom of thought, conscience and religion; this right includes freedom to change his religion or belief and freedom, either alone or in community with others and in public or private, to manifest his religion or belief, in worship, teaching, practice and observance.

2. Freedom to manifest one's religion or beliefs shall be subject only to such limitations as are prescribed by law and are necessary in a democratic society in the interests of public safety, for the protection of public order, health or morals, or for the protection of the rights and freedoms of others.

A rticle 10 - Freedom of expression

1. Everyone has the right to freedom of expression. This right shall include freedom to hold opinions and to re ceive and impart information and ideas without interference by public authority and regardless of frontiers. This article shall not prevent States from requiring the licensing of broadcasting, television or cinema enterprises.

2. The exercise of these freedoms, since it carries with it duties and responsibilities, may be subject to such formalities, conditions, restrictions or penalties as are prescribed by law and are necessary in a democratic society, in the interests of national security, territorial integrity or public safety, for the prevention of disorder or crime, for the protection of health or morals, for the protection of the reputation or rights of others, for preventing the disclosure of information received in confidence, or for maintaining the authority and impartiality of the judiciary.

A rticle 11 - Freedom of assembly and association

1. Everyone has the right to freedom of peaceful assembly and to freedom of association with others, including the right to form and to join trade unions for the protection of his interests.

2. No restrictions shall be placed on the exercise of these rights other than such as are prescribed by law and are necessary in a democratic society in the interests of national security or public safety, for the prevention of disorder or crime, for the protection of health or morals or for the protection of the rights and freedoms of others. This article shall not prevent the imposition of lawful restrictions on the exercise of these rights by members of the armed forces, of the police or of the administration of the State. 


\section{Article 12 - Right to marry}

Men and women of marriageable age have the right to marry and to found a family, according to the national laws governing the exercise of this right.

Article 13 - Right to an effectiveremedy

Everyone whose rights and freedoms as set forth in this Convention are violated shall have an effective remedy before a national authority notwithstanding that the violation has been committed by persons acting in an official capacity.

\section{Article 14 - Prohibition of discrimination}

The enjoyment of the rights and freedoms set forth in this Convention shall be secured without discrimination on any ground such as sex, race, colour, language, religion, political or other opinion, national or social origin, association with a national minority, property, birth or other status.

\section{A rticle 15 - D erogation in time of emergency}

1. In time of war or other public emergency threatening the life of the nation any High Contracting Party may take measures derogating from its obligations under this Convention to the extent strictly required by the exigencies of the situation, provided that such measures are not inconsistent with its other obligations under international law.

2. No derogation from Article 2, except in respect of deaths resulting from lawful acts of war, or from Articles 3, 4 (paragraph 1) and 7 shall be made under this provision.

3. Any High Contracting Party availing itself of this right of derogation shall keep the Secretary General of the Council of Europe fully informed of the measures which it has taken and the reasons therefor. It shall also inform the Secretary General of the Council of Europe when such measures have ceased to operate and the provisions of the Convention are again being fully executed.

Article 16 - Restrictions on political activity of aliens

Nothing in Articles 10, 11 and 14 shall be regarded as preventing the High Contracting Parties from imposing restrictions on the political activity of aliens.

\section{A rticle 17 - Prohibition of abuse of rights}

Nothing in this Convention may be interpreted as implying for any State, group or person any right to engage in any activity or perform any act aimed at the destruction of any of the rights and freedoms set forth herein or at their limitation to a greater extent than is provided for in the Convention.
Article 18- Limitation on use of restrictions on rights

The restrictions permitted under this Convention to the said rights and freedoms shall not be applied for any purpose other than those for which they have been prescribed.

\section{PROTOCOL TO THE ECPHR}

The governments signatory hereto, being members of the Council of Europe

Being resolved to take steps to ensure the collective enforcement of certain rights and freedoms other than those already included in Section I of the Convention for the Protection of Human Rights and Fundamental Freedoms signed at Rome on 4 N ovember 1950 (hereinafter referred to as "the Convention"),

Have agreed as follows:

\section{A rticle 1 - Protection of property}

Every natural or legal person is entitled to the peaceful enjoyment of his possessions. No one shall be deprived of his possessions except in the public interest and subject to the conditions provided for by law and by the general principles of international law.

The preceding provisions shall not, however, in any way impair the right of a State to enforce such laws as it deems necessary to control the use of property in accordance with the general interest or to secure the payment of taxes or other contributions or penalties.

\section{A rticle 2 - Right to education}

No person shall be denied the right to education. In the exercise of any functions which it assumes in relation to education and to teaching, the State shall respect the right of parents to ensure such education and teaching in conformity with their own religious and philosophical convictions.

Article 3 - Right to free elections

The High Contracting Parties undertake to hold free elections at reasonable intervals by secret ballot, under conditions which will ensure the free expression of the opinion of the people in the choice of the legislature.

\section{Article 4 - Territorial application}

Any High Contracting Party may at the time of signature or ratification or at any time thereafter communicate to the Secretary General of the Council of Europe a declaration stating the extent to which it undertakes that the provisions of the present Protocol shall apply to such of the territories for the international relations of which it is responsible as are named therein.

Any High Contracting Party which has communicated a declaration in virtue of the preceding paragraph may from time to time communicate a further declaration modifying 
the terms of any former declaration or terminating the application of the provisions of this Protocol in respect of any territory.

A declaration made in accordance with this article shall be deemed to have been made in accordance with paragraph 1 of Article 56 of the Convention.

\section{A rticle 5 - Relationship to the Convention}

As between the High Contracting Parties the provisions of Articles 1, 2, 3 and 4 of this Protocol shall be regarded as additional articles to the Convention and all the provisions of the Convention shall apply accordingly.

\section{PRotocol No. 4 TO THE ECPHR}

The governments signatory hereto, being members of the Council of Europe,

Being resolved to take steps to ensure the collective enforcement of certain rights and freedoms other than those already included in Section 1 of the Convention for the Protection of Human Rights and Fundamental Freedoms signed at Rome on 4th November 1950 (hereinafter re ferred to as the "Convention") and in Articles 1 to 3 of the First Protocol to the Convention, signed at Paris on 20th March 1952,

Have agreed as follows:

\section{A rticle 1 - Prohibition of imprisonment for debt}

No one shall be deprived of his liberty merely on the ground of inability to fulfil a contractual obligation.

\section{A rticle 2 - Freedom of movement}

1. Everyone lawfully within the territory of a State shall, within that territory, have the right to liberty of move ment and freedom to choose his residence.

2. Everyone shall be free to leave any country, including his own.

3. No restrictions shall be placed on the exercise of these rights other than such as are in accordance with law and are necessary in a democratic society in the interests of national security or public safety, for the maintenance of ordre public, for the prevention of crime, for the protection of health or morals, or for the protection of the rights and freedoms of others.

4. The rights set forth in paragraph 1 may also be subject, in particular areas, to restrictions imposed in accordance with law and justified by the public interest in a democratic society.

\section{A rticle 3 - Prohibition of expulsion of nationals}

1. No one shall be expelled, by means either of an individual or of a collective measure, from the territory of the State of which he is a national.

2. No one shall be deprived of the right to enter the territory of the state of which he is a national.
A rticle 4 - Prohibition of collective expulsion of aliens

Collective expulsion of aliens is prohibited.

\section{A rticle 5 - Territorial application}

1. A ny High Contracting Party may, at the time of signature or ratification of this Protocol, or at any time thereafter, communicate to the Secretary General of the Council of Europe a declaration stating the extent to which it undertakes that the provisions of this Protocol shall apply to such of the territories for the international relations of which it is responsible as are named therein.

2. Any High Contracting Party which has communicated a declaration in virtue of the preceding paragraph may, from time to time, communicate a further declaration modifying the terms of any former declaration or terminating the application of the provisions of this Protocol in respect of any territory.

3. A declaration made in accordance with this article shall be deemed to have been made in accordance with paragraph 1 of Article 56 of the Convention.

4. The territory of any State to which this Protocol applies by virtue of ratification or acceptance by that State, and each territory to which this Protocol is applied by virtue of a declaration by that State under this article, shall be treated as separate territories for the purpose of the references in Articles 2 and 3 to the territory of a State.

5. A ny State which has made a declaration in accordance with paragraph 1 or 2 of this Article may at any time thereafter declare on behalf of one or more of the territories to which the declaration relates that it accepts the competence of the Court to receive applications from individuals, non-governmental organisations or groups of individuals as provided in Article 34 of the Convention in respect of all or any of Articles 1 to 4 of this Protocol.

\section{A rticle 6 - Relationship to the Convention}

As between the High Contracting Parties the provisions of Articles 1 to 5 of this Protocol shall be regarded as additional Articles to the Convention, and all the provisions of the Convention shall apply accordingly.

\section{PROTOCOL NO. 6 TO THE ECPHR}

The member States of the Council of Europe, signatory to this Protocol to the Convention for the Protection of Human Rights and Fundamental Freedoms, signed at Rome on 4 N ovember 1950 (hereinafter referred to as "the Convention"),

Considering that the evolution that has occurred in several member States of the Council of Europe expresses a general tendency in favour of abolition of the death penalty;

Have agreed as follows: 


\section{A rticle 1 - A bolition of the death penalty}

The death penalty shall be abolished. No-one shall be condemned to such penalty or executed.

\section{A rticle 2 - Death penalty in time of war}

A State may make provision in its law for the death penalty in respect of acts committed in time of war or of imminent threat of war; such penalty shall be applied only in the instances laid down in the law and in accordance with its provisions. The State shall communicate to the Secretary General of the Council of Europe the relevant provisions of that law.

\section{Article 3 - Prohibition of derogations}

No derogation from the provisions of this Protocol shall be made under Article 15 of the Convention.

\section{Article 4 - Prohibition of reservations}

No reservation may be made under Article 57 of the Convention in respect of the provisions of this Protocol.

\section{Article 5 - Territorial application}

1. Any State may at the time of signature or when de positing its instrument of ratification, acceptance or approval, specify the territory or territories to which this Protocol shall apply.

2. Any State may at any later date, by a declaration addressed to the Secretary General of the Council of Europe, extend the application of this Protocol to any other territory specified in the declaration. In respect of such territory the Protocol shall enter into force on the first day of the month following the date of receipt of such declaration by the Secretary General.

3. Any declaration made under the two preceding paragraphs may, in respect of any territory specified in such declaration, be withdrawn by a notification addressed to the Secretary General. The withdrawal shall become effective on the first day of the month following the date of receipt of such notification by the Secre tary General.

\section{Article 6 - Relationship to the Convention}

As between the States Parties the provisions of Articles 1 to 5 of this Protocol shall be regarded as additional artides to the Convention and all the provisions of the Convention shall apply accordingly.

\section{PRotocol NO. 7 TO THE ECPHR}

The member States of the Council of Europe signatory hereto,

Being resolved to take further steps to ensure the collective enforcement of certain rights and freedoms by means of the Convention for the Protection of Human Rights and
Fundamental Freedoms signed at Rome on 4 November 1950 (hereinafter referred to as "the Convention"),

Have agreed as follows :

Article 1 - Procedural safeguards relating to expulsion of aliens

1. An alien lawfully resident in the territory of a State shall not be expelled therefrom except in pursuance of a decision reached in accordance with law and shall be allowed:

(a) to submit reasons against his expulsion,

(b) to have his case reviewed, and

(c) to be represented for these purposes before the competent authority or a person or persons designated by that authority.

2. An alien may be expelled before the exercise of his rights under paragraph 1.a, b and c of this Article, when such expulsion is necessary in the interests of public order or is grounded on reasons of national security.

A rticle 2 - Right of appeal in criminal matters

1. Everyone convicted of a criminal offence by a tribunal shall have the right to have his conviction or sentence reviewed by a higher tribunal. The exercise of this right, including the grounds on which it may be exercised, shall be governed by law.

2. This right may be subject to exceptions in regard to offences of a minor character, as prescribed by law, or in cases in which the person concerned was tried in the first instance by the highest tribunal or was convicted following an appeal against acquittal.

\section{Article 3 - Compensation for wrongful conviction}

When a person has by a final decision been convicted of a criminal offence and when subsequently his conviction has been reversed, or he has been pardoned, on the ground that a new or newly discovered fact shows conclusively that there has been a miscarriage of justice, the person who has suffered punishment as a result of such conviction shall be compensated according to the law or the practice of the State concerned, unless it is proved that the non-disclosure of the unknown fact in time is wholly or partly attributable to him.

A rticle 4 - Right not to be tried or punished twice

1. No one shall be liable to be tried or punished again in criminal proceedings under the jurisdiction of the same State for an offence for which he has already been finally acquitted or convicted in accordance with the law and penal procedure of that State.

2. The provisions of the preceding paragraph shall not prevent the reopening of the case in accordance with the law and penal procedure of the State concerned, if there is evidence of new or newly discovered facts, or if there has been a fundamental defect in the previous proceedings, which could affect the outcome of the case. 
3. No derogation from this Article shall be made under Article 15 of the Convention.

Article 5 - Equality between spouses

Spouses shall enjoy equality of rights and responsibilities of a private law character between them, and in their relations with their children, as to marriage, during marriage and in the event of its dissolution. This Article shall not prevent States from taking such measures as are necessary in the interests of the children.

A rticle 6 - Territorial application

1. Any State may at the time of signature or when de positing its instrument of ratification, acceptance or approval, specify the territory or territories to which the Protocol shall apply and state the extent to which it undertakes that the provisions of this Protocol shall apply to such territory or territories.

2. Any State may at any later date, by a declaration addressed to the Secretary General of the Council of Europe, extend the application of this Protocol to any other territory specified in the declaration. In respect of such territory the Protocol shall enter into force on the first day of the month following the expiration of a period of two months after the date of receipt by the Secretary General of such declaration.

3. Any declaration made under the two preceding paragraphs may, in respect of any territory specified in such dedaration, be withdrawn or modified by a notification addressed to the Secretary General. The withdrawal or modification shall become effective on the first day of the month following the expiration of a period of two months after the date of receipt of such notification by the Secretary General.

4. A declaration made in accordance with this Article shall be deemed to have been made in accordance with paragraph 1 of Article 56 of the Convention.

5. The territory of any State to which this Protocol applies by virtue of ratification, acceptance or approval by that State, and each territory to which this Protocol is applied by virtue of a declaration by that State under this Article, may be treated as separate territories for the purpose of the reference in Article 1 to the territory of a State.

6. A ny State which has made a dedaration in accordance with paragraph 1 or 2 of this Article may at any time thereafter dedare on behalf of one or more of the territories to which the declaration relates that it accepts the competence of the Court to receive applications from individuals, non-governmental organisations or groups of individuals as provided in Article 34 of the Convention in respect of Articles 1 to 5 of this Protocol.

Article 7 - Relationship to the Convention

As between the States Parties, the provisions of Article 1 to 6 of this Protocol shall be regarded as additional Artides to the Convention, and all the provisions of the Convention shall apply accordingly. 


\section{REFERENCES}

A

A bensour, M. (1997) ........................ da démocratie contre l'Etat, M arx et le moment machiavélien, Presses Universitaires de France, Paris

Adviesr. Int. Vraagstukken (1998)

rsaliteit van de rechten van de mens en culturele verscheidenheid, advies nr. 4, Den Haag

Akehurst, M. (1991) A M odern Introduction to International Law, Harper Collins, London

Alliot, M. (1995) ............................. roits de l'homme et autres traditions, in Le Courrier de Juristes-Solidarités, 10

A merican A nthropologist (1947) ......Statement on Human Rights, 49.4

Ankersmit, F.R. (1997) ....................M acht door representatie, Kok A gora/ Pleckmans, Kampen/ Kapellen

Arendt, H. (1970) .......................... n n Violence, Harcourt/ Brace, San Diego/ New York/ London

Arendt, H. (1979) ........................... The O rigins of T otalitarianism, Harcourt/ Brace, San Diego/ New York/ London

Arendt, H. (1982) .............................ectures on Kant's Political P hilosophy, University of Chicago Press, Chicago

Arendt, H. (1983) ...........................Condition de l'homme moderne, Calmann-Lévy, Paris

Arendt, H. (1990) ............................. n Revolution, Penguin Books, Harmondsworth

Arendt, H. (1992) .......................... La crise de la culture, Gallimard, Paris

Arendt, H. (1994) ........................... ussen verleden en toekomst, Garant, Leuven/ A peldoorn

Aristotle(1998) Politics, Oxford University Press, Oxford/ New York

\section{$\mathbf{B}$}

Baechler, J. (1994).........................P récis de la démocratie, Calmann-Lévy/ UNESCO, Paris

Baehr, P.R. (1991)...........................D e rechten van de mens, een universeel aandachtsgebied, Boom, Meppel/ Amsterdam

Baehr, P.R. (1998)...........................D e rechten van de mens: universaliteit in de praktijk, Boom, Amsterdam

Barber, B.R. (1984) .........................Strong D emocracy, Participatory Politics for a N ew A ge, University of California Press, Berkeley/ Los Angeles

Barber, B.R. (1998) .........................M ore D emocracy!, M ore Revolution!, in The N ation, 26/ 10

Barro, R.J. (1996) ............................ emocracy and Growth, in Journal of E conomic Growth, 1

Barro, R.J. (1997) ............................D eterminants of Economic Growth, A Cross-Country Empirical Study, MIT, Cambridge/ London

Batiffol, H. (1960) .......................... La philosophie du droit, PUF, Paris

Bauer/ Bell (1999)......................... The East A sian Challenge for H uman Rights, Cambridge University Press

Beatty/ Johnson (ed.) (1987)...........H eritage of W estern Civilization, V olume II, Prentice-Hall, N ew Jersey

Beetham, D. (ed.) (1995)................Politics and H uman Rights, Blackwell, Oxford

Béji, H. (1997)................................Equivalence des cultures et tyrannie des identités, in Esprit, 228

Bell, D. (1997)..............................A Communitarian Critique of A uthoritarianism, The Case of Singapore, in Political Theory, 25.1

Berlin, I. (1996) ...............................T wee opvattingen van vrijheid, Boom, A msterdam/ Meppel

Bielefeldt, H. (1995) ........................M uslim V oices in the H uman Rights D ebate, in H uman Rights Q uarterly, 17.4

Brems, E. (1999) ............................ H uman Rights, U niversality and D iversity, Katholieke Universiteit Leuven, Leuven (proefschrift)

Burke, E. (1960)............................R eflections on the French Revolution, Harvard Classics, Collier, New York

Cassese, A . (1992).......................... International Law in a Divided W orld, Clarendon Press, Oxford

Castoriadis, C. (1991) .....................Philosophy, Politics, A utonomy, Odéon/ Oxford University Press, New York/ Oxford

Chatelet, F. (1975) ...........................e Capital, Profil d'une oeuvre, Hatier, Paris

Chong Ho Yu .................................Chinese Ethics and U niversal H uman Rights, http:/ / seamonkey.ed.asu.edu/ alex/ ed

Civis M undi (1993)........................U niversaliteit van de mensenrechten (themanummer), 32, 2

Cliteur, P.B. (1997)........................D e fil osofie van mensenrechten, Ars A equi Libri, Nijmegen

Cohen/ Fermon (ed.) (1996)...........P rinceton R eadings in Political Thought, Princeton University Press, Princeton 
de Benoist, A. (1979)..... ..Les idées à l'endroit, Hallier, Paris

De Tavernier/ Pollefeyt (ed.) (1998) . ..H eeft

de traditie van de mensenrechten toekomst?, Acco, Leuven/ Amersfoort,

De Visscher, J. (1992) D e zorg voor het avondland, Kok Agora-DNB/ Pelckmans, Kampen

De Visscher, J. (1997) Levende traditie, Damon, Best

DeVisscher/ Van den Bossche/

Weyembergh (ed.) (1992)........... H annah A rendt en de moderniteit, Kok Agora, Kampen

De Vlieghere, M. (1994)...................D e geschiedenis van het parlement en de 'rule of law', O ver de geschiedkundige veronderstelingen achter Friedrich A. H ayeks rechtsfilosofie, in Tijdschrift voor sociale wetenschappen, Universiteit Gent, nr. 1, 39ste jaargang

Denayer, W. (1994) ........................M ichel Foucault over macht in relatie met schaarste en mimese, in Tijdschrift voor sociale wetenschappen, Universiteit Gent, nr. 1, 39ste jaargang

Derichs, $\mathrm{Cl}$. D er westliche U niversalitätsanspruch aus nicht-westlicher Perspektive, Institut für Ostasienwissenschaften, Duisburg

Diamond, L. (1995)......................Promoting D emocracy in the 1990s, http:/ / www.ccpdc.org/ pubs/ diamond/ diamond.htm

Donnelly, J. (1996)..........................U niversal H uman Rights in Theory and Practice, Cornell University Press, Ithaca/ London

\section{$F$}

Finkielkraut, A . (1989) ...... ...D e ondergang van het denken, Contact, A msterdam

Finkielkraut, A. (1993) ..Zinloze herinnering, Contact, Amsterdam/ Antwerpen

Finkielkraut, A. (1996) ..La crise de la transmission, in Esprit, 227

Finkielkraut, A. (1997) ..D e verloren beschaving, Contact, Amsterdam/ Antwerpen

Foquél Weyembergh (ed.) (1997) ..Filosofische aspecten van het privépubliek debat, VUBPress, Brussel Fukuyama, F. (1992) ...The End of $\mathrm{H}$ istory and the Last $\mathrm{M}$ an, Penguin Books, Harmondsworth

Furet, F. (1996) ....H et verleden van een illusie, Meulenhoff/ Kritak, A msterdam

\section{$\mathbf{G}$}

Garapon, P. (1997) ...La fièvre identitaire, in Esprit, 228

Girardet, R. (1996). N ationalismes et nation, Ed. Complexe, Bruxelles

Guéhenno, J-M (1995) La fin de la démocratie, Flammarion, Paris

\section{H}

Hamilton/ Madison/ Jay (1954)...... n the Constitution, Selections from the Federalist Papers, Liberal Arts Press, New York Harrison, R. (1996) ........................D emocracy, Routledge, London/ N ew York Held, D. (1998)...............................M odels of D emocracy, Polity Press, Cambridge Hersch, J. (1988) ..............................Pourqu oi I' homme a-t-il des droits?, in A mnesty Suisse, 1 Hersch, J. (1991) ............................. Le concept des droits de l'homme est-il un concept universel? , in Cadmos, 14 Hinkmann, J. (1996) ........................Philosophische A rgumente für und wider die U niversalität der M enschenrechte, Tectum Verlag, Marburg

Hobbes, T. (1984) ............................ eviathan, Penguin, Harmondsworth

Hottois/ Van den Bossche/ Weyembergh (ed.) (1994)..........Richard Rorty, Hadewijch, Antwerpen/ Baarn

\section{K}

Kant, I. (1992) ...W at is verlichting?, Kok A gora, Kampen

Kausikan, B. (1993) A sia's Different Standard, in Foreign Policy, 32.92

Kekes, J. (1999)... .A gainst Liberalism, Cornell University Press, Ithaca/ London

Khushalani, Y. (1983). Human Rights in A sia and A frica, in H uman Rights Law Journal, 4

Kooijmans, P.H. (1994)

Koolschijn, G. (1996) Internationaal publiekrecht in vogelvlucht, Wolters-N oordhoff, Groningen

Kymlicka, W. (1997) Plato, D e strijd tegen het democratische beest, Ooievaar, A msterdam Contemporary Political Philosophy, Clarendon Press, Oxford

\section{L}

Lefort, C. (1992) Het democratisch tekort, Boom, M eppel/ A msterdam

Lefort, C. (1994) L'invention démocratique, Fayard, Paris 
Leleux, C. (1997) .............................La démocratie moderne, les grandes théories, Cerf, Paris

Le Roy, E. (1992) ..............................es fondements anthropologiques des droits de I' homme, Crise de l' universalisme et postmodernité, in Revue de la recherche juridique D roits prospectif, XVII-48

Little, D. (1996) .............................Tolerance, Equal Freedom, and Peace, in U nited States Institute for Peace

Locke, J. (1994)............................... ver het staatsbestuur, Boom, A msterdam

\section{M}

Machiavelli, N. (1980) The Prince, NAL Penguin, New York

Mahbubani, K. (1993) ...................The Dangers of D ecadence, W hat the Rest Can Teach the W est, in Foreign A ffairs, Sept/ Oct 1993

Mahbubani, K. (1995) ....................The Pacific W ay, in Foreign A ffairs, 74.1

Maier, H. (1997) .............................W ie universal sind die M enschenrechte?, Herder Verlag, Freiburg/ Basel/ Wien

Manglapus, R. (1978)..................... u uman Rights A re N ot a W estern Discovery, in W orldview , 4

Maritain, J. (1989) ..........................es droits de l' homme et la loi naturelle, Desclée de Brouwer, Paris

Marx, K. (1992) .............................. a apital, A Student Edition, Lawrence \& Wishart, London

Marx/ Engels (1985) .......................The Communist M anifesto, Penguin Books, Harmondsworth

Mau Tse-Toeng (1967) ................... et rode boekje, Bruna, Utrecht/ Antwerpen

McLellan, D. (1986a)....................... arx, Fontana Press/ Harper Collins, London

McLellan, D. (1986b).......................The Thought of Karl M arx, Second Edition, MacMillan, London/ Basingstoke

Memmi, A. (1997) ..........................es fluctuations de l' identité culturelle, in Esprit, 228

Meuwissen, D.H.M. (1984) ............G rondrechten, Spectrum, Utrecht/ Antwerpen

Mill, J.S. (1946) ................................Considerations on Representative Government, Basil Blackwell, Oxford

Mill, J.S. (1977) ............................... n Liberty, Classics of W estern Philosophy, Hackett, Indianapolis/ Cambridge

Montesquieu (1998) ....................... v ver de geest der wetten, Boom, Amsterdam/ Meppel

Mourgeon, J. (1996)......................... es droits de l' homme, PUF, Paris

\section{N}

Nagel, T. (1995).......

..Personal Rights and Public Space, in Philosophy and Public A ffairs, 24

Nelson, W.N. (1980) ..On Justifying D emocracy, Routledge and Kegan, London

O'Rourke, P.J. (1993) ..G eef oorlog een kans, Prometheus, A msterdam

\section{P}

Paine, Th. (1992) ..........................Rechten van de mens, Pelckmans, Kapellen

Paine, Th. (1995) ...........................The Crisis, Penguin Books, Harmondsworth

Panikkar, R. (1984)........................A D ial ogue on H uman Rights, in Interculture, XVII, 2, 83

Popper, K. (1991)...........................The P overty of H istoricism, Routledge, London/ New York

Popper, K. (1995) ..........................The 0 pen Society and its Enemies, Routledge, London

\section{Q}

Qian Qichen/ Zhao Qizheng/

Zhu Muzhi (1998)
.Zum G edenken des 50. Jahrestages der Allgemeinen M enschenrechtserklärung, Lecture at a Symposium in Beijing

\section{$\mathbf{R}$}

Rawls, J. (1999) A Theory of Justice, Oxford University Press, Oxford

Rials, S. (1982) Textes constitutionnels français, Presses Universitaires de France, Paris

Robertson, G. (1999). .Crimes A gainst H umanity, The Struggle for Global Justice, Allen Lane/ Penguin Press, Harmondsworth 
Sen, A. (1997). .H uman Rights and A sian Values, in The N ew Republic, 07/ 1997

Sinha, S.P. (1981) H uman Rights, A N on-W estern V iewpoint, in A rchiv für Rechts- und Sozialphilosophie, 67

Sinha, S.P. (1984) Freeing H uman Rights from N atural Rights, in A rchiv für Rechts- und Sozial philosophie, 70

Sohn/ Buergenthal (1973) International Protection of $\mathrm{H}$ uman Rights, Bobbs-Merrill, New York

Suy, E. (1992). Corpus I uris Gentium, Acco, Leuven/ A mersfoort

\section{T}

Taylor, Ch. (1994) D e mal ai se van de moderniteit, Kok Agora/ Pelckmans, Kampen/ Kapellen

Taylor, Ch. (1996) .D e politieke cultuur van de moderniteit, Kok Agora/ Pleckmans, Kampen/ Kapellen

Thomassen, J.J .A . (1981) D emocratie, theorie en praktijk, Samson, Alphen aan den Rijn/ Brussel

Tucker, R.C. (ed.) (1978) ..The M arx-Engels R eader, W. W. Norton, New York/ London

Tugendhat, E. (1993) Die Kontroverse um die M enschenrechte, in A nalyse und Kritik, 15

van der Graaf, M. (1996)... ...M ensenrechten in spiegel beeld, Damon van Weers, A.J.M. (1989) De rechten van de mens en de filosofie van de persoon, Kok Agora, Kampen Velaers, J. (1996) .W etboek Publiek Recht, deel 1, Maklu, Antwerpen/ A peldoorn

Vienna D eclaration and Programme of A ction (1993), A dopted by the W orld Conference on H uman Rights, doc UN

A/ CONF.157/ 23

\section{W}

Weyembergh/ Van den Bossche

(ed.) (1995)

Het einde van de geschiedenis?, SUN, Nijmegen

World Bank (1993) ...The East-A sian M iracle, Washington

\section{X}

Xiaorong Li (1998). Postmodernism and U niversal H uman Rights, in http:/ / www.SecularHumanism.org/ library/ fi/ 


\section{ALPHABETICAL INDEX}

\section{A}

\section{A bi-Saab $\cdot 283$}

absolute $\cdot 5,14,21,24,60,62,105$, $120,127,128,133,134,138,183$, $212,231,233,248,249,258,262$, 263, 267, 279, 284, 295

absolute majority $\cdot 231,233,295$

absolute relativism $\cdot 133$

absolutely free $\cdot 178$

absolutism · 45, 48, 128

abstain $\cdot 42,54,68,168,169,212$

abstention $\cdot 54,170$

abstract · 10, 14, 60, 74, 84, 111, 140, $208,209,211,224,225$

abundance $\cdot 166$

acceptability $\cdot$ 204, 217, 222, 227, 285

acceptable $\cdot 3,4,15,17,24,25,44$, $46,52,67,68,91,104,114,119$, $127,129,134,147,166,182,183$, $184,185,188,202,203,204,205$, $208,210,212,213,217,222,223$, $225,229,234,242,254,255,256$, $258,263,275,283,297$

accountability $\cdot$ 62, 72, 90, 219, 273

accountable $\cdot 62,88,91,94,154,222$, $239,240,242,275$

accumulation $\cdot 153$

active $\cdot 3,19,30,40,42,82,91,92$, $93,94,100,101,104,151,155$, $166,167,184,191,203,205,216$, 226, 227

active citizens $\cdot 104$

activity $\cdot 13,14,18,22,23,27,32,34$, $39,55,81,83,90,91,92,104,155$, $170,171,173,185,198,223,224$, 252, 256, 264, 268, 290, 291, 300, 302, 306

actor $\cdot 85,110,222$

acts of state $\cdot 112,133$

a-cultural $\cdot 140$

Adams $\cdot 163$

adherents $\cdot 4,43,44,101,220$

administration $\cdot 34,84,104,202,273$, 291, 299, 300, 305

administrative $\cdot 171,291$

admissibility $\cdot 99$

adults $\cdot 74,203,249,255,292$

advance guard $\cdot 181$

adventures $\cdot 179$

adversarial $\cdot 7,138,140,156,191$

advocates $\cdot 86,135,146,160$

Africa $\cdot 129,311$

African $\cdot 123,129,146,157$

A frican Charter $\cdot 146$

African democracy $\cdot 129$

agenda $\cdot 79,80,92,99$

agenda setting $\cdot 92$ agendas $\cdot 224$

aggregate $\cdot 76,87,93,98$

aggression · 36, 166, 180, 181, 184

$186,226,263$

agnosticism $\cdot 41,42$

agreements · 107, 179, 236

Akehurst $\cdot 146,186,188,310$

alien $\cdot 25,31,79,119,120,125,148$

$186,188,292,308$

alien subjugation $\cdot 186,188$

alienate $\cdot 184,192$

alienation $\cdot 95,193$

aliens $\cdot 64,68,103,286,306,307,308$

allies $\cdot 42,123,177$

almighty $\cdot 148,239$

alternatives $\cdot 5,73,74,152,175,184$, 205, 250

altruism · 168, 247, 248, 255, 270

a-morality $\cdot 129,199$

amusement $\cdot 166$

an eye for an eye - 136

anarchism · 16, 250, 261, 262, 263

anarchy $\cdot 33,39,140,154,217,218$

238, 267

Ancient Rome $\cdot 167$

anger $\cdot 99,180$

animal $\cdot 164,208,211$

Ankersmit · 48, 85, 101, 239, 310

antagonism · 39, 61, 67, 129

antagonistic $\cdot 7,130,138,177,191$

anthropologists $\cdot 126$

anti-democratic $\cdot 1,7,11,13,42,44$ $116,177,178,199,227,241,258$ 280

anti-democrats $\cdot 6,225,226,227,285$

anti-individual $\cdot 142$

anti-natural rights $\cdot 165$

anti-politics $\cdot 91,228,263$

anti-racism $\cdot 85,284$

anti-Semitism · 128, 134

anti-social $\cdot 52,97,142,268,270$

apathetic. 99, 100, 101, 196

apathy $\cdot 91,101,238$

apostasy $\cdot 135$

apostates $\cdot 2,134$

arbitrariness $\cdot 202,240$

arbitrary . 5, 16, 20, 23, 29, 31, 95, 97, 199, 202, 210, 222, 223, 224 , 226, 264, 265, 286, 288, 289, 292 , 293

arbitrary arrest $\cdot 29,286,288,292$

archaic. 181

arena $\cdot 157$

Arendt $\cdot$ 20, 21, 23, 27, 50, 54, 60, 85, $92,108,110,112,163,167,219$, 220, 229, 246, 260, 263, 265, 279, 310, 311

argumentation $\cdot 28,38,76,77,79,86$, $94,125,199,202,205,220,222$, 223, 224 arguments $\cdot 4,5,6,7,9,12,14,21$, $23,25,76,78,79,80,85,92,98$, 99, 100, 138, 191, 198, 199, 201, 202, 204, 207, 216, 220, 221, 222, $223,225,226,230,246,279$

aristocracy $\cdot 10,16,52,59,90,198$, 201, 272

aristocratic $\cdot 97$

aristocrats $\cdot 203$

A ristotle $\cdot 93,94,104,310$

arithmetic $\cdot 86,101,199$

armies $\cdot 181$

arms $\cdot 38,85,125,177,279$

arms race $\cdot 177$

army $\cdot 203$

arrogance $\cdot 137,208$

artifact $\cdot 32,119,136$

Asia $\cdot 15,123,152,311$

Asian · 16, 122, 123, 124, 129, 130, 159, 310, 313

Asian democracy $\cdot 129,130$

Asian values · 16, 122, 123, 124, 159

Asians · 124, 133

aspirations $\cdot 136,170,172,210$

assemblies $\cdot$ 29, 92, 93, 96, 100

assembly · 29, 31, 63, 86, 94, 100, $140,154,196,197,286,289,294$, 305

assertive $\cdot 207$

assimilate $\cdot 115,126$

assimilation $\cdot 120,124$

assist $\cdot 6,14,36,80,94,126,140,155$, $157,158,168,169,171,172,173$, $183,184,185,202,211,238,255$, $279,290,293,299,300,301,303$, 305

assistance · $36,126,157,168,169$, $171,172,184,211,238,255,279$, 290, 293, 299, 300, 301, 303, 305

associate $\cdot 29,63,65,71,80,107,191$ association - 28, 29, 101, 104, 140, 144, 154, 197, 286, 289, 305, 306

associations · 50, 88, 101, 107, 154, 191, 193

asylum $\cdot 115,172,289$

asylum seeker $\cdot 115$

atomism $\cdot 140$

atomization $\cdot 139$

attack - 38, 41, 43, 47, 107, 120, 131, $136,145,146,164,176,177,179$, 220, 252

attentiveness $\cdot 73,104$

attitude $\cdot 1,40,69,103,124,181,260$

attractive $\cdot 4,71,233$

attractiveness · 44, 231, 233, 244

Auden $\cdot 24$

Auschwitz $\cdot 128$

authentic $\cdot 127,148,299$

authoritarian · 10, 11, 18, 24, 26, 35, $44,48,56,60,67,80,121,122$, 
$123,124,129,139,146,151,152$, $153,155,156,157,158,159,171$ $176,181,183,185,187,190,191$, 192, 197, 219, 227, 238, 275

authoritarian rule $\cdot 11,56,121,123$, $139,157,171,219,227$

authoritarianism $\cdot 15,16,123,130$, $139,151,157,159,181,284$

authority $\cdot 20,26,44,45,48,65,83$, $96,112,119,121,123,124,126$, $128,130,136,159,197,208,218$ $225,287,289,291,293,304,305$, 306, 308

authors $\cdot 83,93,180$

autonomous $\cdot 24,30,31,32,45,166$, $214,244,245,247,248,249,250$, $251,254,256,259,265$

autonomy $\cdot 3,8,14,45,50,61,91$, $92,93,139,144,165,169,188$, 191, 193, 194, 229, 244, 245, 246, $247,248,249,250,251,252,254$, $255,256,257,258,259,260,261$, $262,263,264,265,268,269,270$, 271

aware $\cdot 21,23,60,73,100,114,128$, $147,157,167,174,184,192,207$, $210,214,219,221,254$

\section{B}

back-seat driving $\cdot 87$ backward $\cdot 123,151,181$

Baehr $\cdot 125,310$

balance $\cdot 9,49,67,96,102,103,177$, $188,221,222,271$

balance of power $\cdot 177$

Balkans $\cdot 192$

ballot $\cdot 87$

Bangkok NGO Declaration on Human Rights · 132

barbaric 183

barbarism · 126, 183

Barber $\cdot 14,42,60,61,66,79,81,90$ $91,92,93,94,95,98,99,105,168$, $198,217,222,223,224,225,226$, $228,240,270,310$

bargaining $\cdot 87,168$

basic needs $\cdot 159,162,163,164,165$, $167,168,169,173,174,257$

basic norms · 46, 143, 149

basic rights $\cdot 284$

basic values $\cdot 92$

Bauer/ Bell · 6, 151, 310

beautiful $\cdot 126$

Beetham · 24, 55, 56, 57, 58, 61, 72, $127,132,133,134,136,138,148$, $155,157,241,277,310$

behavior $\cdot 24,25,30,45,69,74,96$, $97,111,112,134,137,177,228$, $232,245,260,268,279$

behind bars $\cdot 60,148$

Belgium · 112, 176

bellum justum $\cdot 180$

belonging $\cdot 23,25,29,64,78,79,80$, $108,126,140,141,143,145,146$,
$164,166,170,188,191,203,260$, 279, 294

beneficial $\cdot 2,37,40,45,55,70,99$, $123,136,151,153,155,216,236$, $238,250,255,262,263,275$

benefit $\cdot 27,42,43,46,57,97,138$, $162,163,170,173,212,214,234$, 235, 257, 291, 293, 299, 302

benefits $\cdot 40,41,42,43,51,67,68$, $80,104,107,114,121,161,169$, $171,173,177,182,186,187,212$, 231, 234, 235, 236, 237, 239, 241, $248,251,290,301,302$

benevolent · 156, 213

benevolent dictator $\cdot 213$

Berlin · 239, 245, 255, 271, 310, 312

Bible $\cdot 48$

big government $\cdot 105,239,240$

bigness $\cdot 95$

bill of duties $\cdot 283$

bill of rights $\cdot 283$

biological $\cdot 107,109,162,164,165$, 245

biological needs $\cdot 162,165,245$

biologically $\cdot 248$

biology $\cdot 25,211,267$

birth $\cdot 64,92,112,210,226,278,288$, 291, 294, 299, 306

blacksmith $\cdot 202$

bodily matters $\cdot 164$

bodily sensations $\cdot 164$

body $\cdot 27,32,37,50,51,60,61,66$, $85,95,96,107,134,135,136,146$, $162,164,166,180,198,274,283$

body of human rights · $134,146,180$, 283

body of rights $\cdot 283$

body politic $\cdot 107$

border $\cdot 24,33,42,53,190,236,242$, 248,269

borders $\cdot 25,44,60,116,130,146$, 188, 286, 289

boundaries $\cdot 21,30,60,61,96,188$, 189, 261

bourgeois $\cdot 16,58$

bourgeoisie $\cdot 52,58,59,84$

brain drain $\cdot 155$

Brazil $\cdot 158$

bribery $\cdot 87$

brutal $\cdot 49,181$

budgetary control $\cdot 84$

burdens $\cdot 170,171,237,283$

bureaucracy $\cdot 20,34,105,202,239$

bureaucratic $\cdot 56,238$

Burke $\cdot 86,310$

business class $\cdot 228$

businesses $\cdot 171$

by lot $\cdot 97,295$

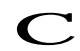

cacophonic · 218

calculations $\cdot 202$

Calvin and Hobbes · 136

candidate $\cdot 12,90,171,210$ capabilities $\cdot 74,95,102,240$

capital $\cdot 67,94,99,235,292$

capital punishment · 94, 99, 292

capitalism · 58, 59, 125, 131, 159, 251, 252

capitalist $\cdot 59,213,251,252$

care $\cdot 7,24,25,61,100,103,140,166$, $169,177,240,247,248,255,287$, 290, 300

careers $\cdot 152$

caricature $\cdot 101$

caritas $\cdot 168,267$

Cassese $\cdot 274,283,310$

cast system $\cdot 133$

Castoriadis · 5, 6, 20, 27, 32, 197, 202, 250,310

Catholic $\cdot 48,127$

Catholicism · 11, 43, 48, 121

central government $\cdot 95,96$

centralized · 95, 192, 193, 194, 281

centrifugal $\cdot 146$

centripetal $\cdot 182$

centuries - 45, 86, 119, 135, 136, 181, 184

certain knowledge $\cdot 9,73,201$

certainty · 14, 15, 16, 42, 71, 176, 201, 216, 218, 221, 222, 224, 225

challenge $\cdot 1,112,167,204,205$

challenges $\cdot 226,227$

chaos $\cdot 78,115,140,190,191,216$, $217,218,263$

character $\cdot 22,56,60,85,90,97,108$, $180,199,223,231,238,269,292$, 295, 304, 308, 309

charisma $\cdot 90,93,99$

charismatic 129

chauvinism $\cdot$ 173, 193, 208

cheap products $\cdot 160$

checks and balances $\cdot 273$

children · 6, 24, 34, 68, 74, 97, 102, $110,156,168,169,203,204,208$, 254, 256, 287, 290, 293, 294, 300, 301,309

China $\cdot 56,65,123,124,130,148$

Chinese $\cdot 4,123,158,299,310$

choice $\cdot 8,15,24,25,43,48,52,63$, $67,73,74,75,77,78,79,85,88$, $90,97,99,100,101,121,137,141$, $145,152,156,158,168,180,183$, 184, 194, 197, 201, 212, 220, 222 , $223,227,233,239,246,248,249$, $250,256,257,258,271,286,287$, 293, 294, 300, 306

Christ $\cdot 85$

Christian · 2, 4, 48, 211

Christianity · 49, 131, 208, 211

Christians $\cdot 47,224$

church · 20, 24, 43, 45, 48, 128, 163, $192,245,246,256$

churches · 20, 22, 93

Churchill $\cdot 93$

circumstances - 10, 13, 41, 55, 56, 67 , $68,69,71,72,92,95,97,118,119$, $129,130,134,153,168,169,172$, $180,184,187,189,196,198,201$, 
$213,221,222,223,224,251,260$, 280, 282, 285, 290, 292, 293, 305 citizenry $\cdot 91,93,222,234$ citizenship · 3, 14, 37, 110, 113, 114, $115,117,168,224$

civil disobedience $\cdot 34,187$

civil liberties · 105, 157, 272

civil rights $\cdot 13,16,18,105,272,305$

civil servants $\cdot 75,194$

civil society · $30,31,32,33,59,101$, $105,155,238,264,265$

civil strife $\cdot 179$

civil war $\cdot 180,182,188,190$

civilization · 42, 181, 207, 208, 209, 295

civilized · 126, 181

claims · 6, 44, 45, 46, 47, 59, 61, 71, $95,110,111,112,121,125,128$, $129,139,143,152,154,160,167$, $172,190,205,214,221,225,235$, 239, 269, 296

darity $\cdot 16,33,85,216,218$

class $\cdot 6,48,49,52,57,74,84,86,99$, $102,107,153,173,207,210,211$, 213

class rule $\cdot 213$

classes · 52, 102, 108, 152, 162, 210, 211, 214, 237, 275, 276

classic . 56, 190

classical rights $\cdot 161,162,163,164$, 166, 167, 168, 170, 171, 172

Clausewitz $\cdot 180$

Clemenceau $\cdot 279$

climate $\cdot 119,170,242$

Cliteur $\cdot$ 136, 310

coalition governments · $16,231,232$, 237

coalitions $\cdot 8,194,230,233$

coercion $\cdot 2,8,28,30,43,47,60,67$, $68,87,116,185,203,244,245$, $247,248,249,250,254,259,260$, $261,262,263,264,265,267,269$, 270, 281, 293

coexistence $\cdot 20,37,38,39,43,44,45$, 47, 48, 153, 191

cognitive $\cdot 5,221,223$

coherence $\cdot 156,259,274$

coherent · 12, 87, 126, 129, 160, 217

cohesion · 79, 101, 139, 159, 191, 192, 218

coincidence $\cdot 74,86,151,229$

cold war · 15, 123

collective $\cdot 3,14,16,18,32,45,59$, $61,72,75,78,87,127,138,143$, $144,145,146,147,218,236,237$, $239,264,304,306,307,308$

collective goal $\cdot 218$

collective good · 127, 138, 236

collective goods · 236

collective identity $\cdot 3,18$

collective right $\cdot 16,143,144,145$, 146, 147

collective rights $\cdot 16,143,145,146$, 147

collective rights of women $\cdot 144$

collective will $\cdot 78$ collectivism · 60, 78

collectivist $\cdot 123,143$

collectivity $\cdot 78,145$

colonial $\cdot 120,121,122,126,137,188$

colonialism · $120,122,123,124,126$, 128, 182, 194, 208

colonies - 128, 146, 186

colonization $\cdot 21,136,181$

colonizing $\cdot 181$

colony $\cdot 146$

colored people $\cdot$ 143, 144, 278

comfort · 162, 165, 169, 248

comfortable $\cdot 165,169$

commitment · 57, 91, 148

common action $\cdot 26,37,80,92,105$

$175,192,224,236,252$

common goal · 192, 193, 218

common human values $\cdot 118$

common identities · 245

common identity $\cdot 79,146$

common interest $\cdot 26,37,86,139$, 237, 281

common language $\cdot 113,146,237$

common opinion $\cdot 12,23,77,86,133$

common values · 14, 46, 108, 110, 227

common will $\cdot 41,78,79,87,98,113$ 140, 218

communal · 129, 130, 190, 191, 192, 193

communal divisions · 130

communal struggle $\cdot 130$

communication $\cdot 4,19,20,22,24,25$, $50,60,76,141,149,152,153,162$, 194, 240, 269, 270, 291, 296, 297

communism · 57, 59, 123, 211, 219, 220, 237, 258, 266

communist · 11, 35, 123, 152, 157, 220,252

communitarian · 130, 138, 140, 142

communitarians $\cdot 61$

communities · $3,11,44,45,46,49$, $67,75,78,80,85,91,93,95,100$, $125,138,140,141,143,145,184$ 190, 192, 193, 224, 242, 258, 270

community $\cdot 3,4,9,10,11,14,18$, $20,21,23,24,39,42,45,46,47$ $50,58,59,78,80,87,91,95,97$, $104,113,115,120,123,130,131$ $138,139,140,141,142,143,145$ $153,159,169,170,190,191,198$ $201,229,236,237,242,249,258$ 269, 270, 285, 287, 289, 290, 292, 293, 294, 299, 304, 305

community life $\cdot 4,9,18,91,104$ 138, 139, 140, 141, 143, 170, 201 community spirit · $123,138,139,142$, 169, 191

companies · 33, 55, 93, 156, 241, 252

compassion · 247, 255

compatible $\cdot 8,10,120,133,134,142$, $147,159,196,233,245,251,256$ $258,262,263,264,265,268,269$, $271,277,278,300$

competence . 30, 96, 136, 162, 204, $273,276,295,296,300,303,307$, 309 competent · 202, 203, 286, 288, 291, 292, 293, 302, 304, 308

competition · $32,48,87,139,140$, 191, 235, 237, 251

competitive $\cdot 12,46,70$ competitive elitism · 12

competitor $\cdot 160$

complacent $\cdot 153,159$

complain · 41, 185

complex · 56, 75, 99, 101, 102, 129

complexity · 72, 102, 216, 218

compromise · 39, 87, 98, 101, 194, 216, 231, 232, 237

compromises · 8, 9, 194, 216, 231, 232,233

computer · 94, 215

conceit $\cdot 128$

concerns · 40, 61, 77, 81, 88, 92, 103, 250, 283, 296

condemnations $\cdot 182$

confident · 31, 218

confirmation $\cdot 2,44,70,119,202$

conflict . 8, 9, 10, 18, 37, 38, 39, 40, $53,62,63,64,66,67,70,81,85$, $112,122,139,140,161,165,176$, 180, 189, 191, 201, 217, 219, 220, $221,223,225,226,237,270,274$, 275,284

conflicts $\cdot 8,9,10,18,22,36,37,38$, $39,47,63,130,139,140,166,179$, $180,182,191,199,216,217,218$, 219, 220, 223, 224, 225, 226, 231

conform · 31, 45, 69, 83, 91, 132, 133, $138,145,146,221,225,273,274$, 278,301

conformism · 22, 78, 134, 146, 245 , 246, 248, 249

Confucianism · 123, 124

confusion · 13, 20, 85, 216, 218, 283

connected $\cdot 1,10,11,13,27,29,31$, $32,43,51,82,92,101,113,114$, $120,159,175,191,192,193,262$, 263

conquer · 186, 234

conscience $\cdot 48,83,163,277,283,288$, 289, 293, 305

consensus · 2, 5, 25, 41, 45, 47, 67, $139,140,148,149,150,189,216$, $218,219,222,223,225,226,227$, 228, 229, 237

consensus-democracy $\cdot 194$

consent · 5, 72, 104, 183, 184, 185, $186,194,219,240,278,279,289$, 292, 294, 297, 301

conservatism $\cdot 229$

conservative $\cdot 274$

consistency $\cdot$ 85, 136, 156, 185

consociational democracy $\cdot 193$

Constant $\cdot 279$

constitution · $32,42,58,110,112,148$, $226,228,229,273,274,276,277$, 278, 279, 280, 288

constitutional · $20,32,54,88,112$, 193, 291, 298, 302, 303

constitutionality $\cdot 274$

constitutions · 112, 228, 282, 298, 303 
consultation · $87,175,217,296,297$, 302,303

consumer $\cdot 164,236$

consumer goods $\cdot 164$

consumption $\cdot 153,155,156,159,164$, $165,166,171,211$

content $\cdot 31,32,39,69,90,108,122$,

$124,136,145,147,149,180,197$

203, 204, 209, 220, 225, 273, 279

contestability $\cdot 224$

contestable $\cdot 224,261$

contestation $\cdot 44,66,67,122,130,204$

context · 9, 50, 126, 131, 207, 282, 283, 284

context-dependent $\cdot 128$

contextuality $\cdot 283$

continuation of life $\cdot 162,163$

continuity · 53, 119, 136, 216, 223, 276

contract $\cdot 60,226$

contradict · 30, 31, 33, 40, 45, 50, 64, $72,111,114,118,119,120,132$, $135,137,148,163,167,173,183$, 205, 211, 212, 213, 219, 225, 246, $258,271,273,274,275,284$

controversial · 6, 224

convention $\cdot 245,248,249$

conversation $\cdot 23,25,47,150,157$, 237

conviction $\cdot 4,5,6,14,29,31,35,42$, $52,78,135,153,166,191,204$, $217,218,226,249,256,258,259$, 293, 304, 308

cooperate $\cdot 80,96,155,192,193,194$ 243

cooperation $\cdot 3,7,92,95,140,156$, $159,175,182,189,193,194,218$, $234,237,242,243,270,288$

core - 135, 283, 287

corporal punishment $\cdot 121$

corrupt $\cdot 75,152$

corruption $\cdot 93,125,154,235,276$ costly $\cdot 170$

council $\cdot 89,93,99$

council meeting $\cdot 89,99$

councils $\cdot 93$

court of justice $\cdot 34,54,114,170$

court procedure $\cdot 35,37,112,279$

court-proceedings $\cdot 97$

courts of justice $\cdot 123,191,228$

cover up · 127, 150, 179, 213, 214

creativity $\cdot 108,155,229$

credibility · 157, 231, 232, 237, 240, 241

crime $\cdot 4,22,36,61,99,138,140$, $284,291,292,293,304,305,307$

crimes · 107, 112, 130, 169, 191, 289, 291, 292

crimes against humanity $\cdot 107,112$, 130

criminal $\cdot 20,24,36,38,52,53,75$, $209,263,288,292,293,305,308$

criminals $\cdot 68,203,204$

criterion $\cdot 74,146,164$

criticism $\cdot 1,19,31,32,40,41,45,56$, $58,59,60,73,78,94,121,122$,
$126,128,133,148,157,172,175$, 198, 199, 203, 219, 232, 243, 257 crusade $\cdot 181$

crusades $\cdot 49,126$

Cuba 65

cult of foundation $\cdot 228$

cultural $\cdot 1,6,7,10,11,16,19,34$, $50,52,81,107,113,115,116,118$, $119,120,121,122,123,124,125$, $126,127,128,129,130,131,132$, $133,134,135,136,137,138,139$, $140,141,144,145,146,148,149$, $153,158,159,162,163,182,184$, 194, 210, 227, 228, 282, 287, 289, 290, 291, 299, 300, 302

cultural argument - 120, 121, 122, $125,126,127,134,138,148,158$ cultural criticism $\cdot 133$

cultural determinism $\cdot 228$

cultural identities $\cdot 7,11,119,120$, $124,127,128,132,133,136,159$, 184

cultural identity $\cdot 16,113,115,116$, $118,120,121,122,123,124,125$, $126,127,132,133,134,135,137$, $139,144,146,153,158,159,182$, 227

cultural imperialism $\cdot 7,11,126,128$, $133,140,159,182$

cultural imperialists · 148

cultural life $\cdot 118,119,120,138,287$, 290, 302

cultural murder $\cdot 124$

cultural relativism · $16,126,127,128$, 130, 136, 137

cultural relativists $\cdot 128$

cultural values - 118, 119, 124, 127, 149, 159

culturally determined $\cdot 42,119,149$

culturally relative $\cdot 6,119,127$

culture $1,7,11,19,25,39,43,107$, $108,114,115,118,119,120,121$, $122,123,124,125,126,127,128$, $129,130,131,132,133,134,135$, $136,137,138,142,146,150,151$, $153,158,159,182,192,193,210$, 226, 227, 229, 255, 257, 294, 302, 310

cultures $\cdot 1,7,11,19,39,44,59,80$, $108,118,119,120,121,123,124$, $125,126,127,128,129,131,132$, $133,134,136,137,138,139,140$, $142,143,147,149,150,159,182$, $211,228,282,283,310$

custom · 41, 126, 291, 300

customs · $41,113,124,126,127,128$ cyclical $\cdot 164$

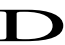

Dahl $\cdot 5,69,96,157,188,189,193$, $203,262,310$

dangerous · $31,32,37,39,48,55,59$, $63,87,104,114,122,131,167$,
$177,179,181,191,208,234,237$,

$248,255,258,280,284,301$

dark · 24, 163, 164

darkness $\cdot 29,49,50,163$

death penalty $\cdot 99,291,307,308$

debate $\cdot 1,3,5,9,12,14,15,21,28$,

$37,38,40,43,47,67,77,78,82$,

$94,98,99,100,101,121,191,199$

$216,217,220,221,224,225,274$

decay $\cdot 140,199$

decent $\cdot 161,162,163,171,172,300$

decentralization $\cdot 97,188$

decisive $\cdot 103,233$

decisiveness $\cdot 216,217,231,232,234$

D éclaration $\cdot 66,161,268,278$

Déclaration of $1793 \cdot 161$

D eclaration of Independence · 56

Declaration on the Right to Development · 163

decolonization $\cdot 145$

decomposition $\cdot 217,236$

defense $\cdot 1,36,42,55,60,121,122$,

$176,219,225,242,258,261,286$

definitions $\cdot 2,11,13,14,15,164$,

$189,210,212,244,271,283$

deformalization $\cdot 87,217$

degenerate $\cdot 12,37,40,152$

degrading · 160, 208, 209, 257, 288,

292, 304

degrading labor conditions · 160

delegates $\cdot 88,96$

delegation $\cdot 89$

delegitimize $\cdot 184$

deliberation $\cdot 14,86,91,92,94,100$,

198, 199, 203, 204, 205, 222, 223, 224

demagogy $\cdot 199$

democratic aspirations $\cdot 152$

democratic culture $\cdot 226,227,229$

democratic equality $\cdot 197,210$

democratic hangover $\cdot 155$

democratic imperialism $\cdot 15,181,182$

democratic oppression $\cdot 273,279$

democratic revolution $\cdot 186,187,228$

democratic rule of law · 31, 35, 265,

267, 277, 278

democratic separation $\cdot 187$

democratization $\cdot 65,183$

dependence $\cdot 159,169,207,248$

deportation $\cdot 114,116,304$

deportee $\cdot 114$

deregulated markets $\cdot 170$

Descartes $\cdot 225$

desert $\cdot$ 52, 53, 197, 208

desirability $\cdot 5,14,15,149,153,293$

desire $\cdot 15,19,68,83,85,98,116$,

$118,145,164,170,197,208,218$,

$234,236,254,278$

desires $\cdot 68,69,73,85,91,157,170$,

$172,189,244,254,255,260,266$

despair $\cdot 152$

despotism $\cdot$ 101, 105

destabilize $\cdot 158,172$

destabilizes $\cdot 162,190$

destabilizing $\cdot 152$

destiny $\cdot 42,191$ 
destruction - $24,43,125,144,183$, $217,226,227,258,281,290,291$, 300, 306

detachment $\cdot 162$

detail $\cdot 2,13,17,22,32,37,39,57$, $62,71,74,76,102,103,131,147$, $160,269,272,293,305$

détente $\cdot 177$

detention $\cdot 35,286,288,292,304,305$ detest $\cdot 204$

developing countries $\cdot 170$

developing country $\cdot 56,143$

development $\cdot 3,10,11,13,22,49$, $55,59,66,79,80,84,93,112,124$, $125,126,127,140,141,151,152$, $153,154,155,156,157,158,159$, $160,161,163,171,172,179,181$, 186, 211, 227, 229, 237, 254, 257, $258,267,274,283,288,289,290$, 291, 299, 300, 301, 302

development aid · 112, 171, 172, 179 deviant $\cdot 86$

Dewey 66

dialectical $\cdot 108$

dialogue $\cdot 20,21,133,150$

dialogue de sourds $\cdot 150$

dictator $\cdot 216$

dictatorial $\cdot$ 105, 216, 218, 272

dictators $\cdot 126,149$

dictatorship $\cdot 8,12,17,32,67,104$, $105,123,156,180,181,184,194$, 216, 228, 235, 240, 252, 272, 277 dictatorship of the majority $\cdot 8,12$, $17,105,194,272$

dictatorship of the minority $\cdot 194$

dictatorships · 123, 158

difference $\cdot 1,8,10,17,19,22,24,25$, $32,33,39,40,41,43,45,46,47$, $53,56,66,70,75,81,82,84,89$, $92,93,96,97,103,104,105,108$, $111,112,115,116,126,128,131$, $143,144,146,151,153,165,166$, $172,181,183,188,191,199,202$, 203, 205, 206, 211, 212, 214, 215, $221,246,254,276,280$

difference between society and the state $\cdot 104$

dignified $\cdot 172$

diplomacy $\cdot 15,182$

direct democracy $\cdot 13,23,74,81,82$, $83,87,88,89,90,91,92,93,94$, $95,98,99,100,101,102,104,105$, $198,223,234,235,237$

direct election $\cdot 88,230$

disadvantaged $\cdot 115,143$

disaffection $\cdot 226$

disagree $\cdot 40,89,149,204,222,260$

disagreement · 39, 101, 216, 219, 220, 260

disappointment $\cdot 231$

disarmament $\cdot 177$

disaster $\cdot$ 166, 282

discipline - 155, 159, 166, 175, 254, 260

disciplined $\cdot 124$

discontinuity $\cdot 216$ discord · 7, 191, 192, 193, 220

discriminate $\cdot 41,43,44,51,136,143$, 212,250

discriminated $\cdot 43,51,52,130,143$, 144, 191, 192, 193, 233, 235

discrimination $\cdot 43,51,52,114,122$ $128,133,135,136,143,144,145$, $152,173,208,212,235,256,267$ $271,278,286,288,289,291,294$, 299, 301, 306

discrimination of women $\cdot 128,133$, 135

discussion $\cdot 6,9,12,14,15,16,25$, $26,27,65,75,76,78,79,80,86$, $89,94,102,105,108,120,123$ $124,126,135,139,140,157,159$ $162,185,191,197,198,199,202$, $205,208,217,219,220,221,225$, $228,237,240,258,280$

disdain $\cdot 123$

disillusionment · 237

disintegration $\cdot 87,96,140,190,191$ disinterested $\cdot$ 99, 226

disposable · 207, 208

disproportional $\cdot 194,234,278$

dispute $\cdot 2,108,204,298$

dissident $\cdot 148$

dissidents $\cdot 122,179$

distance $\cdot$ 50, 95, 105, 164, 165, 248

distant places $\cdot 131$

district $\cdot 233$

distrust . 96, 125, 139, 193, 256

diversity $\cdot 1,3,26,39,40,42,43,45$, $47,67,115,119,120,122,124$, $126,127,131,132,133,136,137$, $141,143,146,149,153,175,211$ $212,220,221,223,225,228,283$

divided societies $\cdot 194$

divided society $\cdot 191$

dividends $\cdot 156$

divine $\cdot 32,134$

division · 19, 34, 66, 67, 116, 117, $191,211,214,217,235,276$

doctor $\cdot 166,255$

domination $\cdot 7,8,60,176,244,248$, $251,259,265,277$

dominos $\cdot 123$

Donnelly · 52, 56, 108, 111, 158, 161, 311

doubt $\cdot 2,15,42,43,96,119,148$ 216, 225

drug traffic $\cdot 182$

drugs · 241, 255

due process $\cdot 56,287$

dumb $\cdot 204$

durability $\cdot 27$

durable $\cdot 71$

duties - 39, 55, 110,111, 119, 127 , $137,138,139,140,141,142,154$, $155,159,168,169,171,173,260$, 283, 290, 294, 296, 299, 305

dwelling $\cdot 164$

dynamic $\cdot 41,67,78,157$

dynastical $\cdot 152$
E

earth $\cdot 44,45,115,270$

East-A sia $\cdot 157$

Eastern Europe $\cdot 152,157$

eastern rights $\cdot 283$

eating $\cdot 100,137,164$

ecological $\cdot 81,111,173,202$

economic argument · 152, 158

economic backwardness $\cdot 144$

economic crisis · 152, 217, 228

economic development . 7, 81, 118,

$123,124,125,151,152,153,154$,

$155,156,158,159,160,161,162$, 171,180

economic equality $\cdot 3,157,161,196$, 240, 267

economic freedom - 153, 251, 252, 266, 300

economic growth $\cdot 154,155,161,171$, 284

economic logic $\cdot 235,236$

economic paradise $\cdot 102$

economic policy $\cdot 151$

economic rights $\cdot 3,16,33,37,50,54$, $56,58,63,113,114,115,130,139$, $140,143,144,148,156,157,158$, $159,160,161,162,163,164,165$, $166,167,168,169,170,171,172$, $173,176,180,196,212,214,250$, 261, 267, 283, 284, 287, 299

economic ruin $\cdot 159$

economically disadvantaged · 144 , 154

economy · 3, 7, 9, 16, 25, 55, 95, 103, $146,151,152,153,154,155,156$, $158,159,160,164,169,171,176$, 191, 192, 193, 226, 227, 235, 238, $240,241,242,251,252,264,267$, 299

ECPHR · 35, 63, 130, 286, 287, 303, $306,307,308$

educated $\cdot 56,81,103,208$

educating $\cdot 34,166$

education $\cdot 5,9,22,23,24,40,63,73$, $74,75,81,93,102,124,152,154$, $162,202,213,214,219,236,237$, 254, 257, 284, 287, 288, 290, 294, $300,301,302,306$

effective $\cdot 12,30,55,64,79,89,113$, $121,122,139,159,166,181,192$, 193, 236, 276, 278, 282, 285, 288, 291, 294, 296, 303, 304, 306, 308, 309

effectiveness $\cdot 55,175,213$

efficiency $\cdot 8,9,16,91,102,112,151$, 216, 217

efficient - 87, 155, 216, 218, 232, 233, 301

effort $\cdot 2,7,24,43,57,103,153,185$, $197,208,216,218,228,239,254$, 289

egalitarian $\cdot 8,23,211$

egocentrism $\cdot 258,270$

egoism · 7, 40, 50, 58, 59, 113, 139, $141,142,178,248,249,258,270$ 
egoistic · 25, 52, 58, 59, 61, 64, 97, $121,122,123,160,192,199,248$, 251, 269

elected positions $\cdot$ 196, 231

election $\cdot 12,55,62,63,66,67,70,71$, $72,73,74,77,81,83,84,85,86$, $87,88,90,91,92,97,214,230$, 231, 232, 233, 235, 275, 295

elections - 12, 28, 37, 38, 62, 63, 64, $65,70,71,73,74,77,80,92,149$, 191, 214, 228, 230, 287, 289, 294, 306

electoral fidelity $\cdot 234$

electoral system · 230, 233

electorate - 12, 62, 63, 85, 86, 97, 101, 222, 230, 231

elite $\cdot 8,92,121,188,198,201,208$, $226,237,247,260$

elites · 92, 99, 121, 122, 125, 199, 247

elitism · 16, 102, 198, 208, 219, 227

elitist $\cdot 7,15,90,201$

e-mail $\cdot 94$

emancipating $\cdot 166$

emancipation $\cdot 24$

embezzlement $\cdot 154$

emergency · 38, 157, 285, 291, 292, 304, 306

emotional $\cdot$ 12, 46, 74, 79, 94, 99, 199

emotionality $\cdot 99$

emotions · 6, 94, 99, 166, 199

employers $\cdot 240$

employment $\cdot$ 85, 289, 300, 301

empowerment $\cdot 168$

enemies · 41, 42, 50, 66, 116, 211

enemy $\cdot 122,175$

enforce $\cdot 20,21,26,28,29,30,31,32$, $36,37,38,44,51,53,55,57,70$, $75,84,90,102,110,112,114,144$ $145,148,156,164,171,176,183$, $203,217,218,233,241,249,251$, $257,270,272,277,279,281,283$, 291, 306

enforceable · 30, 53, 69, 70, 108, 110, $111,137,155,170,172,292,305$

Engels · 282, 312

enlightened despot $\cdot 68$

Enlightenment · 131

entertaining $\cdot 90$

entertainment · 166

enthusiasm · 100, 258

enthusiastic · 155

entrepreneurs · 154, 171

environment · 95, 147, 202, 241, 242, 248

epistemological $\cdot 224$

equal citizenship $\cdot 147$

equal consideration · 9, 197, 207

equal development $\cdot 161$

equal dignity $\cdot 207$

equal influence $\cdot 9,63,197,205,207$, 235

equal opportunities $\cdot 161$

equal participation $\cdot 1,3,74,93,97$ $102,140,143,144,161,162,173$, 194, 196, 197, 198, 202, 216, 217, 218, 223, 266 equal possession $\cdot 162$

equal property $\cdot 214,252$

equal rights $\cdot 1,18,26,39,51,52,53$,

$63,130,143,161,173,188,196$,

197, 210, 213, 214, 215, 235, 257,

$266,278,280,288,289$

equal treatment $\cdot 52,143,145,218$

equal value $\cdot 207,208,209,210,300$

equal weight $\cdot 3,201,207$

equal worth $\cdot 207$

equality before the law - 143, 161, $210,212,213,214,215,266,279$

equality of freedom $\cdot 252$

equality of outcome $\cdot 199,212,213$

equality of procedure $\cdot 212,213$

equality of the sexes 134

equivalence $\cdot 7,128,207,208,256$

equivalent . 9, 30, 65, 108, 119, 127,

$128,137,199,202,210,246,249$,

$256,257,289$

erga omnes $\cdot 52,168$

error · 120, 184, 185, 201, 223, 237

errors · 21, 116, 122, 157, 184, 255

escalate $\cdot 180$

escalation · 39, 226

essence $\cdot 54,97,104,108,120,219$

essential · 14, 43, 64, 75, 102, 162, 288, 292, 301

ethical $\cdot 45,260,283$

ethical relativism $\cdot 283$

ethics · 149, 232

ethnic $\cdot 79,129,130,145,191,194$, 294, 301

ethnic census · 129

ethnocentric $\cdot 126,159$

$\mathrm{EU} \cdot 241$

eurocentric $\cdot 129$

eurocentrism $\cdot 140$

Europe $\cdot 134,151,181,303,304,306$, $307,308,309$

evil · 38, 54, 55, 56, 61, 148, 180, 188, $190,246,249,255,262,263,267$, 270

évolués $\cdot 145$

evolution $\cdot 226,307$

evolve $\cdot 27,283$

exaltation $\cdot 123$

exceptional $\cdot 14,29,67,94,148,184$, 207, 208, 292

exchange of opinions $\cdot 152$

exclusion · 74, 116, 117, 194, 219

exclusive norms · 46, 47

ex-colonies $\cdot 128$

excuse $\cdot 11,122,123,124,136,151$, $152,158,176,178,188,192,267$, 283, 285

execute $\cdot 44,83,85,86,87,105,203$, $222,230,231,232$

executive $\cdot 29,35,82,84,85,87,88$, $110,112,136,147,148,272,273$, $274,275,276$

executive functions $\cdot 82,147$

executive officers $\cdot 88$

executive power $\cdot 29,35,87,88,148$

exile $\cdot 116,288$

expansion $\cdot 168,182$ expansionist $\cdot 126$

expendable $\cdot 137,207$

expensive $\cdot 13,56,170,235$

experience $\cdot 3,14,18,99,119,124$,

$126,127,128,137,171,193,202$,

$208,225,270,276,282,295$

experimental $\cdot 223$

expert $\cdot$ 98, 201, 202, 275

expertise $\cdot 276$

experts $\cdot 20,75,102,198,201,202$, 298

exploitation · 125, 143, 171, 208, 213,

214, 301

expropriate $\cdot 147$

expropriation $\cdot 26,50$

expulsion $\cdot 202,286,293,307,308$

extenuating circumstances $\cdot 249$

extermination camps $\cdot 111$

external domination $\cdot 176$

extraordinary · 207, 208, 209

extreme $\cdot 7,59,87,90,96,117,123$,

$132,141,142,146,149,150,158$,

$159,164,179,181,182,187,190$,

191, 204, 217, 222, 232, 236, 237,

238, 270

extreme cases $\cdot 7,90,181,182$

extreme relativists $\cdot 149$

extremist $\cdot 227,232$

$F$

face-to-face $\cdot 93,94,97,98,153,169$, 193

factions $\cdot 48,190$

factory · 93, 131

facts $\cdot 5,13,49,64,76,77,94,119$, $120,126,165,167,170,184,202$, 216, 221, 227, 281, 297, 308

fair - $9,35,64,70,80,87,113,120$, $161,170,184,213,223,262,270$, $277,286,288,293,305$

fair distribution of prosperity $\cdot 170$

fair elections $\cdot 64$

fair trial $\cdot 213,277,305$

faith $\cdot 4,42,135,150,218,225,256$, 288

false $\cdot 22,35,144,156,198,202,221$, $267,272,274$

false blessing $\cdot 156$

family $\cdot 24,34,49,74,103,124,138$, 140, 141, 207, 276, 286, 288, 289, 290, 293, 294, 299, 300, 301, 305, 306

fanatically $\cdot 220$

fanaticism $\cdot 42$

fanatics $\cdot 42,225,227$

farmers $\cdot 166$

fashion $\cdot 14,94,145$

fatal $\cdot 178,203,214,237$

fatal ism · 10, 121

fate $\cdot 48,104,129,172,176,178,188$, $197,225,241,245,264$

fear $\cdot 4,35,36,39,45,57,99,124$, $132,140,147,193,216,217,232$ 238, 239, 248, 288, 290, 299 
federal · 95, 96, 147, 192, 193, 194, 203, 276, 281, 298, 303

federal system · 95, 96, 147, 194, 203, 276, 281

federalism · 95, 193

federation $\cdot 96$

feelings · $6,74,79,99,121,122,128$, $170,181,209,257,282$

female - 46, 132, 133, 134, 207

female circumcision $\cdot 132,133,134$

feminism $\cdot 215$

feminist $\cdot 145$

fertility $\cdot 134$

feudal $\cdot 59$

fifth column $\cdot 124$

financial · 56, 141, 156, 169, 171, 234

Finkielkraut · $23,137,165,166,218$, 311

first-past-the-post $\cdot 233$

fiscal revenues 176

Fishkin - 97

flagrant $\cdot 107$

flexibility $\cdot$ 17, 129, 130, 283, 284, 285

flexible $\cdot 129,147,193,282,284$

flight of capital $\cdot 111,155,241$

fluctuating $\cdot 198$

follow-thy-instructions $\cdot 87$

food $\cdot 25,56,156,162,251,271,290$, 301

forbearance $\cdot 32,54,55,56,58$

forced labor · 156

forced to be free $\cdot 254$

forcing people to be free $\cdot 166$

forefathers · 121, 229

foreign $\cdot 53,124,154,176,177,180$, $181,182,185,186,188,192,226$, 242

foreign affairs · 177

foreign investments · 154

foreign occupation · 176, 181

form of government $\cdot 3,5,8,13,28$, $32,53,57,65,69,71,86,101,104$, $128,143,146,151,152,155,159$, $167,186,187,190,192,201,205$, 214, 218, 227, 228, 250, 255

formal · $8,16,28,62,102,197,205$, $213,214,237$

formal equality $\cdot 16,213$

foundation · $2,5,14,44,116,133$, 140, 228, 229, 261, 288, 290, 299, 304

founding fathers $\cdot 229$

fragile $\cdot 18,28,110,112$

fragility $\cdot 28,53$

fragmentation · 96, 192, 193, 218, 236

France $\cdot 116,181,310,312$

franchise $\cdot 84$

fraternity $\cdot 181,261$

free choice $\cdot 78,155,166,172,175$, $184,185,226,248,258,289$

free competition $\cdot 235$

free flows of information $\cdot 65,72,77$, 154

free market · 32, 33, 152, 161, 171, 252, 266

free press $\cdot 154$ free speech $\cdot 27,28,29,51,55,58,72$, $73,77,115,173,204,212$

free trade $\cdot 170,171$

freedom from · $31,34,155,247,249$, 263, 270, 288, 290, 299

freedom from politics $\cdot 263$

freedom of association $\cdot 29,31,32,45$, $46,63,144,145,294,305$

freedom of expression $\cdot 20,28,40,43$, $49,59,63,64,65,124,130,140$, $149,150,154,155,173,178,214$, 237, 267, 284, 294, 305

freedom of movement · 29, 50, 154, 289

freedom of opinion . $72,168,170$, 197, 267, 289

freedom of speech $\cdot 29,60,64,93$, $158,204,285,287,288$

freedom of thought $\cdot 28,42,48,60$, 289, 293, 305

freedom rights $\cdot 13,16,18,19,21,28$, $56,63,66,112,113,114,115,159$ $160,161,162,163,164,165,167$, $168,196,217,261,266,272,280$, 284, 285

freedom to $\cdot 13,20,29,43,50,58,63$, $65,72,130,184,199,246,248$ 249, 251, 252, 254, 256, 257, 261, $263,265,268,270,271,282,289$ 292, 293, 294, 305, 307

freedoms · 31, 52, 64, 69, 132, 141 $163,272,274,288,290,291,292$ $294,297,299,300,301,302,304$ $305,306,307,308$

free-riding $\cdot 97$

freeze $\cdot 168$

French $\cdot 23,24,58,66,116,167,181$, 278, 299, 310

French Revolution · 66, 167, 310

Friedman $\cdot 153$

friendship · 9, 217, 290, 301

frightened $\cdot 185$

frivolous extravagancies $\cdot 162$

frustration · 67, 114, 180

Fukuyama · 42, 121, 152, 209, 311

fundamental interests $\cdot 67,190,194$

fundamentalism · 15

fundamentalist · 46, 135

Furet $\cdot 181,311$

future $\cdot 11,15,27,38,44,62,67,68$ $89,112,113,150,156,164,199$, 204, 221, 229, 231, 263, 285

future consumption · 164

future knowledge $\cdot 199$

\section{$\mathbf{G}$}

GDP $\cdot 152,158$

gender discrimination $\cdot 143$

general interest $\cdot 8,25,26,41,59,86$,

$87,97,101,102,103,124,130$,

$138,139,140,141,157,173,191$,

$192,218,235,236,237,272,280$, 306

generation $\cdot 24,147,153,161,229$ generations $\cdot 27,119,161,165,229$

generations of rights $\cdot 161$

genetic engineering · 223, 283

genetically $\cdot 226$

genocide $\cdot 143,145,182,291$

geographical · 123, 147, 169, 189,

194, 295

geographically $\cdot$ 147, 188, 193

German Reich · 116

Germany · 11, 116, 176, 184

gift · 57, 72, 228, 246

global · 21, 28, 48, 131, 148, 149, 150, $182,242,283$

global consensus · 149, 150

globalization · 48, 53, 55, 111, 169, 176

globalized economy · 150

glory · 44, 140, 284

goal-setting $\cdot 193$

God · 4, 39, 44, 47, 48, 49, 51, 135, $136,137,208,211,220,225,229$,

256, 260, 279

God-given · 135, 184

good life - 16, 51, 145, 166, 201, 244, $246,247,248,249,251,254,255$,

256, 257, 262

good relations $\cdot 179,235$

government by decree $\cdot 273$

government machinery · 104, 169

government officials $\cdot 273$

government policy $\cdot 13,71,72,74$, 75, 81, 102, 122, 230, 231, 233, 240

grandiose $\cdot 154$

grassroots $\cdot 233$

Great Britain · 232

Great Leap Forward · 56, 157

Greek · 13, 60, 64, 87, 164, 196, 236

group discrimination $\cdot 145$

group identification · 104, 245

group life $\cdot 19,78,80,264$

group rights $\cdot 143,145$

growth $\cdot 3,153,154,158,161,170$, 238, 239

growth enhancing $\cdot 154$

guaranteed minimum representation - 147

guaranteed representation $\cdot 234,276$

guilt $\cdot$ 121, 122, 166, 293

Gulag $\cdot 128$

\section{H}

Habermas · 20, 66

habit $\cdot 3,87,133,153,184,185,192$, 246, 266

Halliday · 132, 134, 136

Hamilton/ Madison/ Jay · 57, 98, 240, 276, 281, 311

happiness · 139, 156, 198, 261, 262

happy · 18, 74, 111, 139, 166, 184, 208

hard work · 123, 155, 159

harmless $\cdot 8,18,63,78$ 
harmonious $\cdot 98,124,130,160,241$ 250

harmony · 16, 119, 139, 140, 159, 218 Harrison · 68, 196, 201, 202, 203, 205 , 213, 246, 251, 260, 261, 280, 311

harsh measures · 124

hate $\cdot 34,96,162,219$

hatred $\cdot 267,294$

Hayek · 31, 236

head of state $\cdot 43,88$

health · 162, 164, 211, 236, 238, 290 , 292, 293, 294, 301, 305, 307

health care $\cdot 236$

healthy $\cdot 164,248,300,301$

hedonistic $\cdot 19,254$

Hegel $\cdot 261$

hegemony $\cdot 127$

Held · 31, 94, 97, 198, 235, 242, 251 311

helpless $\cdot 169$

helplessness $\cdot 169$

hereditary · 238, 276

heresy $\cdot 2,135$

heritage $\cdot 304$

Hersch · 165, 311

heterogeneous · 194, 233

heteronomy $\cdot 229$

hidden agenda $\cdot 121$

hierarchical · 23, 48, 79, 211, 238, 251

hierarchy $\cdot 9,10,48,60,119,124$, 130, 173, 227

higher law · 111, 112, 274, 277

higher way of life $\cdot 166$

historical · 44, 48, 55, 59, 71, 84, 87, 127, 129, 132, 134, 184, 210, 224

history $\cdot 45,48,60,71,84,119,127$

$146,156,158,166,167,192,194$, $208,215,219,226,282$

Hitler · 93, 180, 199, 249, 258

Hobbes · 37, 137, 259, 311

honest elections · 149

honesty $\cdot 121$

Hong Kong · 65

honor · 137, 286

hostile $\cdot 11,53,86,132,176,181,191$, 192

hostility $\cdot$ 190, 192, 294

house $\cdot 24,25,33,49,50,162$

household $\cdot 164$

human nature $\cdot 61,108,262,263,267$

humanitarian · 165, 166, 211

humanitarian organizations · 165 166

humanity $\cdot 19,21,22,26,28,49,52$, $58,61,64,107,108,111,112,116$, $117,120,127,130,137,140,141$, $146,165,181,198,207,211,245$, 254, 292

humility $\cdot 128,159$

hunger · 156, 158, 164, 165, 301

hungry $\cdot 156$

hygiene $\cdot 134,301$

hypocrisy $\cdot 1,4,148$
CCPR · 65, 112, 113, 148, 175, 187, 209, 278, 283, 286, 287

ICESCR · 148, 171, 283, 286, 287

ideal $\cdot 5,12,13,15,30,32,34,43,59$, $61,64,65,68,70,72,75,77,80$, $85,89,93,105,112,113,116,118$, $127,182,189,192,198,199,210$, $211,227,236,238,240,251,263$, $272,273,274,275,278,279,290$, 299

ideological · 22, 141, 144, 232, 233, 244, 246

ideologies · 16, 149, 177, 211, 219, 231, 233

ideology · 7, 43, 87, 115, 124, 166, 244, 256

Idi Amin $\cdot 180$

idiom $\cdot 134$

ignorance $\cdot$ 184, 185, 223, 256

illegal · 54, 111, 112

illegitimate $\cdot 42,111,169,210,212$

illiberal democracy · 12, 16, 70

illiteracy $\cdot 23,94$

illness $\cdot 166$

image $\cdot 7,23,24,70,90,98,113,126$, $159,182,208,216,225,232,234$

imagination $\cdot 21,123,223$

immature $\cdot 121$

immigrant · 99, 147

immigrants · 99, 112, 147, 215

immoral · 75, 134, 174

impartial · 35, 36, 38, 44, 191, 261, $273,286,288,293,305$

impediments · 28, 259, 260, 270

imperialism · 126, 128, 136, 140, 182, 185

imperialist · 137, 182

imperialistic $\cdot$ 7, 123, 128, 141

imperium paternale $\cdot 166$

import $\cdot 154$

impose $\cdot 3,7,14,15,32,40,42,44$, $46,53,58,70,86,120,124,128$, $134,135,146,159,172,182,183$, $184,185,187,196,201,213,218$, $225,241,246,248,249,255,256$, 257, 260, 279, 281, 284

imposition $\cdot 7,43,184,185,293,294$, 300, 305

impossibility $\cdot 44,90,93,113,151$, 221, 239

impulsive $\cdot 99,222$

impunity $\cdot 122$

inalienable $\cdot 20,107,288,290,299$

incapable $\cdot 7,8,121$

inclusive $\cdot 46,47,70,283$

inclusive norms · 46, 47

income $\cdot 93,141,170,210,238$

incompatibility $\cdot 8,17,33,70,99$, $122,132,134,151,218,261,281$

incompatible $\cdot 9,11,14,30,31,39$, $42,47,50,51,62,67,68,72,75$, $86,93,94,118,119,120,132,138$, $139,141,151,154,155,156,158$, $159,169,176,181,186,187,188$,
191, 205, 216, 219, 225, 227, 231, $234,237,240,241,245,248,250$, $252,254,255,256,257,258,259$ $261,262,265,266,268,269,273$, 278, 281

inconsistencies · 125, 178

inconsistency $\cdot 2,178$

incontestable $\cdot 43,136$

indecisiveness $\cdot 218,232,233$

independence $\cdot 7,16,32,77,85,95$, $112,121,125,141,144,169,176$, $186,214,223,238,241,248,249$, $250,251,254,255,260,261,264$ $265,269,270,271,273$

independent $\cdot 4,24,29,30,31,32$, $44,48,59,71,98,105,107,110$, $128,136,144,155,169,175,176$ $177,188,190,201,205,215,222$, $223,224,236,244,248,249,250$, $265,266,270,273,274,277,286$, 288, 293, 305

independent grounds $\cdot 222,223$ independent of culture $\cdot 128$

India $\cdot$ 120, 133, 152, 157

indifference $\cdot 40,41,59,95,106,220$, 226, 227

indifferent · 10, 99, 100, 227, 231

indigenous people $\cdot 145,147$

indigenous populations $\cdot 143$

indirect democracy $\cdot 82,85,87,88$, 89, 92, 99, 100, 105, 198

individual development $\cdot 141$

individual freedom $\cdot 127,138,141$

individual interest · 26, 141, 192, 218

individual rights $\cdot 59,72,130,138$, $139,143,144,145,146,147,280$

individualism $\cdot 7,59,78,123,124$, $125,127,138,139,140,141,142$, 145, 218, 248

individualistic $\cdot 52,123,130,138$ $139,142,146,156,159,160,269$, 280

individuality $\cdot 3,22,23,145,165,211$ indivisibility · $31,43,49,50,167$, 168, 180

indivisible $\cdot 29,49,164,165$

indoctrination $\cdot 245,249$

Indonesia $\cdot 227$

industrial · 131, 153, 301

industrialization $\cdot 125,142,153$

industry $\cdot 85,125,175$

ineffective · 57, 111, 127, 154, 231

inefficient · 8, 217, 230

inequality $\cdot 8,16,51,52,53,102$, $161,171,173,197,198,201,207$ $210,211,212,213,214,215,235$, 265

inescapable $\cdot 184$

inevitable $\cdot 125,166,168,172,217$, 218, 220, 226, 228, 237

infallible · 43, 198, 199

infants $\cdot 254$

inferior · 108, 141, 149, 197, 207, 208, 209, 255, 300

inferior beings . 149, 197

inferiority $\cdot 149$ 
inflation $\cdot 149$

influence $\cdot 6,14,16,44,48,63,73$, $79,83,87,88,89,91,92,93,94$, $95,99,102,122,123,148,150$, $153,154,159,162,177,182,196$, 197, 205, 207, 212, 213, 214, 215, 228, 231, 233, 235, 238, 242, 243, $246,248,252,263,268,273,284$

information $\cdot 6,20,23,25,28,29,36$, $53,72,73,75,76,77,94,100,101$, $130,134,162,198,205,208,221$, 286, 289, 294, 297, 302, 305

informed · 3, 73, 78, 81, 93, 101, 154, 205, 208, 292, 293, 304, 305, 306

infrastructure $\cdot 84,215$

infrastructures $\cdot 147$

inheritance $\cdot 229$

injustice $\cdot 36,38,51,52,111,154$, $172,198,214,258,277,282$

injustices · 38, 71, 111, 124, 214, 215, 267, 282

innovation $\cdot 229$

insecurity · 37, 216, 217, 218, 263

insignificant $\cdot 95$

instability $\cdot 180,232,239$

institution $\cdot 18,28,36,38,48,93,96$, $97,116,178,242,273$

institutionalization $\cdot 63,65$

institutions · $15,22,28,34,37,41,42$, $48,53,54,56,59,65,69,92,96$, $97,104,107,119,126,127,136$, $152,153,162,165,167,185,186$, $193,199,217,226,227,228,229$, $231,232,238,240,241,242,246$, 280, 301

insufficient resources $\cdot 170$

integrity · $32,36,50,53,60,188,284$, 286

intellect $\cdot 63$

intellectual freedom $\cdot 155$

intellectually $\cdot 150,248$

intelligence $\cdot 205$

intelligent $\cdot 198$

interchangeable $\cdot 166$

interconnected $\cdot 115$

intercultural dialogue $\cdot 150$

interdependence $\cdot 115,117$

interdependent $\cdot 13,95,165,182,262$

interest groups $\cdot 8,235,236,237,240$

interested $\cdot 3,69,73,100,101,104$, $138,159,183,184,226,232,233$, 248, 257

interest-group politics $\cdot 192$

interests . 3, 8, 9, 25, 26, 40, 52, 58, $61,68,69,81,84,86,87,96,98$, $102,105,122,123,127,130,137$, $139,141,143,147,156,157,160$, $173,182,191,193,197,198,207$, 212, 214, 216, 217, 218, 219, 224, 233, 235, 236, 237, 239, 247, 250, 255, 256, 268, 270, 276, 278, 281, 289, 290, 293, 294, 300, 302, 305, $307,308,309$

interference $\cdot 7,28,30,31,33,34,49$, $54,58,60,61,72,96,127,129$, $130,155,169,175,176,177,178$,
$182,244,248,251,261,263,264$, $268,270,271,272,273,289,293$, 294, 305

internal affairs $\cdot 7,137,148,177,179$, 182, 194

internal policies of states $\cdot 177$

internal warfare $\cdot 187$

international $\cdot 7,14,30,37,53,55$,

$57,65,95,96,110,111,112,115$

$116,117,134,148,150,154,160$,

$162,171,172,173,175,176,177$

$178,179,180,182,186,187,241$

$242,243,273,277,283,285,287$,

288, 289, 290, 291, 293, 296, 298,

299, 300, 301, 302, 303, 305, 306, 307

international agreements · 179, 298

international community $\cdot 30,115$,

$117,154,171,172,178,273,285$

international contacts · 150, 302

international cooperation · 182,241 , 242

international crime $\cdot 111,182,241$

international institutions $\cdot 7,116,241$

international law $\cdot 110,182,186,187$,

289, 291, 293, 296, 299, 305, 306

international peace $\cdot 7,37,175,177$, 179,182

international problems $\cdot 241,242$

international relations $\cdot 7,177,182$ 306, 307

international war $\cdot 179,180$

Internet $\cdot 53,74,81,94,101,146,150$, 215

interpretation $\cdot 4,9,20,134,135,274$ intersubjective $\cdot 202$

intervention $\cdot 15,54,56,71,127,130$

$134,135,170,171,177,179,180$

$182,185,186,188,194,238,240$ 267

intimate $\cdot 20,24,33,34,49,164,234$ intolerance $\cdot 41,42,52,122,136,259$ intolerant $\cdot 41,42,46,136,150$

intra-national · 175, 177

intra-national peace $\cdot 175,177$

intuitively · 208

invade $\cdot 177,271,281$

invariability $\cdot 216$

invasion $\cdot 180$

inversion of means and ends . 158 160

investment · 154, 251

investments · 154, 155, 156, 170

investors · 154, 241

inviolable $\cdot 60,137,268,283$

Invisible Hand · 161, 263, 264, 267

involvement · 19, 42, 91, 99, 100, $105,152,190,226,263$

Iran $\cdot 64$

irrational $\cdot 79,86,199,225,254$

irrelevance $\cdot 220$

irrelevant $\cdot 9,13,52,69,94,210,215$, 220, 221, 256

irresponsible $\cdot 98,204$

isegoria. 196

Islam · 132, 135
Islamic · 64, 134, 135, 136, 143, 146, 283

Islamic misogyny $\cdot 134$

Islamic rights $\cdot 283$

Islamist $\cdot 135$

Islamists · 132

isolated $\cdot 13,14,21,48,58,59,60,78$, $80,104,132,248,269,270,278$, 280

isolation · 96, 123, 169, 191, 248, 249, $269,270,273$

isophephia $\cdot 196$

issues · $12,74,79,89,90,99,100$, $101,105,198,224,233,297$

\section{J}

Japan · 151, 184, 186

jargon $\cdot 162$

Jew $\cdot 166$

Jewishness $\cdot 166$

Jews $\cdot 115,211$

job · 21, 56, 70, 102, 115, 152, 169, $170,173,201$

joke $\cdot 39,153,163$

journalist $\cdot 284$

journalists $\cdot 285$

judge $\cdot 29,35,36,38,41,44,59,71$, $72,73,74,75,89,99,100,102$, $110,112,122,126,136,137,155$, 170, 198, 202, 203, 224, 236, 240, $241,246,273,274,275,276,277$, $279,286,292,304$

judges $\cdot 18,36,88,110,166,191,201$, $228,247,273,274,277$

judgment $\cdot 14,38,54,62,71,74,75$, 77, 85, 90, 91, 99, 122, 133, 202, $203,223,224,257,285$

judgments - 126, 129, 202, 203, 246, 262,276

judicial $\cdot 3,28,30,32,35,37,38,39$, $46,53,54,55,56,88,108,110$, $111,112,179,188,213,214,228$, $273,274,275,276,279,284,287$, 291, 292, 304

judicial power $\cdot 35,37,38,88,110$, 292, 304

judicial redress $\cdot 188$

judicial remedy $\cdot 3,287,291$

judicial review $\cdot 274,276$

judicial system $\cdot 28,37,56,108,112$, $179,228,284$

judiciary $\cdot 35,272,273,274,275,276$, 305

jungle $\cdot 226$

juries $\cdot 97,98$

jurisdiction · 93, 112, 113, 288, 291, $302,304,308$

jury $\cdot 97,98,275$

jury-system · 34, 275

just economic development · 156

justice $\cdot 35,36,37,38,39,52,54,170$, 171, 180, 191, 195, 205, 213, 219, 224, 251, 262, 288, 290, 293, 299, $304,305,308$ 
justice of outcome $\cdot 205$

justification $\cdot 2,4,5,6,8,9,14,16$

$19,24,47,58,62,66,78,82,86$,

$104,108,110,116,118,119,130$,

$149,157,172,184,196,256,258$, 281

justified war $\cdot 180$

\section{$K$}

Kant $\cdot$ 20, 21, 166, 310, 311

Kekes $\cdot$ 161, 249, 311

king $\cdot 20,84,279$

Kissinger $\cdot 37$

know-how $\cdot 155$

knowledge $\cdot 4,6,8,9,14,18,24,25$, $35,36,42,68,73,74,75,77,81$, $87,93,100,101,103,104,113$, $154,166,184,201,202,204,205$, $210,214,219,222,223,224,225$, 229, 255, 257, 264, 275, 301

knowledgeable $\cdot 100$

Koran $\cdot 135$

Korea $\cdot 152$

Kymlicka $\cdot 138,256,311$

\section{L}

labor $\cdot 34,50,75,79,93,154,155$ $167,170,171,172,175,215,240$, 241

labor movement $\cdot$ 167, 171, 215

labor movements · 167, 171

labor unions . 75, 79, 93, 154, 240, 241

landowners $\cdot 155$

language $\cdot 4,5,23,24,53,61,113$, $114,115,126,134,144,158,172$, 194, 224, 227, 248, 278, 288, 291, 293, 294, 295, 299, 304, 305, 306

large groups of people $\cdot 93,158,199$, 227

large profits $\cdot 170$

large-scale · 95, 96, 98, 100, 217, 225

last resort · 187, 288

lawyers · 93, 166

laziness $\cdot 169$

leader $\cdot 70,93,245,254,260$

leaders $\cdot 12,37,62,63,70,73,79,83$, $89,90,93,122,123,151,156,157$, $198,227,235,245,256$

leadership $\cdot 12,31,90,93,158,175$

leadership democracy $\cdot 12,90$

Lefort · 1, 62, 63, 217, 311

legal person $\cdot 110,306$

legal personality $\cdot 110$

legal rights $\cdot 107,110,111,112$

legislation · 33, 35, 44, 56, 84, 92, $205,212,215,247,273,274,277$, 278

legislative chambers · 147, 278

legislative power $\cdot 35,88,272,273$, $274,275,276$ legislator $\cdot 66,112,205,273,274,275$, 278,279

legislature $\cdot 63,83,273,306$

legitimacy $\cdot 1,12,70,119,121,123$, $145,155,156,157,179,219,224$, $225,228,232,237,240,280$

legitimate $\cdot 3,11,33,58,63,82,96$, $105,108,113,116,119,135,143$, $145,242,249,250,255,268,269$, 281, 283

leisure $\cdot 102,152,164,171,214,284$, $287,290,300$

Leroux $\cdot 61,131$

lesser evil · 185

level playing field $\cdot 155,161$

lever $\cdot 158$

liberal $\cdot 42,70,134,247,261,263$, 274

liberal autocracy $\cdot 70$

liberalism · 16, 59, 250, 258, 261, 262, 263

liberalization $\cdot 158$

liberals · 158, 159, 224, 261, 262, 263

liberate $\cdot 176,181,183,187$

liberation · 165, 186, 187, 228

libertarian $\cdot 170$

libertarians $\cdot 172$

liberty $\cdot 6,10,35,42,43,49,56,91$, $93,181,257,259,263,269,270$, 288, 292, 294, 301, 304, 307

license $\cdot 249,254,259$

lies $\cdot 53,66,75,148,199,219$

Lijphart · 193

limitations - 19, 52, 190, 239, 270, $271,290,293,298,300,303,305$

limited freedom · 165, 269, 270

limited state $\cdot 8,30,31,32,33,43,54$, $155,238,240,264,265$

limits $\cdot 8,14,24,28,31,32,37,55$, $60,63,82,97,100,108,113,115$, $116,129,131,132,133,138,142$, $148,156,158,172,194,198,208$, $210,212,234,239,246,249,251$, $254,256,259,260,261,262,263$, $268,269,271,272,275,278,279$, 281, 283, 284, 285, 301

linguistic minorities $\cdot 294$

literacy $\cdot 157$

lobbies $\cdot 102$

lobby · 213, 214

lobbying $\cdot 34,93$

lobbyists $\cdot 240$

local $\cdot 26,66,84,86,92,93,95,96$, $97,112,124,125,126,127,128$, $129,135,141,147,154,191,282$

local meeting $\cdot 66$

Locke $\cdot 51,208,312$

Ioneliness $\cdot 23,34,140$

lonely $\cdot 279$

long term $\cdot 47,68,75,156,171,194$, 227, 237

longer term $\cdot 226$

love $\cdot 9,24,41,96,140,194,208,219$, 240

low labor costs $\cdot 157$

lower classes $\cdot 94$ loyal $\cdot 204,258$

loyalty $\cdot 9,190$

luxuries 159

luxury $\cdot 125,156,162$

luxury cars $\cdot 125$

lynching $\cdot 199$

\section{M}

majority decision $\cdot 25,67,197,203$, 205, 222, 279, 281

majority government · 147

majority rule - 12, 196, 203, 213, 227, $242,272,279,280$

majority-democracy $\cdot 68,194$

majority-system $\cdot 196$

Malaysia $\cdot 65$

management $\cdot$ 53, 154, 229

manifesto $\cdot 72,74,75,77,87,230$, 231,233

manipulation $\cdot 75,99,123$

mankind · 3, 11, 169, 229, 288

Mao · 56, 157, 219

margin of appreciation $\cdot 285$

market · 32, 33, 163, 235, 241, 252

Marx · 58, 60, 269, 282, 310, 312

Marxism · 16, 39, 59, 213, 214

Marxist $\cdot 139$

mass $\cdot 7,74,98,198,251$

massive participation $\cdot 205,222$

material $\cdot 3,50,63,79,94,102,135$, $140,152,153,161,162,166,167$,

$168,210,211,212,213,228,235$, $250,251,252,265,266,290,301$, 302

material equality $\cdot 3,210,212,213$, 266

material inequality · 162, 212, 213, 266

material means $\cdot 153,162,166,212$ 250, 251, 266

material resources $\cdot 102,162$

mathematically $\cdot 194$

mathematics $\cdot 202$

mature $\cdot 10,11,66,118$

maximum $\cdot 3,86,162,163,216,219$, 239, 299

maximum participation $\cdot 163$

mayor $\cdot 88$

means of production $\cdot 214,252$

meddle $\cdot 96,184$

media $\cdot$ 10, 65, 75, 80, 81, 90, 150,

152, 199, 203, 228, 289, 294

mediocre $\cdot 7,209,254$

megalomania $\cdot 181$

mega-projects 154

Mendus · 58, 61, 148

mentality $\cdot 47,124,169,179$

mentally ill $\cdot 203,204$

merit · 52, 202, 290

meritocracy $\cdot 16,74$

metabolism · 164

metaphysical $\cdot 223,224$

Michels $\cdot 98$

Middle Ages · 84 
migration $\cdot 147$

militarism $\cdot 181$

military · 175, 177, 181, 182, 192, 226 ,

228, 292, 304

military intervention · 177, 182

Mill · 22, 44, 69, 157, 184, 198, 239,

$255,257,268,312$

millionaire $\cdot 153$

minimal global consensus · 149

minimalism · 149, 284

minimalist $\cdot 12,108,128,151$

minimum · 46, 54, 146, 154, 162, 168,

$170,173,197,209,212,213,251$,

260, 262, 263, 271, 293, 300, 301, 305

minimum prosperity $\cdot 173$

ministers $\cdot 194$

minorities $\cdot 10,12,23,67,130,140$,

$143,144,145,146,147,194,196$,

$232,234,237,243,266,276,278$, 294

minority groups $\cdot 143$

misfortune $\cdot 152,166$

missionaries $\cdot 184$

missionary $\cdot 126$

mistakes · 20, 119, 157, 198, 204, 248 , 276, 278

misused $\cdot 237,268,284$

mobile phones $\cdot 94$

mobility · 48, 146, 152, 202, 210

mobilize $\cdot 82,101,172,235,236$

model $\cdot 85,124,127,129,181,182$, 192, 193, 194

moderate $\cdot 141,155,158$

modern · 54, 84, 93, 94, 95, 101, 102, $103,124,128,146,166,203,238$, 279

momentum $\cdot$ 158, 185

monarchy $\cdot 88$

money · 55, 56, 63, 84, 93, 102, 113, $152,170,171,176,213,234,235$, 241, 284

monopoly of violence $\cdot 38,57,240$

moral · 5, 9, 34, 45, 73, 98, 108, 110, $111,112,126,128,140,149,167$, $171,177,199,203,210,224,249$, 256, 290, 294, 295, 301, 302

moral claims · 110, 112

moral relativism $\cdot 5,249,256$

moral superiority $\cdot 128$

moralists $\cdot 128$

morality $\cdot$ 7, 45, 129, 191, 195, 199, 244, 290

morally · 111, 157, 207, 249

motivation $\cdot 122,128,145,166,231$

motives $\cdot 24,122,160$

Mourgeon · 55, 178, 312

movements · $24,32,37,65,121,135$, 179, 185, 192

Muhammad $\cdot 135$

multicultural $\cdot 192$

multiculturalism · 113, 193

multinational $\cdot$ 169, 176, 240, 241

multinational companies · 169,176 , 240, 241

multinationals $\cdot 241$ multi-party systems · 230, 233

multi-stage representation $\cdot 100$

municipalities · 92, 93, 94, 116

murder · 99, 149, 212

murderers $\cdot 179$

musical $\cdot 145$

Muslim · 44, 132, 135, 136, 310

Muslims · 47, 132, 135

mutilation $\cdot 128$

mutually reinforcing $\cdot 159$

myth $\cdot 57,61,123$

\section{$\mathbf{N}$}

name $\cdot 12,13,59,72,83,85,90,94$ $125,127,166,167,179,211,225$ $258,261,268,294$

Napoleon $\cdot 181$

napoleontism $\cdot 181$

narcism $\cdot 248$

narrow-minded $\cdot 21,141$

narrow-mindedness $\cdot 137,140$

nation $\cdot 28,49,55,60,86,99,112$,

$114,115,118,124,129,137,140$,

$146,156,186,193,239,242,252$,

260, 291, 306, 311

nation state $\cdot 55,60$

national character $\cdot 119$

national community $\cdot 138$

national defense $\cdot 95,96,182,241$

national goals $\cdot 155$

national interest $\cdot 96$

national liberation · 176, 186

national matters $\cdot 93,96$

national minority $\cdot$ 146, 306

national pride $\cdot 121,181,184$

national rights $\cdot 114$

national security $\cdot 72,292,293,294$, $300,305,307,308$

national sovereignty $\cdot 148,176,178$ 242

national unity $\cdot$ 130, 190, 191, 192 193, 194, 195, 226, 227

nationalists $\cdot 223$

nationality $\cdot 6,112,113,114,115$ $116,117,286,289,294$

nationalized $\cdot 155$

nationals $\cdot 116,286,295,297,307$

nations $\cdot 144,181,183,184,241,242$, $288,290,293,301,305$

nation-state $\cdot 93,97$

native language $\cdot 113$

NATO $\cdot 241,242$

natural · $21,26,40,55,57,93,94$, $102,103,104,105,107,110,111$ $112,119,125,128,140,154,161$, $162,164,165,166,184,207,210$ $211,219,234,238,252,261,289$ 291, 294, 298, 299, 300, 301, 303, 306

natural freedom $\cdot 261$

natural hierarchies $\cdot 238$

natural leaders $\cdot 93,102$

natural needs $\cdot$ 165, 166

natural order $\cdot 238$ natural rights $\cdot 55,57,107,110,111$,

112, 165, 261

naturalization $\cdot 112,113,115$

nature $\cdot 2,10,22,24,36,37,72,75$, $78,87,89,104,108,111,119,130$, $135,140,145,148,162,164,165$, $166,172,182,184,188,211,219$, $221,225,227,229,232,236,240$, $242,245,249,259,282,293,300$, 302,305

nazi $\cdot 115$

nazi-Germany $\cdot 67$

nazism $\cdot 123,152,181,211,219,220$, 237

necessary condition $\cdot 1,10,31,39,51$, $70,72,118,120,151,152,153$, $155,159,163,167,175,178,186$, 198, 217, 259, 269

necessary conditions $\cdot 1,10,31,51$, $70,118,120,155,159,167,186$, 217, 269

necessary evil $\cdot 55,85,95,180,262$ necessities $\cdot 161,162,164$

necessity $\cdot 2,55,66,116,133,149$, $156,164,165,167,201,227,240$, 249

negative freedom · 16, 270, 271

negative rights $\cdot 16,270$

neglect $\cdot 60,111,117,123,130,140$, 165,240

negotiate $\cdot 87,98,101$

negotiation $\cdot 39,87,98,150,168,191$, 237

negotiations $\cdot 230,231,234$

neighborhood $\cdot 93,115$

neighboring countries $\cdot 115,173,180$, 236

neighbors $\cdot$ 50, 179, 193

neo-colonialism · $121,126,127,128$, 182

nepotism $\cdot 152$

neutral $\cdot 43,44,45,46,47,64,101$, $167,205,226,256,264,265,273$, 278

neutrality $\cdot$ 44, 45, 192, 258, 274, 279

never-ending $\cdot 198$

Niebuhr $\cdot 217$

nihilism · 41, 42, 129, 199

no taxation without representation .

84

nomenclatura $\cdot 155$

non-arbitrary $\cdot 225$

non-autonomous $\cdot 249$

non-believers · 108, 128, 211

non-citizens $\cdot 112,113,114$

non-democracy $\cdot 187$

non-democratic $\cdot 13,64,65,89,139$, $181,183,188,192,207,217,228$, 241, 251, 278, 279

non-discrimination · $37,51,52,140$, 143, 144, 179, 267

non-interference $\cdot 58,60,148,263$, 268

non-Muslim · 207

non-M uslims · 134

non-party democracy $\cdot 129$ 
non-western · 120, 125, 139, 140, 146 normative consensus $\cdot 148$ normative universality $\cdot$ 148, 149 normlessness $\cdot 140$

norms $\cdot 4,14,45,46,47,48,77,112$,

$118,119,120,122,126,127,128$,

$134,136,137,144,149,150,171$, $222,224,225,238,274$

North $\cdot 121$

nostalgia $\cdot 155$

now and then $\cdot 38,68,85,97,188$

Nozick $\cdot 60$

nuances · 94, 101, 221

nuclear $\cdot 79,177,242$

nuclear energy $\cdot 79$

\section{O}

obedience $\cdot 36,57,122,249,259,260$ obey $\cdot 62,66,69,73,92,204,245$, $247,254,259,260$

objection $\cdot 2,74,78,93,105,292$

objectionable $\cdot 10,149,216,217$

objective $\cdot 57,74,116,130,172,177$, 189, 201, 202, 225, 236, 278

obligation · $36,91,141,148,248,249$, 290, 291, 292, 299, 304, 307

obscurity $\cdot 75,163,216,228$

occupation · 102, 126, 176, 181, 182, 186

offer and demand $\cdot 235$

office $\cdot 83,85,97,100,230,295$

official $\cdot 24,43,48,82,83,88,89,115$,

$124,145,155,291,306$

oikonomia $\cdot 164$

old $\cdot 10,11,15,60,66,72,119,123$,

$126,127,128,130,133,134,136$,

$137,159,184,276,283,289,290$, 305

oligarchies $\cdot 202$

oligarchy $\cdot 64,90$

one man, one vote $\cdot 147,194,196$

one-party system $\cdot 129,217$

open-ended · 21, 204, 216, 221

openness · $24,26,72,73,75,101$ 130, 137, 152, 154, 191, 208

opinion poll $\cdot 13,94,97,98$

opportunism $\cdot 232$

opportunities $\cdot 91,103,139,143,154$, 214,225

opportunity $\cdot 7,31,35,38,51,65$, $121,192,193,204,210,214,257$ $268,294,300$

opposition $\cdot 1,25,37,63,65,66,73$, $77,87,122,185,190,192,194$, 227, 277

oppressed $\cdot 26,124,130,143,186$, 187, 214

oppression · 35, 59, 60, 117, 121, 124, $127,137,138,155,156,158,178$, $180,181,185,188,190,191,237$, $244,255,260,261,277,278,288$ oppressive $\cdot 60,146,177,187,194$, $273,277,278,279,280$

organic unity $\cdot 66$ organized · 53, 88, 105, 160, 193, 201, $230,252,303$

oriental $\cdot 123$

origin $\cdot 49,59,69,77,80,112,113$, $115,119,127,131,134,135,139$, $147,166,172,278,288,291,294$, 299, 306

orthodoxy $\cdot 124,141$

ought implies can · 168, 170

outsiders · 116, 138, 147, 184

outstanding $\cdot 7$, 126, 207

outvoted $\cdot 96,242,279$

overlap · 24, 33, 82, 193

overlapping consensus $\cdot 45$

oversized state $\cdot 169,171$

\section{$\mathbf{P}$}

pacification-democracy $\cdot$ 147, 193, 194 pacifists $\cdot 181$

pain $\cdot 36,135,164,165,166,240$

Paine $\cdot 73,312$

palaver $\cdot 129$

paradox $\cdot$ 184, 205

paradoxes $\cdot 1,184,224,227$

paradoxical $\cdot 227$

parliament · 34, 37, 81, 85, 86, 87, 88, $105,230,233,272,275$

parliaments $\cdot 37,59,84,191,228$

party coalitions · 230, 231

party-democracy $\cdot 129$

passion $\cdot 246,256,257$

passive $\cdot 19,42,43,90,93,96,169$, $205,225,248$

passivity $\cdot 42,56,91,103,185,225$

paternalism · 128, 169, 256

paternalistic $\cdot 166,248,255$

patriotism · 96, 190, 192, 229

peace $\cdot 3,4,7,9,16,37,39,40,41$, $48,49,81,103,149,175,176,177$, $179,180,181,182,183,185,186$, $187,188,190,191,192,196,226$, $227,258,261,268,269,284,288$, 290, 299, 301, 304

peaceful $\cdot 12,37,38,39,49,63,104$, $132,177,179,181,183,185,191$, 193, 289, 294, 305, 306

penetration $\cdot 30,194$

people within a people $\cdot 187$

perfect democracy $\cdot 285$

permanence $\cdot 27,32,36,71,113,203$, 204

permanent $\cdot 28,53,62,63,66,67,69$, 70, 74, 113, 120,147, 151, 158, $166,188,193,194,204,211,217$, 229, 239, 251

permanent minorities · 147, 188, 193, 194, 251

perpetrators · 36, 125, 166

perpetual $\cdot 221$

persecuted $\cdot 43,123,143,144$

persecution - 115, 286, 289

personal development $\cdot 66,138,254$, 257

personal identity $\cdot 79,80,130$ personal judgment $\cdot 83$

personality $\cdot 22,23,50,61,70,78,83$, $90,99,110,140,166,211,258$

289, 290, 301

persuasion $\cdot 42,78,79,110,112,113$,

$150,185,202,204,205,219,220$, 228,255

petition $\cdot 99$

petty sovereignty $\cdot 60$

philanthropy · 157, 169

Philippines $\cdot 157$

philosophy $\cdot 5,123,221,267$

physical $\cdot 2,24,27,36,60,112,113$,

$141,144,162,166,217,244,269$,

$279,284,301$

physical integrity $\cdot 24,284$

planning $\cdot 155,156,202$

Plato $\cdot 311$

pleasure $\cdot 41,249,254,255,257$

plural $\cdot 32,49,211,223,251$

pluralism · 57, 75, 124, 132, 133, 139, $251,252,256,276$

plurality $\cdot 2,9,14,26,30,32,39,45$, $46,47,48,59,67,68,77,78,79$, $96,124,133,199,210,219,220$, $223,235,281$

plutocracy $\cdot 102$

polarization $\cdot 69,96$

police $\cdot 18,29,36,37,38,39,54,56$, $110,148,170,228,273,284,294$, 300,305

police force $\cdot 56,148,284$

policies $\cdot 38,65,71,73,74,76,77,82$, $83,84,85,92,156,169,171,177$, $213,230,231,232,233,234,241$, 255,300

policy $\cdot 71,73,74,92,157,162,177$, $182,231,233,256$

polis · 13, 22, 64, 76, 87, 94, 202

political agenda $\cdot 79,82,105,207$, 231

political autonomy $\cdot 144$

political conflict $\cdot 63,274$

political culture $\cdot 113,227,228$

political equality $\cdot 3,67,157,162$, $210,213,214,215,216,230,233$, 234, 266

political freedom $\cdot 153,156,262,266$, 290

political participation $\cdot 15,34,63,73$, 79, 103, 144, 157, 162, 168, 203, $204,207,214,215,228,230,232$, $250,252,271$

political parties $\cdot 12,23,34,71,74$, $79,81,87,105,129,154,194,214$, $215,230,231,232,235,237$

political party $\cdot 79,167,232,274$

political rights $\cdot 1,13,16,55,56,62$, $65,113,115,116,117,140,143$, $144,159,160,161,162,163,164$, $165,167,196,214,261,280,285$, 290, 291, 299

political unity $\cdot 113,116,188,191$, 192

politically incorrect $\cdot 41$ 
politician $\cdot 75,85,89,90,157,235$, 284

politicians $\cdot 20,24,33,45,75,85,89$, 90, 99, 100, 101, 102, 187, 191, $231,232,234,235,239,285$

pollution $\cdot 182,242$

poor $\cdot 50,51,58,59,102,104,113$, $152,156,158,160,161,162,163$, $168,170,172,173,174,207,212$, $213,214,215,235,249,287$

popular sovereignty $\cdot 260$

population $\cdot 7,35,84,86,93,98,102$, $122,139,144,147,152,175,184$, $187,192,212,216,228,234,236$, 241, 251, 278

Portugal $\cdot 121$

positive discrimination $\cdot 144$

positive freedom $\cdot 270,271$

positive law $\cdot 111,112,148,283$

positive rights $\cdot 55,58,60$

positivism $\cdot 111$

posterity $\cdot 229$

post-institutional $\cdot 53$

post-war $\cdot 11,184$

poverty $\cdot 54,56,124,154,157,158$, $161,162,163,164,168,171,214$, 263

power of the people $\cdot 73,89,104$, 192, 229, 239, 263

power politics $\cdot 158$

power sharing $\cdot 252$

power struggle $\cdot 62,63,64,86,140$, 275

powerless $\cdot 7,61,80,111,241,279$

practices $\cdot 1,14,17,46,122,128,131$, $132,133,134,137,138,179,181$, $182,219,281$

pragmatic $\cdot 146,241$

pragmatism $\cdot 232$

pre-democratic $\cdot 10,238$

predictability $\cdot 32,33,36,154,260$

predictable $\cdot 28,31,36,112,162,233$, 240, 261, 264, 265

prejudice $\cdot 99,291,293,294,297,298$, 299, 300, 305

prejudices $\cdot 21,74,79,86,123,134$, 140, 205, 245, 249, 266

pre-modern $\cdot 44,92,96$

pre-political $\cdot 224,261$

prerequisite $\cdot 10,11,27,49,56,64$, 75, 91, 151, 162, 164, 165, 175, 180, 185, 190, 191, 226, 227, 240, 246, 261

prerequisites $\cdot 1,2,10,11,36,63,91$, $98,101,113,118,152,162,163$, $164,193,227,260,280,283$

prerogative $\cdot 273$

present-day knowledge $\cdot 199$

preservation · 151, 152, 164, 190, 228, 229, 258

president $\cdot 275,276$

presidential regime $\cdot 88$

press $\cdot 26,219,236,293,305$

pressure $\cdot 22,34,48,95,97,112,154$, $177,214,222,235,236$ pressure groups $\cdot 34,95,154,214$, 235, 236

pride $\cdot 209$

prime minister $\cdot 88$

principle $\cdot 1,2,31,42,51,53,56,66$ $69,84,105,114,116,128,139$ $143,147,148,149,167,168,183$, $184,194,207,210,212,213,267$, 268, 291, 299, 302

priority $\cdot 10,16,17,67,85,103,118$, $132,134,137,138,140,141,158$ $159,202,265,272,274,282,284$

privacy $\cdot 18,29,35,49,58,139,173$ $238,240,251,284,285,286,289$, 293

private initiative $\cdot 170$

private interests $\cdot 25,26,37,79,86$ $87,97,101,102,104,140,191$ $215,236,237,280$

private property $\cdot 18,32,33,49,50$, $57,58,61,62,164,165,173,176$ $213,235,251,252,282$

private sector $\cdot 157,170$

private space $\cdot 18,24,25,26,30,31$, $32,33,34,49,50,81,139$

privatization $\cdot 75$

privileged $\cdot 26,42,59,64,152,155$ $213,252,276,278$

privileges · $44,51,52,57,84,152$, 161, 208, 235, 238, 276, 298

probability $\cdot 157,225$

probable $\cdot 225,281$

procedural democracy $\cdot 12$

procedural justice $\cdot 205$

procedures $\cdot 16,26,37,38,39,62,63$, $65,69,70,73,78,87,98,102,152$ $154,156,190,191,193,199,203$, $204,205,213,221,222,223,224$ $225,226,229,237,247,258,280$, 289, 296, 298

production methods $\cdot 155$

production units $\cdot 170$

productivity $\cdot 170$

products $\cdot 155$

profession $\cdot 7,100$

professional · 93, 100, 102, 290

profit $\cdot 103,147,156,161$

profits $\cdot 59,170$

progress $\cdot 57,136,152,155,156,157$, $158,171,184,215,285,288,296$, 302

progressive achievement · 171

promotion - 31, 102, 127, 133, 140, $167,177,225,288,290,299,300$

propaganda $\cdot 22,57,59,75,158,192$, 231, 233, 245, 294

property $\cdot 49,50,51,58,59,61,62$, $77,113,115,153,155,162,164$ $165,168,173,174,178,212,213$, $214,252,266,267,269,278,280$ $284,286,288,289,291,294,299$, 306

property rights $\cdot 168,174,266$

proponents $\cdot 17,185,218$

proportional $\cdot 240$ prosperity $\cdot 4,7,54,113,149,151$, $152,153,154,155,156,157,158$, $159,161,169,170,171,172,173$, $180,196,213,228,252,284$ prosperous $\cdot 152,153,158,254$ Protestant $\cdot 48,120$

Protestantism · 11, 48, 49, 131, 159 proud $\cdot 137$

provincialism $\cdot 96$

provisional $\cdot 15,25,62,199,200,204$, 205, 221, 223, 224, 225

psychologically $\cdot 145,248$

public affairs · 65, 92, 94, 104, 294

public benefits 114

public figure $\cdot 3,284$

public funds $\cdot 154$

public opinion $\cdot 63,94,217,245$

public prosecutors $\cdot 88$

publication $\cdot 23,284$

publicity $\cdot 3,9,12,19,20,21,22,23$, $24,28,34,35,36,43,49,50,53$, $63,71,72,75,77,80,81,87,93$, $98,101,205,219,260,268,293$, 305

punishment $\cdot 4,29,31,35,36,37,38$, $40,52,121,128,155,197,249$, $255,271,281,286,288,292,293$, 304, 305, 308

qualifications · 198, 201, 295

quality $\cdot 4,7,21,94,97,100,102$, 197, 198, 199, 205, 220, 221, 225 quasi-universal values 149

\section{$\mathbf{R}$}

race $\cdot 6,107,113,146,207,210,220$, 237, 278, 288, 289, 291, 294, 299, 306

racism $\cdot 116,133,143,145,208,267$, 284

racist $\cdot 85,116$

rain forests $\cdot 125$

ratified $\cdot 149$

rational $\cdot 6,46,74,99,199,222,223$, 225, 254

rationality $\cdot 99,125,223,225$

Rawls · 31, 35, 41, 42, 198, 210, 214, 312

reaction $\cdot 7,38,71,126,146,181,217$

Reagan $\cdot 171$

realism $\cdot 16$

realistic · 13, 151, 177, 207, 219, 262, 263

realists $\cdot 177$

reality $\cdot 14,15,23,34,48,64,67,85$, $108,110,111,113,118,123,129$, $130,136,143,148,158,163,172$, 192, 198, 209, 211, 246, 273

reason $\cdot 1,2,7,8,10,13,20,22,35$, $36,37,41,44,45,46,52,53,54$, 
$57,63,67,68,75,81,83,84,86$ $89,90,95,97,98,99,100,102$, $103,107,108,109,113,114,118$, $119,122,123,124,128,130,131$, $132,139,142,143,146,149,155$, $158,159,161,162,165,166,169$, $171,172,175,177,178,181,183$, $184,186,188,190,191,193,194$, 197, 198, 199, 201, 203, 205, 210, $211,212,217,218,219,220,224$, $226,228,230,232,242,244,245$, $246,247,249,250,255,257,258$, $263,264,280,282,283,287,288$

reasonable $\cdot 5,36,63,67,79,82,86$, $103,116,119,142,146,175,197$, 199, 203, 204, 222, 223, 224, 225, 226, 236, 255, 290, 292, 300, 301, 302, 304, 305, 306

reasonableness $\cdot 79,222,223,225$

reassuring $\cdot 216$

rebel movements $\cdot 179$

rebellion - 186, 288

record · 65, 77, 91, 224, 297

re-deliberate $\cdot 204$

re-deliberation $\cdot 80,204$

redistribute $\cdot 162,169,171,213,267$

redistribution $\cdot 50,93,141,157,159$,

$162,168,169,171,173,174,212$.

$213,215,238,240$

redistributive $\cdot 194$

redress · 56, 170, 210, 273, 286

re-election $\cdot 151,156,295$

referenda $\cdot 13,59,80,81,92,94,98$, 99, 191

referendum · $13,66,80,89,91,92$, $94,97,99,101,223,275$

Reformation · 48, 49

refugee $\cdot 114,115,180,182,241$

refugees $\cdot 112,115,172,202,241$

region $\cdot 127$

regional $\cdot 127,132,193,242,283,303$

regret · 126, 246

regular elections · 148

reign $\cdot 75,161,180,219$

rejection $\cdot 9,10,17,85,101,113,129$, 218, 226, 227, 230, 232, 244, 249

relationships $\cdot 20,23,28,35,37,41$, $49,50,52,54,58,59,60,61,149$, $153,170,177,214,217,248,249$, 250, 258, 262, 269, 270, 271, 283

relative $\cdot 14,42,103,128,137,216$, $217,224,231,233,235$

relative majority $\cdot 233$

relativism $\cdot 41,42,127,129,130,133$, $136,137,150,199$

relativistic $\cdot 42,199$

relativity $\cdot 133$

reliance $\cdot 9,169$

religion $\cdot 4,20,24,43,44,45,46,47$, $48,49,113,115,119,126,127$, $135,137,144,145,146,149,164$, 191, 192, 193, 194, 211, 229, 278, 286, 288, 289, 291, 293, 294, 295, 299, 305, 306

religions $\cdot 4,43,44,45,47,48,108$, $133,144,211,228$ religious $\cdot 3,4,6,20,37,43,44,45$, $46,47,48,49,79,98,120,123$, $132,135,139,140,141,143,144$, 147, 179, 181, 191, 192, 194, 224, 228, 238, 290, 294, 301, 306

religious identity $\cdot 135$

religious liberty $\cdot 3,37,43,44,46$, $48,49,120,140,143,144,228$

religiously divided $\cdot 192$

remarkable $\cdot 207$

remedy · 29, 170, 211, 275, 288, 291, 306

repatriation $\cdot 99$

reprehensible · 37, 164, 169

representation $\cdot 13,84,85,87,88,92$, $94,95,97,98,100,101,105,115$, 194, 233, 234, 235, 276, 278, 295

representative $\cdot 11,12,13,16,34,44$, $73,74,82,83,84,85,86,89,90$, $91,92,93,96,97,99,100,101$, $102,103,146,152,198,223,233$, 239, 275, 278

representative democracy $\cdot 12,13$, $16,74,82,83,89,90,91,92,100$, $101,103,198,223$

representative system $\cdot 11,83,84,91$, $92,93,97,99,102,239,275$

representatives · $65,66,70,73,81$, $83,84,85,86,87,88,91,92,94$, $98,100,102,103,104,125,149$, $154,194,214,215,235,239,276$, 277, 278, 286, 289, 294, 295

resentment · 114, 181, 182

reserved domains of power $\cdot 88$

resettle $\cdot 147$

residents $\cdot 113,117$

resolve $\cdot 153,216,223,226$

resources $\cdot 63,102,111,147,154,155$, $168,170,171,240,242,252,257$, 289, 291, 296, 298, 299, 301, 303

respect for the law · $31,69,70,179$, 228

responsibilities - 103, 138, 166, 168, $169,172,294,296,297,298,302$, 303, 305, 309

responsibility $\cdot 3,18,40,50,83,91$, $92,99,104,112,127,140,141$, 166, 168, 169, 172, 197, 204, 207, $222,232,248,249,264,271,290$, 291, 299

responsible $\cdot 3,31,36,91,92,101$, $104,124,169,170,178,205,222$, $223,239,300,306,307$

revenge $\cdot 35,38,180,191,261$

revenues $\cdot 169,241$

reverse causation · $31,40,64,152$, 167

revise $\cdot 204$

revolt · 37, 49, 122, 152, 154, 155, $156,158,162,163,177,180,185$, $187,188,190,191,192,193$

revolution $\cdot 59,71,112,144,177,186$, $187,188,213,228$

revolutionary $\cdot 71,93,155,181,228$, 229 rich $\cdot 50,51,58,59,102,115,120$, $152,153,159,161,162,163,172$, $173,197,198,213,214,215,234$, 235

right to asylum · 115, 172, 287 right to belong to a state $\cdot 114$ right to belong to humanity - 108 , 114

right to citizenship · 114, 115, 287 right to democracy $\cdot 65,66,188,281$ right to development - 283

right to free movement $\cdot 53,147$

right to identity - 132, 137, 145

right to intervention $\cdot 176,177,178$, 188

right to life $\cdot 50,53,60,107,135,143$

$162,163,287,288,291,304$

right to nationality $\cdot 114$

right to naturalization $\cdot 114,115$

right to oppression $\cdot 137$

right to peace $\cdot 175$

right to revolution - $177,178,186$, 187

right to self-determination $\cdot 3,50$,

$129,143,144,146,175,176,178$, $179,186,187,188$

right to separation $\cdot 187,188$

right to sunshine $\cdot 163$

rights inflation $\cdot 283$

rights of citizens $\cdot 114,115$

ritualization $\cdot 217$

rival factions $\cdot 138$

robots $\cdot 85$

Roosevelt $\cdot 198$

Rorty $\cdot$ 6, 311

rotation in office $\cdot 36,130,156,194$, 214

Rousseau $\cdot 93,103$

royal prerogatives $\cdot 88$

rule of law $\cdot 29,30,31,32,33,34,35$, $43,57,63,66,69,70,105,154$, $155,179,180,191,238,249,259$, $260,261,265,266,273,277,278$, $279,288,304,311$

rural $\cdot 93$

Russia $\cdot$ 273, 282

Russians $\cdot 183$

sacred $\cdot$ 129, 136, 137, 183

sacrifice $\cdot 7,137,139,140,141,155$, $158,177,212,237$

sacrificed $\cdot 103,137,155,158,167$, 180, 216

sadness · 99

safety · 180, 234, 293, 294, 305, 307

safety net $\cdot 234$

sans-culottes $\cdot 167$

satellite $\cdot 146$

satisfaction · $89,101,169,196,207$, 296, 297

scale $\cdot 24,67,92,95,97,98,99,116$, $145,169,223,226,242$

scandal $\cdot 184$ 
scarce $\cdot 155,234$

scarcity $\cdot 56,166,284$

Schmitt · 29, 30, 110, 116, 273, 312

school · 16, 22, 34, 40, 93, 97, 102, 177, 199, 210, 301

science $\cdot 104,125,202,208,220,223$, $224,225,255,302$

scientific $\cdot 5,21,206,219,220,223$, 224, 283, 290, 292, 301, 302

scientifically $\cdot 224$

scientists $\cdot 209,223$

seats $\cdot 233$

secede $\cdot 144$

second level rights $\cdot 115$

secret ballot - 63, 65, 87, 294, 295, 297, 306

secret vote $\cdot 65,87,289$

security - 16, 36, 37, 38, 39, 49, 50, $56,63,122,123,154,162,242$, 260, 261, 262, 263, 264, 268, 270, $271,276,281,284,287,288,290$, 292, 304

selective compassion · 173

selectivity $\cdot 122,125,173$

self-contradictory $\cdot 125$

self-control · 66, 67, 73, 92, 93, 95, 96, $104,113,116,147,254,260$

self-defeating - $169,183,213,256$, 258, 271

self-destructive $\cdot 37,42,47,132,136$, 183, 199, 227, 254, 258, 271

self-determination - 124, 144, 146, $175,176,177,178,181,186,187$, $188,244,245,248,249,256,290$, 291, 299

self-development · 139

self-discipline $\cdot 39,254$

self-fulfilling prophecies 121

self-government · $12,64,66,68,74$, $91,92,93,95,113,117,124,146$, $147,165,176,186,187,188,189$, 194, 241, 242, 243, 244, 245, 247, $249,250,251,252,254,257,260$, 261, 262, 263, 264, 265, 271

self-imposed $\cdot 148,260,287$

self-improvement $\cdot 256$

self-interest $\cdot 8,25,26,38,121,122$, $127,138,139,140,157,159,231$, $234,236,247$

self-preservation $\cdot 81,136$

self-protection · 38, 176

self-realization - $254,256,257,258$, $259,260,261,262,265,266,269$, 270

self-sufficiency · 96,123

self-sufficient · 20, 59, 104, 248, 269

self-support · 169, 171, 172, 173

self-supporting $\cdot 169$

Sen $\cdot 11,313$

Senate $\cdot 96,276$

Seneca $\cdot 167$

separate $\cdot 19,24,41,48,49,78,90$, $104,105,116,140,144,162,187$, $188,190,191,192,193,242,281$, 292, 307, 309 separation $\cdot 8,16,20,28,30,31,32$, $33,39,43,44,45,48,60,63,69$ $77,89,105,112,123,135,187$, $188,189,190,192,193,242,252$, $269,272,274,275,276,277,278$ 279

separation between religion and the state $\cdot 135$

separation of powers $\cdot 30,39,69,112$ $272,274,275,276,277,278,279$

separation of state and religion $\cdot 45$

separation of state and society . 16 , $31,33,63,105$

separatist $\cdot 146$

sex · 100, 113, 207, 278, 288, 291, 294 299, 306

sexual $\cdot 284$

sexual habits $\cdot 284$

shame $\cdot 126$

shared growth $\cdot 157$

short run · 151, 156, 171, 177, 190, 237

shortsightedness $\cdot 151$

sick $\cdot 164,173,287$

sickness · 164, 165, 290, 301

silent $\cdot 21,33,36,45,94,102,112$ 185, 237

silent voices $\cdot 102$

simplicity $\cdot 216,217,222$

simplistic · 58, 101, 134, 152

simultaneously · $10,16,24,63,84$, 97, 114, 141, 164, 194

Singapore $\cdot 65,310$

single mothers $\cdot 144$

skepticism · 42, 199

skills · 210, 215

slave · 51, 244, 288

slavery · 50, 51, 136, 149, 180, 208 286, 288, 292, 304

slaves · 24, 51, 64, 103, 110, 158, 167 slogan $\cdot 136$

slowness · 216, 218, 221

small towns $\cdot 93$

smart . 99, 100

social policy $\cdot 154$

social security · $56,113,114,238,239$ 289, 300, 301

socialism $\cdot 23$

socialists $\cdot 23,61$

solidarity $\cdot 7,139,140,141,159,191$, 267, 287

solitude $\cdot 21,23$

South $\cdot 121,146$

South-A merican · 152

sovereign · $33,59,60,69,175,176$, $186,188,208,260,280,281$

sovereignty $\cdot 66,176,187,239,241$, $242,243,278,279,280,288$

sovereignty of the people $\cdot 187,239$, $241,279,280$

Soviet $\cdot 57,121,157,273$

Spain $\cdot 121$

special minority rights $\cdot 144$

specialist $\cdot$ 75, 102, 103

specialization $\cdot 103$

species · 6, 107, 108, 109, 110, 198 spectator $\cdot 98$

spiritual $\cdot$ 162, 245

spontaneous mutual assistance $\cdot 169$

squandering $\cdot 154$

stability $\cdot 113,120,139,156,167,190$, $216,223,231,232,233,234$

stable · 28, 31, 62, 113, 121, 190, 217, $223,232,233,239,261,264$

\section{stagnation $\cdot 157$}

Stalin $\cdot 183,273$

standard of living · 171, 287, 290, 301

stand-still $\cdot 97$

starvation $\cdot 249$

starving · 58, 158, 173, 251, 271

state apparatus $\cdot 72,238$

state help kills self-help · 169

state of emergency $\cdot 192$

state of mind · 153, 238

stateless · 111, 112, 114, 115, 263

stateless liberty $\cdot 263$

stateless people $\cdot 111,112$

stateless person $\cdot 114$

States-General $\cdot 84$

status · $60,67,68,111,113,129,144$, $177,207,210,224,278,288,291$, 292, 294, 297, 299, 306

stock cars · 202

strangers $\cdot 116$

strategic $\cdot 13,147,149$

strategy $\cdot 6,42,145,171,182,215$, 231

strike $\cdot 67,71,172,271,287,300$

strong hand $\cdot 190,218$

strong leadership $\cdot 175$

strong man · 16, 217

strong state $\cdot 121,124,155,156,217$, 218, 266

struggle $\cdot 1,2,12,18,23,36,42,46$, $48,55,63,64,66,70,86,87,112$, $121,122,132,139,152,154,156$, $158,162,164,167,171,175,179$, $181,183,186,191,214,216,217$, $220,221,237,239,240,248,270$, 275

struggle to survive $\cdot 152,154,162$, 164

study · 23, 40, 53, 91, 94, 157, 221, $254,287,296,302,303$

stupid · 12, 14, 84, 100, 101, 198, 204, 207, 217, 225, 226, 246, 254, 257

stupidity $\cdot 101,219,223$

subjective $\cdot 166,202,225$

subjugate $\cdot 208$

subsidies $\cdot$ 215, 234, 256

subsidized $\cdot 154$

subsistence $\cdot$ 291, 299

succession · 20, 161, 179

suffer . $7,11,50,65,86,128,130$, $133,138,139,140,146,157,166$, $176,179,180,184,186,193,229$, 231, 239, 241, 249, 262, 266

suffering · 164, 166, 212

sufficient condition · $31,70,75,152$, 153, 155, 163, 166, 176, 178, 251

sufficient conditions · 155, 166

suffrage $\cdot$ 65, 70, 71, 287, 289, 294 
suffragette $\cdot 215$

suicidal $\cdot 183$

superficial $\cdot 214,254$

superfluous $\cdot 53,90,143,283$

superfluous right $\cdot 283$

superior - $14,37,42,68,75,96,97$,

$100,102,111,122,128,133,150$,

$166,181,182,199,203,207,208$,

209, 213, 219, 229, 262, 274

superiority complex $\cdot 128$

supermarkets · 166

supernatural $\cdot 229,238$

support $\cdot 40,47,48,76,85,111,155$,

$169,176,185,204,218,221,227$,

$228,232,233,236,248,258,261$

supporters $\cdot 77,79,236$

supranational $\cdot 130$

supremacy $\cdot$ 128, 139, 159

survival · $10,11,13,46,47,56,70$,

$71,140,144,146,161,162,175$,

$218,226,227,251,260$

survival of the fittest $\cdot 140$

survive $\cdot 27,36,52,94,132,153,162$,

$164,190,198,226,227,284$

swiftness $\cdot 216$

sword $\cdot 180,202$

sympathy $\cdot 6,74,97$

Synchronicity $\cdot$ 159, 164

\section{T}

tactics $\cdot 179$

Taiwan · 152

talents $\cdot 7,93,208,210$

target $\cdot 166$

$\operatorname{tax} \cdot 55,102,154,169,234,241$

tax breaks $\cdot 234$

tax burden $\cdot 102$

tax cut $\cdot 234$

tax evasion $\cdot 169$

tax fraud $\cdot 169$

taxation $\cdot 84,169,171,212$

taxes $\cdot 55,84,103,113,114,115,169$, $170,212,241,306$

tax-money $\cdot 113$

taxpayers $\cdot 84,234$

Taylor $\cdot 6,23,27,105,192,236,252$, 313

teargas $\cdot 125$

technocracy $\cdot 75$

technocrat $\cdot 75$

technological · 94, 150, 283

technological innovations · 150

technologies · 74, 101, 155, 159, 238

technology · 94, 125, 146, 154

television · 93, 94, 103, 305

televoting $\cdot 94$

temperature $\cdot 170$

temporary - 41, 62, 67, 72, 78, 151, $164,167,180,198,211,221,285$, 295

temporary reality $\cdot 67,198$

temptations · 166

tension · 38, 172, 179, 191, 193, 211

tensions · 180, 182, 190, 191, 192, 193 territorial · 128, 175, 182, 187, 188, 305

territorial integrity $\cdot 175,187,188$, 305

territories - 128, 146, 186, 211, 288, 302, 306, 307, 308, 309

territory $\cdot 60,94,112,113,128,145$, $146,147,176,182,186,188,242$, 288, 291, 292, 302, 307, 308, 309

terrorism · 182, 284

theatrical $\cdot 110$

theft $\cdot 128,149$

theory of relativity $\cdot 223$

thieves $\cdot 179$

thinking $\cdot 4,14,20,21,22,23,25,36$, $43,45,58,60,91,94,127,130$, $136,139,145,164,198,246,270$, 278

Third World · 7, 122, 123, 126, 145, $152,160,181,194,283,287$

threshold $\cdot 233$

ties · 48, 91, 95, 124

Tocqueville $\cdot 275$

toilets $\cdot 172,282$

toiling $\cdot 164$

tolerance $\cdot 3,26,39,40,41,42,43$, $46,51,52,120,136,137,139,140$, $144,150,153,179,191,193,228$, $257,258,290,301$

tolerate $\cdot 39,40,41,42,44,52,115$, $136,137,168,257$

tolerate intolerance $\cdot 136$

torture $\cdot 36,50,133,149,286,288$, 292, 304

totalitarian · 11, 139

totalitarianism · 219

tourism $\cdot 150$

tourists $\cdot 112,113$

trade-off $\cdot 159$

tradition $\cdot 11,42,58,59,60,74,111$, $119,123,134,136,153,171,184$, $225,226,245,248$

traditional $\cdot 11,56,66,74,78,79,82$, $92,119,123,127,133,134,135$, $136,137,147,153,161,162,172$, 211, 229, 238, 252, 265, 272

traditions - 11, 119, 121, 124, 125, $127,129,130,132,133,134,135$, $136,150,159,184,228,229,304$, 310

tranquility $\cdot 48,103$

transhistorical $\cdot 136$

transition $\cdot 65,179,227$

transitory $\cdot 223$

transnational $\cdot 130,242$

transparency $\cdot 72$

transparent $\cdot 21,240$

transportation $\cdot 152$

treaties $\cdot 35,108,148,149,273,287$

trial $\cdot 35,38,277,286,289,292,293$, 304, 305

tribal $\cdot 129,130,153$

tribal interest $\cdot 129$

tribalism $\cdot 130$

tribes $\cdot 129,147$

trickle down $\cdot 161,171$ trust $\cdot 193,217,239,241,288$

truth $\cdot 5,8,14,16,40,119,150,151$, $201,202,204,218,219,220,221$ $222,223,224,225,226,245$

TV $\cdot 94,146$

two-party system $\cdot 230,232,233,234$ 235

two-way causation · 31, 154, 191, 227

tyrannies $\cdot 60,63,180,209,245$

tyranny $\cdot 14,42,48,60,70,122,124$, $179,184,213,217,219,226,241$. $265,267,270,271,273,279,282$, 288

tyranny of the majority $\cdot 213,273$, 279

tyrant $\cdot 20,61,75,78,101,184,264$, 265, 271

tyrants $\cdot 158,181,184$

\section{U}

UDHR · 28, 29, 35, 65, 72, 108, 114, $115,116,140,161,180,207,209$, $282,283,286,287$

UK $\cdot 186$

UN Commission on Human Rights 65

unacceptable $\cdot 12,14,44,51,52,75$, $87,103,105,116,129,137,138$, $139,149,157,169,170,173,183$, 187, 201, 205, 209, 217, 219, 221, $231,249,281,283$

unanimity $\cdot 26,67,68,69,196,197$, $203,220,250$

unanimous $\cdot 67,68,69,203,295$

uncertainty $\cdot 218,222,223$

unconditional $\cdot 32,52,57,108,133$, 279

undemocratic $\cdot 2,11,12,14,15,69$, $75,102,103,129,148,158,175$, $177,183,185,186,187,188,225$, $242,274,276,278,279,280$

underdeveloped $\cdot 126,158$

undesirability $\cdot 151$

undesirable $\cdot 10,46,52,68,119,122$ $129,132,151,164,191,222,244$, 250, 282

undifferentiated $\cdot 116$

unemployed $\cdot 161,287$

unemployment · 241, 289, 290

unfair competition $\cdot 160$

unfree $\cdot 80,157,214,245$

Unified People $\cdot 217$

uniform $\cdot 7,124,166,167,219,238$, 239, 282

uniformity $\cdot 17,131,134,143,175$, $218,220,282$

uninformed $\cdot 12,100$

union activity $\cdot 156$

unity $\cdot 26,49,66,67,77,85,117,121$, $122,130,131,133,145,150,175$, 190, 191, 192, 193, 199, 211, 217 $223,225,226,228,229,256,276$, 304 
unity of vision $\cdot 175,225,226,228$, 229

universal acceptance $\cdot 6,47$, 149, 175

universal application . 1, 7, 10, 15, $47,49,66,108,118,119,125,128$, 133, 148, 151, 155, 158, 255

Universal Islamic Declaration of Human Rights · 134

universal rights $\cdot 59,120,127,149$, 177, 280

universal suffrage $\cdot 97,99,100,283$

universal truth $\cdot 149$

universal validity $\cdot 1,47$

universal values . 4, 5, 16, 89, 108 , $118,119,126,127,149,158$

universities $\cdot 93$

university $\cdot 100$

unjust $\cdot 38,52,112,170,181,214$, 276, 281

unlimited · $8,49,54,82,105,136$, $141,240,261,263,264,265,268$, 270, 279

unlimited freedom $\cdot 8,261,263,268$, 270

unlimited state $\cdot 54,240$

unofficial $\cdot 89$

unpopular $\cdot 156$

unpredictability $\cdot 36,70,216$

unpredictable $\cdot 71,217,230,234,264$

unrealistic $\cdot 172,189,250$

unregulated markets $\cdot 138$

UN-resolutions $\cdot 182$

unskilled $\cdot 113$

untouchable $\cdot$ 154, 241

uprisings $\cdot 124$

uprooted · 122, 127

urbanization $\cdot 142,153$

urgencies $\cdot 162,175$

urgent · 37, 97, 101, 159, 164, 221, 222, 225

USA · 144, 151, 186, 229, 274, 279

usurpation · 169, 276

utilitarian $\cdot 86$

vague $\cdot 4,31,85,90,113$

vagueness $\cdot 232$

valid law $\cdot 205,273$

valuable $\cdot 2,4,5,6,19,21,24,25$, $41,42,81,101,104,108,118,119$, $127,128,133,136,159,198,199$, $202,205,207,208,209,228,248$, 250, 255

value-free $\cdot 126$

verdict $\cdot$ 38, 112, 273, 275, 277

Versailles Peace Treaty · 161

veto $\cdot 147,276$

victims $\cdot 112,122,125,133,166,172$, 259, 260, 262

victory $\cdot$ 62, 71, 190, 191, 211, 215

Vienna Declaration · 132, 148, 188, 313

violation $\cdot 1,29,36,49,53,56,107$, $108,115,116,122,128,130,133$,
$144,151,170,188,273,280,288$, 291, 306

violations · $11,36,41,42,46,52,53$, $54,55,56,57,95,99,107,112$ $115,116,117,120,122,125,130$, $132,133,135,136,138,142,148$ $150,157,158,160,164,170,172$ $175,176,177,178,179,180,184$, $186,188,190,192,194,213,216$, 226, 229, 243, 249, 252, 260, 265, $266,267,272,273,277,278,283$, 284, 286

violator $\cdot 170$

violators · 125, 148

violence $\cdot 2,30,34,35,36,37,38,39$ $40,48,57,60,69,71,140,162$ $179,180,182,183,187,190,191$, $192,204,217,218,226,236,247$, 281, 284, 294, 304

violent conflicts · 39, 154, 191

violent struggle $\cdot 47,175$

virtual $\cdot 94$

virtue $\cdot 91,107,148,290,299,300$, 306, 307, 309

virtuous $\cdot 166$

visible $\cdot$ 18, 22, 72, 235, 238, 275

visions $\cdot 224,283$

visitors $\cdot 112,113$

vocabulary $\cdot 134$

voice $\cdot 3,26,29,63,78,79,85,86,93$, $95,102,154,185,207,214,216$, 279

voluntary $\cdot 123,171,173,185,222$, 242, 245, 260, 261, 267, 270

vote $\cdot 16,63,64,65,66,67,69,72$, $79,81,83,84,85,87,89,90,91$ $93,94,100,103,147,188,192$ $196,198,199,205,210,214,215$ $220,231,233,234,235,236,237$ $239,273,274,277,278,287,294$ 296, 297

vote buying $\cdot 16,103,192,234,235$ 236, 237, 239

voters · 85, 99, 101, 156, 233, 234, 237 votes $\cdot 12,65,71,79,84,90,95,102$ $213,230,231,233,234,235,236$, 239, 295

voting $\cdot 12,65,66,69,79,87,94,199$, $204,214,257,279,289,295,298$ 303

\section{W}

war · 38, 48, 84, 112, 146, 175, 177 , $179,180,181,182,186,208,217$, $236,261,263,294,306,308$

war effort · 175

war industry $\cdot 175$

warfare $\cdot 84$

warrior $\cdot 202$

wars $\cdot 48,116,180$

wasting $\cdot 155$

wealth · 58, 92, 130, 140, 152, 158, $162,171,174,194,210,211,213$, 214, 215, 267, 291, 298, 299, 303 wealthy $\cdot 84,93,113,168,212,214$, 251

welfare $\cdot 7,66,93,115,147,290,300$

well-being $\cdot 69,80,138,139,156$, $212,213,241,245,252,255,257$, 290, 292, 304, 305

well-fed $\cdot 158,159$

W eltethos $\cdot 149$

West . 6, 7, 15, 48, 56, 103, 119, 120, $121,122,123,124,125,126,127$, $128,129,130,131,132,133,136$, $137,139,140,142,147,152,159$, $160,173,182,312$

western · 1, 2, 7, 11, 21, 45, 59, 79, $118,121,122,123,124,125,126$, $127,128,129,130,131,132,133$, $135,137,138,139,140,142,146$, 157, 159, 160, 166, 182, 215, 283

western culture . 7, 126, 127, 128, 130, 131

western identity $\cdot 127,132$

western individualism · 137

western rights $\cdot 123,125,127,131$, 142, 283

western supremacy $\cdot 133$

western values $\cdot 118,139,141,159$

westerners · $121,122,126,127,128$, $136,137,139,160,180$

westernize $\cdot 125$

westernized $\cdot 122$

Weyembergh $\cdot$ 1, 24, 311, 313

widow sacrifice $\cdot 121$

will power $\cdot 217$

winner-takes-all $\cdot$ 233, 235

wisdom $\cdot 204$

withdrawal · 152, 250, 268, 270, 297 , 308, 309

without distinction - 113, 161, 166, 188, 288, 291, 300

witness · 1, 53, 98, 207, 210, 217, 219

Wollheim · 205

woman · 107, 152

women · $1,14,24,60,64,79,92,132$, $134,143,149,198,215,283,288$, 289, 291, 292, 294, 299, 300, 306

work · 14, 24, 39, 55, 64, 65, 75, 79, $83,90,91,97,102,115,126,134$, $139,144,150,156,164,167,170$, $173,180,191,202,227,252,254$, $256,273,287,289,292,300,301$, 302,304

workers · 24, 153, 160, 161, 171, 252, 300

working conditions $\cdot 175,300$

working hours $\cdot 156,290,300$

World Bank · 157, 313

World War $2 \cdot 218$

worshipping $\cdot 145$

worthless - 94, 207, 221

worthy $\cdot 10,111,207,208,289$

wrong . 6, 8, 9, 15, 22, 33, 42, 44, 51, $52,56,57,73,83,85,100,101$, $111,118,119,120,126,129,131$, $132,133,134,137,139,140,144$, $149,158,159,183,185,198,201$, 
202, 204, 208, 219, 221, 223, 237,

246, 255, 269, 273, 274, 281

wrongs · $33,91,282,283$

$\times$

xenophobia $\cdot$ 143, 193

Y

youths $\cdot 145$

$z$

Zapata $\cdot 93$

zookeeper $\cdot 268$

zoo-keeping $\cdot 60$ 